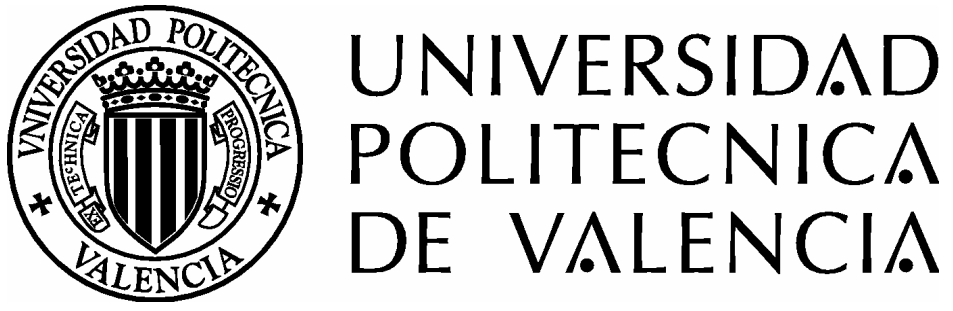

DEPARTAMENTO DE INGENIERÍA TEXTIL Y PAPELERA

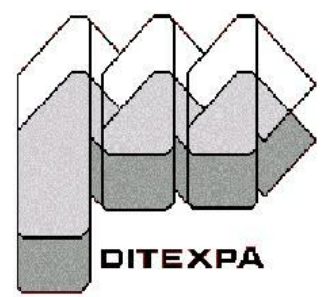

\title{
UNA PROPUESTA METODOLÓGICA PARA LA GESTIÓN Y EVALUACIÓN DEL TRABAJO COOPERATIVO APLICADA AL APRENDIZAJE DEL ENLACE QUÍMICO EN EDUCACIÓN SECUNDARIA
}

\section{Tesis Doctoral}

Presentada por: Juan José Olmos Perelló

Dirigida por: Dr. D. Rafael Llopis Castelló

Dr. D. Juan Antonio Llorens Molina

Dra. Dña. Mónica Edwards Schachter 

El éxito no se logra sólo con cualidades especiales. Es sobre todo un trabajo de constancia, de método y de organización.

J.P. Sergent 



\section{AGRADECIMIENTOS}

Al Director y a los miembros del Departamento de Ingeniería Textil y Papelera de la Universidad Politécnica de Valencia (DITEXPA) por permitirnos presentar esta intervención bajo la estructura del departamento, a pesar de que sus núcleos principales de investigación, tanto en Química Física como en Ingeniería Textil se encuentran alejados de esta área de trabajo.

Al Director y a los miembros del Departamento de Didáctica de las Ciencias Experimentales y Sociales de la Universidad de Valencia por la admisión y posibilidad de obtención del Diploma de Estudios Avanzados, tanto en la realización de los cursos de Doctorado como en el trabajo de investigación.

A los compañeros Maria Martínez Soler, Eva Pérez Sánchez, Esperanza Pérez Castelló, Maria Luisa Pitarch Tonda, Elvira Trilles Gil y Alejandro López-Ibarra Moreno, por su desinteresada e imprescindible ayuda en la ejecución de las propuestas llevadas a cabo en esta investigación.

Al compañero Pepe Satoca Valero, por su revisión y corrección final del trabajo. Además de una rigurosa corrección gramatical y ortográfica ha conseguido mejorar la legibilidad de un trabajo que, aunque resulta familiar para los autores, se vuelve arduo en su estudio.

A todos los alumnos que han colaborado en este trabajo, pues ellos han sido los que, en realidad, han llevado a cabo las experiencias y han mostrado los comportamientos que les son propios en relación con nuestras propuestas. 



\section{ÍNDICE}

PRIMERA PARTE: EL TRABAJO COOPERATIVO Y LA EVALUACIÓN COMO INTRUMENTOS DE REGULACIÓN EN EL AREA DE QUÍMICA EN EDUCACIÓN SECUNDARIA.

1.- APRENDIZAJE Y ENSEÑANZA DE LA QUÍMICA ............................. 19

1.1.- La química dentro del actual sistema educativo .......................... 19

1.1.1- Finalidad .................................................. 19

1.1.2.- Perspectiva curricular ...................................... 27

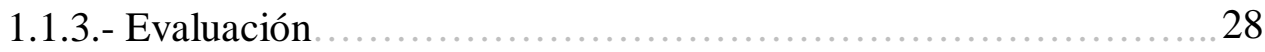

1.2.- Aprendizaje de la química ............................................ 32

1.2.1.- Teorías de aprendizaje ........................................ 32

1.2.2.- Dificultades conceptuales ................................... 36

1.2.2.1.- Ideas previas y prerrequisitos ........................... 42

1.2.2.2.- Comprensión de conceptos básicos ....................... 46

1.3.- Enseñanza de la química ............................................. 50

1.3.1.- La química como la ciencia de los modelos ....................... 50

1.3.2.- Necesidad de una contextualización del currículo ................. 55

1.3.3.- Estrategias de aprendizaje frente a la enseñanza tradicional .........62 62

1.3.4.- El tratamiento de las relaciones CTSA como alternativa didáctica. 74

\section{2.- PAPEL DEL ENLACE QUÍMICO COMO NÚCLEO FUNDAMENTAL EN LA} COMPRENSIÓN DE LA ESTRUCTURA DE LA MATERIA EN EDUCACIÓN

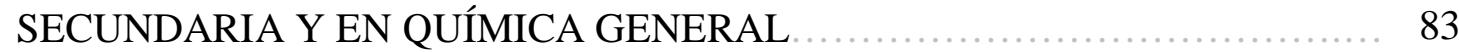

2.1.- Evolución histórica del concepto de enlace químico ........................83

2.2.- El enlace químico como concepto inclusor .................................. 92

2.3.- Utilización de modelos en enseñanza del enlace químico ....................92

2.4.- Ideas previas y preconcepciones en el enlace químico ..................... 95

2.5.- Estructuras de aprendizaje del enlace químico en los niveles básicos .........99

2.6.- Problemas de aprendizaje en el enlace químico ............................ 99 
3.1.- El trabajo cooperativo .......................................... 103

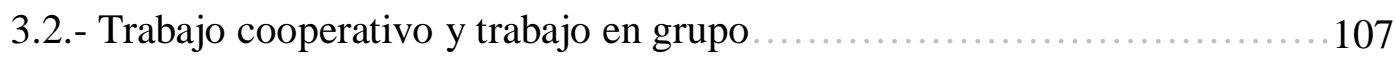

3.3.- Posibilidades y conveniencia del trabajo cooperativo .................... 109

3.4.- Dinámica del trabajo cooperativo ................................ 112

3.5.- Condicionantes en el trabajo cooperativo ............................. 116

3.6.- La evaluación en el trabajo cooperativo ........................... 118

4- APLICACIÓN DE LA TEORÍA DE LA ZDP DE VYGOTSKY AL APRENDIZAJE

DE LAS CIENCIAS

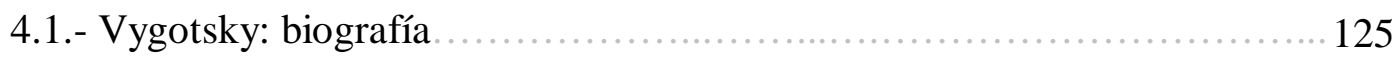

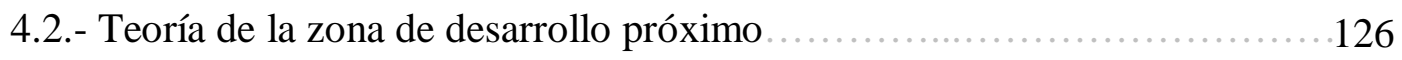

4.3.- Teoría de Vygotsky y trabajo cooperativo ............................. 128

4.4.- Utilización de la teoría de la ZDP como instrumento de regulación ..........129 
SEGUNDA PARTE: PLANTEAMIENTO DE LA INVESTIGACIÓN: UTILIZACIÓN DE MECANISMOS DE REGULACIÓN EN EL APRENDIZAJE COOPERATIVO, COMO PROPUESTA DE MEJORA.

5.- OBJETIVO, FUNDAMENTACIÓN Y METODOLOGÍA DE LA INVESTIGACIÓN.

5.1.- Deficiencias y problemas en la enseñanza de la química ....................133

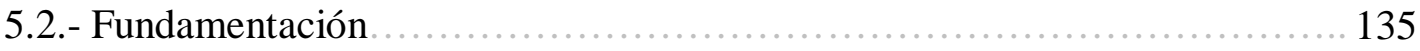

5.2.1.- Fundamentación teórica ...................................... 135

5.2.2.- Fundamentación didáctica ..................................... 136

5.3.- Metodología de la investigación .......................................... 146

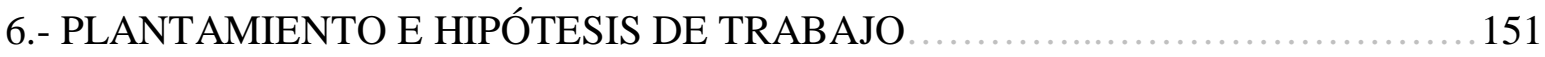

6.1.- Planteamiento general del problema .................................. 151

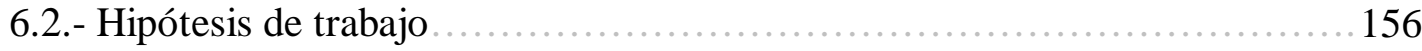

6.3.- Marco curricular de la intervención didáctica ........................... 158

6.4.- Actividades previas/diagnósticas ........................................... 165

6.4.1.- Actividades diagnósticas en tercero de ESO ....................... 172

6.4.2.- Actividades diagnósticas en segundo de Bachillerato ......................191

7.- METODOLOGÍA, DESARROLLO Y RESULTADO DE LAS

INVESTIGACIONES PREVIAS/DIAGNOSTICAS ................................... 209

7.1.- Diseño experimental ...............................................2 210

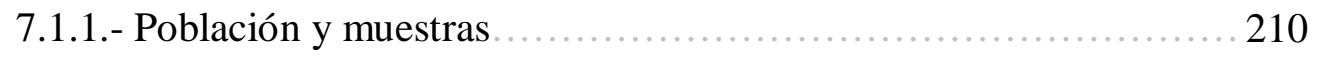

7.1.2.- Variables ...................................................... 212

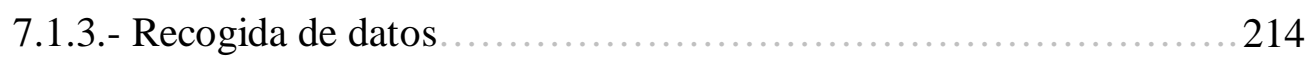

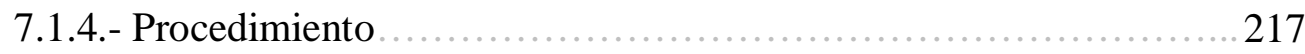

7.1.5.- Análisis de datos ............................................... 218

7.2.- Diseño y validación de cuestionarios ..................................... 220

7.2.1.- Diseño de los cuestionarios ..................................... 220

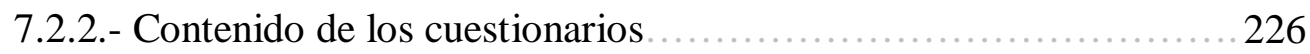

7.2.3.- Metodología seguida en la validación de cuestionarios ............. 252

7.2.4.- Análisis de la validez y fiabilidad de los cuestionarios............. 254 
7.3.- Análisis de los resultados de las actividades diagnósticas. 265

7.3.1.- Síntesis del planteamiento experimental .................... 265

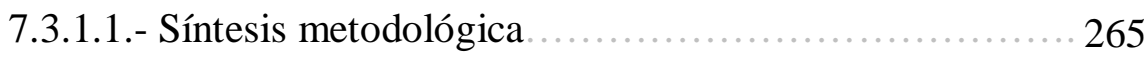

7.3.1.2.-Equivalencia de los grupos experimentales y de control 266

7.3.2.- Resultados de los cuestionarios ........................ 270

7.3.2.1.- Resultados obtenidos en el Pre-ESO ................ 270

7.3.2.2.- Resultados obtenidos en el Post-ESO ................ 283

7.3.2.3.- Resultados obtenidos en el Pre-Bac ................. 297

7.3.2.4.- Resultados obtenidos en el Post-Bac ................. 308

7.3.3.- Análisis de la relación entre los cuestionarios .................. 322

7.3.3.1.- Relación entre el Pre-ESO y el Post-ESO ............. 323

7.3.3.2.- Relación entre el Pre-Bac y el Post-Bac............... 338

7.3.4.- Influencia de la intervención ...............................346

7.3.4.1.- Resultados cuantitativos de la intervención ............ 346

7.3.4.2.- Resultados cualitativos de la intervención ...............348

7.3.4.3.- Conclusiones generales respecto a la intervención

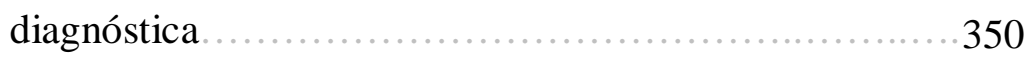

\section{8.- PLANTEAMIENTO DE UNA INTERVENCIÓN COOPERATIVA CON UNA}

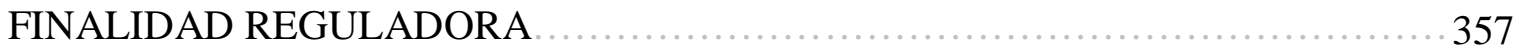

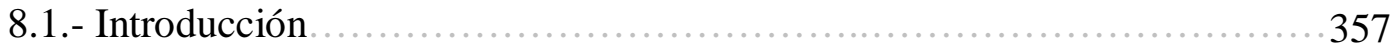

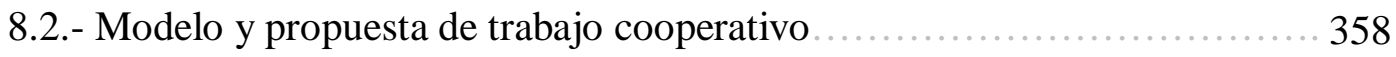

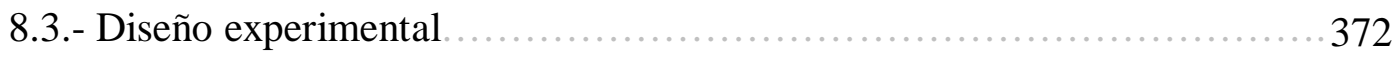

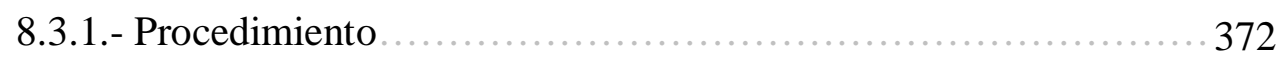

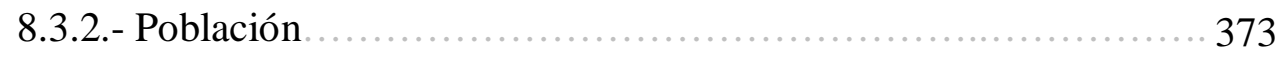

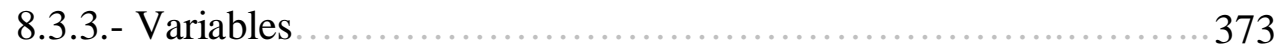

8.3.4.- Instrumentos de medida ............................... 373

8.3.5.- Análisis de datos ...................................... 374

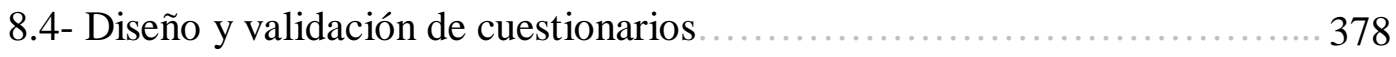

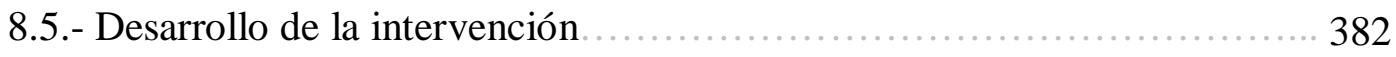


TERCERA PARTE: ANALISIS DE RESULTADOS, CONCLUSIONES Y PERSPECTIVAS: EFECTO DE LA APLICACIÓN DE UN MODELO PARA LA GESTIÓN Y EVALUACIÓN DEL APRENDIZAJE COOPERATIVO BASADO EN EL CONCEPTO DE ZDP DE VIGOTSKY

9.- EL MODELO DE TRABAJO COOPERATIVO Y SU ORGANIZACIÓN 397

9.1.- Síntesis del procedimiento experimental ................................. 397

9.2.- Resultados de la intervención ........................................... 398

9.2.1.- Efecto del trabajo cooperativo sobre grupos aleatorios ...............400

9.2.2.- Aplicación del mecanismo de regulación basado en la ZDP ...........404

9.2.3.- Efecto del trabajo cooperativo sobre grupos organizados según la

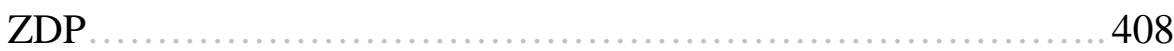

9.3.- Establecimiento de las variables significativas ............................ 413

9.4.- Estudio de la influencia del tipo de ítem ................................. 418

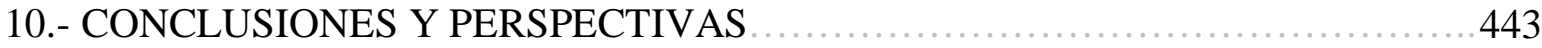

10.1.- Verificación de las hipótesis .............................................443

10.2.- Conclusiones finales ............................................... 446

10.3.- Implicaciones didácticas y perspectivas futuras ............................449

REFERENCIAS BIBLIOGRÁFICAS . . . 
Colores utilizados en las tablas:

Recuperación bibliográfica

\begin{tabular}{|c|c|c|}
\hline \multirow{2}{*}{$\begin{array}{l}\text { O } \\
\text { xI }\end{array}$} & 1er curso & Obligatoria para todos los alumnos en la materia \\
\hline & $2^{\circ}$ curso & Agrupa la física, química, biología y geología. \\
\hline
\end{tabular}

Resultados de la intervención diagnóstica

\begin{tabular}{|c|c|}
\hline \multicolumn{2}{|c|}{ ¿Explica que se trata de un átomo? } \\
\hline $\mathrm{Si} \rightarrow 47,7 \%$ & No $\rightarrow 52,3 \%$ \\
\hline $\begin{array}{l}\text { - Un } 47,7 \% \text { de los alumnos } \\
\text { indica explícitamente que se } \\
\text { trata de un átomo. }\end{array}$ & $\begin{array}{l}\text { - Aproximadamente un } 20 \% \text { de } \\
\text { los alumnos no explican de } \\
\text { que se trata el esquema. }\end{array}$ \\
\hline
\end{tabular}

Resultados estadísticos

\begin{tabular}{|l|l|l|l|l|}
\hline \multicolumn{1}{|c|}{ Grupo } & $\Delta x / \bar{x}_{i}$ & $L A$ & $L A_{R}$ & $L A_{W}$ \\
\hline 1 & 0.55 & 0,55 & 0,569 & 0,500 \\
\hline 2 & 0,64 & 0,58 & 0,598 & 0,375 \\
\hline 3 & 0,33 & 0,59 & 0,609 & 0,556 \\
\hline
\end{tabular}

Finalidad y Validación de cuestionarios

\begin{tabular}{|c|l|c|}
\hline $\begin{array}{c}\text { Pareja de } \\
\text { ítems }\end{array}$ & \multicolumn{1}{|c|}{ Estadístico empleado } & Valor \\
\hline \multirow{2}{*}{$1-5$} & Coeficiente de contingencia & 0,408 \\
& Gamma de Goodman & 0,631 \\
& R de Pearson & 0,424 \\
\hline
\end{tabular}

\section{Propuestas}

\begin{tabular}{|c|c|}
\hline $\begin{array}{c}\text { Nueva } \\
\text { ordenación }\end{array}$ & Anterior ordenación \\
\hline $01-a$ & $1-a$ \\
\hline $01-b$ & $3-c$ \\
\hline $01-c$ & $3-d$ \\
\hline $02-a$ & $1-b$ \\
\hline
\end{tabular}




\section{ANEXOS}

ANEXO I: CUESTIONARIO PARA LA COMPROBACIÓN DE CONOCIMIENTOS REFERENTES A CONCEPTOS BÁSICOS DE QUÍMICA.

ANEXO II: CORRECCIÓN DEL CUESTIONARIO PARA LA COMPROBACIÓN DE CONOCIMIENTOS REFERENTES A CONCEPTOS BÁSICOS DE QUÍMICA................................................. 485

ANEXO III: CUESTIONARIO PARA LA DETECCIÓN DE IDEAS ALTERNATIVAS SOBRE LA ESTRUCTURA DE LA MATERIA (Pre-ESO) ................................................. 491

ANEXO IV: CORRECCIÓN CUESTIONARIO Pre-ESO.......................... 497

ANEXO V: CUESTIONARIO PARA LA DETECCIÓN DE CONOCIMIENTOS ACERCA DEL ENLACE QUÍMICO EN TERCER CURSO DE ESO (Post-ESO) ................................................. 505

ANEXO VI: CORRECCIÓN CUESTIONARIO Post-ESO.......................... 511

ANEXO VII: CUESTONARIO PARA LA DETECCIÓN DE CONOCIMIENTOS PREVIOS EN EL ESTUDIO DEL ENLACE QUÍMICO (Pre-Bac)...... 519

ANEXO VIII: CORRECCIÓN CUESTIONARIO Pre-Bac.......................... 525

ANEXO IX: CUESTIONARIO PARA LA DETECCIÓN DE CONOCIMIENTOS ACERCA DEL ENLACE QUÍMICO EN SEGUNDO DE BACHILLERATO (Post-Bac) ................................ 533

ANEXO X: CORRECCIÓN CUESTIONARIO Post-Bac........................... 539

ANEXO XI: REDES DE ANÁLISIS EMPLEADAS EN LA CORRECCIÓN DE LOS CUESTIONARIOS PREVIOS/DIAGNÓSTICOS................. 549

ANEXO XII: PARÁMETROS ESTADÍSTICOS EMPLEADOS $\ldots \ldots \ldots \ldots \ldots \ldots \ldots \ldots \ldots \ldots$

ANEXO XIII: CUESTIONARIO SOBRE LAS LEYES DE LA QUÍMICA (Test 1)... 561

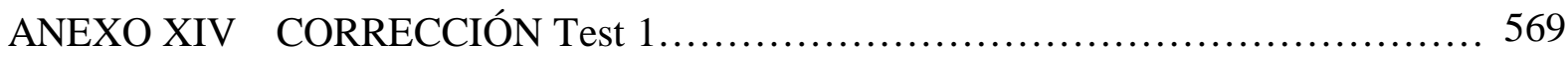

ANEXO XV: CUESTIONARIO SOBRE ESTRUCTURA ATÓMICA (Test 2)........ 573

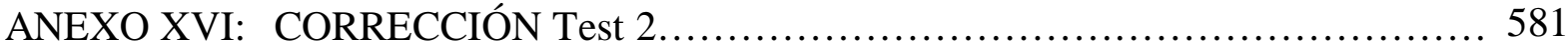

ANEXO XVII: CUESTIONARIO SOBRE ENLACE QUÍMICO (Test 3).............. 585

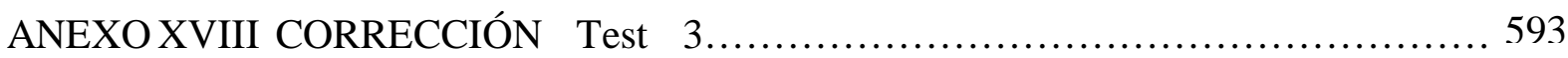


ANEXO XIX: CUESTIONARIO SOBRE FORMULACIÓN (Test 4).................597

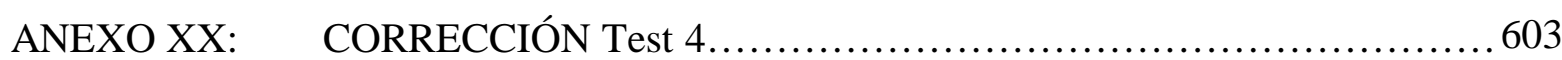

ANEXO XXI: CUESTIONARIO SOBRE ESTEQUIOMETRIA (Test 5)............607

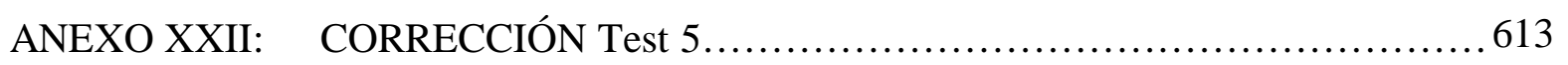

ANEXO XXIII: CUESTONARIO PARA RECOGER LAS IMPRESIONES DE LOS

PROFESORES PARTICIPANTES...........................6 617

ANEXOXXIV: RELACIÓN DE CENTROS CUYOS PROFESORES Y ALUMNOS

HAN PARTICIPADO EN LA INVESTIGACIÓN....................623 


\section{RESUMEN}

En este trabajo se expone la investigación realizada durante cuatro cursos académicos consecutivos, (de 2005/06 a 2008/09) sobre la utilización de una metodología basada en el trabajo cooperativo en la enseñanza-aprendizaje de química a nivel de enseñanza secundaria.

En la primera parte de la memoria de esta investigación se expone la situación de la enseñanza y aprendizaje de la química tanto en secundaria obligatoria como postobligatoria, considerando la articulación de sus objetivos, contenidos y métodos de evaluación dentro del sistema educativo. Asimismo, se analizan cuáles son las dificultades que encuentran los alumnos a la hora de estudiar esta materia y las aportaciones de la investigación didáctica realizadas al respecto, justificando la posibilidad de mejorar y potenciar su aprendizaje a través del trabajo cooperativo.

A continuación, se comentan las principales características del aprendizaje basado en dicha metodología y la posibilidad, de mejorar el rendimiento académico desde el punto de vista cognitivo, identificando aquellos aspectos que pueden ser aplicados dentro del desarrollo de un programa ordinario de química en secundaria. Sobre esta base, se establece una propuesta que trata de conjugar, de forma óptima, el currículo establecido, con una dinámica fundamentada el uso del trabajo cooperativo, diferente a la transmisión directa de conceptos por parte del profesor y con una mejor contextualización de la materia.

Seguidamente, se investiga la posibilidad de establecer un mecanismo de regulación sobre la configuración de los grupos, basado en el análisis de las diferencias cualitativas y cuantitativas observadas entre los resultados del trabajo cooperativo y las aportaciones personales previas de los miembros de cada grupo. De ese modo, se pretende mejorar la eficacia de esta metodología con el objeto de desarrollar el currículo de secundaria para elaborar una propuesta de estudio que lo haga más próximo a las situaciones habituales de nuestro entorno y que permita a los alumnos mejorar su comprensión y rendimiento académico. 
En una primera fase del trabajo empírico, se llevó a cabo un estudio exploratorio con alumnos de bachillerato y de primeros cursos de universidad, para detectar cuáles son sus deficiencias y las dificultades que encuentran en el aprendizaje de la química. En función de los resultados obtenidos, se determinaron los temas nucleares en los que se evidencia mayor dificultad: el enlace químico.

A partir de este diagnóstico, se diseñó una intervención didáctica, tratando de seguir un método basado en el trabajo individual y se hizo en dos direcciones: una para tercer curso de ESO, donde los alumnos toman contacto por primera vez con el concepto de enlace químico, y otra para el segundo curso de bachillerato, donde se estudia este tema con mayor profundidad siendo, además, el curso que precede a la selectividad y al acceso universitario, en su caso. En ambas propuestas, se intenta, partiendo de situaciones de la vida cotidiana, salvar la barrera que supone la abstracción de los conceptos que lleva implícita la química en sí misma.

Una vez aplicado el diseño experimental, se procedió a estudiar los resultados obtenidos, comparándolos con grupos de control y a confirmar la validez de la propuesta en los dos niveles de estudio.

En una segunda fase de esta investigación diagnóstica, se indagaron las relaciones que pueden existir entre los resultados obtenidos por los alumnos, centrándonos en la influencia que existe entre las competencias iniciales y finales de cada uno de ellos. Concretamente, se ha buscado la existencia de concordancias entre aquellos contenidos de interés que deberían conocerse previamente al comienzo del estudio del tema y aquellos que domina el alumno tras la intervención, lo que permite establecer unas variables en términos de conocimientos iniciales y conocimientos finales que, desde un punto de vista puramente constructivista, definen los aspectos que son necesarios como prerrequisitos para aprender otros de mayor dificultad y qué aspectos no lo son.

Una vez definidos los problemas que se encuentran en la enseñanza tanto de los conceptos básicos como los propios del enlace químico, se procedió a desarrollar un núcleo de contenidos de química de primero de bachillerato, utilizando una metodología cooperativa. El eje principal de la investigación consistió en buscar cual sería la mejor 
forma de organizar los grupos en un aula, a partir de un mecanismo de realimentación que permitiera de una forma dinámica la interacción positiva entre los alumnos. Para ello, se realizó una secuencia de actividades en las que los alumnos trabajaron de forma conjunta.

Inicialmente, los grupos se formaron de forma aleatoria y, después, se realizaron reordenamientos en base a los resultados que se fueron obteniendo. Esta reordenación obedece a un intento de sacar provecho a la interacción entre los alumnos, tal como expone Vygotsky en su teoría de la "zona de desarrollo próximo".

Tras desarrollar las actividades propuestas y sus ejercicios de evaluación correspondientes se ha llevado a cabo un tratamiento estadístico para cuantificar el efecto producido sobre los alumnos de estas dinámicas. Hemos podido contrastar la eficacia del trabajo cooperativo, la posibilidad de ejercer una rápida valoración de las interacciones de cada alumno en su grupo de trabajo, y la mejora que se experimenta tras la reordenación.

Después de realizar este trabajo, ha quedado claro se puede optimizar el trabajo cooperativo, lo que supone una confirmación de la propia teoría de Vygotsky en cuanto que confirma que la mejora del rendimiento se consigue a través de una interacción constructiva, más allá de un simple aumento de aportaciones individuales.

La principal aportación de esta metodología es la posibilidad de ejercer rápida y eficazmente la realimentación durante el propio proceso. De ese modo, se consigue una reordenación en la configuración de los grupos de trabajo que busca mejorar el rendimiento de cada uno de ellos y obtener una herramienta que permita al profesor disponer de forma relativamente rápida de una información que le permita distribuir al alumnado en este tipo de trabajo grupal. 
\begin{tabular}{l|l|}
\begin{tabular}{l|l} 
Fundamentación \\
teórica / didáctica
\end{tabular} & $\begin{array}{l}\text { Cursos de nivelación } \\
2^{\circ} \text { Bachillerato } \\
1^{\circ} \text { Universidad }\end{array}$ \\
\hline
\end{tabular}

Planteamiento del problema

Hipótesis de trabajo

\section{Metodología}

Primera fase:

Investigación diagnóstica

\footnotetext{
Segunda fase:

\section{Intervención \\ didáctica \\ Investigación}

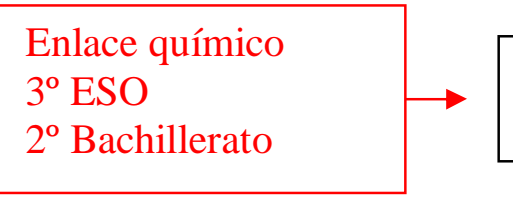

Problemas acerca del enlace como concepto clave
Determinación de problemas que se encuentran en al aprendizaje de la química y posibles variables que influyen en el proceso

Podemos encontrar mecanismos de control para optimizar el trabajo cooperativo a partir de un análisis inicial de los alumnos.

Desarrollo individual y colectivo de actividades, comparación y búsqueda del mejor proceso.
Constatación de las deficiencias que presentan los alumnos respecto a los conceptos básicos.

¿Cómo podremos contribuir a mejorar el aprendizaje del enlace químico mediante el trabajo cooperativo?

Establecimiento de una herramienta para optimizar el trabajo cooperativo

Desarrollo de un módulo de química de $1^{\circ}$ de Bachillerato mediante un trabajo cooperativo regulado por la ZDP de
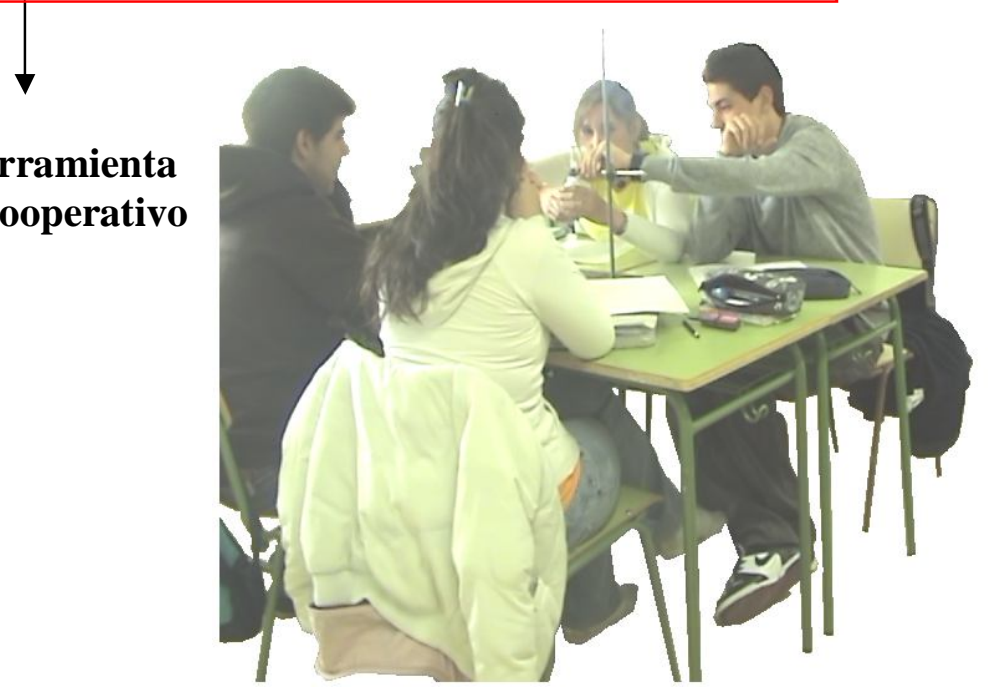


\begin{abstract}
This study explains the research carried out over four consecutive academic years (from 2005/06 to 2008/09) regarding the use of a cooperative learning methodology in secondary-level chemistry lessons.
\end{abstract}

The first part of this investigation explains how chemistry is taught and learned in both compulsory and post-compulsory secondary education, considering the way in which its objectives, contents and methods of assessment are organised within the education system and the method by which specific contents and assessment methods are established. We also analyse the pupils' difficulties encountered by pupils when studying chemistry and the relevant contributions of educational research, thus enabling us to explore the possibility of ensuring more successful learning through cooperative classroom work.

We then go on to explain the most important aspects of learning based on the cooperative learning methodology and the possibility of improving the students' performance from a cognitive point of view, identifying several critical aspects within the development of an ordinary secondary school chemistry programme. We put forward a teaching model that seeks to achieve an optimum combination of the standard curriculum.

On the basis of this analysis, we propose a mechanism for regulating the formation of groups based on an evaluation of the qualitative and quantitative differences between the results of cooperative learning and the previous individual contributions of the members of each group. The aim of this is to improve the effectiveness of the cooperative methodology in order to develop the secondary-level curriculum throughout a programme of studies that will adapt it to common situations in our environment and help pupils improve their understanding and academic performance. 
We first carried out an exploratory study with students at baccalaureate level and in their first years at university to identify the most significant shortcomings and difficulties involved in learning chemistry. According to the results of this study, we focused on one of the subject topics where students appear to encounter the greatest difficulties: chemical bonding.

This initial diagnosis was used to design a teaching method based on individual work. This was done on two levels. Firstly, the third year of compulsory secondary education, where the pupils first come into contact with the concept of chemical bonding; and secondly, the second year of the baccalaureate, where this topic is studied in greater depth. This is also the year before they take their university entrance exams and begin university in many cases. For both levels the intention was to overcome the barrier posed by the abstract nature of the concepts that are implicit to chemistry itself by presenting them within the context of everyday situations.

Having applied the experimental design, we analyzed the results that were obtained, comparing them with the control groups' results and confirming the validity of the proposal for both study levels.

The second application of this diagnostic investigation involved examining the relationship between the results achieved by pupils, focusing on the influence between each student's skills and knowledge at the beginning and end of the period that we studied. Specifically, we wanted to find out whether there is any concordance between the relevant contents that need to be known before the topic is studied and the knowledge that the pupil has gained after our intervention. A set of variables was therefore established in terms of the pupils' knowledge at the beginning and end. From a constructivist perspective, this defined which aspects are necessary initially as prerequisites for learning other more difficult ones, as well as those aspects which are not necessary. 
Having defined the problems encountered in education in terms of basic concepts and the concepts of chemical bonding, we developed core chemistry contents for the first year of the baccalaureate using a cooperative methodology. The key research purpose is to find the best way to organise groups within the classroom, based on a dynamic feedback mechanism that enables positive interaction between pupils. It was achieved through a series of activities in which the pupils worked together. Initially, the groups were randomly put together and they were later reorganised on the basis of the results achieved. This reorganisation responded to an attempt to take advantage of the interaction between the pupils as explained by Vygotsky in his "zone of proximal development" theory.

The main advantage offered by this methodology is the possibility of quickly and effectively supplying feedback during the process itself. This made it possible to reorganise the composition of the work groups, improving each group's performance and provide a tool that allows the teacher to obtain information relatively quickly about how to distribute the pupils in this type of group work. 


\section{RESUM}

En aquest treball s'exposa la investigació realitzada durant quatre cursos acadèmics consecutius, (de 2005/06 a 2008/09) sobre la utilització d'una metodologia basada en el treball cooperatiu a l'ensenyamet-aprenentatge de química a nivell d'ensenyament secundari.

En la primera part de la memòria d'aquesta investigació s'exposa la situació de l'ensenyament i aprenentatge de la química tant en secundària obligatòria com postobligatòria, considerant la articulació dels seus objectius, continguts i mètodes d'avaluació dins del sistema educatiu. Així mateix, s'analitzen quines són les dificultats que troben els alumnes a l'hora d'estudiar aquesta matèria i les aportacions de la investigació didàctica realitzades al respecte, justificant la possibilitat de millorar i potenciar el seu aprenentatge mitjançant el treball cooperatiu.

A continuació, se comenten les principals característiques de l'aprenentatge basat en aquesta metodologia i la possibilitat, de millorar el rendiment acadèmic des de el punt de vista cognitiu, identificant aquells aspectes que poden ser aplicats dins del desenvolupament d'un programa ordinari de química en secundària. Sobre aquesta base, s'estableix una proposta que tracta de conjugar, de forma òptima, el currículum establert, amb una dinàmica fonamentada amb l'ús del treball cooperatiu, diferent a la transmissió directa de conceptes per part del professor i amb una millor contextualització de la matèria.

Seguidament, s'investiga la possibilitat d'establir un mecanisme de regulació sobre la configuració dels grups, basat en l'anàlisi de les diferències qualitatives i quantitatives observades entre els resultats del treball cooperatiu i les aportacions personals prèvies dels membres de cada grup. D'aquesta manera, se pretén millorar la eficàcia d'aquesta metodologia amb l'objecte de desenvolupar el currículum de secundària per a elaborar una proposta d'estudi que el faça més proper a las situacions habituals del nostre entorn i que permeta als alumnes millorar la seua comprensió i rendiment acadèmic. 
En una primera fase del treball empíric, se porta a terme un estudi exploratori amb alumnes de batxillerat i de primers cursos universitaris, per detectar quines són les seues deficiències i les dificultats que troben en l'aprenentatge de la química. En funció dels resultats obtinguts, es determinaren els temes nuclears en els que s'evidencia major dificultat: l'enllaç químic.

A partir d'aquest diagnòstic, es dissenyà una intervenció didàctica, tractant de seguir un mètode basat en el treball individual i es va fer en dos direccions: una per a tercer curs d'ESO, on els alumnes prenen contacte per primera vegada amb el concepte d'enllaç químic, i altra per al segon curs de batxillerat, on s'estudia aquest tema amb major profunditat sent, a més a més, el curs que precedeix a la selectivitat i a l'accés universitari, en el seu cas. En ambdues propostes, s'intenta, partint de situacions de la vida quotidiana, lliurar la barrera que suposa l'abstracció dels conceptes que porta implícita la química en ella mateixa.

Una vegada aplicat el disseny experimental, es va procedir a estudiar els resultats obtinguts, comparant-los amb grups de control i a confirmar la validesa de la proposta als dos nivells d'estudi.

En la segona fase d'aquesta investigació diagnostica, s'indagaren les relacions que poden existir entre els resultats obtinguts pels alumnes, centránt-nos en la influència que existeix entre les competències inicials i finals de cada un d'ells. Concretament, s'ha buscat l'existència de concordàncies entre aquells continguts d'interès que deurien conèixer-se prèviament al començament de l'estudi del tema i aquells que domina l'alumne després de la intervenció, el que permet establir unes variables en termes de coneixements inicials i coneixements finals que, des d'un punt de vista purament constructivista, defineix els aspectes que són necessaris com a prerrequisits per a aprendre altres de major dificultat i quins aspectes no ho són.

Una vegada definits els problemes que es troben a l'ensenyament tant dels conceptes bàsics com els propis de l'enllaç químic, es va procedir a desenvolupar un nucli de continguts de química de primer de batxillerat, utilitzant una metodologia cooperativa. L'eix principal de la investigació va consistir en buscar quina seria la millor forma d'organitzar els grups a l'aula, a partir d'un mecanisme de realimentació 
que permetera d'una forma dinàmica la interacció positiva entre els alumnes. Per a durho a terme, es va realitzar una suculència d'activitats en les quals els alumnes treballaren de forma conjunta.

Inicialment, els grups es varen formar de forma aleatòria i, després, es varen realitzar reordenaments en base als resultats que s'anaren obtenint. Aquesta reordenació obeeix a un intent d'obtindre profit a la interacció entre els alumnes, tal com exposa Vygotsky a la seua teoria de la "zona de desarrollo próximo".

Després de desenvolupar les activitats proposades i els seus exercicis d'avaluació corresponents s'ha realitzat un tractament estadístic per a quantificar l'efecte produït per aquestes dinàmiques en els alumnes. Hem pogut contrastar la eficàcia del treball cooperatiu, la possibilitat d'exercir una ràpida valoració de les interaccions de cada alumne en el seu grup de treball, i la millora que s'experimenta després de la reordenació.

Després de realitzar aquest treball, ha quedat clar que es pot optimitzar el treball cooperatiu, el que suposa una confirmació de la pròpia teoria de Vygotsky en quant a que confirma que la millora del rendiment s'aconsegueix a través d'una interacció constructiva, més enllà d'un simple augment d'aportacions individuals.

La principal aportació d'aquesta metodologia és la possibilitat d'exercir de forma ràpida i eficaç la realimentació durant el propi procés. D’aquesta forma, s'aconsegueix una reordenació en la configuració dels grups de treball que busca millorar el rendiment de cadascú d'ells i obtindre una eina que permeta al professor disposar de forma relativament ràpida d'una informació que li permeta distribuir al alumnat en aquest tipus de treball grupal. 


\section{INTRODUCCIÓN}

La realización de la presente Tesis obedece a la preocupación por contribuir a la resolución de algunas cuestiones que se plantean en enseñanza secundaria, dentro del desarrollo normal de las clases de química.

La incorporación a la universidad es un momento importante en la trayectoria académica de cualquier estudiante. En España, el paso de la escuela secundaria a la universidad es especialmente conflictivo. Se produce un salto muy acusado, hasta el punto de que la adaptación resulta demasiado compleja, lo que deriva en una importante tasa de abandono en los primeros cursos universitarios y una prolongación excesiva en el tiempo empleado para finalizar los estudios (Anglés, 2007).

La mayoría de docentes culpan de este problema a la LOGSE, por su permisividad para con los alumnos de Secundaria, ya que permite situaciones como la de pasar directamente de curso en ESO, por promoción automática, tras haber repetido, aun teniendo muchas asignaturas suspendidas (MEC, 2006).

El informe PISA (Programme For Internacional Student Assessment) correspondiente al año 2003 coloca a los escolares españoles, en rendimiento académico medio, por debajo del resto de países de la OCDE. Entre los 29 países analizados, España quedó situada en el puesto 20 en cuanto a conocimientos en matemáticas, en el puesto 22 en lectura y en el puesto 21 en materias científicas, sólo por delante de Portugal, Italia y Grecia. (Aranda y Gómez, 2005; MEC, 2004).

La competencia básica principal estudiada en el informe PISA correspondiente al año 2006 ha sido ciencias, después de que en el informe PISA del año 2000 fuera la lectura y en el del año 2003 lo fuesen las matemáticas. En 2006 han participado 57 países, incluidos los 30 de la OCDE y otros 27 países asociados. Los resultados promedio de España en ciencias son similares a los del resto de países de la OCDE (media de alumnos) y ligeramente inferiores a los del Promedio OCDE (media de países) (MEC, 2007).

Los resultados de este último informe aconsejan una reflexión que debería extenderse a los diferentes aspectos que afloran como debilidades o fortalezas del 
sistema educativo español, en concreto la mejora del rendimiento de todos los alumnos en cuanto a equidad, que no en calidad.

A la vista de los datos, no es extraño que la mayoría de expertos coincidan en señalar el paso de la enseñanza secundaria a la Universidad como una etapa cargada de deficiencias en el aprendizaje de determinadas materias. Para tratar de minimizar estos aspectos se están utilizando desde hace algunos años los "cursos cero" de diferentes materias, de igual forma que se hace en otros países (Argentina, Francia...), bien como clases previas al curso o bien como cuatrimestres, pero siempre de forma inicial (Olmos, 2006).

En el caso concreto de la química existen dificultades que derivan tanto de la estructura y organización del bachillerato como de los aspectos característicos propios de la disciplina. De hecho, una dificultad importante es la gran optatividad con que cuentan los alumnos (MEC, 2007), lo que, en muchos casos, les lleva a evitar la química, dentro de una población que estudia cada vez menos bachillerato de ciencias.

El estudio de la química presenta dificultades conceptuales específicas, que derivan de su propia epistemología y que surgen como consecuencia de la abstracción intrínseca de sus contenidos, que en numerosas ocasiones resultan difíciles de ubicar en la vida real por parte del alumno (Caamaño e Izquierdo, 2003). Del mismo modo, se observa que, como en la mayoría de las disciplinas, hay un gradiente de dificultad según avanzan los cursos y que, siendo los iniciales más sencillos en cuanto a contenidos, son los que sientan las bases para los siguientes.

En nuestra materia, existen unos conocimientos básicos que condicionan notablemente la adquisición de contenidos posteriores (Azcona, Furió, Intxausti y Álvarez, 2004). A ello hay que añadir que, con el tiempo, los alumnos deben ir adquiriendo unas herramientas propias, como la formulación, el conocimiento de material de laboratorio, la utilización de unidades o el manejo de la estequiometría ya que, llegados a un curso superior, deben dominarlas.

Frente a esta situación, que se va definiendo claramente a medida que los alumnos van progresando en sus estudios, cabe buscar alternativas que permitan obtener un aprendizaje significativo que forme científicamente a los alumnos, permitiéndoles 
acceder a los estudios universitarios y al mismo tiempo les haga comprensible y amena la materia.

Desde principios del siglo pasado existe el convencimiento por parte de muchos pedagogos de que la educación, además de servir como elemento transmisor de cultura y organización social, también debe contemplar la preparación de los alumnos para una vida con valores democráticos en la que cada uno pueda disfrutar de aprender el significado de las cosas, la resolución de conflictos, la negociación y la cooperación en la realización de tareas (Fabra, 1992).

Tras el cambio de sistema educativo llevado a cabo en nuestro país en la década de los noventa y la implantación de la LOGSE, aumentan considerablemente los objetivos procedimentales y actitudinales frente a los puramente conceptuales. Se desplaza la preocupación por los contenidos a la preocupación por la forma de obtenerlos, cómo desarrollarlos y cómo aplicarlos. Por tanto, el profesorado debe ir cambiando su papel de transmisor unidireccional de conocimientos a una figura que ayude al alumno adquirir las competencias necesarias y a madurar como persona.

En una situación más próxima, y en el ámbito de la educación universitaria, podemos encontrar ese mismo fenómeno tras la Declaración de Bolonia de 1999, ya que la pretensión de crear un Espacio Europeo de Educación Superior conlleva importantes cambios relacionados con el papel del profesor y, sobre todo, del alumno, que pasa a ser el eje del proceso de enseñanza-aprendizaje y del que se espera que adquiera mayores competencias instrumentales e interpersonales.

Desde esa perspectiva es desde la que se justifica la conveniencia e importancia del trabajo cooperativo.

El enfoque curricular de la química o de cualquier otra materia de ciencias a nivel de secundaria hace que la metodología difiera considerablemente de la empleada con una metodología basada en el trabajo en grupo en cuanto a su organización, motivación e implicación de los alumnos y sobre todo en cuanto a su finalidad, puesto que en ésta se persigue la resolución en grupo y de forma autónoma, de problemas abiertos, con soluciones múltiples y relacionados con cuestiones de la vida real que se 
hace patente en campos muy específicos, lejos de la rigidez que impone el temario y las pruebas de acceso universitario en segundo de bachillerato (Gómez-Crespo, Gutiérrez y Martín-Díaz, 2003), (Calatayud y Hernández, 2003).

En Secundaria, el enfoque curricular que se da a la química o a cualquier otra materia de ciencias hace que la metodología que se utiliza la mayor parte de las veces difiera considerablemente de la que usaríamos con una metodología basada en un trabajo en grupo, tanto en lo que hace referencia a la organización, motivación e implicación de los alumnos como, sobre todo, en lo relacionado con su finalidad, puesto que en ésta se persigue la resolución, en grupo y de forma autónoma, de problemas abiertos, con soluciones múltiples y relacionados con cuestiones de la vida real, lo que queda muy lejos de la rigidez que impone el temario y las pruebas de acceso a la Universidad en segundo de bachillerato (Gómez-Crespo, Gutiérrez y Martín-Díaz, 2003), (Calatayud y Hernández, 2003).

Parece, pues, sensato buscar aquellos aspectos de la dinámica grupal que puedan ayudar a conseguir los objetivos que se persiguen en Educación Secundaria Obligatoria y en Bachillerato, es decir, sin perder el marco curricular de la secundaria. De ese modo, se pueden intentar adoptar aquellas técnicas que resulten provechosas e intentar buscar puntos de mejora en nuestra actividad docente. Desde ese punto de vista, lo razonable sería buscar el modo de hacer compatible la metodología cooperativa con el currículo oficial, así como identificar los obstáculos que conllevaría su utilización en la enseñanza secundaria actual.

El tema del enlace químico recibe un tratamiento relevante en los textos y su localización es siempre al principio de la química, hecho que queda patente al considerar la extensión que se le dispensa (de Posada, 1993). Es por ello, por lo que seleccionaremos ese tema como contexto de aprendizaje para nuestra investigación.

Desde un punto de vista curricular, el tema del enlace se encuentra ubicado, en todos los niveles académicos, a continuación de los temas que estudian aspectos básicos de química y antes de abordar otros más complejos como el equilibrio, la química orgánica o la química industrial. Podemos, por tanto, establecer un antes y un después 
del tema del enlace químico y ese es otro motivo por el que hemos elegido este tema como objeto de investigación diagnóstica.

Además de ello, en este tema se presenta, en todo su alcance, el conocido e importante problema de la relación entre modelo y realidad, lo que lo convierte en relevante en todo lo que concierne a su seguimiento.

A la vista de los contenidos y de la presión que impone el sistema educativo en lo que hace referencia a la temporalización de los mismos, el margen de operación, a la hora de extenderse en un punto concreto del temario, es mucho mayor en tercer curso de ESO que en segundo de bachillerato. Ello se debe a que hay menos contenidos y mayor flexibilidad para distribuir las sesiones a lo largo del curso, al tiempo que es la primera vez que los alumnos estudian el tema de forma explícita. Por otro lado, el número de estudiantes que lo cursan es mucho mayor que en bachillerato. Dado que, además, la mayoría de ellos no cursará química y, por tanto, no volverá a estudiar estos aspectos, la vertiente finalista es marcadamente más importante que en bachillerato, donde prima el carácter propedéutico.

Situándonos en la intervención diagnóstica que pretendemos desarrollar, el objetivo consiste, por un lado, en enmarcar el tema dentro de un problema que perfectamente puede plantearse un alumno en su vida diaria, tal como promueven las actuales tendencias $\operatorname{CTSA}^{1}$ y que servirá para contextualizar el estudio y justificar el porqué de la necesidad de aprender aquello, a partir de la posible aplicación real. Por otro lado, basamos el desarrollo del tema en la explicación de las propiedades físicas propias de cada tipo de sustancias, explicitables a través de los métodos de separación de sustancias y los modelos de enlace químico en segundo de bachillerato, y el conflicto cognitivo que puede crearse en un alumno de tercero de ESO cuando se plantean situaciones donde un mismo elemento forma parte de sustancias muy diferentes.

Por tanto, se formulan dos propuestas, una en cada curso, siendo en ESO más abierta y en bachillerato más limitada, en ambos casos el objetivo será el mismo: ofrecer al alumno una perspectiva del enlace más cercana a la realidad, acompañada del porqué de la necesidad de su estudio.

\footnotetext{
${ }^{1}$ CTSA: Ciencia, Tecnología, Sociedad y Ambiente.
} 
Lo que pretendemos es utilizar una metodología de trabajo cooperativo durante el desarrollo del temario, de modo que el papel esencial del profesor sea el de diseñador y facilitador del proceso de aprendizaje, proporcionando en cada momento a los alumnos la realimentación adecuada en un contexto de trabajo colaborativo. No obstante, nos enfrentamos al obstáculo que suponen los amplios temarios y unas pruebas de acceso a la universidad que imponen una pauta muy determinada al desarrollo del curso que, sobre todo, en segundo de bachillerato obliga a centrarse en la resolución de problemas de "lápiz y papel" de forma rutinaria y/o memorística, abordando de forma algorítmica contenidos susceptibles de ser enfocados de modo significativo convirtiendo una materia eminentemente práctica en una variante más algorítmica, más árida, más abstracta, más alejada del modo científico de abordar los problemas y, por supuesto, con menor atractivo para los estudiantes, con la consecuencia lógica de que los alumnos evitan la química en bachillerato ante la posibilidad de optar por otras materias, con las que se crea una clara competencia (Caamaño, 2003) (Ametlla, 2003).

Centrándonos en la investigación que pretendemos desarrollar, el aspecto innovador de este trabajo reside la propuesta y evaluación de una metodología para la gestión del trabajo cooperativo basada en el análisis de la diferencia entre las aportaciones individuales de los miembros de un grupo y el resultado del trabajo cooperativo, a través de tareas de evaluación ordinarias. Dicha metodología se caracteriza, frente a otros enfoques procedentes de la investigación educativa, por la posibilidad de ejercer una realimentación rápida y eficaz durante el propio proceso de aprendizaje.

El fundamento teórico de esta metodología es el concepto ZDP, en el marco del constructivismo social de Vygotsky. Desde ese punto de vista, la diferencia entre esos dos niveles, individual y colectivo, reside en la interacción que ejercen entre sí los individuos cuando trabajan junto a otros de mayor nivel o entre iguales, definiendo la zona de desarrollo próximo como la diferencia entre lo que un individuo es capaz de aprender por sí mismo o con la ayuda de otros, sin olvidar que la optimización de esa interacción requiere una adecuada gestión del trabajo cooperativo y éste, a su vez, un proceso continuo de realimentación durante el aprendizaje. 


\section{PRIMERA PARTE}

EL TRABAJO COOPERATIVO Y LA EVALUACIÓN COMO

INTRUMENTOS DE REGULACIÓN EN EL AREA DE QUÍMICA EN EDUCACIÓN SECUNDARIA 


\section{1.- ENSEÑANZA Y APRENDIZAJE DE LA QUÍMICA}

\section{ENSEÑANZA Y APRENDIZAJE DE LA QUÍMICA}

\section{La química dentro del actual sistema educativo}

\subsubsection{Finalidad}

En enseñanza secundaria, el currículo de química ha evolucionado a lo largo de las últimas décadas, debido a los sucesivos cambios que han ido ocurriendo en el sistema educativo (Caamaño, 2001).

Hasta los años setenta del siglo pasado, el sistema educativo comprendía una enseñanza obligatoria hasta los diez años, donde apenas se enseñaban algunos conceptos científicos básicos; desde los diez a los dieciséis se podía estudiar un bachillerato elemental y un bachillerato superior, que sólo cursaba un 3\% de la población escolar (Furió y otros, 2001) y, a continuación, un curso preuniversitario necesario para acceder a la Universidad.

Con la reforma de los años setenta, la enseñanza obligatoria se extendió hasta los 14 años, introduciéndose la EGB (Educación General Básica), donde sí había una carga importante de contenidos científicos. Tras esa etapa obligatoria había dos opciones: cursar una formación profesional (de baja consideración social) o un bachillerato, con una finalidad claramente basada en un enfoque universitario y que era cursado por un $80 \%$ de los estudiantes. Este bachillerato era seguido, mayoritariamente, por un curso de orientación universitaria que, prácticamente, era otro curso de bachillerato, lo cual se explica al tener en cuenta la formación del profesorado que lo impartía, generalmente licenciado, sin una formación docente específica que fuese más allá de la derivada de su motivación o voluntad propia.

A partir de los años noventa, con la introducción de la LOGSE, se trató de eliminar una visión de la ciencia centrada exclusivamente en la adquisición de conceptos científicos, pasando a prestar mayor atención a los procesos y buscando una mayor conexión con la realidad social más próxima. 
Con los planes de estudio actuales, se pretende formar a los alumnos para que se conviertan en ciudadanos con conocimientos científicos y tecnológicos que les permitan tener un pensamiento, de cara al medio que nos rodea, crítico y consciente en lo que respecta a la resolución de problemas cotidianos o a la asunción de valores como el respeto al medio ambiente o a un desarrollo sostenible.

El hecho de que la enseñanza secundaria tenga como uno de sus objetivos la alfabetización científica, implica que el currículo tienda a priorizar la comprensión de la naturaleza, al tiempo que presta atención a sus aplicaciones y al desarrollo de una actitud crítica con el entorno, frente a otros contenidos disciplinares que forman un cuerpo de conocimientos que, en el caso de la química, son fundamentales, sobre todo en los estudios posteriores.

Dentro de la LOGSE se han ido implementando diversos cambios desde su implantación, que no pueden ser denominados reformas ni cambios de sistema educativo, puesto que la actual ley sustituye a la de 1971, siendo éste el único cambio realmente significativo que se produce en cuanto a materias, horarios, edades de los alumnos, etc. Sin embargo, en su evolución pueden distinguirse dos fases claramente diferenciadas, marcadas por sendos Reales Decretos de los años 1991 y 2000.

Por lo que respecta a la educación obligatoria, estos dos periodos son tremendamente esclarecedores de cuál es la situación real. Durante el primer periodo, el currículo mantenía un carácter relativamente abierto y señalaba unos contenidos de química que los centros debían distribuir a lo largo de los cuatro años de ESO. En cambio, a partir del año 2000, con el citado Real Decreto se introducen criterios de evaluación al final del primer ciclo y se distribuyen los contenidos en cada curso, haciéndolo más cerrado (Perales, 2003). Así mismo se engloban las cuatro materias (Física, Química, Biología y Geología) en el área de ciencias naturales, con lo que se pierde la posibilidad de un currículo en espiral donde se puedan distribuir los contenidos en función de las observaciones del profesor, introduciéndose un fuerte carácter disciplinar en la materia (Gómez-Crespo, Gutiérrez y Martín-Díaz, 2002).

Con el RD de 2000 (MEC, 2000) se aumentan en gran medida los contenidos de química, lo que presenta la dificultad que supone la falta de tiempo para impartir todo el 
temario. Problema que se antoja mayor en la ESO, donde los alumnos toman contacto por primera vez con la química y deben sentar las bases para un correcto aprendizaje de la misma y una adecuada motivación, lo que convierte en objetivo principal el proporcionar una cultura científica básica, centrada en el manejo de conceptos y la utilización de procedimientos en distintos contextos.

Con el planteamiento actual $\mathrm{y}$, desde un punto de vista curricular, los cálculos matemáticos adquieren mayor importancia, introduciéndose en tercer curso los relacionados con el concepto de cantidad de sustancia y con la estequiometría de reacciones que, previamente, se habían desplazado al bachillerato tras estar situados previamente en el nivel equivalente a cuarto de ESO (Gómez-Crespo, Gutiérrez y Martín-Díaz, 2002).

Si se pretende conseguir un aprendizaje significativo de estos contenidos cabe considerar que gran parte de los alumnos no tienen el nivel cognitivo adecuado para asimilarlos con garantías de éxito, ya que en esta edad tan solo alrededor de un $25 \%$ de ellos alcanza el nivel de pensamiento formal inicial y un $10 \%$ el formal avanzado, mientras que el mayoría de alumnos se encuentran en un estadio concreto, que no permite este tipo de operaciones. (Shayer y Adey, 1984).

Puede afirmarse que, por lo general, la enseñanza suele dar preponderancia al tratamiento matemático, descuidando los aspectos conceptuales. Ello, además de reflejarse en la introducción de cálculos químicos, se observa también en la utilización de unidades tan poco eficaces para realizar estimaciones por parte del alumno como el $\mathrm{m}^{3} \mathrm{o}$ el kg/m $\mathrm{m}^{3}$ en primer curso de ESO, o en tercer y cuarto curso de ESO con el cálculo de masas en reacciones químicas y relaciones estequiométricas y volumétricas, respectivamente.

Autores como Llorens (1994) consideran que la enseñanza de la química tiene como objetivos fundamentales introducir conceptos que permitan organizar y dar sentido a experiencias relacionadas con el medio físico, favoreciendo una relación positiva con el entorno, o incorporar al desarrollo personal y social determinados modos de enfocar los problemas, propios de la metodología científica, que se concretan en la 
adquisición de contenidos procedimentales y de actitudes que enriquecen la formación humana integral de alumnos y alumnas.

Esto lleva a un planteamiento propio del diseño curricular: ¿Qué hay que enseñar? Esta cuestión se puede resolver con un doble enfoque, el primero encaminado a ayudar a las personas a identificar la diversidad de la materia, así como explicar sus regularidades y comportamiento. Y, por otro lado, ver el medio físico que se trata de interpretar con la funcionalidad y significado que tiene para el alumno. Se trata, pues, de asumir un enfoque que contemple las relaciones entre Ciencia, Tecnología, Sociedad y Medio ambiente.

Dejando a un lado la situación en la enseñanza obligatoria, en el siguiente nivel educativo, de acuerdo con los nuevos currículos de bachillerato de ciencias, la química se estudia de forma obligatoria únicamente en primer curso, junto a la física, y en segundo curso en el bachillerato de ciencias de la naturaleza y de la salud, no siendo siquiera materia de modalidad en el bachillerato tecnológico. Esto último va en detrimento de aquellos estudiantes que desean estudiar ingenierías o ciclos formativos donde se requieren conocimientos de química.

Los objetivos generales y los objetivos de las diferentes áreas del Bachillerato en los que se establecen las capacidades que esta etapa ha de contribuir a desarrollar en los alumnos derivan del artículo 26 de la LOGSE que, a título de introducción, presenta como objetivo general el siguiente:

"El Bachillerato tiene como finalidad la formación general de los alumnos y de las alumnas, así como su orientación y preparación para alcanzar una madurez intelectual y humana que les permita integrarse en la vida activa o continuar estudios superiores, tanto universitarios como de formación profesional específica de grado superior". 
De aquí se extrae un doble objetivo para el bachillerato:

1. Finalista, en tanto en cuanto ha de dotar a los alumnos de un conocimiento general de las diferentes materias, que les permita alcanzar una madurez personal. Esto supondría la formación personal del individuo que, en principio, ha alcanzado un nivel medio de estudios y perfectamente puede adaptarse al mundo laboral y social, dejando su actividad académica.

2. Propedéutico, ya que se debe conseguir en el alumno una formación, tanto en contenidos como actitudes y procedimientos, que le permita abordar unos estudios superiores con garantías de mantener un avance acorde con los programas establecidos.

Frente a estos objetivos, la postura del profesorado actual de ciencias está muy definida. La mayoría de docentes en activo o en formación asume el carácter básicamente propedéutico de la enseñanza (Furió, Vilches, Guisasola y Romo, 2001). Si tal y como pretenden las reformas educativas se debe virar hacia una formación global del alumno será necesaria una formación que implique al profesorado directamente en los procesos de enseñanza-aprendizaje, que se originan diariamente en su actividad docente.

En términos prácticos, el Real Decreto 3474/2000 de enseñanzas mínimas supuso una disminución del porcentaje de horas lectivas dedicadas a las materias de modalidad y una disminución en términos absolutos de horas dedicadas a las materias optativas (Caamaño, 2003). Junto a esta situación encontramos varios factores que influyen en la situación actual de los bachilleratos de ciencias.

Por un lado, el bachillerato científico compite en muchos centros con el tecnológico, como itinerario hacia las ingenierías. En el bachillerato tecnológico son pocos los alumnos que escogen química, pues compite con la tecnología industrial, la mecánica, la electrónica y el dibujo técnico. 
Por otro lado, el descenso de la natalidad y la dispersión de los estudios, provoca que en algunos centros existan grupos con 10 alumnos, lo que cuestiona la existencia de centros mixtos de ESO y Bachillerato.

Y, por último, desde un punto de vista organizativo, el alumnado dedica un 50\% de su horario al estudio de materias comunes y sólo un $30 \%$ a las asignaturas de modalidad de ciencias (Ametlla, 2003). Así mismo, las actividades experimentales no están especificadas ni en objetivos ni en contenidos, ni están presentes en las pruebas de acceso a la universidad.

Para muchos alumnos, no es fácil adaptarse al bachillerato por lo que supone en esfuerzo personal, ritmo de clase, contenidos y, sobre todo, nivel de abstracción de conceptos. Debido a ello, su preparación para los estudios posteriores no es adecuada, si no se ha producido un abandono previo.

Los alumnos han de asimilar conceptos abstractos (orbitales, equilibrios, entalpía, entropía, etc.) cuyas representaciones conceptuales contradicen a lo que sugiere el sentido común de una persona no instruida y deben ser ilustrados con abundantes ejemplos y complementados con la resolución de problemas. En opinión de algunos investigadores (Ametlla, 2003), la respuesta de las autoridades educativas debería pasar por ampliar la temporalización en una hora adicional, dedicada a laboratorio, y obligar a todos los alumnos a cursar la química al menos en un curso, tanto a alumnos de bachillerato de ciencias como de bachillerato tecnológico.

Hay autores que apuntan que el actual currículo es una suma del currículo anterior más los decretos mínimos, por lo que el temario es absolutamente inalcanzable y supera en mucho al del anterior COU (Calatayud y Hernández, 2003), lo que impide el tratamiento de otros contenidos.

En realidad el currículo enseñado dista bastante del currículo propuesto y, al final, la práctica es la que valida el currículo, siendo las pruebas externas las que determinan el programa, haciendo necesario alcanzar acuerdos con los coordinadores de las universidades. 
Este problema es compartido con otras asignaturas de ciencias. La falta de tiempo se traduce en la eliminación de trabajos prácticos que didácticamente ayudarían a superar la abstracción que suponen las ciencias y su falta de atractivo (Caamaño e Izquierdo, 2003) y que suponen un aspecto fundamental de la química, al ser ésta una ciencia experimental. Asimismo, muchas de las competencias pretendidas por los currículos están vinculadas a estas actividades, por lo que su eliminación, podría suponer la eliminación de la química como materia y su utilización como herramienta en otras materias como biología, geología o ciencias del medio ambiente.

En consecuencia, la química de bachillerato presenta un currículo con exceso de contenidos y falta de tiempo para desarrollarlos (Gómez-Crespo, Gutiérrez y MartínDíaz, 2003; Calatayud y Hernández, 2003). Algunos autores consideran que se han mantenido los esquemas antiguos del BUP y COU, pero con unas finalidades diferentes encaminadas a la formación científica personal.

El currículo debe perseguir, a través de los contenidos, que los alumnos adquieran determinadas capacidades. Se debe formar ciudadanos para recibir mensajes de ciencia y tecnología pero formándolos en dicha ciencia. La clave está en buscar un equilibrio entre formar con profundidad en las diferentes teorías, dando una base sólida de conocimientos y conjugarlo con la vida social y personal.

Ambos aspectos se trataron de conjugar, en lo que hace referencia a la formación del profesorado en el R.D. de 1992, sin obtener éxito, por lo que fue eliminada esa postura en el R.D. de 2000. No obstante, hay muchos factores que influyen de cara a construir un currículo de química adecuado, ya que no hablamos de una situación aislada, sino que está relacionada con la motivación, la edad, las diferencias de aprendizaje, etc.

Como un intento de contextualizar los contenidos química y su relación con el entorno hay que considerar los resultados de la adaptación y experimentación del proyecto británico Salters Advanced Chemistry en España y en otros países europeos como Suecia, Estonia, Rusia y Alemania. La adaptación y experimentación en Cataluña, Madrid y Valencia del proyecto Química Salters (Grup Salters, 1999,2000a, 2000b) durante los cursos 96-97, 97-98 y 98-99 mostró que la aplicación de la química como 
hilo conductor resultaba muy sugestiva, pero que abordar esta materia desde de punto de vista CTS era muy difícil con el tiempo de que se dispone y con el tipo de la prueba de acceso actual. No obstante, se hace necesario considerar este tipo de propuestas para conseguir un currículo más contextualizado.

Con lo hasta aquí expuesto, observamos que hay unos fines claros en ambas etapas de la educación secundaria y que las autoridades educativas tratan de encontrar el punto óptimo en la formación de los alumnos, mientras que la investigación didáctica trata de analizar y fundamentar todos esos procesos. Parece positivo, por tanto, todo intento de contribuir en la mejora de los aspectos didácticos de la química como materia y de la educación como bien de todos los alumnos. 


\subsubsection{Perspectiva curricular}

La química se imparte a lo largo de toda la enseñanza secundaria, aunque en los cursos superiores no es obligatoria y los alumnos pueden elegirla o no en función de sus expectativas. La presencia de esta materia es la siguiente:

\begin{tabular}{|c|c|c|}
\hline \multirow{4}{*}{$\begin{array}{l}0 \\
\mathscr{W} \\
\text { I }\end{array}$} & 1er curso & $\begin{array}{l}\text { Obligatoria para todos los alumnos en la materia "ciencias de la } \\
\text { naturaleza", que agrupa la física, química, biología y geología. }\end{array}$ \\
\hline & $2^{\circ}$ curso & $\begin{array}{l}\text { Obligatoria para todos los alumnos en la materia "ciencias de la } \\
\text { naturaleza", que agrupa la física, química, biología y geología. }\end{array}$ \\
\hline & 3er curso & $\begin{array}{l}\text { Obligatoria para todos los alumnos en la materia "física y } \\
\text { química". }\end{array}$ \\
\hline & $4^{\circ}$ curso & Optativa; se elige entre otras materias. \\
\hline
\end{tabular}

\begin{tabular}{|c|c|c|}
\hline$\stackrel{\ominus}{=}$ & 1er curso & Obligatoria en el bachillerato de Ciencias y Tecnología. \\
\hline 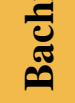 & $2^{\circ}$ curso & $\begin{array}{l}\text { De modalidad en el bachillerato de Ciencias y Tecnología. Los } \\
\text { alumnos pueden escoger o no esta asignatura }\end{array}$ \\
\hline
\end{tabular}

Tabla 1.1.- Presencia de la química en los cursos de Secundaria Obligatoria $^{1}$ y Bachillerato ${ }^{2}$.

\footnotetext{
${ }^{1}$ MEC (2007). Real Decreto 1467/2007, de 2 de noviembre, (BOE, 6 de noviembre de 2007) por el que se establece la estructura del bachillerato y se fijan sus enseñanzas mínimas.

2 MEC (2006). Real Decreto 1631/2006, de 29 de diciembre, (BOE, 5 de enero de 2007) por el que se establecen las enseñanzas mínimas correspondientes a la Educación Secundaria Obligatoria.
} 


\subsubsection{Evaluación}

En las últimas décadas se viene produciendo un cambio de paradigma en las teorías del aprendizaje, del conductivismo al constructivismo, con notables consecuencias metodológicas. Algunos autores consideran que se está abandonando progresivamente la enseñanza por transmisión-recepción y cambiando el rol de profesor de transmisor de conocimientos a orientador en los procesos de enseñanza-aprendizaje. No obstante, para que se pueda considerar que ha habido un cambio real de paradigma es necesario que se acompañe de un cambio en la concepción de la evaluación y en la forma en que se lleva a cabo (Linn, 1987).

Tradicionalmente, la evaluación se ha utilizado para verificar el rendimiento del alumno después del periodo de instrucción (Martínez Torregrosa el al, 1999), por lo que es conveniente distinguir entre evaluación y calificación. Persiste la idea tradicional de evaluación como medida cuantitativa de lo que el alumno sabe, mientras que la concepción actual de evaluación se refiere a la concepción de aprendizaje como construcción de conceptos, procedimientos y actitudes. En este mismo sentido, la evaluación debe entenderse como un análisis de la situación, en cuanto a la verificación del cumplimiento de un objetivo, confirmación de un grado de aprendizaje, o estimación de un cambio conceptual, que conlleve a una visión crítica del proceso, convirtiéndose en un instrumento para su mejora. Por ello enseñar, aprender y evaluar son procesos inseparables (Jorba y San Martín, 1996).

La evaluación suele confundirse con la calificación, como tarea destinada a medir lo que un alumno sabe, utilizando exámenes o pruebas, en los que las preguntas y los problemas conducen a decidir si lo que se sabe es suficiente o no, por comparación con patrones que tiene establecidos el profesor a partir de la programación o basándose en pruebas externas como las pruebas de acceso a la universidad o pruebas propuestas por compañeros. La evaluación no debe centrarse únicamente en contenidos declarativos, ya que se persigue un aprendizaje significativo. Se debe indagar en las relaciones entre los nuevos conceptos y la estructura cognitiva del alumno.

Por ello se puede distinguir entre calificación como obtención de una expresión cuantitativa del grado de adquisición y desarrollo de aspectos conceptuales, procedimentales y actitudinales, y la evaluación como recogida y análisis de 
información del proceso de enseñanza-aprendizaje para intervenir sobre él, siendo la calificación un aspecto de la misma (evaluación sumativa).

En este sentido cabe preguntarse de forma objetiva cual es la función del proceso de evaluación, al margen de la pura calificación, planteándonos de este modo, el carácter pedagógico que conlleva. Previa estimación de los objetos de estudio como pueden ser por una parte el grado de conocimiento declarativo, procedimental o actitudinal, y por otra la idoneidad de los objetivos, la metodología empleada por alumnos y por el profesor, sus interacciones, el ambiente en clase, la actitud del profesor o las propias técnicas de evaluación, debe adaptarse todo el proceso al progreso, características y necesidades del alumno a fin de mejorar su aprendizaje.

Centrándonos en el aspecto sumativo de la evaluación, ésta es una valoración por parte de un profesor que conlleva una toma de decisiones que repercute fuertemente en la vida del alumno sobre todo desde el punto de vista social, académico y personal, sin embargo ésta se reduce a pruebas escritas de las que generalmente no se prueba su validez ni homogeneidad respecto al contexto educativo de cada situación particular, ni de la materia en general. Más bien las decisiones no se basan en un modelo estructurado, sino que son decisiones ad hoc, es decir surgen a demanda de la situación de clase o de exigencias institucionales.

Una importante consecuencia es que la preocupación de los estudiantes reside entonces en superar los exámenes, por lo que se buscan estrategias de estudio, no de aprendizaje (Novak, 1991). No obstante también influyen los resultados de los exámenes en el comportamiento de los profesores (Alonso et al, 1995) al identificar la evaluación con la recogida "objetiva“de datos, acercándose a los aspectos más fácilmente medibles.

En conclusión, la evaluación supone obtener datos del proceso de enseñanzaaprendizaje pero también debe suponer una reflexión crítica sobre los factores que intervienen es este proceso (Alonso Tapia, 1997).

La evaluación, para ser coherente con el paradigma constructivista debe ser una evaluación continua formativa. Es decir debe ser un proceso que se inicia en el comienzo del proceso de aprendizaje con la evaluación inicial y continúa durante toda la instrucción. Trata de determinar la posición del alumno respecto a un patrón 
previamente establecido, además informa al alumno de su progreso para servir como instrumento regulador (Ayensa, 2001), tratando además, de promover la reflexión del alumno sobre su propio aprendizaje.

Desde un punto de vista pedagógico la evaluación debe determinar el punto de partida de los estudiantes, con el fin de modificar las actividades programadas ajustándose a sus ideas. Además debe contemplar cómo se desarrollan las actividades de clase para facilitar la interacción en el aula y adaptar la acción pedagógica según precise cada alumno, con lo que también se contribuye a su propia autoestima. Por último, debe actuar como sistema de control y regulación para el profesor y la propia de los alumnos, aumentando la autonomía de estos últimos (Ayensa, 2001).

A partir de estas premisas cabe indagar en el mecanismo de evaluación que se contempla dentro del sistema educativo ordinario. Para ello, el Ministerio de Educación y las Consejerías de las CCAA con competencias transferidas, establecen unas directrices en forma de criterios de evaluación que, junto a los objetivos de cada materia y a sus contenidos, configuran el primer nivel de concreción curricular y que son la referencia para establecer los patrones de evaluación en segundo y tercero de éstos, donde se articula la tarea del aula.

En el caso concreto del enlace químico, dentro del área de química, encontramos las directrices de evaluación en los Reales Decretos donde se contempla este contenido para cada uno de los cursos:

- REAL DECRETO 1631/2006, de 29 de diciembre, por el que se establecen las enseñanzas mínimas correspondientes a la Educación Secundaria Obligatoria.

- REAL DECRETO 1467/2007, de 2 de noviembre, por el que se establece la estructura del bachillerato y se fijan sus enseñanzas mínimas.

En ambos Reales decretos se establecen los principios básicos de evaluación:

1. La evaluación del proceso de aprendizaje del alumnado de la Educación Secundaria Obligatoria será continua y diferenciada según las distintas materias del currículo.

2. Los profesores evaluarán a sus alumnos teniendo en cuenta los diferentes elementos del currículo. 
3. Los criterios de evaluación de las materias serán referente fundamental para valorar tanto el grado de adquisición de las competencias básicas como el de consecución de los objetivos.

4. El equipo docente constituido por el conjunto de profesores del alumno, coordinados por el profesor tutor, actuará de manera colegiada a lo largo del proceso de evaluación y en la adopción de las decisiones resultantes del mismo, en el marco de lo que establezcan las administraciones educativas.

5. En el proceso de evaluación continua, cuando el progreso de un alumno no sea el adecuado, se establecerán medidas de refuerzo educativo. Estas medidas se adoptarán en cualquier momento del curso, tan pronto como se detecten las dificultades y estarán dirigidas a garantizar la adquisición de los aprendizajes imprescindibles para continuar el proceso educativo.

6. Los profesores evaluarán tanto los aprendizajes del alumnado como los procesos de enseñanza y su propia práctica docente. 


\subsection{Aprendizaje de la química}

\subsubsection{Teorías de aprendizaje}

Una teoría es un cuerpo coherente de explicaciones fundamentadas en conceptos, todo lo cual es construido en forma lógica para responder hipótesis y proposiciones, interpretando sistemáticamente un área del conocimiento. En el caso de una teoría didáctica, se refiere a las explicaciones y fundamentaciones coherentes que se proporcionan para dar respuesta al dilema de cuál es la mejor forma de enseñar determinada materia como fin último.

A lo largo del siglo XX, se han definido dos paradigmas claros dentro del ámbito de la psicología del aprendizaje: El conductivismo y el cognitivismo.

El conductivismo, como teoría de aprendizaje, se centra en el estudio de conductas que se pueden observar y medir; ve a la mente como una "caja negra" en el sentido de que las respuestas a estímulos se pueden observar cuantitativamente excluyendo totalmente la posibilidad de conocer los procesos que puedan darse en su interior. Su objetivo es conseguir una conducta determinada, para lo cual analiza el modo de conseguirla.

De esta teoría se plantearon dos variantes:

- El condicionamiento clásico, basado en la asociación entre estímulo y respuesta contigua, de forma que si sabemos plantear los estímulos adecuados, obtendremos la respuesta deseada.

- El condicionamiento instrumental y operante, que desarrollado por Skinner, persigue la consolidación de la respuesta según el estímulo, buscando los refuerzos necesarios para implantar esta relación en el individuo.

El cognitivismo, surgió en la psicología norteamericana durante la década de los 50. Principales protagonistas en su desarrollo fueron, el suizo Jean Piaget, quién ya planteó los principales aspectos de esta teoría durante los años 20, estableciendo niveles cognitivos en los estudiantes, o el estadounidense Jerome Brunner, quien planteaba que 
las estrategias metodológicas deben variar según el estado de evolución y desarrollo del alumno.

El cognitivismo abandona la orientación mecanicista pasiva del conductismo y concibe al sujeto como procesador activo de la información a través del registro y organización de la misma, para llegar a su reorganización y reestructuración en el aparato cognitivo del aprendiz. Esta reestructuración no se reduce a una mera asimilación, sino a una construcción dinámica del conocimiento, es decir, los procesos mediante los que el conocimiento cambia. En términos piagetianos, la acomodación de las estructuras de conocimiento a la nueva información.

Ausubel, dentro de este modelo describe dos tipos de aprendizaje ${ }^{3}$ :

- Aprendizaje repetitivo: conlleva la memorización de la información que pretende ser aprendida, ya que su relación con la información existente esta ya definida.

- Aprendizaje significativo: La información es comprendida por el alumno si hay una relación importante entre la nueva información y la previamente existente en la estructura cognitiva.

Según los autores cognitivos, el estudiante debe desarrollar habilidades y estrategias para desenvolverse en otras situaciones de aprendizaje, aplicando los conocimientos adquiridos. Es decir, el alumno debe entenderse como un sujeto activo procesador de información y que posee esquemas y estrategias para resolver problemas.

El constructivismo es el principal exponente de las teorías cognitivas. En realidad, cubre un espectro amplio de teorías acerca de la cognición que se fundamentan en que el conocimiento existe en la mente como representación interna de una realidad externa. En el constructivismo, el aprendizaje tiene una dimensión individual, ya que al residir el conocimiento en la propia mente, el aprendizaje es visto como un proceso de

\footnotetext{
${ }^{3}$ Desde otro punto de vista el aprendizaje puede ser por recepción, donde el alumno es un mero receptor de información, o por descubrimiento, donde el alumno asimila el conocimiento tres haberle facilitado los elementos necesarios.
} 
construcción individual interna de dicho conocimiento. Desde esa óptica, se describen dos líneas principales basadas en los trabajos de Piaget, que condiciona el aprendizaje al desarrollo cognitivo, y en otro sentido el constructivismo social propuesto por Vygotsky.

Según Piaget, las estructuras de pensamiento se construyen, pues nada está dado desde el comienzo. Según él, el desarrollo de conocimientos en el niño tiene lugar a través del desarrollo de los mecanismos intelectuales. Esas estructuras, ubicadas dentro de estadios evolutivos, se ordenan jerárquicamente integrándose cada una en otra superior, construyendo así nuevos caracteres cognoscitivos.

\begin{tabular}{|c|c|l|}
\hline $\begin{array}{c}\text { Inteligencia } \\
\text { sensorio-motora }\end{array}$ & 0 a 2 años & $\begin{array}{l}\text { Los elementos iniciales son los reflejos del } \\
\text { neonato. Aparece la diferenciación entre "uno" y } \\
\text { el mundo de los objetos }\end{array}$ \\
\hline $\begin{array}{c}\text { Pensamiento } \\
\text { preoperatorio }\end{array}$ & 2 a 7 años & $\begin{array}{l}\text { El niño comienza a hacer uso de pensamientos } \\
\text { sobre hechos u objetos que no son perceptibles, } \\
\text { mediante símbolos dibujos o lenguaje, } \\
\text { interiorizando la palabra, es decir, aparece el } \\
\text { pensamiento. }\end{array}$ \\
\hline $\begin{array}{c}\text { Operaciones } \\
\text { concretas }\end{array}$ & 7 a 12 años & $\begin{array}{l}\text { El niño se encuentra con la posibilidad de utilizar } \\
\text { intuiciones que atañen a objetos concretos, como } \\
\text { clasificaciones, seriaciones o correspondencias, } \\
\text { pero no a hipótesis }\end{array}$ \\
\hline $\begin{array}{c}\text { Operaciones } \\
\text { formales }\end{array}$ & 11 a 15 años & $\begin{array}{l}\text { El preadolescente comienza a elaborar hipótesis y } \\
\text { razona sobre las proposiciones sin necesidad de } \\
\text { hacer comprobaciones. Combina ideas e hipótesis } \\
\text { en forma de afirmaciones y negaciones. }\end{array}$ \\
\hline
\end{tabular}

Tabla 1.2.- Estadios evolutivos propuestos por Piaget.

Desde este punto de vista, el alumno es un constructor activo de su propio conocimiento, por lo que debe actuar en el aula, debiéndose fomentar actividades que surjan libremente del estudiante. En cambio, el profesor debe promover el desarrollo y autonomía de los alumnos, conociendo con profundidad los problemas del aprendizaje y las etapas del desarrollo cognoscitivo. La evaluación debe realizarse sobre procesos, nociones y competencias cognoscitivas del alumno

Vygotsky desarrolla la idea de una perspectiva social de la cognición, que ha dado lugar a la aparición de nuevos planteamientos educativos en la enseñanza. A través de ella, y a diferencia de Piaget, sostiene que ambos procesos, desarrollo y aprendizaje, 
interactúan entre sí, considerando el aprendizaje como un factor del desarrollo. La adquisición de aprendizajes se explica como forma de socialización. Concibe al hombre como una construcción más social que biológica, en donde las funciones superiores son fruto del desarrollo cultural e implican el uso de mediadores.

La interpretación que da Vygotsky a la relación entre desarrollo y aprendizaje permite evidenciar la raíz social que le atribuye al conocimiento humano y el gran aporte que ha recibido el análisis de las prácticas educativas y el diseño de estrategias de enseñanza con su teoría sobre la "zona de desarrollo próximo (ZDP)", la cual concibe como “...la distancia entre el nivel de desarrollo, determinado por la capacidad de resolver independientemente un problema y el nivel de desarrollo potencial, determinado a través de la resolución de un problema bajo la guía de un adulto o en colaboración con un par más capacitado".

Puesto que se encuentra en entre la zona de desarrollo potencial y el máximo nivel alcanzable, la ZDP es donde deben situarse los procesos de enseñanza y de aprendizaje y en donde se desencadena el proceso de construcción de conocimiento del alumno y se avanza en el desarrollo.

Tal vez la teoría de aprendizaje utilizada dependa de la situación del que aprende, al igual que se utiliza la teoría atómica, depende de la situación del que aprende. El modelo de Rutherford se utiliza, con frecuencia, para introducir el concepto de protones, neutrones y electrones en educación básica. Tal vez el conductismo sea adecuado para ciertas situaciones básicas de aprendizaje, mientras que en otras "la teoría cuántica" el constructivismo resulte mejor para situaciones avanzadas de aprendizaje.

De cualquier modo, todos los modelos de aprendizaje persiguen un mismo objetivo y, en sí mismos, todos presentas ventajas e inconvenientes en su utilización. En la siguiente tabla se presentan los más significativos: 


\begin{tabular}{|c|c|c|}
\hline & Ventaja & Inconveniente \\
\hline Conductismo & $\begin{array}{l}\text { El que aprende sólo tiene que } \\
\text { concentrarse en metas claras } \\
\text { y es capaz de responder con } \\
\text { rapidez y automáticamente } \\
\text { cuando se le presenta una } \\
\text { situación relacionada con esas } \\
\text { metas. }\end{array}$ & $\begin{array}{l}\text { El que aprende podría encontrarse } \\
\text { en una situación en la que el } \\
\text { estímulo para la respuesta correcta } \\
\text { nunca ocurre; por lo tanto el } \\
\text { aprendiz no responde. }\end{array}$ \\
\hline Cognitivismo & $\begin{array}{l}\text { La meta es capacitar al } \\
\text { aprendiz para que realice } \\
\text { tareas repetitivas y que } \\
\text { aseguren consistencia. }\end{array}$ & $\begin{array}{l}\text { El aprendiz aprende a realizar una } \\
\text { tarea, pero podría no ser la mejor } \\
\text { forma de realizarla o la más } \\
\text { adecuada para el aprendiz o la } \\
\text { situación. }\end{array}$ \\
\hline Constructivismo & $\begin{array}{l}\text { Como el que aprende es capaz } \\
\text { de interpretar múltiples } \\
\text { realidades, está mejor } \\
\text { preparado para enfrentar } \\
\text { situaciones de la vida real. }\end{array}$ & $\begin{array}{l}\text { En una situación donde la } \\
\text { conformidad es esencial, el } \\
\text { pensamiento divergente y la } \\
\text { iniciativa podrían ser un } \\
\text { problema. }\end{array}$ \\
\hline
\end{tabular}

Tabla 1.3.- Ventajas e inconvenientes instruccionales de los modelos de aprendizaje. Mergel $^{4}, 1998$.

El docente tiene que entender las debilidades y fortalezas de cada teoría de aprendizaje para poder optimizar su uso en el diseño de la estrategia adecuada ${ }^{5}$.

\subsubsection{Dificultades conceptuales}

Las investigaciones realizadas por el profesor Johnstone, en el campo de la enseñanza de la química, resultan muy apropiadas para abordar el tema de investigación que nos ocupa. Afirma que "Lo que realmente sabemos y entendemos controla lo que aprendemos" (Johnstone, 1999). En este sentido y, hablando desde una perspectiva constructivista, es necesario asimilar correctamente los conceptos básicos de cualquier materia antes de profundizar en su estudio. En el caso particular de la química, los conceptos tienen una difícil percepción por parte del alumno, ya que a veces hablamos

\footnotetext{
${ }^{4}$ Mergel sugiere un símil entre las teorías de aprendizaje y los modelos atómicos, en el que compara:

- El modelo de Dalton con el conductivismo, ya que ambos interpretan fenómenos observables sin contar con lo que ocurre en el interior.

- Los modelos de Thompson, Rutherford y Bohr, con el cognitivismo; en todos ellos se busca una explicación en el interior que justifique el comportamiento.

- El modelo mecánico-cuántico con el constructivismo, como una búsqueda de estabilidad o formación en cambio continuo.

${ }^{5}$ Para el diseñador experimentado, las teorías de aprendizaje son de gran ayuda, porque le permiten tener una visión más amplia del proceso para identificar nuevas posibilidades y formas diferentes de ver el mundo. Como quiera que sea, adoptemos o no la mejor decisión sobre el diseño, ésta debe estar sustentada en nuestros propios conocimientos sobre esas teorías.
} 
de sustancias con propiedades macroscópicas que tratamos de explicar de forma microscópica, lo que requiere un profundo dominio de la materia para entenderlo

Johnstone propone para las ciencias, los niveles macroscópico, submicroscópico y simbólico de pensamiento (Johnstone, 2006):

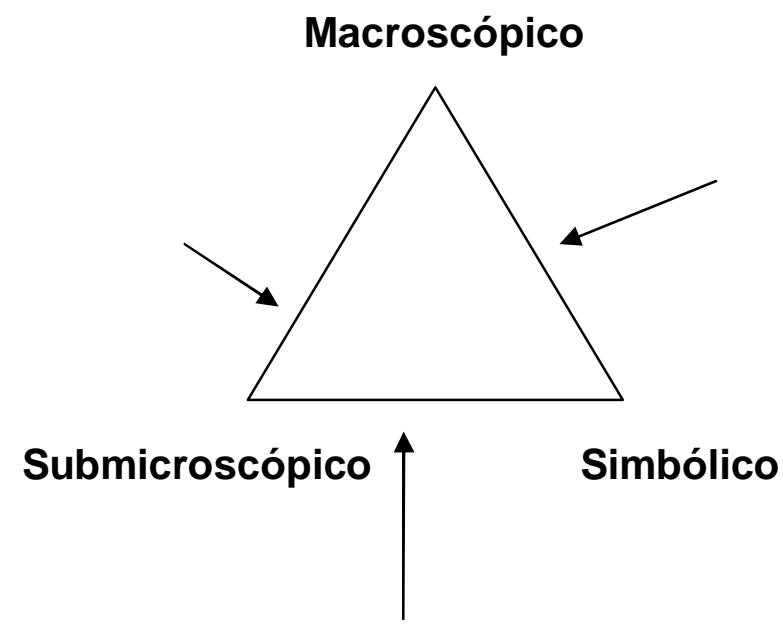

Figura 1.1. Árbol de niveles conceptuales de química

El nivel macroscópico corresponde a las representaciones mentales a partir de la experiencia sensorial directa.

El nivel submicroscópico hace referencia a las representaciones mentales abstractas que tiene un experto en la materia y que no se corresponden con el fenómeno real sino con modelos que explican de forma satisfactoria los hechos macroscópicos, es decir, que de forma inductiva se crea un sistema que justifique los hechos reales

El nivel simbólico es un recurso que permite expresar de forma verbal y escrita la explicación submicroscópica que se da del entorno macroscópico. Por tanto, para poder entender las ciencias, en especial la química, es necesario desenvolverse en estos tres niveles y ser capaz de relacionarlos de forma fluida.

En posteriores investigaciones (Galagovsky, 2003) se refleja que entre los profesores y los alumnos hay dificultades de comunicación, debido a la diferencia existente entre el lenguaje cotidiano y el lenguaje científico. Esta dificultad reside en el diferente plano en que se encuentran ambos. Cuando un profesor explica, tiene un 
amplio conocimiento de la materia, que le permite ir relacionando los conceptos según estime conveniente y con ello siempre encontrará contextualizado aquello que explica y lo verá lógico y razonado. En cambio el alumno extrae de esta información aquello que puede ir comprendiendo, atribuyendo a las palabras recibidas el significado más relacionado con su entorno. Prácticamente todos los conceptos que nos son familiares tienen algo que puede ser reconocido por nuestros sentidos y, su aprendizaje nos resulta más sencillo que el de los conceptos abstractos Galagovsky (2003).

Por otro lado, está también la dificultad que representa la diferencia entre las representaciones mentales de los expertos sobre el mundo natural y las de los alumnos. Incluso en el caso de posibles errores en la expresión de ideas o sintaxis, tanto por parte del alumno como del profesor, siempre vienen controlados por este último ya que es quien dirige, temporiza y se expresa en las clases, marcando las tendencias con su sistema de evaluación y calificación (Galagovsky,1993).

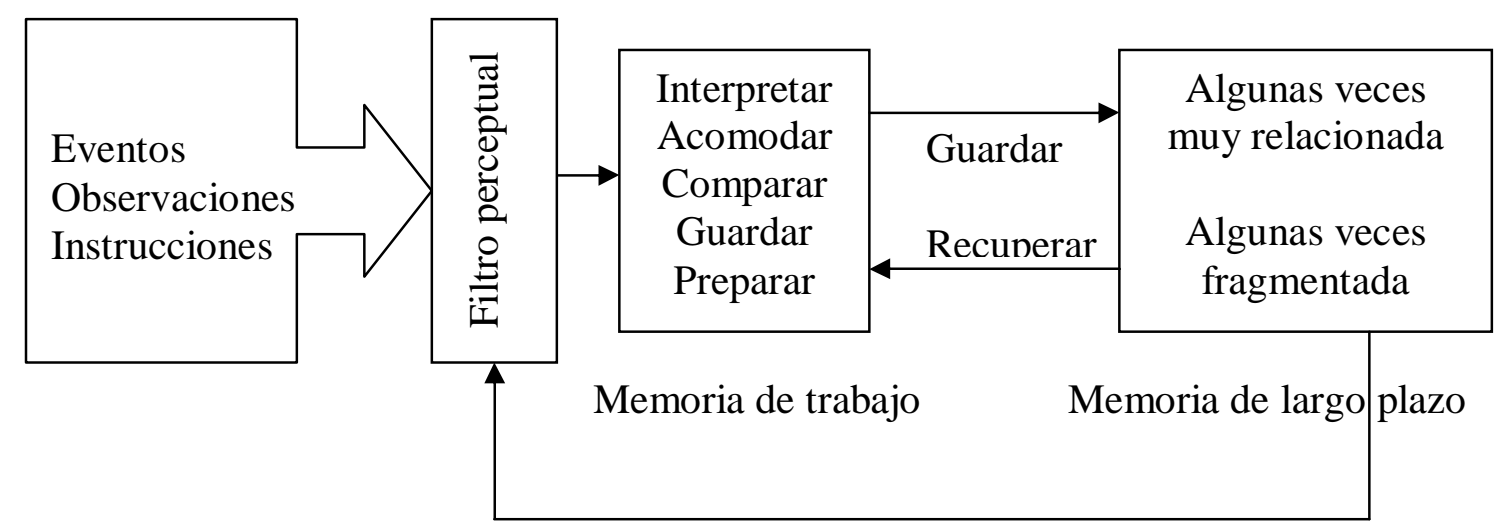

Circuito de retroalimentación del filtro perceptivo

Figura 1.2. Modelo de aprendizaje propuesto por Johnstone (1997) que muestra cómo los aprendizajes anteriores condicionan los nuevos.

A la luz de estas reflexiones, Johnstone propone un aprendizaje basado en las siguientes premisas:

- las percepciones que registramos a través de los sentidos no son objetivas; están filtradas e interpretadas en forma idiosincrásica 
- lo que ya sabemos es lo que controla la significación de las informaciones sensoriales que recibimos, filtrando aquello que vamos a aprender

- nuestra memoria de trabajo presta atención a una situación dada y es en la que se fija nuestra percepción, otorgándole un sentido

- dar sentido a un concepto es ubicarlo y agregarlo a algo ya conocido

- la función de la memoria de trabajo es mantener la información a corto plazo y darle un formato para guardarla, teniendo una capacidad limitada.

- una información que supere esta capacidad no podrá ser asimilada.

- según Ausubel, las ideas nuevas solo se aprenden y se retienen útilmente si se refieren a otros conceptos ya comprendidos

En contra de la visión asociacionista del aprendizaje tras la asimilación del discurso del experto en una tabula rasa en la mente del alumno, la comunidad educativa puede aceptar la existencia de un amplio consenso acerca de la visión constructivista (Pozo, Marín Martínez, 1999) que define el aprendizaje como un proceso de construcción activa. Por lo que conocer, no es sinónimo de reproducir información, sino que se trata de que esta sea asimilada y relacionada con los conocimientos anteriores del alumno.

Los contenidos que aprenden los individuos en un contexto escolar dependen de los esquemas cognitivos previos en cada uno de ellos (Galagovsky, 2002), pero también, y en gran medida, de la interacción con el docente, que es el responsable de seleccionar, organizar e impartir las explicaciones y evaluar los conocimientos adquiridos de forma óptima.

Aunque de forma operativa podemos definir el aprendizaje significativo como la capacidad de transferir el aprendizaje a contextos diferentes a los que se produjo, el modelo de Ausubel-Novak (Novak, 1982) lo define como aquel en el que los conceptos se encuentran jerárquicamente organizados y apunta que si los conceptos estudiados en clase no encuentran relación con conceptos inclusores existentes previamente en la mente del alumno, el aprendizaje que se producirá será memorístico y se distribuirán de forma arbitraria en la estructura mental, sin relacionarse con los conceptos específicos existentes. Según Galagovsky (Galagovsky, 1999) la estructura cognitiva de un sujeto se concibe como una configuración reticular compuesta por nodos, que representan 
conceptos, y relaciones entre ellos (figura 1.3), considerando información todo elemento externo a la estructura mental del alumno y conocimiento a esta misma, una vez transformada y asimilada por el mismo.

En otro sentido, se define el aprendizaje significativo como aquel en que los conceptos inclusores, existentes previamente en el alumno, permiten la adición de nueva información. Este tipo de aprendizaje aumenta la capacidad del alumno, puesto que aumenta el número de conceptos potencialmente inclusores para otros nuevos. En otro lado estará el aprendizaje memorístico, que corresponderá a una situación en la que no existen conceptos inclusores o bien el alumno no sabe que los tienen o no los utiliza correctamente, formando un islote de comprensión que no se relacionará con la estructura cognitiva existente.

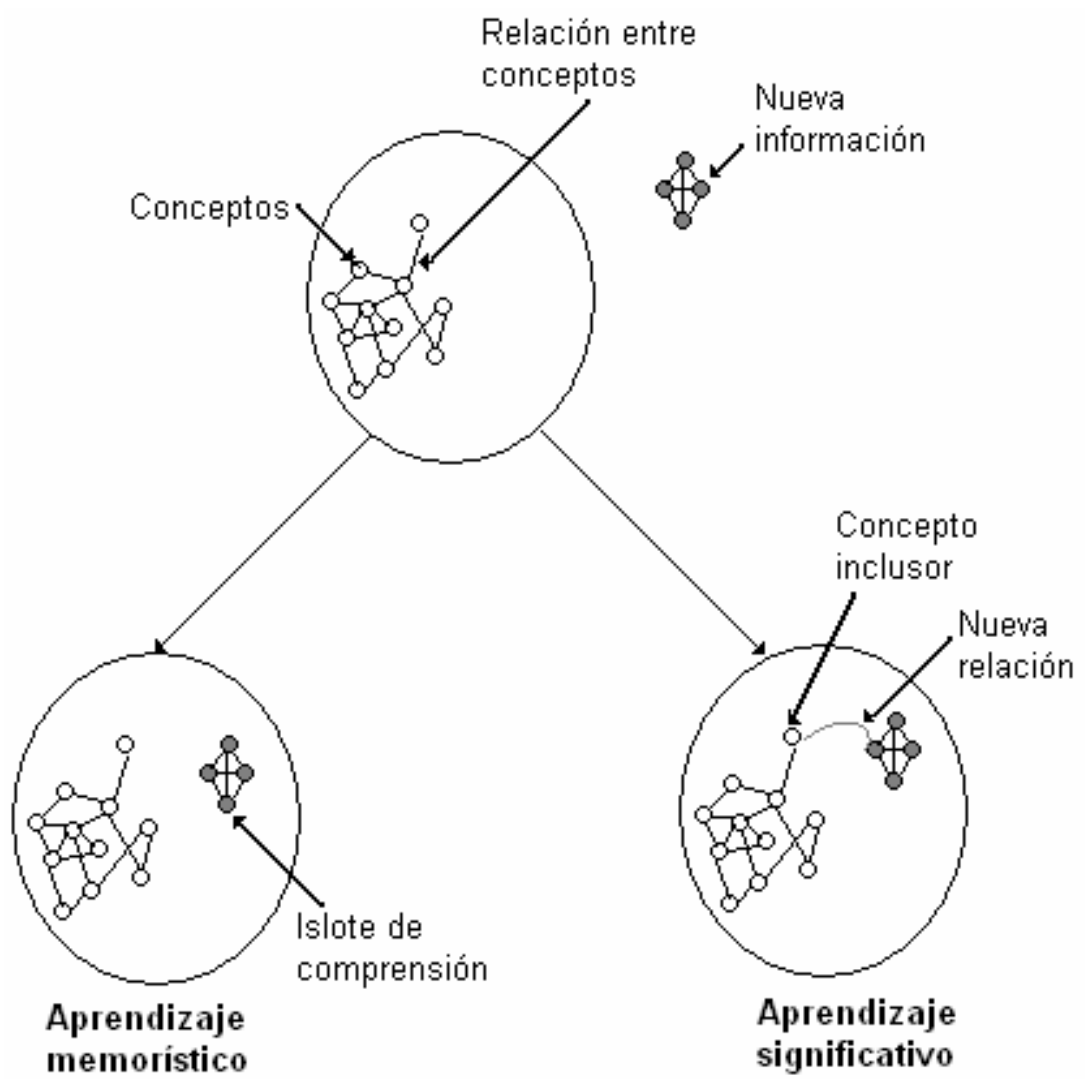

Figura 1.3.- Modelo de aprendizaje basado en el concepto inclusor (Galagovsky, 1999) 
Esta clasificación entre aprendizaje memorístico y aprendizaje significativo es una situación llevada al extremo, puesto que todo aprendizaje significativo necesita un aporte memorístico y todo aprendizaje memorístico se apoya en algún tipo de razonamiento.

Actualmente, se recae en esa distinción. No obstante, cabe notar que no se trata de correcto o incorrecto, puesto que se trata de una terminología propuesta por Ausubel dentro de un mismo marco cognitivista y en ambos se entiende al alumno como un procesador de información. En ambos casos puede realizarse una asimilación de conocimientos acertada o errónea; más aún, se deben dar ambos conjuntamente dentro de un proceso de enseñanza-aprendizaje.

En relación con esto, Johnstone plantea que la mayoría de los conceptos utilizados en química no son fácilmente perceptibles por los alumnos desde un punto de vista sensorial. Los expertos, sin embargo, sí pueden situarse en otros contextos y extraer otra información que, aunque útil para ellos, no es comprensible por los alumnos.

Más aún; hay conceptos como electrón, enlace químico, ión, etc. que, además de ser completamente ajenos a la experiencia sensorial de los alumnos, estos no tienen ninguna experiencia previa que les permita imaginar con un mínimo de aproximación la idea que se les pretende transmitir.

Enseñar consiste en que la información que el instructor tiene en mente debe hacerse explicita mediante expresiones, diferentes lenguajes $\mathrm{y}$, facilitando la articulación de los formatos sintácticos. La práctica pedagógica debería disponer de tiempo suficiente para consensuar representaciones y asociar correctamente los niveles perceptuales o macroscópico y el microscópico. 


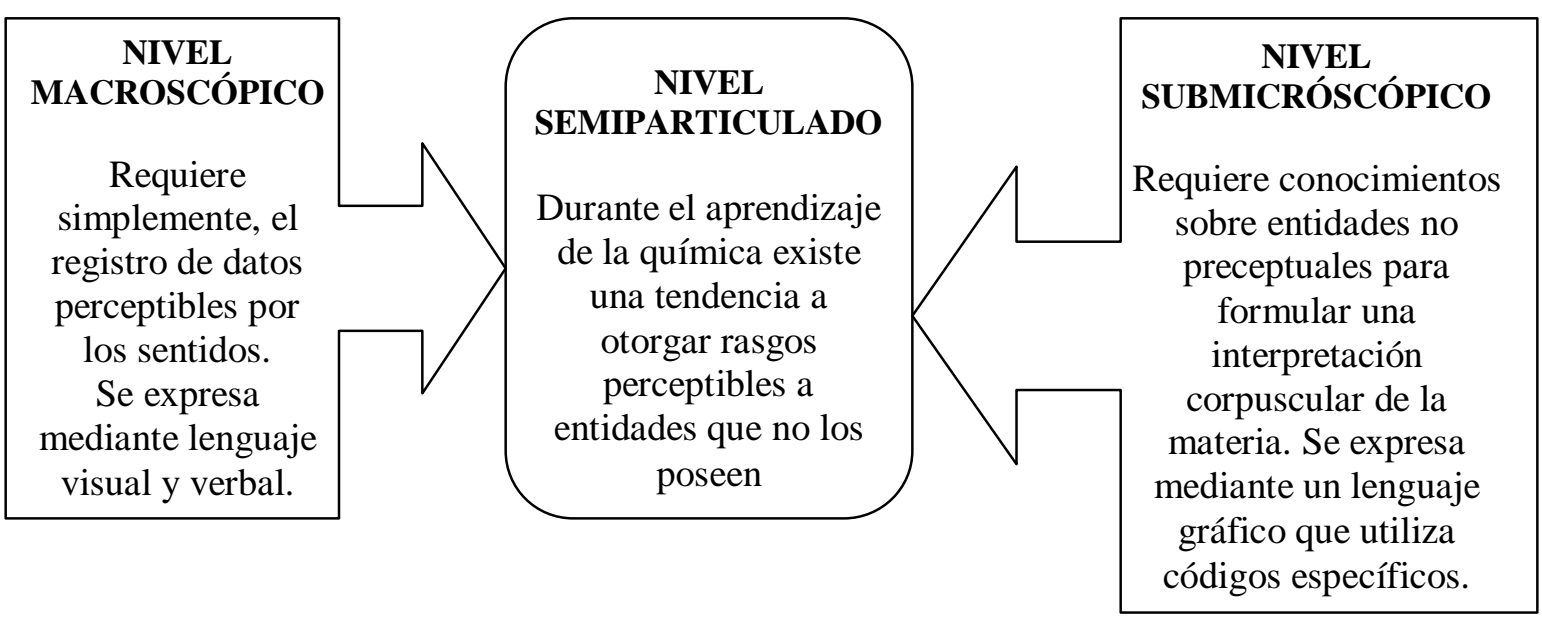

Figura 1.4.- Nivel de interpretación semiparticulado durante el aprendizaje erróneo de conceptos químicos.

\subsubsection{Ideas previas y prerrequisitos.}

A partir de aportaciones cognitivas y constructivistas, pueden generarse opciones concretas de trabajo en el aula, acercando la investigación didáctica a la propia práctica docente (Llorens, 1991).

La concepción constructivista requiere de un cambio conceptual y metodológico que, además de lento y progresivo, requiere un cambio actitudinal de toda la comunidad educativa. En ese sentido, durante la década de los años 70, se desarrolló una línea de investigación basada en la caracterización de las ideas previas del alumno y de cómo podían ser modificadas por el aprendizaje escolar, concibiendo la idea incorrecta como un elemento constitutivo del propio desarrollo. Los resultados de las investigaciones a este respecto que se sucedieron dieron lugar a ciertas conclusiones:

1.- Muchas de las ideas que el alumno utiliza al resolver ciertas tareas son espontáneas, fruto de la intuición. Estas ideas poseen cierta coherencia y son utilizadas frecuentemente en su ámbito cotidiano, pero suelen diferir de las escolares prevaleciendo las primeras.

2.- Estas ideas son interpretadas como construcciones personales, generadas por la propia actividad intelectual del alumno frente a los problemas ${ }^{6}$. Estas ideas o

\footnotetext{
${ }^{6}$ En ocasiones se detecta en los alumnos la presencia de ideas diferentes a las aceptadas por la comunidad científica, y se identifican como ideas alternativas (Ballesteros, 2002).
} 
intuiciones cobran validez en la medida en que son un conocimiento cotidiano, poseen una estructura diferente a la del conocimiento científico y quedan fuera de un posible análisis racional. De ahí la gran resistencia al cambio y la dificultad de asociarse a las ideas transmitidas en el aula.

3.- Suelen ser ideas científicamente incorrectas, lo cual es obvio, puesto que no podemos concebir el aprendizaje simplemente como un proceso de descubrimiento autónomo por parte del alumno. Aun cuando existe una motivación intrínseca por el aprendizaje, éste no necesariamente ha de ser correcto y se encuentra influenciado por otras ideas alternativas. Por tanto, el aprendizaje será un proceso de triple cambio: actitudinal, metodológico y conceptual, ya que los alumnos han de encontrar sentido al hecho de cambiar sus ideas acercándolas a la ciencia y que éste les reporte algún beneficio

4.- Las ideas alternativas se caracterizan por un lenguaje impreciso existiendo, en ocasiones, una elevada dificultad para su explicitación.

5.- Son persistentes, mostrándose a veces insensibles al aprendizaje escolar y llegándose a evidenciar, incluso, en estudiantes universitarios y profesores. Situación que, lejos de alarmar, debe suponer una clave para abordar el cambio conceptual.

No todas las dificultades de aprendizaje son necesariamente explicables en términos de ideas alternativas. García Hourcade y Rodríguez de Ávila, (1988) delimitan el significado de todas las expresiones que hemos señalado como ideas previas o alternativas. Señalan que hay una valoración excesiva de la coherencia y la generalidad del pensamiento del alumno, distinguiendo entre intuición y errores postinstruccionales, producto de una defectuosa comprensión de los conocimientos transmitidos en la escuela. Hay incluso autores como McClelland (1984) que consideran las respuestas erróneas como una simple consecuencia de la falta de interés y atención por parte del alumno.

Hay otros puntos de vista (Llorens, 1991) que ven difícil creer que la complejidad y creatividad que muestran estas ideas, así como la convergencia que se observa entre diferentes alumnos y cuando se estudia un mismo problema a través de 
diferentes metodologías sean simplemente una construcción que elabora el alumno para salir del paso.

Llegados a este punto, es necesario buscar medios que permitan a los alumnos transformar la información disponible en sus ideas previas en herramientas de aprendizaje en que basar su formación.

El uso de maquetas y objetos para enseñar ciencias permite, gracias a su carácter descriptivo y cualitativo, que el alumno transforme sus primeras ideas en otras más elaboradas (Gómez y De Andrea, 2004), haciendo un papel intermedio entre la realidad observable y sus propias teorías.

A título de ejemplo, cabe señalar que los alumnos presentan diversas dificultades, como son:

- Problemas respecto a los modelos, en general. El grado de abstracción es alto y, debido a las preconcepciones, no se conciben las limitaciones existentes y se espera una mayor relación entre la realidad que se quiere explicar y modelo utilizado.

- Respecto a las leyes de los gases, sólo identifican la presión en situaciones dinámicas; presentando, además, grandes limitaciones al no podérseles mostrar el extremadamente pequeño tamaño de las partículas gaseosas.

- Respecto a la teoría cinética, y debido a las preconcepciones, tienen una visión estática de la materia y les resulta complicado asumir la relación entre la velocidad de las partículas y la temperatura.

- El mol, como unidad de cantidad de sustancia del Sistema internacional de Unidades, resulta un concepto muy difícil para los estudiantes en la escuela secundaria (Garritz, Gasque, Hernández y Martínez, 2002; Furió, 1993; Furió, Azcona y Guisáosla, 1999); incluso los profesores muestran dificultades conceptuales sobre este tópico. 
- El preconcepto de "peso", como propiedad accidental de los cuerpos, relacionado con las sensaciones de pesadez o ligereza.

En general, las ideas alternativas están presentes a lo largo del desarrollo de todo el currículo, teniendo orígenes muy diversos (Valcarcel y Ruiz, 2000) como, por ejemplo:

- El lenguaje utilizado durante la enseñanza, que solapa el lenguaje cotidiano con el científico, mezclando términos iguales en diferentes ámbitos y, por tanto, con diferente significado.

- Utilización de metáforas que, lejos de ser comprendidas, se atribuyen de forma literal al concepto tratado.

- Adjudicación de propiedades macroscópicas a las partículas microscópicas.

- Relación entre la construcción y utilización de modelos y las estructuras cognitivas del alumno. 


\subsubsection{Comprensión de conceptos básicos}

Los estudiantes desconocen y confunden los conceptos, lo que nos obliga a revisar la forma de enseñar química, prestando atención a los conocimientos previos de los estudiantes y sugerir un proceso de enseñanza-aprendizaje inmerso en ambiente de desarrollo cognoscitivo y lingüístico (Ballesteros, 2002). Los conceptos básicos deben ser explicados con claridad y orden (Hurst, 2002)

Existe un extenso conocimiento descriptivo de las concepciones alternativas y dificultades de aprendizaje en la adquisición de los conocimientos básicos de química, reconociéndose un triple origen para las concepciones alternativas de los alumnos: El perceptivo, el analógico y el cultural (Llorens, 1994). Y desde un punto de vista actitudinal, cabria considerar un cuarto factor, relacionado con los fines y aspiraciones personales del alumno cuando elabora sus ideas.

En un primer momento del desarrollo conceptual, el rasgo más característico de las ideas del alumno es que la observación de la realidad material está dominada por los aspectos más accesibles desde el punto de vista perceptivo, siendo a menudo irrelevantes en la construcción de conceptos químicos. Dentro de este marco, dominado por lo perceptivo, es lógico que existan dificultades para adquirir conceptos como el de sustancia pura (Llorens, J. A., 1987, Sanmartín, N., 1989).

En la fase del desarrollo conceptual el lenguaje empleado por los alumnos también presenta características peculiares. Por una parte, es interesante observar la gran dificultad en usar un lenguaje explicativo. El lenguaje empleado es eminentemente descriptivo. Por otro lado, el lenguaje ordinario aparece como una fuente de significados que apoyan u obstaculizan la adquisición de conceptos y muestra el impacto del medio cultural en el origen de las concepciones alternativas, configurándose conjuntos de experiencias o prácticas cotidianas, transferidas por el ambiente familiar, social o de los medios de comunicación, que son susceptibles de interaccionar con el aprendizaje escolar en la construcción de un núcleo de específico de conceptos (Llorens y De Jaime, 1987). 
La utilización de analogías provenientes del conocimiento escolar es un rasgo muy característico de las concepciones alternativas observadas. Existen ideas cuya simplicidad y potencia explicativa hacen que sean un instrumento que los alumnos utilizan de una manera generalizada para de explicar diversas situaciones.

En los años setenta la enseñanza de la química estaba centrada en el conocimiento de las sustancias, reacciones, obtención y aplicaciones. En los años ochenta se puso énfasis en los principios químicos. Estos cambios pretendían mejorar la preparación para posteriores estudios universitarios (Caamaño y Oñorbe, 2004). En los noventa, con la implantación del nuevo sistema educativo, se abrió un periodo de renovación de objetivos y contenidos que prestaba una mayor atención a los procedimientos disminuyendo el aspecto formal de la materia. Los nuevos programas y materiales permitieron incidir más en la vida cotidiana y disponer de una oferta más amplia de actividades de aprendizaje.

El objetivo principal de la química es el estudio de los cambios que experimenta la materia y la modelización de las sustancias y las reacciones químicas. Esta finalidad se refleja en un cuerpo de conocimientos que suele presentarse como un conjunto definido de conceptos muy consolidado. Pero la adquisición de estos conceptos presenta obstáculos que se ponen de manifiesto en estudios donde se analizan un gran número de concepciones alternativas y dificultades de aprendizaje.

En la tabla siguiente se recogen los principales problemas que presentan los alumnos y que han sido tratados por la investigación didáctica. 
Dificultades intrínsecas de la química

- Existencia de tres niveles de descripción de la materia: macroscópico, microscópico y simbólico.

- Carácter evolutivo de los modelos y teorías. Uso de diferentes modelos y teorías en el aprendizaje escolar.

- Ambiguiedad de lenguaje respecto de los niveles descriptivos.

- Ausencia de términos apropiados para un nivel estructural determinado

- Términos cuyo significado varía según el contexto teórico en el que se enmarcan

- Términos y fórmulas químicas con significados múltiples.

- Términos con significado diferente en la vida cotidiana y en química.

Dificultades de aprendizaje de los conceptos químicos relativas al pensamiento y forma de razonamiento de los estudiantes.

- La influencia de la percepción macroscópica en el análisis del mundo microscópico.

- La tendencia a transferir las propiedades macroscópicas de las sustancias a las propiedades microscópicas de las partículas.

- La tendencia a utilizar explicaciones metafísicas de tipo teleológico o finalista en lugar de explicaciones físicas.

- El uso superficial del pensamiento analógico

- La dificultad de transferir un concepto a un contexto distinto al que se ha aprendido.

- La dificultad de comprensión global de procesos que exigen ser pensados mediante una serie de etapas.

- La modificación de las características de los modelos frente a hechos que no se pueden explicar.

- La construcción de modelos híbridos alternativos.

Dificultades de aprendizaje de conceptos químicos atribuibles al proceso de instrucción

- Presentación de forma acabada de conceptos y teorías.

- Atención insuficiente a los aspectos estructurales de la materia, en especial, del nivel multiatómico, multimolecular o multiiónico.

- Utilización de ejemplos sesgados que pueden llevar a conclusiones erróneas cuando son generalizados.

- Uso frecuente de actividades basadas en algoritmos que no buscan la comprensión de los conceptos sino su aplicación mecánica

Tabla 1.4.- Dificultades en el aprendizaje de los conceptos químicos (Caamaño y Oñorbe, 2004) 
Para conseguir una enseñanza de la química más efectiva y un mejor aprendizaje conceptual, es necesario identificar la naturaleza y las causas de las concepciones alternativas de los estudiantes. Así mismo, es necesario facilitar la superación de estas dificultades con estrategias como:

- Una presentación evolutiva de conceptos teorías y modelos.

- Desarrollo continuado y progresivo de las ideas desde lo cualitativo a lo cuantitativo y de lo más simple a lo más complejo.

- Situar los conceptos con relación al ámbito experimental en que se construyen y se cuantifican.

- Una adecuada secuenciación de contenidos.

- Un uso apropiado del lenguaje, que explicite el significado de los términos.

En busca de un óptimo tratamiento de los contenidos cabría:

- Intentar seleccionar y consensuar los conceptos y procedimientos más importantes, para poder aligerar el peso de los contenidos en los programas actuales

- Poner mayor énfasis en la comprensión de los conceptos, elaboración de modelos, argumentación, experimentación y comunicación de ideas

- Potenciar los trabajos prácticos que se requieran en la interpretación de experiencias y de carácter investigativo

- Adoptar una aproximación a la química de los elementos de la vida cotidiana, especialmente en la ESO

- Introducir con coherencia los aspectos prácticos, sociales y medioambientales de la química en la estructura de las asignaturas. 


\section{3.- Enseñanza de la química}

\subsubsection{La química como la ciencia de los modelos}

Un modelo es una construcción imaginaria de un fenómeno que reemplaza a un aspecto de la realidad con la finalidad de poder realizar su estudio teórico. En el caso particular de la química, los modelos representan un papel muy importante en la construcción del conocimiento, hasta el punto de que las soluciones a los problemas vienen determinadas y limitadas por el modelo utilizado (Sánchez y Valcarcel, 2003). El comportamiento del modelo debe aproximarse a la realidad en las condiciones definidas, aunque siempre será incompleto respecto al referente, pudiéndose utilizar más de uno.

La aceptación, modificación o rechazo de un modelo, requiere una amplia contrastación a fin de suponer una respuesta específica para el problema. El modelo será más apropiado en la medida en que pueda ser modificado y aproximarse al sistema real, dependiendo, en definitiva, su éxito de la correspondencia que exista entre las manifestaciones del sistema real y los resultados extraídos de él mismo.

La principal finalidad de los modelos es que los alumnos y las alumnas comprendan el porqué de los hechos científicos relativos a las propiedades y cambios de la materia prediciendo los hechos estudiados. Sin embargo hay otro aspecto importante, que es la compresión de cómo se construye el conocimiento de la materia al tiempo que ofrecer una imagen adecuada de la ciencia como construcción de conocimientos en evolución.

La química trata de economizar los modelos, buscando explicar la mayor cantidad posible de fenómenos utilizando la mínima cantidad de estos.

Puede hablarse de una regla de economía de los modelos que fue definida por el profesor D. José Beltrán al comparar la Física con la Química, según la cual, los físicos no se conforman con una explicación superficial de los hechos, sino que profundizan y 
buscan sus causas. En cambio los químicos, ante una situación que no consiguen explicar (debido a su complejidad) de forma satisfactoria, buscan una explicación más o menos superficial, que permita razonar los hechos observados.

Los modelos son una buena herramienta epistemológica y motivacional en la enseñanza de las ciencias, resultando especialmente atractivos, ya que permiten explicar conceptos abstractos de una forma familiar, visual y, a menudo, tangible. Siendo este aspecto peligroso, en tanto que los modelos pueden ser confundidos por el alumno con los objetos reales que representan.

Al finalizar el bachillerato, algunos estudiantes son capaces de construir un modelo interactivo de cambio químico coincidente con la explicación aceptada científicamente. Otros elaboran modelos corpusculares, bien sobre el fenómeno macroscópico observado o bien sobre su explicación microscópica, aunque también hay un amplio porcentaje (Solsona y Martín, 2004) que no es capaz de construir ningún modelo.

Los modelos atribuidos por los alumnos al cambio químico suelen estar fundamentados en las cualidades macroscópicas de la materia y no en su naturaleza corpuscular, utilizando criterios que no permiten distinguir entre cambios físicos y químicos y que ofrecen una visión descriptiva, ligada a lo espectacular, siendo muy ambigua e imprecisa.

Los estudios realizados en este sentido señalan que los problemas que encuentran los alumnos se basan en su percepción, que se refleja en la sustancialización de las propiedades y en el traslado de lo directamente observable a lo microscópico, existiendo dificultades para aceptar todo aquello que no es percibido por los sentidos. 
Por ejemplo:

Sustancialización: Transferencia de las propiedades del cobre al hierro en la deposición de $\mathrm{Cu}$ sobre $\mathrm{Fe}$ en $\mathrm{Cu}^{2+}$ (Llorens, De Jaime y Llopis, 1987).

Disolución: El soluto queda atrapado por el disolvente.

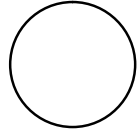

Molécula de disolvente

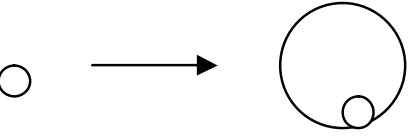

disolución

Pese a que la química recurre a los modelos constantemente, tratando de economizar su planteamiento y uso, estos no están exentos de dificultad.

- El estudio de la naturaleza de la materia se inicia en la ESO con la teoría cinéticomolecular (Valcarcel y Ruiz, 2000), explicando sus propiedades y transformaciones físicas a partir de los supuestos de que toda materia está formada por pequeñas partículas entre las que solo hay vacío, dotadas de movimiento continuo y entre las que hay interacciones, siendo además estas partículas diferentes, dependiendo de la sustancia implicada.

Pese a la simplicidad de estas ideas, los alumnos presentan dificultades en cuanto a su comprensión. Pero es necesario adquirir estos conceptos para poder comprender el concepto de sustancia pura y las transformaciones químicas, así como la distinción entre cambio físico y químico, a través del estudio de las interacciones entre partículas como átomos, moléculas o iones de interacciones como enlaces químicos o fuerzas intermoleculares

- En cuanto a la modelización sobre el átomo, su conceptualización es asimilada, al igual que la de una molécula. Con frecuencia, los alumnos asignan a los átomos las propiedades macroscópicas (color, dureza...) de las sustancias que forman. Aunque acepten que en su mayor parte el átomo es espacio vacío, los alumnos no proporcionan una estimación realista del átomo ni de la relación de tamaño entre núcleo y resto de partículas constituyentes. Confunden los conceptos de molécula y célula (célula para seres vivos y molécula para inertes). 
- Respecto a la estructura de la materia, los alumnos mantienen modelos discretos y concretos de la estructura electrónica, manteniendo preferentemente el modelo planetario de electrones girando alrededor del núcleo y una descripción del átomo como una esfera maciza.

- Por lo que se refiere a la interacción entre núcleo y electrones, los alumnos presentan dificultades cuando deben razonar el porqué de la atracción entre núcleo y electrones, considerando que se reparte entre los electrones la fuerza disponible, sin considerar la repulsión entre ellos. Por otro lado, es frecuente que los alumnos escriban con éxito las configuraciones electrónicas de los átomos, sin que ello garantice su comprensión, puesto que se trata de un ejercicio algorítmico, quedando el concepto estudiado poco claro y con posibilidades de construir ideas alternativas.

Cuando un alumno se enfrenta por primera vez ante un modelo determinado es frecuente que encuentre dificultades en su compresión y que se formule preguntas acerca de lo desconocido que se justifican, precisamente, con la introducción del modelo. Sin embargo, se observa que, con frecuencia, los alumnos no los interpretan correctamente Por ello es necesario que el profesor defina claramente los límites y términos empleados dentro del contexto científico. Así mismo, es necesario conocer los conocimientos previos, para intentar asegurar una correcta comprensión de los modelos propuestos y establecer los vínculos necesarios para que los alumnos relacionen correctamente los niveles macroscópico, submicroscópico y simbólico.

El cambio químico es uno de los contenidos curriculares más estudiados (Solsona, 2004). Los modelos que construyen los alumnos les permiten explicar los fenómenos, a la par que van evolucionando a lo largo de la escolarización.

Las dificultades del alumnado se explican por el traslado de las propiedades de lo observable a lo microscópico y viceversa, manteniendo dificultades para aceptar lo que no es perceptible por los sentidos. Los razonamientos de los alumnos suelen ser de carácter causal y en un solo sentido, detectándose además problemas de cuantificación. Así mismo la influencia del lenguaje cotidiano y del contexto cultural se manifiesta en un lenguaje eminentemente descriptivo. 
La relación entre los distintos contenidos conceptuales y la progresión en su formulación hace necesario entender que la enseñanza de la química debe estar dirigida hacia el establecimiento de relaciones entre una serie de nociones específicas y ejemplos, por lo que es necesario formar al profesorado en los procesos de transposición didáctica del conocimiento, dentro de experiencias docentes, como vía para construir conocimientos sobre el aprendizaje escolar.

Los modelos deben ser sencillos al inicio del aprendizaje y serán más complejos a medida que el alumno vaya extendiendo el ámbito de fenómenos que debe explicar, superando las explicaciones adecuadas para un pequeño número de fenómenos. La construcción del modelo ha de ser sugerida por las situaciones planteadas por el alumno y deben permitirle razonar a partir de ellas.

El punto de partida para la elaboración de un modelo de materia respondería, en primer lugar, a la relación entre los niveles de descripción macroscópico (basado en el concepto de elemento y sustancia) y el microscópico basado en el átomo.

Los alumnos aprenden en un contexto social que da sentido a cualquier conocimiento. Este contexto, formado por el entorno social, el centro educativo, valores presentes en él, etc., puede hacerles sentir la necesidad de aprender aquello que no conocen. De aquí que, para abordar el estudio de un aspecto concreto mediante un modelo, sea importante seleccionar un contexto de aprendizaje que permita al alumno familiarizarse con unas experiencias o con unas cuestiones al respecto que le resulten interesantes. 


\subsubsection{Necesidad de una contextualización del currículo.}

Tanto profesores como alumnos consideran que existe un fracaso generalizado en el aprendizaje de las ciencias (Oñorbe y Sánchez, 1996), encontrando una mayor dificultad cuando se trata de aplicar los conceptos aprendidos a la resolución de problemas, atribuyéndola a la dificultad de comprensión de los enunciados. Pero la mayor carencia se encuentra, según profesores y alumnos, en la falta de interés y de trabajo por parte de estos últimos.

Ahondando en la realidad que podemos observar, encontramos que el alumnado no aplica en la vida lo que aprende en el aula. No es habitual, por ejemplo, que un alumno pueda clasificar los productos domésticos como ácidos o bases (Jiménez, Sánchez y De Manuel, 2001). En cambio sí que identifican los términos agrio con fuerte, ácido con dañino o creen que no se pueden tomar alimentos o bebidas con $\mathrm{pH} \neq 7$.

En referencia a la naturaleza, hay concepciones como que la lluvia ácida es aquella que contiene partículas de ácido puro en su interior. Y, por supuesto, se tiende a identificar lo natural con puro (leche, agua, aceite...) y, en un caso tan extremo como habitual, a identificar la química con lo artificial y con lo tóxico.

Estas concepciones tienen su origen en la desconexión entre la teoría y su aplicación, por lo que los contenidos que se enseñan no deben estar desligados de lo cotidiano, sino que debe existir una simbiosis entre ambos, de forma que los fenómenos observables de la vida cotidiana sirvan para ejemplificar los contenidos teóricos del aula, al tiempo que estos debe permitir explicar el porqué de las situaciones diarias (Oñorbe, 2001; Jiménez, Sánchez y De Manuel, 2001).

Una posible solución para encontrar puntos de unión entre ambas vertientes podría ser la utilización de la vida a modo de ejemplos inmersos en la teoría (Moreno, 1994) abogando por la transversalidad.

Buscando una mayor implicación, podría estructurarse la materia a partir de los contenidos habituales y plantear las situaciones diarias como una secuencia de actividades susceptibles de ser estudiadas. Para ello, cabría plantear los cursos de 
ciencias en torno a experiencias cotidianas que actuarían como base para el planteamiento de los contenidos.

En ese sentido, se trabaja en proyectos como el Salters, (explicado en el apartado 1.3.3) en el que, a partir de una orientación CTS, estructuran los dos cursos de química de bachillerato en torno diferentes aplicaciones de la química.

La química no es algo exclusivo del ámbito escolar, industrial o de laboratorio, sino un aspecto más de la vida diaria. Es necesario, por tanto, organizar el aprendizaje en torno a ella, sin olvidar al resto. Cabría buscar formas para que el aprendizaje de la química se relacionase, en mayor medida, con situaciones de la vida real (casa, cocina, tiendas, peluquería, cine...) suponiendo, en definitiva, la alfabetización científica que se pretende conseguir con los actuales planes de estudio (Furió, Vilches, Guisasola y Romo, 2001).

En ese sentido, encontramos trabajos a nivel de aula, con actividades pensadas para trabajar la química a través de juegos puntuales, donde se pueden resolver problemas como la geometría molecular (Myers, 2003) u otros más propios del ámbito doméstico (Solsona, 2002a; Solsona, 2002b), donde se trabaja la transversalidad del trabajo en la cocina y sus fundamentos químicos desde una perspectiva de educación no sexista y cuyo objetivo es revalorizar la importancia de los saberes domésticos del entorno y destacar la tarea indispensable para la vida de las personas y el buen funcionamiento de las familias y la sociedad, teniendo en cuenta que este conocimiento del hogar incluye una gran cantidad de conocimientos matemáticos y científicos (Durán, 1988).

A partir de los fenómenos cotidianos observables pueden introducirse conceptos como:

- Propiedades específicas que permiten identificar las diferentes sustancias.

- Técnicas de separación basadas en la diferencia de estas propiedades.

- Cambios físicos

- Cambios químicos, que al igual que los físicos, conllevan cambios de propiedades de las sustancias que intervienen. 
Podemos, por tanto, establecer una comparación entre actividades en que se trabajen contenidos como tales con la única intención de estudiarlos y otras actividades que estén relacionadas con situaciones habituales para el alumno.

\begin{tabular}{|c|c|}
\hline Situaciones lejanas al alumnado & Situaciones cotidianas \\
\hline $\begin{array}{l}\text { La actividad no es real, se mueve en el } \\
\text { plano simbólico. }\end{array}$ & $\begin{array}{l}\text { La actividad es real. Se producen } \\
\text { conexiones afectivas. Lo concreto } \\
\text { (cotidiano) sirve para cimentar las bases } \\
\text { teóricas. }\end{array}$ \\
\hline La actividad no es productiva. & $\begin{array}{l}\text { El producto que se obtiene es la explicación } \\
\text { de lo cotidiano, la abstracción teórica y la } \\
\text { extensión de nuevos contextos. }\end{array}$ \\
\hline $\begin{array}{l}\text { Conocimientos } \\
\text { objetivas de un modelo mecánico del } \\
\text { mundo. }\end{array}$ & $\begin{array}{l}\text { El modelo surge como necesidad para } \\
\text { simplificar la complejidad de lo real. Los } \\
\text { alumnos y las alumnas serán conscientes de } \\
\text { ello. }\end{array}$ \\
\hline $\begin{array}{l}\text { El sistema simbólico esencial y dominante } \\
\text { es el verbal. El aprendizaje es individual } \\
\text { (actividad mental interna) }\end{array}$ & $\begin{array}{l}\text { El trabajo en grupo de observación, de } \\
\text { experimentación y la expresión de los } \\
\text { procesos (verbales o no) son el eje central } \\
\text { del aprendizaje. }\end{array}$ \\
\hline $\begin{array}{l}\text { El mundo de los contenidos académicos se } \\
\text { mantiene paralelo y no integrado con el } \\
\text { mundo de los contenidos fuera de la } \\
\text { escuela. }\end{array}$ & $\begin{array}{l}\text { Los contenidos científicos escolares surgen } \\
\text { de los cotidianos. }\end{array}$ \\
\hline $\begin{array}{l}\text { El conocimiento escolar no es significativo } \\
\text { para los alumnos y las alumnas ni está } \\
\text { integrado con el de la calle. El } \\
\text { conocimiento tiene un carácter mosaico. }\end{array}$ & $\begin{array}{l}\text { El aprendizaje será significativo cuando el } \\
\text { conocimiento científico escolar coincida } \\
\text { con el conocimiento científico (académico } \\
\text { y cotidiano) }\end{array}$ \\
\hline $\begin{array}{l}\text { El rol de los alumnos ante el aprendizaje es } \\
\text { pobre y poco variado }\end{array}$ & $\begin{array}{l}\text { Las situaciones cercanas al alumnado son el } \\
\text { eje central de la enseñanza y lo convierten } \\
\text { en el protagonista de su aprendizaje. }\end{array}$ \\
\hline
\end{tabular}

Tabla 1.5.- Comparación de las características de modelos de enseñanza. (Jiménez, Sánchez y De Manuel, 2001)

Existen muchas interpretaciones de cómo aprenden los alumnos y de cómo se produce resistencia a los cambios en los errores conceptuales.

- La teoría de aprendizaje de Ausubel (1978) destaca la importancia de las ideas previas, pero no desarrolla un estudio adecuado sobre la persistencia de estas.

- Las ideas de Vygotsky (1962) hace referencia a los conceptos espontáneos, pero falta un criterio que relacione los conceptos entre sí. 
- La teoría causal de Piaget (1974), en la opinión de algunos investigadores, debería centrarse más en el contenido real de las ideas de los alumnos en lugar de la supuesta estructura lógica.

Para asociar las teorías del aprendizaje a los problemas relacionados con la química, se hace necesario profundizar en una unificación de los fundamentos psicológicos en que se apoya la didáctica de las ciencias. Es posible armonizar algunos puntos de estas teorías, en cuanto se trata de justificar las ideas alternativas de los alumnos (De Posada, 1996).

La percepción cotidiana es importante en la formación de recuerdos ubicada en la memoria práctica diaria, y a partir de la atención que el alumno le presta, va construyendo elementos basados en la experiencia más elaborados. Las ideas así formadas van adquiriendo precisión gracias al aprendizaje que se produce tanto en un contexto escolar, como extraescolar, de ahí que sea importante crear un entorno favorable.

La percepción cotidiana es importante en la formación de recuerdos. Con la práctica diaria, a partir de la atención que le presta, el alumno va construyendo elementos más elaborados, basados en la experiencia. Las ideas, así formadas, van adquiriendo precisión gracias al aprendizaje que se produce tanto en un contexto escolar, como extraescolar. De ahí que sea importante crear un entorno favorable.

En lo que respecta al trabajo de laboratorio, no hay consenso sobre su utilidad, pero no hay duda de que es un hecho diferencial propio de la enseñanza de las ciencias $\mathrm{y}$, aunque ya estaba introducido en los currículos de ciencias de Inglaterra y Estados Unidos desde finales del siglo XIX, también es cierto que se ha criticado mucho su utilización. A partir de los años setenta, aparecieron proyectos como Biological Sciences Curriculum Study, Chemical Education Material Study, Physical Science Study Committee o Nuffield de biología, física y química, que trataban de promocionar un estilo de enseñanza en el que el trabajo práctico llevaba a los alumnos hasta los fundamentos conceptuales, pero los resultados han sido poco concluyentes, no obteniéndose prácticamente ningún beneficio (Clakson y Writght, 1992). 
La mayor parte de la investigación realizada para estudiar la efectividad del trabajo práctico en la enseñanza de las ciencias no ha mostrado resultados concluyentes, ocupando un papel muy discutido en los currículos de ciencias (Barberá y Valdés, 1996)

Existe un amplio grupo de autores que explica cuáles son los posibles objetivos del trabajo experimental entre los que podemos encontrar: Oportunidad de aprender formas de razonamiento, proporcionar una visión de conjunto (Anderson, 1976), proporcionar experiencias concretas, dar oportunidad de manipular con ordenadores o construir y comunicar valores relacionados con la naturaleza de las ciencias (Lazarowitz y Tamir, 1994). También podemos encontrar autores que tratan de utilizar el método científico como vehículo de transmisión de conocimientos, lo cual proporciona una visión extremadamente empírica e inductivista de la ciencia y de los científicos.

Por otra parte, cuando se les pregunta a los profesores por los objetivos que persiguen con la realización de prácticas, las respuestas son mucho más simples y evidentes. Hodson las clasifica en seis categorías (Hodson, 1992, 1994, 1996 y 1998):

1. Para motivar, ya que estimulan el interés y son entretenidas

2. Para desarrollar actitudes científicas

3. Para mejorar el aprendizaje del conocimiento científico

4. Para adiestrarse en el método científico

5. Para enseñar las técnicas de laboratorio

6. Para desarrollar la capacidad de llevar a cabo investigaciones científicas y obtener experiencia de ello.

Algunos investigadores consideran que el trabajo de laboratorio es una pérdida de tiempo ${ }^{10}$ y de recursos (Hofstein y Lunetta, 1982; Pickerig, 1980; Toothacker, 1983), otros piensan que no se cumplen los objetivos propuestos (Igelsrud y Leonard, 1988; Lederman,1992; Reif y St. John, 1979; Tamir y Lunetta, 1978 y 1981; Tobin, 1986; White, 1979) y la mayoría concluyen que el trabajo de laboratorio que se realiza actualmente se limita a seguir unas instrucciones "tipo receta" para confirmar hechos y teorías, en lugar de plantearse como una pequeña investigación. Por otro lado, los

\footnotetext{
${ }^{10}$ Hay autores que admiten que las prácticas están en crisis, especialmente en España, puesto que no se hacen (Nieda, 1994) Citado por Barberá y Valdés, 1996.
} 
estudios realizados para comparar los resultados de aprendizaje utilizando metodologías convencionales carentes de trabajos prácticos con otros métodos que sí los tienen señalan que en el mejor de los casos se muestran igual de eficaces (Hofstein y Lunetta, 1982; Clackson y Wrigth, 1992).

Desde el punto de vista de la evaluación, observamos dos problemas: En primer lugar, cuando se trata de evaluar el trabajo práctico, aparece el inconveniente del método en sí, que no puede ajustarse al estandarizado lápiz y papel y, por tanto, no permite ser concluyente en cuanto a su valoración (Doran et al., 1994; Lazarowitz y Tamir, 1994; Tamir, 1974). En segundo lugar, encontramos que cuando la evaluación del trabajo experimental no se incluye en la global del proceso de aprendizaje, éste va quedando progresivamente al margen hasta prácticamente desaparecer (Black, 1993).

Por lo que respecta a los países de nuestro entorno (Europa), encontramos situaciones como la de Francia, donde hay una gran organización de las clases prácticas y otros como España o Italia donde se produce lo contrario (Caamaño, Corominas, Düll, Furnémont, Maurel, Mouton, Ralle, Schwob, Serafini y Tinnes, 2002).

En Francia la enseñanza científica se ha caracterizado por su interés por las actividades de laboratorio. Desde el año 2000, con los nuevos planes de estudios, los alumnos dedican a la actividad experimental una parte definida de su horario. La práctica experimental es considerada formativa y motivadora, aunque se carece de profesores de laboratorio. En lo que respecta a física y química, los alumnos reciben en el instituto, a los 16 años, dos horas semanales de clase y una hora y media de sesiones prácticas. A los 17 y 18 años, en función de la especialidad escogida, cursan entre hora y media y dos horas semanales de prácticas, incluso en las ramas de letras o tecnológica. Los objetivos pedagógicos asignados por el profesor pueden ser: aprender técnicas experimentales, sensibilizarse con un concepto nuevo o construir un modo operativo que responda a un problema planteado. La tendencia de los exámenes nacionales de fin de estudios es reducir los cálculos matemáticos y priorizar las cuestiones cualitativas y experimentales. 
En Alemania, el equipamiento técnico es bastante bueno, lo que permite realizar prácticas de laboratorio con el alumnado. El problema con que se encuentran es la disminución en el número de estudiantes universitarios en física y química, lo que está llevando a realizar campañas publicitarias para su promoción.

En la zona francófona belga, la pedagogía en el área científica se centra en el desarrollo de competencias basando el aprendizaje en la resolución de problemas extraídos de la vida cotidiana. No obstante, las prácticas de laboratorio van disminuyendo paulatinamente, debido a la reducción de horas, cosa que preocupa a profesores y autoridades educativas que las consideran necesarias para adquirir competencias técnicas, como vocabulario específico y utilización del instrumental, así como para familiarizarse con el planteamiento, análisis y resolución de problemas.

En Italia la enseñanza secundaria se caracteriza por su gran variedad de currículos, por lo que al hablar de prácticas de laboratorio podemos encontrar situaciones muy variadas. Hay un gran número de profesores motivados que utilizan muy a menudo el laboratorio utilizando, incluso, material muy barato y llegando a proponer a grupos de alumnos el desarrollo de equipamiento.

La tendencia actual es aceptar que las prácticas, tal como están propuestas, no son nada eficaces en cuanto a su utilización como vehículo de transmisión de conceptos, pero sí como herramienta de alfabetización en cuanto al instrumental de laboratorio y la adquisición de técnicas de laboratorio (Martín y Martín, 2003). Por cuanto se refiere a la utilización del trabajo experimental para aprender ciencias, actualmente se sigue apuntando a la necesidad de plantear las prácticas como resolución de problemas, como ya se proponía hace algún tiempo (Gil, 1982), aunque esto supone invertir la tendencia de muchos años de un contexto educativo en el que las prácticas se han realizado de forma algorítmica, lo que supone una visión distorsionada de lo que es el trabajo científico (Raigosa y Jiménez, 2000). En esa línea, algunos trabajos muestran que el trabajo de laboratorio, con un enfoque de investigación, mejora la comprensión conceptual de los temas estudiados (Jiménez, 2000), así como la relación entre hipótesis, observaciones y experimentos, aumentando la capacidad investigadora y el conocimiento de la ciencia y de la naturaleza del trabajo científico. 


\subsubsection{Estrategias de aprendizaje frente a la enseñanza tradicional.}

Los métodos clásicos de enseñanza en ciencias han mostrado ciertos problemas, como la estructura de los conceptos presentados, su exigencia formal o la influencia de las concepciones previas de los alumnos (Campanario, 1999). Actualmente la investigación en didáctica se orienta hacia la epistemología, estrategias de razonamiento o la metacognición.

Según estos factores, los métodos tradicionales dan lugar a que muchos de los alumnos consideren el conocimiento científico como un conjunto de ecuaciones y definiciones sin más, sin estructura, sin conceptos ni objetivos. Se observa una imagen acumulativa de la ciencia, donde los cursos se secuencian y que hay que cursar porque así se ha establecido. Recurren, por tanto, a memorizar y asimilar de forma independiente los conceptos, en lugar de razonarlos y comprenderlos. Esto supone un gran obstáculo en el aprendizaje de las ciencias y es responsable de muchos de los casos de fracaso escolar (Linder, 1993). También hay importantes evidencias de que los alumnos abordan los problemas científicos de forma superficial (Carrascosa y Gil, 1985).

Parece evidente que las estrategias utilizadas son poco eficaces para promover un aprendizaje significativo. En la actualidad, el modelo más utilizado es el de la enseñanza por transmisión. Su fundamento se basa en las siguientes suposiciones, consideradas inadecuadas (Calatayud, Gil y Gimeno, 1992):

a) Enseñar es una tarea fácil y no requiere una especial preparación.

b) El proceso de enseñanza-aprendizaje se reduce a una simple transmisión y recepción de conocimientos elaborados.

c) El fracaso de muchos alumnos se debe a sus propias deficiencias: falta de nivel, falta de capacidad, etc.

Enseñar es una tarea realizada entre personas y, por tanto, queda fuera de duda la subjetividad de este proceso, siendo además un problema abierto el lograr la forma más eficaz de hacerlo. Por tanto, es conveniente cambiar la noción de método de enseñanza 
por la de estrategia de enseñanza. Como llevar a cabo estas estrategias es un punto a considerar en cualquier investigación en didáctica y el objeto principal de muchos trabajos de investigación, vamos a analizar diferentes modelos de aprendizaje que se han descrito recientemente en la literatura científica:

\section{a) Aprendizaje por descubrimiento}

El aprendizaje por descubrimiento fue una de las primeras alternativas que surgieron a la enseñanza tradicional basada en la transmisión de conocimientos unidireccionalmente de profesor a alumnos. Constituyó un intento de aproximar el aprendizaje de las ciencias a las características del trabajo científico. Los defensores de este método fundamentan su propuesta en la teoría de Piaget, según la cual "cada vez que se enseña prematuramente a un niño algo que hubiera podido descubrir solo, se le impide inventarlo y, en consecuencia, entenderlo completamente".

Esta metodología se desarrolló durante los años sesenta y parte de los setenta. Su principal característica era el papel central de la actividad autónoma de los alumnos, llegando a veces al extremo de rechazar cualquier dirección de aprendizaje (Ausubel, Novak y Hanesian, 1983), lo que impediría mantener cierto rigor en los contenidos concretos, frente a los métodos (Gil, 1994). No obstante, permitiría a los alumnos abordar cualquier tipo de problema, puesto que han establecido sus propios principios y leyes, y aún más, habiéndose implicado de forma activa en el aprendizaje se conseguirá una mayor motivación (Pozo y Carretero, 1987).

Pronto se observaron deficiencias en el método:

- La búsqueda "libre" por parte del alumno daría lugar a un conjunto de adquisiciones dispersas (Gil, 1983).

- Otros autores señalan que a menudo se confunde la participación activa con la mera manipulación.

- Presenta una visión de la ciencia simplista y excesivamente inductivista (Hodson, 1994) 
- Según Ausubel, ni todo el aprendizaje receptivo es forzosamente memorístico, ni todo el aprendizaje por descubrimiento es necesariamente significativo (Ausubel, Novak y Hanesian, 1983).

Por supuesto, esta forma de aprendizaje presenta aspectos positivos, como es el hecho de hacer responsables a los alumnos de su propio aprendizaje o enseñar a los alumnos a observar con ojos críticos.

Una vez constatado el fracaso de este modelo queda, sin embargo una importante contribución y es la idea de que el aproximar el aprendizaje de las ciencias a la actividad científica supone un buen hilo conductor en la enseñanza, que se ha mostrado aceptado e incluso reforzado por las actuales orientaciones constructivistas. Por ello los resultados conseguidos con este modelo suponen el origen de las reestructuraciones posteriores que han tratado de dinamizar la enseñanza.

\section{b) Aprendizaje por recepción significativa.}

Se desarrolló como reacción frente al aprendizaje por descubrimiento, no suponiendo un retorno a la enseñanza tradicional ya que mantenía como principal objetivo familiarizar a los alumnos con la naturaleza del trabajo científico.

La recepción significativa apunta, en defensa de la enseñanza por transmisión, que los alumnos no tienen capacidad para descubrir autónomamente todo lo que deben saber (Ausubel, 1968) pero concede gran importancia a los conocimientos previos de los alumnos y a la integración de los nuevos las estructuras conceptuales existentes, resaltando el papel que la guía del profesor puede jugar facilitando el aprendizaje significativo.

No obstante, este modelo presenta como inconveniente el hecho de plantear la asimilación de conceptos, renunciando a que los alumnos participen en su construcción (Gil, 1993). De ese modo el papel del profesor se convierte en facilitador de conocimientos ya elaborados y, como señala Ausubel, la verdadera asimilación de conceptos exige un proceso activo, que los integre con los ya existentes. 


\section{c) Aprendizaje por cambio conceptual}

Es el punto de partida de las concepciones llamadas constructivistas y surge como alternativa, tanto a la enseñanza tradicional como a la enseñanza por descubrimiento. Se insiste en la necesidad de permitir a los alumnos explicitar sus ideas previas y en la necesidad de ciertas condiciones para cambiarlas (Posner, Strike, Hewson y Gertzog, 1982), como son, que exista insatisfacción con las concepciones existentes, que las nuevas concepciones permitan estructurar las experiencias anteriores o que las nuevas concepciones proporcionen nuevos puntos de vista.

1.- Identificación y aclaración de las ideas que ya poseen los alumnos

2.- Puesta en cuestión de las ideas de los estudiantes, a través del uso de contraejemplos (conflictos cognoscitivos)

3.- Introducción de nuevas ideas, mediante brainstorming, entre los alumnos o presentadas por el profesor.

4.- Proporcionar oportunidades a los alumnos para usar las nuevas ideas en diferentes contextos

Figura 1.5.- Estrategia para un aprendizaje por cambio conceptual

Actualmente, el cambio conceptual se ha extendido como paradigma a otras áreas e, incluso, los documentos de la actual reforma educativa se refieren al aprendizaje como cambio conceptual (Hewson, 1992). El currículo se concibe como un conjunto de experiencias mediante la cual el alumno construye su propia concepción del mundo (Driver, 1988). El papel del profesor es el de animar a sus alumnos a expresar sus ideas e ir modificando sus explicaciones. Según indica Hewson, las ideas de los alumnos deben explicitarse en el aula y ser estos conscientes de su opinión, de las de sus compañeros y la del profesor, estando todas al mismo nivel. Posteriormente, se deben 
discutir y justificar, desempeñando la metacognición un papel central en el cambio conceptual, puesto que han de explicitar sus propios criterios de comprensión.

Este método implica disponer de un amplio repertorio de técnicas y recursos que pongan de manifiesto las ideas previas $\mathrm{y}$, mediante ellos, conseguir disminuir el estatus de las ideas erróneas de los alumnos y justificar las nuevas ideas, así como aquellas que sean correctas. Estas técnicas se basan en el empleo de analogías, discusiones guiadas, modelizaciones, comparaciones, etc. (Raghavan y Glaser, 1995).

El éxito conseguido con este método es satisfactorio aunque no excesivamente amplio. Esto se debe a que este método puede ser muy aceptado en poblaciones de científicos, dado su grado de implicación en el tema; sin embargo, esto es difícil de conseguir con alumnos (Pintó, Aliberas y Gómez, 1996). Además, no siempre los contraejemplos o los conflictos cognitivos son útiles para promover un cambio conceptual.

La realidad de este método es que, para conseguir algún efecto importante, es necesario que las estrategias no se apliquen de forma aislada, sino como un enfoque coherente y común a varias asignaturas con cierta persistencia temporal, puesto que los profesores mantienen una perspectiva a largo plazo en sus actividades que no se da, en general, en los alumnos (Duit, 1991). Los profesores mantienen que no pueden aplicar este método a gran escala, ya que no disponen del material curricular adecuado, siendo los libros de texto lo más utilizado, careciendo de ese enfoque.

A todo ello cabe añadir que el cambio conceptual se centra exclusivamente en los conocimientos y no considera ciertos aspectos importantes como el hecho de que el conflicto cognitivo puede crear problemas en algunos alumnos, llegando a desarrollar actitudes negativas o muestras de ansiedad (Dreyfus, Jungwirth y Eliovitch, 1990), siendo por tanto necesario hablar de cambio conceptual, metodológico y actitudinal (Carrascosa y Gil, 1985). 


\section{d) Aprendizaje por investigación dirigida}

Esta propuesta comienza a desarrollarse junto a las primeras teorías cognitivas, a principios del siglo $\mathrm{XX}$, pero en los últimos años se ha desarrollado notablemente, sobre todo desde las posiciones denominadas constructivistas.

Según Gil cuando una persona se integra en un grupo de investigación, se deja dirigir por otras que son expertas en aquellas experiencias que va realizando. De igual modo se puede trasladar este método a la enseñanza de las ciencias en secundaria (Gil, 1993). La estrategia propuesta (Gil, 1993; Gil, 1994; Gil, Carrascosa, Furió y MartínezTorregrosa, 1991), consiste en una secuencia de actuaciones en la que se debe plantear situaciones de interés para los alumnos, que deben estudiar cualitativamente el problema y, con ayuda de la bibliografía, delimitarlo. Posteriormente, se procede a una orientación científica, con emisión de hipótesis, análisis, comparación de resultados, etc. Aquí puede aplicarse el conflicto cognitivo como estrategia y extender los nuevos conocimientos a otras situaciones para afianzar y profundizar en aquello que se ha aprendido. A diferencia del aprendizaje por cambio conceptual, aquí se utiliza el conflicto como medio para resolver un problema, no como un fin.

1.- Plantear situaciones problemáticas que generen interés y proporcionen una concepción preliminar de la tarea.

2.- Proponer el estudio cualitativo de las situaciones problemáticas planteadas y la toma de decisiones, con la ayuda de las necesarias búsquedas bibliográficas

3.- Orientar el tratamiento científico de los problemas, emisión de hipótesis, estrategias de resolución, diseños experimentales, análisis de resultados...

4.- Plantear el manejo reiterado de los nuevos conocimientos en una variedad de situaciones, para afianzarlos

Figura 1.6.- Estrategias para un aprendizaje como investigación dirigida 
Este modelo se contrapone, tanto al aprendizaje por transmisión, como al realizado por descubrimiento. Presenta el problema del desfase entre los currículos de ciencias y lo que es posible enseñar a lo largo de un curso, por lo que es preciso descargar a los primeros para prestar más atención a los aspectos metodológicos, a la construcción del conocimiento y a la relación ciencia-tecnología-sociedad (Gil,1994). Recientemente, se ha insistido en la integración entre prácticas y resolución de problemas (Gil y Valdés, 1995). Hay infinidad de profesores e investigadores en didáctica que abogan por una integración de las prácticas en una enseñanza constructivista (Furió, 1994).

El problema de esta visión es la reducida capacidad investigadora de los alumnos, que lleva consigo un marcado carácter de investigación dirigida llegando incluso a ser necesario que el profesor compare frecuentemente los resultados de los alumnos con los resultados reales.

Además del problema existente por la limitación del tiempo, que obliga a tratar de equilibrar los contenidos tratados y su profundización, cuenta con el inconveniente de la pasividad de gran parte del alumnado, que ve más cómodo escuchar una explicación, que tratar de razonarla.

\section{e) Enseñanza basada en el uso de problemas}

Cabe la opción de organizar unidades didácticas articuladas fundamentalmente como colecciones de problemas, que han de ser seleccionados cuidadosamente y secuenciados de forma que se consiga un aprendizaje significativo (Lopes y Costa, 1996).

El aprendizaje basado en problemas (ABP) surge como búsqueda un curso que no se base únicamente en el contenido, donde el alumno es un sujeto pasivo del grupo que recibe información, sino un marco en el que el alumno es quien busca la información que considera necesario aprender para resolver los problemas que se le plantean. 
La palabra problema debe entenderse como un término que incluye pequeños experimentos, observaciones, tareas de clasificación, etc. Todos ellos son intentos de encontrar alternativas más prácticas al método tradicional. La diferencia de este método con el de la enseñanza por descubrimiento está en que aquí existe un grado variable de direccionalidad por parte del profesor. Desde ese punto de vista se trata, más bien, de dar relevancia a los conceptos que a descubrirlos.

Esencialmente, se trata de introducir al alumnado en el contexto de un problema, lo más vinculado posible a la realidad social o profesional ${ }^{11}$, de modo que deba planificar, mediante un trabajo cooperativo y bajo la supervisión del profesor, un proceso de resolución que implique, como aspectos esenciales, la búsqueda y delimitación de los conocimientos técnicos necesarios para abordar el problema, el planteamiento de hipótesis de trabajo, el diseño de experimentos, etc. En definitiva, los procesos característicos de la actividad científica, teniendo en cuenta, además, que la dinámica establecida posee un importante grado de apertura, no teniendo por qué desembocar en una solución univoca.

Respecto a la metodología basada en una investigación dirigida, su principal diferencia es que la metodología basada en el uso de problemas puede centrarse fácilmente en el ámbito profesional. Asimismo, la enseñanza convencional queda integrada siempre que el alumno la perciba como algo necesario para resolver el problema.

Este método presenta como principal ventaja (Birch, 1986) el hecho de que la ciencia, en sí misma, se presenta como situaciones problemáticas a las que hay que encontrar solución y, por tanto, esta estrategia hace explícita la aplicación de los conocimientos. Otro aspecto importante es que el alumno debe movilizar constantemente sus conocimientos, puesto que las situaciones planteadas interrelacionan constantemente varios conceptos y sus aplicaciones prácticas.

El tutor no se convertirá en la única figura transmisora de conocimientos, sino que hará el papel de director, diseñador, facilitador de actividades, orientador, etc..., por

\footnotetext{
${ }^{11}$ Esta metodología se lleva a cabo desde hace varias décadas en estudios universitarios, especialmente en medicina e ingenierías.
} 
lo cual los alumnos sólo se apoyarán en él para la búsqueda de información. El objetivo no se centra en resolver el problema, sino en que éste sea utilizado como base para identificar los temas de aprendizaje para su estudio de manera independiente o grupal.

El método de aprendizaje basado en problemas implica un cambio en casi todas las circunstancias que rodean al aprendizaje y plantea ciertas dificultades e, incluso, ciertas barreras. Principalmente, encontramos que muchos profesores encuentran esta metodología muy importante en aspectos como la motivación y para la relación de los alumnos con la ciencia, pero no ven su potencialidad de cara a la introducción de conceptos (Bennett, Gräsel, Parchmann y Waddington, 2005).

Así mismo, este método requiere una mayor dedicación por parte del profesor, puesto que toda la asignatura va a depender de su capacidad para fundamentar teóricamente, investigar en el aula y trabajar en colaboración con los demás profesores a la hora de seleccionar y secuenciar las actividades. De estos factores dependerán también la coherencia de los contenidos y la motivación de los alumnos, siendo esta última de gran importancia, ya que esta estrategia va a requerir una mayor participación y esfuerzo por su parte, lo que en muchos casos puede chocar con una pasividad adquirida a lo largo de varios años. 


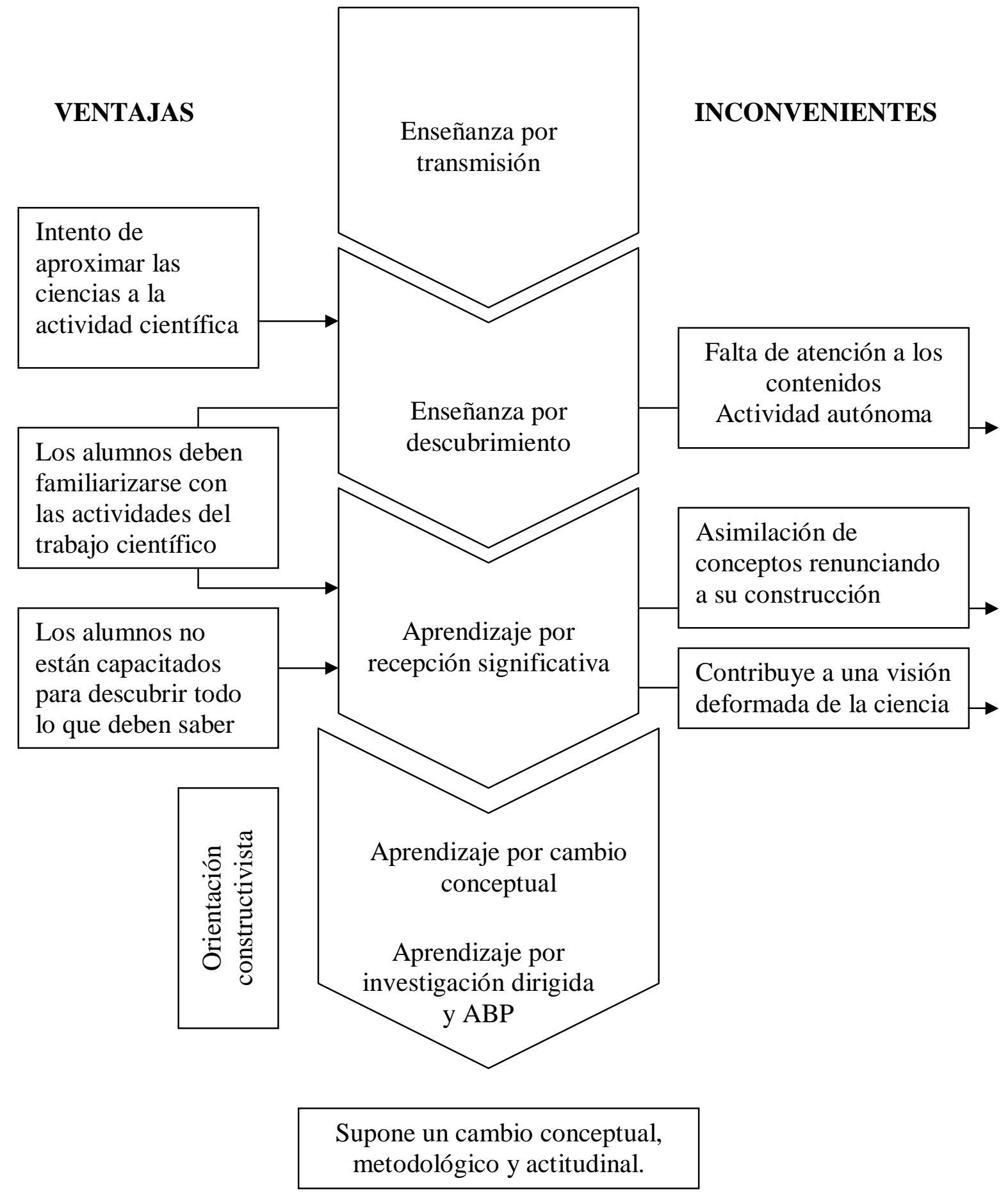

Figura 1.7.- Estrategias de aprendizaje frente a la enseñanza tradicional

La división de las materias en "teoría", "problemas" y "prácticas" se toma como normal en el ámbito universitario, (Gil et Al., 1999) aun cuando hay numerosas investigaciones al respecto y se constata que dicha separación no está justificada, suponiendo además un obstáculo para la renovación de la enseñanza de las ciencias. 
En las materias científicas, el aprendizaje significativo requiere la participación de los estudiantes en la construcción de los conocimientos, habiéndose demostrado que los estudiantes desarrollan mejor su compresión conceptual y su aprendizaje sobre la naturaleza de la ciencia cuando participan (no llevando a cabo por sí mismos, pero sí reflexionando posteriormente acerca de lo aprendido) en investigaciones científicas y realizan una reflexión posterior.

Para conseguir una orientación adecuada del aprendizaje como investigación, es necesario que el profesorado supere las visiones deformadas sobre ciencia, puesto que todos hemos ido adquiriendo, a lo largo del tiempo, numerosas concepciones, ideas y actitudes que asumimos como normales. Estas ideas llevan a buscar una convergencia entre los tres aspectos, que pasa por la transformación de todos ellos.

En el caso de las prácticas de laboratorio, lejos de plantear las materias basadas exclusivamente en trabajos prácticos dejando de lado los aspectos conceptuales o de utilizarlas como "recetas" que, a su vez, dan una visión deformada de la ciencia, cabe señalar que cuando se favorece una discusión detenida de la naturaleza del trabajo científico, los propios profesores ven la necesidad de vincular dichas prácticas al tratamiento de un problema relevante.

En el caso de los problemas de lápiz y papel, la realidad es que en las clases no se enseña a resolver problemas, sino a explicar las soluciones, con lo que un leve cambio en el planteamiento no puede superarse, no obteniendo de ese modo un aprendizaje significativo. Debería aceptarse la idea de que un problema es una situación ante la cual se desconoce un procedimiento definido a seguir, no se conocen datos iniciales ni las ecuaciones a emplear, de modo que el alumno frente a la ambigüedad manifiesta tenga que operativizar todos sus conocimientos y enfrentarse a un problema abierto, relacionando sus propias experiencias con la situación planteada. Con ello, cabe la posibilidad de englobar trabajos prácticos con problemas escritos, como dos caras de una misma actividad, aproximándose mejor a lo que supone un trabajo científico.

El tratamiento más coherente en la adquisición de conceptos es aquel que asocia el aprendizaje al tratamiento de situaciones problemáticas abiertas (Gil y Martínez- 
Torregrosa, 1987), que puedan generar el interés de los estudiantes. Es decir, una mayor contextualización del trabajo científico, relaciones CTS...

Con todo, cabe concluir que estas vertientes de una misma actividad nos aportan la necesidad de una búsqueda de la comprensión de la ciencia a través de una identificación de problemática de nuestro entorno, consiguiéndose así un mejor aprendizaje en tanto y cuanto sean los alumnos capaces de cuestionar y explicar los fenómenos observables.

El proceso de cambio de una clase, basada en la transmisión-recepción a otro, donde se busque el aprendizaje activo y en grupo ha de ser gradual. Es un error dar este paso de golpe. Se necesita mucha práctica y pruebas para llevar a cabo correctamente este aprendizaje (Paulson, 1999). Las estrategias de aprendizaje activo deben ser introducidas en la forma de trabajar del profesor lentamente, así como explicar a los alumnos el porqué de la utilización de estas nuevas técnicas, ya que ellos las aceptarán mejor si conocen las razones. Incluso cabe la posibilidad de mezclar ideas en una misma clase y comenzar un tipo de metodología como puede ser una actividad práctica para continuar de otra forma a partir de ella (Criswell, 2006).

Una ventaja de enseñar con diferentes estilos es que los alumnos tienen diferentes formas de aprender y el resultado global será normalmente más enriquecedor. Lo cierto es que llevando a cabo algunas de las ideas, podremos seleccionar el material que puede utilizarse. Es importante reconocer que fuera de campo de las ciencias pueden encontrarse ideas cotidianas. Es preferible que los alumnos conozcan la base científica de estas ideas y busquen la relación existente entre ellas y el currículo escolar, en lugar de conocer un montón de información que no recordaran seis meses después. Esto se pone de manifiesto cuando por ejemplo se pide a los alumnos que representes las estructuras de Lewis para el $\mathrm{HNO}_{3}$, y la mayoría de los alumnos dan una única estructura coincidente con la vista en clases anteriores. La han memorizado frente a la gran cantidad de material que deben aprender, pero no lo han comprendido. 


\subsubsection{El tratamiento de las relaciones CTSA como alternativa didáctica}

Los objetivos de la química, en particular, y de las ciencias de la naturaleza, en general, han ido cambiando con la aplicación de las reformas del sistema educativo, prevaleciendo la finalidad de una ciencia para todos. Esta situación se materializa en este objetivo en detrimento de la importancia de los contenidos disciplinares, por lo que se da prioridad a la comprensión de la naturaleza de la ciencia, al conocimiento de sus aplicaciones prácticas y al desarrollo de actitudes críticas y responsables para valorar las implicaciones sociales y técnicas.

De acuerdo con esta orientación, en España se han introducido nuevos contenidos relacionados con el trabajo científico y la relación "Ciencia-TecnologíaSociedad", con la intención de incorporar avances y aplicaciones prácticas de las materias, así como prestar mayor atención a los procedimientos y trabajos prácticos experimentales (Caamaño, 2001).

La introducción de las relaciones CTS en la enseñanza constituye un campo multidisciplinar centrado en los aspectos sociales de la ciencia y la tecnología, tanto en lo que concierne a sus condiciones sociales como en lo que atañe a sus consecuencias sociales, políticas, económicas, éticas y ambientales, además la educación CTS es una innovación del currículo que incluye nuevos contenidos a los que, según la opinión de muchos investigadores, debería prestarse más atención.

Desde las universidades, diversas asociaciones nacionales e internacionales han impulsado programas educativos CTS en muchos países. Como por ejemplo:

- La NASTS (National Association for Science, Technology and Society) en los EE.UU.,

- la ASE (Association for Science Education) en Gran Bretaña,

- la internacional IOSTE (International Organization of Science and Technology Education) con sede en Canadá,

- la europea EASTS (European Association of STS) en la que Holanda es uno de los principales líderes. 
- la OEI (Organización de Estados Iberoamericanos para la Educación, la Ciencia y la Cultura) con su programa Ciencia, Tecnología Sociedad e Innovación $(C T S+I)$.

- la NLSC (natural learning science center) de York.

Debido a sus finalidades y objetivos, en secundaria la educación en CTS suele considerarse, sobre todo, una innovación del currículo escolar (Acevedo, 1997; Vázquez, 1999) que da prioridad a los contenidos actitudinales (cognitivos, afectivos y valorativos) y axiológicos (valores y normas) relacionados con la intervención de la ciencia y la tecnología en la sociedad (y viceversa), con el propósito de formar personas capaces de actuar como ciudadanos responsables que puedan tomar decisiones razonadas y democráticas sobre estos problemas en la sociedad civil. Sustenta, además, que incluir las relaciones mutuas entre ciencia, tecnología y sociedad en los currículos de ciencias para la educación secundaria no supone ninguna desviación en la enseñanza de las ciencias, como algunas veces se ha querido hacer creer, sino que puede:

- Dar sentido a los conocimientos que aprenden los estudiantes, potenciando su utilidad y funcionalidad fuera del aula.

- Colaborar a formar ciudadanos capaces de opinar libremente, con conocimiento de causa (fundamentos) y responsabilidad social (formación axiológica), sobre muchos problemas de nuestro tiempo, lejos de posiciones extremas en las que o se sacralizan la ciencia y la tecnología o se las denigra como responsables de todos los males que nos aquejan.

- Contribuir a evitar rupturas drásticas entre la ciencia y la tecnología, que tienen una frontera común bastante difusa y difícil de definir en el mundo actual (tecnociencia).

- Servir de elemento motivador para el alumnado, favoreciendo las actitudes hacia el aprendizaje de la ciencia y la tecnología.

Uno de los problemas más importantes con los que se encuentra el profesorado ante cualquier innovación educativa es la falta de materiales curriculares para la enseñanza y el aprendizaje de nuevos contenidos. 
Podemos distinguir entre dos modos de enfocar la educación CTS a la hora de introducir los contenidos CTS en los currículos, una centrada en cuestiones científicas y tecnológicas relevantes que afectan a la sociedad y otra basada en los aspectos sociales y culturales de la ciencia y la tecnología. El primero de ellos permite, probablemente, conectar mejor con los intereses de alumnos y profesores, pero por su carácter más específico puede conducir a una educación CTS parcial. El segundo es más generalista y quizás podría proporcionar a los estudiantes una estructura conceptual CTS más amplia y duradera En la educación secundaria y preuniversitaria de los años noventa, la realidad era que la mayoría de los proyectos CTS utilizaba el primero de los enfoques en los currículos basados en las materias o las áreas de conocimiento científicas y técnicas, porque gran parte del profesorado de ciencias y tecnología lo considera más interesante e innovador. Por otro lado, también se considera más compatible con la organización curricular

A partir de la síntesis realizada por Aikenhead (1994), los proyectos y materiales CTS se pueden clasificar estructuralmente como sigue:

1.- Inserción ocasional o intencionada en los cursos de ciencia y tecnología.

- Mencionando CTS para motivar.

- Complementando cursos tradicionales con unidades CTS.

- Integrando actividades CTS en las unidades de una disciplina o área de conocimientos.

2.- Ciencia y tecnología organizada y secuenciada con criterios CTS.

- De carácter disciplinar.

- De orientación multidisciplinar.

3.- CTS como eje vertebrador de los contenidos.

- Inclusión de contenidos de ciencia y tecnología, que se integran en las explicaciones sociales, filosóficas, etc.

- Inserción de contenidos de ciencia y tecnología como ejemplos de explicaciones sociales, filosóficas, etc. 
- Contenidos totalmente de CTS, basados en explicaciones sociales, filosóficas, etc.

Hofstein, Aikenhead y Riquarts (1988) reconocen que, hasta ese momento, la integración de aspectos CTS en los materiales de los cursos de ciencia ya existentes, haciendo añadidos o modificaciones coherentes en los currículos basados en una disciplina o área, era el procedimiento preferido por la mayoría de profesores. Aunque posteriormente se ha avanzado mucho en la elaboración de proyectos y materiales CTS más holísticos, los primeros continúan siendo los más populares entre el profesorado de ciencias experimentales.

Todos los proyectos CTS deben ocuparse de asuntos sociales de la ciencia y la tecnología, si bien los contenidos concretos pueden ser muy variados, ya que aquí suelen tener cabida aspectos propios de los denominados temas transversales: educación para la salud, para el consumo, para la paz, medioambiental, la coeducación (perspectiva social del género en la ciencia y la tecnología), etc. Así mismo, cada vez hay más acuerdo en prestar mayor atención a la naturaleza de la ciencia y la tecnología (Acevedo, 2000; Acevedo y Acevedo, 2002), aunque no todos los proyectos CTS la tratan explícitamente.

Algunas de las características generales que presentan los proyectos CTS más importantes son las siguientes:

- Tienen fundamentos psicopedagógicos y didácticos.

- Poseen una orientación que da relevancia, en mayor o menor medida, a las interacciones entre ciencia, tecnología y sociedad, así como a la toma de decisiones responsables sobre problemas y cuestiones controvertidas sociocientíficas y socio-tecnológicas.

- Abarcan la programación de una etapa o de un ciclo completo.

- Están constituidos por un conjunto de materiales, entre los cuales son de gran importancia las actividades de aprendizaje y de evaluación. Estos materiales suelen ser un libro del alumno, con información y actividades de aprendizaje, y una guía del profesor, en la que figuran los objetivos y los fundamentos teóricos del proyecto, las orientaciones didácticas, un esquema de evaluación y una relación de recursos didácticos. En bastantes casos también hay materiales 
audiovisuales (cintas de vídeos y programas informáticos) diseñados específicamente para las actividades prácticas.

- Su elaboración y experimentación supone la participación de un amplio número de expertos, procedentes de la educación, la industria, la ciencia, etc., y profesores, siendo la intervención de éstos cada vez mayor en los últimos años.

- Hay siempre una fase de experimentación y evaluación previa a la publicación de los materiales definitivos.

La existencia de proyectos con estas características requiere un sistema educativo más o menos abierto o flexible, que favorezca la elaboración de materiales curriculares y la existencia de fuentes de financiación diversas (públicas y privadas) para su desarrollo y experimentación.

A continuación expondremos, a modo de ejemplo tres proyectos CTS que han adaptado a nuestro sistema educativo y que se han estado llevando a cabo en mayor o menor medida.

\section{El Proyecto APQUA}

APQUA (Aprendizaje de los Productos Químicos, sus Usos y Aplicaciones) es un proyecto educativo de ciencias dirigido a la población, en general, que se desarrolla desde 1988 en el Departamento de Ingeniería Química de la Universidad Rovira i Virgili de Tarragona (Abelló, Medir, Jiménez y Gilabert, 2001). Nació como resultado de la colaboración establecida con el programa CEPUP y se centra en los productos y los procesos químicos, así como en el riesgo que su uso puede representar para las personas y el medio ambiente (Abelló y Medir, 1997). La elaboración de los materiales curriculares y la difusión del proyecto tiene en la AEQT (Asociación Empresarial Química de Tarragona) uno de sus principales patrocinadores.

APQUA consta en la actualidad de cuatro líneas diferentes de trabajo (Medir, El Boudamoussi y Abelló, 2000):

- El programa APQUA escolar, dirigido a los estudiantes y docentes del ciclo superior de educación primaria y la educación secundaria obligatoria. El 
programa escolar de APQUA se ha difundido desde Cataluña a toda España, realizándose la formación del profesorado en los Centros de Profesores.

- El programa público, iniciado en 1989 y dirigido a todas las personas adultas.

- El Centro de Información Química (CIQ), una base de datos informatizada que, de manera sencilla, pone a disposición de toda la población información básica sobre los productos químicos.

- El programa de formación de profesionales, dirigido a todo tipo de personas que trabajan en la industria o en la administración, así como a otros grupos profesionales que tengan relación con los productos químicos o interés por el tema.

APQUA es uno de los pocos proyectos educativos de química españoles con un enfoque CTS basado en problemas y cuestiones químicas de interés social (Rosenthal, 1989; SEPUP, 1993, 1995; Thier, 1985; Thier y Nagle, 1994), tales como la toxicidad de los aditivos en los alimentos, la contaminación del agua de consumo, el riesgo en las actividades cotidianas, la peligrosidad y la gestión de los residuos contaminantes, la elección entre plástico o papel, etc. Por su estructura puede clasificarse como un proyecto de química con tecnología desarrollado a través de las coordenadas CTS.

\section{El Proyecto Salters}

El Salters Advanced Chemistry (Burton, Holman, Pilling y Waddington, 1994, 1995) es un proyecto británico para la enseñanza de la química, desarrollado por el Science Educational Group de la Universidad de York, que cubre los contenidos de química de los dos cursos del A-Level destinado a alumnos de 17-18 años. Las aplicaciones de la química y sus implicaciones sociales son su eje organizador (Bennett y Lubben, 2006).

En 1995 se firmó un convenio entre tres administraciones educativas (Centro de Desarrollo Curricular del Ministerio de Educación y Ciencia, Departament d'Ensenyament de la Generalitat de Catalunya y Conselleria de Cultura, Educació y Ciència de la Generalitat Valenciana) para subvencionar la adaptación del proyecto al Bachillerato de España (Caamaño, 1997). Se formó un equipo de profesores dividido en tres grupos de trabajo que, entre 1995 y 1999, ha preparado dos ediciones (en español y 
catalán). En la versión española se ha respetado el espíritu original del proyecto y sus objetivos principales:

- Organizar el currículo de química tomando como criterio las aplicaciones tecnológicas y su influencia en la sociedad actual.

- Resaltar la relación entre la química y nuestra vida cotidiana.

- Mostrar algunos de los métodos de trabajo que se utilizan en química.

- Presentar algunas líneas de investigación química más recientes.

- Ampliar el abanico de actividades que se utilizan en la enseñanza de la química.

El proyecto Salters en español consta de ocho unidades didácticas, la realización de una investigación individual y visitas a diferentes industrias. Cada unidad tiene tres secciones: Química y Sociedad, Conceptos Químicos y Actividades. Además, incluye una Guía Didáctica o Guía del Profesor (Gómez-Crespo, Gutiérrez-Julián, Martín-Díaz y Caamaño, 2000). Su principal aportación, para dar una orientación CTS al proyecto es Química y Sociedad, una lectura que sirve de hilo conductor para cada unidad. Su estructura también es la de un proyecto de química con tecnología que se desarrolla a través de las relaciones CTS.

\section{Los proyectos $S A E$ y $S A W$}

El proyecto SAE (Science Across Europe) nació bajo el patrocinio de la ASE (Association for Science Education) en colaboración con la BP (British Petroleum) y se inició como una extensión del proyecto británico SATIS. La primera reunión de profesores del equipo europeo de SAE tuvo lugar en Brujas (junio de 1990), repitiéndose desde entonces con periodicidad anual. En estos encuentros se revisan las unidades en funcionamiento, se programan y experimentan otras nuevas y se difunden a nuevos países e idiomas (Parejo, 1995; Parejo y Juan, 2000). El material de cada unidad incluye información para el profesor, hojas del alumno e información adicional sobre el tema. En la actualidad, Ciencia a través de Europa es una sección integrada en el proyecto SAW (Science Across World), que mantiene lazos con las restantes del mundo, de las que Iberoamérica es posiblemente la de mayor interés para los españoles. La estructura de ambos proyectos no va más allá de la inserción de unidades CTS en el currículo ordinario, si bien están bastante elaboradas. 
Como señalan los responsables en España (Parejo y Juan, 2000), los principales objetivos son:

- Mayor conocimiento de la influencia de la ciencia y la tecnología en la sociedad actual.

- Permitir a los alumnos conocer opiniones y formas de vida de compañeros de otros países, lo que sirve para transferir el conocimiento desde lo local a lo global.

- Desarrollar habilidades de comunicación incluyendo otros idiomas.

- Facilitar les relaciones entre escuelas de diferentes países.

Algunos expertos en educación científica creen que el movimiento CTS se ha quedado anticuado y han certificado su defunción (Layton, 1994). En parte esto es lo que ha sucedido en los EE.UU., donde CTS continúa teniendo una presencia significativa en la enseñanza superior, pero la ha perdido en la enseñanza secundaria y preuniversitaria, pese a que todavía hay una representación minoritaria de calidad. El avance del movimiento CTS ha sido frenado por la dirección que ha tomado, a finales del pasado siglo XX, la reforma de la enseñanza de las ciencias orientada hacia una alfabetización científica y tecnológica basada en conocimientos normalizados.

Por el contrario, en otros países avanzados en educación científica y tecnológica como Canadá, Holanda, Australia, etc., el movimiento CTS aún tiene mucha pujanza, así como también en Iberoamérica. 


\section{PAPEL DEL ENLACE QUÍMICO COMO NÚCLEO FUNDAMENTAL EN LA COMPRENSIÓN DE LA ESTRUCTURA DE LA MATERIA EN SECUNDARIA Y EN QUÍMICA GENERAL}

\subsection{Evolución histórica del concepto de enlace químico}

La existencia del enlace químico se concibe desde la antigüedad, al igual que la del átomo, ya que la idea en sí de suponer partículas constituyentes de la materia obliga a reflexionar sobre la forma en que están unidas. Naturalmente, durante mucho tiempo se trató de conocimientos basados en ideas especulativas, que iban desde la existencia de ganchos que unían a los átomos según Demócrito, a

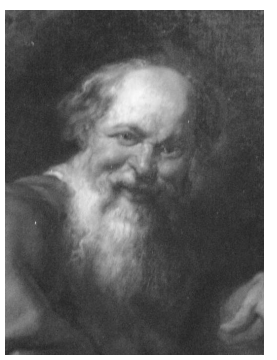

Demócrito sentimientos de afinidad en la edad media.

Las primeras teorías físicas acerca del enlace aparecen en el siglo XIX, y desde sus inicios implican la división de la química en orgánica e inorgánica, y en su virtud la clasificación en enlaces covalentes o iónicos respectivamente.

El inicio del estudio del enlace químico se remonta al descubrimiento por parte de J.T. Berzelius (1812) de que ciertas sustancias eran capaces de disolverse en agua y conducir la corriente eléctrica, apareciendo la idea de polos positivos y negativos y, sustituyendo la noción de afinidad por la de atracción electrostática entre iones de carga opuesta. Con ello se asigna el enlace iónico a todos los compuestos electrolizables o inorgánicos.

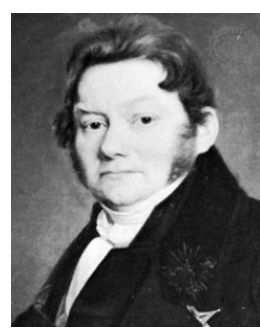

Berzelius

Por otro lado J.B. Dumas (1834), propone otro modelo de enlace para las sustancias que por el contrario no son electrolizables, denominado enlace covalente y que supone la perdida de identidad del átomo cuando se une con otros formando moléculas, con lo que sus propiedades serán otras diferentes a las suyas propias. Además introdujo la idea de valencia y asignó a los enlaces la categoría de simples, dobles o triples, tal como se

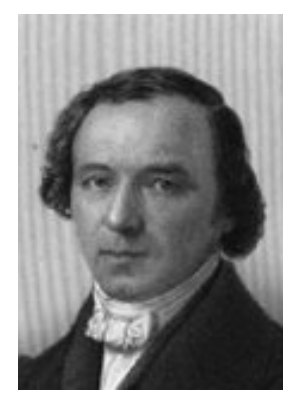

Dumas. considera en la actualidad 


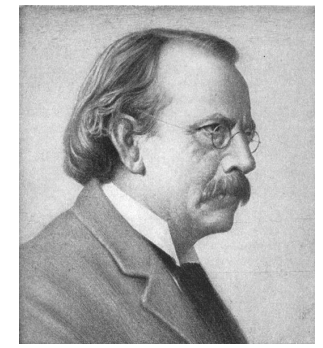

Thomson

La comprensión del enlace químico desde un punto de vista similar al actual, se inicia tras el descubrimiento del electrón en 1897, por J.J. Thomson, llevando a comprender que el enlace no depende de la globalidad del átomo sino de sus electrones, y se pudo tener una visión clara de los fenómenos electrónicos implicados en el transcurso de la formación de un enlace, a partir del método propuesto por N. Bohr en 1913.

El modelo de Bohr y la idea propuesta de situar a los electrones girando en órbitas, ofrece una visión clara de los fenómenos electrónicos que tienen lugar en la formación de un enlace. En este modelo, los electrones se colocan en órbitas sucesivas en cada una de las cuales sólo puede haber un número limitado de electrones según la expresión $2 \mathrm{n}^{2}$, donde $\mathrm{n}$ es el número de orbita. El hecho de que haya átomos con número de electrones cercanos a estos valores, permite explicar la formación de cationes

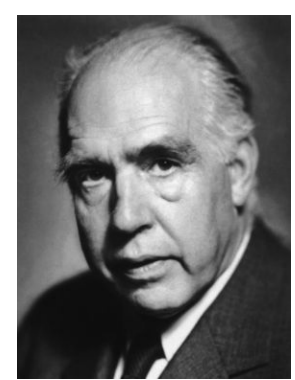

Bohr en el caso de excederlo y de aniones en caso contrario.

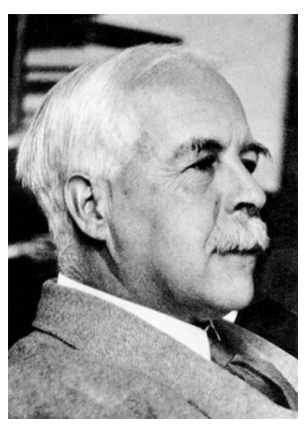

Lewis

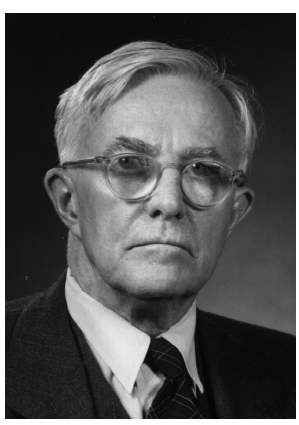

Irving

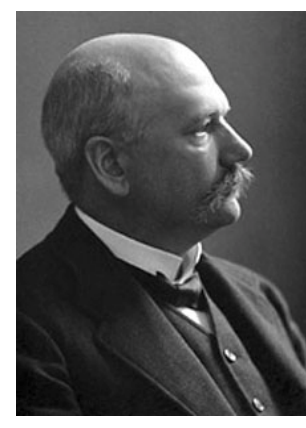

Langmuir

En el periodo 1916-1919, los americanos G.N. Lewis, e Irving Langmuir, y el alemán Walter Kossel formulan una propuesta sobre el enlace químico, desarrollando la denominada teoría de Lewis, y cuyas ideas básicas son:

1.- los electrones, especialmente los de la capa más externa, juegan un papel fundamental en el enlace químico.

2.- en algunos casos se transfieren electrones de un átomo a otro, formándose iones positivos y negativos que se atraen entre sí mediante fuerzas electrostáticas denominadas enlaces iónicos. 
3.- en otros casos se comparten entre los átomos uno o más pares de electrones. Esta compartición se denomina enlace covalente.

4.- los electrones se transfieren o se comparten de manera que los átomos adquieren una configuración electrónica especialmente estable, generalmente con ocho electrones que constituyen un octeto.

En el caso de compuestos iónicos el átomo metálico ha perdido todos sus electrones de valencia, mientras que el no metal ha ganado los suficientes para completar su último nivel. Exceptuando los pares iónicos que pueden encontrarse en estado gaseoso (como el $\mathrm{Na}^{+} \mathrm{y} \mathrm{Cl}^{-}$) no existen las entidades separadas, sino que cada anión está rodeado por cationes y viceversa. Estos iones en número muy grande, se disponen en redes ordenadas denominadas redes iónicas.

Cuando estudiamos situaciones en las que dos átomos tienden a captar electrones, el enlace implica una compartición de electrones que conlleva un enlace covalente. La compartición de un único par de electrones entre átomos enlazados da lugar a un enlace covalente simple, mientras que en el caso de quedar átomos con déficit de electrones se recurre a implicar en el enlace a otros electrones desapareados, con lo que aparecen enlaces dobles y triples. A medida que aumenta la multiplicidad de un enlace aumenta su fuerza y disminuye su longitud de enlace.

La estabilidad atribuida a las órbitas electrónicas llenas lleva a G.N. Lewis en 1916 a proponer el modelo de enlace covalente, en el que cada enlace se justifica con la compartición de electrones y la consiguiente presencia de dos u ocho de ellos, estableciendo la regla del octeto. Con esto no se modifican los conceptos del siglo XIX, pero sí se justifica el hecho empírico.

Realmente los enlaces no pueden clasificarse simplemente en iónicos o covalentes, ya que en este último caso los átomos no comparten los electrones por igual, formando enlaces covalentes polares. En ellos los electrones se encuentran desplazados hacia el átomo más no metálico. 
La polaridad de los enlaces junto con la forma de las moléculas, que viene dada por las longitudes y ángulos de enlace permiten dar una explicación de las propiedades de las sustancias moleculares.

En el caso de la teoría de Lewis, la teoría VSEPR (Valence Shell Electron Pair Repulsion) propuesta por R.J. Gillespie y R.N. Nyholm en 1957, propone una disposición de los pares de electrones alrededor de un átomo de forma que se minimicen las repulsiones entre ellos.

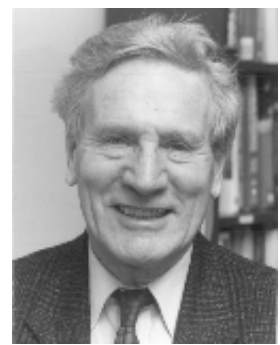

Gillespie

La ventaja de la teoría de Lewis es la facilidad con que se aplica, y con la teoría VSERP se pueden proponer formas geométricas moleculares que generalmente están de acuerdo con los datos experimentales, sin embargo, no proporcionan información cuantitativa sobre las energías y longitudes de enlace, presentando además problemas para las especies con un número impar de electrones y para situaciones en las que no es posible representar la molécula mediante una única estructura electrónica.

Poco después de la propuesta Lewis se da un gran paso, y se desarrollan las teorías cuánticas, con lo que se origina el actual concepto de enlace químico. En 1924 E. Schrödinger propone el carecer ondulatorio del electrón y en 1926, L. de Broglie y lo describe con la ayuda de una función de onda para el caso concreto de un átomo de hidrógeno. El cuadrado de esta expresión matemática puede interpretarse como la probabilidad de encontrar al electrón y, del que según el principio de incertidumbre de Heisenberg, enunciado en 1927 no se puede conocer su posición, pero se ubica en una zona del espacio con forma de nube electrónica (orbital), dando lugar a una idea más precisa del enlace. La explicación de un enlace covalente a partir de la existencia de orbitales fue introducida por las teorías de enlace de valencia y del orbital molecular.

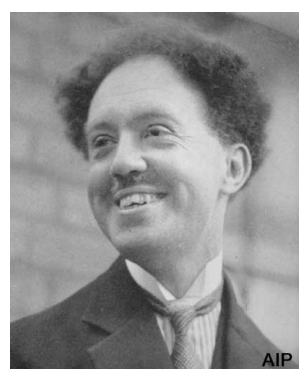

De Broglie

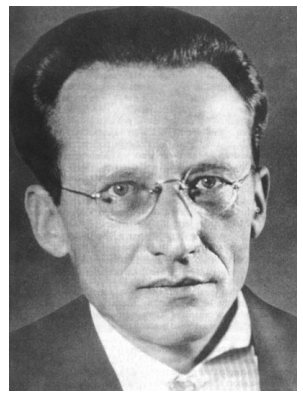

Schrödinger 


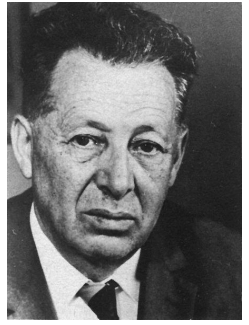

Heitler

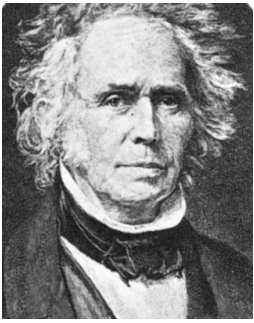

London

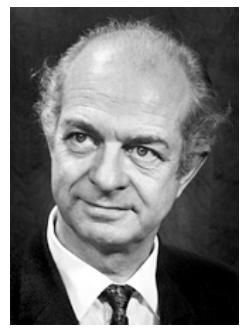

Pauling

En el mismo 1927, Heitler y London desarrollan la teoría del enlace de valencia. Posteriormente, Pauling y Slater la modifican para tener en cuenta la geometría y la disposición de los enlaces en el espacio. Esta teoría trata al enlace como una intersección o solapamiento de un orbital de un átomo con un orbital del otro átomo de modo que en el conjunto de los dos orbitales solapados existan dos electrones con sus momentos de spin apareados. Estos solapamientos pueden ser de tipo $\sigma$ o $\pi$ dependiendo de si es frontal o lateral.

Energéticamente la formación de un enlace covalente se puede interpretar con una gráfica que representa la energía del sistema formado por dos átomos, en función de la separación entre los núcleos.

En el caso de la molécula de hidrógeno, a medida que los átomos se aproximan entre sí las fuerzas atractivas aumentan, disminuyendo la energía potencial del sistema, pero, a partir de cierta distancia adquiere importancia la repulsión entre los núcleos. El equilibrio entre ambas fuerzas presenta un mínimo que corresponde a la distancia de enlace.

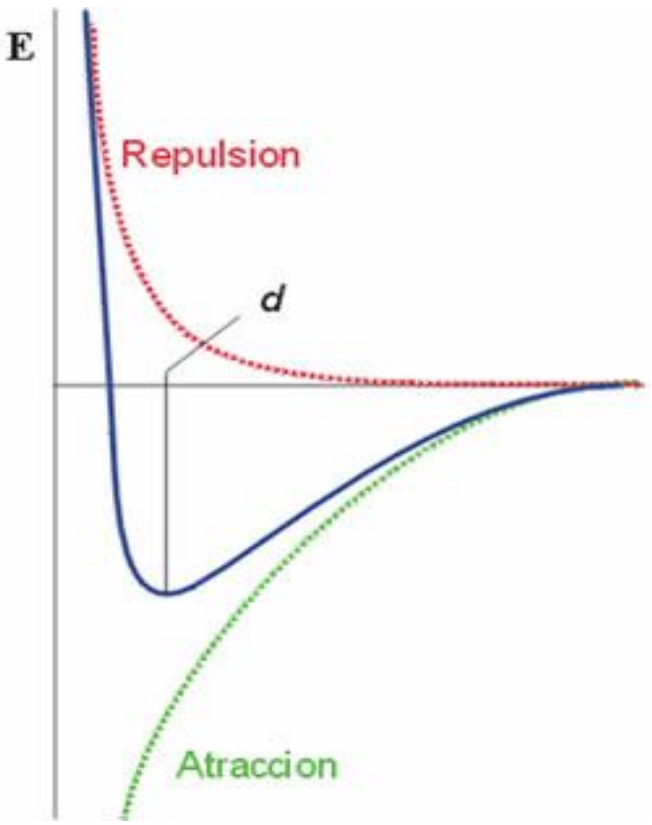


A partir de esta teoría se confirma que cada átomo puede formar tantos enlaces como electrones desapareados tenga. Sin embargo el solapamiento directo, en muchos casos no explica la dirección correcta de los enlaces, por los que se propone que durante la reacción y, previo a la formación del enlace se produce una recombinación de los orbitales atómicos puros resultando unos nuevos orbitales atómicos híbridos, iguales en número a los iniciales, y caracterizados por ser iguales en forma y energía, manteniendo además, unos ángulos iguales entre todos ellos facilitando el recubrimiento.

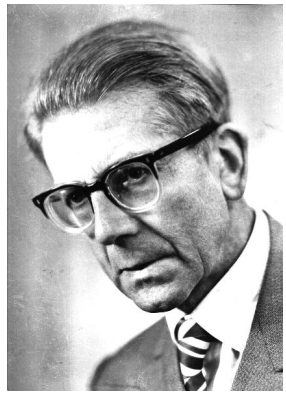

Hund

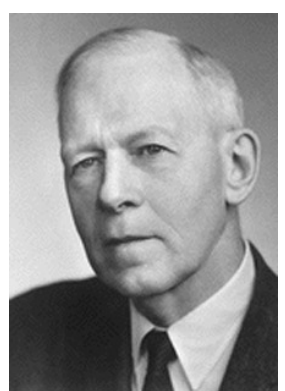

En 1930 Hund y Mulliken propone el método CLOA (combinación lineal de orbitales atómicos) y que se mantiene actualmente. Éste método propone que todos los electrones de los átomos que se unen para formar una molécula están bajo la influencia de los núcleos. Propone que los orbitales atómicos, que son soluciones correctas de la ecuación de Schrödinger para el átomo aislado no lo son cuando el átomo está unido a otro. Es decir que tal como para el átomo aislado existen orbitales atómicos, para las moléculas la teoría propone la existencia de orbitales moleculares. Un orbital molecular es una zona de la molécula en la que es probable que se encuentre un determinado electrón.

Mulliken

Las funciones de onda moleculares se obtienen según un proceso matemático según el cual a partir de dos funciones de onda de dos átomos $\mathrm{A}$ y $\mathrm{B}, \Psi_{\mathrm{A}} \mathrm{y} \Psi_{\mathrm{B}}$, se obtienen dos orbitales moleculares $\Psi=\mathrm{c}_{1} \Psi_{\mathrm{A}} \pm \mathrm{c}_{2} \Psi_{\mathrm{B}}$, que suponen, uno con un menor nivel energético que los de partida $(+)$ y se denomina enlazante y otro con un mayor nivel energético (-) denominado antienlazante.

Con esta explicación el enlace covalente tiene lugar en virtud de un aumento de densidad electrónica entre los núcleos y no solamente por compartir un par electrónico. Este enlace presenta un carácter fuertemente dirigido e impone unas formas geométricas características a las moléculas. 
Con esta explicación, se puede alegar que las nubes electrónicas de diferentes moléculas presentan entre si, débiles interacciones que en determinadas condiciones conllevan estados diferentes. Estas uniones se clasifican como fuerzas de Van der Waals, y se interpretan con los fenómenos de polarización de la nube electrónica y presencia de momentos dipolares, que alcanzan su máxima importancia en moléculas con grupos de momentos muy elevados, formando enlaces por puente de hidrógeno. Este tipo de unión presenta características de enlace químico puesto que puede estimarse un $\Delta \mathrm{H}_{\mathrm{f}}^{\mathrm{o}}$ de enlace. Estos momentos dipolares se presentan únicamente en parejas de átomos con gran diferencia de electronegatividad en los casos de los enlaces entre fluor e hidrógeno, oxígeno e hidrógeno y nitrógeno e hidrógeno.

Esta visión del enlace tan solo puede describir moléculas discretas y con los electrones compartidos por un número concreto de átomos. Sin embargo existen otras estructuras para la materia, como es el caso de los metales, donde los electrones presentan deslocalización y por tanto se recurre a un modelo de esferas rígidas donde el enlace es no direccional.

En este caso, atribuido al enlace metálico, se recurre a una situación en la que el metal se representa por una red infinita formada por los átomos y una nube electrónica formada por los electrones móviles completamente deslocalizados, pudiéndose así justificar su movilidad y propiedades físicas. Al no estar los electrones localizados, el enlace pierde su carácter direccional y podemos considerar al metal como un apilamiento infinito de átomos esféricos unidos fuertemente. Los metales constituyen un $80 \%$ de los elementos conocidos y presentan unas propiedades comunes que los caracterizan. Las teorías que los explican deben justificar las propiedades típicas como la elevada conductividad térmica y eléctrica.

En primer lugar la teoría de los electrones libres, supone que todos los átomos están ionizados por la pérdida de sus electrones de valencia, la fuerza neta de los núcleos sobre los electrones es nula, por lo que estos pueden moverse libremente. Estos electrones desligados de los átomos se conocen como nube electrónica o gas de electrones. 
La teoría del enlace de valencia o teoría de deslocalización apunta que ya que los metales no pueden formar enlaces covalentes localizados por falta de electrones, los enlaces tienen que estar deslocalizados y por tanto enlazados alternativamente con unos y otros átomos vecinos. De este modo los electrones de valencia no están sujetos a ningún átomo concreto de la red, sino que se pueden mover libremente por el cristal.

En último lugar, la teoría de bandas supone al metal formado por $\mathrm{n}$ átomos, disponiendo de una sucesión de n orbitales moleculares, que formarán una sucesión de bandas energéticas, cada una de los cuales puede albergar a 2 electrones y que estarán llenas, vacías o parcialmente llenas dependiendo del número de electrones de valencia. Con ello pueden deducirse las propiedades electrónicas de estas sustancias, en especial su conductividad eléctrica cuando la última banda no está completa.

Estos modelos no pueden explicar el porqué de la formación de iones de distinto signo en la disolución de sales inorgánicas, por lo que se recurre a otro en el que se propone un intercambio de electrones entre átomos buscando completar la última capa y adquirir una simetría esférica de la función de onda que se traduce en mayor estabilidad. Así pues el enlace iónico se puede interpretar como un cúmulo de iones de distinto signo que se ordenan de forma regular atendiendo a razones electrostáticas. No obstante aun cuando el enlace iónico puede justificarse fundamentalmente gracias a estas fuerzas electrostáticas que mantienen unidos a núcleos y electrones (Magnasco, 2004), es importante admitir la importancia de los efectos de dispersión (Magnasco, 2005), y por tanto el enlace no es una consecuencia de la estructura cristalina (Craig, 2002).

Con esto, tanto la justificación clásica, como la cuántica permiten explicar con relativa facilidad la naturaleza de las sustancias habituales. No obstante en las últimas décadas, se han estudiado sustancias en las que sus propiedades físicas pueden asignarse a diferentes modelos de enlace atendiendo a las condiciones en que se encuentran, por lo que podemos encontrar sustancias iónicas cuyo momento dipolar se aleja del que se puede calcular teóricamente, sustancias que son conductoras o no, dependiendo de la temperatura o hidrocarburos conductores de la electricidad.

Por tanto la química, como ciencia que es basada en modelos, puede permitirse clasificar los enlaces entre iónico, covalente o metálico, pero que no dejan de ser una 
traducción útil y práctica de diferentes aspectos de un mismo fenómeno electrónico. De hecho el carácter iónico depende de las cargas parciales de los átomos implicados, el metálico por la diferencia entre el mayor y menor orbital molecular ocupados, por tanto los enlaces no son estrictamente covalentes, iónicos o metálicos (Meek and Garner, 2005; Guillespie, 2001) Los enlaces que se originan, dependen de los desplazamientos que experimenten los electrones, de si abandonan o no el átomo o de si se comparten por un número finito de átomos o en el conjunto de una red.

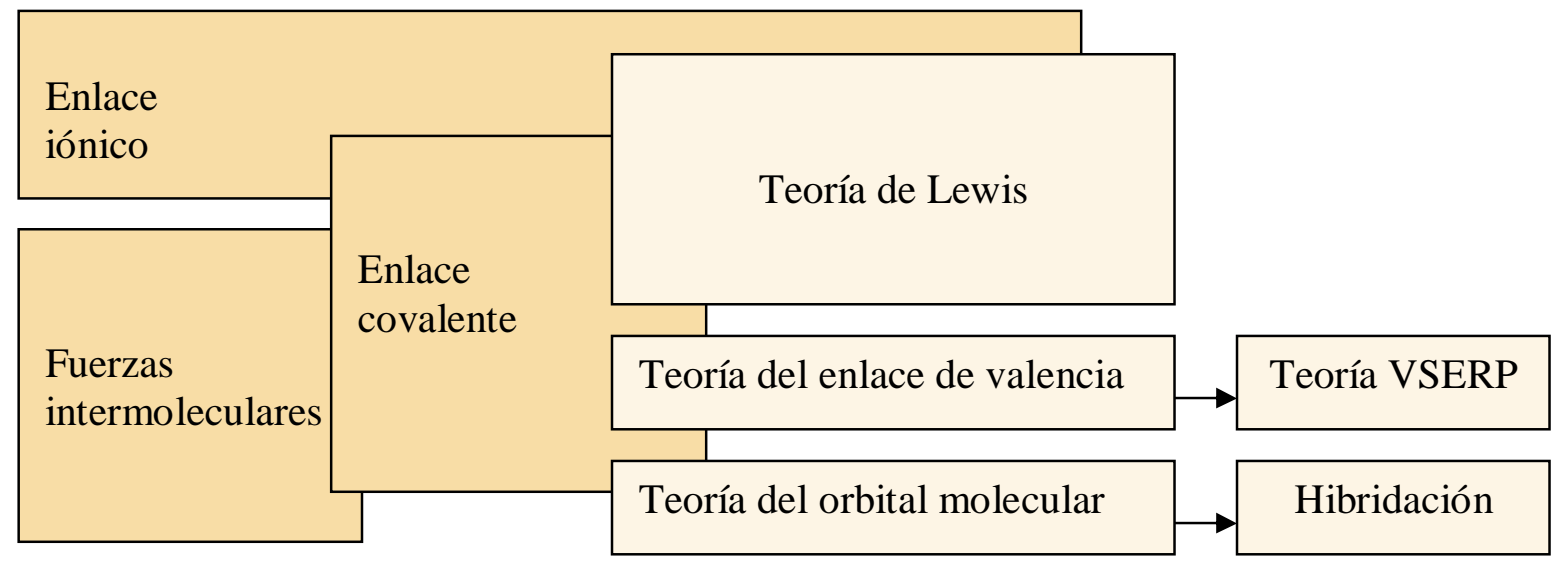

\section{Fuerzas}

interatómicas

Enlace

metálico

Teoría de electrones libres

Teoría del enlace de valencia o de deslocalización

Teoría de orbitales moleculares o de bandas

Figura 2.1.- Teorías utilizadas para explicar las uniones entre átomos en las diferentes sustancias. 


\subsection{El enlace químico como concepto inclusor}

El estudio del enlace químico es introducido en los nuevos currículos en tercer curso de ESO con alumnos de 14 a 15 años y posteriormente se retoma en el bachillerato científico o tecnológico en primer curso, y finalmente se profundiza en él durante el segundo curso, con alumnos de entre 16 y 17 años. Para muchos investigadores, el concepto de enlace químico es considerado crucial (De Posada, 1999; Solbes y Vilches, 1991) y podría ser considerado como concepto estructurante y por tanto inclusor de nuevos conceptos. A partir de esta premisa sería necesario un adecuado conocimiento de la estructura de la materia y del enlace químico para abordar de forma satisfactoria otros temas propios de química o de otras disciplinas como la biología.

Gran parte de la química general es enseñada por razones históricas, y con frecuencia no hay una estructura conceptual clara dando lugar a confusión en los alumnos. Por ello y dada su importancia, la teoría del enlace y los conceptos relacionados deben ser centrales para una correcta comprensión de la química general y necesitan ser explicados con claridad y de un modo uniforme (Hurst, 2002; Rabinovich. 2003)).

Por tanto se hace necesario promover acciones que favorezcan la integración entre los conceptos (Ausubel, Novak y Hanesian, 1983) de forma que se potencie el papel de concepto estructurante. La profundidad de los conceptos debe estar en proporción con los que posteriormente se van a introducir.

\subsection{Utilización de modelos en la enseñanza del enlace químico}

En el caso del enlace químico la mayor parte de los problemas de aprendizaje no reside en las preconcepciones o ideas alternativas sino en las deficiencias que inevitablemente llevan implícitas los modelos sobre los que construyen su aprendizaje los alumnos. Estas dificultades que pueden causar los modelos derivan de su propia naturaleza, puesto que se trata de identificar una cosa con otra que realmente no lo es, y la generalización tiene como consecuencia la propia falta de concreción. En el aula no se considera esta idea y se cae en la simple identificación de la realidad con sus modelos (De Posada y Conejo, 2000). 
Con ello sólo unos pocos alumnos llegan a entender de forma correcta el modelo correspondiente al enlace químico, bien por falta de claridad, en las exposiciones por parte del profesor, por la adecuación de dicho modelo, por la secuencia de actividades, o por el sistema de evaluación. Las dificultades encontradas en los diferentes enlaces químicos son:

Enlace iónico:

- Las dificultades aparecen cuando se pasa de razonar la interacción entre iones de carga opuesta al concepto de red cristalina y la consiguiente justificación de las propiedades de la sustancia originada.

- Los alumnos encuentran que ión y átomo son conceptos similares, no comprendiendo la relación que existe entre la estructura del ión y sus propiedades específicas, diferentes de los átomos correspondientes.

- Los alumnos admiten con claridad la existencia de las especies iónicas en disolución pero no en estado sólido.

- Otro problema de importancia es la confusión que añade el hecho de que las fórmulas sean iguales en el caso de las sustancias iónicas y covalentes, pese a su gran diferencia en cuanto a estructura interna.

- En otro sentido, los alumnos también asocian la idea de que iones de distinto signo se anulan entre sí no experimentando interacciones con los iones vecinos, existiendo únicamente fuerzas de carácter atractivo y no repulsivo, lo que da gran estabilidad a la red cristalina.

Enlace metálico

- Esta bastante extendida la concepción de materia continua en el caso de los metales.

- El modelo de mar de electrones comienza a ser utilizado por los alumnos pero no se representan correctamente los electrones que no participan directamente en el enlace

- Los alumnos no entienden la naturaleza de la corriente eléctrica en los metales, confundiendo términos de energía, con conductividad a través de electrones o 
movimientos de partículas. El origen puede estar en que no comprenden los conceptos de campo y potencial, y sus efectos cuando el campo se crea en un conductor

Enlace covalente

- Aunque el concepto de molécula se adquiere con facilidad, no se comprende fácilmente la idea de que el enlace se origina por compartir pares de electrones.

- Se constata la dificultad de admitir la presencia de varios átomos en una molécula, y que las uniones se produzcan entre algunos de ellos y no entre todos a la vez, siendo que la unión, realmente depende de toda la molécula.

- Resulta complicado identificar las propiedades macroscópicas con una molécula, por lo que se hace necesario hablar y representar un conjunto numeroso de ellas.

Fuerzas intermoleculares

- Las fuerzas de Van Der Waals y los enlaces por puente de hidrógeno son muy poco utilizadas en las explicaciones de los estudiantes para justificar los estados de agregación ni los procesos físicos como cambios de estado o disolución.

- Los libros de texto destinan muy poco espacio a este tipo de interacciones, respecto al otro tipo de enlaces, por lo que la mayoría de alumnos aprende reglas fijas y evita los razonamientos.

- En este apartado en particular y en la química en general se suele tener cierta permisividad a la hora de utilizar términos que no son del todo correctos.

El correcto conocimiento de la estructura de la materia es decisivo para la adecuada comprensión de los fenómenos físicos y químicos. Los alumnos presentan dificultades en la concepción corpuscular de la materia (Llorens, 1988, Furió y Hernández, 1983).

Los alumnos tienen dificultades en concebir la idea de vacío y aplicación de la teoría cinético-molecular en la explicación de los fenómenos de dilatación, compresión y difusión. Son muy pocos alumnos los que consiguen relacionar propiedades físicas macroscópicas con el mundo atómico; así mismo, en el proceso de disolución se encuentra que gran parte de los alumnos muestra una visión continua del soluto 


\subsection{Ideas previas y preconcepciones en el enlace químico}

Si tratamos de concretar las ideas previas de los alumnos y particularmente las que pueden influir de forma errónea en el aprendizaje podemos resumir las concepciones alternativas detectadas (Riboldi, Pliego y Odetti, 2004)

Respecto a procesos donde se agrupan átomos de un mismo o de distintos elementos:

- La unión de dos átomos formando una molécula supone un cambio de estado de agregación, lo que supone una confusión entre cambios físicos y químicos a nivel corpuscular.

- Átomos de un mismo elemento se pueden unir por enlace iónico

- Átomos de distintos elementos se unen solamente por enlace iónico

- La unión de átomos de oxígeno para formar moléculas supone un proceso físico

- El enlace iónico es más fuerte que el enlace covalente.

En relación con la espontaneidad del enlace químico

- Para que átomos de un mismo o diferentes elementos se unan mediante un enlace químico es necesario suministrar energía, concibiéndose por tanto como procesos espontáneos.

En relación a la estructura de las sustancias unidas mediante enlaces iónicos o covalentes.

- Cuando dos átomos del mismo o de diferentes elementos se unen mediante un enlace químico, formando una molécula, estos permanecen sin modificar en absoluto su estructura, como si solo se hubiesen acercado.

- En el sentido contrario, al unirse átomos de un mismo o de diferentes elementos formando una molécula biatómica, se unen sus núcleos.

- Existen moléculas iónicas. 
Respecto a las causas del enlace químico

- La causa del enlace es la naturaleza de los átomos involucrados, llegando incluso a adjudicar cierta intencionalidad al comportamiento de uno de los elementos implicados.

- El enlace iónico se debe a que cada uno de los elementos completa el octeto electrónico

- Las concepciones alternativas se activan o no según el contexto en el que el sujeto razone (Driver, 1988). En un mismo estudiante existen diferentes ideas sobre un mismo tema, pudiendo guardar o no relación entre ellas.

En definitiva, existe una comprensión deficiente respecto de la estructura que adquieren los átomos al unirse mediante enlaces químicos, existiendo poca relación por parte de los estudiantes entre la estructura de la materia y su tipo de enlace. Este hecho puede justificarse, ya que habitualmente las sustancias se representan mediante su fórmula química, pudiéndose asociar con facilidad un carácter molecular aunque no corresponda.

Los alumnos parecen decantarse por el enlace iónico ante la duda, puesto que parece de mayor comprensión por su parte, se justifica mediante fuerzas electrostáticas, mientras que el covalente lo hace por compartición de electrones, concepto que resulta más abstracto y de peor comprensión.

Hay algunos alumnos confunden la dureza de una sustancias iónicas con la fuerza del enlace químico. Lo que avala la idea de que el alumno traslada al campo microscópico lo que percibe del macroscópico. 


\subsection{Estructuras de aprendizaje del EQ en los niveles básicos}

La perspectiva constructivista expone que el aprendizaje con comprensión real, ocurre cuando el alumno construye y transforma activamente sus propios significados y no cuando acumula pasivamente conocimientos que le han sido transmitidos.

Ausubel, Novak y Hanesian (1983) distinguen entre aprendizaje memorístico y aprendizaje significativo. El primero se caracteriza por una mera adición de contenidos, mientras que el segundo se produce cuando el nuevo conocimiento es relacionado por el alumno con otros conceptos relevantes dentro de su propia estructura cognitiva, siendo los conceptos de mayor generalidad (organizadores) los que los que van a permitir la incorporación de otros nuevos.

Vygotsky (1962) afirma que el dominio de los conceptos científicos por parte de los alumnos promueve en ellos un aumento del nivel de los conceptos espontáneos. Un concepto espontáneo debe evolucionar hasta alcanzar un determinado nivel para adquirir otros conceptos afines.

Ambas propuestas parecen lógicas y tanto el aprendizaje ascendente como el descendente son necesarios para adquirir un correcto aprendizaje. Los conceptos deben ir conectándose de forma progresiva, de ahí la dificultad de producir aprendizajes significativos en algunas áreas.

Los libros de texto abordan el estudio del enlace químico de forma explicita en tercer curso de la ESO, sin hacer referencia al aspecto energético, aunque si a algunas propiedades macroscópicas sencillas.

El estos libros hay tendencia a introducir el tema de dos formas diferentes:

a) Proponiendo una clasificación directa según el tipo de enlace, iónico, covalente o metálico. Posteriormente se justifica el papel de los electrones en cada uno de ellos, asociándolos a cesión-captación, compartición o cúmulo de electrones deslocalizados 
b) Proponiendo una clasificación atendiendo al tipo de agrupación de los átomos, según sean átomos aislados, moléculas o cristales, para posteriormente distinguir entre cristales covalentes, iónicos o metálicos.

En ambos casos suele enmarcarse el estudio del enlace entre el estudio de los modelos atómicos y las reacciones químicas, puesto que estas últimas son la consecuencia de los cambios en los enlaces en los primeros. Estos tres bloques de contenidos son los que forman el cuerpo de la materia que se comparte con la física.

En los textos de bachillerato el enlace aparece también ubicado tras el estudio del átomo y de las propiedades periódicas, pero generalmente se atiende a una clasificación entre iónico, covalente o metálico, siendo el enlace covalente el más complicado por introducir varios conceptos nuevos como la resonancia, polaridad del enlace y de la molécula, fuerzas intermoleculares... 


\subsection{Problemas de aprendizaje en el enlace químico}

Hay gran cantidad de trabajos que expresan la dificultad de los alumnos en general para explicar la naturaleza de las sustancias y algunas de sus propiedades observables, sin embargo hay pocos estudios acerca de la concepción de los estudiantes sobre el enlace químico (De Posada, 1999).

Estas concepciones alternativas de los estudiantes pueden considerarse como mecanismos de adaptación al medio (Bello y García, 2005), por ello es necesario conocerlos tanto en la enseñaza, como en cualquier ámbito del conocimiento. En el caso de que la información aportada contradiga los esquemas mentales anteriores difícilmente será aceptada, ignorándola, rechazándola, no creyéndola o simplemente interpretándola según sus propios esquemas.

Resulta muy importante conocer los esquemas representacionales de los alumnos respecto al enlace químico porque además de esta limitación del aprendizaje, determinan la concepción global de la química que deben tener, incidiendo en todo el periodo educativo.

De acuerdo con el modelo constructivista de aprendizaje, tienen gran importancia los conceptos y la estructura cognitiva del sujeto (Ausubel, 1963). Pese a que hay numerosas investigaciones sobre concepciones alternativas, el tema del enlace químico se ha abordado en pocas investigaciones dentro de esta línea, por lo que resulta interesante plantear si hay concepciones alternativas por parte de los alumnos y, en su caso cuales son.

Los estudiantes establecen muy poca relación entre la estructura o representación de una sustancia y su tipo de enlace (Riboldi, Pliego y Odette, 2004). Esto se debe a que, en el proceso de aprendizaje, cuando se hace referencia a una sustancia y a fin de representarla, se recurre mayoritariamente a su fórmula química y no a la estructura espacial característica. Observando tales fórmulas es fácil imaginar que los alumnos extrapolen la relación mínima en que se combinan los átomos a la estructura real de la sustancia, que además es cierto en algunas sustancias moleculares. 
Podría establecerse una larga lista acerca de los problemas más frecuentes que encuentran los alumnos cuando abordan el estudio del enlace químico, respondiendo generalmente a los mismos aspectos, por lo que la investigación didáctica localiza y estudia algunos de ellos. Hay varios autores que han realizado pruebas diagnósticas con el objeto de determinarlos y buscar su relación con el nivel cognitivo del alumno o con sus representaciones mentales.

En este sentido encontramos por ejemplo, que los alumnos acogen mejor la idea de enlace iónico que la de enlace covalente, pues para ellos es más fácil entender la naturaleza de una fuerza electrostática que la generada por la "compartición de electrones", que resulta más abstracta. Esta declinación hacia uno de ellos es un obstáculo importante para adquirir una noción clara del tema. Pese a esto los alumnos tienen dificultades para interpretar correctamente la estructura de las sustancias iónicas.

Los alumnos aplican nociones macroscópicas al mundo microscópico, no obstante esta tendencia disminuye a medida que aumenta el nivel de estudio de la química.

La naturaleza del enlace covalente no es bien comprendida confundiéndose con fuerzas atractivas, electrostática o de cualquier otro carácter. Esto se justifica con la idea que se trasmite con frecuencia, de que la compartición de electrones provoca la atracción entre átomos, así como la tendencia de los alumnos de rehuir el aprendizaje significativo frente a la sencillez de aplicar reglas más o menos simples, que les resuelvan la asignatura a corto plazo.

Las fuerzas intermoleculares son menos interiorizadas que el enlace covalente y por tanto se utilizan pocas veces en las explicaciones debido a que tanto las fuerzas de Van der Waals, como los puentes de hidrógeno son tratadas con menor amplitud que el resto de enlaces (De Posada, 1993), y en definitiva, juega en contra de la distinción entre la unión entre átomos para formar moléculas, y las uniones entre las propias moléculas. Esto supone una gran dificultad para comprender la estabilidad de las sustancias moleculares. 
El concepto de ión es especialmente complejo. El ión podría apoyarse en el concepto de átomo como concepto inclusor ya que guarda una evidente vinculación, sin embargo debe trabajarse con cuidado para evitar que los alumnos los utilicen indiferentemente.

Además en opinión de muchos alumnos, los átomos e iones no deben tener comportamientos muy diferentes, por lo que los utilizan indistintamente en la explicación de la estructura de la materia. Con ello se explican fenómenos como la disolución o la conductividad eléctrica por la separación de átomos o por el intercambio de electrones entre ellos. Por tanto ya que los alumnos pueden explicar satisfactoriamente para ellos estos fenómenos no hay una preocupación por aprenderlo, pese a ser un concepto perfectamente comprensible por su parte.

El problema de la interpretación del concepto de ión y su existencia transciende más allá de su participación y explicación en el tema del enlace químico, ya que este concepto es utilizado en secciones del currículo, especialmente en segundo curso de bachillerato y, por supuesto en estudios superiores. Nos referimos al estudio del equilibrio químico redox entre otros. Hay alumnos que no distinguen claramente entre átomo e ión y en consecuencia, verán las ionizaciones como si se tratase de disociaciones y del mismo modo, los subíndices utilizados en la notación de los iones pueden interpretarse erróneamente como protones ganados en el caso de los cationes. Ante esta situación muchos alumnos optan por no intentar comprender lo que se les plantea e inclinarse por un sentido memorístico, irreflexivo y acrítico.

En último lugar y, al vista de esta dificultad frete al concepto de ión, junto con la utilización de formulas de las mismas características gráficas para referirse a sustancias moleculares e iónicas, los alumnos tienden a identificar las sustancias principalmente como moleculares.

Frente a estos problemas De Posada (1999) propone varias acciones a tener en cuenta:

- Utilizar sistemáticamente dibujos donde se distribuyan en el espacio los diferentes tipos de partículas para reforzar con imágenes la discontinuidad de la materia y los tipos de agregación. 
- Incluir además abundante número de partículas para evitar la visión de moléculas para cualquier tipo de sustancia.

- Acompañar a las reacciones químicas de dibujos donde se muestren tanto el aspecto macroscópico de las sustancias como el microscópico.

- Seleccionar cuidadosamente experiencias muy próximas a la vida cotidiana del alumno, para que en conexión con los esquemas conceptuales de los alumnos analicen y asimilen la discontinuidad de la materia, la existencia de iones, la formación de redes atómicas, moleculares, cristalinas y metálicas, etc.

- Utilizar una notación gráfica de iones de diferente tamaño y color al de los átomos de procedencia para remarcar sus diferencias.

- Recordar los tipos de enlaces rotos y formados en diferentes unidades didácticas al enlace químico 


\section{APRENDIZAJE COOPERATIVO COMO PARADIGMA EDUCATIVO}

\subsection{El trabajo cooperativo}

La cooperación es una importante característica humana y que nos separa de otras especies animales, habiendo permitido una evolución hasta la forma de vida actual. La cooperación es un factor común en la vida diaria, en empresas, comunidades y humanidad en general. Dado que la cooperación es una condición necesaria para cualquier actividad de la vida real, resulta crucial la implementación de la cooperación en la escuela de cara a formar ciudadanos en plenitud (Ovejero, 2005), y su utilización desde el punto de vista didáctico.

Históricamente y aún en muchos casos en la actualidad, la educación se contempla como una transmisión vertical de conocimientos y valores de aquellos que saben más a favor de otros que saben menos. De esta forma, además de clasificar a los alumnos según su preparación para puestos futuros, se asegura el mantenimiento de la cultura en una sociedad.

Sin embargo, desde principios del siglo pasado, muchos pedagogos han explicitado la necesidad de una educación ligada a valores democráticos donde se prepare a los alumnos para la vida cotidiana a través de la recreación del significado de las cosas, la cooperación, la discusión, la negociación y la resolución de problemas. Es decir, se debe ir abandonando la idea de la clase magistral a favor de programas centrados en las necesidades, intereses y preferencias de los que van a aprender.

En términos más explícitos, si queremos que nuestros alumnos adquieran habilidades mentales y sociales, se debe desplazar la preocupación por los contenidos a la preocupación por el proceso (Fabra, 1992). Para ello el profesorado debe adoptar el rol de "persona que ayuda al alumnado a madurar y a resolver problemas con relativa dependencia”. El aprendizaje cooperativo prepara a los estudiantes para la sociedad de hoy (Blosser, 1992). Se promueve un aprendizaje activo cuando ellos hablan y trabajan juntos, en lugar de escuchar pasivamente. Motiva, mejora los resultados académicos y mejora las habilidades lingüísticas. Ayuda a construir habilidades cooperativas, 
comunicación, interacción, planificación, exposición de ideas, toma de decisiones, escucha, respeto y no es caro de llevar a cabo (Lyman and Foyle, 1988 ${ }^{1}$ ).

Hay diversos autores que apuntan hacia el trabajo en grupo como herramienta para que los profesores asuman un papel en el que el alumno pueda perder la dependencia excesiva del profesor y promover el pensamiento autónomo como fuente para descubrir sus propios recursos así como los de sus compañeros y compañeras.

Los grupos de trabajo pueden ser muy diferentes en cuanto a su estructura y grado de implicación del docente, pero las finalidades que se persiguen son:

1.- Desarrollo de las habilidades de comunicación

2.- Desarrollo de las competencias intelectuales y profesionales

3.- Crecimiento y maduración personal del alumnado (y del profesorado)

Con el trabajo cooperativo pretendemos esta estimulación del pensamiento creativo, la consecución de un espíritu crítico con rigor y voluntad de compartir experiencias, al tiempo que se disfruta aprendiendo. Por este motivo es necesario establecer un clima adecuado de democracia tanto fuera como dentro de la clase, así como una adecuada formación de los profesores en Dinámica de Grupo y Técnicas grupales.

El aprendizaje cooperativo es un paradigma intruccional en el cual equipos de estudiantes en grupos estructurados bajo ciertas condiciones: interdependencia positiva, esfuerzo individual, interacción directa, uso apropiado de habilidades de colaboración y un funcionamiento regular en grupo (Kaufman, Felder y Fuller, 2000).

Se tiende a agrupar dentro de "aprendizaje cooperativo" a lo que anteriormente se llamaba "trabajo en grupo" y "trabajo en equipo", pero cabe destacar que son situaciones distintas.

En general los profesores de secundaria, cuando realizan trabajos en grupo, estos son formados libremente por los alumnos. No obstante, hay autores como Cousinet ${ }^{2}$ que

\footnotetext{
${ }^{1}$ Citado por Blooser, 1992.

${ }^{2}$ Citado por Fabra, 1992.
} 
insisten en la necesidad de que sea el profesorado quien construya los subgrupos. En otro sentido hay autores que se refieren a la conveniencia do formar grupos homogéneos o heterogéneos en cuanto a los niveles de competencia del alumnado. Slavin y Halliman $^{3}$, como versiones contrapuestas concluyen que ni el agrupamiento de alumnos ni la reducción de la ratio profesor/alumno mejoran los logros del alumnado y que el proceso instruccional que afecta al éxito académico debe ser examinado por profesionales de las ciencias sociales valorando así la forma de agrupamiento. Hay autores que describen tipos de interacciones diferentes dependiendo de la constitución de los grupos (Haller, Gallagher, Weldon y Felder, 2000). Concretamente la experiencia ha sido mejor en grupos femeninos, aunque dividir por géneros puede disminuir la efectividad.

El trabajo en grupo o en equipo evoluciona a trabajo cooperativo con tal de evitar algunos aspectos negativos de estos primeros, como son el excesivo liderazgo par parte del profesor, libertad de los alumnos en la formación de los grupos, simple yuxtaposición de trabajos individuales o simplemente el de alguno de ellos y con frecuencia un sistema de calificación individual y no colectivo.

Las características del aprendizaje cooperativo según Slavin son:

a) el paso de un estructura de recompensas competitiva a una cooperativa

b) el paso de una estructura de tarea individual a una estructura basada en la interacción de los estudiantes en pequeños grupos.

c) El paso de una estructura de autoridad centralizada en el docente a otra basada en la autoridad de la clase.

El trabajo cooperativo se fundamenta en cuatro perspectivas teóricas:

- La Vygotskiana, que sostiene que nuestras funciones mentales y nuestros logros tienen su origen en nuestras relaciones sociales y cuyo desarrollo individual requiere de la colaboración grupal.

- La ciencia cognitiva, según la cual las características del entorno de aprendizaje ideal se encuentran en los métodos de aprendizaje cooperativo.

\footnotetext{
${ }^{3}$ Citados por Fabra, 1992.
} 
- La teoría social del aprendizaje, cuyo principio es que los estudiantes se esfuerzan más en aquellas tareas que les proporcionan algún tipo de recompensa y que alega que el aprendizaje mejora cuando es el fruto del trabajo en equipo y no competitivo.

- La teoría piagetiana. Los profesores de esa escuela utilizan el aprendizaje cooperativo para acelerar el desarrollo intelectual de los estudiantes haciéndolos trabajar por parejas y confrontando puntos de vista diferentes.

Y puede definirse como una estrategia estructurada que funciona de forma sistemática en la que pequeños grupos trabajan juntos para conseguir un producto común e implica:

a) Interdependencia positiva

b) Interacción directa entre los estudiantes

c) Responsabilidad individual para conseguir el material necesario

d) Uso correcto de las habilidades interpersonales y en pequeños grupos.

Desde un punto de vista operativo, el aprendizaje cooperativo utiliza la dinámica de grupos para promover el aprendizaje y, además la motivación intrínseca del contacto social sirve para mantener a los alumnos interesados en las actividades académicas (Perkins, 1995). Por ello es necesario fomentar las estructuras cooperativas con el fin de motivar a los estudiantes y evitarles la situación de verse obligados a defender persistentemente sus percepciones de competencia que se ven amenazadas en otro tipo de estructuraciones en la clase (González y Tourón, 1994).

El potencial de las aulas cooperativas reside en su capacidad para fomentar razones constructivas para aprender que se hallan al alcance de todos los estudiantes (Covington, 2000). En las aulas competitivas la distribución desigual de un suministro insuficiente de recompensas hace que los estudiantes compitan entre ellos lo que se traduce en agresión y resentimiento mutuo e impide la cooperación. Cuando las metas son competitivas uno se esfuerza mientras tiene éxito pero no continúa si el resultado es la vergüenza y las recriminaciones a uno mismo.

Además, el profesor en una estructuración cooperativa debe facilitar formas de interacción positivas (Alonso Tapia, 1996), debe modelar y definir el modo en que los 
alumnos intercambian la información, la forma en que reaccionan ante las aportaciones de los demás miembros del grupo y la manera de afrontar las tareas consiguiendo así, que se eviten consecuencias negativas para la motivación. Con este tipo de actuaciones el maestro favorecerá que el alumnado tenga como meta principal e aprendizaje y no la de preservar su autoestima, situación que podría derivar en una excesiva preocupación por la evaluación de los compañeros hacia uno mismo o la no aceptación del grupo.

\subsection{Trabajo en grupos y trabajo cooperativo.}

Muchos educadores, científicos, empresarios, militares y grupos políticos asumen que la gente que resuelve problemas en equipos y grupos lo hará mejor como consecuencia de ello y lo hará mejor que gente que no haya trabajado en este tipo de experiencias (Laughlin, Carey y Kerr, 2008). Se dan mejores resultados en grupos donde todos sus componentes tienen experiencia en trabajo cooperativo, en cambio son peores cuantos estos son más inexpertos. Por tanto en general la resolución de problemas es más eficaz en grupo que de forma individual. No obstante el proceso no es sencillo y se requieren estrategias efectivas para este aprendizaje: formación de grupos, secuencias de colaboración, transferencia de conocimientos, etc. (Felder y Brent, 2001). Es mejor hacer trabajar juntos a los alumnos de forma efectiva que simplemente ponerlos a trabajar juntos aunque, es cierto que hay técnicas que en determinadas situaciones son satisfactorias y otras que no lo son.

Cuando la estructura de la clase es cooperativa, tanto en situaciones de éxito como de fracaso, aumentan las atribuciones al esfuerzo. En las estructuras competitivas las atribuciones de capacidad prevalecen con su consiguiente efecto sobre la autoestima (Ames, 1978). En las situaciones de aprendizaje cooperativo los estudiantes suelen atribuir el éxito a causas personales y controlables, a las capacidades y esfuerzos del grupo al que pertenecen. En cambio ante el fracaso, suelen buscar causas externas como la dificultad de la tarea o la mala suerte si bien en ocasiones también atribuyen el fracaso a la falta de esfuerzo de los miembros del grupo (Ovejero, 1990).

Los estudiantes aprenden mejor cuando se sienten seguros, es decir, cuando las metas del aprendizaje son realistas y se favorece la cooperación en el aula (Covington, 1984). En el aula cooperativa conviven motivaciones intrínsecas y extrínsecas pero es 
indudable que el apoyo social generado por los compañeros aumenta el compromiso personal por aprender. Cada estudiante siente que se confía en él y sabe que esforzándose en su aprendizaje ayudará a sus compañeros y que de lo contrario los perjudicará (Gavilán, 2000).

Existen numerosas de definiciones de grupos y equipos de trabajo, sin embargo ambos términos han utilizados con frecuencia de forma análoga e indistintamente (Gómez y Acosta, 2003).

La tendencia actual y que utilizaremos en este trabajo en considerar como grupo a un conjunto de dos o más personas que interactúan en busca de objetivos comunes. Pueden ser de tipo formal, en los que existe una organización y unas determinadas funciones, o informal en el caso de que estén creados en función de un contacto social.

Como equipo de trabajo en el que se produce una cooperación, podemos definir un grupo de trabajo formal como aquel en el que sus individuos coordinan sus esfuerzos ideas y conocimientos en una toma de decisiones por consenso. Con ello se persigue una meta común y resultados de alta calidad.

\begin{tabular}{|l|l|}
\hline \multicolumn{1}{|c|}{ Grupo de trabajo } & \multicolumn{1}{|c|}{ Equipo de trabajo } \\
\hline $\begin{array}{l}\text { Liderazgo, responsabilidad y valoración } \\
\text { de los resultados individuales. }\end{array}$ & $\begin{array}{l}\text { Liderazgo, responsabilidad y valoración } \\
\text { de los resultados compartidos. }\end{array}$ \\
\hline $\begin{array}{l}\text { El trabajo se considera como una } \\
\text { imposición. }\end{array}$ & $\begin{array}{l}\text { El trabajo se considera como una } \\
\text { oportunidad. }\end{array}$ \\
\hline La actividad se centra en la tarea. & $\begin{array}{l}\text { La actividad se centra en la tarea y en el } \\
\text { plano socio-emocional de sus miembros. }\end{array}$ \\
\hline
\end{tabular}

Tabla 3.1.- principales diferencias entre el trabajo de grupo y trabajo en equipo. Faria de Mello FA ${ }^{4}$.

Los grupos de trabajo no se crean con la intención de reducir el trabajo individual, sino para potenciarlo. Se forman para cumplir los objetivos concretos con mayor facilidad. Estos grupos solo tienen sentido cuando existe una meta común y las

\footnotetext{
${ }^{4}$ Citado por Gómez y Acosta, 2003.
} 
tareas de los miembros son interdependientes, pero la unión permite completar un trabajo de mayor calidad.

Cuando se pretende un trabajo cooperativo, los miembros comparten identidades, metas, éxitos y fracasos, se establecen tareas específicas y se toman decisiones colectivas. Debe haber un ambiente de apoyo, una claridad en el papel de cada integrante y un liderazgo adecuado.

Las principales ventajas de un trabajo cooperativo es en primera instancia que aumenta la calidad del trabajo y se reduce el tiempo empleado, pero además se trabaja con menos tensión, se comparte la responsabilidad y son más diversos los puntos de vista. El trabajo en equipo aplicado a cuestiones concretas da buenos resultados en adultos. Los estudiantes que verbalmente no suelen cambiar sus conceptos previos, no los comprenden tras la instrucción, en cambio el hecho de discutirlos en pequeños grupos favorece su razonamiento (Basili y Sanford, 1991).

\subsection{Posibilidades y conveniencia del trabajo cooperativo}

Como forma de aumentar la motivación de los alumnos, pueden crearse estructuras de aprendizaje donde el estudiante pueda incrementar la competencia percibida y atribuir tanto el éxito como el fracaso al esfuerzo, que como causa interna, inestable y controlable le permitirá sentirse capaz de regular su propio aprendizaje (Echeita, 1995).

Los métodos de aprendizaje cooperativo son los que permiten un incremento de la competencia percibida dado que el grupo cooperativo tiende a generar más capacidad que el individuo aislado. Asimismo, este tipo de organización facilita el refuerzo de los progresos de los estudiantes ya que la comparación es con uno mismo no con los demás. Favorece el reconocimiento como base de los progresos de atribuciones basadas en el esfuerzo e incluso en el caso de que un resultado sea negativo es posible asignar la causa del fracaso a una falta de esfuerzo colectivo. Por el contrario en las estructuras individualistas o competitivas donde prevalece la capacidad personal es normal que el estudiante que no se siente competente se aleje de aquellas tareas académicas que le producen sentimientos negativos y que disminuyen su autoestima. 
Hay diversos estudios en que se observa de forma objetiva y clara que, tras haber desarrollado el currículo de un curso utilizando un trabajo cooperativo se obtienen mejores resultados que en grupos de control que han seguido otros tipo de estrategias didácticas (Cooke y Kernaghann, 1987; Osgood, Mitchell y Anderson, 2005). En estos trabajos se concluye que los alumnos adquieren un nivel superior de conocimientos y además valoran muy positivamente su experiencia de aprendizaje. También se apunta que el hecho de estructurar a los alumnos en pequeños grupos de trabajo, ayuda a que estos tomen más responsabilidad el aprendizaje de los conceptos en ciencias (Basili y Sanford, 1991) mejorando los resultados con la experiencia en ellos (Laughlin, Carey y Kerr, 2008), aunque hay muchas investigaciones centradas en situaciones de resolución de problemas en grupos frente a la forma individual, y en algunas de ellas los resultados han sido inconsistentes. (Cooke y Kernaghan, 1987)

Habitualmente los profesores dicen que utilizan el trabajo en grupo sobre todo en el laboratorio, pero los expertos mantienen que no es lo mismo este tipo de trabajos que el trabajo cooperativo. En este sentido también se observa que en la mayoría de revistas de ciencia se habla de actividades manuales (o prácticas), realizadas en parejas o pequeños grupos y que resultan imprescindibles dada la naturaleza cooperativa de la ciencia. Incluso se realizan trabajos con alumnos en los que deben resolver problemas semanalmente utilizando una metodología cooperativa y con una realimentación basada en la comprensión de los conceptos (Jacobs, 2000).

Esta metodología, aunque ha existido desde hace muchos años no ha sido utilizada en ciencias. Sin embargo muchos de los proyectos curriculares en estas materias lo están incorporando como una técnica esencial (Blosser, 1992). Los autores de estos documentos lo justifican diciendo que el aprendizaje cooperativo promueve el éxito académico y aumenta la autoestima de los demás (Wooley et al., 1990) ${ }^{5}$. Como principales motivos para utilizar esta metodología se puede apuntar:

- la naturaleza colaborativa del trabajo científico y tecnológico debe reforzarse con actividades en grupo dentro del aula. Frecuentemente los científicos e ingenieros trabajan mayoritariamente en equipos.

\footnotetext{
${ }^{5}$ Citado por Blosser, 1992.
} 
- De forma similar los estudiantes en grupo toman responsabilidades e informan al resto sobre su trabajo. En este contexto hay una realimentación y comunicación más amplia que en el trabajo individual.

- Las principales responsabilidades de los educadores son, enseñar y socializar. Aunque hoy en día en la mayoría de las clases se opta por un trabajo individual.

- Los estudiantes necesitan participar activamente en su propio aprendizaje.

- Un correcto aprendizaje debe contemplar los tres tipos de actitud: competitiva, cooperativa y trabajo individual.

- Hay autores como Johnson y Jonson ${ }^{6}$, que piensan que si el trabajo cooperativo fuese utilizado más ampliamente y más a menudo, en el sistema educativo americano los estudiantes aprenderían más matemáticas y más ciencias.

Y desde un punto de vista más práctico en el aula se presentan otras ventajas, los alumnos sienten menos presión, aprenden a tener responsabilidades en sus tareas, mejoran las habilidades de dirección y organización, los alumnos con mayor iniciativa aprenden técnicas para explicar al resto al tiempo que aumenta la interacción con el profesor (Deavor, 1987).

Evaluando la efectividad en numerosos grupos de trabajo pequeños, en técnicas de aprendizaje y valorado la motivación, el aprendizaje de la química, el desarrollo en la resolución de problemas, y el desarrollo de las habilidades comunicativas, encontrando que hay muchos alumnos que responden positivamente frente a esta nueva situación de aprendizaje (Munk y George, 2003), pudiendo concluir que:

- Los alumnos encuentran interesante el material y comprenden conceptos químicos de baja dificultad.

- El nivel de motivación en el estudio de la química aumenta después de participar en sesiones de grupo de trabajo.

- Los estudiantes no prefieren el trabajo por parejas.

- En el siguiente curso los alumnos que han trabajado en grupo son capaces de recordar y volver a utilizar el material del año anterior.

- Los alumnos reconocen esta realimentación.

\footnotetext{
${ }^{6}$ Citado por Blosser, 1992.
} 
Los grupos suponen un excelente vehículo para desarrollar el proceso de toma de decisiones (Gómez y Acosta, 2003). Cuando se implementa correctamente mejora la adquisición y retención de los conceptos, mejora las habilidades de pensamiento, mejora la relación interpersonal. Muchos expertos opinan que esto se consigue en mejor grado si los equipos se ajustan a partir de logros individuales (Kaufman, Felder y Fuller, 2000).

La argumentación en la enseñanza científica mejora los resultados (Osborne, Erduran y Simon, 2004). Comparando la realización de tests de forma individual frente a la decisión por consenso en un grupo se observa que los logros del grupo no tienen como limite el nivel de su mejor componente, sino que el grupo puede mejorar dicho nivel. (Michaelsen, Watson y Black, 1989), Este hecho se define mejor utilizado ejemplos contextualizados, no como en la mayoría de los estudios en que se utilizan ejemplos ficticios.

\subsection{Dinámica del trabajo cooperativo}

El trabajo en grupo supone una actividad en la que dos o más personas interactúan para alcanzar objetivos comunes (Gómez y Acosta, 2003). Supone, además una forma específica de coordinar los esfuerzos de un conjunto de individuos para producir resultados de alta calidad. Habiéndose estudiado la diferencia de toma de decisiones cuando se hacen en grupo y cuando se hacen de forma individual dentro del grupo, así como la influencia del miembro más competente del grupo (Gallupe, 1990). Los premios son irrelevantes en el trabajo cooperativo, puesto que la motivación es intrínseca (Casa, Casquete del prado, Cubero, Hidalgo y Lemus, 1986)

Aunque la formación de los grupos depende de los objetivos (Felder y Brent, 2001), dependiendo de la situación particular de cada caso, se considera que 3 personas son necesarias y suficientes para obtener resultados mejores que trabajando de forma individual (Laughlin, Hatch, Silver y Boh, 2006), aunque en ocasiones y dependiendo de la dificultad de las tareas puede recomendarse trabajar con grupos entre dos y cinco alumnos (Egerbladh, 2006). 
Así mismo, aunque puede considerarse la experiencia de los integrantes de un grupo como variable (Baumann y Bonner, 2004), cabe considerar que los grupos deben tener una interacción social heterogénea (Goikoetxea, 1988), por lo que es necesario ordenar los grupos y ajustar el número de componentes del grupo.

A título ilustrativo comentaremos brevemente Algunas dinámicas utilizadas en el del aprendizaje cooperativo:

\section{Círculos de aprendizaje}

Propuesto por David y Roger Johnson y referido a como "aprender juntos", este método propone una dinámica basada en varios pasos. En ellos se incluye estructurar grupos de seis alumnos como máximo, de forma homogénea y dar instrucciones de trabajo. En estos grupos los alumnos se dispondrán en círculos para mejorar la comunicación. Cada alumno adquirirá un rol en el equipo y trabajarán con una interdependencia que debe ser positiva. El profesor debe mantener un comportamiento colaborador e introducir los conceptos necesarios, así como evaluar el trabajo de los estudiantes y hacer observaciones al final de cada lección.

\section{Rompecabezas}

O método de Aronson. Cada estudiante, integrado en un grupo de cinco componentes recibe información de una parte de la lección, y diferente de la de cada uno de sus compañeros. Todos los estudiantes necesitan conocer toda la información para finalizar la actividad. Cada uno de los participantes abandona su grupo original y se reúne con los miembros de cada grupo que tienen la misma información, formando un "grupo de expertos" en ese apartado. Este nuevo grupo trabaja junto estudiando la información que poseen y cual es la mejor forma de presentarla al resto. A continuación se vuelven a formar los grupos iniciales y se trata de resolver el problema. Con esto se consigue haber trabajado en dos grupos diferentes, con niveles de razonamiento diferentes.

\section{Rompecabezas II}

Esta modificación fue desarrollada por Slavin, en ella se da una competición entre equipos de aprendizaje en busca de una recompensa para el grupo y que está basada en una actuación individual. Los puntos son obtenidos por cada componente de 
forma individual a partir de su respuesta a algunas cuestiones previas. Todos los estudiantes leen un texto común y a cada uno de le asigna un tema determinado sobre el que se va a especializar (dentro de la actividad).

\section{Rompecabezas III}

Este método desarrollado por Spencer Kagan, se utiliza en clases bilingües. Los grupos se constituyen con una persona que habla la lengua extranjera, otra que no la habla y una tercera bilingüe. Todos los materiales son bilingües.

\section{Equipos de estudiantes}

Desarrollado por Slavin implica competición entre grupos. Los estudiantes son agrupados heterogéneamente por habilidades, género, raza y étnia. Los estudiantes toman los materiales en grupo pero resuelven las pruebas de forma individual. La puntuación de grupo contribuye a la puntuación del grupo. La puntuación propia del grupo esta basada en la mejora experimentada por los alumnos respecto a cuestiones previas.

\section{Equipos-juegos-torneos}

Desarrollado por De Vries y Slavin incluyen la misma técnica que la dinámica anterior para adquirir la estructura de los grupos y la información, pero en la fase de torneo son agrupados de tres en tres de forma que tengan habilidades parecidas. Aunque el estudio se prolongue en el tiempo, estos nuevos grupos se irán reemplazando semanalmente.

Algunos profesores utilizan estos torneos para realizar pruebas individuales y tomarlas como calificaciones intermedias y finales. Slavin propones utilizar esta técnica tanto para introducir conceptos básicos como para la realización de prácticas de laboratorio. A los alumnos les resulta divertido el hecho de ir cambiando de grupo en los torneos y la propia competitividad con sus compañeros con similares habilidades.

\section{Grupos de investigación}

Este método desarrollado por Sharan (Sharan, 1980) da prioridad al control y decisiones del alumno frente a otros métodos cooperativos. Los alumnos están implicados en lo que estudian y en cómo lo estudian. 
Estos grupos cooperativos están formados en base a intereses comunes y en aspectos particulares de un tema general. Todos los miembros del grupo ayudan a planificar cual será el tema a estudiar y se reparten el trabajo entre ellos. Este método pretende combinar un proceso democrático y un proceso de investigación. El profesor debe adoptar un estilo indirecto de liderazgo actuando como un recurso personal guiando y clarificando cuando sea necesario. Su tarea es crear un clima de trabajo estimulante. Podemos distinguir varios pasos dentro de esta metodología:

a) inicialmente el profesor debe identificar el problema general y ayudar a los alumnos a establecer los subtemas a través de una discusión. A continuación ellos deben organizarse el trabajo.

b) los alumnos trabajan juntos para planificar como llevaran a cabo la investigación de sus subtemas.

c) a continuación los alumnos trabajan propiamente en su investigación, el profesor debe ayudarles a localizar los recursos y planificar las actividades necesarias.

d) más tarde los alumnos analizan y evalúan toda la información obtenida y discriminar la necesaria de la que no lo es.

e) cada grupo presenta un resumen de su investigación al resto de la clase, con lo que todos tienen una amplia perspectiva amplia del problema.

f) por último los alumnos presentan un informe individual y cada grupo se somete a unas preguntas por parte del profesor que se utilizan como examen final.

Esta dinámica permite a los alumnos controlar su aprendizaje permitiéndoles trabajar juntos sobre intereses comunes. Además promueve una responsabilidad en el estudio, profundizando en una actitud de colaboración. 


\subsection{Condicionantes y variables en el trabajo cooperativo}

El trabajo cooperativo se química se está siendo utilizando por algunos profesores en el primer curso, ya que los cursos de preparación introducen muchos conceptos no intuitivos de forma vertical y requieren que los alumnos resuelvan problemas que no han visto nunca. Hay profesores que asignan tareas semanales mediante trabajos cooperativos (Jacobs, 2000), con lo que mejoran los conocimientos, la comprensión, la aplicación y análisis. Por tanto será interesante ver como pueden llevarse a cabo análisis en ente tipo de tareas.

Dado que el trabajo cooperativo es aquel en cual se estructura a los alumnos en equipos de trabajo para realizar tareas para casa, experiencias de laboratorio o realización de proyectos, es importante conocer cual es la influencia de los criterios de formación de los grupos sobre los resultados obtenidos.

Las diferencias entre grupos de estudiantes que se han asociado ellos mismos y grupos impuestos por el instructor no son significativas. Los mejores alumnos contribuyen de forma más activa en el trabajo en grupo. Las mujeres obtienen unas calificaciones ligeramente inferiores a los hombres en el trabajo en grupo (aunque la diferencia no es significativa). Hay asociaciones en las que se utilizan grupos que se han estructurado previamente en base a cuestionarios de verdadero o falso en ejercicios realizados con anterioridad (Kaufman, Felder y Fuller, 2000; Gijlers y Jong, 2005) en los que constatan que los conocimientos previos condicionan el proceso de aprendizaje por descubrimiento. Los análisis indican que la colaboración en grupos extremadamente heterogéneos es muy difícil cuando los mas preparados no desean construir información y trabajar en los logros mas bajos de la zona de desarrollo próximo.

Cuando se llevan a cabo experiencias combinando varios niveles de experiencia en trabajo en grupo en sus participantes se obtienen resultados bastante interesantes (Laughlin, Vanderstoep y Hollingshead, 1991), comprobando que existe un gradiente de mejora en los resultados a medida que esta aumenta. Los grupos resuelven el incremento de dificultad de una prueba aumentando su intención de emitir votos y opiniones, aumentando el número de hipótesis y proposiciones. Sin embargo muy 
pocas de estas hipótesis emergentes son correctas. Los grupos reconocen y adoptan las hipótesis correctas propuestas por sus miembros, pero no surgen hipótesis que hayan no sido propuestas previamente por alguno de ellos. Aunque existen diferencias entre la decisiones que se toman de forma individual dentro del grupo y las que hace el miembro más competente del grupo (Gallupe, 1990).

Los equipos no se crean para reducir la carga de trabajo individual sino para potenciarlo en determinadas condiciones (Gómez y Acosta, 2003), sin embargo existen problemas, porque hay alumnos que encuentran en el trabajo cooperativo la oportunidad de trabajar lo menos posible (Deavor, 1987). Quieren abandonar la tarea en cuanto la terminan y esto es difícil de aceptar por el resto de los miembros del equipo, aunque esto podría solucionarse colocando juntos a alumnos de la misma intención escolar.

El trabajo cooperativo es positivo, sin embargo en algunos equipos es difícil (Haller, Gallagher, Weldon y Felder, 2000). Se ha estudiado la efectividad de pequeños grupos de trabajo, las interacciones verbales entre los alumnos y las interacciones en los grupos de trabajo en la resolución de problemas (Kempa y Ayob, 1991) obteniendo que los alumnos en los grupos de trabajo hablan poco sobre los conceptos en si, siendo las interacciones dentro del grupo muy poco uniformes. Con frecuencia se producen diálogos entre parejas en un grupo mientras los demás callan y en muchas otras ocasiones es el alumno más motivado o con mayor capacidad el que lo hace todo, por lo que es necesario que los profesores analicen y estructuren los grupos de trabajo y sobre todo que haya un dialogo fluido entre profesor y alumnos.

Trabajando con alumnos de niveles anteriores (10-12 años), se ha propuesto la utilización del trabajo cooperativo como un componente clave (Howe, 2007) y se ha comprobado que los resultados obtenidos en estos cursos pueden modificarse según estén organizados los grupos de trabajo. Howe y su grupo de trabajo han mostrado cómo grupos organizados de forma homogenea trabajando de forma cooperativa consiguen mejores resultados que otos de control. 


\subsection{La evaluación en el trabajo cooperativo}

Los continuos cambios, tanto en los sistemas educativos, como en la sociedad actual requieren la implantación de nuevas orientaciones en la enseñanza-aprendizaje y hacen imprescindible la búsqueda por parte de todos los implicados, de repuestas frente a las nuevas situaciones.

El uso de metodologías activas en el aula para estimular y mejorar el aprendizaje conlleva nuevos enfoques en la evaluación que se correspondan con los objetivos de aprendizaje. Estos enfoques requieren definir unas estrategias de evaluación de forma que además de servir como impulso para la mejora de la adquisición del conocimiento, constituyan un proceso de aprendizaje en si mismas. En este trabajo la estrategia docente se centra en el trabajo en grupo y en la evaluación formativa.

Como en cualquier proceso de cambio socioeducativo, se requiere una reflexión desde la práctica que permita en cada momento reconducir el proceso en función de los objetivos. El proceso de mejora educativa que se platea supone detectar las deficiencias que puedan surgir en los procesos de formación y realizar un análisis crítico de las estrategias docentes utilizadas, asentando las herramientas pedagógicas en las que se concretan tales innovaciones.

La vertiente de la evaluación que vamos a contemplar en esta investigación , tiene importantes implicaciones, ya que sitúa la actividad evaluadora en un contexto mucho más amplio. La evaluación en si misma se contempla como un instrumento de aprendizaje, desde un conjunto de actividades son capaces de proporcionar situaciones de realimentación eficaz (evaluación formativa) tanto para los alumnos como para los profesores, al tiempo que se incide en los contenidos, la organización en el aula o materiales didácticos.

Desde el punto de vista didáctico, el impacto de la evaluación afecta a todas las facetas del aprendizaje, desde la motivación e intereses de los alumnos a la activdad desarrollada en el aula (Crooks, 1998). En definitiva, las innovaciones introducidas en la evaluación inciden directamente en los objetivos y la metodología de enseñanzaaprendizaje. Un hecho claramente constatable desde la práctica docente es que el 
contenido de las actividades de evaluación y el conocimiento claro de los criterios de valoración de las mismas constituyen un mensaje que ha de ser claro y directo para el alumno, mediante el cual puede entender los objetivos de aprendizaje: qué se considera importante, qué tipo de destrezas y habilidades hay que perseguir, etc. No es posible plantear la evaluación fuera del marco del proceso de formación o al margen de un análisis crítico acerca de sus fines.

El trabajo en grupo implica el adquirir contenidos y producir resultados en común. Autores como Adams y Ham (1998) afirman que la albor cooperativa es un método de indagación científica que permite a los alumnos observar fenómenos y comprender las realidades del universo. Al compartir ideas y recursos los problemas y las preguntas se convierten en herramientas didácticas para el descubrimiento. La investigación sobre la efectividad del trabajo en grupo en comparación con esquemas de trabajo individual, según el meta-análisis de Johnson, Johnson y Stanne (2000), demuestran que el trabajo cooperativo renta resultados cognitivos más altos. La colaboración con otros alumnos propicia un aprendizaje más proactivo e independiente, al tiempo que permite abarcar de forma colectiva un grado mayor de contenidos que lo que ofrece una visión individualizada (Higher Education Academy, 2004).

El trabajo cooperativo procura un aprendizaje intenso y significativo, ya que permite que el alumno adquiera un conjunto de competencias interpersonales, instrumentales y sistémicas. Facilita las destrezas interpersonales para la colaboración y el trabajo en equipo, tales como la negociación, la resolución de conflictos y problemas, la toma de decisiones y la revisión constructiva que permite avanzar en los procesos; estas destrezas son un valor añadido en la vida académica, profesional y personal. El trabajo en equipo enriquece especialmente las tareas complejas al aportar diferentes perspectivas y habilidades de los componentes del grupo que se complementan entre sí (Crooks, 1998). A todo ello cabe añadir que la especialización y la educación globalizada es ya una realidad que la que poco hay que no requiera del concurso interdisciplinar.

El trabajo en grupo es una plataforma de encuentro donde los alumnos se conocen y forman relaciones de trabajo que les aportan beneficios más allá de las tareas asignadas. Se ejercitan las estrategias cooperativas propuestas por Axelrod (1984) con 
las que todos ganan frente a estrategias donde unos ganan y otros pierden o todos pierden; se genera incluso un "capital social" de la clase (Putman, 1993). La clave es compartir (Tinto, 1998), de este modo se forma una comunidad de aprendizaje en la que se comparte la inquietud y el conocimiento sobre un tema, los valores sociales e intelectuales y la responsabilidad de llevar a cabo las tareas planteadas.

La mayoría de los alumnos considera que el trabajo en grupo es agradable, siendo ésta una de las razones por lo que se incrementa la motivación intrínseca en ellos (Crooks, 1988). Investigaciones sobre la efectividad educativa demuestran que el sentido de la comunidad de aprendizaje previene el abandono y cumple la función de incrementar el flujo de información entre alumnos, la disponibilidad de apoyo, el compromiso con los objetivos del grupo, la cooperación entre sus integrantes y la satisfacción general con los esfuerzos del grupo (Rovai, 2002).

El estudio del comportamiento de las variables que intervienen en la evaluación del trabajo en equipo se convierte pues es una labor esencial. Si los procesos y los resultados no se miden y valoran adecuadamente, la eficacia del método no está garantizada.

Las ventajas que ofrece el trabajo cooperativo invitan a los docentes a plantearlo como estrategia básica de enseñanza-aprendizaje. El reto es superar los inconvenientes de evaluar el progreso en el conocimiento y las distintas habilidades adquiridas. Para ello, un primer paso es conocer bien los aspectos que deben considerarse para una evaluación más fiable.

Es importante establecer adecuadamente una serie de parámetros antes de emprender una metodología basada en el trabajo cooperativo. El tamaño del grupo ha de ir en función de características propias de la disciplina y del tipo de tarea. En cualquier caso, si los grupos suponen más de tres o cuatro personas se tiende, por lo general, a perder la entidad de equipo y a trabajar en subgrupos. Una segunda cuestión es la duración de la tarea, que puede ocupar una sesión de clase, un día, una semana, un semestre o todo un curso. Si la duración es prolongada, exige marcar los objetivos intermedios, pautas de revisión y acuerdo con los alumnos. La tercera cuestión es la formación de los grupos de trabajo; si los forma el profesor ha de explicitar los criterios 
para la agrupación, por ejemplo, una agrupación basada en el nivel de conocimientos similares. La cuarta cuestión es la especificación de las tareas a realizar, bien por el profesor, por el grupo de trabajo o por consenso de ambas partes. Una última cuestión es determinar qué producto se persigue: un informe de la tarea o proyecto, una presentación oral, una exposición, un objeto, un portafolio, o quizás alguna combinación de éstos (adaptado de OCSLD, 2002).

En la evaluación del trabajo en grupo se plantean las mismas cuestiones de qué, quién, cómo, cuándo y para qué (Rodríguez Neira et al., 1995) que plantean otros tipos de evaluación. Las preguntas planteadas de forma precisa serían: ¿se evalúa el proceso o el producto del trabajo en grupo, o una combinación de ambos?; ¿qué tipo de evidencia o prueba se evalúa en el producto, un informe colectivo, informes individuales, una práctica individual o del grupo, una simulación?; ¿quién evalúa qué? y ¿cuándo tiene lugar la evaluación?

Desde el punto de vista del proceso, la evaluación del trabajo en grupo ha de servir como una constatación continua de la realización de las tareas. Stufflebeam y Shinkfield (1993) apuntan que otro objetivo es comprobar hasta qué punto los participantes aceptan que son capaces de asumir sus responsabilidades y desempeñar sus tareas. Esta valoración se puede llevar a cabo por los mismos componentes del grupo de trabajo, bien evaluándose los unos a los otros (evaluación entre pares o peer Assessment) o bien cada uno a si mismo (autoevaluación o self assessment). Este enfoque puede aportar un efecto formativo considerable por el incentivo que supone gestionar e incidir directamente en el progreso del grupo. Esta estrategia puede contribuir a corregir algunas anomalías y carencias que a menudo se producen en el trabajo colectivo. Por ejemplo, un alumno puede dominar a otras personas del grupo en detrimento de los más tímidos e inseguros, o puede agazaparse en el grupo sin trabajar y oculto a los ojos del profesor. La detección temprana o antes de avanzar demasiado en las tareas, mediante encuesta o puesta en común de los componentes del grupo y con la ayuda del profesor, puede paliar deficiencias que pueden resquebrajar el grupo y conducir al fracaso. 
Por otra parte, si la evaluación del proceso constituye parte de la calificación final individual, a los alumnos les preocupa que la calificación refleje el nivel de contribución personal. Existe la posibilidad de que se otorgue una calificación a cada miembro del grupo y que todos los componentes reciban la media de las calificaciones individuales. El profesor se puede apoyar en los diarios de actividad llevados por los grupos, en las actas de las reuniones de grupo y en la observación directa del proceso. Es fundamental que los criterios de evaluación estén predeterminados, bien por el profesor o consensuados por los alumnos. Tanto la claridad de criterios como el control del trabajo del grupo ayudan a los alumnos a centrarse en el proceso, que en sí mismo ya constituye una experiencia de aprendizaje (James, McInnis y Devlin, 2002). Sin embargo, la información obtenida con la evaluación del proceso puede tener tintes subjetivos y, por tanto, ofrecer problemas de fiabilidad, además, supone una carga adicional en el tiempo de dedicación del profesor. Una consideración importante es que los premios, becas o cualquier otro beneficio que el estudiante puede alcanzar se conceden sobre la base de las calificaciones de los aspirantes, por lo que se debe meditar antes de otorgar una calificación uniforme para todos los componentes del grupo en la calificación final de una asignatura. Por ésta última razón, Isaacs (2002) aboga por una calificación individual; afirma que la calificación individual premia a los alumnos destacados y penaliza la actuación de los sujetos-parásitos.

Si se pretende avaluar el producto, Stufflebeam y Shinkfield (1993) opinan que se debe explicar diferentes técnicas de valoración, ya que no existe una fórmula única válida para todos los casos. Lo deseable es proporcionar el mayor número de comprobaciones de los resultados de aprendizaje y conseguir una visión amplia de los logros. Por ejemplo, puede evaluarse el producto del grupo y otorgarse la misma calificación a cada componente. Esto premia la efectividad de la colaboración entre los componentes pero a los alumnos con mayor dedicación puede parecerles injusto que a todos se les califique igual y con ello premiar a los de menos dedicación. De igual modo, se le puede otorgar una única calificación al producto en sí mismo, que el grupo puede distribuir individualmente por medio de puntos según criterios consensuados previamente. Si la asignación individual de calificaciones se justifica y se basa enteramente en los criterios, se reduce el peligro de que se premie a los alumnos con habilidad para la negociación. Una tercera manera de dividir la valoración del trabajo en grupo es que cada componente pida que se le asigne un parte definida del trabajo y que 
se le evalúe según su parte. Esta manera de proceder en la evaluación puede parecer más justa pero no alienta la colaboración. Los procedimientos mencionados pueden combinarse de varios modos. En el caso de que los alumnos reciban la misma calificación por el producto del trabajo en grupo, a la vez pueden recibir una calificación por su contribución individual, la cual puede ser evaluada por el profesor al observar el grupo durante el proceso y por la reflexión de cada componente sobre el proyecto o tarea, sobre el proceso y sobre su dedicación y lo que han aprendido.

Es factible también que los alumnos reciban una calificación grupal pero que se asigna en las diferentes fases o actividades de trabajo. El grupo entonces acuerda quienes han de recibir más o menos puntos en cada etapa o tarea. Para mantener el promedio los alumnos comparan y ponderan sus contribuciones. Una breve entrevista con cada persona del grupo también dará al profesor idea de la naturaleza e intensidad de la contribución de cada alumno respecto del grupo. El profesor podría ajustar la calificación del grupo, por ejemplo, hasta el $10 \%$ en base a la entrevista.

El producto puede ser un informe individual escrito defendido por el alumno en una representación oral ante el profesor o ante el profesor y los demás alumnos de la clase. Los alumnos trabajan en grupo pero cada uno entrega su propio informe. Esta estrategia de evaluación aporta el beneficio de compartir información y puntos de vista pero los alumnos han de llegar a conclusiones propias.

Cuando se trata de trabajo individual, cabe mencionar el peligro del plagio, entendiendo éste como la utilización del trabajo de otros son el reconocimiento de la fuente. Es conveniente advertir a los alumnos de que el plagio es equiparable a copiar en un examen. Asimismo, hay que enseñar la forma correcta de reconocer y referenciar el trabajo ajeno, así como los límites aceptables de colaboración entre compañeros en la producción individual. 
En definitiva, la estructura de la evaluación ha de centrarse en cuatro factores que inciden en las variables que intervienen en ella:

a) Producto o proceso. ¿Se va a evaluar del producto del trabajo en grupo, el proceso del trabajo en grupo o ambos y en qué proporción?

b) Criterios. ¿Qué criterios se van a utilizar para evaluar las tareas en grupo? ¿quién determinará estos criterios, el profesor, los alumnos o ambos?

c) Evaluador. ¿Quien va a aplicar los criterios de evaluación y determinar las calificaciones? (el profesor, los alumnos entre pares, autoevaluación o una combinación)

d) Asignación de las calificaciones. ¿Una nota del grupo compartida, el promedio del grupo, una calificación individual o una combinación de estos indicadores? (adaptado de James et al., 2002).

El trabajo en grupo es aconsejable pedagógica y profesionalmente, pero requiere una planificación adecuada, clara, guiada y una evaluación fiable. 


\section{APLICACIÓN DE LA TEORÍA DE LA ZDP DE VYGOTSKY EN CIENCIAS}

\subsection{Vygotsky: biografía}

Lev Semiónovich Vygotsky nació el 17 de noviembre de 1896 en la ciudad de Orsha, Rusia (actualmente, Bielorrusia), en una próspera familia judía, siendo el segundo de una familia de ocho hijos. Se inscribe en medicina y luego en Leyes en la Universidad de Moscú, terminando en 1917 las dos carreras. En la ciudad de Gómel, donde creció, enseña lengua y literatura en la Escuela del Trabajo para los obreros; enseña psicología y lógica en el Instituto Pedagógico; Estética e Historia del Arte en el Conservatorio, dirige la sección teatral de un periódico y funda una revista literaria.

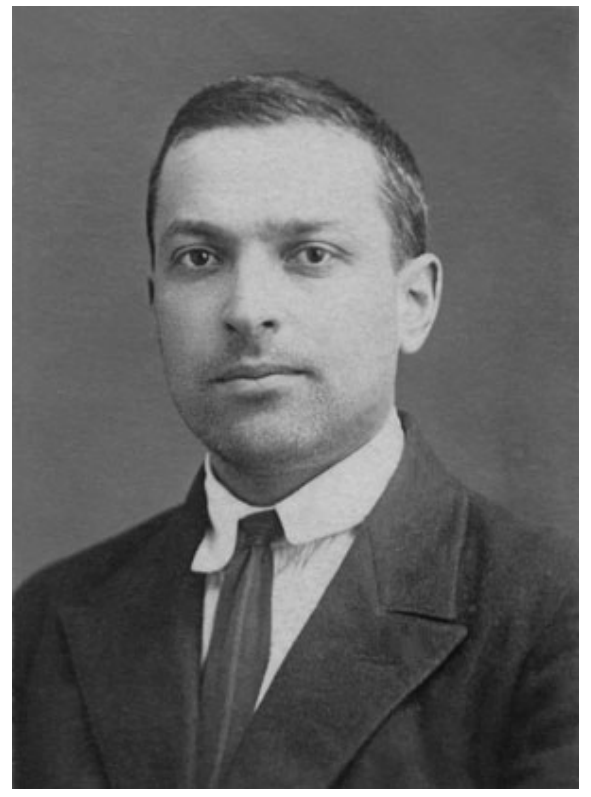

En 1924, en el marco de El Segundo Congreso de Psiconeurología en Leningrado, presenta un ensayo sobre Los métodos de investigación reflexológica y psicológica en el que manifiesta que sólo los seres humanos poseen la capacidad de transformar el medio para sus propios fines.

En 1925, Vygotsky crea un laboratorio de psicología para la infancia anormal, transformado, luego, en el Instituto de Defectología Experimental de la Comisaría del Pueblo para la Educación, el mismo que él tendrá la misión de presidir.

En 1926 retoma una larga actividad de investigación con sus alumnos, surgida de una nueva concepción histórica cultural del psiquismo y de la enseñanza en psicología, ciencias sociales, educación y defectología. En 1931, comienzan a aparecer críticas en contra de su teoría histórico-cultural y este grupo de investigadores se divide. Su obra más importante es «Pensamiento y lenguaje» (1934).

Vygotsky, es el fundador de la teoría socio cultural en psicología. Su obra en esta disciplina se desarrollo entre los años 1925 y 1934 fecha en la que falleció a los 38 años a causa de una enfermedad infecciosa. La principal influencia que le da una cierta unidad a su obra, son los escritos del materialismo dialéctico e histórico Marx y Engels, de los que era un profundo conocedor. De hecho, Vigotsky como los psicólogos soviéticos de su época se planteó la tarea de construir una psicología científica acorde con los planteamientos marxistas. 


\subsection{Teoría de la zona de desarrollo próximo}

Para Vygotsky existen dos tipos de funciones mentales: Las inferiores y las superiores.

a) Las funciones mentales inferiores, son aquellas con las que nacemos, son las funciones naturales y están determinadas genéticamente. El comportamiento derivado de estas funciones es limitado, está condicionado por lo que podemos hacer.

b) Las funciones mentales superiores, que se adquieren y se desarrollan a través de la interacción social. Puesto que el individuo se encuentra en una sociedad específica con una cultura concreta, estas funciones están determinadas por la forma de ser de esa sociedad.

El conocimiento es resultado de la interacción social; Para Vygotsky, a mayor interacción social, mayor conocimiento, más posibilidades de actuar y más sólidas funciones mentales. Des de esta perspectiva, el ser humano es ante todo un ser cultural y esto es lo que establece la diferencia entre el ser humano y otro tipo de seres vivientes. El punto central de esta distinción entre funciones mentales inferiores y superiores es que el individuo no se relaciona únicamente en forma directa con su entorno, sino también a través de y mediante la interacción con los demás individuos.

Por lo tanto "sostiene que en el proceso cultural del niño, toda función aparece dos veces, primero a escala social, y más tarde a escala individual. Primero entre personas (interpsicológica) y después en el interior del propio niño (intrapsicológica). Afirma que todas las funciones psicológicas se originan como relaciones entre seres humanos".

Vygotsky considera que en cualquier punto del desarrollo hay problemas que el niño está a punto de resolver, y para lograrlo sólo necesita cierta estructura, claves, recordatorios, ayuda con los detalles o pasos del recuerdo. La zona de desarrollo próximo es "la distancia entre el nivel real de desarrollo - determinado por la solución independiente de problemas - y el nivel del desarrollo posible, precisado mediante la solución de problemas con la dirección de un adulto o la colaboración de otros compañeros mas diestros...". 
A menudo, el adulto ayuda al niño a resolver un problema o a cumplir una tarea usando apoyos verbales y estructuración. Este andamiaje puede reducirse gradualmente conforme el niño se haga cargo de la orientación. Al principio, quizá se presente los apoyos como habla privada y, finalmente, como habla interna.

Dentro de la zona de desarrollo próximo encontramos dos importantes implicaciones: la evaluación y la enseñanza.

\section{a) evaluación}

Casi todas las pruebas miden únicamente lo que los estudiantes hacen solos, y aunque la información que arrojan puede ser útil, no indica a los padres o maestro cómo apoyar a los estudiantes para que aprendan más. Una alternativa puede ser la evaluación dinámica o la evaluación del potencial de aprendizaje. Para identificar la zona de desarrollo próximo, estos métodos piden al niño que resuelva un problema y luego le ofrecen apoyos e indicaciones para ver como aprende, se adapta y utiliza la orientación. Los apoyos se aumentan en forma gradual para ver cuánta ayuda necesita y cómo responde. El maestro observa, escucha y toma notas cuidadosamente acerca de la forma en que el niño emplea la ayuda y el nivel de apoyo que necesita. Esta información servirá para planear agrupamientos instruccionales, tutoría entre compañeros, tareas de aprendizaje, trabajos para casa, etc.

b) enseñanza

Los estudiantes deben ser colocados en situaciones en las que si bien tienen que esforzarse para atender, también disponen del apoyo de otros compañeros o del profesor. En ocasiones, el mejor maestro es otro estudiante que acaba de resolver el problema, ya que es probable que opere en la zona de desarrollo proximal del primero. Vygotsky propone que además de disponer el entorno de forma que sus alumnos puedan descubrir por sí mismos, los profesores deben guiarlos con explicaciones, demostraciones y el trabajo con otros estudiantes que haga posible el aprendizaje cooperativo. 


\subsection{Teoría de Vygotsky y trabajo cooperativo}

La idea central en la psicología de Vygotsky reside en el concepto de "zona de desarrollo próximo" y define un margen de mejora en la formación del individuo. Esta posibilidad puede conseguirse a través de otros con mayores conocimientos. Por otro lado, el trabajo cooperativo supone una vía para que los alumnos consigan desarrollar unas habilidades sociales al tiempo que mejorar su formación individual. En este sentido se han realizado estudios sobre la toma de decisiones de forma individual frente a la adoptada por consenso en un grupo (Michaelsen, Watson y Black, 1989) obtenidendo como conclusión de muchos de los logros del grupo no tienen como limite el nivel de su mejor componente, sino que el grupo puede mejorar dicho nivel.

La importancia del trabajo cooperativo aumenta al pasar de estudios universitarios al mundo laboral, pero también se debe considerar en la educación secundaria. Por tanto a este nivel es necesario dirigir la atención al trabajo cooperativo como mejora del desarrollo integral del alumno. Desde esta perspectiva es necesario considerar el concepto de "zona de desarrollo próximo" puesto que va a ser este tipo de actividades el instrumento que permita alcanzar un máximo en las competencias del alumno. El papel del discurso verbal y no verbal en el proceso de construcción de conocimientos en grupo es importante (Kittleson y Southerland, 2004). La interaccion con otros contribuye al desarrollo de la conversación conceptual. 


\subsection{Utilización de la teoría de la ZDP como instrumento de regulación}

Si aceptamos que el trabajo cooperativo es eficaz y aconsejable en la educación secundaria, también deberemos aceptar que será conveniente llevarlo de la mejor forma posible, es decir que se produzca una mejoría notable en los resultados.

Dado que la interacción entre los miembros de cada grupo va a ser el factor que va a determinar el progreso del grupo, será necesario conocer la formación optima de los grupos y en este sentido hay estudios y experiencias (Rao, Collins y Dicarlo, 2002) enmarcados en la resolución de test de forma individual y en grupo. Se concluye que las cuestiones son una buena herramienta de aprendizaje y que a partir de la realización de estos de forma individual y a continuación, del mismo en equipos, la nota es mucho mejor en grupo que por separado. Esta mejora además facilita el estudio individual, promueve el intercambio de ideas, conecta aspectos pasados con otros actuales. 
4.- Teoría de la zona de desarrollo próximo 


\title{
SEGUNDA PARTE
}

\author{
PLANTEAMIENTO DE LA INVESTIGACIÓN: UTILIZACIÓN DE
}

MECANISMOS DE REGULACIÓN EN EL APRENDIZAJE COOPERATIVO, COMO ALTERNATIVA DE MEJORA. 


\section{OBJETIVOS, PLANTEAMIENTO Y METODOLOGÍA DE LA INVESTIGACIÓN.}

En este apartado trataremos de presentar el planteamiento de la investigación, con la intención de justificarla y contribuir a la formulación concreta del problema.

\subsection{Problemas en la enseñanza-aprendizaje de los conceptos básicos en química}

Cuando nos introducimos en el tratamiento de los conceptos básicos de química con alumnos de secundaria, nos enfrentamos a diversas dificultades con diferentes orígenes y que es necesario explicitar antes de abordar la propuesta didáctica de la presente investigación:

a) Utilización de varios niveles de representación de la materia. La propia didáctica de la disciplina hace necesario delimitar los campos de descripción, que aunque difiere en terminología según el autor, se trabaja en tres niveles (Johnstone, 1999; Llorens, 1994):

$>$ Macroscópico: corresponde a la experiencia sensorial directa

> Microscópico: es un modelo que explica satisfactoriamente los hechos macroscópicos. Puede distinguirse entre multiatómico o multimolecular, según hablemos de propiedades de estructuras formadas por colectividades muy grandes de átomos, moléculas o iones, o bien atómico-molecular al estudiar las propiedades directamente ligadas a átomos.

$>$ Representacional: Es un recurso a nivel simbólico que permite verbalizar y representar el mundo microscópico.

b) La utilización de modelos permite disponer de una buena herramienta epistemológica y emocional, puesto que explica fenómenos de forma familiar y visual. No obstante presenta el peligro de no distinguir correctamente cuando se habla de la realidad o del modelo. Ello trae consigo que en cada uno de los conceptos enlazados con los modelos se presenten ideas equivocadas (Valcárcel y Ruiz, 2000; Sánchez y Valcárcel, 2003; Solsona y Martín, 2004). Así mismo el propio uso de modelos conlleva un elevado grado de generalización en la medida en que se tratan de economizar las explicaciones ${ }^{1}$.

\footnotetext{
${ }^{1}$ Regla de economía de los modelos, tratada en el apartado 1.3.1.
} 
c) La presencia de ideas alternativas en los alumnos hace que ciertas tareas se lleven a cabo desde la intuición. Estas soluciones a menudo son coherentes pero con frecuencia difieren de las escolares, pero si interpretamos el aprendizaje como un proceso de construcción de conocimientos es necesario trabajar con estas aportaciones espontáneas y orientarlas en el sentido correcto.

d) Se constatan dificultades en la comprensión de conceptos básicos, y resultan necesarios, por parte de los alumnos antes de abordar el tema del enlace químico. El profesorado se encuentra con alumnos que no tienen claros los conceptos sobre la concepción de la materia en la ESO o acerca de estructura de la materia o sistema periódico en bachillerato.

e) Falta de contextualización de la materia, pese a lo real de la misma y de la gran cantidad de proyectos involucrados en el desarrollo de la tendencia CTS. Los alumnos no saben aplicar lo que aprenden en el aula en la vida real. Desde el propio Piaget, hasta investigaciones más cercanas apuntan a que cabría centrarse más en el contenido real de los conceptos que en su estructura lógica (Oñorbe y Sánchez, 1996; Jiménez, Sánchez y De Manuel, 2001; Moreno, 1994; Solsona, 2002) puesto que esto ayudaría al desarrollo de la materia.

f) Los alumnos presentan importantes problemas de aprendizaje asociados al propio carácter abstracto de la materia (Caamaño y Oñorbe, 2004), a la ambigüedad del lenguaje empleado, a los mismos términos empleados en contextos diferentes y también en gran medida a la práctica de ejercicios basados en la resolución algorítmica que no buscan la comprensión, sino la aplicación mecánica. 


\subsection{Fundamentación}

El interés de llevar a cabo esta investigación, se fundamenta como búsqueda de la adaptación de la teórica química general a la didáctica, puesto que la investigación didáctica pone de manifiesto la existencia de carencias que es necesario estudiar, al tiempo que la experiencia docente las evidencia. Por ello en primer lugar justificaremos teóricamente la conveniencia de este trabajo y posteriormente analizaremos los resultados de tareas en clase que apuntan en el mismo sentido.

\subsubsection{Fundamentación teórica}

En el proceso de enseñanza de las ciencias es necesario que el profesor conozca con la mayor precisión posible lo que los alumnos son capaces de hacer antes de llegar al aula e iniciar un nuevo curso o incluso en cada apartado del mismo puesto que ellos poseen sus propios puntos de vista y explicaciones acerca de los fenómenos observables, aunque a menudo tienen dificultades para razonarlos. Algunas veces no lo hacen por falta de interés y en otras ocasiones el lenguaje cotidiano lleva a crear controversia con el punto de vista científico (Trinidad-Velasco y Garritz, 2003). Todo este conjunto de ideas alternativas llevan a tomar uno $\mathrm{u}$ otro enfoque por parte del profesor, y en el caso del enlace químico es necesario conocer las ideas previas de los alumnos respecto a la estructura de la materia.

Los estudios realizados en didáctica señalan que los estudiantes mantienen sus concepciones después de concluir los estudios de química (Trinidad-Velasco y Garritz, 2003) manteniendo sus representaciones macroscópicas basadas en la experiencia directa de la realidad, concibiéndola como continua, estática y sin espacio es su interior, es decir, volvemos al problema del nivel microscópico.

Numerosos estudios muestran las dificultades que tienen los alumnos respecto al aprendizaje del enlace químico tanto antes como después de su tratamiento en el aula (Riboldi, Pliego y Odette, 2004; Peterson y Treagust, 1989; Dumon y Merlin, 1988; Caamaño y Casassas, 1987; De Posada, 1999). Tras estos trabajos se constata que los alumnos presentan dificultades a la hora de explicar correctamente cada tipo de enlace, que no atribuyen correctamente la geometría de las moléculas o simplemente no 
distinguen la coexistencia de los enlaces interatómicos e intermoleculares en una misma sustancia.

La consecuencia inmediata de estos problemas es que a continuación los alumnos deben relacionar el tipo de enlace con la estructura de cada sustancia. Dada la falta de claridad en el primero de ellos no hay una relación con el segundo (Riboldi, Pliego y Odette, 2004), y los alumnos no lo asimilan correctamente.

Por ello y a la luz de las investigaciones realizadas resulta conveniente realizar propuestas metodológicas que ayuden a alcanzar una mejor forma de desarrollar los contenidos relacionados con el enlace.

\subsubsection{Fundamentación didáctica}

Desde el punto de vista didáctico cabe plantearse cuál es la situación de los alumnos en un plano general, donde podamos estudiar si los alumnos evolucionan en el curso de una forma correcta. Por ello será interesante conocer aspectos que son necesarios a lo largo del estudio de la asignatura y que están relacionados con el enlace químico.

Situándonos en un curso avanzado de química general en secundaria, como es un segundo de bachillerato o un primer curso de química general, observamos que el enlace químico marca un antes y un después en la asignatura, puesto que anteriormente se estudian contenidos que se han visto con mayor o menor extensión en cursos anteriores (formulación, leyes de los gases, Estequiometría, estructura atómica y sistema periódico) mientras que posteriormente se tratan otros temas nuevos para el alumno. Estos nuevos temas (equilibrios, química orgánica, química medioambiental y química industrial) se apoyan en el concepto del enlace químico.

Por ello y con la intención de establecer una relación entre los alumnos que cursan química y su nivel de formación, previamente a establecer formalmente nuestra investigación, hemos realizado una exploración que justifique la importancia de buscar este punto de inflexión curricular (Olmos, 2006). Este trabajo se ha focalizado en el nivel con que los alumnos comienzan sus estudios de química general en una escuela 
universitaria, por un lado, y por otro el nivel con el que abordan el estudio del enlace químico los alumnos de segundo curso de bachillerato.

Para realizar esta exploración hemos utilizado tres grupos de alumnos de segundo curso de bachillerato de tres centros de la Comunidad Valenciana, y alumnos de 3 cursos de la asignatura de fundamentos químicos de la ingeniería de primer curso de la ETSMRE ${ }^{2}$

Es obvio que cuando un alumno accede a un primer curso universitario debe tener unos conocimientos mínimos sobre química, y desde un punto de vista didáctico, con una doble finalidad:

En primer lugar y situándonos en el actual paradigma constructivista, estos conocimientos deben utilizarse como base a partir de la cual ir formando otros nuevos, que se elaboran a partir de la estructura cognitiva anterior. Y en segundo lugar, y desde otro punto de vista la química como materia presenta la particularidad de utilizar herramientas características, como una terminología, unidades, modelos (entre ellos, los modelos de enlace), símbolos, etc. que hacen necesaria cierta preparación antes de abordar temas concretos. Así mismo hay que considerar que muchos términos químicos resultan abstractos para el estudiante, su carencia se arrastra a lo largo de cada tema, dificultando su aprendizaje, y por tanto con facilidad se producen colapsos en el estudio de esta materia, o en muchos casos se conduce a un aprendizaje memorístico, en absoluto significativo y por tanto no aconsejable en la formación de un alumno.

Sin embargo la realidad que se presenta es diferente, hay un elevado número de alumnos de química general en el primer curso universitario que presentan carencias importantes en su formación. Los motivos de esta deficiencia son muy variados:

En cuanto a su procedencia podemos encontrar alumnos que han cursado ciclos formativos, otros que han accedido por pruebas de acceso directo, y otros que lo han hecho a través de bachillerato, donde la química sólo es obligatoria en su modalidad de ciencias de la naturaleza y la salud.

\footnotetext{
${ }^{2}$ ETSMRE: Escuela Técnica del Medio Rural y Enología de la UPV
} 
En cuanto a su formación particular, situándonos en el mejor de los casos (y el más frecuente) los alumnos que han estudiado química en primer y segundo curso de bachillerato, se han enfrentado a temarios oficiales demasiado extensos como para poder profundizar en todos los aspectos como sería deseable.

Esta situación se esta traduciendo en la utilización de cursos iniciales en algunas facultades de nuestro entorno que tratan de dotar a los alumnos de unos conocimientos que se supone que deberían tener previamente a su ingreso y que el hecho de no poseerlos imposibilita su normal proceso de aprendizaje en el aula.

La investigación didáctica a través de la bibliografía nos permite establecer con relativa coincidencia cuales son los conocimientos mínimos que deben adquirirse antes de iniciar unos estudios superiores. Estos conocimientos cuando se concretan en el currículo se plasman en forma de contenidos conceptuales, procedimentales y actitudinales. En esta investigación nos vamos a referir a contenidos conceptuales, por ser los que pueden tratarse de una forma más objetiva y por ser más fácilmente organizados como un conjunto de conocimientos mínimos.

Los contenidos que resultan más necesarios para iniciar un primer curso universitario, son los relacionados con la formulación, estequiometría, leyes de los gases estructura atómica y sistema periódico. El por qué de su importancia queda justificado en cuanto a que son herramientas utilizadas a los largo del curso y nuestro problema consistirá en intentar identificar cuales son los problemas que están teniendo los alumnos para utilizarlos.

Actualmente los contenidos básicos de química se están estudiando principalmente durante el primer trimestre de $2^{\circ}$ de bachillerato utilizando 4 horas semanales y a nivel universitario se está haciendo en cursos de nivelación y refuerzo durante unas pocas semanas. En ambos casos se persigue el mismo objetivo, pero con una metodología diferente.

Así pues, podemos fijar el qué y el por qué de estos contenidos básicos, pero cuando tratamos de reflexionar acerca de la asimilación de los mismos, podríamos cuestionarnos, si se consigue este objetivo, ver las diferencias entre ambos métodos, 
pero sobre todo extraer conclusiones acerca de las competencias de los alumnos, tras la intervención. No obstante lo que vamos a necesitar obtener en este proceso son las carencias que van a presentar los alumnos una vez concluido.

Es obvio que si los alumnos adquieren correctamente los contenidos básicos de química general, podrán superar con relativa facilidad el resto de temas de química, puesto que en cualquier situación dentro de esta área hay que utilizarlos con frecuencia, y son herramientas intrínsecas en la resolución de cualquier ejercicio. En el caso contrario, tendrán importantes dificultades puesto que al trabajo que suponga asimilar cualquier nuevo concepto se le añadirá el hecho de tener que trabajar en un contexto confuso.

Dado que es posible establecer un núcleo de contenidos conceptuales necesarios para afrontar con garantías de éxito un primer curso universitario y que además estos contenidos pueden haberse obtenido en estudios de bachillerato o bien intentar suplirlos en los cursos de nivelación ofertados en algunas facultades, hemos decido realizar una intervención didáctica similar en ambos lugares. El proceso se ha basado en el desarrollo de explicaciones y actividades acerca de estos conceptos, utilizando un material común desarrollado a tal efecto, con una misma forma de intervención y con la única variable que supone el tiempo empleado. 
El proceso de este ejerció exploratorio puede esquematizarse de la forma:

Idea inicial: los alumnos tienen dificultad para asimilar los conceptos relacionados con el enlace químico a lo largo del curso

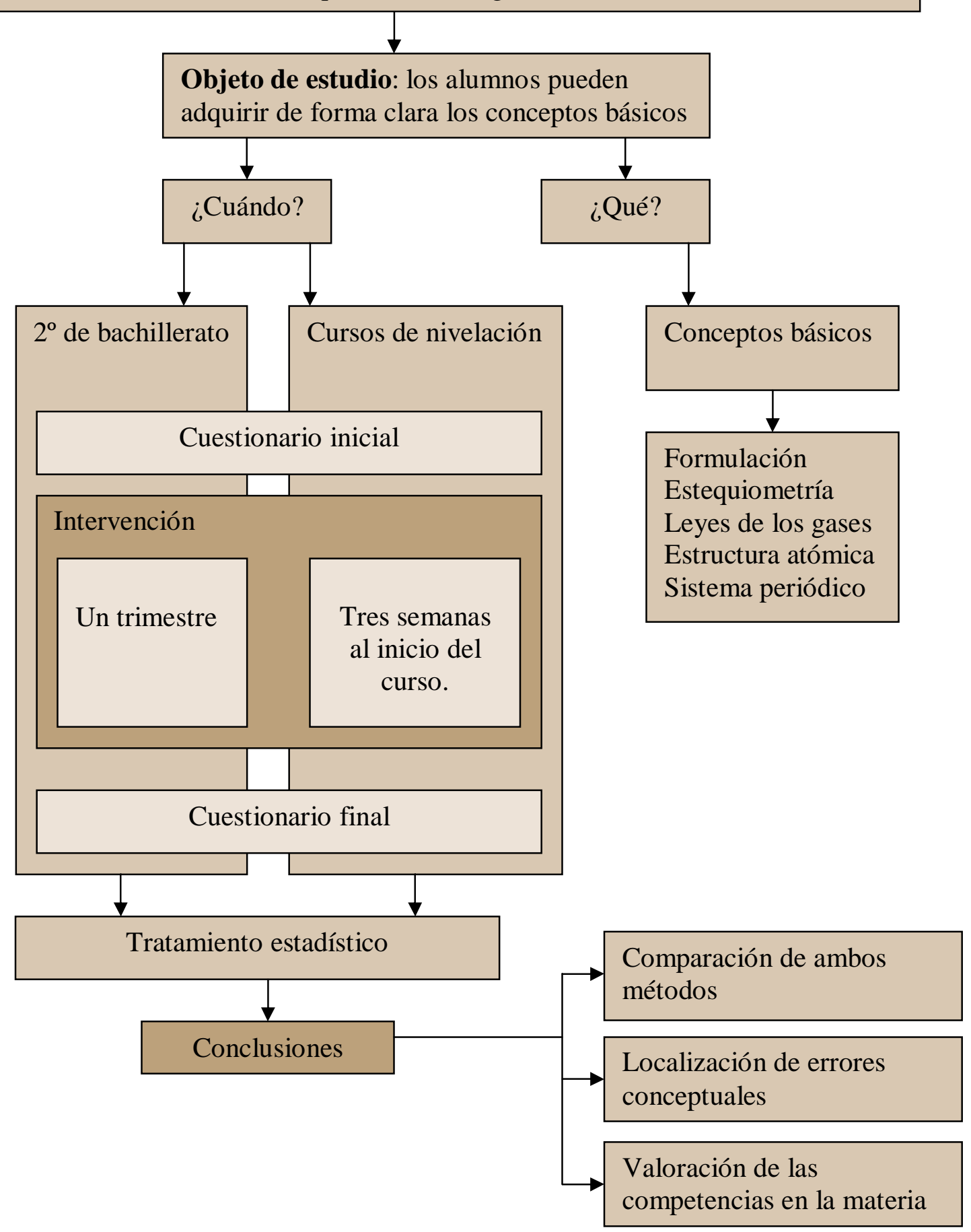

Figura 5.1.- Esquema de la intervención exploratoria destinada a conocer los problemas de los alumnos previo al estudio del enlace químico 


\section{Procedimiento seguido en el trabajo exploratorio}

1.- Instrumentos de recogida de datos

Con tal de evaluar los conocimientos de los alumnos sobre los conceptos seleccionados se confeccionó un cuestionario (anexo I), basado en cuestiones con respuesta de elección múltiple y que fueron extraídas de un banco de ítems de la $\mathrm{ACS}^{3}$.

Se pasó el mismo cuestionario antes y después de la intervención, para poder valorar el aumento de competencias por simple diferencia, lo que permitió un sencillo análisis específico en cada apartado.

Las cuestiones estaban estructuradas en cinco bloques conceptuales referidos cada uno de ellos a los temas que se estudian, tanto en $2^{\circ}$ de bachillerato, repasando contenidos de cursos anteriores para afrontar el temario ordinario, como en los cursos de nivelación y refuerzo que se imparten en algunas facultades previamente al curso de química general, siendo estos:

- Formulación

- Leyes de los gases

- Estequiometría

- Estructura atómica

- Sistema periódico

En cada uno de ellos se trató de incluir ítems que abarcasen aquellos aspectos generales que incluye cada tema y, que sin ser demasiado específicos, permitiesen identificar el grado de conocimiento así como las desviaciones más importantes y con ello identificar la causa del error cometido. Dentro de cada uno de estos cinco bloques se han especificado los aspectos más relevantes de cada uno de ellos dentro del currículo escolar, y que se exponen en la tabla siguiente:

\footnotetext{
${ }^{3}$ ACS: American Chemical Society, fundada en 1876, en la New York University está formada por más de 160.000 miembros de todos los niveles y campos de la Química, la ingeniería química y todos los aspectos relacionados, dándoles soporte científico, a través de publicaciones, conferencias, etc.
} 


\begin{tabular}{|c|c|c|}
\hline Bloque & Aspecto estudiado & Ítems \\
\hline \multirow{3}{*}{ Formulación } & Compuestos binarios & $1,2,3,7$ \\
\hline & Compuestos ternarios & $4,5,6,7$ \\
\hline & Comportamiento de iones & 8,9 \\
\hline \multirow{4}{*}{ Leyes de los gases } & Teoría cinético-molecular & 10,11 \\
\hline & Gases ideales & $12,13,17$ \\
\hline & Presión atmosférica & 14 \\
\hline & Cantidad de sustancia & $15,16,18$ \\
\hline \multirow{6}{*}{ Estequiometría } & Conservación de la masa & 19 \\
\hline & Ajuste de reacciones & 20 \\
\hline & Interpretación de ecuaciones químicas & 21,28 \\
\hline & Fórmula molecular & 22,23 \\
\hline & Cálculos estequiométricos & $24,25,26,27,28$ \\
\hline & Reactivo limitante & 29 \\
\hline \multirow{3}{*}{ Estructura atómica } & Modelo atómico & $30,32,35,36$ \\
\hline & Propiedades & 31 \\
\hline & Configuración electrónica & 33,34 \\
\hline Sistema periódico & Propiedades periódicas & $37,38,39,40,41$ \\
\hline
\end{tabular}

Tabla 5.1.- Relación de los ítems relacionados con cada contenido estudiado

\section{2.- Población}

El cuestionario se pasó a tres grupos de química de $2^{\circ}$ de Bachillerato de tres institutos de tres pueblos diferentes cercanos a la ciudad de Valencia. La muestra fue de 40 de alumnos, no teniendo en cuenta los cursos anteriores puesto que de que se trataba era de estimar desviaciones en su conocimiento de la materia.

En el caso de los alumnos de fundamentos químicos de la ingeniería el cuestionario se paso a un total de 130 alumnos de los grupos de hortofruticultura y jardinería, explotaciones agropecuarias y, mecanización y construcciones rurales de la ETSMRE. 
3.- Proceso seguido en la recogida de datos

Los cuestionarios se pasaron con la intención de conocer cual era la situación de los alumnos respecto a estos contenidos, y dado que se trata de cursos que suponen la finalización de la secundaria, dentro de la obligatoriedad de una materia de modalidad, o bien en un primer curso universitario donde se comienzan a especificar los contenidos generales, pareció adecuado pasarlos de forma repetida antes y después de repasarlos en ambos casos. De este modo podríamos también estimar el grado de progreso dentro de estos cursos.

Así pues el cuestionario se pasó a todos los alumnos en septiembre de 2005, tanto en los institutos, como en la escuela universitaria, utilizando copias del cuestionario y hojas de lectura óptica, para la corrección. En cambio, la segunda parte, se pasó al cabo de tres semanas en la escuela, mientras que en bachillerato se pasó durante el mes de febrero de 2006, cuando se habían concluido los temas. En el caso de los alumnos universitarios, la segunda fase se realizó utilizando el programa informático PARÍS ${ }^{4}$, resultando muy sencillo este proceso.

\section{Conclusiones del ejercicio exploratorio:}

a) Sobre formulación:

La intervención ha sido muy poco significativa o nula, cuando se ha tratado de compuestos binarios. Era de esperar puesto que desde segundo curso de la ESO se han ido repitiendo sistemáticamente, y el factor intuitivo es muy útil para nombrar a estos compuestos.

Cuando se trata de nombrar o formular sales ternarias, este factor intuitivo pierde su valor porque hay que buscar combinaciones en las que con poca frecuencia se puede relacionar las valencias de los elementos implicados con los subíndices que aparecen el la fórmula, por tanto las desviaciones que se producen en las respuestas son

\footnotetext{
${ }^{4}$ PARIS: Programa para el $\underline{A}$ nálisis y $\underline{R}$ esultados de $\underline{\mathbf{I}}$ tem $\underline{\mathbf{S}}$ generación y corrección de exámenes. Programa informático creado por Antonio Martínez Ramírez, analista programador informático de la ETSMRE de la UPV, pensado con la finalidad de ofrecer al profesorado una gestión profesional e integral en el desarrollo, mantenimiento y control de muchas de las tareas relacionadas con el proceso evaluador de los alumnos sin requerir los servicios de un centro de proceso de datos.
} 
mayores. En este aspecto la mejoría experimentada en bachillerato es mejor que en el curso de nivelación y refuerzo.

Cuando se forma un compuesto a partir del conocimiento de los iones que lo integran se facilita mucho su compresión, sobre todo en $2^{\circ}$ de bachillerato, aumentando mucho la facilidad para contestar de forma correcta.

No obstante hay una gran dificultad para separar de forma correcta los iones que forman un compuesto ternario, incluso después de la mejoría experimentada tras la intervención el resultado es demasiado bajo como para pensar que un alumno pueda abordar un problema en el que aparezcan sustancias en disolución y que consiga identificar con qué está trabajando.

Los alumnos no son capaces en su mayoría de interpretar como se disocia un compuesto iónico en disolución.

b) sobre las leyes de los gases:

Los alumnos aplican con relativa solvencia las leyes de los gases en cuanto a su utilización matemática, pero tienen problemas cuando se trata de identificar a una partícula gaseosa como una molécula, sea cual sea su tamaño o masa, así como a reconocer las sustancias diatómicas, habiendo utilizado en el ejemplo el oxígeno gaseoso, que debido a su cotidianeidad se debería haber identificado rápidamente.

Presentan problemas con el concepto de cantidad de sustancia, en varias cuestiones se confunde en gran medida el mol con el gramo o el litro.

Se acusa la falta de familiarización con la teoría atómica de Dalton.

No se asimila el estado gaseoso con un conjunto de partículas entre las que puede haber moléculas de cualquier sustancia.

c) sobre estequiometría:

No se interpreta en gran medida la reacción química como una reordenación de los átomos que implica ruptura y formación de enlaces, como indica la teoría atómica 
de Dalton, es más hay cuestiones que llevan a pensar que un porcentaje elevado atribuye a las reacciones una relación 1 a 1 para todas las sustancias que intervienen.

En este último ejemplo se equivoca el ajuste por excesiva simplificación del proceso, se hace excesivamente intuitivo.

No se tiene una idea clara de la molécula como entidad química, se trabaja de forma algorítmica en lugar de razonar las propiedades que se derivan de la fórmula molecular.

Se conoce claramente el concepto de masa molecular y se aplica correctamente.

\section{d) sobre estructura atómica:}

Los resultados obtenidos en cuanto a la estructura atómica son bastante satisfactorios, los alumnos han asimilado bien el papel de las partículas subatómicas y son capaces de hacer cálculos sencillos sin dificultad.

Las transiciones entre diferentes orbitales se entienden pero no se interpretan correctamente, se duda entre absorción o emisión de energía.

La principal confusión que se detecta consiste en confundir el número másico con el número de neutrones.

e) sobre tabla periódica:

Las propiedades periódicas (EI, EA, Tamaño, EN, Carácter metálico) se conocen de forma memorística y no razonada.

La definición y significado de las propiedades periódicas, no se conocen correctamente.

Las propiedades periódicas se relacionan con su posición en la tabla. Aunque es una de sus funciones, también requiere un mínimo razonamiento de porqué es así, por el contrario se incurre en una excesiva simplificación.

Con todo esto podemos concluir que entre los alumnos hay una gran diversidad de situaciones aun después de haber seguido un mismo proceso de instrucción, así mismo observamos que sigue habiendo muchos conceptos que deberían tenerse 
asumidos y que distan de dominarse, por tanto parece razonable pensar que desde el punto de vista didáctico una intervención basada en un problema tangible, que permita superar la barrera de la abstracción que supone el temario ordinario sería una forma de estimular y motivar en el interés por el enlace en el desarrollo del curso.

El interés de esta investigación inicial se basa en la confirmación de las teorías constructivistas en nuestro ámbito de trabajo. Queremos contrastar su principio según el cual, para desarrollar un concepto es necesario apoyarse en conceptos anteriores.

\subsection{Metodología de la investigación}

La metodología empleada en la investigación, podría considerarse como investigación de campo, puesto que vamos a analizar los comportamientos de varios grupos de alumnos, dentro del ambiente habitual que suponen sus clases ordinarias, tras modificar algunas de las variables que intervienen en su proceso formativo. Interviniendo y modificando actividades y metodología de trabajo con objeto de mejorar el aprendizaje de estos conceptos.

Al igual que en otras investigaciones de campo tenemos la ventaja de poder realizar una experimentación en situación real y por tanto fácilmente extrapolable. Somos conscientes de la interacción de múltiples variables, donde únicamente podemos controlar unas pocas.

En la presente investigación vamos a utilizar una metodología tanto cuantitativa, como cualitativa. La metodología cuantitativa es frecuente en la mayoría de las ciencias experimentales y se caracteriza por cuantificar las variables que intervienen en el proceso, mantener constantes aquellas que se consideren y estudiar el efecto del proceso en las restantes, denominadas dependientes. La metodología cualitativa es más empleada en relaciones sociales, donde se estudian las reacciones de los individuos a distintos estímulos, sus causas y se analizan de forma descriptiva los hechos.

La investigación se ha llevado a cabo a lo largo de los cursos académicos 2005/2006 y 2006/2007, en su fase de investigación previa o diagnostica y durante el curso 2008-2009 en su fase de aplicación. 
a) fase previa/diagnóstica

En la primera de las partes se ha estudiado la secuencia de aprendizaje de alumnos de segundo curso de bachillerato en temas básicos en el estudio de la química general, como son la formulación, la Estequiometría, las leyes de los gases y el sistema periódico. Con ello se ha obtenido el modelo de cuestionario a utilizar, se ha analizado cual es la situación conceptual de los alumnos en el momento previo al estudio del enlace químico, se ha observado la respuesta de los alumnos a una actividad guiada, y se han sentado las bases para fundamentar didácticamente esta investigación.

En el segundo de los cursos de la fase diagnóstica se ha llevado a cabo una intervención previa. Se ha planteado en los cursos de $3^{\circ}$ de ESO y $2^{\circ}$ de bachillerato, tal como se ha justificado en el planteamiento del problema, y ha consistido en ofertar a los alumnos el tema desde un punto de vista práctico, mostrando un problema de la vida ordinaria, y que trata de ilustrar el por qué de conocer los enlaces que intervienen en la formación de unas u otras sustancias.

Desde el punto de vista operativo la intervención se ha llevado a cabo, tras una primera experiencia diagnóstica realizada durante el primero de los cursos y sobre la cual no recaerían las estrategias de intervención y otra en el segundo curso, y que sería el procedimiento propuesto como mejora. La propuesta ha comenzado con un cuestionario acerca de los conocimientos sobre la estructura de la materia (Pre-ESO, anexo III) en tercer curso de ESO y otro sobre conocimientos previos sobre el enlace químico (Pre-Bac, anexo VII) en segundo curso de bachillerato. A continuación se ha presentado un problema en cada uno de los niveles. En tercero de ESO, se ha partido de la idea de que un mismo tipo de átomos pueden aparecer en sustancias muy diferentes, mientras que en bachillerato se han buscado las propiedades de cada tipo de enlace y se han relacionado con las técnicas de separación que ellos conocen de cursos anteriores.

Tras la presentación de los problemas se han secuenciado los contenidos siguiendo un hilo conductor que relacionaba la situación expuesta con los contenidos cuniculares. En último término se han pasado a los alumnos una nueva serie de cuestionarios, para determinar su grado de asimilación de los contenidos. En tercero más relacionado con determinar el tipo de enlace (Post-ESO, anexo V) y en bachillerato otro más centrado en conocer las propiedades de las sustancias en base al enlace utilizado (Post-Bac, anexo IX). Paralelamente al proceso se han establecido grupos de 
control en ambos niveles, que serán los que nos indiquen la conveniencia o no de esta metodología.

Transcurrido el desarrollo de la intervención recurriremos al tratamiento estadístico, tanto cuantitativo como cualitativo, para determinar los resultados obtenidos. Distinguiendo dos objetivos, por un lado cuantificar el grado de mejora en caso de que se produzca y en otro plano, detectar las causas de los posibles errores cometidos.

El proceso puede esquematizarse como:

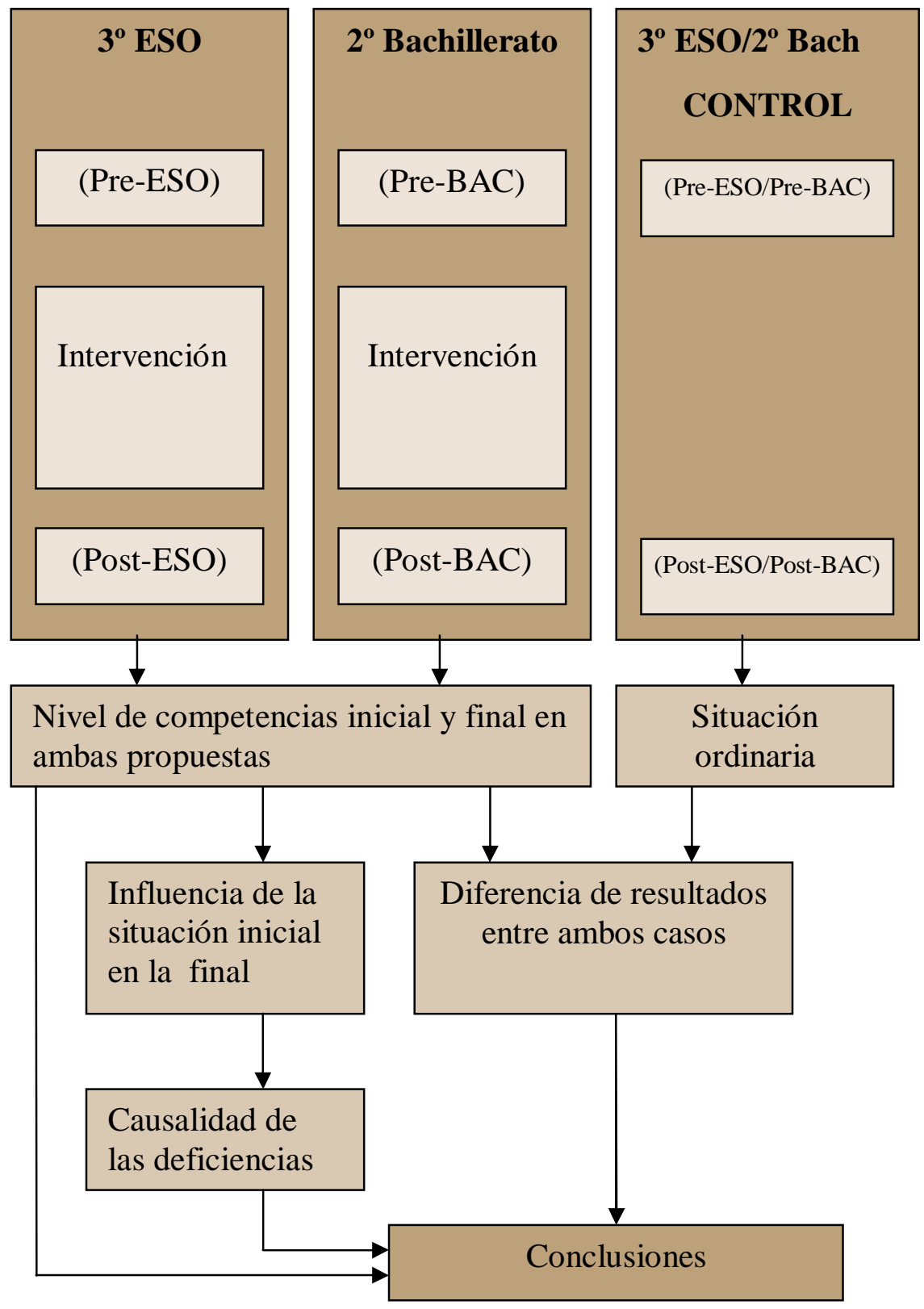

Figura 5.2.- Esquema de la fase previa/diagnóstica centrada en el enlace químico. 
Una vez concluido el tratamiento estadístico, el objetivo es determinar cuáles son las deficiencias post-instruccionales, tanto en el caso de haber utilizado la propuesta como en el caso de no haberlo hecho. En segundo término trataremos de encontrar una relación entre aquellos conceptos iniciales y finales que puedan tener estrecha relación entre sí para poder concluir cuales son los conocimientos mínimos con los que un estudiante puede abordar el tema del enlace químico con una cierta garantía.

b) fase experimental para el desarrollo del mecanismo propuesto.

Esta segunda parte supondrá el cuerpo de la investigación y se llevará a cabo con alumnos de primer curso de bachillerato. La intención es desarrollar un mecanismo para la regulación del trabajo cooperativo, en virtud de los resultados de los trabajos la fase diagnóstica.

Por ello a la luz de las conclusiones obtenidas se van a desarrollar unas actividades de aprendizaje, que supondrán el desarrollo de los temas de primer curso de bachillerato, en los cuales se van a tratar los conceptos básicos de química que se han trabajado tanto en la fase exploratoria que ha justificado el trabajo, como la fase diagnóstica.

Esta propuesta comienza con el desarrollo de clases en las que los alumnos trabajan los primeros temas de forma individual y cuya evaluación final se hará de forma doble, en primer lugar de este mismo modo y posteriormente, de forma colectiva. Para ello se cuenta con los cuestionarios elaborados a tal efecto (anexos XIII y XV).

A continuación se trabajará el tema del enlace químico utilizando una metodología cooperativa, tanto en el trabajo diario en clase como en su evaluación final (anexo XVII).

A partir de los resultados obtenidos acerca de sus interacciones personales, se procederá a llevar a cabo el mecanismo de regulación propuesto, como eje principal de este trabajo.

Como último punto cabrá utilizar este mecanismo en temas posteriores y evaluar su eficiencia. En nuestro caso se trabajarán los temas de formulación y estequiometría 
(anexos XIX y XXI), con lo que se completan los contenidos que hemos denominado básicos y que hemos utilizado para fundamentar, plantear y llevar a cabo en esta investigación.

El trabajo llevado a cabo en esta etapa puede esquematizarse de la forma:

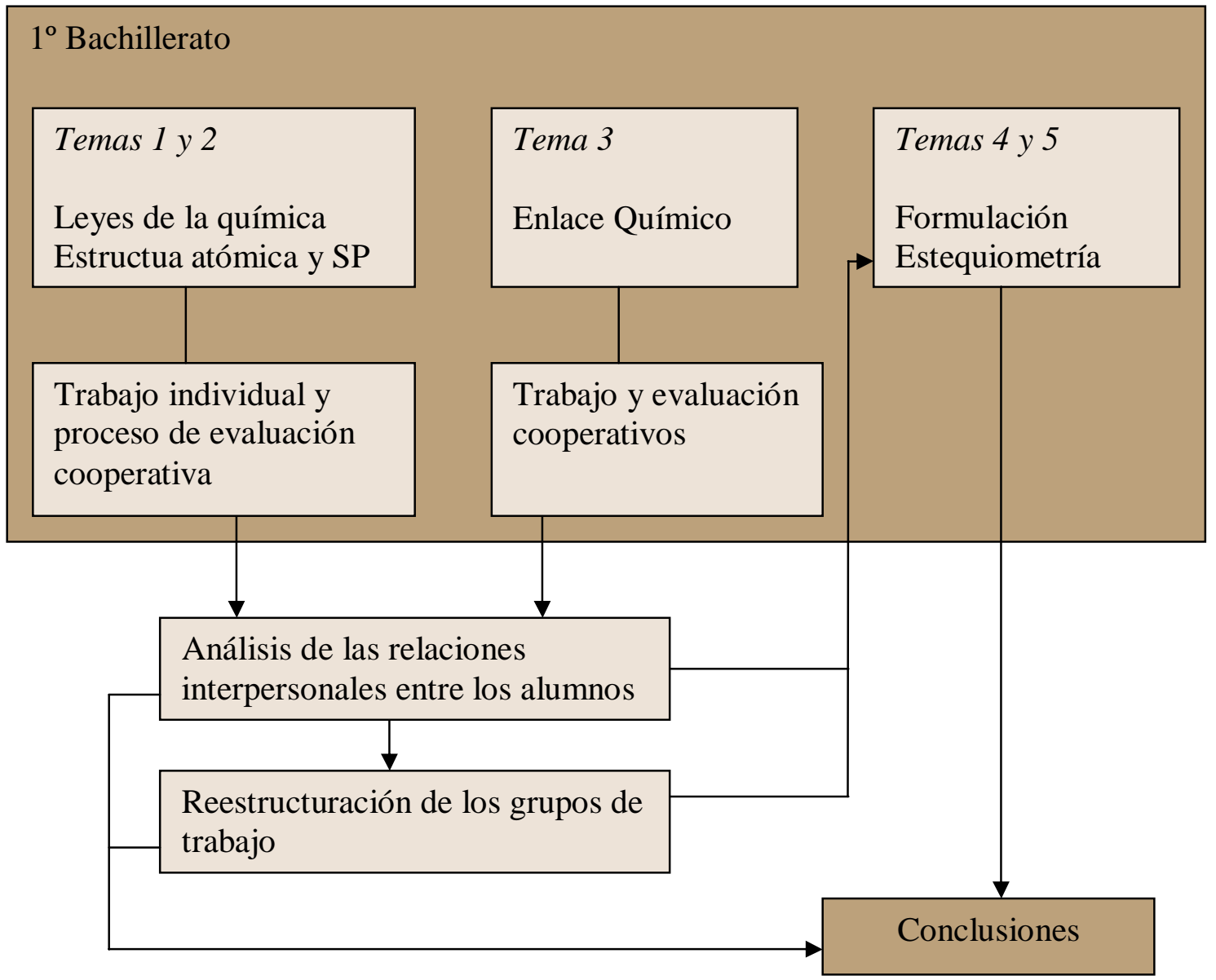

Figura 5.3.- Esquema de la fase experimental 


\section{MODELO PROPUESTO E HIPÓTESIS}

\subsection{Planteamiento del problema}

En España desde las últimas décadas y a través de las reformas educativas de la LOGSE (1990) y la LOE (2006) se ha venido insistiendo en la necesidad de introducir cambios metodológicos, aumentando la importancia atribuida al desarrollo de competencias asociadas a contenidos procedimentales y actitudinales frente a la tradicionalmente atribuida a los conceptuales.

Diversos estudios, tanto teóricos como empíricos, han puesto de manifiesto que la adquisición y desarrollo de competencias científicas requiere que el estudiante despliegue su capacidad de interacción y participación con otros compañeros mediante la aplicación del aprendizaje colaborativo y cooperativo (Slavin, 1990; Johnson, Johnson y Holubec, 1999a y b; Ovejero, 1990; Gómez y Acosta, 2003; Poveda Serra, 2007).

La influencia del aprendizaje cooperativo en la adquisición de conceptos, destrezas y actitudes ha sido ampliamente contrastada en diferentes contextos y niveles educativos (Shibley y Zimmaro, 2002; Doymus, 2007; Phillips et al., 2007; Syh-Jong, 2007; Schray et al. 2009). En tal sentido, Glinz sostiene que mediante el uso de metodologías colaborativas y el aprendizaje cooperativo, a diferencia de la enseñanzaaprendizaje tradicional, "los alumnos aprenden de manera significativa los contenidos, desarrollan habilidades cognitivas (razonamientos, observación, análisis, juicio crítico, etc.), socializan, toman seguridad, se sienten más aceptados por ellos mismos y por la comunidad en que se desenvuelve" (Glinz, 2005, p. 3).

En el campo de la química general, sobre todo a nivel universitario, existe una amplia literatura relacionada con aspectos tales como su relación con la mejora de la comprensión y la efectividad del cambio conceptual (Rodríguez y Escudero, 2000; Basili y Sandford, 1991; Bilgin y Geban, 2006; Doymus, 2007; Acar y Tarhan, 2008) y de actividades experimentales (Pogacnik y Cigic, 2006; Tribe y Kostka, 2007; Van Engelen et al., 2007). Diversos investigadores han demostrado su influencia positiva en la adquisición y desarrollo de estrategias cognitivas (Pratt, 2003; Hager et al., 2003; Deming y Cracolice, 2004), el fomento de la creatividad (Tang et al., 1999) y el 
desarrollo de actitudes positivas hacia la ciencia (Hinde y Kovac, 2001; Shibley y Zimmaro, 2002; Barbosa, Jofili y Watts, 2004). Otro de los aspectos que han sido estudiados y de especial relevancia en el ámbito universitario es su incidencia en la mejora del aprendizaje en grupos numerosos (Carpenter y McMillan, 2003; Hockings, DeAngelis y Frey, 2008; Wanous, Procter y Murshid, 2009). De un modo similar, también se ha investigado la percepción de los estudiantes acerca de la efectividad positiva de proyectos de trabajo cooperativo, frente a estrategias basadas en la clase magistral, tratando de identificar específicamente los factores que contribuyen a la mejora del aprendizaje (Munk y George, 2003).

En particular recientemente puede observarse también un creciente interés hacia el estudio de cómo tiene lugar el propio trabajo cooperativo en el seno de un grupo (Poveda Serra, 2007). Así, por ejemplo, la naturaleza de las interacciones verbales durante sesiones de aprendizaje cooperativo ha sido analizada en detalle con estudiantes universitarios (Haller et al., 2000; Wanous, Procter y Murshid, 2009). En estos trabajos a partir del estudio de los roles desempeñados por los miembros de los grupos se propone un conjunto de orientaciones para la intervención didáctica capaces de mejorar sensiblemente la calidad del trabajo cooperativo (Dinan, 2006; Mahalingam, Schaefer y Morlino, 2008). No obstante, en general, todavía continúa siendo muy escasa la investigación relativa a la organización de los grupos, las interrelaciones y sus influencias entre los miembros de un grupo con respecto a cada individuo, el papel de los líderes y su vinculación con la mejora del aprendizaje, especialmente en el ámbito de educación secundaria (Rué,1998; Priest y Sterling, 2003; Shachar y Fischer, 2004; Poveda Serra, 2007).

La evaluación del aprendizaje cooperativo requiere analizar cómo y en qué medida la interacción entre los estudiantes contribuye a mejorar su aprendizaje. Las técnicas cualitativas tales como: entrevistas, transcripciones de grabaciones de audio y video, parrillas de observación, etc., constituyen, en ese sentido, un valioso recurso. Sin embargo, en estos métodos, la recogida, selección e interpretación de datos es a menudo un proceso largo y costoso. Por ello, conviene disponer en la práctica docente de instrumentos que faciliten una realimentación rápida y eficaz, para adoptar decisiones en la gestión del trabajo cooperativo. La realización consecutiva de una misma tarea, 
individualmente y en grupo promueve los procesos de autorregulación y puede ser una herramienta útil en la caracterización de modelos de trabajo cooperativo en los grupos (O’Donnell y Dansereau, 1992; Llorens Molina, 2007). Concretamente, sería deseable conocer en qué medida las diferencias entre la realización individual y cooperativa de una tarea provienen de un cambio cualitativo en las ideas de los estudiantes como consecuencia de su interacción o de la influencia de las relaciones de liderazgo dentro del grupo. Como afirma Barco (2006, p. 106): “En el aprendizaje cooperativo no basta con dejar que los alumnos se pongan a trabajar en grupo o con promover la interacción entre ellos para obtener, de manera inmediata, unos efectos favorables sobre el desarrollo, la socialización y el aprendizaje. Lo importante no es la cantidad de interacción, sino la calidad de la misma. Las personas que se unen para trabajar adquieren todas las características de los grupos sociales: presión de grupo, conflictos, adopción de roles... La toma de conciencia de estos problemas, plantea la búsqueda de soluciones que den lugar a interacciones entre los alumnos, ricas y constructivas, en cuanto a sus efectos”.

Es de interés señalar las diferencias existentes entre aprendizaje en grupo y aprendizaje en equipos, o lo que es lo mismo, entre aprendizaje colaborativo y aprendizaje cooperativo (Johnson y Johnson, 1999; Lobato Fraile, 1998).

Por grupo de trabajo entendemos una alianza no estructurada en la que varias personas interactúan con independencia para alcanzar objetivos comunes, mientras que en un equipo existe una organización con tareas específicas y unas normas en busca de unos resultados de "alta calidad" (Gómez y Acosta, 2003). Los equipos o grupos de aprendizaje cooperativo se basan en una interdependencia positiva entre los miembros del grupo, donde el liderazgo es compartido por todos los componentes y la meta es que cada uno aprenda lo máximo posible.

En palabras de Poveda (2005, p. 7) la cooperación es "una situación social en la que los objetivos de los individuos están estrechamente vinculados ya que existe una correlación positiva con respecto a su consecución, de tal manera que un individuo puede alcanzar sus objetivos si y sólo sí los demás alcanzan los suyos”. De allí que, 
como sostiene esta autora que las metas de cada individuo están en función de las metas de los demás y la consecuencia de los objetivos individuales está fuertemente ligada a la consecución de los objetivos de los demás miembros del grupo. En una situación de aprendizaje cooperativo, cada miembro del grupo se preocupa no sólo de su propio rendimiento sino también del de sus compañeros (Laughlin, Vanderstoep y Hollingshead, 1991).

Nuestro trabajo pretende analizar metodologías para la gestión de la dinámica del grupo, estableciendo relaciones entre el rendimiento académico (nivel de competencia alcanzado) como consecuencia de la interacción social en un grupo con el rendimiento académico alcanzado individualmente. Nuestro análisis se sustenta en las aportaciones teóricas de Vygotsky, fundamentalmente en el concepto de Zona de Desarrollo Próximo de Vygotsky que representa el espacio entre lo que el alumno es capaz de hacer por sí solo (zona de desarrollo real) y aquello que es capaz de realizar con ayuda de otros (zona de desarrollo potencial) (Vygotsky, 1980; Dahms et al. 2008).

La investigación se sitúa en grupos de estudiantes de secundaria y bachillerato, considerando el estudio de un tema clave en la enseñanza de la química: el enlace químico. Se trata de un tema complejo, que tiene atribuida una gran importancia a nivel curricular durante toda la educación secundaria, tanto obligatoria como postobligatoria así como en estudios superiores. Se pretende profundizar en el conocimiento del proceso del cómo se lleva a cabo el trabajo cooperativo durante el desarrollo del proceso de enseñanza y aprendizaje en torno a esta temática:

- Identificando cuáles son las características más notorias de un grupo de trabajo a partir de las cuales se pueden establecer pautas de gestión de sus interrelaciones y del contexto

- Determinando un conjunto de parámetros a partir de los cuales se pueda caracterizar y establecer una tipología de grupos con la finalidad de mejorar su dinámica desde el punto de vista de la teoría de la Zona de Desarrollo Próximo (ZDP). 
Como afirma Alonso Tapia (1996) el profesor en una estructuración cooperativa del aprendizaje debe facilitar formas de interacción positivas, debe modelar y definir la forma en que los alumnos intercambian la información, el modo en que reaccionan ante las aportaciones de los demás miembros del grupo y la manera de afrontar las tareas consiguiendo así que se eviten consecuencias negativas para la motivación y la participación. Consideramos que es importante para el docente disponer de estrategias que le ayuden a gestionar la dinámica de estas interrelaciones, contextualizadas y vinculadas en función de la complejidad de los contenidos temáticos a trabajar en el proceso de enseñanza-aprendizaje.

La problemática que se aborda queda reflejada en las siguientes preguntas:

- ¿Podríamos mejorar el rendimiento de un grupo de química en enseñanza secundaria mediante la utilización de una metodología basada en el trabajo cooperativo de los estudiantes?

- ¿Qué tipo de competencias pueden mejorarse a través del trabajo cooperativo?

- ¿Cómo podemos optimizar mediante la evaluación el aprendizaje cooperativo?

- ¿Puede determinarse cual es la implicación de un alumno en el trabajo realizado en un grupo?

- ¿Resulta más provechoso organizar a los alumnos en grupos con características académicas e implicaciones similares respecto al grupo?

- ¿Puede establecerse una metodología de control basada en la retroalimentación sobre los componentes de cada grupo de forma que optimice el proceso de enseñanza y aprendizaje cooperativos? 


\subsection{Hipótesis de trabajo}

\section{Hipótesis 1}

La utilización del trabajo cooperativo como metodología favorecedora de las interrelaciones personales dará lugar a una mejora del rendimiento académico en el desarrollo de un curso ordinario de química en Educación Secundaria.

Esta mejora deberá manifestarse al contrastar los resultados obtenidos por cada alumno cuando interactúa dentro del grupo frente a los obtenidos a partir del trabajo que él mismo hubiera realizado de forma individual. De este modo, puede lograrse una aproximación experimental al concepto de Zona de Desarrollo de Vygotsky, lo que fundamenta la segunda hipótesis de trabajo:

\section{Hipótesis 2}

La realización de tareas de evaluación individualmente y en grupo, de manera consecutiva, mostrará la existencia de una mejora del rendimiento como consecuencia de la interacción entre los miembros del grupo.

La contrastación de esta hipótesis, además de constituir una caracterización experimental de la citada Zona de Desarrollo Próximo en una tarea concreta, requiere abordar la relación entre las aportaciones individuales previas y la propuesta por el grupo como tal. De este modo, consideramos que un mejor conocimiento de la dinámica interna de los grupos, puede dar lugar a una optimización del trabajo cooperativo.

Por otra parte, desde el punto de vista del trabajo ordinario del profesorado en sus centros docentes, el logro de este objetivo requiere disponer de instrumentos de evaluación capaces de proporcionar un rápido feed-back que permita una adecuada gestión del trabajo cooperativo, principalmente, en cuanto a la composición de los grupos. Para ello, en esta investigación, se formula una propuesta metodológica cuya aplicación y evaluación constituye el fundamento de la tercera y cuarta hipótesis de trabajo: 


\section{Hipótesis 3}

A través del análisis comparativo de los resultados individuales y de grupo en tareas de evaluación ordinarias, puede establecerse un conjunto de parámetros mediante los cuales pueden caracterizarse algunos rasgos relevantes del trabajo cooperativo, principalmente, la relación entre cada una de las aportaciones individuales y la formulada por el grupo como tal, como aproximación a la identificación de las relaciones de liderazgo dentro del mismo.

\section{Hipótesis 4}

La reestructuración de los grupos llevada a cabo como consecuencia de la información obtenida a partir de los citados parámetros permitirá mejorar la eficacia del trabajo cooperativo en cuanto a los resultados del aprendizaje de los conceptos y procedimientos vinculados a los objetivos del curso en el que se aplica esta metodología.

\section{Hipótesis 5}

El enriquecimiento cognitivo referido en la hipótesis II será tanto más evidente en la medida en que las tareas implicadas correspondan a procesos cognitivos más complejos, que implican, principalmente, la aplicación de relacionales causales complejas.

En este sentido, la aplicación de la metodología propuesta resulta de especial interés en la introducción del enlace químico, dado el carácter estructurante de este concepto en química general y la importancia de las relaciones entre los conceptos que permiten coordinar adecuadamente los niveles de descripción macroscópico, atómicomolecular y simbólico en el estudio de los sistemas materiales. 


\subsection{Marco curricular de la intervención didáctica}

ESO

En tercer y cuarto curso de la ESO se imparte la física y química como materia obligatoria en el primero, no siéndolo en el segundo. Por otro lado, y según se establece en el currículo oficial, la distribución de los contenidos a impartir es asimétrica, de forma que en el tercer curso hay una mayor incidencia en los contenidos de química, y en el cuarto ocurre lo propio con la física. Esta distribución se justifica atendiendo a la necesidad por parte de la física de un mejor nivel de matemáticas, intentando conseguir al final de la etapa una homogeneización de ambas disciplinas. En cualquier caso, esto sólo se conseguirá con aquellos alumnos que elijan cursar estas materias los dos cursos.

Con respecto a nuestro problema, será más conveniente una intervención en tercer curso que en cuarto por dos motivos:

En primer lugar es más sencillo en este curso establecer un hilo conductor a lo largo del curso, ya que previamente se ha estudiado la metodología científica, los estados de agregación de la materia y se ha trabajado con bastante profundidad sobre el átomo.

Normalmente, en cuarto se declina la materia hacia la física, y en cuanto a la química, en el mejor de los casos, se suele abordar el estudio de la formulación, cantidad de sustancia y cálculos estequiométricos.

Por ello realizaremos en este curso la intervención, teniendo en cuenta el marco que supone todo el segundo ciclo de secundaria en física y química, y por tanto considerando todos los aspectos relacionados con nuestra investigación, tanto en el currículo de tercero, como de cuarto curso.

Para plantear la actividad, y con la intención de centrar y acotar lo que queremos estudiar hemos recurrido a extraer del currículo oficial aquellos aspectos que consideramos que pueden estudiarse desde el enlace químico, dentro del protocolo habitual que supone una programación de aula estableciendo previamente unos objetivos, unos contenidos y unos criterios de evaluación. 


\section{Objetivos generales}

Dentro de los objetivos generales de las ciencias naturales en la ESO, podemos identificar la importancia del trabajo cooperativo en:

a) Participar en la planificación y realización en equipo de actividades científicas, valorando las aportaciones propias y ajenas en función de los objetivos establecidos, mostrando una actitud flexible y de colaboración y asumiendo responsabilidades en el desarrollo de las tareas. Iniciarse en el conocimiento y aplicación del método científico.

b) Elaborar criterios personales y razonados sobre cuestiones científicas y tecnológicas básicas en nuestra época, utilizando de forma autónoma diferentes fuentes de información, incluidas las nuevas tecnologías de la información y la comunicación, mediante el contraste y la evaluación de su contenido.

\section{Objetivos académicos de la intervención}

a) Utilizar los conceptos básicos de las Ciencias de la naturaleza para elaborar una interpretación científica de los principales fenómenos naturales

b) Elaborar una interpretación científica que interprete las características de sólidos, líquidos y gases, y explicar como se producen los cambios de estado.

c) Comprender que la materia es discontinua.

d) Entender por qué los átomos tienden a ganar, perder o compartir electrones.

e) Explicar las características de los diferentes tipos de enlace entre átomos

f) Distinguir los tipos de enlace que se dan en las sustancias, en relación con las propiedades que presenten.

g) Asociar la idea de elemento químico a sustancias constituidas por átomos con características comunes (igual número atómico), y la idea de compuesto a agregados o asociaciones de átomos diferentes.

h) Explicar las propiedades de las substancias en relación con es enlace que presentan.

i) Dar una explicación de las transformaciones químicas, basada en el modelo cinético-molecular. 


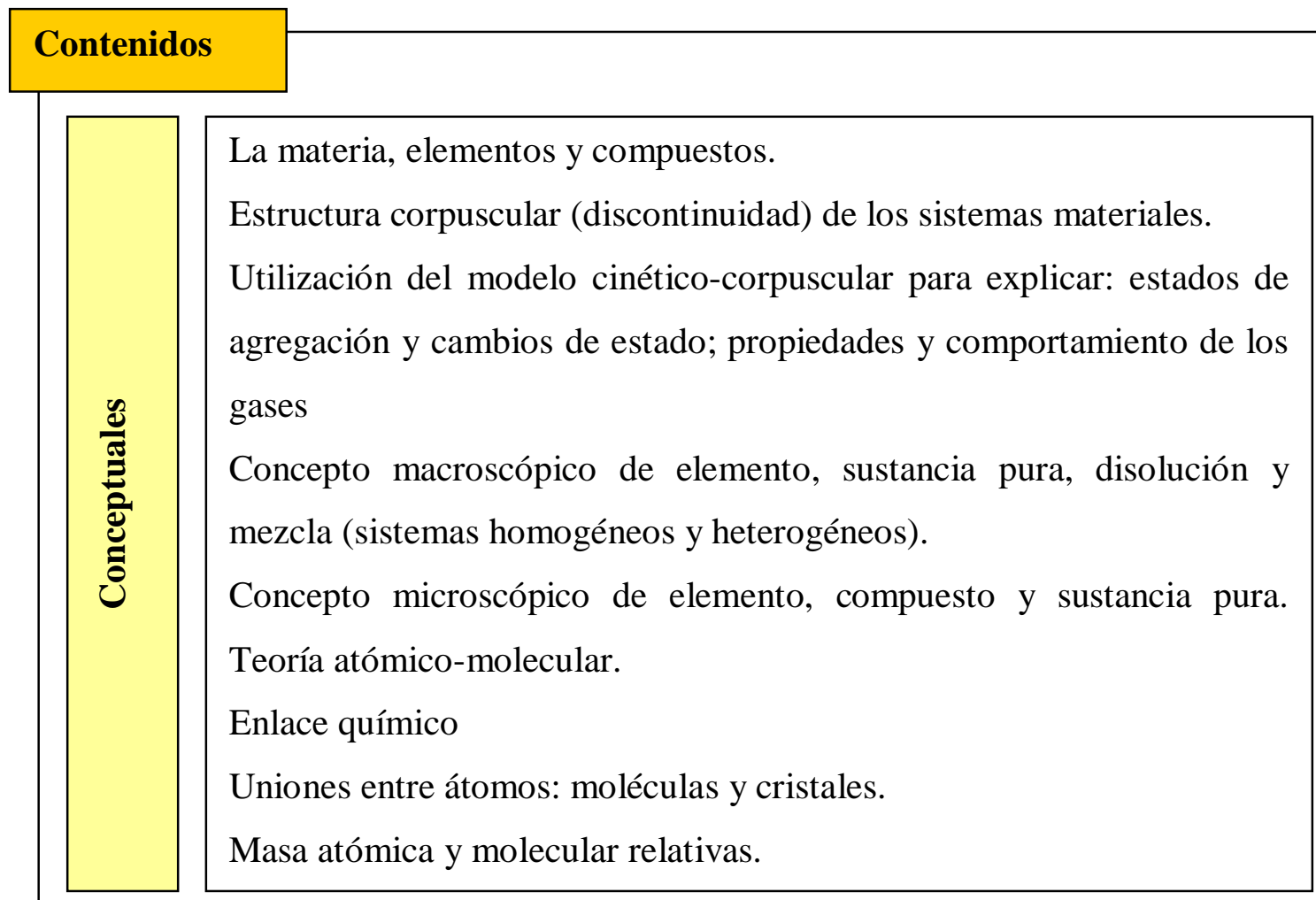

\begin{tabular}{|c|c|}
\hline & $\begin{array}{l}\text { a) Distinción de los estados de agregación de la materia, a partir de sus } \\
\text { propiedades. } \\
\text { b) Proponer ejemplos de sustancias que permitan establecer diferencias } \\
\text { entre elementos químicos y compuestos. } \\
\text { c) Relación entre la masa de una sustancia, cantidad de átomos, } \\
\text { moléculas u otras partículas que la componen. } \\
\text { d) Comparar los metales con los no metales, a partir de algunas de sus } \\
\text { propiedades. } \\
\text { e) Comparar experimentos que representen fenómenos físicos y } \\
\text { químicos a fin de establecer las diferencias existentes entre ellos. }\end{array}$ \\
\hline 异 & $\begin{array}{l}\text { a) Curiosidad por conocer las características de la materia. } \\
\text { b) Atención al material utilizado y sus efectos colectivos. } \\
\text { c) Valoración del trabajo en equipo y respeto a las opiniones de los } \\
\text { demás. } \\
\text { d) Reconocimiento de la importancia de los modelos científicos. } \\
\text { e) Curiosidad por la constitución de la materia y por el significado de la } \\
\text { labor científica. }\end{array}$ \\
\hline
\end{tabular}




\section{Criterios de evaluación}

a) Utiliza la teoría cinético-molecular para explicar las principales características de sólidos, líquidos y gases.

b) Interpreta, mediante el modelo cinético-molecular, como se produce el proceso de disolución.

c) Interpreta, utilizando el modelo de la teoría atómica, las posibilidades de transformación, de unas sustancias en otras.

d) Describe como están situados los electrones en los átomos.

e) Explica por qué los átomos tienden a ganar, perder o compartir electrones, a partir de la regla del "octeto".

f) Explica las propiedades de las sustancias en relación al enlace que presentan.

g) Se intenta comprobar que los alumnos interpretan, desde el modelo de estructura de los átomos y sus uniones, las posibilidades de crear nuevos materiales y valorar su importancia para mejorar la calidad de vida. 


\section{BACHILLERATO}

Durante el bachillerato el estudio de la química, de una forma semejante a como ocurre en el segundo ciclo de la ESO es obligatoria en primer curso, donde es una asignatura común, en las modalidades de ciencias de la salud y el medioambiente y en la científico-tecnológica. En cambio en segundo tan solo lo es en el primer caso como asignatura troncal, siendo optativa de modalidad en el segundo y compitiendo con otras asignaturas como física, matemáticas II, dibujo técnico II, geología, ciencias de la tierra, psicología, o educación física, entre otras.

Esta circunstancia hace que el número de alumnos es segundo de bachillerato que cursan química se reduzca bastante, sobre todo en aquellos que no tienen como primera opción realizar estudios superiores en ciencias.

Teniendo en cuenta el currículo de bachillerato, nos parece conveniente situar la intervención en el segundo curso ya que, en él se estudia con toda profundidad el enlace químico y las propiedades que de él derivan, mientras que en el primer curso este estudio se limita a los conceptos teóricos del mismo.

\section{Objetivos generales de la química de bachillerato}

a) Utilizar las estrategias o destrezas propias de la investigación científica, tanto documentales como experimentales, para resolver problemas, realizar trabajos prácticos y, en general, explorar situaciones y fenómenos desconocidos para ellos; reconociendo el carácter de la ciencia como proceso cambiante y dinámico.

b) Mostrar actitudes científicas como la búsqueda de información exhaustiva, la capacidad crítica, la necesidad de verificación de los hechos, la puesta en cuestión de lo obvio, la apertura ante nuevas ideas.

c) Valorar la información proveniente de diferentes fuentes para formarse una opinión propia, que les permita expresarse críticamente sobre problemas actuales relacionados con la Química. 


\section{Contenidos}

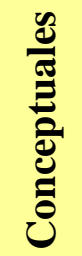

Introducción del enlace covalente a partir del modelo de solapamiento de orbitales atómicos. Geometría de las moléculas utilizando el modelo de repulsión de pares de electrones. Concepto de polaridad. Interpretación de alguna de las propiedades asociadas a sustancias que presentan enlace covalente.

Estructuras de Lewis. Parámetros moleculares. Hibridación de orbitales atómicos $\left(\mathrm{sp}, \mathrm{sp}^{2}, \mathrm{sp}^{3}\right)$.

Enlace iónico. Justificación de la existencia del retículo en los compuestos iónicos. Concepto de índice de coordinación y factores de los que depende. Introducción del ciclo de Born-Haber.

Los enlaces intermoleculares.

Enlaces de hidrógeno y por fuerzas de Van der Waals: diferencias entre el enlace intermolecular y el intramolecular y propiedades.

Estudio cualitativo del enlace metálico a partir del modelo de los orbitales moleculares aplicado a elementos con pocos electrones de valencia y a la consiguiente existencia de niveles energéticos muy próximos. Propiedades de los compuestos como consecuencia del enlace.

Modelo elemental de reacción a partir de las colisiones que provocan roturas y formación de nuevos enlaces. Existencia de reacciones endotérmicas y exotérmicas con este modelo.

Justificación de las propiedades de las sustancias en relación con el enlace.

Predicción del tipo de enlace que se formará entre dos o más átomos.

En cuanto a estos contenidos, el currículo insta a considerarlos a lo largo de cada tema de forma transversal, en nuestro caso, consideraremos principalmente:

a) Procedimientos que constituyen la base del trabajo científico: planteamiento de problemas, formulación y contrastación de hipótesis, diseño y desarrollo de experimentos, interpretación de resultados, comunicación científica, estimación de la incertidumbre de la medida, utilización de fuentes de información.

b) Hábitos de trabajo e indagación intelectual. 


\section{Criterios de evaluación}

a) Contrastar diferentes fuentes de información y elaborar informes con relación a problemas físicos y químicos relevantes de la sociedad.

b) Conseguir que los estudiantes, a partir de un modelo elemental de capas lleguen a la regla del octeto, que les permita justificar la situación de algunos elementos y propiedades como la electronegatividad para poder entender el modelo de Lewis sobre el enlace iónico y el covalente, justificando su fórmula en casos sencillos, así como deducir algunas propiedades características de estos compuestos tales como el estado físico en el que se encuentran en condiciones ambientales y la posible solubilidad en agua o en disolventes orgánicos.

c) Aplicar el concepto de enlace a diferentes sustancias, deduciendo en cada caso la estructura que cabe esperar así como algunas de sus propiedades, tales como estado físico, dureza y conductividad.

d) Describir las características básicas del enlace covalente. Escribir estructuras de Lewis.

e) Relacionar el tipo de hibridación con el tipo de enlace en los compuestos del carbono.

f) Identificar en cada tipo de reacción química orgánica (eliminación, sustitución, adición) los enlaces que se rompen y los que se forman de nuevo. Conocer ejemplos concretos de cada una de estas reacciones orgánicas.

g) Describir la estructura general de algunos polímeros naturales y artificiales, conociendo su interés desde el punto de vista económico, biológico o industrial.

Dado que el profesorado de química debe tener presente que la evaluación de su trabajo, y el de los alumnos pasa inevitablemente por las pruebas de acceso a la universidad, cabrá considerar como criterio de evaluación y como ejemplo de practicidad didáctica una revisión de las cuestiones propuestas en los exámenes de selectividad sobre el enlace, de los últimos años. Con ello podrá extraerse una secuencia de contenidos, que en definitiva, son los que se estudian de uno u otro modo en el aula. 


\subsection{Actividades previas/diagnósticas}

De lo que se tata en esta investigación es de establecer una metodología didáctica que permita a los alumnos mejorar en su formación en química como materia, pero al mismo tiempo que les ayude a desenvolverse en un ambiente de trabajo cooperativo.

En primer lugar y a través del estudio diagnóstico tratarán de estudiar en qué consisten los modelos de enlace químico, qué consecuencias tiene y sobre todo cómo permite interpretar las propiedades macroscópicas de la materia, que de ello se derivan, cuando pueden ser explicadas a través de este modelo.

La Propuesta de esta intervención es que parte de la idea de que el tema del enlace químico puede utilizarse como punto de referencia para organizar los grupos en el desarrollo de un curso utilizando la metodología cooperativa.

El hilo conductor para el estudio del enlace químico, como concepto clave para la construcción de todos los conceptos relacionados con él, con la estructura de la materia y sus propiedades macroscópicas, así como la base para el estudio de los temas posteriores, será:

1.- En primer lugar en la educación primaria y dentro del área de conocimiento del medio, puede desarrollarse el concepto de "materia", con las diferentes formas de presentarse y con propiedades definidas. Concretamente en los últimos cursos de esta etapa se estudian los minerales y rocas. Aunque se hace en cursos anteriores, cuando se llega al final de la etapa se estudian las propiedades macroscópicas color, brillo, olor, densidad, aspecto, dureza, etc. Con ello se puede introducir al alumno la idea de la clasificación de cada sustancia según el criterio establecido de ordenar según una propiedad o discriminar en función de esta. Trabajando en este sentido se están desarrollando multitud de procedimientos manipulativos y operatorios basados en técnicas cotidianas y adquirir un conocimiento empírico en tanto y cuanto son los alumnos los que realizar sus propias experiencias.

2.- Una vez superada la enseñanza primaria, alguno de los alumnos alrededor de los 12 años comienzan a desarrollar un pensamiento inicial de operaciones formales (Shayer y 
Adey, 1984). Curricularmente se introducen contenidos de relevancia en el campo de las ciencias y es el momento de profundizar en las propiedades características de la materia (dimensiones, masa, densidad) que ya no son intuitivas o perceptibles por los sentidos como eran las estudiadas anteriormente.

En este mismo periodo, refiriéndonos a primer curso de ESO, corresponde el estudio de los estados de agregación de la materia, distinción entre sustancias puras y mezclas, homogeneidad y heterogeneidad, así como una primera introducción a la existencia de átomos y moléculas. Dada la relevancia de estos contenidos y la corta edad de los alumnos cabe prever la posible formación de ideas alternativas que afloraran en cursos posteriores y por ello es necesario introducir los conceptos de sustancia y sus propiedades de forma clara y en contextos sencillos.

3.- Cuando los alumnos alcanzan el segundo curso de ESO, ya se les explica directamente cual es la naturaleza de la materia, se les habla de elementos y compuestos $\mathrm{y}$, se conduce a la unión entre átomos. A esta temprana edad los alumnos no pueden razonar formalmente acerca de estos aspectos en cambio se produce una adquisición memorística de los mismos. Por ello seria razonable sentar correctamente las bases para cursos posteriores en lo que respecta a la distinción entre elementos y compuestos, así como su naturaleza, dejando para el curso siguiente los aspectos relacionados con el enlace químico.

4.- En el siguiente nivel educativo, correspondiente al tercer curso de ESO los alumnos tienen entre 15 y 16 años y muchos de ellos comienzan a desarrollar su estadio de pensamiento formal. A esta edad ya podemos introducir los conceptos de la estructura de la materia desde una óptica superior y tratar con rigurosidad las propiedades de la materia, su naturaleza corpuscular y sus cambios tanto físicos como químicos. Con ello se debe abordar el estudio de la estructura de la materia basado en la hipótesis de Dalton y a partir de aquí la estructura atómica.

Llegados a este punto entra en juego nuestra propuesta didáctica para abordar el estudio del enlace químico en este curso, basado en la contextualización de las actividades, con la intención de que desde una perspectiva CTS los alumnos asimilen 
correctamente las ideas que definen a cada uno de los tipos de enlace. A partir de ello se continúa con el estudio de la estequiometría.

5.- Después de concluida la intervención, y ya en cuarto curso de ESO, se vuelve a revisar y en su caso ampliar el estudio del enlace químico y la estequiometría, pero en este nivel educativo, la materia "física y química" es optativa, tiene mayor presencia curricular la física y en definitiva no se avanza en el aspecto conceptual dentro de la estructura de la materia.

6.- Finalizada la enseñanza obligatoria, en el bachillerato se cuenta con dos cursos con muy diferente estructura. En primero y obligatorio para todos los alumnos de ciencias, se procede a un estudio formal de la naturaleza de la materia, su estructura, sus cambios y a la química del carbono. En el segundo y de carácter obligatorio en el bachillerato de ciencias de la naturaleza y la salud, pero optativo en el tecnológico, se abordan estos aspectos con mayor extensión y mayor rigurosidad matemática. En este nivel los alumnos entre 17 y 18 años ya se encuentran en un estadio de pensamiento formal avanzado, han desarrollado su personalidad y se encuentran en el paso previo a sus estudios universitarios.

Se encuentran en el momento de abordar es estudio de la estructura de la materia con rigor científico, utilizando los aspectos CTS en su totalidad, extraer las ideas correctas que nos proporcionan los modelos. Curricularmente y desde la perspectiva del enlace químico en dato de mayor interés es la introducción de las fuerzas intermoleculares. En este contexto proponemos el estudio del enlace a partir de una situación problemática contextualizada que permita a los alumnos desarrollar su capacidad de trabajo y mejorar la comprensión de este tema y todos los aspectos relacionados con él.

Por tanto la secuencia de contenidos será:

- Concepto de materia y sus propiedades características.

- Desarrollo de procedimientos manipulativos y operatorios.

- Propiedades generales de la materia. Sustancias puras, mezclas homogéneas y heterogéneas. Estructura de la materia. Modelos atómicos. 


\section{Intervención en tercer curso de ESO}

1.- Tipos de átomos en el sistema periódico y necesidad de razonar la posibilidad de unión o no entre ellos.

2.- El enlace covalente, iónico y metálico.

3.- Estados de agregación que conlleva cada uno de los tres.

4.- Posteriormente y relacionado con los estados de agregación cabrá analizar los posibles estados físicos y las variables que intervienen.

5.- Como conclusión, y aplicación directa de lo estudiado se pueden estudiar las propiedades macroscópicas de las sustancias.

- Cambio químico y estequiometría.

- Repaso del enlace químico y estequiometría.

\section{Intervención en segundo curso de bachillerato}

1.- Estructura de la materia.

2.- Enlace covalente molecular.

3.- Enlace covalente reticular.

4.- Enlace iónico.

5.- Fuerzas intermoleculares.

6.- Enlace metálico.

Los alumnos previo su primer contacto con el enlace químico, tienen conocimientos respecto a la estructura de la materia, en tanto y cuanto han estudiado los estados de agregación de la materia, explicados a través de la teoría cinética. Además también deben haber aprendido que en la naturaleza la materia, habitualmente se encuentra formando parte de mezclas que pueden ser homogéneas o heterogéneas. A partir de estos conocimientos que pueden interpretarse de un modo general dentro de la vida habitual de una persona y regido por un razonamiento basado en lo perceptivo, podremos buscar una relación con los modelos de enlace buscando sus posibles relaciones 


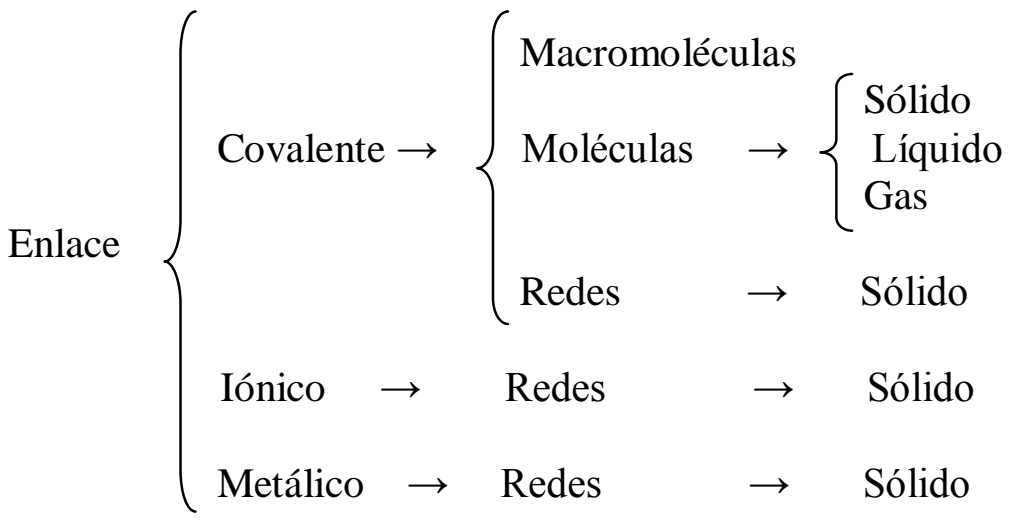

Figura 6.1.- Relación entre tipos de enlace y estados de agregación presentados en $3^{\circ}$ de ESO

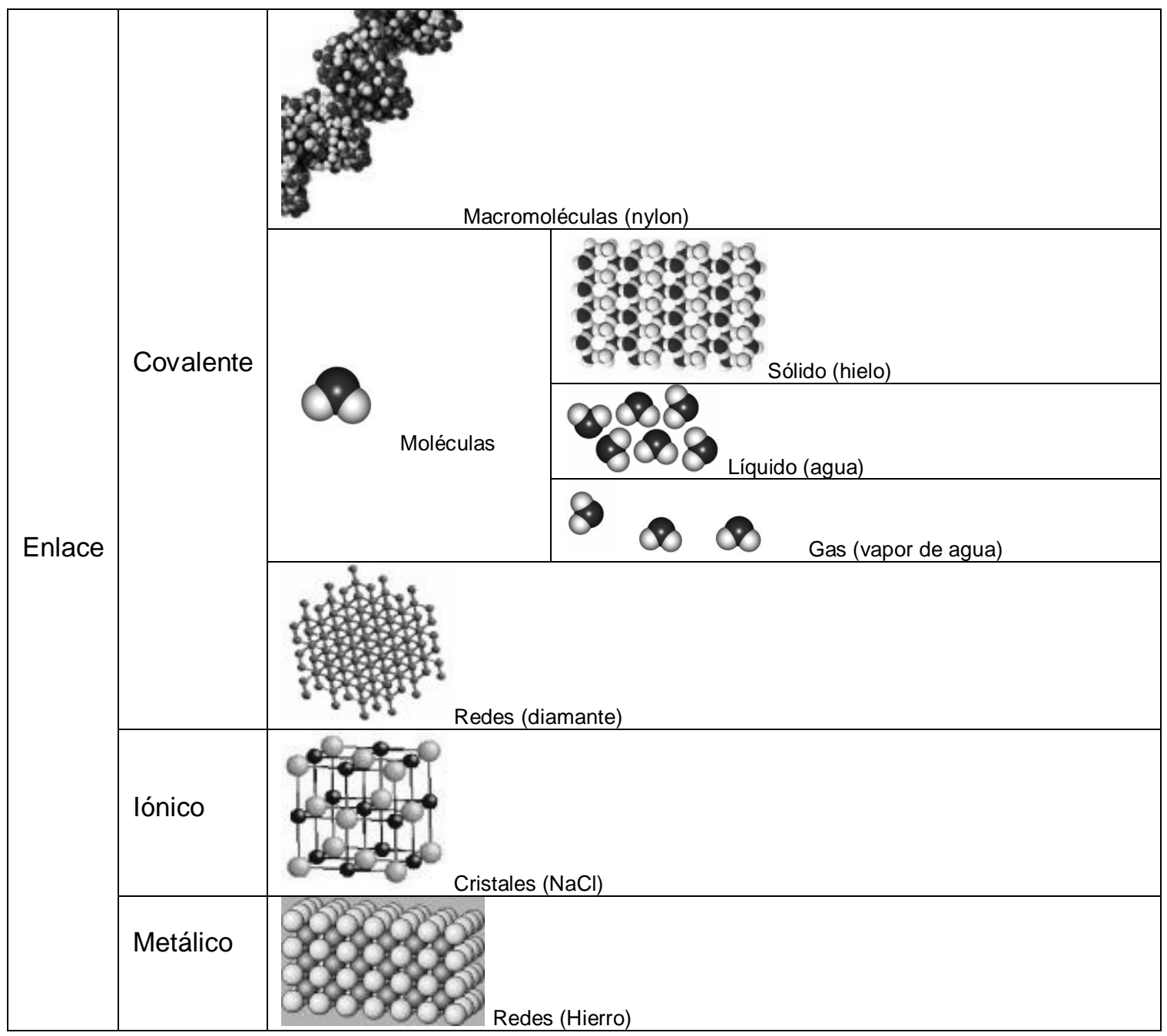

Figura 6.2.- Relación gráfica entre tipos de enlace y estados de agregación presentados en $3^{\circ}$ de ESO 
Estos estados de agregación son los habituales en la naturaleza, pese a ello las condiciones de presión y temperatura pueden hacer que varíen y que encontremos sustancias en cualquiera de los tres estados, respondiendo a unos u otros modelos de enlace. Es decir, sustancias iónicas o metálicas en estado sólido como consecuencia de una elevada temperatura o sustancias habitualmente gaseosas en forma de gas o sólidos debido a elevadas presiones. No obstante no será este el objetivo dentro de los cursos de ESO.

Por otro lado, se introduce la diferencia entre cambio físico y cambio químico, justificándolo con la permanencia de la naturaleza de la sustancia o no respectivamente. Por lo que implícitamente se habla de cambio químico, si hay una reordenación atómica y de cambio físico en el caso contrario.

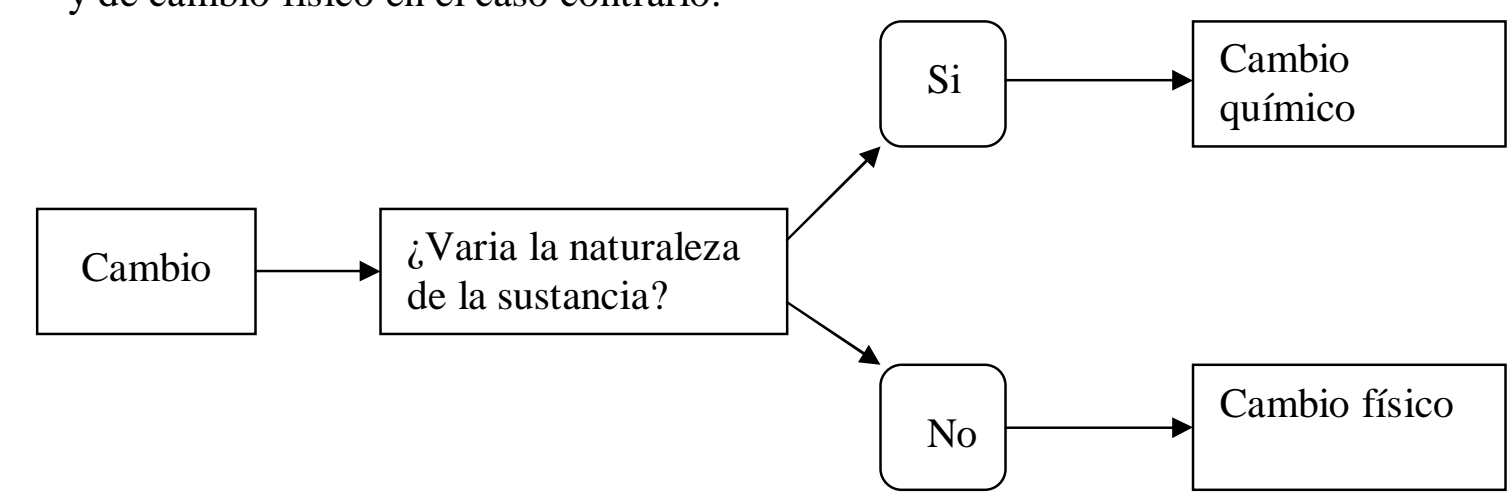

Figura 6.3.- Discriminación entre cambio físico o químico en $3^{\circ}$ de ESO

En cambio en el segundo curso de bachillerato, aunque ya se habrá introducido en primero, se va a plantear el cambio físico, a partir del razonamiento de existencia como la puesta en juego de las fuerzas intermoleculares.

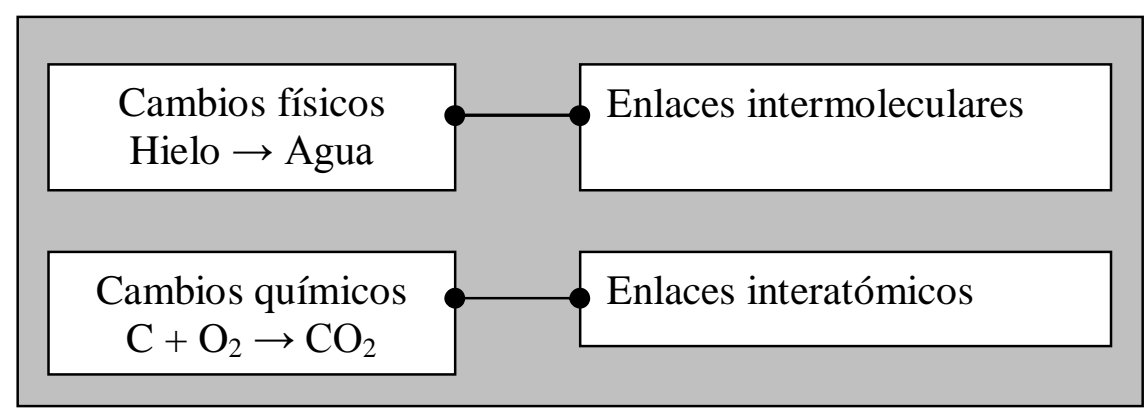

Figura 6.4.- Cambios y tipos de enlace relacionados. 
En este curso a partir de la profundización en la teoría del enlace y sus consecuencias se conducirá hasta el razonamiento de

- Fortaleza de los enlaces

- Enlace y fuerzas intermoleculares como responsable de la estructura macroscópica de la materia

Así como la relación de las propiedades macroscópicas que de ello se derivan

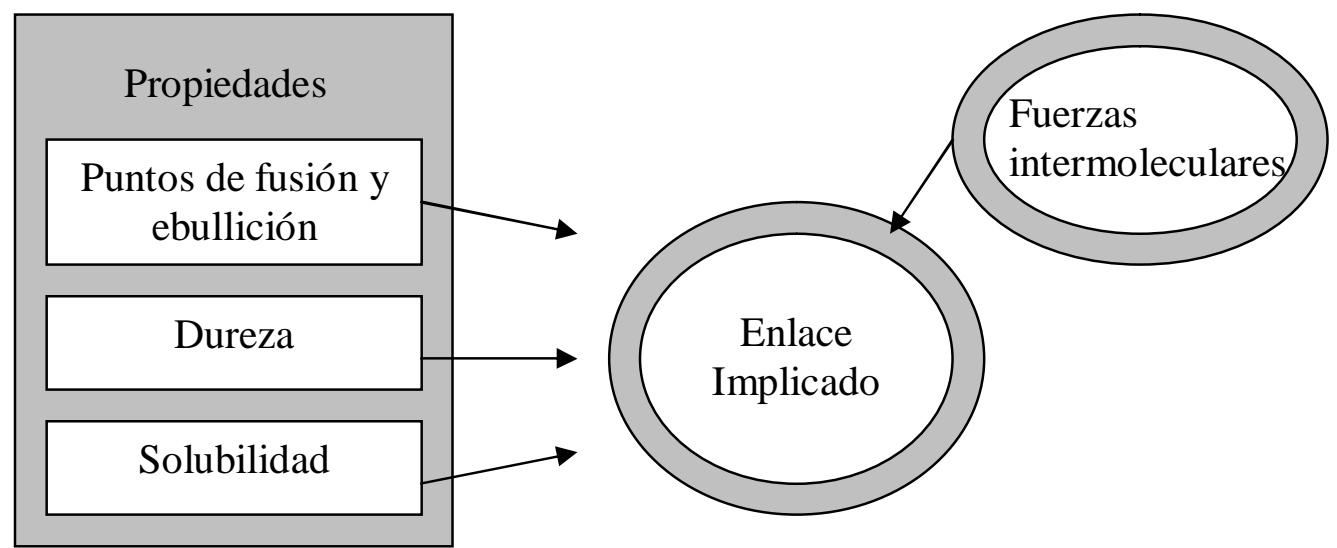

Figura 6.5.- Origen de las propiedades macroscópicas estudiadas en $3^{\circ}$ de ESO

Quedando una secuencia para justificar las propiedades macroscópicas de la forma:

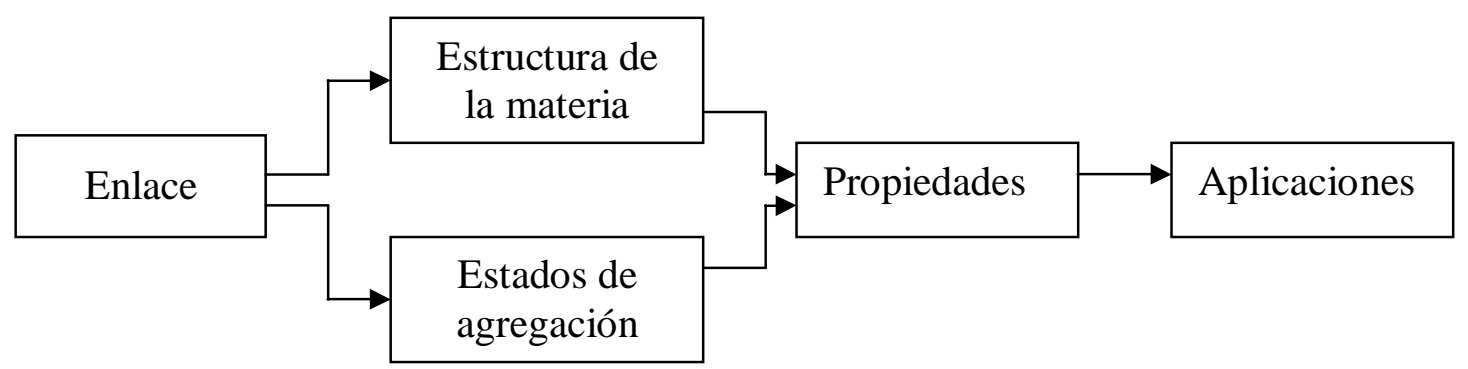

Figura 6.6.- Relación entre enlace y aplicaciones.

Así pues será necesario buscar actividades que permitan ligar todas estas ideas de forma secuenciada, lógica y clara para que el alumno a partir del nombre de una sustancia determinada, pueda conocer cuales van a ser los átomos con los que trabaja y su comportamiento, siempre basándose en una idea clara, no intuitiva de la interacción entre los átomos, sea cual sea su de agrupación. 
Para ello es necesario que las actividades tengan un carácter práctico e intente evadir en lo posible el carácter abstracto de la química en general y de la estructura de la materia y del átomo en particular

Aunque desde primer curso de secundaria ya se hace referencia al concepto de átomo o molécula, el enlace propiamente dicho no se estudia como tal hasta tercero y cuarto de ESO. Realmente se suele estudiar en uno de los dos cursos, generalmente en tercero, donde todavía es obligatoria la física y química, puesto que en cuarto curso se trata de una materia optativa encaminada a quienes desean cursar un bachillerato de ciencias de la salud y del medio ambiente o bien un bachillerato tecnológico.

Por otro lado durante el bachillerato, en primer curso se comparte la asignatura con física, por lo que se suelen estudiar temas de formulación, estequiometría o sistema periódico, dejando el tema del enlace para el segundo curso.

Por estos motivos presentaremos dos propuestas diferentes:

\subsubsection{Actividades diagnósticas en tercero de ESO}

Para tercer curso de ESO hemos preparado una propuesta cuyo objetivo es conocer las posibles estructuras de la materia atendiendo a los átomos que la forman y que pueden predecirse las propiedades de muchas sustancias, a partir de los enlaces implicados. La intervención en este nivel va a estar bastante influida por la acción del profesor, puesto que el concepto de enlace, así como su clasificación van a resultar más sencillos de transmitir, y además las pocas horas semanales de que se dispone van a dispersar demasiado los contenidos. Por otro lado el hecho de no haber estudiado nunca este tema, y el tener cierta flexibilidad en el tiempo permite recalcar aquellos aspectos que se consideren oportunos.

Inicialmente se proponen seis sesiones para realizar la intervención, aunque si fuese necesario, podría ampliarse este periodo, aunque se intenta que no se produzca para llevar a cabo la experiencia de la forma más homogénea posible. Dado que se dispone de dos horas de clase semanales, las actividades se llevaran a cabo durante tres 
semanas. Se entregará a los alumnos desde el primer momento un dossier que irán utilizando diariamente.

Para introducir el tema se presenta a los alumnos una cuestión, en la que un niño se pregunta cómo es posible que un mismo elemento se encuentre en varias sustancias, y que además éstas tengan aspectos tan diferentes. En concreto se habla de uno de los elementos más conocidos a nivel cotidiano, como es el hierro. A partir de este momento se les pide que investiguen en fuentes bibliográficas sobre este elemento y, con ello introducir el estudio de la tabla periódica. Con ello se profundizará en la clasificación entre metales y no metales, dando lugar a los modelos de enlace iónico, covalente o metálico, según se combinen, metales con no metales, no metales entre sí o metales entre sí respectivamente.

Llegados a este punto, si los alumnos conocen esta sencilla regla, y son capaces de diferenciar entre elementos metálicos y no metálicos, deberían poder clasificar cualquier compuesto según uno u otro de los tres modelos de enlace. En el dossier se facilita espacio para que los alumnos redacten y dibujen las explicaciones del profesor sobre los tipos de enlace, así como en el paso siguiente, esquematicen el tipo de agrupaciones que estos enlaces permiten.

Seguidamente se proponen actividades encaminadas a consolidar desarrollar estos conceptos, reflexionando acerca de las propiedades, calculando la masa molecular en el caso de compuestos covalentes, o bien realizando clasificaciones de los compuestos.

Para concluir se plantea una práctica de laboratorio, siempre dentro del mismo dossier, en la que se estudia la oxidación del hierro. Se ha tomado este elemento por la familiaridad tanto suya como la de su óxido por parte de profesores y alumnos como por la gente en general. Con ello se reflexiona sobre la diferencia de propiedades entre el hierro metálico y el óxido, siendo que se ha comprobado que ambos tienen a los mismos átomos y del mismo elemento. A continuación se comprueban las propiedades físicas de varios elementos y compuestos. 
Como conclusión se llega a una búsqueda de la respuesta al planteamiento inicial del tema.

Se pretende que los alumnos aprendan que:

- Hay tres posibilidades de agrupación de la materia, como átomos aislados, formando moléculas o formando cristales.

- Hay ciertos átomos en la naturaleza, cuya propia estructura es muy estable y por tanto se hallan de forma aislada.

- Hay átomos que alcanzan la estabilidad compartiendo electrones con uno o más átomos, formando una nueva entidad llamada molécula, y que está es la unidad de una nueva sustancia llamada compuesto en oposición a los átomos por sí solos en cuyo caso hablamos de elementos.

- Hay átomos que alcanzan su estabilidad uniéndose entre si de forma indefinida en las tres direcciones del espacio, alternando átomos de diferentes elementos, formando cristales.

- Según la teoría cinético-molecular la materia esta formada por partículas, que interaccionan entre sí, dando lugar a sólidos, líquidos o gases, pudiendo ser estas átomos o moléculas.

- Los átomos aislados se encuentran en la naturaleza en forma gaseosa.

- Las moléculas se encuentran formando parte, tanto de sólidos, como de líquidos, como de gases.

- Los cristales se encuentran en estado sólido.

- El enlace responsable de la formación de las moléculas es el enlace covalente, mientras que el responsable de la formación de cristales, puede ser covalente, metálico o iónico. 


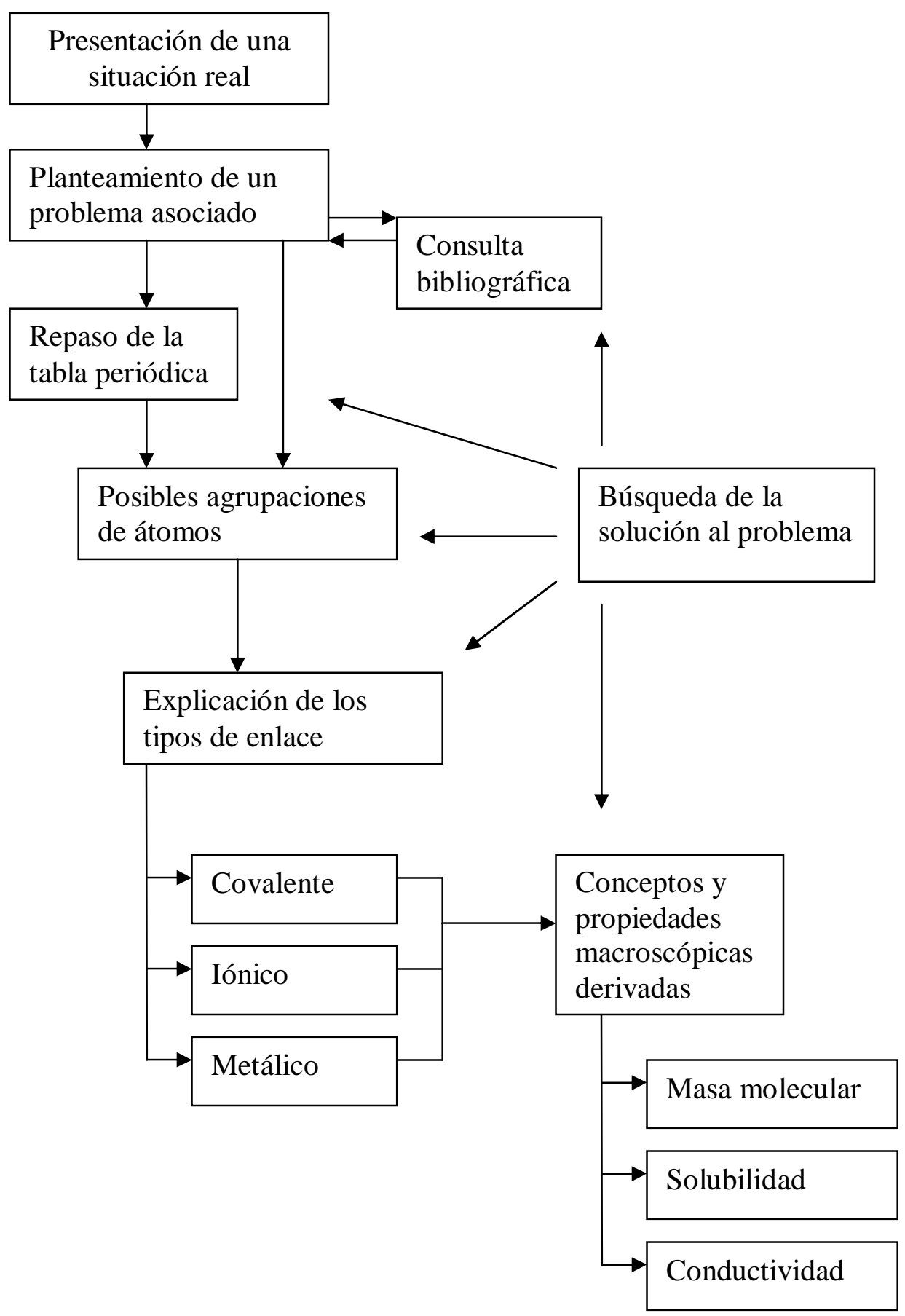

Figura 6.7. Esquema del modelo propuesto en ESO

\section{Organización general de las actividades en Tercero de ESO}

Antes de empezar debe quedar claro que la organización de las actividades, es una propuesta que cada profesor debe llevar a cabo según su criterio personal, pero tratando de ceñirse lo mejor posible al guión establecido para todos los grupos.

Cada alumno trabajará de forma individual sobre el dossier que se le entregará y que a continuación se reproduce, como muestra de las actividades de aprendizaje desarrolladas en el estudio de este tema: 


\section{El enlace Químico}

Nombre y apellidos

¿Cómo es el hierro?

Luis ha escuchado con frecuencia a su madre decir que debe comerse las lentejas por que tienen mucho hierro, lo mismo le ocurre cuando su hermana mayor le prepara espinacas o cuando en el colegio le sirven un trozo de hígado.

Por otro lado, Luis sabe que las puertas de su casa son de hierro, que el puente que hay cerca de su casa es de hierro, y que las barras de hierro que ha visto en la obra que están haciendo en su casa son de color marrón y muy fuertes.

Hasta hoy no se había parado a pensar en estas diferencias, pero es que hoy, viendo el telediario un señor ha dicho que en el río que hay en su pueblo han encontrado cantidades importantes de cobre y de hierro en el agua.

¿Cómo es posible? Se habla de un mismo elemento y su apariencia es completamente diferente. Las espinacas no son duras, las barras de hierro son de color gris y sin hacerles nada se oxidan y se ponen de color marrón, el hierro puede disolverse en el agua....

\section{DEFINICIÓN DEL PROBLEMA}

El problema esta relacionado con la idea de que un mismo elemento se puede encontrar solo o unido a otros elementos.

Como estudiantes de $3^{\text {er }}$ curso de la ESO debéis encontrar una explicación al hecho que se plantea Luis e intentar explicar cual es la diferencia entre unas sustancias y otras que contienen el mismo elemento. 


\section{Actividades}

A-1.- Busca información sobe el elemento "hierro". Intenta informarte de cuáles son sus propiedades, qué tipo de elemento es, cómo se encuentra en la naturaleza, o qué importancia tiene en nuestras vidas.

\section{A-2.- Completa la siguiente tabla periódica}

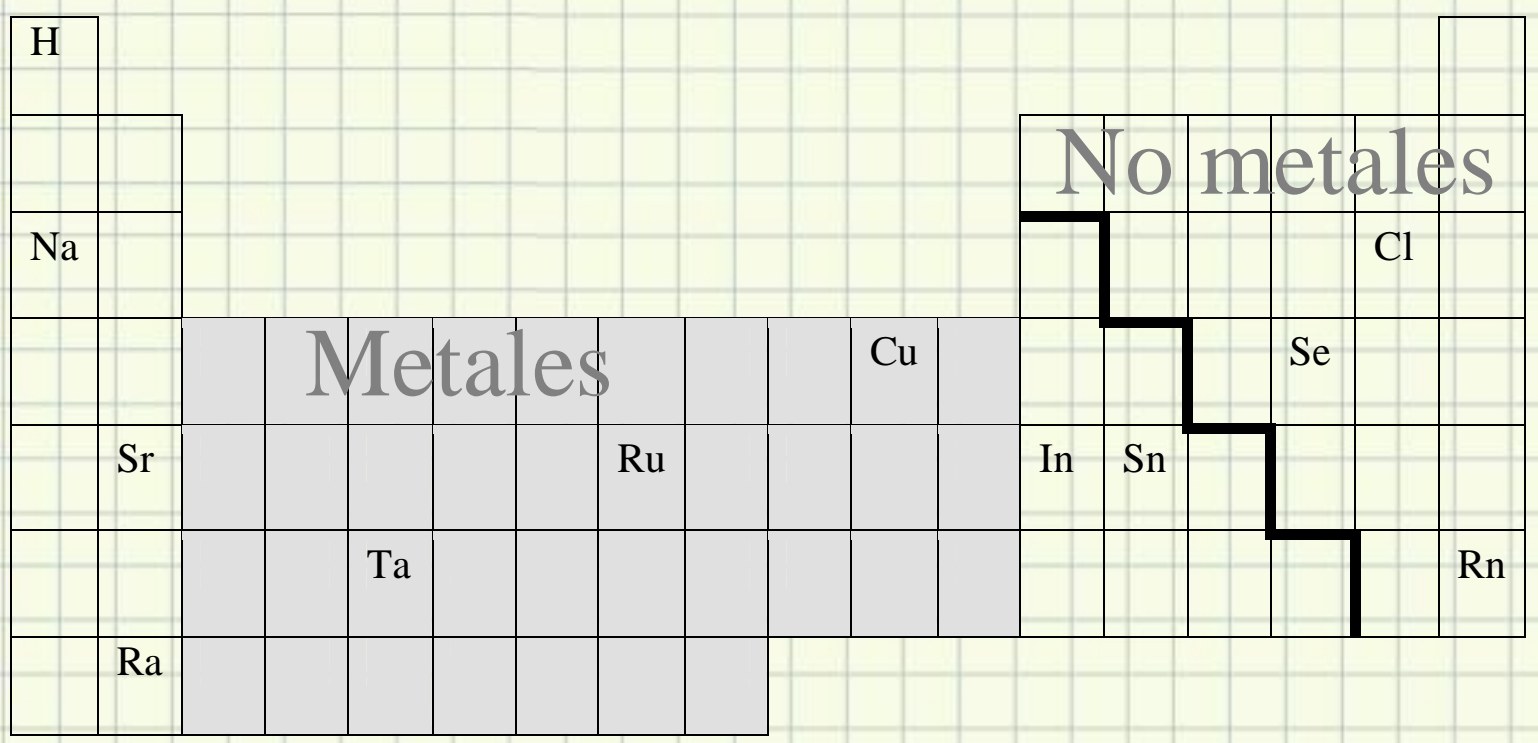


Tipo de enlace

A-3.- Que tipo de enlace puede tener lugar entre átomos de estos elementos:

\begin{tabular}{|l|l|}
\hline Elementos & Enlace \\
\hline Hierro y Oxígeno & \\
\hline Azufre y Oxígeno & \\
\hline Cloro y Fósforo & \\
\hline Cobre y Estaño & \\
\hline Oxígeno y Oxígeno & \\
\hline Helio y Helio & \\
\hline Carbono y Oxígeno & \\
\hline
\end{tabular}

\begin{tabular}{|l|l|}
\hline Elementos & Enlace \\
\hline Hierro y Cobre & \\
\hline Silicio y Oxígeno & \\
\hline Cloro y Potasio & \\
\hline Aluminio y Fluor & \\
\hline Calcio y Magnesio & \\
\hline Fluor y Francio & \\
\hline Hierro y Azufre & \\
\hline
\end{tabular}

A-4.- ¿Todas las sustancias que contienen hierro presentan el mismo tipo de enlace? ¿Por qué? 


\section{Agrupaciones de átomos}
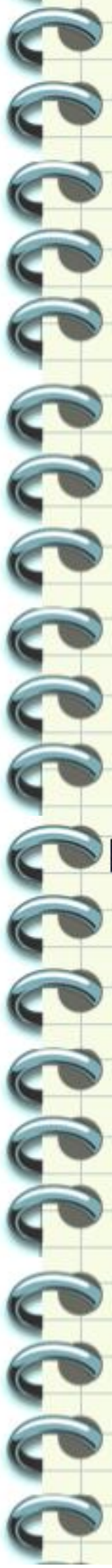
A-5.- Explica si son verdaderas o falsas las afirmaciones siguientes:

a) El enlace iónico da lugar a la formación de moléculas

b) En el enlace covalente se unen átomos metálicos y comparten electrones

c) El enlace covalente puede producir la formación de moléculas

A-6.- ¿Es correcto decir que la molécula de cloruro de sodio está formada por un átomo de sodio y otro de cloro? ¿Por qué?

A-7.- El cloruro de potasio es sólido a temperatura ambiente, funde a temperatura elevada, es moderadamente soluble en agua y su disolución conduce la corriente eléctrica. Indica que tipo de sustancia es.

\section{A-8.- Calcula la masa molecular de:}

\section{$\mathrm{AgBr}$}

$\mathrm{CO}_{2}$

$\mathrm{HNO}_{3}$

$\mathrm{Fe}_{2} \mathrm{O}_{3}$

$\mathrm{H}_{2} \mathrm{SO}_{4}$

Calcula la composición centesimal de las mismas sustancias. 
A-9.- Completa la tabla:

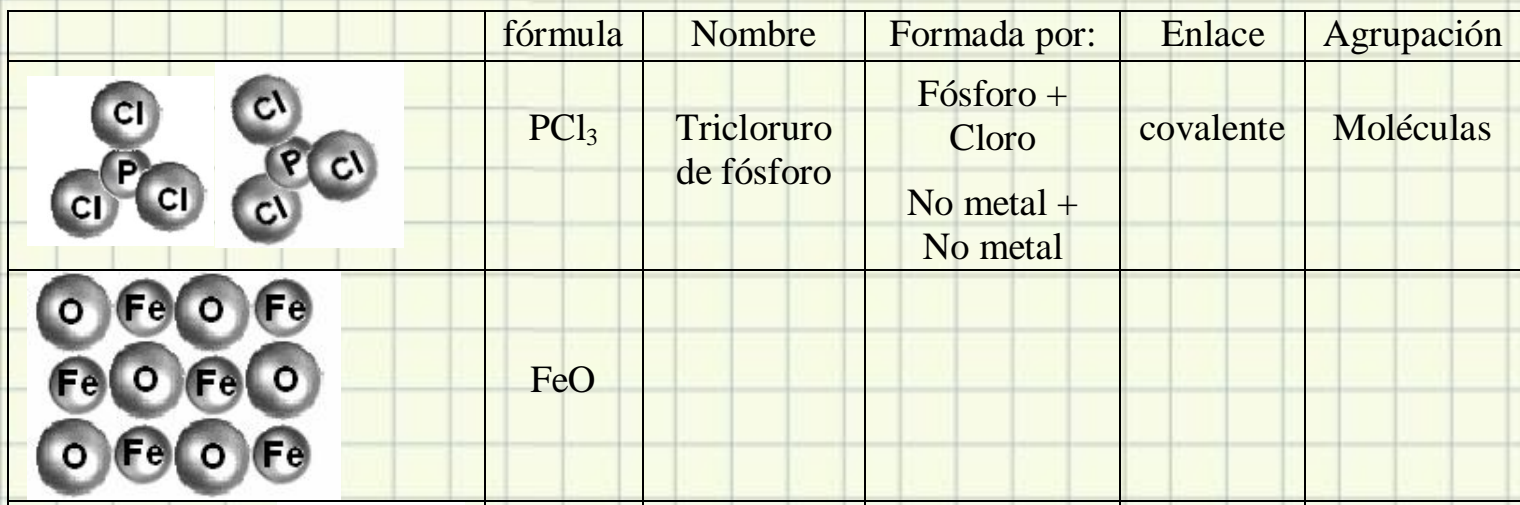

\section{0 (c) 0}

\section{Br $A g$ Br \\ Ag $\mathrm{Br} A g \mathrm{Br}$ \\ $\mathrm{Br} \mathrm{Ag} \mathrm{Br}$}

$x_{e} \mathrm{Xe}$

Xe $\mathrm{Xe}$

\section{$\mathrm{Cu} \mathrm{Cu} \mathrm{Cu} \mathrm{Cu}$ \\ Cu $\mathrm{Cu} \mathrm{Cu}$ \\ $\mathrm{Cu}$ \\ $\mathrm{Cu} \mathrm{Cu} \mathrm{Cu}$}

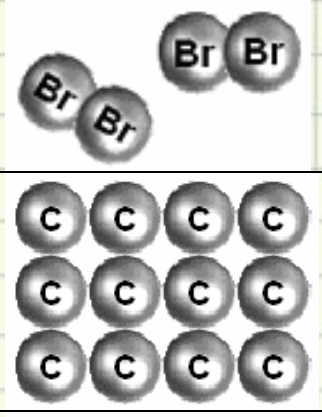

(He) $\mathrm{He}$

(He)

(He) $\mathrm{He}$

$\mathrm{Fe} F \mathrm{Fe} \mathrm{Fe}$

$\mathrm{Fe} \mathrm{Fe} \mathrm{Fe} \mathrm{Fe}$

$\mathrm{Fe} F \mathrm{Fe} F$ 
A-10.- Clasifica estas 10 sustancias según sean:

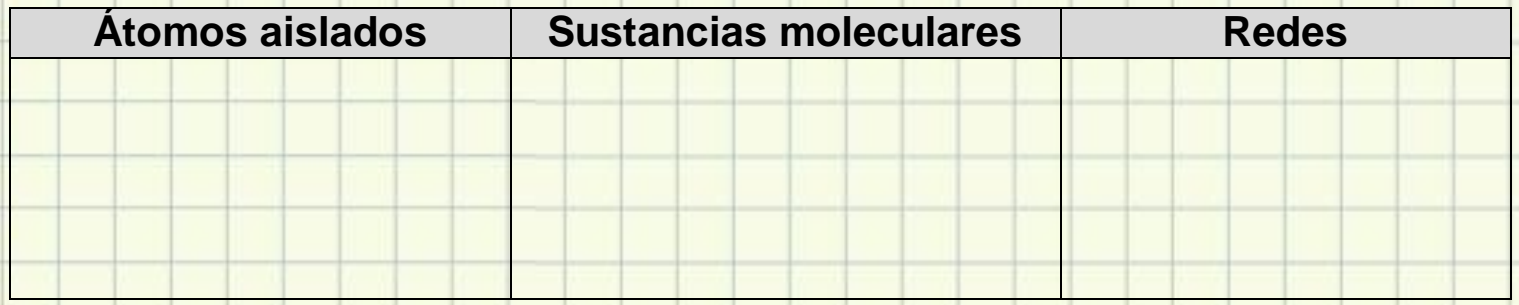

Y también según su enlace sea:

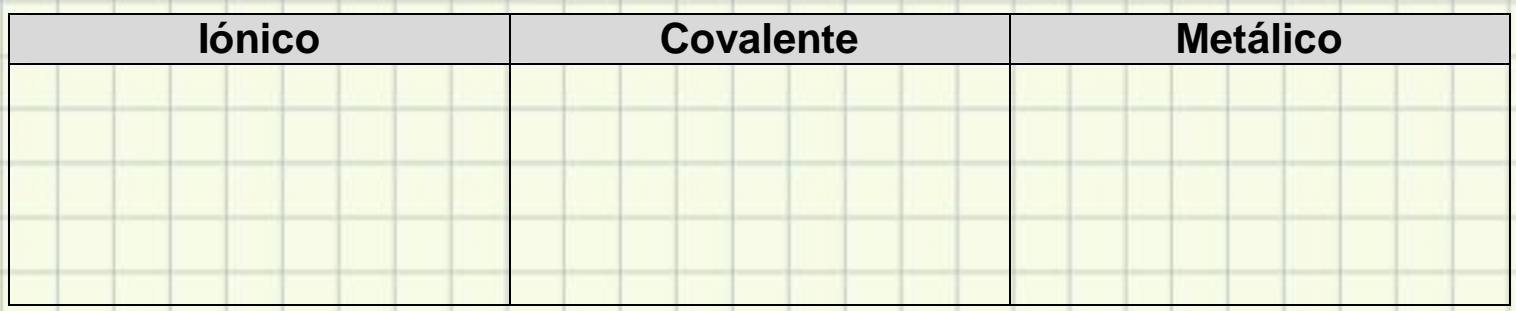

¿Qué relación hay entre las dos?

A-11.- Enumera las propiedades de las sustancias anteriores 
Experiencia

\section{$\mathbf{1}^{\mathrm{a}}$ Parte (Oxidación del hierro)}

El objetivo de esta parte de la experiencia es observar como el elemento hierro se puede encontrar en forma de red metálica mediante la unión de átomos de hierro únicamente o bien junto a otro elemento como ahora el oxígeno formando una sustancia de aspecto y propiedades muy diferentes.

\section{Material:}

Lana de hierro

Probeta

Cristalizador

\section{Montaje:}

Probeta

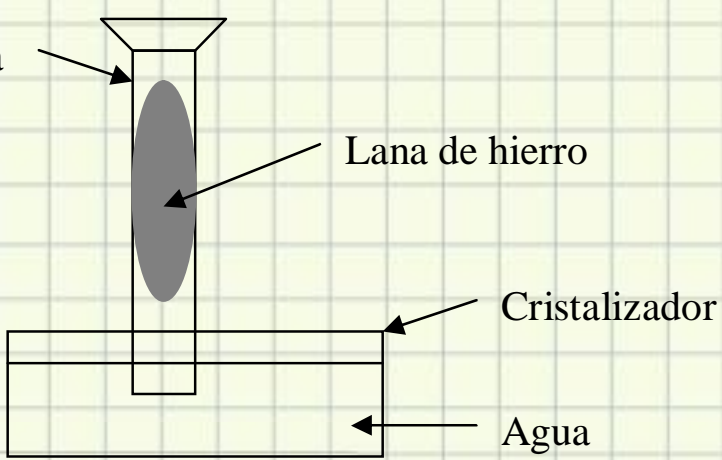

\section{Procedimiento:}

Esta parte es muy sencilla y se limita a introducir la lana de hierro dentro de la probeta, colocarla de forma invertida dentro del cristalizador y dejarlo unos días para ver lo que ocurre.

Será necesario tomar nota del nivel de agua dentro de la probeta, para ver si hay algún cambio.

Al cabo de unos días veremos lo que ha ocurrido:

E-1.- ¿Qué cambios aprecias?

E-2.- ¿A qué es deben?

E-3.- ¿Cómo explicas que se haya producido óxido férrico? 
$2^{\mathbf{a}}$ Parte (estudio de las propiedades de algunas sustancias)

El objetivo de esta parte es comprobar que cada tipo de sustancia tiene unas propiedades características y que con unos montajes relativamente sencillos seremos capaces de clasificar algunas sustancias según el tipo de enlace que las forman. Además también podremos comprobar que esta clasificación coincide con lo que nos han explicado en clase.

\section{Material:}

Circuito eléctrico

Vaso de precipitados

Varilla de vidrio

Imán

\section{Sustancias:}

Cobre

Cloruro sódico

Carbón en polvo

Hierro
Sulfato de cobre (II)

Dióxido de silicio (arena)

Óxido de hierro

\section{Montaje:}

1.- Conductividad eléctrica

Instalaremos un circuito eléctrico como el de la figura

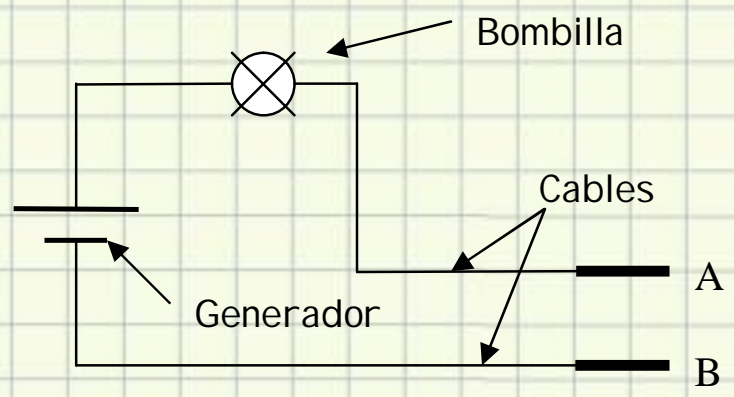

Al tocar con los dos extremos A y B una sustancia veremos, en el caso de ser conductora, que se cierra el circuito y que se enciende la bombilla. En el caso de no serlo no se encenderá

\section{2.- Solubilidad.}

Con la punta de la varilla de vidrio tomaremos un poco de la sustancia y la introduciremos dentro de un vaso de precipitados con un poco de agua, después lo agitaremos, para ver si se disuelve o no. En el caso de ser soluble ha de quedar el agua con color o transparente, pero no con partículas en suspensión.

\section{3.- Magnetismo}

Al acercar un imán a las substancias podremos comprobar si se atraen o no. 
E-4.- Rellena la siguiente tabla:

\begin{tabular}{|l|l|l|l|l|l|l|}
\hline & \multicolumn{3}{|c|}{ Aspecto físico } & & \\
\hline & Color & ¿Brilla? & ¿Es duro? & Conductor & Soluble & Magnético \\
\hline Cobre & & & & & & \\
\hline Cloruro de sodio & & & & & & \\
\hline Carbón en polvo & & & & & & \\
\hline Hierro & & & & & & \\
\hline Sulfato de cobre & & & & & & \\
\hline Óxido férrico & & & & & & \\
\hline Dióxido de silicio & & & & & & \\
\hline
\end{tabular}

Clasifícalos según el tipo de enlace que presentan

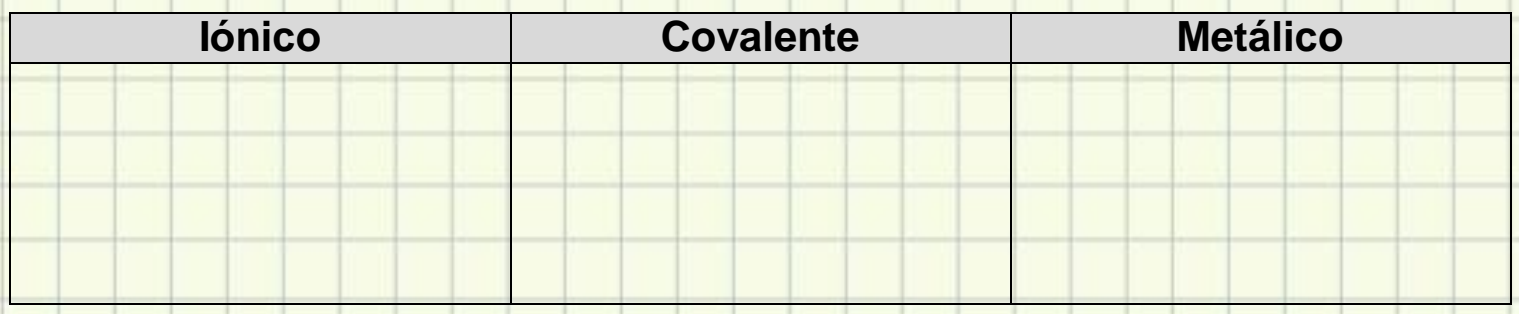

E-5.- ¿Qué diferencias encuentras entre el hierro y el óxido de hierro?

¿Cuándo hablamos del hierro se trata del mismo tipo de átomos en los dos casos? 
Vuelve a leer el problema que se planteaba Luis en la primera página, y con tus palabras trata de darle una explicación.

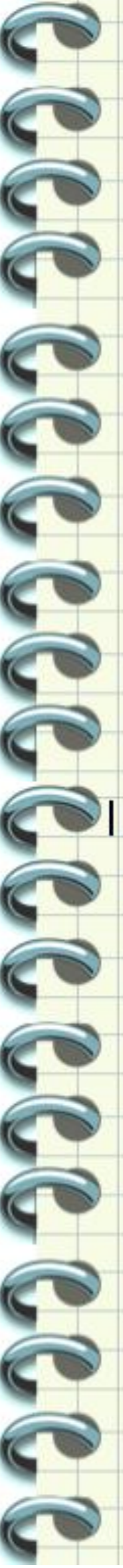


De modo orientativo se han distribuido las tareas a lo largo de seis sesiones. Todas ellas se realizan siguiendo el dossier entregado a cada alumno inicialmente (anexo XI). En el dossier hay espacios en blanco destinados a que los alumnos cumplimenten con la explicación del profesor y ejercicios que la reforzaran. Cada día se mandarán actividades para realizar en casa, que también se realizarán en el mismo ejemplar (señaladas con el icono

I) Sesión inicial

a) Cuestionario: "Cuestionario de detección de conocimientos previos en $3^{\circ}$ de ESO acerca de la estructura de la materia" (Pre-ESO, anexo III)

Los alumnos realizaran esta prueba inicial, sin conocer todavía el por qué. El tiempo estimado para su realización será de unos 30 minutos, con lo que durante la misma sesión se puede continuar trabajando.

b) Presentación del problema

Tras entregar el dossier correspondiente (anexo XI), se leerá el texto y a continuación se plantea la situación problemática y se establece el objetivo de estudiar la situación.

7 Como tarea para casa se puede proponer un primer intento de conocer las sustancias de las que se les ha hablado. Para ello sería conveniente pedir a los alumnos que busquen información sobre el hierro, en concreto, ¿qué tipo de elemento es? ¿Qué propiedades tiene? y compuestos en los que aparezca. (A-1). 
En la siguiente sesión los alumnos deberán traer la información que hayan encontrado acerca del elemento "hierro". Con ello se procederá a las siguientes tareas:

a) Discusión sobre el elemento "hierro", intentando hacer referencia a la diferencia entre metales y no metales, y a la posibilidad de que se encuentre en diferentes compuestos.

b) Presentación de una tabla periódica, sus grupos y periodos, distinguiendo a los metales de los no metales (A-2)

c) Explicación acerca de:

- Necesidad del enlace químico. Estructura electrónica de los átomos.

- Tipos de enlace

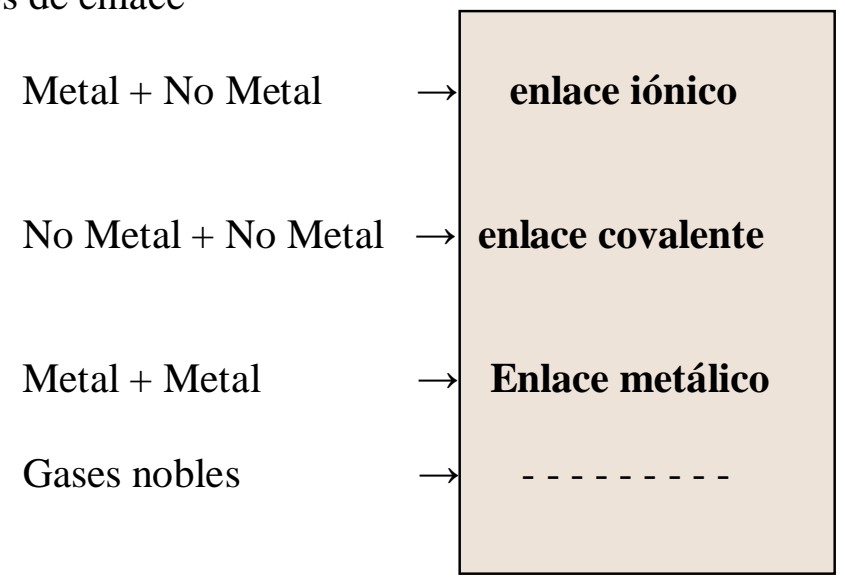

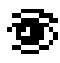

Como tarea individual se les puede pedir a los alumnos que relacionen el tipo de enlace con los elementos que intervienen. (A-3)

En ella simplemente se debe observar de que elementos se habla y clasificarlos en cada uno de los tipos anteriores. 
III) Continuación de las actividades

En la siguiente sesión se puede corregir el ejercicio para que, atendiendo a la clasificación anterior se introduzcan los tipos de estructuras que se pueden originar en cada caso, por ello se propone:

a) Corrección y discusión de la actividad anterior

b) Explicación de las estructuras que se forman, según el esquema:

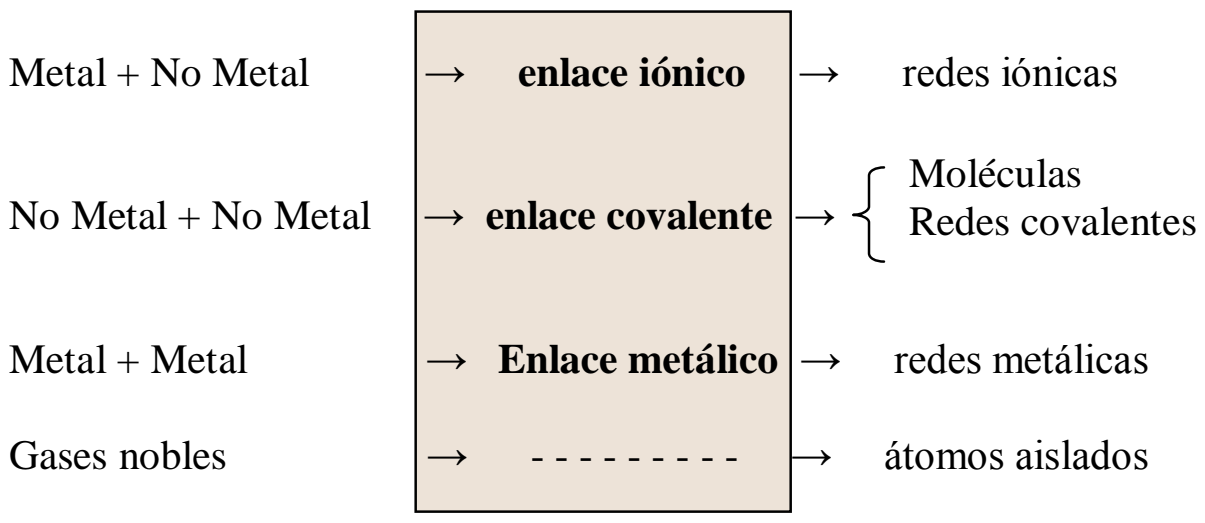

Los alumnos deberán tomar apuntes de lo explicado en el lugar del dossier destinado a ello.

c) Propiedades de los diferentes tipos de sustancias

政 A-4, A-5, A-6 y A-7

IV) Continuación de las actividades

En esta sesión se corregirán las actividades anteriores y posteriormente se dará paso al estudio de aspectos que sin ser características de los tipos de enlace, se encuentran curricularmente asociados a este tema, como es el cálculo de la masa molecular y composición centesimal:

a) Corrección de actividades

b) Explicación de los conceptos de masa molecular y composición centesimal, (A-8)

c) Preparación de la experiencia (primera parte)

Actividades A-9, A-10 y A-11 
V) continuación de las actividades

Inicialmente en esta sesión, de nuevo se corregirán las actividades propuestas, y se realizará la práctica propuesta.

a) Corrección de actividades, dentro de las cuales se observará lo ocurrido con la preparación de la experiencia comenzada en la sesión anterior, donde ya se debe haber producido la oxidación del hierro y cabrá reflexionar sobre la asociación del oxígeno atmosférico con el hierro, y la consiguiente disminución del volumen de aire en una proporción del $21 \%$, tal como es su porcentaje en el elemento que ha reaccionado.

b) Realización de la experiencia

La experiencia está detallada en el dossier y consiste en clasificar unas cuantas sustancias según sean iónicas, covalentes o metálicas atendiendo a sus propiedades físicas de conductividad, solubilidad o aspecto. Con ello se concluye el tema y se responde a unas preguntas como planteadas.

Fealizar las actividades propuestas en la experiencia

VI) Actividades finales

Como sesión final, se corregirán las tareas de casa y posteriormente en un tiempo de unos 40 minutos se contestará el cuestionario final.

a) Corrección de las actividades de la experiencia

b) Realización del cuestionario: "Cuestionario para establecer los conocimientos acerca del enlace químico en $3^{\circ}$ de ESO" (Post-ESO, anexo V) 


\subsubsection{Actividades diagnósticas en segundo de bachillerato}

Proponemos otra intervención para segundo curso de bachillerato, donde se dará mayor peso a la parte teórica, de una forma más tradicional, pero tratando de vincular los conceptos estudiados con las propiedades físicas que de cada enlace se derivan.

No podemos olvidar que nuestra intervención va a ser muy limitada en este curso puesto que está plenamente orientado hacia un examen de selectividad y el profesorado implicado no puede dedicar más tiempo del estrictamente necesario, ni el alumno puede afrontar un tema, aunque de forma puntual, de forma diferente y no centrándose en la consecución de su objetivo principal, que es obtener la mayor nota posible.

En concreto plantearemos un problema relacionado con las técnicas de separación que son estudiadas en cursos anteriores. La clave reside en la estructura de las sustancias implicadas. A partir del enlace que intervenga se tratará de concluir si las sustancias son solubles, conductoras o si son solubles entre sí.

Con la intención de homogeneizar el proceso en todos los grupos, se organiza el tema en 10 sesiones, aunque es de esperar que en algunas, con mayor necesidad de explicaciones teóricas sea necesario utilizar alguna más. A lo largo de estas sesiones se han secuenciado los contenidos de forma que se van a ir estudiando de forma guiada a través de un hilo conductor, basado en las técnicas de separación. De este modo lo que se pretende es priorizar las propiedades que derivan de cada tipo de enlace, así como ofrecer un porqué del estudio de dicha unión, pretendiendo de esta forma evitar el componente abstracto que conlleva la enseñanza tradicional y aumentar de este modo el interés de los alumnos, así como su posterior utilización en los temas posteriores.

El problema que se plantea a los alumnos consiste en evaluar el proceso de separación de las sustancias contenidas en una muestra de aguas residuales, y estudiar la viabilidad del proceso a escala industrial. Inicialmente se les ofrece un dossier donde se detalla el problema a estudiar y las características técnicas necesarias. A partir de esta información, y con la ayuda del profesor, deben establecer los procesos necesarios, realizar la separación a escala de laboratorio y calcular el coste del proceso, para 
posteriormente extrapolarlo a escala teóricamente real. Por supuesto el coste es absolutamente desorbitado y se pretende mostrar su inviabilidad.

Paralelamente a este calculo se irá desarrollando el tema, tratando de que esta propuesta no reste demasiado tiempo de clase pero que permita una contextualización de los contenidos y oferte al alumno, el porqué de estudiar cada tipo de enlace, así como tener de antemano una visión real y de primera mano de las propiedades de las sustancias.

El tema se dividirá en cinco partes que concordarán con los métodos de decantación, filtración, destilación, cristalización e imantación, dando paso cada uno de ellos al estudio del enlace covalente molecular, estructuras covalentes cristalinas, enlaces intermoleculares, enlace iónico y enlace metálico respectivamente, de la siguiente forma:

i) En primer lugar utilizaremos la técnica de la decantación para introducir la ideas de que sustancias polares y sustancias apolares son inmiscibles. Con ello argumentaremos la necesidad de conocer qué sustancias son polares y cuales no, y con ello introduciremos el estudio del enlace covalente con todo lo que curricularmente conlleva. Situados en este marco se introducirán la teoría y estructuras de Lewis para el enlace covalente, tipos de enlace covalente, resonancia, teoría la repulsión de pares de electrones solitarios, hibridación y por supuesto como conclusión, la geometría y polaridad de las moléculas.

En la propuesta se han utilizado sustancias de diferente densidad para facilitar el proceso, de un lado tenemos una fase más densa formada por tetracloruro de carbono, cuarzo y hierro, y por otro lado la fase más ligera formada por agua, alcohol y sulfato de cobre.

Para este apartado se han dedicado dos sesiones de trabajo.

ii) A continuación utilizaremos la filtración para separar, dentro de la fase pesada del apartado anterior, el tetracloruro de carbono del cuarzo y el hierro, de esta forma vamos a tener en el papel de filtro dos sustancias que no son solubles, con lo que 
introduciremos el concepto de redes, y centrándonos en el cuarzo nos dará pie a estudiar el enlace covalente en el interior de estructuras cristalinas.

Para esto dedicaremos una sesión de trabajo.

iii) Seguidamente, y utilizando la técnica de la destilación, se procederá a destilar la mezcla compuesta por alcohol, sulfato de cobre y agua. Con ello podremos incidir en el por qué de los diferentes puntos de ebullición, del agua y por supuesto de la disolución de sulfato de cobre. Centrándonos en el caso del agua y el alcohol, dada su similitud física, podremos estudiar las interacciones entre moléculas

iv) Llegados a este punto nos quedará del apartado anterior una disolución de agua y sulfato de cobre que se separará por cristalización, obteniendo cristales y originando el estudio del enlace iónico, tras haber observado su elevado punto de fusión y su solubilidad en agua.

v) Finalmente y recuperando la mezcla alojada en el papel tras la filtración procederemos a separar por imantación el hierro del cuarzo. Y aún sabiendo de antemano que las propiedades magnéticas no son comunes a todos, introduciremos el estudio del enlace metálico.

El tratamiento teórico de cada uno de los apartados se desarrollará por parte del profesor siguiendo el libre de texto, secuenciando todos los contenidos tal y como se expresa en el currículo oficial de la materia, e intercalando los ejercicios sobre papel, que se han facilitado en el dossier del alumno.

La diferencia entre los grupos experimentales y de control, radica exclusivamente en la introducción del tema, en el seguimiento del hilo conductor que ofrecen las técnicas de separación y las propiedades de las sustancias, así como en la conclusión final que ofrece el cálculo numérico del coste del proceso.

En el apartado 7.3.4.3 se describen los aspectos más relevantes que han surgido durante el desarrollo de las actividades. 

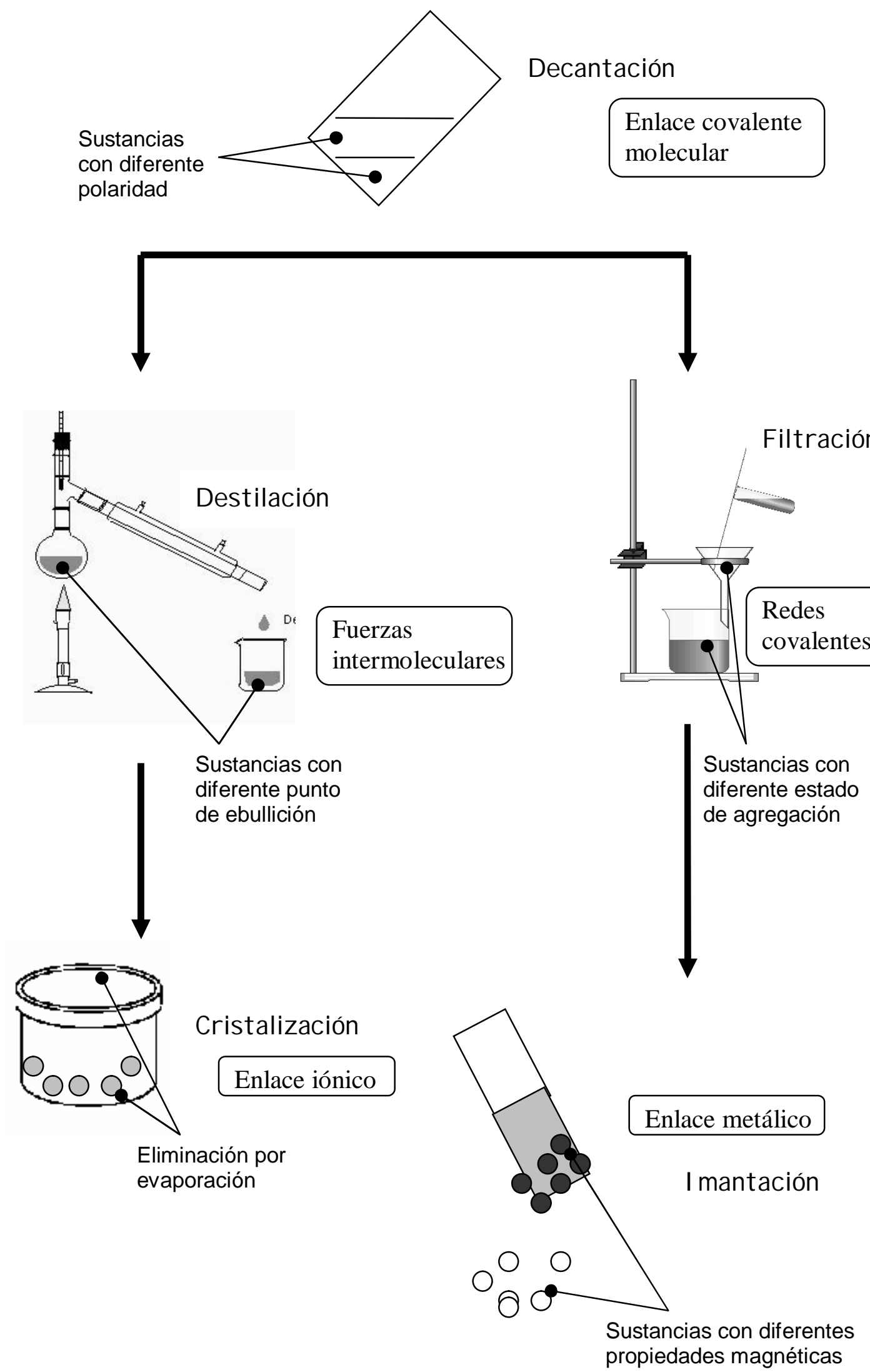

Figura 6.8. Esquema del modelo propuesto en bachillerato 
TRATAMIENTO DE AGUAS RESIDUALES

Recientemente hemos encontrado esta noticia en un conocido periódico de tirada comarcal:

\section{La estación depuradora de aguas residuales debe tratar demasiadas sustancias industriales}

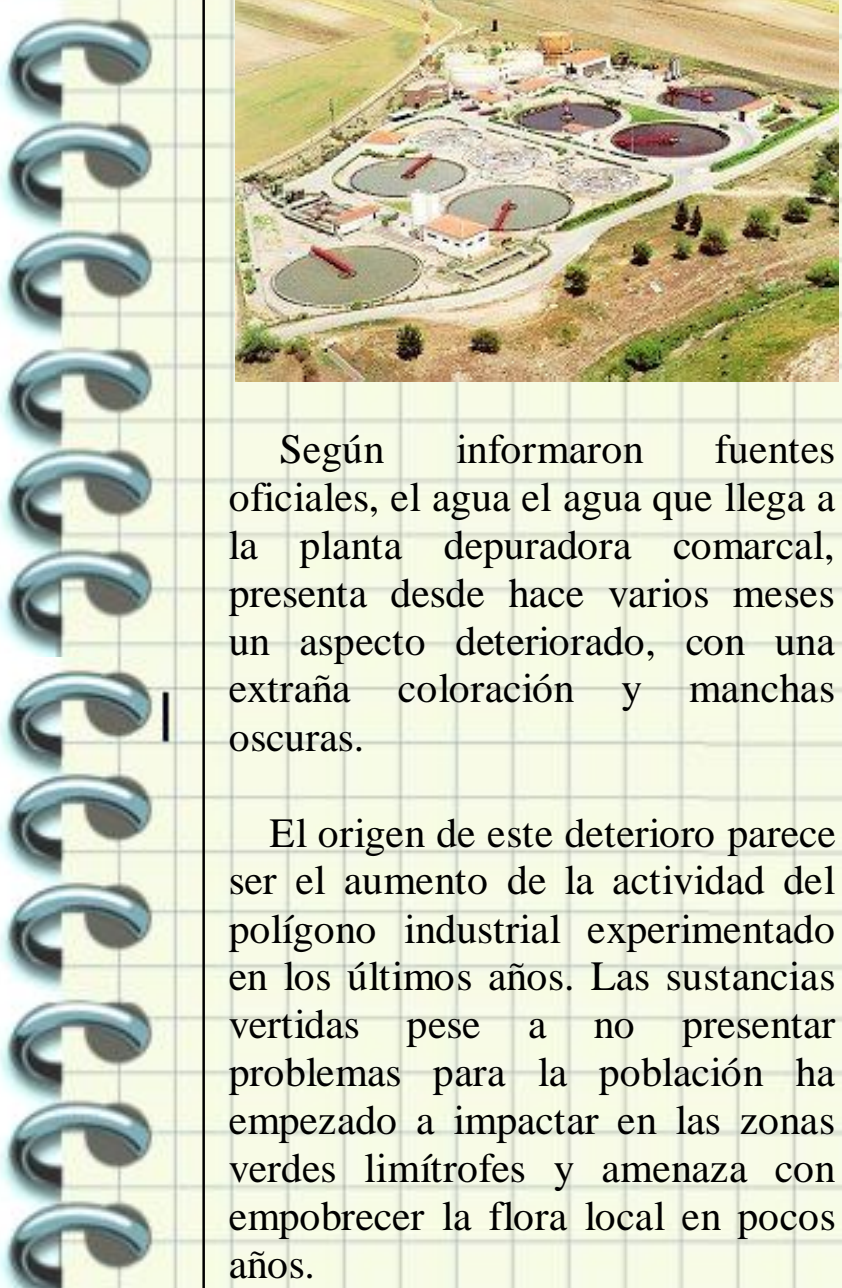

Este aumento tanto de sustancias peligrosas, como de caudal de agua a tratar de forma permanente ha provocado que las instalaciones no puedan extraer todas las sustancias y parte de ellas sean vertidas, disminuyendo la efectividad del proceso.

Actualmente se baraja la posibilidad de crear una nueva estación que trabaje independientemente para el sector industrial, con el objetivo de facilitar los trabajos de extracción de las sustancias. Los costes de construcción y de mantenimiento serian financiados conjuntamente por las empresas usuarias del servició y los ayuntamientos implicados.

La cuestión que se debate en estos momentos es, si será conveniente la creación de esta nueva planta, qué debería hacer y estimar su rentabilidad económica y medioambiental.

Paco López

Como estudiantes de química se nos propone que tratemos de plantear una forma de tratar estos residuos en lugar de la creación de una nueva planta y evaluar cual sería el coste del proceso de recuperación de las sustancias que contiene el agua vertida y que posteriormente llega a la planta y en consecuencia, la conveniencia de una $u$ otra alternativa. 


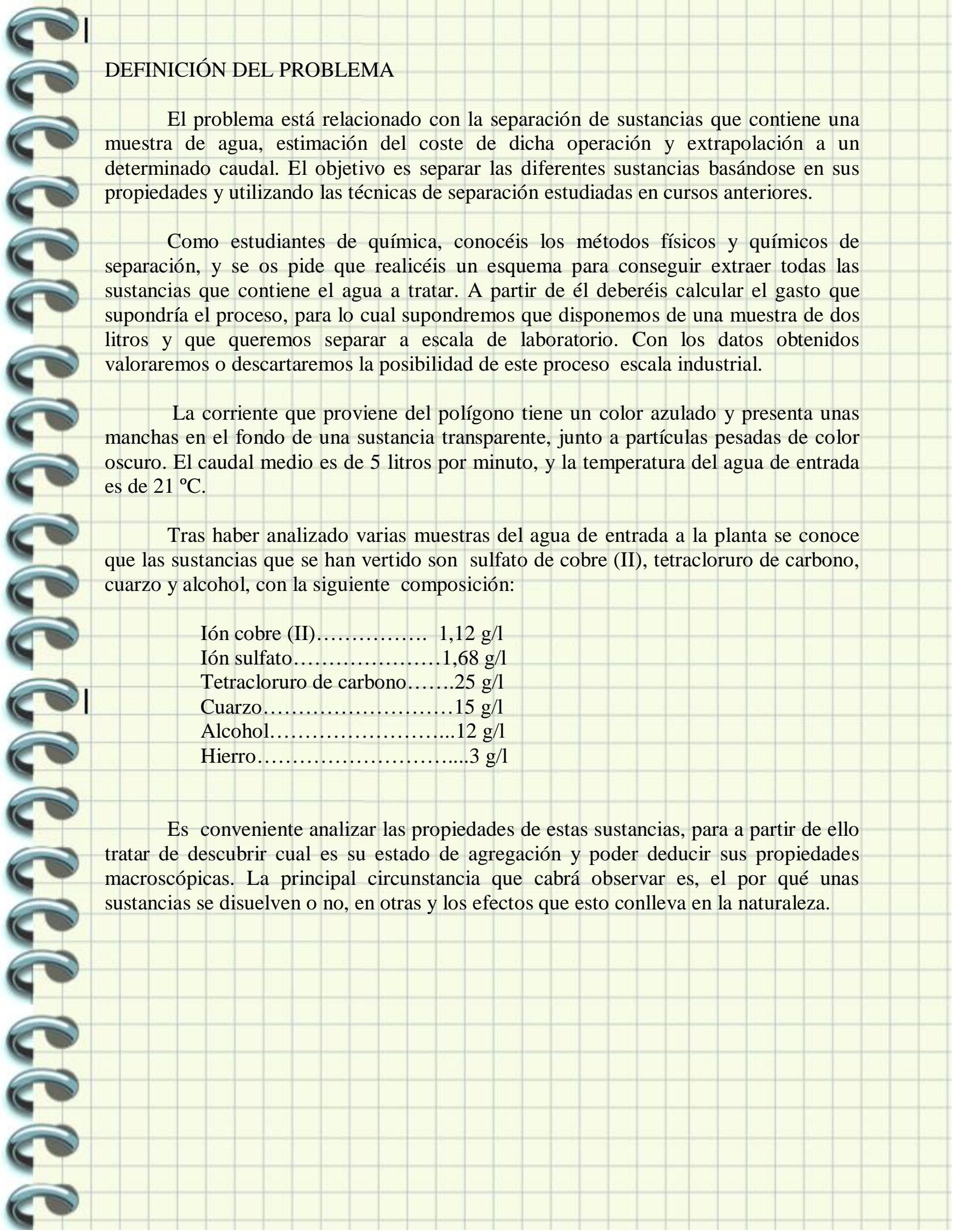




\section{DATOS TÉCNICOS}

Agua

Calor específico del agua $=4,18 \mathrm{~J} \cdot \mathrm{g}^{-1} \cdot{ }^{\circ} \mathrm{C}^{-1}$

Calor de vaporización del agua $=2253 \mathrm{~J} \cdot \mathrm{g}^{-1}$

Densidad del agua $=1 \mathrm{~g} / \mathrm{ml}$

\section{Metanol}

Temperatura de ebullición del metanol $=64,65^{\circ} \mathrm{C}$

Calor de vaporización del alcohol $=39,2 \mathrm{~kJ} / \mathrm{mol}$

Densidad del alcohol $=0,79 \mathrm{~g} / \mathrm{ml}$

\section{Tetracloruro de carbono}

Densidad $=1,59 \mathrm{~g} / \mathrm{ml}$

Temperatura de ebullición $=76,5^{\circ} \mathrm{C}$

\section{Cuarzo}

Temperatura de fusión $>1000^{\circ} \mathrm{C}$

Densidad $=2.65 \mathrm{~g} / \mathrm{ml}$

\section{Sulfato de cobre (II)}

Temperatura de fusión $=650^{\circ} \mathrm{C}$

Solubilidad $\left(\mathrm{a} 21^{\circ} \mathrm{C}\right)=200 \mathrm{~g} / \mathrm{l}$ de agua

\section{Hierro}

Temperatura de fusión $=1535^{\circ} \mathrm{C}$

Densidad $=7,87 \mathrm{~g} / \mathrm{ml}$

Tiene propiedades magnéticas

\section{DATOS ECONÓMICOS}

Precio que puede obtenerse por las sustancias recuperadas:

Sulfato de cobre... $.2,56 € / \mathrm{kg}$

Tetracloruro de carbono $.4,00 € / \mathrm{kg}$

Cuarzo $.0,05 € / \mathrm{kg}$

Metanol $0,5 € / \mathrm{kg}$

Hierro $0,2 € / \mathrm{kg}$

Coste energético

$1 \mathrm{~kW}-\mathrm{h}=3600000 \mathrm{~J}$

Precio de la energía 8,6726 cent.€/kWh

Costes por mano de obra

Se establece un coste de $5 €$ por litro para cada uno de los procesos de decantación, filtración e imantación y un coste de $12 €$ por litro para los procesos de destilación y cristalización 


\section{INTRODUCCIÓN}

En la naturaleza podemos encontrar:

Diferentes estados de agregación de la materia, con diferentes tipos de enlace

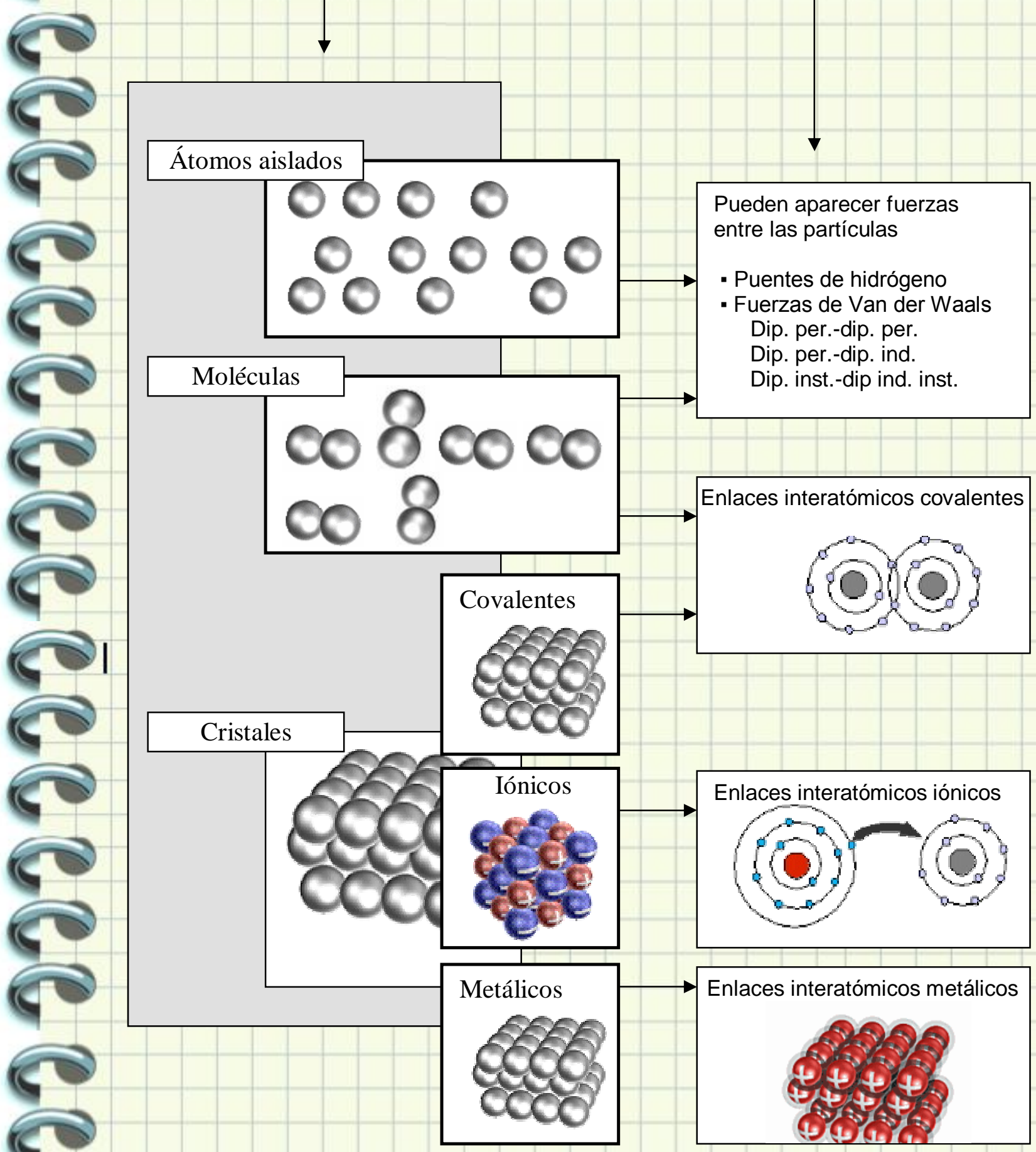




\section{Cuestiones}

C-1.- ¿Qué propiedades tienen estas sustancias?

C-2.- Agrupa las siguientes sustancias según las consideres que son semejantes a unas u otras de las sustancias del problema (ayúdate de la tabla periódica)

$\mathrm{NH}_{3}, \mathrm{CCl}_{4}, \mathrm{NaBr}, \mathrm{PCl}_{5}, \mathrm{NO}, \mathrm{CO}_{2}, \mathrm{SO}_{2}, \mathrm{KBr}, \mathrm{F}_{2}, \mathrm{Mg}, \mathrm{BH}_{3}, \mathrm{He}, \mathrm{CH}_{4}, \mathrm{SiO}_{2}, \mathrm{Ag}, \mathrm{PCl}_{3}$, $\mathrm{NaCl}, \mathrm{K}_{2} \mathrm{Cr}_{2} \mathrm{O}_{7}, \mathrm{Au}, \mathrm{C}, \mathrm{KBr}, \mathrm{MgS}, \mathrm{CH}_{3} \mathrm{COH}, \mathrm{KNO}_{3}$

Indica en cada grupo si las sustancias se encuentran como:

Átomos aislados

Moléculas

Cristales iónicos, covalentes o metálicos

\section{A.- Flotación (enlace covalente)}

C-3.- Escribe las estructuras de Lewis de las moléculas de cloro, oxígeno y metano.

C-4.- Indica la estructura de Lewis y la forma de las moléculas de trifluoruro de boro, agua, metano, eteno y la del ión sulfito. Indica en cada caso, si el enlace está polarizado.

\section{C-5.- Ídem para $\mathrm{C}_{2} \mathrm{H}_{6}, \mathrm{HCN}, \mathrm{CH}_{2} \mathrm{O}$ y $\mathrm{NH}_{4}^{+}$.}

C-6.- Experimentalmente se ha determinado en la molécula de metano $\left(\mathrm{CH}_{4}\right)$ que los átomos de hidrógeno están colocados en los vértices de un tetraedro regular cuyo centro es el átomo de carbono, es decir, las longitudes de los cuatro enlaces C-H son idénticas, así como los ángulos de enlace $\left(109,5^{\circ}\right)$. Dar una interpretación de la geometría de la molécula $\mathrm{CH}_{4}$ teniendo en cuenta las repulsiones electrónicas

C-7.- Del mismo modo, interpretar la geometría de las siguientes moléculas:

a) $\mathrm{H}_{2} \mathrm{O}$ (ángulo de enlace, $105^{\circ}$ )

b) $\mathrm{NH}_{3}$ (ángulo de enlace, $107^{\circ}$ ) (molécula piramidal regular, de base triangular)

c) $\mathrm{BCl}_{3}$ (plana triangular con ángulos de enlace de $120^{\circ}$ )

d) $\mathrm{BeCl}_{2}$ (lineal con ángulo de enlace de $180^{\circ}$ )

e) $\mathrm{PCl}_{5}$ (Bipirámide trigonal regular)

f) $\mathrm{SF}_{6}$ (octaedro regular)

C-8.- predecir cuáles de las siguientes moléculas serán polares: $\mathrm{H}_{2} \mathrm{O}, \mathrm{BCl}_{3}, \mathrm{NH}_{3}, \mathrm{CHCl}_{3}$

C-9.- ¿Por que el tetracloruro de carbono no es soluble en el agua mientras que el alcohol sí lo es?

C- 10.- Describe la geometría de la molécula:

$\mathrm{HC} \equiv \mathrm{C}-\mathrm{BH}-\mathrm{CH}_{3}$

Indicando la hibridación de los distintos enlaces 
C-11.- Esquematiza todas las características de las sustancias covalentes moleculares

\section{B.- Filtración (redes covalentes)}

C-12.- ¿Qué sustancias quedarán en el filtro después de la operación?

C-13.- ¿Por qué el filtro retiene a las sustancias con estructura de cristal covalente o metálico y no lo hace con las iónicas?

C-14.- Una de las formas cristalinas del $\mathrm{SiO}_{2}$, el cuarzo, funde a la temperatura de $1610^{\circ} \mathrm{C}$ y el $\mathrm{CO}_{2}$ sublima a $-79^{\circ} \mathrm{C}$. Basándote en estos datos ¿Qué diferencias puede haber entre ambas estructuras cristalinas?

C-15.-Dibuja la estructura del $\mathrm{SiO}_{2}$ y del diamante

C-16.- Enumera las propiedades de las sustancias covalentes

\section{C.- Destilación (Fuerzas intermoleculares)}

C-17.- Comparada con la temperatura de ebullición de sustancias similares como el $\mathrm{H}_{2} \mathrm{~S}$ o el $\mathrm{H}_{2} \mathrm{Se}$, el agua tiene un punto de ebullición muy elevado, ¿A que se debe?

C-18.- ¿Qué tipo de interacción puede mantener unidas en un sólido moléculas como las de $\mathrm{I}_{2}$ ?

C-19.- Justifica los siguientes resultados experimentales:

\begin{tabular}{|l|r|c|c|c|}
\hline \multicolumn{1}{|c|}{ Sustancia } & $\mathrm{F}_{2}$ & $\mathrm{Cl}_{2}$ & $\mathrm{Br}_{2}$ & $\mathrm{I}_{2}$ \\
\hline $\mathrm{T}_{\text {fus }}\left({ }^{\circ} \mathrm{C}\right)$ & -223 & -102 & -7.3 & 114 \\
\hline $\mathrm{T}_{\text {eb }}\left({ }^{\circ} \mathrm{C}\right)$ & -187 & -33.7 & 58.78 & 183 \\
\hline $\mathrm{Q}_{\text {fus }}(\mathrm{kJ} / \mathrm{mol})$ & 1.5 & 6.8 & 10.8 & 16.8 \\
\hline $\mathrm{Q}_{\text {vap }}(\mathrm{kJ} / \mathrm{mol})$ & 11.7 & 20 & 30 & 45 \\
\hline
\end{tabular}

C-20.- Dibuja la estructura que mantiene unidos a los átomos dentro de una molécula de agua y a varias de estas entre si. Haz lo mismo en el caso del $\mathrm{HF}$ y del $\mathrm{Br}_{2}$

C-21.- Explica la formación del helio líquido a temperaturas próximas al cero absoluto.

C-22.- Enumera las propiedades de las sustancias afectadas por fuerzas intermoleculares

\section{D.- Cristalización (enlace iónico)}

C-23.- Dibuja la estructura de una red de cloruro de sodio.

C-24.- Justificar a partir de la teoría del enlace iónico el hecho de que las temperaturas de fusión de estos compuestos sean relativamente altas. 
C-25.- Indica como quedarían las siguientes sustancias tras ser disueltas en agua:

$\mathrm{NH}_{4} \mathrm{Cl}, \mathrm{KNO}_{3}, \mathrm{NaClO}, \mathrm{H}_{2} \mathrm{SO}_{4}, \mathrm{ZnCl}_{2}, \mathrm{Fe}(\mathrm{OH})_{3}, \mathrm{CO}_{2}, \mathrm{O}_{2}, \mathrm{NH}_{3}, \mathrm{CaSO}_{4}, \mathrm{CCl}_{4}, \mathrm{AgBr}$, $\mathrm{SnCl}_{4}, \mathrm{Mg}(\mathrm{OH})_{2}$

Justifica la respuesta y agrúpalos según sea su comportamiento

C-26.- Justifica la solubilidad o no en agua de las sustancias siguientes:
a) $\mathrm{CCl}_{4}$
d) $\mathrm{CH}_{3}-\mathrm{CH}_{3}$
b) $\mathrm{BaF}_{2}$
e) $\mathrm{NaCl}$
c) $\mathrm{CH}_{3}-\mathrm{CH}_{2} \mathrm{OH}$

C-27.- Interpreta de forma cualitativa la siguiente tabla:

\begin{tabular}{|c|c|c|c|c|}
\hline Compuesto & $\mathrm{NaF}$ & $\mathrm{NaCl}$ & $\mathrm{NaBr}$ & $\mathrm{NaI}$ \\
\hline $\mathrm{T}^{\mathrm{a}}$ de fusión $\left({ }^{\circ} \mathrm{C}\right)$ & 1000 & 800 & 750 & 670 \\
\hline
\end{tabular}

C-28.- Interpreta cualitativamente la solubilidad y la fragilidad de los compuestos iónicos

C-29.- Comenta razonadamente la conductividad eléctrica de los siguientes sistemas:

a) Un hilo de cobre

b) Un cristal de $\mathrm{Cu}(\mathrm{NO})_{3}$

c) Una disolución de $\mathrm{Cu}(\mathrm{NO})_{3}$

C-30.- Enumera las propiedades de las sustancias iónicas

\section{E.- Imantación (Enlace metálico)}

C-31.- Explica a qué es debida la elevada densidad de los metales.

C-32.- ¿Por qué los metales conducen la corriente eléctrica?

C-33.- De los siguientes metales, indica cuál tendrá mayor temperatura de fusión:
a) El magnesio,
b) El litio,
c) El aluminio

C-34.- Enumera las propiedades de las sustancias metálicas

C-35.- Ordena por orden creciente de punto de fusión las siguientes sustancias:

$\mathrm{NH}_{3}, \mathrm{CCl}_{4}, \mathrm{Na}, \mathrm{H}_{2} \mathrm{O}, \mathrm{NaBr}, \mathrm{PCl}_{5}, \mathrm{NO}, \mathrm{CO}_{2}, \mathrm{SO}_{2}, \mathrm{KBr}, \mathrm{F}_{2}, \mathrm{Mg}, \mathrm{BH}_{3}, \mathrm{He}, \mathrm{CH}_{4}, \mathrm{SiO}_{2}$, $\mathrm{Ag}, \mathrm{PCl}_{3}, \mathrm{NaCl}, \mathrm{K}_{2} \mathrm{Cr}_{2} \mathrm{O}_{7}, \mathrm{Au}, \mathrm{C}, \mathrm{KBr}, \mathrm{MgS}, \mathrm{CH}_{3} \mathrm{COH}, \mathrm{KNO}_{3}, \mathrm{Na}_{2} \mathrm{~S}, \mathrm{~K}_{2} \mathrm{~S}$

Agrúpalas según el tipo de enlace que debe romperse en cada caso y, justifica el orden dentro de cada uno de estos grupos. 


\section{Organización general de las actividades en segundo de bachillerato}

De igual modo que en tercero de ESO, la organización las actividades, es una propuesta que cada profesor puede y debe tratar de mantener. Especialmente en este curso se espera que la propuesta inicial se ajuste a la real, pese a que la temporización no será posible, dada la gran carga de contenidos del tema y, sobre todo se precisará mayor tiempo del indicado en las explicaciones. No obstante esto no supone una variable que afecte al proceso.

Inicialmente se proponen diez sesiones, sabiendo que serán algunas más, sobre todo cuando entren en juego las explicaciones teóricas de los conceptos que abarcan cada uno de los tipos de enlace.

\section{I) Sesión inicial}

En primer lugar se procederá a pasar el cuestionario inicial para establecer los conocimientos previos de los alumnos y, en la misma sesión se presentará el problema. En este mismo acto se les entregará el dossier correspondiente (anexo XII) en el que se les facilitará la definición clara del problema a resolver así como las características técnicas del proceso. Estos datos se facilitan puesto que la investigación debe centrarse en el proceso a seguir y su asociación con el tipo de enlace, por lo que se trata de desviar la atención de los alumnos en otros aspectos que aunque interesantes, no son el objeto de la investigación. Junto a ellos se entrega en el mismo ejemplar una colección de problemas enmarcados habitualmente en el tema y secuenciados según la propuesta.

La distribución quedará de la forma:

a) Realización del cuestionario: "Cuestionario de detección de ideas alternativas en $2^{\circ}$ de bachillerato acerca del enlace químico" (Pre-Bac), para lo que se destinarán unos 30 minutos y posteriormente,

b) Presentación del problema, entrega del dossier y una primera exploración individual a realizar en casa.

Duscar posibles formas de separar las sustancias que contiene el agua 
II) Continuación de las actividades

En esta primera sesión dedicada a comenzar a explicar el tema se procederá en primer lugar a establecer los pasos a seguir para separar la mezcla a escala de laboratorio en base a las opiniones que los alumnos muestran tras su reflexión doméstica.

a) Discusión, reflexión y consenso acerca de los posibles métodos de separación

b) Establecimiento de las técnicas de separación en virtud de las propiedades de cada sustancia.

Tras la discusión se debe llegar a un acuerdo. El proceso de separación propuesto inicialmente sería:

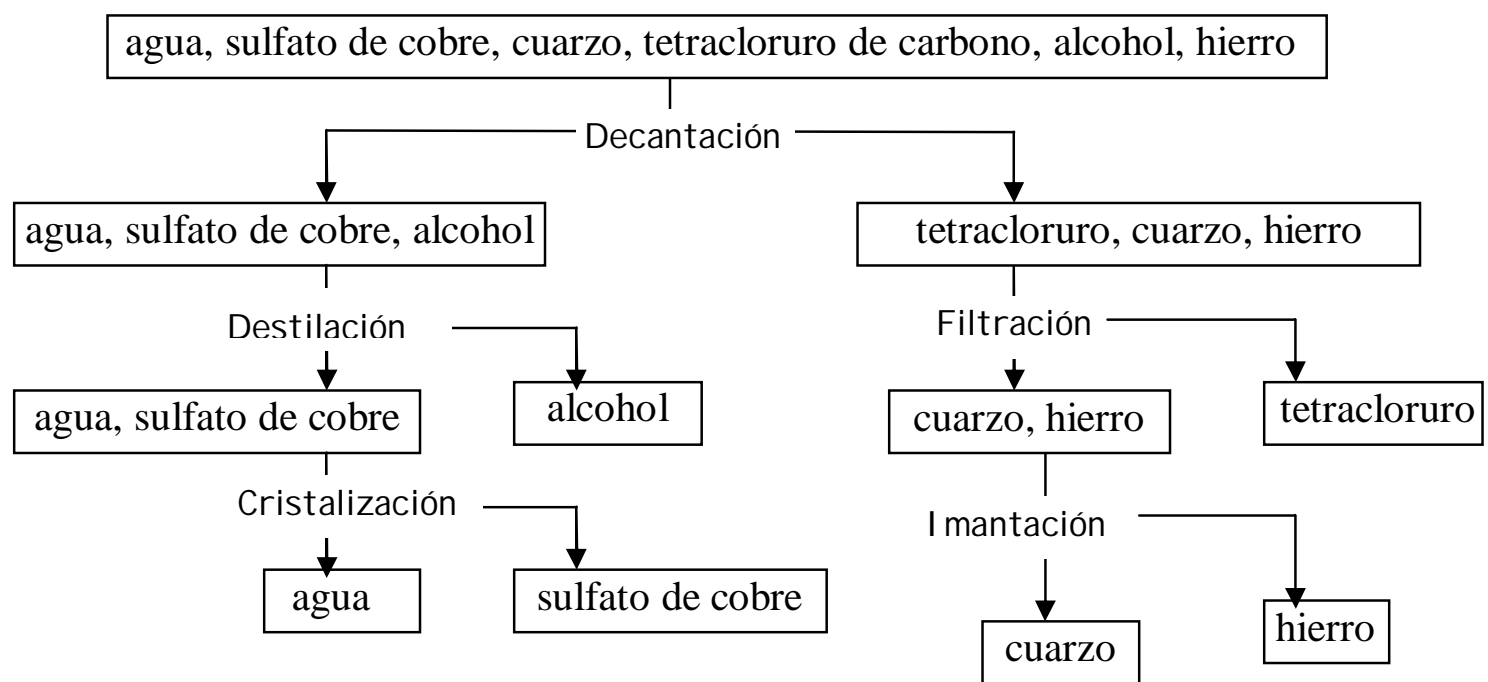

Figura 6.9.- esquema del proceso de separación a seguir durante el tema

Tras llegar a este resultado se explicarán las partes más complicadas del proceso, en especial indicando el cuidado que hay que tener sobre todo con el tetracloruro. A continuación se trabajará con diferentes sustancias para tratar de establecer similitudes entre ellas en la,

c) Actividad C-2

7 Buscar causas de las propiedades evidenciadas. 
III) Continuación de las actividades

a) Puesta en común de las propiedades, haciendo grupos de sustancias, de las que no se interpretará el enlace, sino que se clasificarán según se trate de compuestos con metales, no metales o con ambos.

En esta sesión se procederá a realizar la primera separación. La realizará el profesor o algún alumno delante de los demás. Se trata de una simple decantación que ocupará unos pocos minutos en realizarse, dando lugar a dos fases, con ello se podrá discutir el por qué de que unas sustancias sean miscibles entre sí y otras no.

b) Reflexión: semejante disuelve a semejante, metal con metal,... ¿y por qué el tetracloruro no lo hace con el agua y el metanol o el sulfato, sí?

c) A partir de aquí se plantea la necesidad de establecer por qué el alcohol y el agua no se mezclan con el tetracloruro de carbono, con ello se introducirá toda la teoría del enlace covalente, atendiendo a los puntos:

\section{Enlace covalente. Estructuras de Lewis \\ Teoría de Lewis del enlace covalente \\ Enlaces múltiples \\ Octetos incompletos \\ Octetos ampliados \\ Enlace covalente dativo \\ Estructuras de resonancia}

Este apartado se llevará a cabo en varias sesiones.

ODepresentar estructuras de Lewis (C-3,) 
IV) Continuación de las actividades

En esta sesión los alumnos ya conocerán, la base de la teoría clásica del enlace covalente, por tanto en primer lugar se procederá a la

a) Corrección de las estructuras

Y a continuación, se pasará a la visión espacial de las moléculas, donde se estudiará la direccionalidad del enlace, a partir de las teorías cuánticas

b) Introducción teórica:

Teoría de la repulsión de los pares de valencia

Polaridad de enlaces y moléculas

Hibridación

Con esto daremos por concluido el estudio de este modelo de enlace y los alumnos deberán identificar qué sustancias son polares y cuáles apolares, pudiendo justificar su miscibilidad.

ZD Deducir la geometría y polaridad de moléculas (C-4, C-5, C-6)

Deducir que sustancias se disuelven entre sí (en general)

V) Continuación de las actividades

En primer lugar se procederá a la

a) Corrección de las cuestiones anteriores

Para introducir el enlace covalente dentro de estructuras cristalinas, recurriremos a separar el cuarzo mediante una filtración, obteniéndolo en el filtro junto con el hierro. A simple vista podrán observarse los granos de cuarzo y al preguntarse por qué no se disuelven, daremos paso a la explicación de las estructuras covalentes

b) Introducción teórica:

Redes covalentes

c) Representar una red de $\mathrm{SiO}_{2}$ y justificar por qué se queda en el filtro 
d) Representar redes covalentes frente a moléculas covalentes (grafito-diamante).

Buscar y justificar las propiedades de las redes covalentes (C-15, C-16)

VI) Continuación de las actividades

a) Corrección

Para iniciar esta sesión el profesor tendrá preparado el montaje de la destilación, con lo que en unos minutos se llevará a cabo la separación de alcohol, quedando en el matraz el sulfato de cobre con el agua, de esta forma se introducirá la idea de la diferencia de puntos de ebullición y con ello los enlaces intermoleculares:

b) Introducción teórica

- Tipos de fuerzas intermoleculares

- Fuerzas de Van der Waals

Dip. per.-dip. per.

Dip. per.-dip. ind.

Dip. inst.-dip ind. inst.

- Puente de hidrógeno

c) Justificar, por qué el metanol se disuelve en el agua

73 Representar conjuntamente fuerzas interatómicas e intermoleculares $\rightarrow(\mathrm{C}-20)$

VII) Continuación de las actividades

Para realizar la cristalización previamente se habrá eliminado la mayor parte del agua de la disolución de sulfato de cobre por simple ebullición, hasta que se observe la formación de algún cristal, con ello se introducirá el estudio del enlace iónico

a) Corrección de la actividad propuesta el día anterior

b) Introducción teórica

Redes iónicas

Balance energético Energía reticular

c) Propiedades de los compuestos iónicos

\$2 Representación de redes iónicas frente a redes covalentes o moléculas (C-23) 
VIII) Continuación de las actividades

a) Corrección y ejemplos de redes iónicas

b) Introducción teórica

Ciclo de Born-Haber

75 Disociación de sales binarias y ternarias (C-25)

IX) Continuación de las actividades

a) Corrección

En esta sesión se procederá inicialmente a separar las partículas de cuarzo de las de hierro con la utilización de un imán, la mezcla proviene del filtro tras haberla separado del tetracloruro, como ya han pasado varios días ya estará seca y la separación será muy breve y sencilla.

Al separar el hierro se iniciará la explicación de las sustancias metálicas y con ello la del enlace metálico y sus propiedades.

b) Introducción teórica

Teoría de los electrones libres

Teoría del enlace de valencia o teoría de deslocalización

Redes metálicas

Propiedades de las sustancias metálicas

c) Actividad C-34

En esta última sesión se propone como conclusión el cálculo que supondría, realizar la separación a escala de laboratorio, desglosado la forma que se agrupen los costes y de forma dirigida, para no prolongar esta parte. 
F Cálculo del coste del proceso

Coste energético:

Evaporación de metanol $\rightarrow$

Evaporación de agua $\rightarrow$

Coste en mano de obra:

Decantación $\rightarrow$

Filtración $\rightarrow$

Destilación $\rightarrow$

Imantación $\rightarrow$

Cristalización $\rightarrow$

Ingresos por venta de los productos

Sulfato de cobre $\rightarrow$

Tetracloruro de carbono $\rightarrow$

Cuarzo $\rightarrow$

Metanol $\rightarrow$

Hierro $\rightarrow$

Coste total del proceso por cada dos litros de agua residual $=$

Coste diario de la corriente $(5$ litros/ minuto $)=$

X) Actividades finales

Para concluir la intervención se destinará la sesión a realizar el:

a) Cuestionario final "Cuestionario para establecer los conocimientos acerca del enlace químico en $2^{\circ}$ de bachillerato" (CCEQB)

b) Recogida de las estimaciones del coste y decisión sobre la rentabilidad del proceso 


\section{METODOLOGía, DESARROLlO Y RESUltado DE LAS INVESTIGACIONES PREVIAS/DIAGNOSTICAS}

Tras haber planteado el problema de estudio y haber propuesto las actividades previas para la diagnosis de la situación real de los alumnos, pasamos a analizar las actividades de evaluación, cuyo proceso esquematizamos a continuación:

\section{Actividades previas/diagnósticas}

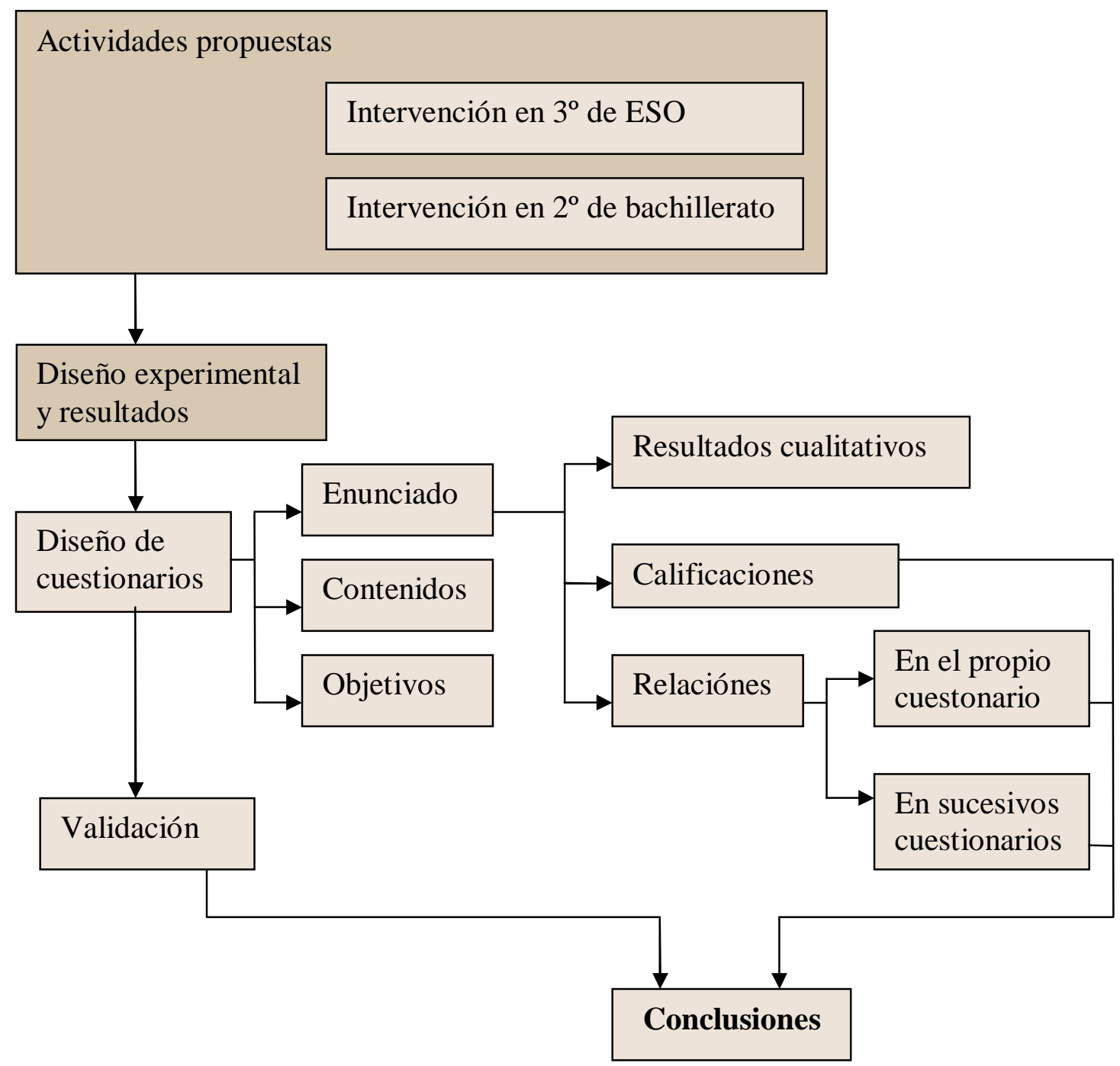

Figura 7.1.- Acciones llevadas a cabo en la investigación previa/diagnóstica. 


\subsection{Diseño experimental}

El planteamiento de esta investigación previa responde a la constatación de que los alumnos presentan carencias en la interpretación de la estructura de la materia, no siendo capaces en muchos casos de razonar las propiedades de una sustancia. Consideramos que una intervención basada en la contextualización del tema y el desarrollo del mismo basado en elementos conocidos por el alumno, puede ayudar a que este asimile mejor los conceptos relacionados con el enlace químico, respecto a otros alumnos que sean evaluados según modelos en los que se priorice el estudio de este tema de forma puramente teórica y sin esforzarse en buscar símiles con la vida cotidiana.

Así mismo consideramos que la perspectiva formativa que se ofrece en la enseñanza obligatoria frente a la finalidad propedéutica del bachillerato, facilitará la intervención, tanto por parte del profesorado como del alumnado y con ello mejorará el rendimiento del proceso, por lo que también se ha considerado este aspecto en el diseño de la investigación.

\subsubsection{Población y muestras}

Con el fin de verificar las propuestas planteadas anteriormente, la intervención se llevó a cabo en varios grupos de los diferentes niveles educativos implicados.

La población estudiada es el conjunto de los alumnos en los que se aplica la investigación. En esta investigación, la población esta constituida por los alumnos de cuatro centros públicos de enseñanza secundaria de la provincia de Valencia. Todos ellos de la zona periférica de la ciudad de Valencia y con un entorno social similar.

Dentro de la población la parte investigada constituye la muestra y que en nuestro caso está formada por 63 alumnos de la asignatura de Química de segundo de bachillerato, y de 135 alumnos de Física y Química de tercer curso de ESO pertenecientes a estos 4 centros (Anexo XXIV). En esta investigación se han realizado pruebas durante los cursos académicos 2005-2006 y 2006-2007, con la participación de 12 profesores, distribuyéndose de la forma: 


\begin{tabular}{|c|c|c|c|}
\hline Estudio realizado & Muestras & Tipo de grupo & Profesor implicado \\
\hline $\begin{array}{l}\text { Cuestionario de detección } \\
\text { de ideas alternativas en } 3^{\circ} \\
\text { de ESO sobre la } \\
\text { estructura de la materia } \\
\text { (Pre-ESO, Anexo III) }\end{array}$ & $\begin{array}{l}\text { Alumnos de } \\
3^{\text {o de la }} \\
\text { ESO }\end{array}$ & $\begin{array}{l}\text { Experimental (7) } \\
\text { De control }^{1}(2) \\
\text { De control Externo } \\
\text { (1) }\end{array}$ & $\begin{array}{l}5 \text { profesores de este } \\
\text { nivel }\end{array}$ \\
\hline $\begin{array}{l}\text { Cuestionario de detección } \\
\text { de conocimientos previos } \\
\text { en } 2^{\circ} \text { de Bachillerato } \\
\text { acerca del enlace químico } \\
\text { (Pre-BAC, Anexo VII) }\end{array}$ & $\begin{array}{l}\text { Alumnos de } \\
2^{\circ} \text { curso de } \\
\text { Bachillerato }\end{array}$ & $\begin{array}{l}\text { Experimental (3) } \\
\text { De control (1) }\end{array}$ & 4 profesores \\
\hline $\begin{array}{l}\text { Cuestionario para } \\
\text { establecer los } \\
\text { conocimientos acerca del } \\
\text { enlace químico en } 3^{\circ} \text { de } \\
\text { ESO (Post-ESO, Anexo } \\
\text { V) }\end{array}$ & $\begin{array}{l}\text { Alumnos de } \\
3^{\text {o de la }} \\
\text { ESO }\end{array}$ & $\begin{array}{l}\text { Experimental (7) } \\
\text { De control (2) } \\
\text { De control Externo (1) }\end{array}$ & $\begin{array}{l}5 \text { profesores de este } \\
\text { nivel }\end{array}$ \\
\hline $\begin{array}{l}\text { Cuestionario para } \\
\text { establecer los } \\
\text { conocimientos acerca del } \\
\text { enlace químico en } 2^{\circ} \text { de } \\
\text { bachillerato (Post-BAC, } \\
\text { Anexo IX) }\end{array}$ & $\begin{array}{l}\text { Alumnos de } \\
2^{\circ} \text { curso de } \\
\text { Bachillerato }\end{array}$ & $\begin{array}{l}\text { Experimental (3) } \\
\text { De control (1) }\end{array}$ & 4 profesores \\
\hline
\end{tabular}

Tabla 7.1.- Muestra y estudios en los que intervienen los alumnos y profesores

\footnotetext{
${ }^{1}$ Grupos de control: grupos que con el profesor común al de los grupos experimentales han realizado los cuestionarios pero que no han compartido la metodología propuesta.

${ }^{2}$ Grupos de control externo: grupos que han realizado los cuestionarios, pero cuyo profesor desconoce por completo la metodología empleada por los grupos experimentales.
} 


\subsubsection{Variables}

A la hora de establecer las variables que van a intervenir en la investigación, resulta conveniente clasificarlas según su función, pudiendo ser variables independientes o dependientes:

a) Variables independientes

En cualquier investigación, todo el proceso puede verse afectado por situaciones contextuales, procedimentales o incluso las propias de cada alumno o profesor implicado. Por tanto y ante la imposibilidad de homogeneizar todas las situaciones, es conveniente tratar de controlar todos los factores posibles y tratar de mantenerlos constantes en la medida de lo posible (tamaño de grupos, tipología de centros, horarios, etc)

En este grupo de variables, que no han sido objeto de la investigación y que por tanto, aunque presentes, no se han considerado encontramos

- Sexo, edad, curso.

- Estilos cognitivos, capacidad de razonamiento, implicación en la investigación.

- Calificaciones previas en Física y Química.

- Profesor que realiza la intervención, centro de estudio, modalidad elegida, optativas que cursa.

b) Variables dependientes

Son aquellas en las que centramos toda investigación y las que van a medir las consecuencias de las intervenciones realizadas. Las hipótesis de trabajo son las que han establecido la relación que hay o puede haber entre ellas, en función de la manipulación que se realice.

En esta investigación vamos a tratar de encontrar las consecuencias de una metodología concreta, basada en un trabajo cooperativo y que sea acorde con el 
desarrollo de los programas actuales en la LOGSE, por tanto, es lógico aceptar que variables con las que trabajaremos son de dos tipos, por un lado las relacionadas con el estado inicial de los alumnos y los grupos, y por otro lado, las relacionadas con la metodología empleada:

i) Nivel inicial

- Presencia de conocimientos previos. Es la variable más importante del proceso y la que se trata de mejorar en la intervención, de hecho el fin último de cualquier proceso de aprendizaje es aumentar el grado de conocimientos, tanto de forma cuantitativa como cualitativa, además en cada unos de sus aspectos, tanto conceptuales, procedimentales como actitudinales.

- Grado de conocimientos. Es importante identificar, el tipo de ideas que presenta el alumno, tanto correctas, como erróneas. La forma de contrastar esta información será a través de los cuestionarios diseñados para conocer esta característica de cada alumno previa a la intervención.

- Expectativas de mejora. Se miden a través de una valoración semicuantitativa, valorando en una escala, el grado de seguridad que tiene en acertar una respuesta.

- Aumento de competencias. Diferencia entre las calificaciones obtenidas por cada alumno en las pruebas realizadas previa y posteriormente a la intervención.

ii) Metodología empleada

- Modelo utilizado. Es la clave de la investigación, pues ésta se basa en la comparación de la modificación de las variables anteriores en según se utilice un modelo ordinario o la propuesta de aproximación al modelo PBL. 


\subsubsection{Recogida de datos}

En este apartado podremos distinguir entre instrumentos de medida que proporcionan datos cualitativos e instrumentos que proporcionan información, tanto cualitativa como cuantitativa. Estos últimos son los cuestionarios propuestos, y de ellos puede obtenerse tanto una calificación numérica como una clasificación de los esquemas mentales de los alumnos, además de permitir un estudio de los errores que se cometen en el proceso de aprendizaje del alumno.

Los instrumentos que sólo permiten apreciaciones cualitativas, son los cuadernos de trabajo, pero su estudio es menos fiable puesto que intervienen otras variables externas en su elaboración. No obstante su análisis puede resultar interesante.

i) instrumentos de obtención de datos cualitativos y cuantitativos

Constituyen el cuerpo principal del análisis y sobre ellos recae la tarea principal de evaluar la intervención, a continuación se detalla su momento de intervención y finalidad: 


\begin{tabular}{|c|c|c|c|}
\hline Instrumento & Contenido & $\begin{array}{l}\text { Momento de } \\
\text { recogida }\end{array}$ & Finalidad \\
\hline $\begin{array}{l}\text { Cuestionario de } \\
\text { detección de ideas } \\
\text { alternativas en } 3^{\circ} \\
\text { de ESO sobre la } \\
\text { estructura de la } \\
\text { materia (Pre-ESO) }\end{array}$ & $\begin{array}{l}5 \text { ítems de respuesta } \\
\text { abierta } \\
4 \text { ítems de } \\
\text { discriminación } \\
\text { conceptual } \\
1 \text { Cuestión de cálculo }\end{array}$ & $\begin{array}{l}\text { Pre-test, antes de } \\
\text { iniciar el tema del } \\
\text { enlace químico. } \\
\text { (mitad de curso } \\
\text { académico) }\end{array}$ & $\begin{array}{l}\text { Diagnosticar los } \\
\text { conocimientos } \\
\text { previos de los } \\
\text { alumnos y posibles } \\
\text { errores conceptuales }\end{array}$ \\
\hline $\begin{array}{l}\text { Cuestionario de } \\
\text { detección de } \\
\text { conocimientos } \\
\text { previos en } 2^{\circ} \text { de } \\
\text { Bachillerato } \\
\text { acerca del enlace } \\
\text { químico (Pre- } \\
\text { BAC) }\end{array}$ & $\begin{array}{l}4 \text { ítems de respuesta } \\
\text { abierta } \\
6 \text { ítems de respuesta } \\
\text { concreta }\end{array}$ & $\begin{array}{l}\text { Pre-test, antes de } \\
\text { comenzar el tema } \\
\text { del enlace químico. } \\
\text { (mitad del primer } \\
\text { trimestre de curso } \\
\text { académico) }\end{array}$ & $\begin{array}{l}\text { Conocer el grado de } \\
\text { conocimientos } \\
\text { respecto a la química } \\
\text { en general antes de } \\
\text { abordar el tema del } \\
\text { enlace. }\end{array}$ \\
\hline $\begin{array}{l}\text { Cuestionario para } \\
\text { establecer los } \\
\text { conocimientos } \\
\text { acerca del enlace } \\
\text { químico en } 3^{\circ} \text { de } \\
\text { ESO (Post-ESO) }\end{array}$ & $\begin{array}{l}3 \text { ítems de respuesta } \\
\text { abierta } \\
5 \text { ítems de elección } \\
\text { múltiple } \\
1 \text { Cuestión de cálculo } \\
1 \text { Ítem de } \\
\text { razonamiento }\end{array}$ & $\begin{array}{l}\text { Post-test, después } \\
\text { de terminar el tema } \\
\text { del enlace químico. } \\
\text { (mitad de curso } \\
\text { académico) }\end{array}$ & $\begin{array}{l}\text { Conocer el resultado } \\
\text { obtenido tanto en los } \\
\text { grupos } \\
\text { experimentales } \\
\text { como en los de } \\
\text { control }\end{array}$ \\
\hline $\begin{array}{l}\text { Cuestionario para } \\
\text { establecer los } \\
\text { conocimientos } \\
\text { acerca del enlace } \\
\text { químico en } 2^{\circ} \text { de } \\
\text { bachillerato } \\
\text { (Post-BAC) }\end{array}$ & $\begin{array}{l}7 \text { Ítems de respuesta } \\
\text { abierta } \\
3 \text { Cuestiones } \\
\text { discriminatorias del } \\
\text { tipo de enlace }\end{array}$ & $\begin{array}{l}\text { Post-test, después } \\
\text { de terminar el tema } \\
\text { del enlace químico. } \\
\text { (final del primer } \\
\text { trimestre de curso } \\
\text { académico) }\end{array}$ & $\begin{array}{l}\text { Conocer el resultado } \\
\text { final de de todo el } \\
\text { proceso educativo } \\
\text { del alumno respecto } \\
\text { al enlace químico }\end{array}$ \\
\hline
\end{tabular}

Tabla 7.2.- Instrumentos de recogida de datos cuantitativos y cualitativos 
ii) Instrumentos de obtención de datos cuantitativos

Son una segunda fuente de información basada en datos semicuantitativos obtenidos a partir del cuaderno, de opiniones, interacciones en el aula, etc.

\begin{tabular}{|l|l|l|l|}
\hline \multicolumn{1}{|c|}{ Instrumento } & \multicolumn{1}{|c|}{ contenido } & \multicolumn{1}{|c|}{ Fuente } & \multicolumn{1}{|c|}{ Destino } \\
\hline $\begin{array}{l}\text { Cuaderno del } \\
\text { alumno }\end{array}$ & Ejercicios de clase & Alumno & $\begin{array}{l}\text { Evolución de la } \\
\text { intervención, grado de } \\
\text { implicación. }\end{array}$ \\
\hline $\begin{array}{l}\text { Cuestionario a } \\
\text { profesores }\end{array}$ & $\begin{array}{l}\text { Desarrollo de las } \\
\text { clases, dificultades, } \\
\text { ventajas, etc. }\end{array}$ & Profesor & $\begin{array}{l}\text { Control de la praxis. } \\
\text { Opinión acerca de la } \\
\text { intervención. }\end{array}$ \\
\hline
\end{tabular}

Tabla 7.3.- Instrumentos de recogida de datos cualitativos. 


\subsubsection{Procedimiento}

El esquema general del proceso es el siguiente:

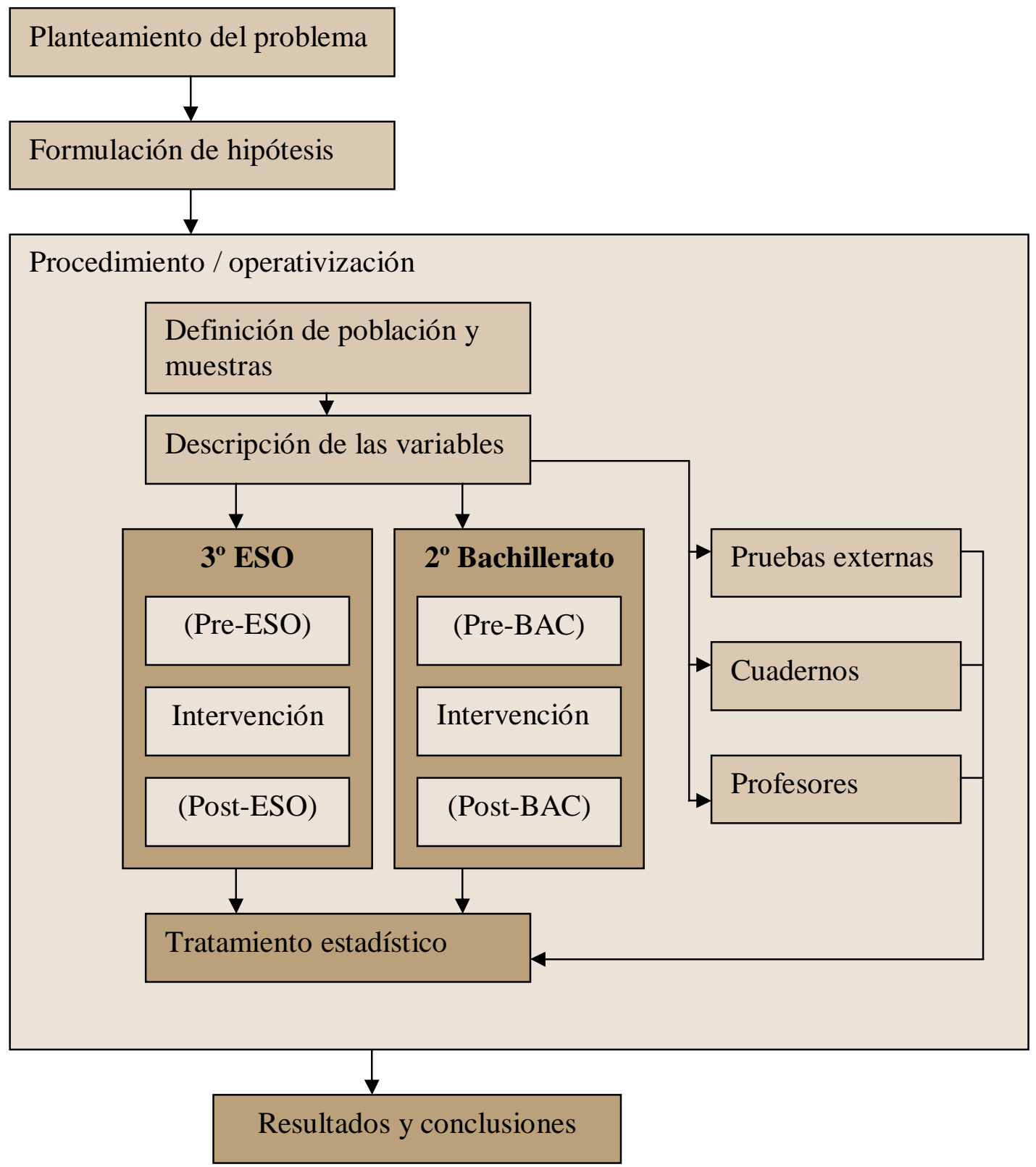

Figura 7.1. Esquema general de la intervención previa/diagnóstica. 


\subsubsection{Análisis de datos}

Para poder analizar los datos es necesario establecer un criterio e intentar extraer de cada cuestión la máxima información posible. En nuestro caso hemos convenido en realizar una doble corrección:

En primer lugar una valoración cuantitativa de cada uno de los ítems contenidos en los cuestionarios, que se reflejará de forma numérica en una tabla de doble entrada, por cada cuestionario, donde cada fila corresponde a un alumno y cada columna a un ítem. Con ello podremos llevar a cabo con comodidad el análisis estadístico utilizando tanto el programa SPSS, como la hoja de calculo excel. A partir de estas tablas podremos estudiar tanto las influencias entre cuestionarios, como las relaciones de dependencia o no en un mismo punto de la investigación.

En segundo lugar llevaremos a cabo una valoración cualitativa, en la que pretendemos extraer conclusiones acerca del aprendizaje. Con esta intención, para cada cuestionario se ha construido una red de análisis en la que se reflejará la información obtenida por cada alumno.

En cada una de estas redes se presenta una primera columna en la que consta una relación de los aspectos que consideramos que pueden extraerse de la realización de cada actividad y que pueden tener interés a la hora obtener conclusiones acerca del aprendizaje de los alumnos. Estas valoraciones pueden ofrecer un aspecto conceptual, procedimental o actitudinal, pero en todos los casos, van a permitir buscar relaciones entre ellos. En la segunda y tercera columnas se indicará si se realiza o no, la acción expresada, y en una última, se indicará posibles observaciones sobre las respuestas aportadas por los alumnos. 
Tanto en el análisis cuantitativo como el cualitativo vamos a buscar relaciones entre las variables, mientras que en apartado cuantitativo además trabajaremos con parámetros estadísticos para la medida de tendencia central y dispersión, así como curvas de distribución en cuanto a la asimetría y curtosis. En el caso del estudio cualitativo trabajaremos con variables dicotómicas (S/N), que no se ajustan a una distribución normal, por lo que se hace necesario recurrir a un análisis estadístico no paramétrico, cuya potencia predictiva es inferior a la paramétrica, pero que requiere menor número de datos (Rosado y col, 1993).

La relación entre variables nominales se obtiene a partir de estadísticos basados en Chi-cuadrado: Chi-cuadrado $\left(\chi^{2}\right)$, coeficiente de contingencia, Phi, V de Cramer y Lambda, mientras que la relación entre variables ordinales se obtiene mejor a partir de los estadísticos, Tau-b y Tau-c de Kendall, Gamma de Goodman y Kruskal, D de Sommer y los coeficientes de correlación de Sperman y de Pearson.

En el análisis estadístico nos hemos decidido por la utilización de la media, desviación típica, asimetría y curtosis, en lo referente al análisis cuantitativo, mientras que en la valoración de las correlaciones aplicado en el apartado cualitativo nos hemos decantado por el coeficiente de contingencia basado en $\chi^{2}$, la V de Cramer y la Gamma de Goodman. Siendo todos los parámetros nombrados relativamente sencillos de obtener a través de la introducción de datos y posterior análisis en el programa informático SPSS ${ }^{1}$ 


\subsection{Diseño y validación de cuestionarios}

\subsubsection{Diseño de los cuestionarios}

Los cuestionarios han sido la principal fuente de información de la evolución del proceso y por tanto su diseño se ha ajustado en la medida de lo posible, por un lado al marco normativo y por otro a la evolución real de temario o tercer nivel de concreción curricular, que es al fin y al cabo el que marca la pauta diaria y que es la que pretendemos mejorar.

\begin{tabular}{|c|c|c|}
\hline & Cuestionario & Finalidad \\
\hline Pre-ESO & $\begin{array}{l}\text { Cuestionario de detección } \\
\text { de ideas alternativas en } 3^{\circ} \text { de } \\
\text { ESO acerca de la estructura } \\
\text { de la materia. }\end{array}$ & Pre-test en $3^{\circ}$ de ESO \\
\hline Pre-BAC & 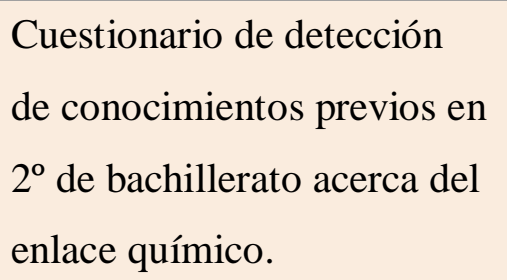 & Pre-test en $2^{\circ}$ de bachillerato \\
\hline Post-ESO & $\begin{array}{l}\text { Cuestionario para establecer } \\
\text { los conocimientos acerca del } \\
\text { enlace químico en } 3^{\circ} \text { de } \\
\text { ESO. }\end{array}$ & Post-test en $3^{\circ}$ de ESO \\
\hline Post-BAC & $\begin{array}{l}\text { Cuestionario para establecer } \\
\text { los conocimientos acerca del } \\
\text { enlace químico en } 2^{\circ} \text { de } \\
\text { bachillerato. }\end{array}$ & Post-test en $2^{\circ}$ de bachillerato \\
\hline
\end{tabular}

Tabla 7.4.- Finalidad de los cuestionarios utilizados.

Para la elaboración de los cuestionarios ha sido necesario recurrir a los currículos oficiales y ajustar para cada uno de ellos los aspectos estudiados con anterioridad 


\section{i) Pre-ESO}

La intención de este cuestionario es evaluar que es lo que los alumnos conocen acerca de la estructura de la materia. No podemos preguntarles nada acerca del enlace por que todavía no conocen este término, sin embargo puede ser muy útil tener información acerca de sus ideas anteriores. Hay autores que explican que un alumno no es una hoja en blanco dispuesta a ser rellenada de conceptos y, en este sentido debemos indagar.

Cuando un alumno se encuentra ubicado en un grupo de $3^{\circ}$ de ESO, debe haber asimilado en mayor o menor medida los contenidos de los cursos anteriores. Por tanto vamos a centrar en ellos este cuestionario, donde creemos conveniente proponer preguntas para entresacar los conocimientos acerca de:

- Propiedades generales de la materia universal: dimensiones (superficie y volumen), masa y densidad (S.I.).

- Estados de agregación de la materia.

- Sustancias puras y mezclas. Homogeneidad y heterogeneidad.

- Átomos y moléculas.

- El aire: origen, localización, composición y propiedades: peso, movimiento de sus Partículas, compresibilidad, capacidad de alterar materiales.

- Importancia del agua y sus propiedades: buen disolvente, gran capacidad calorífica, Capacidad de alterar materiales.

- La corteza terrestre su superficie, composición química y elementos geoquímicas

- Factores que hacen posible la vida en un planeta. Los elementos bioquímicos.

- Sistemas materiales. Escalas de observación macro y microscópica.

- El hidrógeno y el helio: abundancia y propiedades.

- Nitrógeno y oxígeno: abundancia y propiedades.

- Dióxido de carbono y ozono: implicaciones medioambientales.

- El silicio, la base de la materia mineral: abundancia y propiedades

- El carbono; propiedades

Todos estos puntos constan como contenidos conceptuales dentro de los dos primeros cursos de ESO, por tanto los alumnos que alcancen el tercer curso han recibido formación al respecto. El cuestionario se ha confeccionado atendiendo a que un alumno que domine estos puntos obtendrá una calificación elevada. En definitiva se trata de 
valorar tanto lo que aprendió en aquellos cursos, pero de una forma más funcional, que es lo que le queda a la hora de abordar el tema del enlace químico un curso después

\section{ii) Post-ESO}

Este cuestionario se prepara para ser contestado por los alumnos de $3^{\circ}$ de ESO una vez concluido el estudio del tema de la estructura de la materia, en el cual han visto todo lo relacionado con el enlace químico, y tras haber realizado las actividades propuestas. Todas las cuestiones han sido planteadas antes de llevar a cabo la intervención para que esta sea lo más objetiva posible, y versan alrededor de los contenidos curriculares de tema en tercer curso de la ESO

Los contenidos que deberían haber asimilado y de los que queremos comprobar su grado de adquisición son:

- Estados de agregación de la materia: sólido, líquido y gaseoso.

- Propiedades generales de los materiales en cualquier estado de agregación (sólido, líquido y gaseoso): masa, volumen y densidad.

- Estructura corpuscular (discontinuidad) de los sistemas materiales.

- Utilización del modelo cinético-corpuscular para explicar: estados de agregación (sólido, líquido y gaseoso) y cambios de estado; propiedades y comportamiento de los gases; presión atmosférica.

- Concepto macroscópico de elemento, sustancia pura, disolución y mezcla (sistemas homogéneos y heterogéneos).

- Sustancias puras y mezclas.

- Uniones entre átomos: moléculas y cristales.

- Introducción a las reacciones químicas: modelo elemental de reacción. Principio de conservación de la masa.

- Las uniones entre átomos.

- Ordenación de los elementos químicos.

- El enlace químico sobre la base de la posición de los elementos en el sistema periódico.

- Compuestos con enlace iónico. 
- Compuestos con enlace covalente.

- Compuestos con enlace metálico.

Dentro de estos contenidos incluimos los aspectos generales que se trabajan en la intervención y que no son exclusivamente propios del enlace químico.

iii) Pre-BAC

Este cuestionario se pasará a los alumnos de $2^{\circ}$ de bachillerato después de haber terminado los temas referentes a las leyes de la química (leyes ponderales, estequiometría, formulación), a la estructura atómica, y teniendo en cuenta que además han estudiado el enlace químico durante primero aunque de una forma introductoria. Por tanto se espera que cierto dominio de la materia, ya que la edad de los alumnos y el haber cursado varios cursos de química, además los dos anteriores y este, de forma voluntaria hace suponer que existe un mínimo de interés y expectativas de aprendizaje

Los contenidos a que haremos referencia, son los propios del currículo de primer curso de bachillerato, y tratando de abarcar cuestiones de carácter general, serán los siguientes:

- Análisis de algunas sustancias habituales en la naturaleza. Los tres estados físicos y sus modelos.

- La composición de los materiales: mezclas y sustancias, elemento y compuesto.

- Estructura de la materia. Hipótesis de Dalton. Las leyes volumétricas de GayLussac y las hipótesis de Avogadro. El concepto de mol.

- El enlace iónico y el covalente a partir de la regla del octeto, utilizando los diagramas de Lewis. Enlaces múltiples en el covalente para justificar moléculas como la de oxígeno o la de nitrógeno.

- Enlaces de hidrógeno y por fuerzas de Van der Waals: diferencias entre el enlace intermolecular y el intramolecular y propiedades. Introducción al enlace metálico. Propiedades de los compuestos como consecuencia del enlace.

- Introducción de las reglas de la IUPAC para la formulación de los compuestos binarios más comunes. 
- Modelo elemental de reacción a partir de las colisiones que provocan roturas y formación de nuevos enlaces.

No obstante las cuestiones se focalizarán sobre aspectos de no implicados con el enlace directamente, sino sobre aquellos aspectos de la materia que los justifica, como puedan ser la configuración electrónica o las propiedades periódicas.

\section{iv) Post-BAC}

Este cuestionario, se pasará a los alumnos de $2^{\circ}$ de bachillerato tras haber realizado las actividades propuestas y en él habrá que indagar los conocimientos adquiridos en relación al enlace químico, a lo largo de toda su formación.

No podemos olvidar el objetivo finalista del bachillerato, ni por supuesto la evaluación a que está sujeto a través de la selectividad, por tanto las cuestiones propuestas deben contemplar de forma sencilla, si realmente los alumnos entienden los conceptos relacionados con este tema, al tiempo que pueden realizar correctamente las propuestas en estas pruebas.

Los apartados curriculares que se consideran en este nivel son:

- Introducción del enlace covalente a partir del modelo de solapamiento de orbitales atómicos. Geometría de las moléculas utilizando el modelo de repulsión de pares de electrones. Concepto de polaridad. Interpretación de alguna de las propiedades asociadas a sustancias que presentan enlace covalente.

- Estructuras de Lewis. Parámetros moleculares. Hibridación de orbitales atómicos (sp, $\mathrm{sp} 2, \mathrm{sp} 3)$.

- Enlace iónico. Justificación de la existencia del retículo en los compuestos iónicos. Concepto de índice de coordinación y factores de los que depende. Introducción del ciclo de Born-Haber.

- Los enlaces intermoleculares. 
- Estudio cualitativo del enlace metálico a partir del modelo de los orbitales moleculares aplicado a elementos con pocos electrones de valencia y a la consiguiente existencia de niveles energéticos muy próximos.

Realmente deberemos abarcar todo el tema del enlace químico, tal y como se propone para su evaluación en las pruebas de selectividad. 


\subsubsection{Contenido de los cuestionarios}

\subsubsection{Cuestionario de detección de ideas alternativas en $3^{\circ}$ de ESO acerca de la estructura de la materia (Pre-ESO)}

El Pre-ESO, consta de 10 cuestiones, todas ellas relacionadas con contenidos del primer ciclo de enseñanza secundaria obligatoria, por tanto conocidos por los alumnos, aunque se ha pretendido orientar en un sentido general de la materia, donde se puedan expresar concepciones coloquiales acerca de la estructura de la materia.

Consta de 10 Ítems, 4 cuestiones de respuesta abierta, otras 4 de razonar el por qué de una u otra respuesta y dos cuestiones que implican deducir y razonar las respuestas.

Cada uno de los ítems ha sido incluido con la intención de extraer de él alguna información.

\section{Ítem no 1:}

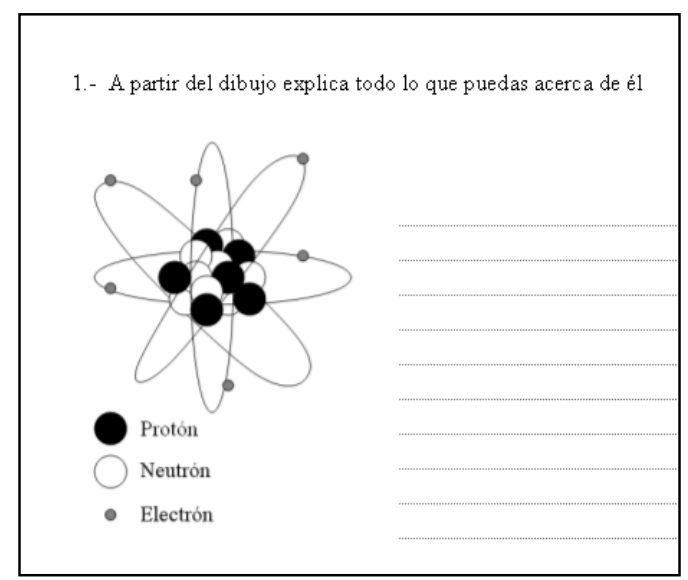

Tratamos de conocer la concepción de los alumnos respecto a la estructura atómica. Este es el esquema que se presenta en segundo curso de ESO y los alumnos, al menos deben saber diferenciar entre el núcleo y el resto del átomo, y saber que dependiendo del número de partículas existentes se trata de uno u otro elemento.

En este nivel por supuesto no debe introducirse ningún concepto cuántico (Solves y otros, 1987), pero sí considerar como partículas a los protones, neutrones y electrones.

El correcto conocimiento de la estructura atómica se hace necesario para conceptualizar las sustancias puras y las transformaciones químicas, y con ello profundizar en la naturaleza de la materia (Valcarcel y Sánchez, 2000). Este primer 
modelo atómico que se presenta a los alumnos, aunque sencillo resulta de gran importancia en cuanto que los alumnos presentan numerosas ideas alternativas respecto al átomo, sobre todo en cuanto a la conceptualización del átomo como partícula global, el concepto de estructura electrónica y la interacción entre núcleo y electrones.

\section{Ítem $n^{0} 2$}

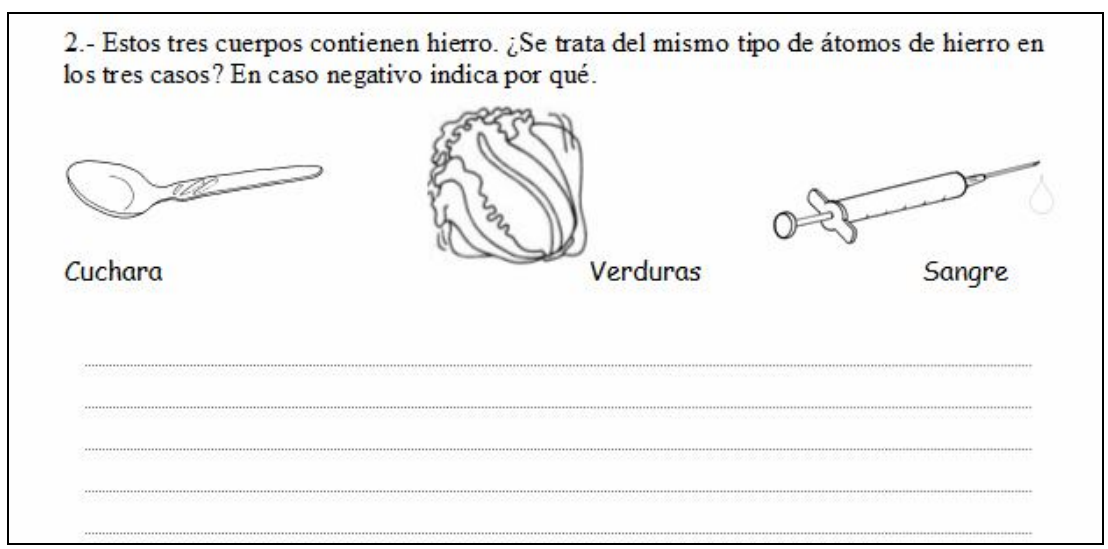

Esta cuestión contempla la idea principal de la intervención, puesto que en ella se trata de obtener la posible respuesta que cada alumno daría individualmente al problema propuesto y supone conocer el punto de partida de cara a asociar un determinado tipo de átomos con una u otra de las estructuras a estudiar.

En esta cuestión se va más allá, puesto que hay muchos alumnos que asocian un esquema atomista para las estructuras de sustancias puras, pero no se da con frecuencia cuando se trata de sustancias compuestas o mezclas (De Posada, 1993) puesto que supone abandonar las ideas dictadas por los sentidos y desplazarse a un pensamiento más abstracto. 


\section{Ítem n $\mathbf{n}^{\circ} 3$}

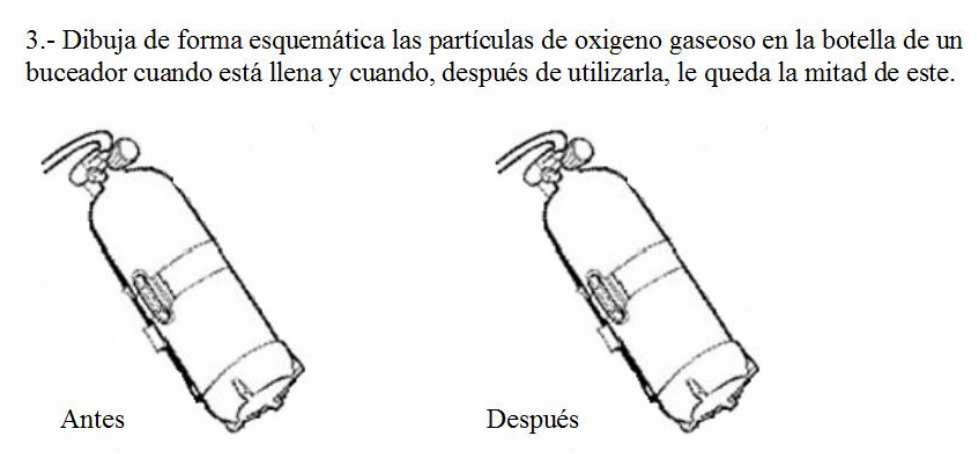

Con esta cuestión se pretende conocer la idea que tienen los alumnos respecto a cual es la estructura de un gas.

Este asunto ha sido tratado antes del comienzo de esta intervención, habiendo hecho lo propio con la teoría cinética, por lo que se deben conocer sus aspectos más relevantes.

La importancia de esta cuestión reside en que el modelo corpuscular que se introduce con el estudio de los gases es la base para iniciar el de la estructura de la materia (De Posada, 1993). Por tanto es necesario confirmar que los alumnos que asimilan la estructura de un gas harán lo propio con la del resto de la materia.

\section{Ítem no 4}

4.- ¿Qué recipiente contiene un solo elemento? ¿Y un compuesto? ¿En cuál o cuales hay una mezcla de elementos?
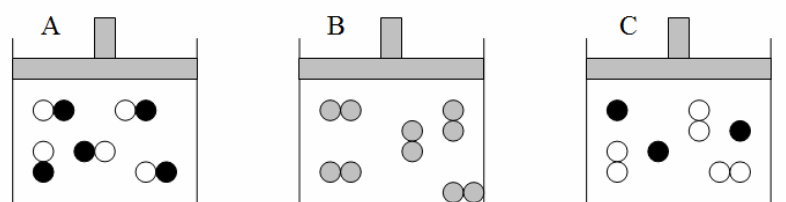
En relación a la estructura de la materia, en cursos anteriores se han descrito las mezclas homogéneas y heterogéneas. En esta cuestión se presentan tres sustancias, de las cuales, una corresponde a un elemento, por ser todos los átomos iguales aunque agrupados por parejas formando moléculas diatómicas, otra de ellas responde a un compuesto por presentar parejas iguales y una última correspondiente a una mezcla, puesto que contiene átomos y moléculas de átomos diferentes distribuidos de forma arbitraria.

Esta cuestión se plantea por la variedad de criterios que aparecen en los textos a la hora de diferenciar entre mezcla y compuesto (Sanmartí, 1989). En la mayoría de estos se definen estos conceptos y ya no se vuelve a hacer ninguna referencia sobre ellos, aún cuando son aplicados con frecuencia en otros temas como las leyes estequiométricas. Incluso hay porcentajes cercanos al 50\% de alumnos de enseñanza secundaria que no reconoce a las sustancias simples formadas por moléculas (Caamaño y Casassas, 1987)

\section{Ítem $\mathbf{n}^{0} 5$}

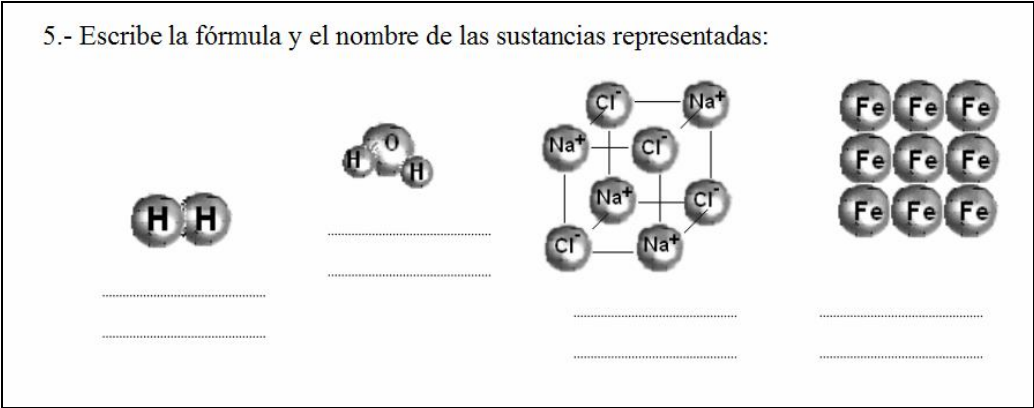

En esta cuestión se quiere comprobar la tendencia que tienen algunos alumnos a asociar estructura de un compuesto con su fórmula molecular. En los casos concretos planteados se pretende ver como nombran los alumnos a una estructura formada por átomos de cloro y sodio, y a otra formada por átomos de hierro. En cualquier caso resultara interesante comparar los resultados con los ejemplos de las moléculas de hidrógeno y agua.

No obstante los alumnos no han estudiado la relación entre el enlace químico y las posibles estructuras de la materia, por tanto la intención de la pregunta es la de explorar 
las ideas que inicialmente se puedan manifestar, en ningún caso se puede evaluar un conocimiento que se supone no debe existir.

\section{Ítem $n^{0} 6$}

6.- Indica si las siguientes afirmaciones son ciertas o falsas. Justificalo brevemente:

a) El oro es amarillo porque los átomos de oro son amarillos.

b) Entre el núcleo atómico y los electrones hay aire.

c) Los electrones son más pequeños que los átomos.

En esta cuestión se pretende comprobar si realmente existen las concepciones alternativas que algunos investigadores han encontrado en otros alumnos y en su caso cuantificar su alcance. Concretamente se hace referencia a la aplicación de las propiedades macroscópicas al mundo microscópico, a la existencia del vacío y estructura atómica.

En este ítem tratamos de corroborar aparición de concepciones alternativas debidas a la utilización de analogías, por parte de los alumnos basadas en la simplicidad y poder explicativo como intento de justificar determinadas situaciones (Llorens, 1994), así como la utilización del lenguaje como origen de estas concepciones.

\section{Ítem $\mathbf{n}^{0} 7$}

7.- Sabiendo que el átomo es la parte más pequeña de un elemento, y que es extraordinariamente pequeña, ¿cuántos átomos crees que pueden haber, aproximadamente en una gota de agua?

$\begin{array}{llllllllll}10^{-10} & 10^{-5} & 10^{-2} & 1 & 10^{2} & 10^{5} & 10^{10} & 10^{20} & 10^{25} & 10^{30}\end{array}$

En esta cuestión se pretende conocer si los alumnos poseen suficiente capacidad de abstracción numérica. Este aspecto resulta muy importante a la hora de introducir los conceptos microscópicos puesto que esto supone una dificultad considerable en cuanto al aprendizaje de la química. 
La cuestión se plantea en forma de respuesta de elección múltiple, dando como posibilidades, una serie de potencias de base 10, sobre las que pueden elegir. Este tema es previo a la estequiometría, donde van a conocer el concepto de cantidad de sustancia, por lo que del mismo modo que no se espera que la mayoría contesten correctamente, también nos dará una aproximación de la intuición del alumno

\section{Ítem n ${ }^{\circ} 8$}

8.- Pon dos ejemplos de sustancia pura y dos de mezcla homogénea.

Relacionada con el cuarto ítem, esta cuestión se ha planteado de forma abierta, para ver si los alumnos además de distinguir a nivel gráfico una mezcla homogénea de otra heterogénea, pueden aportar ejemplos propios de ellas.

En la cuarta cuestión hacíamos referencia al nivel microscópico de la materia, mientras que ahora se hace del macroscópico, por lo que atendiendo al razonamiento del alumno, debe ser más sencillo

\section{Ítem $\mathbf{n}^{0} 9$}

9.- ¿Qué consecuencias tiene para la vida de las personas, la industria química?

Este ítem esta completamente fuera del contenido académico, pero se ha colocado estratégicamente en este cuestionario para poder determinar la relación que hay entre el rendimiento de cada alumno y su concepción social respecto a la química como disciplina. 
El objetivo de esta cuestión es hacer un posterior análisis estadístico en el que podamos comparar los resultados en la formación en química de un alumno con la imagen que este tiene acerca de ella. En función de ello podremos determinar si es posible la existencia de condicionantes externos que influyan directamente en el aprendizaje del alumno.

\section{Ítem $\mathbf{n}^{\mathbf{0}} \mathbf{1 0}$}

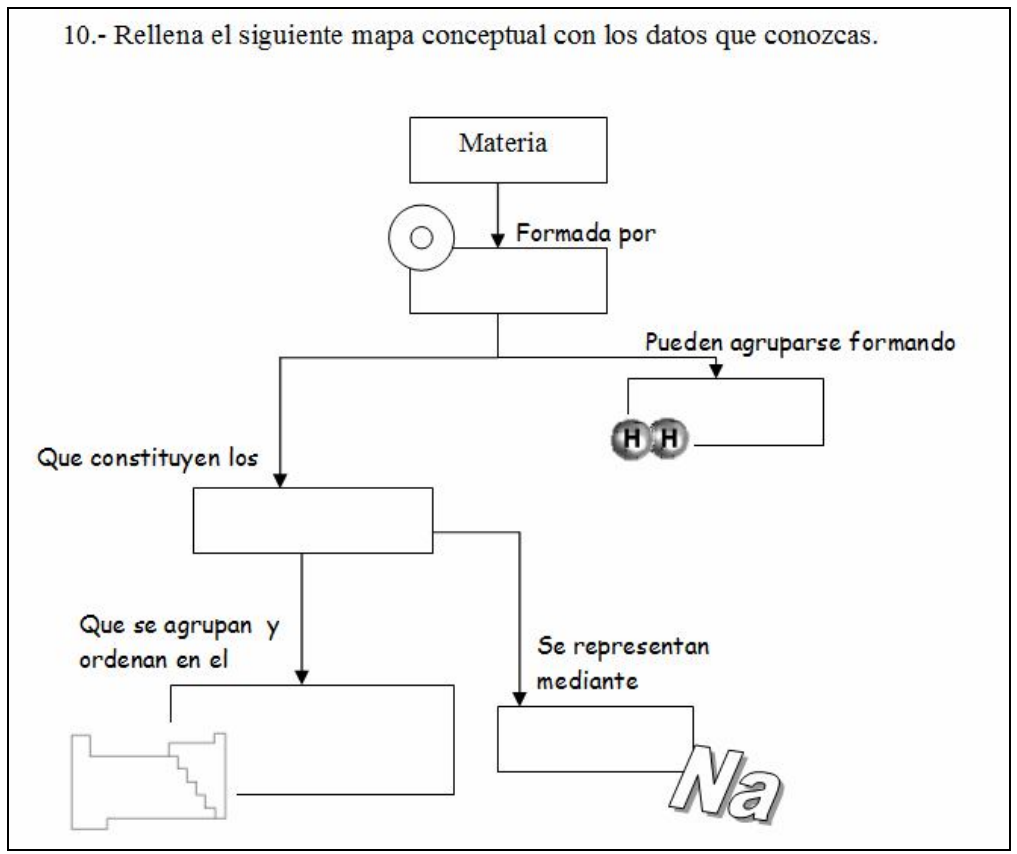

Esta cuestión responde a la necesidad de concretar la concepción de la materia por parte de los alumnos. Este mapa conceptual ha sido tomado directamente de un libro de texto de segundo de ESO, donde se utilizaba a modo de reflexión final del tema. Nosotros pretendemos conocer si las ideas transmitidas en el curso anterior han sido asimiladas con claridad, y poder continuar con el proceso. 


\begin{tabular}{|c|l|}
\hline Cuestión $\mathrm{n}^{\mathbf{0}}$ & \multicolumn{1}{|c|}{ Conceptos relacionados } \\
\hline 1 & El átomo. Partículas constituyentes \\
\hline 2 & Estructuras de la materia \\
\hline 3 & Teoría cinetico-molecular \\
\hline 4 & Clasificación de la materia \\
\hline 5 & Estructura de la materia \\
\hline 6 & Estructura atómica \\
\hline 7 & Capacidad de abstracción numérica \\
\hline 8 & Clasificación de la materia \\
\hline 9 & Imagen de la química \\
\hline 10 & Estructura de la materia \\
\hline
\end{tabular}

Tabla 7.5.- Conceptos implicados en el cuestionario Pre-ESO

\subsubsection{2.- Cuestionario para establecer los conocimientos acerca del enlace químico en $3^{\circ}$ de ESO (Post-ESO)}

Tras la intervención se plantea este cuestionario tanto a los alumnos de los grupos experimentales como de control con un contenido igual al que se hubiera reflejado en un examen normal de esta materia. En él hay contenidas cuatro cuestiones abiertas, 4 cuestiones en las que deben relacionar algunas sustancias bien con sus propiedades, bien con su tipo de enlace, una cuestión de cálculo y una última cuestión de formulación.

\section{Ítem $n^{0} 1$}

1.- ¿Qué es una molécula? ¿A qué se debe su existencia en la naturaleza?


Esta primera cuestión pretende conocer el conocimiento de los alumnos respecto al concepto de molécula. Ha sido introducido en el estudio de este tema, y representa un salto conceptual dentro de la estructura de la materia. Hasta este curso las sustancias que se habían estudiado eran algunas moléculas como el $\mathrm{H}_{2} \mathrm{O}$ o el $\mathrm{CO}_{2}$ y parece interesante conocer su visión tras conocer que todas las sustancias no presentan esta condición A continuación se pregunta acerca del porqué de la formación de las moléculas.

Está constatado en diferentes estudios (De Posada, 1999; Riboldi, Pliego y Odette, 2004) que existe poca relación entre la estructura o representación de una sustancia y su tipo de enlace, por lo que tras haber realizado la intervención nos parece interesante conocer las explicaciones de los alumnos sobre este concepto.

\section{Ítem $n^{0} 2$}

2.- Señala qué sustancias son elementos y cuales son mezclas o compuestos:

Madera Sangre Ácido sulfúrico

Hierro Azúcar Aguarrás

Agua destilada Humo Cobre

Tierra Cal viva Vino

Coca cola Amoniaco Agua mineral

En este ítem se pretende conocer si los alumnos son capaces de clasificar correctamente un grupo de sustancias según su naturaleza. Esta cuestión se propone para comparar los resultados con los obtenidos en el cuestionario inicial respecto a la estructura de la materia y comparar los resultados en ambos casos.

\section{Ítem $n^{0} 3$}

3.- ¿Qué cosas tienen en común los elementos de un mismo grupo? ¿y los de un mismo periodo?

Dentro del conocimiento del sistema periódico, con esta cuestión trataremos de analizar si los alumnos son capaces de asociar los elementos a determinada posición en la tabla y sus propiedades relacionadas con el enlace. 
El interés de esta cuestión es el posterior análisis de la relación entre el conocimiento de la ordenación periódica y la discriminación entre uno u otro tipo de enlace químico. En la intervención se ha incidido en la clasificación de los elementos en metales y no metales, y con ello dicha discriminación por lo que se espera que haya una correlación importante en este aspecto.

\section{Ítem $n^{\circ} 4$}

4.- Indica cuales de las siguientes representaciones de transformaciones de la materia corresponden a cambios químicos:

a)

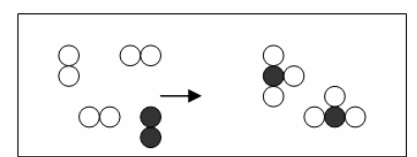

c)

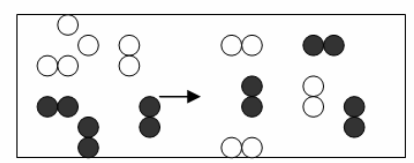

e)

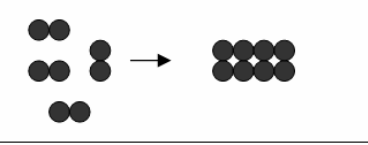

b)

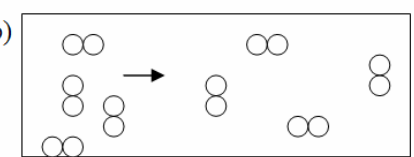

d)

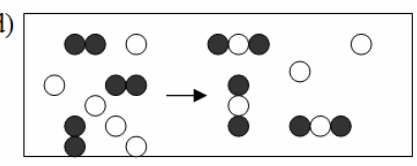

f)

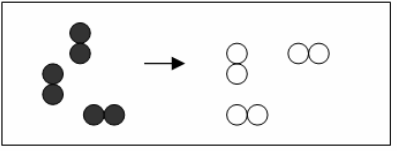

¿Por qué?

En esta cuestión se ha optado por el mismo formato que en el cuarto ítem del cuestionario previo para referirnos al nivel microscópico de la materia $\mathrm{y}$, poder establecer una relación posterior. Durante la intervención no se ha trabajado acerca de los cambios químicos, pero si han entendido conceptos como sustancia pura, mezcla, o moléculas, deben realizar correctamente esta cuestión.

4.- ¿Qué recipiente contiene un solo elemento? ¿Y un compuesto? ¿En cuál o cuales hay una mezcla de elementos?
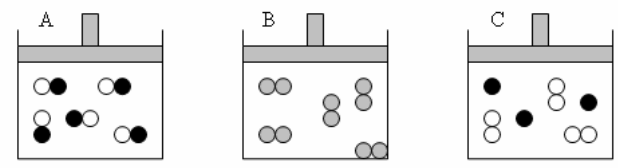

4.- Indica cuales de las siguientes representaciones de transformaciones de la materia corresponden a cambios químicos:
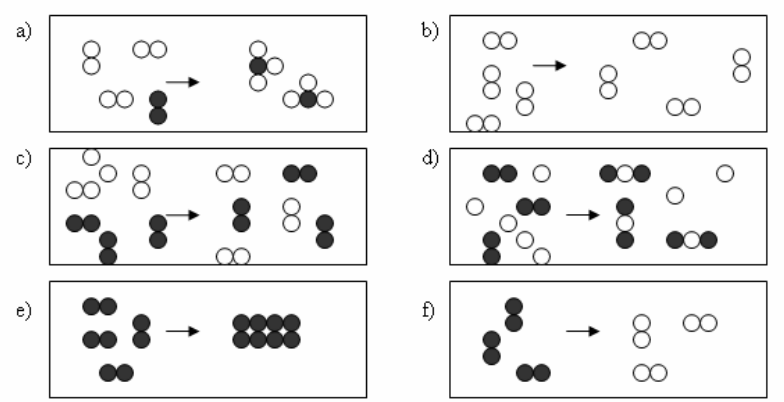

¿Por qué? 
En estas cuestiones se ha ofrecido una visión de la materia "mecanicista" donde se muestra la materia formada por partículas que no presentan las mismas propiedades macroscópicas que podemos percibir (Sanmartí, 1989)

\section{Ítem $n^{0} 5$}

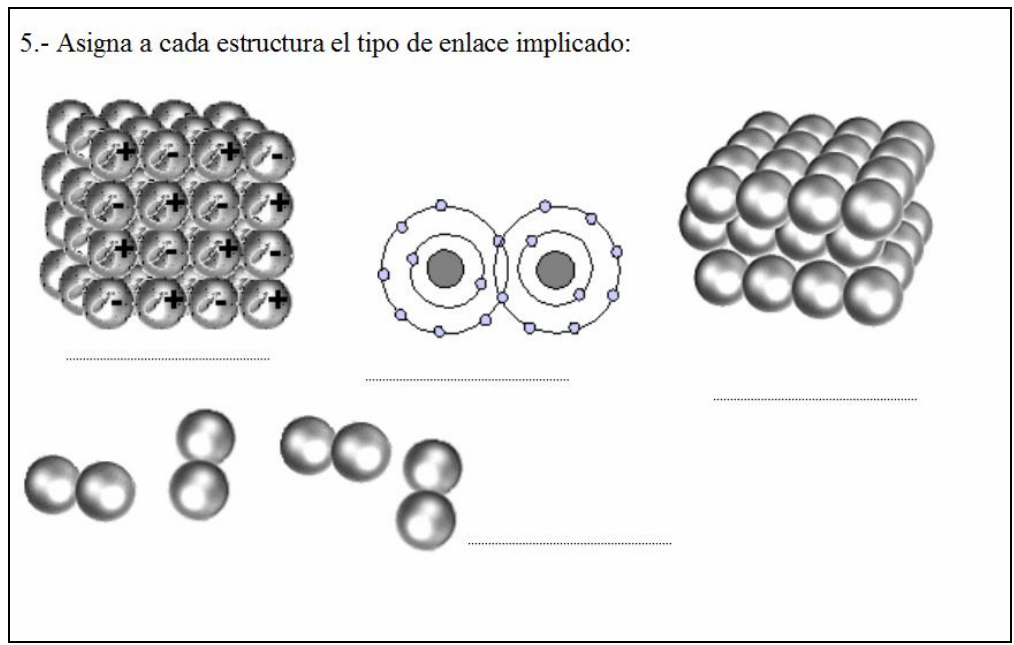

Esta propuesta es clave en la intervención. Pretendemos conocer si los alumnos relacionan el tipo de enlace con alguna estructura en concreto.

Se han planteado cuatro estructuras, para que los alumnos asignen uno u otro tipo de enlace a cada una de ellas. No se ha especificado ningún elemento sino que se han representado esferas, con o sin carga, para representar átomos e iones, con ello se espera que se obtenga una distinción clara entre iónico, covalente o metálico.

\section{Ítem $n^{\circ} 6$}

\begin{tabular}{|l|l|}
\hline 6.- Explica cuales de las siguientes sustancias son iónicas y cuales covalentes: \\
$\mathrm{KI}$ & $\mathrm{BaF}_{2}$ \\
\hline $\mathrm{CuO}$ & $\mathrm{H}_{2} \mathrm{O}$ \\
$\mathrm{NH}_{3}$ & $\mathrm{PH}_{3}$ \\
$\mathrm{MgH}_{2}$ & $\mathrm{H}_{2} \mathrm{~S}$ \\
\hline $\mathrm{CO}$ & $-\mathrm{Li}_{3} \mathrm{~N}$ \\
\hline $\mathrm{HCl}$ & $\mathrm{N}_{2} \mathrm{O}_{3}$ \\
\hline
\end{tabular}


En esta cuestión se pretende averiguar si los alumnos son capaces de atribuir un tipo de enlace a cada sustancia. Esto esta íntimamente relacionado con el conocimiento de la tabla periódica, la clasificación de elementos en metales o no metales y las posibilidades de emparejamiento entre ellos.

La correcta contestación a esta cuestión representa un éxito ya que supone que un alumno es capaz de, dada una sustancia química clasificarla como uno u otro tipo de sustancia y con ello comenzar a atribuirle propiedades e ir identificándola.

\section{Ítem $\mathbf{n}^{0} 7$}

7.- Explica su son verdaderas o falsas las afirmaciones siguientes:

a) El enlace iónico da lugar a la formación de moléculas.

b) En el enlace covalente se unen átomos metálicos y comparten electrones.

c) El enlace covalente puede producir la formación de moléculas, pero no siempre.

Al igual que el quinto ítem pretendemos conocer la relación que establecen los alumnos entre la estructura de la materia y el tipo de enlace. En este caso se hace de forma inversa a la anterior buscando una explicación.

Las afirmaciones no se hacen de forma ambigua, de modo que se busca que los alumnos puedan razonar correctamente cuales son las estructuras originadas con cada tipo de enlace. Esta cuestión responde a la falta de entendimiento de muchos alumnos respecto al modelo de enlace que se les enseña (Caamaño y Casassas, 1987).

\section{Ítem $\mathbf{n}^{\circ} 8$}

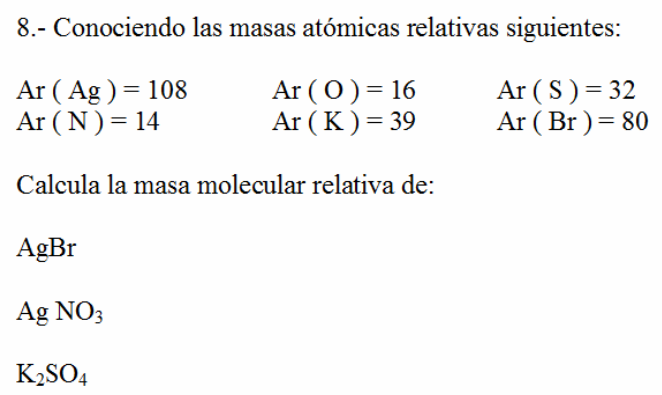


Esta cuestión se incluye como una aplicación directa del concepto de enlace. Aunque se trata de una simple operación matemática, conlleva la asimilación de una nueva entidad material que supone la unión de otras. El cálculo de las masas moleculares es un contenido trabajado en el tercer curso de ESO y nos resulta interesante en cuanto que puede aprovecharse para conocer el aspecto procedimental del alumno.

\section{Ítem $n^{\circ} 9$}

\begin{tabular}{|ll|}
\hline 9.- Relaciona nombres y fórmulas: & \\
\hline - Oompuesto químico & \\
- Óxido de litio & - $\mathrm{H}_{2} \mathrm{H}_{2} \mathrm{CO}_{3}$ \\
- Ácido carbónico & - $\mathrm{Na}_{2} \mathrm{SO}_{4}$ \\
- Hidróxido de potasio & - $\mathrm{PbO}$ \\
- Ácido Clorhídrico & - $\mathrm{HNO}_{3}$ \\
- Ácido nítrico & - $\mathrm{FO}$ \\
- Trióxido de dicloro & - $\mathrm{KOH}$ \\
- Óxido de hierro (II) & - $\mathrm{HCl}$ \\
- Sulfato de sodio & - $\mathrm{Li}_{2} \mathrm{O}$ \\
- Óxido de plomo (II) & - $\mathrm{CaH}_{2}$ \\
- Hidruro de calcio & - $\mathrm{Cl}_{2} \mathrm{O}$ \\
\hline
\end{tabular}

Esta cuestión se introduce como conclusión del cuestionario, y poder comparar si los alumnos asocian mejor las fórmulas y los nombres en función del resultado que han obtenido en el aprendizaje del tema del enlace. Esta cuestión nos parece interesante en cuanto que es una aplicación directa del conocimiento de las sustancias químicas y junto con los ítems tercero y sexto, permitirá establecer relaciones entre sistema periódico y enlace.

\section{Ítem $\mathbf{n}^{\circ} 10$}

10.- Como podrías explicar que tras quemar un tronco de madera la masa de las cenizas sea tan pequeña comparada con la inicial?

Esta cuestión esta pensada para compararla con los resultados obtenidos en el Segundo ítem del cuestionario inicial. En ella se plantea una cuestión de sentido común 
y cuya explicación reside en los cambios materiales y en las diferentes estructuras que adquiere la materia. Se pretende que los alumnos reflexionen acerca de la posibilidad de que exista un mismo tipo de átomos formando parte de sustancias con propiedades muy diferentes. Este es justamente el planteamiento del problema propuesto en clase para abordar el tema del enlace y en la medida que pueda responderse con corrección y coherencia, podremos dar, o no por satisfecha la propuesta.

Por cuestiones, los contenidos sobre los que versan las cuestiones son:

\begin{tabular}{|c|l|}
\hline Cuestión $\mathrm{n}^{\mathbf{o}}$ & \multicolumn{1}{c|}{ Conceptos relacionados } \\
\hline 1 & Estructura de la materia. \\
\hline 2 & Clasificación de la materia \\
\hline 3 & Sistema periódico. \\
\hline 4 & Transformaciones químicas. \\
\hline 5 & Estructura atómica. \\
\hline 6 & Enlace químico. \\
\hline 7 & Enlace químico \\
\hline 8 & Masas moleculares. Enlace covalente \\
\hline 9 & Formulación y nomenclatura químicas \\
\hline 10 & Reacciones químicas. Estructura de la materia. Estados de agregación. \\
\hline
\end{tabular}

Tabla 7.6.- Conceptos implicados en el cuestionario Post-ESO.

\subsubsection{Cuestionario de detección de conocimientos previos en $2^{\circ}$ de bachillerato acerca del enlace químico (Pre-BAC)}

Este cuestionario se pasa a los alumnos, después de haber estudiado el tema de la estructura atómica y el sistema periódico. Por tanto los contenidos a que se hace referencia son recientes para ellos 
Está constituido por 5 cuestiones de respuesta cerrada, donde el alumno debe contestar a cada pregunta con una respuesta concreta, 4 cuestiones de respuesta abierta que permiten su explicación y una última pregunta sobre formulación y nomenclatura, que siendo también de respuesta cerrada, sirve para evaluar de forma explicita los errores cometidos.

\section{Ítem $n^{0} 1$}

\begin{tabular}{|l|l|l|l|}
\hline \multicolumn{2}{|c|}{ 1.- Completa la tabla siguiente: } & \multicolumn{2}{l|}{} \\
\hline Ca & Fluor & Ni & \\
\hline Cs & Estaño & Cd & Plomo \\
\hline Ba & Cobre & & Mercurio \\
\hline & & Sb & \\
\hline
\end{tabular}

El motivo de colocar esta primera cuestión obedece al interés por confirmar un aspecto tan elemental como es el conocimiento de los símbolos de los elementos, ya que si esto no se conoce parece estéril intentar abordar los contenidos propuestos.

\section{Ítem $n^{\circ} 2$}

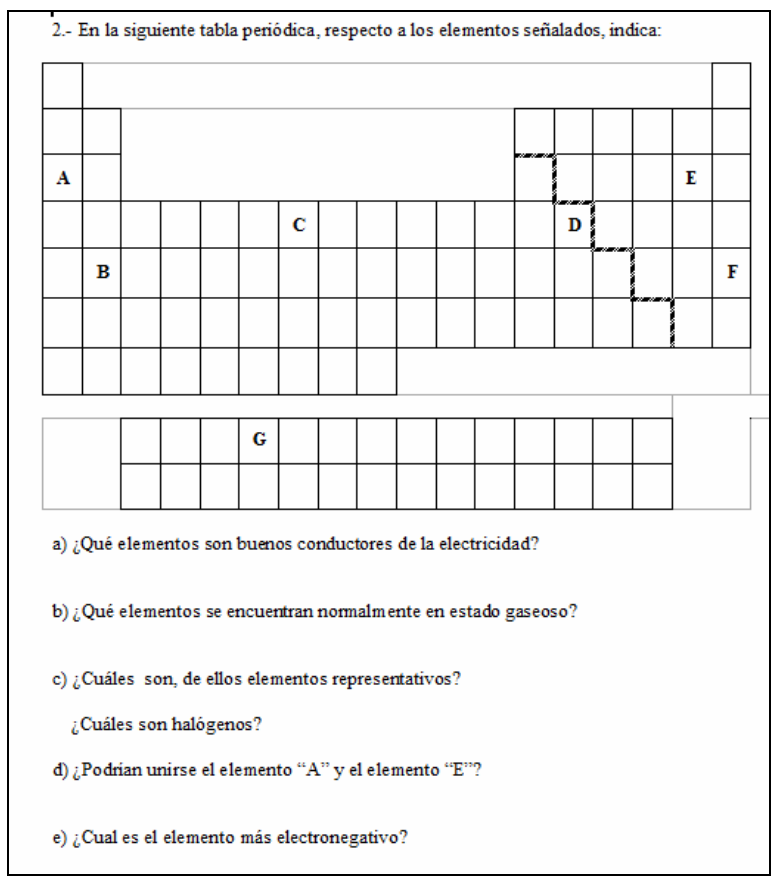


Esta cuestión trata de conocer, si los alumnos conocen la tabla periódica. Al igual que la cuestión anterior se considera imprescindible su conocimiento para abordar con garantías el estudio del enlace químico. El estudio del sistema periódico se ha producido en los días anteriores, por lo que su desconocimiento, puede justificar el caso de que no se produzcan buenos resultados en el tema que nos ocupa, en tanto que será indicativo de otras deficiencias, bien de tipo actitudinal o procedimental.

Asimismo se ha elegido la electronegatividad como propiedad periódica por su importancia en la polaridad de los enlaces así como la formación de iones. Por ello su correcto conocimiento es necesario en este apartado.

\section{Ítem n 3}

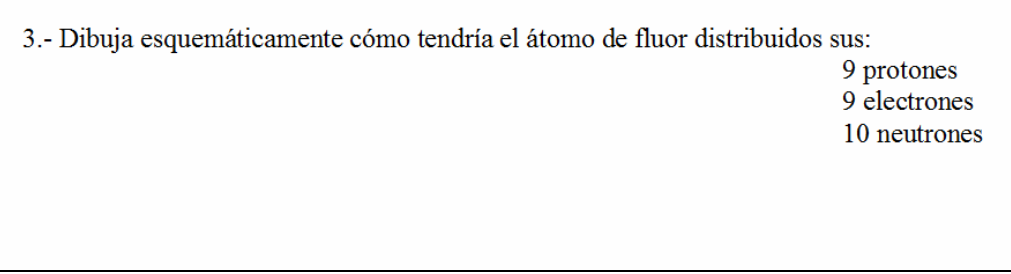

En esta cuestión se pretende al igual que en el primer ítem de la prueba Pre-ESO conocer las ideas de los alumnos respecto a la estructura atómica. Va a resultar de interés poder comparar las respuestas en ambas situaciones. Al igual que en los dos ítems anteriores de este cuestionario es de esperar obtener respuestas satisfactorias dada la sencillez de la propuesta.

Parece de gran interés ver el átomo que dibujan los alumnos, puesto que el modelo de Rutherford o el de Borh, son los aprendidos en el curso anterior y en el principio del que están cursando, y aunque se han introducido conceptos cuánticos, no parece sencillo recurrir a ellos. 


\section{Ítem n ${ }^{\circ} 4$}

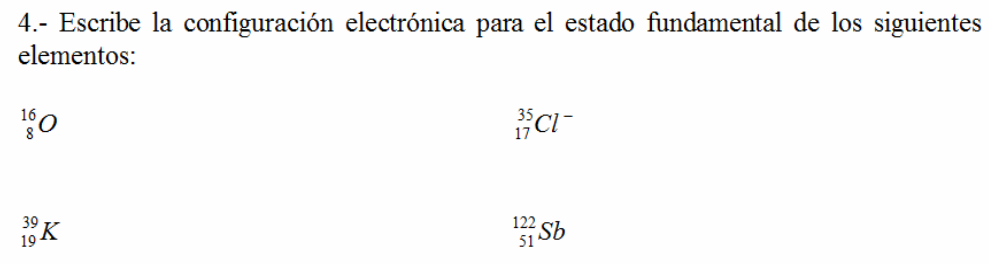

Conjuntamente con el segundo y con el quinto ítem, en esta cuestión se pretende conocer el nivel de conocimiento acerca del sistema periódico. En esta cuestión en concreto además, se relaciona con la estructura electrónica, por lo que al tiempo que se revisa los conceptos de masa atómica y número atómico, se puede establecer su conexión con la ordenación periódica. También estableceremos un vínculo con la siguiente pregunta, donde coincidiendo algunos de los elementos propuestos, compararemos si los alumnos son capaces de deducir la valencia a partir de la configuración electrónica.

Las cuestiones relacionadas con la estructura electrónica suelen contestarse a partir de reglas nemotécnicas que permiten obtener un resultado correcto, no obstante en la siguiente cuestión se tratará rebuscar una reflexión a este punto.

\section{Ítem $n^{0} 5$}

$$
\begin{aligned}
& \text { 5.- ¿Cuál será la valencia iónica más probable de los siguientes elementos? } \\
& \mathrm{O} \rightarrow \\
& \mathrm{F} \rightarrow \\
& \mathrm{K} \rightarrow \\
& \mathrm{Sb} \rightarrow
\end{aligned}
$$

En este ítem, y continuando con la profundización en el sistema periódico, se ha propuesto identificar la valencia iónica más probable para algunos elementos muy frecuentes en el conocimiento coloquial de la química y se supone de antemano que también en cuanto a su situación en la tabla periódica. Posteriormente se cotejará las respuestas obtenidas con el aprendizaje de los modelos de enlace obtenidos. 


\section{Ítem no 6:}

Como conclusión a la información obtenida en los dos ítems anteriores, en este se pretende relacionar el conocimiento que poseen los alumnos respecto al sistema periódico y las consecuencias que conlleva. Pretendemos relacionar las ideas de los alumnos respecto a la reactividad de los elementos y la posterior formación de enlaces.

6.- La configuración electrónica del potasio puede representarse:

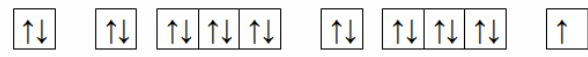

¿Qué información nos indica respecto a su comportamiento químico?

\section{Ítem $\mathbf{n}^{0} 7$}

7.- La última casilla del ejercicio anterior representa la ubicación de un electrón en su átomo. Explica con tus palabras donde se encuentra dicho electrón.

Esta cuestión trata de explicitar la relación entre la estructura electrónica y la distribución física de los electrones en el átomo. En este ejemplo que se ha propuesto se busca que los alumnos asignen alguna función al electrón que aparece solitario en el orbital s. Ello puede dar pie a justificar su participación en alguno de los modelos de enlace propuestos.

\section{Ítem $\mathbf{n}^{\circ} 8$}

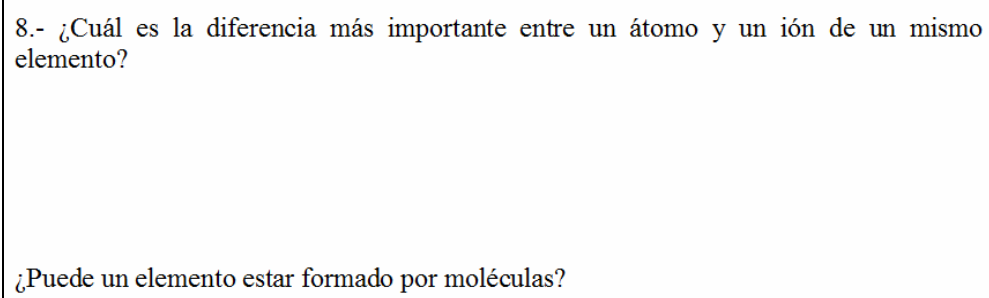


En esta cuestión se pretende obtener principios básicos acerca de las ideas que van a acercar a los alumnos al enlace iónico y al covalente. Ello se va a construir a partir de la concepción de los alumnos respecto a los iones y a las moléculas.

Al mismo tiempo se van a buscar explicaciones acerca de la imagen de los alumnos frente a la posibilidad de encontrar sustancias puras en forma molecular, respondiendo a algunas incorrecciones encontradas por otros investigadores.

\section{Ítem $n^{\circ} 9$}

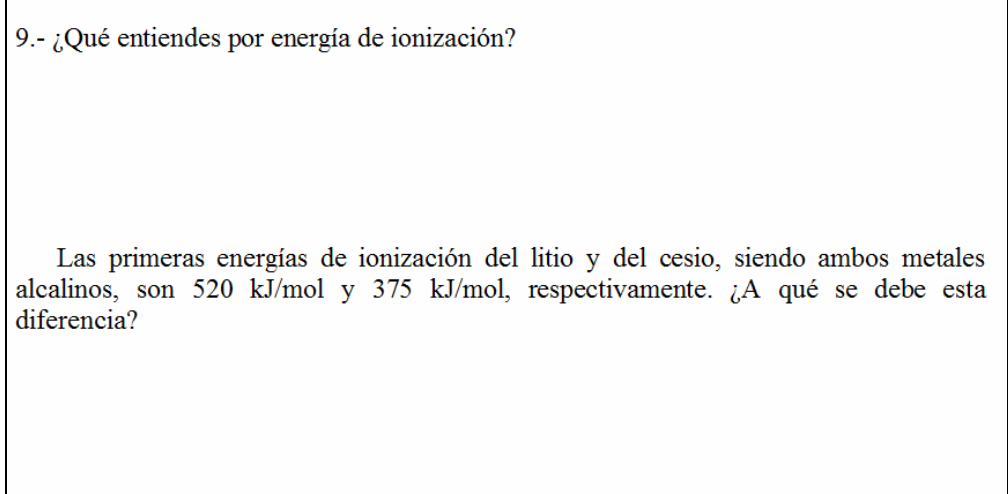

Dentro del estudio del sistema periódico y de las propiedades que se concluyen en él hemos tomado la energía de ionización como suficientemente representativa. Se pretende ver como los alumnos la definen y como razonan el porqué de algunos valores experimentales de esta propiedad.

Se espera que las respuestas dadas a esta cuestión guarden correlación con las del segundo ítem por referirse también a conceptos relacionados con la tabla periódica.

\section{Ítem n $\mathbf{n}^{0} \mathbf{1 0}$}

\begin{tabular}{|ll|}
\hline $10 .-$ Nombra y formula los siguientes compuestos químicos: \\
$\mathrm{HBr}$ & Hidruro de litio \\
$\mathrm{FeCl}_{3}$ & Óxido ferroso \\
$\mathrm{SO}_{2}$ & Ácido carbónico \\
$\mathrm{Cl}_{2}$ & Hidróxido estánnico \\
$\mathrm{Au}(\mathrm{OH})_{3}$ & Ácido bromhídrico \\
$\mathrm{H}_{2} \mathrm{SO}_{3}$ & Anhídrido sulfuroso \\
$\mathrm{HClO}$ & Sulfito sódico \\
$\mathrm{K}_{2} \mathrm{SO}_{4}$ & Fosfato cálcico \\
\hline
\end{tabular}


La formulación química como tal no se ha estudiado en este curso sino en tercero o cuarto de ESO. Se han propuesto unos compuestos y unas formulas, para formular y nombrar, y poder establecer su nivel procedimental.

Al igual que se ha presentado en el cuestionario Pos-Eso, pretendemos buscar una relación entre los resultados obtenidos en la formulación y el resto de ítems implicados en el cuestionario.

\begin{tabular}{|c|l|}
\hline Cuestión $\mathrm{n}^{\mathbf{o}}$ & \multicolumn{1}{c|}{ Conceptos relacionados } \\
\hline 1 & Símbolos y nombres de los elementos químicos \\
\hline 2 & $\begin{array}{l}\text { Bloques, grupos y periodos en la tabla periódica } \\
\text { Propiedades periódicas }\end{array}$ \\
\hline 3 & $\begin{array}{l}\text { Estructura atómica } \\
\text { Partículas subatómicas }\end{array}$ \\
\hline 4 & Configuración electrónica \\
\hline 5 & Valencias de los elementos químicos \\
\hline 6 & Configuración electrónica y sus consecuencias \\
\hline 7 & Orbital atómico \\
\hline 8 & Átomos, iones y moléculas \\
\hline 9 & Propiedades periódicas \\
\hline 10 & Formulación y nomenclatura química \\
\hline
\end{tabular}

Tabla 7.7.- Conceptos implicados en el cuestionario Pre-BAC.

\subsubsection{Cuestionario para establecer los conocimientos acerca del enlace químico en $2^{\circ}$ de bachillerato (Post-BAC)}

Este último cuestionario busca el nivel final conseguido por el alumno antes de abandonar la enseñanza secundaria y esta constituido por preguntas en su mayoría abiertas a excepción de dos de ellas donde se pide respuesta concreta sobre el tipo de enlace o geometría. 


\section{Ítem no 1}

1.- Utilizando los símbolos de Lewis, muestra como se unen los átomos para formar los compuestos:

$\begin{array}{ll}\text { a) } \mathrm{PH}_{3} & \text { b) } \mathrm{CO}_{3}{ }^{2-}\end{array}$

$\begin{array}{ll}\text { c) } \mathrm{AlF}_{3} & \text { d) } \mathrm{ClO}_{3}^{-}\end{array}$

$\begin{array}{ll}\text { e) } \mathrm{HCN} & \text { f) } \mathrm{PBr}_{5}\end{array}$

Esta cuestión se plantea de la misma forma que se hace en las pruebas de acceso a la Universidad y en consecuencia en una clase ordinaria de segundo de bachillerato. El único objetivo buscado en conocer si los alumnos utilizan correctamente el algoritmo propuesto para el cálculo del número de enlaces y su ubicación en una molécula.

Se han elegido moléculas que fuesen representativas de los ejemplos que suelen utilizarse en las actividades del aula, con casos de expansión y contracción del octeto, otras con carga formal, y una con tres átomos diferentes.

\section{Ítem $n^{\circ} 2$}

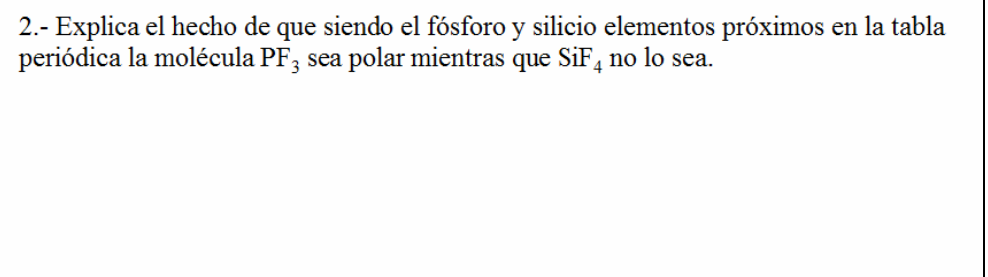

En esta cuestión se pretende conocer las ideas de los alumnos respecto a como pueden relacionar una propiedad macroscópica, como es la polaridad a partir de la estructura de la molécula. En esta primera cuestión se trata de conocer el alcance de la intervención puesto que es uno de los aspectos estudiados en ella.

En la intervención uno de los aspectos que se tratan es la separación de sustancias inmiscibles entre si debido a su diferente polaridad. Por tanto trataremos de 
evaluar si la explicación que dan los alumnos refleja una respuesta correcta acorde con lo experimentado ya que es una situación que se ha interiorizado de forma práctica desde el laboratorio.

\section{Ítem $n^{0} 3$}

3.- Escribe las fórmulas resonantes para las especies $\mathrm{NO}_{2}{ }^{-}$y $\mathrm{HNO}_{3}$. ¿Cuál es el orden de cada enlace?

El concepto de resonancia no hace referencia directa a la intervención propuesta, pero si a estructura molecular. No obstante la realización de estas fórmulas nos mostrará la capacidad del alumno a la hora de decidir como ubicar los enlaces en la molécula y en definitiva no es más que una situación un poco más compleja que la propuesta en el primer ítem.

\section{Ítem $n^{\circ} 4$}

4.- Indica el tipo de enlace químico que predomina en cada una de las siguientes sustancias:

a) bromuro de cesio.

b) cloro...

c) yoduro cálcico

d) dióxido de nitrógeno

e) sodio metálico.

f) agua.......

g) cloruro sódico.

h) óxido de magnesio

i) octano.

¿Cuáles serán los dos enlaces con mayor polaridad de todos ellos?

\begin{tabular}{|c|c|}
\hline Elemento & EN \\
\hline $\mathrm{Br}$ & 2.8 \\
\hline $\mathrm{Cs}$ & 0.8 \\
\hline $\mathrm{O}$ & 3.5 \\
\hline $\mathrm{N}$ & 3.0 \\
\hline $\mathrm{I}$ & 2.1 \\
\hline $\mathrm{Ca}$ & 1.0 \\
\hline $\mathrm{Na}$ & 1.0 \\
\hline $\mathrm{H}$ & 2.1 \\
\hline $\mathrm{Cl}$ & 3.0 \\
\hline $\mathrm{Mg}$ & 1.2 \\
\hline
\end{tabular}

En esta cuestión se pretende que los alumnos establezcan el tipo de enlace que existe entre cada tipo de átomos. Esta misma cuestión se ha planteado también a los alumnos de tercer curso de ESO. Se trata de clasificar a los átomos que intervienen en metales o no metales y asignar uno u otro modelo. 
También se pregunta por la polaridad de los enlaces a partir de las electronegatividades para ver si atribuyen mayor o menor carácter polar a un enlace que se les ha explicado, forma parte de una estructura cristalina.

\section{Ítem $n^{0} 5$}

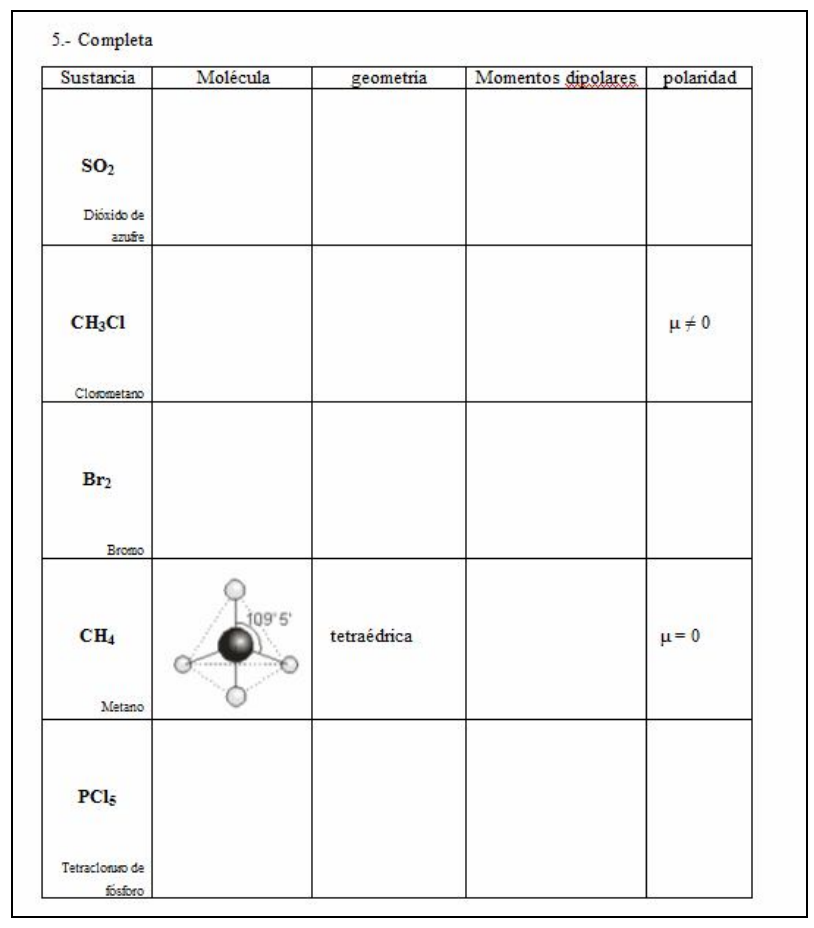

En esta cuestión se pretenden aunar todos los conceptos relacionados con el enlace covalente, desde el cálculo de los enlaces y el dibujo de la molécula a la obtención de la geometría basada en el modelo VSERP y, finalmente la obtención de la polaridad de la molécula a partir de los momentos dipolares de los enlaces. Para facilitar la comprensión de la tarea requerida se introducen en la tabla algunos ejemplos orientativos.

Con esta cuestión pretendemos conocer si los alumnos han consolidado los conocimientos necesarios acerca del enlace covalente molecular. 


\section{Ítem n $\mathbf{n}^{0} 6$}

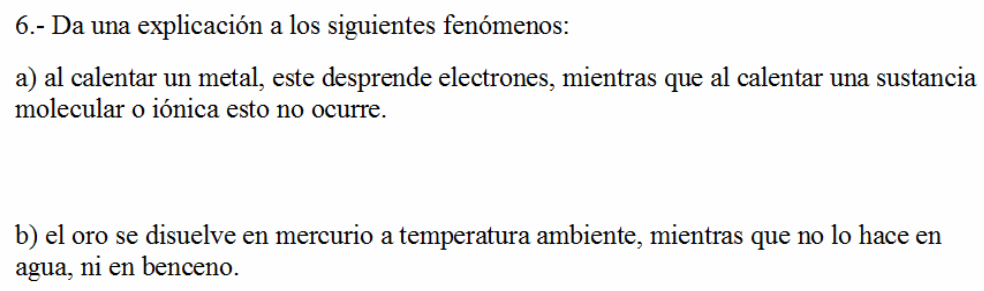

b) el oro se disuelve en mercurio a temperatura ambiente, mientras que no lo hace en agua, ni en benceno.

Tratamos de conocer si los alumnos establecen una conexión entre los tipos de enlace y las consecuencias macroscópicas que se ponen de manifiesto. Esta cuestión se ha presentado de esta misma forma en pruebas de acceso a la Universidad.

La primera hace referencia al enlace metálico y su estructura electrónica, mientras que la segunda lo hace al hecho de que sustancias similares se disuelven entre otras de la misma polaridad.

\section{Ítem $\mathbf{n}^{0} 7$}

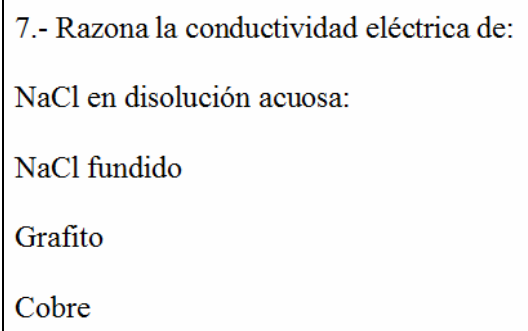

En esta cuestión se hace referencia al hecho de que una misma propiedad macroscópica como es la conductividad eléctrica se puede presentar en sustancias formadas por enlaces covalentes, metálicos o iónicos. Es una cuestión abierta donde se espera que los alumnos argumenten el papel de los diferentes modelos de enlace frente a este hecho concreto.

Hemos considerado que para que un alumno conteste correctamente a estas cuestiones es necesario que conozca la naturaleza de los tres enlaces y además la cuestión deja margen para explicarlo. 


\section{Ítem n $\mathbf{n}^{\circ} 8$}

8.- Tanto las moléculas de cloro como las de yodo están formadas por enlaces covalentes entre dos átomos, a los que falta un electrón en su última capa. ¿Por qué el primero es un gas en condiciones normales, mientras que el segundo es un sólido?

Esta cuestión pretende obtener la opinión de los alumnos frente a las fuerzas intermoleculares y las propiedades periódicas. Se trata de una cuestión frecuente en este tema y representa un ejemplo claro de la variación de la intensidad de las fuerzas intermoleculares, donde además de presentar una situación fácilmente interpretable sensorialmente pone de manifiesto la importancia de la estructura electrónica en polarizabilidad de la molécula y en las propiedades físicas resultantes.

\section{Ítem $n^{\circ} 9$}

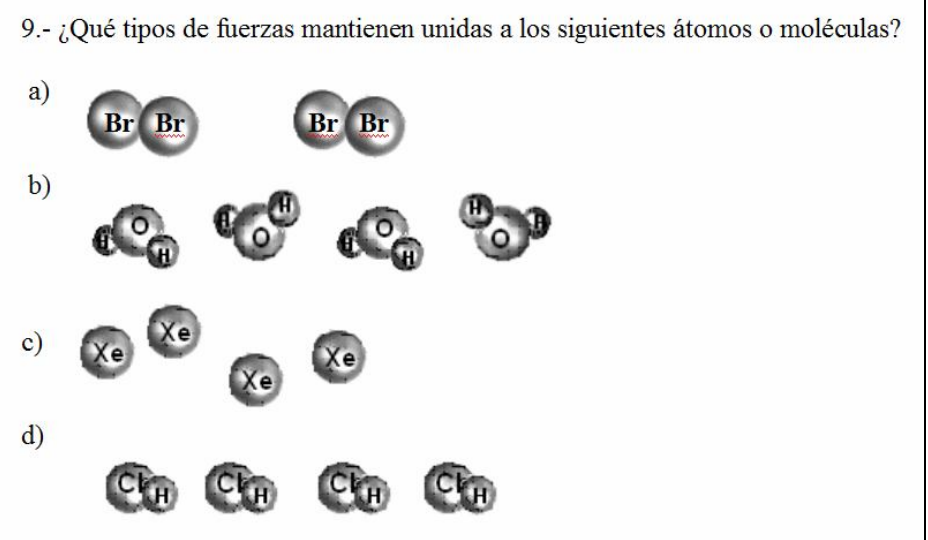

Esta cuestión pretende recoger los conocimientos de los alumnos respecto a las fuerzas intermoleculares en general.

Se plantean varias sustancias con diferentes características de polaridad y polarizabilidad. Se espera que los alumnos indiquen la naturaleza de la interacción y la justifiquen. 


\section{Ítem $\mathbf{n}^{\mathbf{0}} \mathbf{1 0}$}

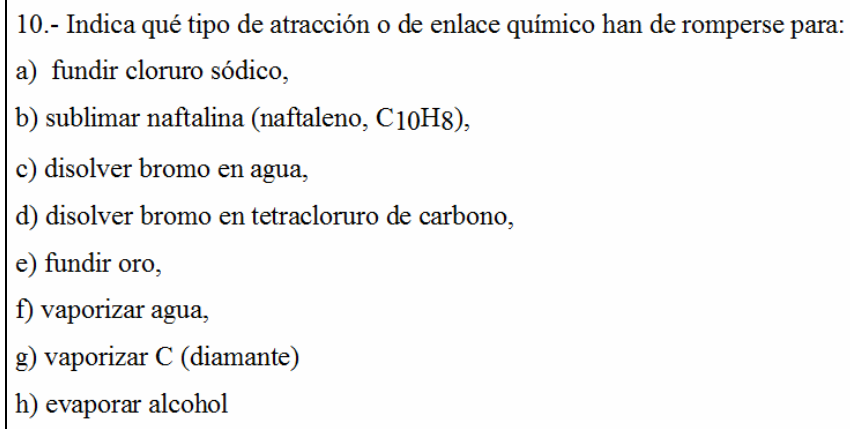

En esta cuestión se hace referencia tanto a los enlaces interatómicos como a las fuerzas intermoleculares. Se plantea de forma abierta con la intención de comprobar si los alumnos advierten y justifican ambos tipos de uniones en una misma sustancia, y consiguen por tanto encontrar una relación entre cambios físicos y químicos.

Esta cuestión se convierte en la parte más atractiva del cuestionario ya que supone la convergencia de todo lo estudiado en el tema. Supone distinguir en que situaciones de produce un cambio químico y por tanto se precisa vencer una atracción interatómico y en cuales un cambio físico supone vencer fuerzas intermoleculares.

Además de ello encontramos ejemplos en los que es necesario vencer tanto fuerzas interatómicas como intermoleculares, lo que supone una perfecta síntesis del tema.

\begin{tabular}{|c|l|}
\hline Cuestión $\mathrm{n}^{\mathbf{o}}$ & \multicolumn{1}{|c|}{ Conceptos relacionados } \\
\hline 1 & Estructuras de Lewis \\
\hline 2 & Estructuras de Lewis. Geometría molecular. Polaridad \\
\hline 3 & Estructuras de Lewis. Formas resonantes. \\
\hline 4 & Tipo de enlace químico. \\
\hline 5 & Geometría molecular. Polaridad. \\
\hline 6 & Propiedades del enlace. \\
\hline 7 & Propiedades del enlace. \\
\hline 8 & Consecuencias del enlace intermolecular \\
\hline 9 & Enlaces interatómicos e intermoleculares \\
\hline 10 & Enlaces interatómicos e intermoleculares \\
\hline
\end{tabular}

Tabla 7.8.- Conceptos implicados en el cuestionario Post-BAC. 


\subsubsection{Metodología seguida en la validación de cuestionarios}

La finalidad de los cuestionarios es evaluativa a la vez que diagnóstica, por tanto han sido elaborados de forma que puedan observarse posibles errores conceptuales de los alumnos y poder estudiar y comparar los estados pre y postinstruccionales. Así mismo los cuestionarios deben ser evaluados de forma que se garantice la fiabilidad y validez de los mismos.

Para considerar válida una prueba, esta debe cumplir el criterio adoptado en la investigación, para ello como mínimo debe contemplar la validez de constructo, la validez de contenido y la validez de concurrencia.

Del mismo modo también debe atender ciertos criterios de fiabilidad y poder discriminatorio.

\subsubsection{Validez de constructo, de contenido y de concurrencia.}

La validez de constructo hace referencia al hecho de que el cuestionario destinado a medir el grado de conocimiento debe ajustarse a las situaciones problemáticas propias del nivel a estudiar y que deben haberse utilizado en investigaciones similares de los mismos contenidos o bien ajustarse a los esquemas conceptuales de los alumnos.

Dicha validez de constructo también implica que debe haber una relación entre el resultado obtenido por un alumno en una prueba y la media de los resultados en otras tareas realizadas por él mismo. En definitiva, que debe haber cierta homogeneidad en su actividad.

La validez de contenido atiende a la necesidad de que un instrumento de medida debe abarcar, en la medida de lo posible, todos los aspectos implicados en la intervención, para ello es conveniente hacer inventarios de los elementos estudiados y recurrir a la opinión de terceros. En este aspecto cabe destacar que todos los cuestionarios se han realizado atendiendo a los contenidos explicitados en los currículos oficiales. 
Por último, un instrumento posee validez concurrente si los resultados obtenidos son iguales o similares a los obtenidos a través de otros instrumentos que midan los mismos aspectos, o bien a los obtenidos mediante un criterio externo.

\subsubsection{Fiabilidad y poder discriminatorio}

Un instrumento es fiable si existe concordancia entre los resultados obtenidos al aplicarlo en varias situaciones en igualdad de condiciones. En nuestro caso debe existir cierta correlación entre los resultados obtenidos tras la intervención realizada con diferentes grupos, así como con diferentes profesores. Más aún, por tratarse de pruebas de carácter abierto, debe existir también una relación entre las respuestas erróneas y también entre las respuestas parcialmente correctas.

Confirmar la fiabilidad de un cuestionario exige el cumplimiento de ciertas pruebas:

- Estimar el coeficiente de correlación entre los resultados de los diferentes grupos - Valorar la estabilidad de las ideas alternativas

El poder discriminatorio es la capacidad de distinguir a unos alumnos de otros y está relacionado con las distribuciones de frecuencia. Para el cálculo del índice de discriminación se comparan las medias de los alumnos situados en el cuartil superior y los del cuartil inferior.

El poder de discriminación también está relacionado con el índice de dificultad de cada una de las cuestiones de la prueba. El índice de dificultad de una prueba viene dado por el promedio de los índices de dificultad de cada ítem, siendo estos la fracción de alumnos que dan respuesta incorrecta. Cuando la dificultad de cada ítem es similar, se dice que el poder discriminatorio de la prueba es bajo y no permitirá establecer diferencias significativas entre alumnos de características diferentes. 


\subsubsection{Análisis de la validez y fiabilidad de los cuestionarios}

En todos los cuestionarios empleados en la investigación se ha tenido presente que la validez de los mismos depende del criterio que se considere. En nuestro caso hemos concretado estos criterios manteniendo como mínimo la validez interna, la validez de constructo, la validez de contenido y la validez de concurrencia, así como las pruebas estadísticas precisas para determinarlas.

La validez interna se pone de manifiesto si se consigue demostrar una causalidad sobre los resultados obtenidos, es decir si existe una influencia real de la variable modificada en el proceso de aprendizaje, o variable independiente, que en nuestro caso es la intervención didáctica, sobre la variable dependiente y que va a ser el resultado postinstrucional.

La validez externa reside en la capacidad de poder extrapolar los resultados de la muestra a toda la población estudiada. Esta confirmación está sujeta a múltiples dificultades, en cuanto que el hecho de intervenir en la investigación condiciona en mayor o menor medida a los individuos implicados. Además el propio desarrollo de la investigación requiere un proceso distinto del ordinario.

Tanto una como otra condición de validez quedarán satisfechas en tanto en cuanto los resultados obtenidos por los grupos experimentales mejoren los de los grupos de control, en el primer caso, y en cuanto la dispersión de los resultados sea similar en todos los casos.

La validez de construto no va a tener que ser comprobada en ningún caso puesto que, como ya se ha indicado anteriormente, ha sido condición indispensable para todos los ítems, estar referidos a aspectos curriculares de los conceptos estudiados. No obstante se ha cuidado el hecho de dar un formato similar al de cuestiones habituales, y más aún, los cuestionarios utilizados con posterioridad a la intervención se han utilizado, previo aviso a los alumnos, como nota evaluativa.

La validez concurrente está relacionada con la coherencia de los resultados obtenidos en otras pruebas diferentes que midan aspectos relacionados con los 
estudiados. En nuestro caso estudiaremos la relación de las notas medias obtenidas a lo largo del mismo curso académico y las obtenidas en las pruebas.

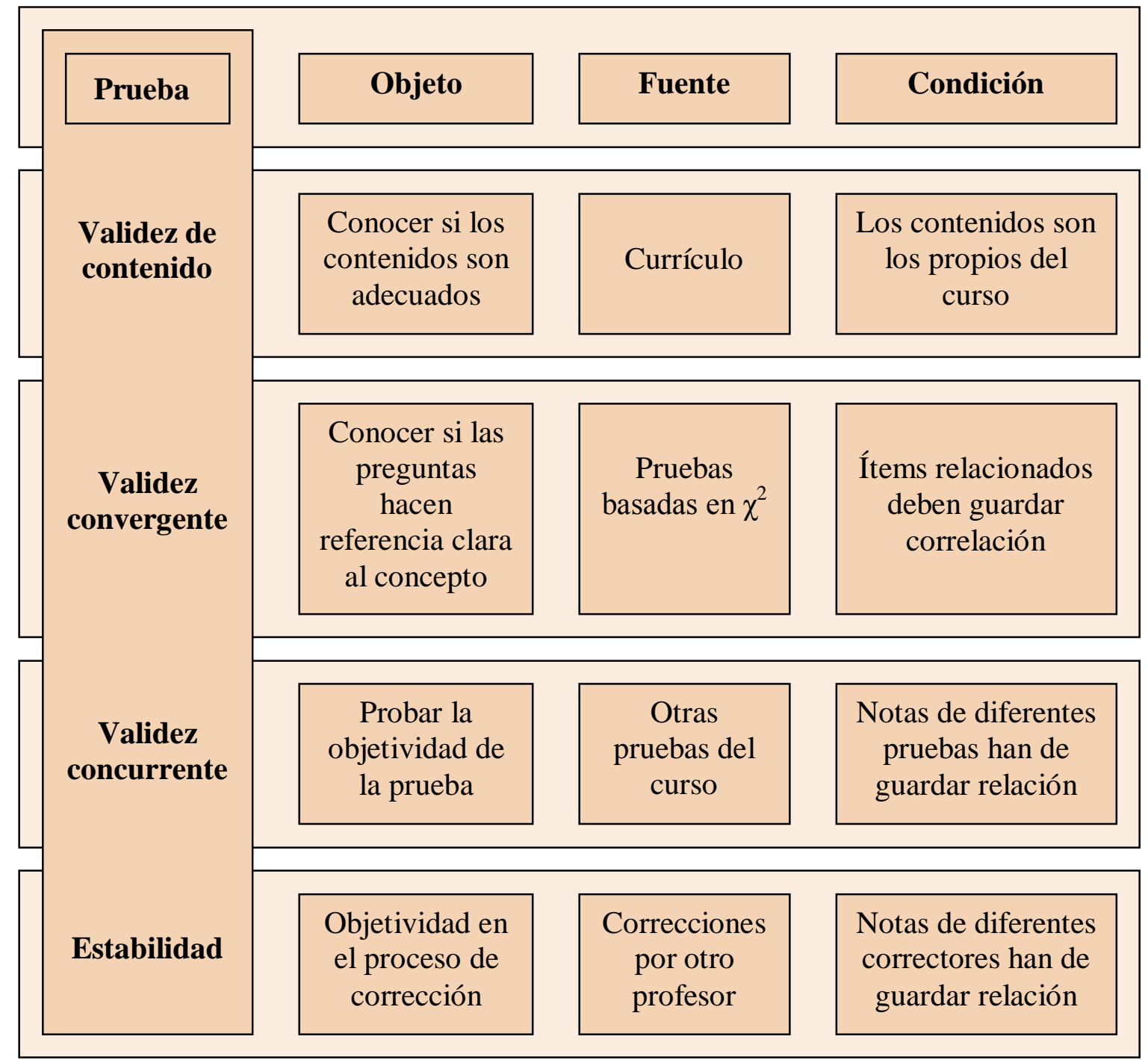

Figura 7.2. Pruebas utilizadas en la validación de cuestionarios. 


\subsubsection{Validez y fiabilidad del Pre-ESO}

En este primer cuestionario se ha tenido en cuenta que los alumnos desconocen prácticamente todo lo relacionado con el tema del enlace químico y por tanto es en este momento cuando mayor debe ser la homogeneidad de resultados. La mayor parte de las preguntas hacen referencia a la vida cotidiana, al sentido común o aspectos muy sencillos de ciencias.

En primer lugar, y teniendo en cuenta esta falta de instrucción de los alumnos realizaremos una prueba de validez convergente. Esto supone que debe existir una correlación entre las respuestas dadas por un mismo alumno a cuestiones relacionadas, es decir que cabe esperar que haya mayor correlación entre las parejas de ítems, 1 - 6, 2 - 5, 3 - 4, 5 -10, 6 -10 y $3-5$, que entre el resto.

En la corrección de los cuestionarios y con la intención de simplificar el tratamiento estadístico se ha puntuado cada cuestión con tres valores distintos, $0,0.5 \mathrm{y}$ 1, dependiendo si la respuesta era incorrecta, parcialmente correcta o correcta respectivamente, según se detalla en el anexo II. A partir de estos datos y utilizando el paquete informático SPSS, concretamente en las herramientas de submenú "tablas de contingencia", dentro del apartado "analizar", hemos procedido a cuantificar las posibles correlaciones.

Para conocer la relación entre los valores de estas variables recurriremos a pruebas no paramétricas para variables ordinales, como el coeficiente de contingencia ${ }^{3}$, la gamma de Goodman ${ }^{4}$ y el coeficiente R de Pearson ${ }^{5}$.

\footnotetext{
${ }^{3}$ El coeficiente de contingencia es una medida de asociación de variables, toma valores entre 0 y 1 para una nula o perfecta correlación respectivamente, considerando que existe de forma aceptable para un valor igual o superior a 0,3 .

${ }^{4}$ La Gamma de Gooman en una medida simétrica que oscila entre -1 y +1 , e indica la relación entre el número de prediccines correctas menos el de incorrectas dividido por el número total de predicciones.

${ }^{5} \mathrm{La} \mathrm{R}$ de Pearson mide la relación lineal entre dos variables cuantitativas. Toma valores entre $-1 \mathrm{y}+1$, indicando la relación inversa o directa respectivamente (el valor 0 indica independencia entre ellas), consideramos un valor aceptable a partir de 0,3 .
} 


\begin{tabular}{|c|c|c|}
\hline $\begin{array}{c}\text { Pareja } \\
\text { de ítems }\end{array}$ & Estadístico empleado & Valor \\
\hline $1-6$ & $\begin{array}{l}\text { Coeficiente de contingencia (basado en } x^{2} \text { ) } \\
\text { Gamma de Goodman } \\
\text { R de Pearson }\end{array}$ & $\begin{array}{l}0,426 \\
0,533 \\
0,369^{*}\end{array}$ \\
\hline $2-5$ & $\begin{array}{l}\text { Coeficiente de contingencia (basado en } x^{2} \text { ) } \\
\text { Gamma de Goodman } \\
\text { R de Pearson }\end{array}$ & $\begin{array}{l}0,281 \\
0,134 \\
0,051\end{array}$ \\
\hline $3-4$ & $\begin{array}{l}\text { Coeficiente de contingencia (basado en } x^{2} \text { ) } \\
\text { Gamma de Goodman } \\
\text { R de Pearson }\end{array}$ & $\begin{array}{l}0,416 \\
0,541 \\
0,356^{*}\end{array}$ \\
\hline $3-5$ & $\begin{array}{l}\text { Coeficiente de contingencia (basado en } x^{2} \text { ) } \\
\text { Gamma de Goodman } \\
\text { R de Pearson }\end{array}$ & $\begin{array}{l}0,231 \\
0,302 \\
0,222^{\star *}\end{array}$ \\
\hline $5-10$ & $\begin{array}{l}\text { Coeficiente de contingencia (basado en } x^{2} \text { ) } \\
\text { Gamma de Goodman } \\
\text { R de Pearson }\end{array}$ & $\begin{array}{l}0,381 \\
0,549 \\
0,393^{*}\end{array}$ \\
\hline $6-10$ & $\begin{array}{l}\text { Coeficiente de contingencia (basado en } x^{2} \text { ) } \\
\text { Gamma de Goodman } \\
\text { R de Pearson }\end{array}$ & $\begin{array}{l}0,394 \\
0,544 \\
0,375^{*}\end{array}$ \\
\hline $7-10$ & $\begin{array}{l}\text { Coeficiente de contingencia (basado en } x^{2} \text { ) } \\
\text { Gamma de Goodman } \\
\text { R de Pearson }\end{array}$ & $\begin{array}{l}0,279 \\
0,223 \\
0,118\end{array}$ \\
\hline $4-8$ & $\begin{array}{l}\text { Coeficiente de contingencia (basado en } x^{2} \text { ) } \\
\text { Gamma de Goodman } \\
\text { R de Pearson }\end{array}$ & $\begin{array}{l}0,273 \\
0,461 \\
0,223^{* *}\end{array}$ \\
\hline $1-9$ & $\begin{array}{l}\text { Coeficiente de contingencia (basado en } \mathrm{x}^{2} \text { ) } \\
\text { Gamma de Goodman } \\
\mathrm{R} \text { de Pearson }\end{array}$ & $\begin{array}{l}0,241 \\
0,273 \\
0,178\end{array}$ \\
\hline $4-10$ & $\begin{array}{l}\text { Coeficiente de contingencia (basado en } \mathrm{x}^{2} \text { ) } \\
\text { Gamma de Goodman } \\
\mathrm{R} \text { de Pearson }\end{array}$ & $\begin{array}{l}0,237 \\
0,457 \\
0,241^{* *}\end{array}$ \\
\hline $9-10$ & $\begin{array}{l}\text { Coeficiente de contingencia (basado en } \mathrm{x}^{2} \text { ) } \\
\text { Gamma de Goodman } \\
\mathrm{R} \text { de Pearson }\end{array}$ & $\begin{array}{l}0,315 \\
0,406 \\
0,279^{\star *}\end{array}$ \\
\hline & \multicolumn{2}{|c|}{${ }^{*}$ Asociación de variables significativas con $p<0,001 ;{ }^{* *}$ idem con $p<0,05$} \\
\hline
\end{tabular}

Tabla 7.9.- Correlación entre respuestas de algunos ítems del Pre-ESO ${ }^{6}$.

Con tal de evaluar la validez concurrente del cuestionario trataremos de comparar los resultados obtenidos con otros resultados relacionados pero que están fuera de la actuación. En nuestro caso hemos considerado como dato más fiable la nota media de cada alumno al finalizar el curso en que se ha intervenido, sabiendo que es un promedio de actividades conceptuales, procedimentales y actitudinales que caracterizan a cada alumno durante un periodo de tiempo amplio antes, durante y después del proceso.

\footnotetext{
${ }^{6}$ Las seis primeras parejas son las que se espera que guaden mayor correlación.
} 


\begin{tabular}{|l|c|c|c|c|}
\hline \multicolumn{1}{|c|}{ Grupo } & $\begin{array}{c}\mathbf{N}^{\mathbf{0}} \text { de } \\
\text { alumnos }\end{array}$ & $\begin{array}{c}\text { Media } \\
\text { intervención }\end{array}$ & Media curso & correlación \\
\hline Experimental & 95 & 5,12 & 5,93 & 0,388 \\
\hline Control & 23 & 5,27 & 4,54 & 0,771 \\
\hline Control externo & 17 & 4,33 & 6,10 & 0,810 \\
\hline Total & 135 & 5,03 & 5,77 & 0,441 \\
\hline
\end{tabular}

Tabla 7.10.- Correlación entre las puntuaciones del pre-ESO y las del curso

Para concluir la fiabilidad de la prueba haremos referencia a la estabilidad de las puntuaciones, para lo cual se ha procedido a realizar dos correcciones diferentes por parte de dos profesores. Si se constata que hay una elevada correlación entre ambas calificaciones quedará acreditada la suficiente objetividad en la corrección.

Teniendo en cuenta que la puntuación final es un único valor numérico por cada alumno y corrección, consideraremos en este caso el coeficiente de correlación de pearson, mientras que para comparar los resultados de cada ítem, atenderemos a coeficientes de contingencia para tablas de 3 x 3, dada la puntuación $0,0.5$ y 1 , y por tanto con 3 grados de libertad.

\begin{tabular}{|l|c|c|c|c|c|c|c|c|c|c|c|}
\hline \multicolumn{1}{|c|}{ Ítem n $^{\mathbf{0}}$} & $\mathbf{1}$ & $\mathbf{2}$ & $\mathbf{3}$ & $\mathbf{4}$ & $\mathbf{5}$ & $\mathbf{6}$ & $\mathbf{7}$ & $\mathbf{8}$ & $\mathbf{9}$ & $\mathbf{1 0}$ & Total \\
\hline $\begin{array}{l}\text { Coef. De } \\
\text { correlación }\end{array}$ & 0,574 & 0,942 & 0,626 & 0,124 & 0,652 & 0,596 & 0,878 & 0,462 & 0,770 & 0,808 & 0,890 \\
\hline $\begin{array}{l}\text { Coef. De } \\
\text { contingencia }\end{array}$ & 0,608 & 0,707 & 0,540 & 0,123 & 0,659 & 0,730 & 0,751 & 0,420 & 0,637 & 0,660 & 0,914 \\
\hline
\end{tabular}

Tabla 7.11.- Correlación entre las puntuaciones otorgadas por dos investigadores diferentes.

A la vista de los resultados obtenidos, podemos concluir que queda garantizada la validez de este cuestionario en todos los aspectos considerados, por los que consideraremos correctos los datos obtenidos en el mismo. 


\subsubsection{Validez y fiabilidad del Post-ESO}

Llegado el momento de realizar este cuestionario, los alumnos ya tienen un conocimiento importante acerca del enlace químico, por lo que se podrán obtener más conclusiones que en el caso anterior.

En primer lugar vamos a buscar la vinculación que tienen entre si los ítems que se refieren a un mismo concepto. En este cuestionario se espera que las parejas 1 - 5, 1 - 6, 2 - 4, y 6-7 guarden mayor relación entre si que el resto.

\begin{tabular}{|c|c|c|}
\hline $\begin{array}{c}\text { Pareja } \\
\text { de ítems }\end{array}$ & Estadístico empleado & Valor \\
\hline $1-5$ & $\begin{array}{l}\text { Coeficiente de contingencia (basado en } x^{2} \text { ) } \\
\text { Gamma de Goodman } \\
\text { R de Pearson }\end{array}$ & $\begin{array}{l}0,408 \\
0,631 \\
0,424^{*}\end{array}$ \\
\hline $1-6$ & $\begin{array}{l}\text { Coeficiente de contingencia (basado en } x^{2} \text { ) } \\
\text { Gamma de Goodman } \\
\text { R de Pearson }\end{array}$ & $\begin{array}{l}0,414 \\
0,596 \\
0,416^{*}\end{array}$ \\
\hline $2-4$ & $\begin{array}{l}\text { Coeficiente de contingencia (basado en } x^{2} \text { ) } \\
\text { Gamma de Goodman } \\
\text { R de Pearson }\end{array}$ & $\begin{array}{l}0,351 \\
0,421 \\
0,324^{*}\end{array}$ \\
\hline $6-7$ & $\begin{array}{l}\text { Coeficiente de contingencia (basado en } x^{2} \text { ) } \\
\text { Gamma de Goodman } \\
\text { R de Pearson }\end{array}$ & $\begin{array}{l}0,360 \\
0,525 \\
0,379^{*}\end{array}$ \\
\hline $3-9$ & $\begin{array}{l}\text { Coeficiente de contingencia (basado en } x^{2} \text { ) } \\
\text { Gamma de Goodman } \\
\text { R de Pearson }\end{array}$ & $\begin{array}{l}0,472 \\
0,612 \\
0,497^{\star}\end{array}$ \\
\hline $5-7$ & $\begin{array}{l}\text { Coeficiente de contingencia (basado en } \mathrm{x}^{2} \text { ) } \\
\text { Gamma de Goodman } \\
\mathrm{R} \text { de Pearson }\end{array}$ & $\begin{array}{l}0,263 \\
0,333 \\
0,250^{\star *}\end{array}$ \\
\hline $6-10$ & $\begin{array}{l}\text { Coeficiente de contingencia (basado en } x^{2} \text { ) } \\
\text { Gamma de Goodman } \\
\text { R de Pearson }\end{array}$ & $\begin{array}{l}0,255 \\
0,239 \\
0,149\end{array}$ \\
\hline $4-5$ & $\begin{array}{l}\text { Coeficiente de contingencia (basado en } \mathrm{x}^{2} \text { ) } \\
\text { Gamma de Goodman } \\
\mathrm{R} \text { de Pearson }\end{array}$ & $\begin{array}{l}0,269 \\
0,294 \\
0,225^{* *}\end{array}$ \\
\hline $4-9$ & $\begin{array}{l}\text { Coeficiente de contingencia (basado en } x^{2} \text { ) } \\
\text { Gamma de Goodman } \\
\text { R de Pearson }\end{array}$ & $\begin{array}{l}0,321 \\
0,419 \\
0,313^{*}\end{array}$ \\
\hline $1-9$ & $\begin{array}{l}\text { Coeficiente de contingencia (basado en } x^{2} \text { ) } \\
\text { Gamma de Goodman } \\
\text { R de Pearson }\end{array}$ & $\begin{array}{l}0,303 \\
0,418 \\
0,284^{\star *}\end{array}$ \\
\hline & \multicolumn{2}{|c|}{${ }^{*}$ Asociación de variables significativas con $p<0,001 ;{ }^{* *}$ idem con $p<0,05$} \\
\hline
\end{tabular}

Tabla 7.12.-Correlación entre las respuestas de diferentes ítems 
En cuanto a la estabilidad de las puntuaciones, a continuación se analiza la relación existente entre las notas otorgadas por los dos correctores diferentes, y observamos que se da una alta correlación tanto entre todos y cada uno de los ítems, como en la nota total del ejercicio:

\begin{tabular}{|l|c|c|c|c|c|c|c|c|c|c|c|}
\hline \multicolumn{1}{|c|}{ Ítem n $^{\mathbf{0}}$} & $\mathbf{1}$ & $\mathbf{2}$ & $\mathbf{3}$ & $\mathbf{4}$ & $\mathbf{5}$ & $\mathbf{6}$ & $\mathbf{7}$ & $\mathbf{8}$ & $\mathbf{9}$ & $\mathbf{1 0}$ & Total \\
\hline $\begin{array}{l}\text { Coef. De } \\
\text { correlación }\end{array}$ & 0,784 & 0,783 & 0,846 & 0,812 & 0,837 & 0,883 & 0,931 & 0,911 & 0,786 & 0,461 & 0,971 \\
\hline $\begin{array}{l}\text { Coef. De } \\
\text { contingencia }\end{array}$ & 0,659 & 0,648 & 0,707 & 0,680 & 0,714 & 0,710 & 0,681 & 0,744 & 0,679 & 0,485 & 0,933 \\
\hline
\end{tabular}

Tabla 7.13.- Correlación entre las puntuaciones otorgadas por dos investigadores diferentes

Y por último se recurre de nuevo a comparar las notas medias del cuestionario y de la nota obtenida en la materia a lo largo del curso para contrastar la validez concurrente:

\begin{tabular}{|l|c|c|c|c|}
\hline \multicolumn{1}{|c|}{ Grupo } & $\begin{array}{c}\mathbf{N}^{\mathbf{0}} \text { de } \\
\text { alumnos }\end{array}$ & $\begin{array}{c}\text { Media } \\
\text { intervención }\end{array}$ & Media curso & correlación \\
\hline Experimental & 95 & 4,58 & 5,93 & 0,388 \\
\hline Control & 23 & 4,05 & 4,54 & 0,771 \\
\hline Control externo & 17 & 2,87 & 6,10 & 0,810 \\
\hline Total & 135 & 4,28 & 5,77 & 0,441 \\
\hline
\end{tabular}

Tabla 7.14.- Correlación entre las puntuaciones del Post-ESO y las del curso

En este caso la correlación entre las notas obtenidas por el grupo experimental y las medias del curso, guardan una relación que aunque suficiente, no es muy alta, cosa que si ocurre con todos los grupos de control.

A la vista de todos estos resultados consideraremos válido este cuestionario en todos sus aspectos. 


\subsubsection{Validez y fiabilidad del Pre-BAC}

Para refrendar la validez del cuestionario, haremos referencia a su planteamiento teórico. En su diseño se tuvo en cuenta que estaba dirigido a alumnos de segundo curso de bachillerato, que ya habían cursado estudios de química, de forma optativa en cuarto curso de ESO y de forma obligatoria en primero de bachillerato. Todos ellos habían estudiado los aspectos relativos a la estructura de la materia, modelos atómicos y propiedades periódicas, por lo que esta prueba debería ser contestada con éxito en la gran mayoría de los casos.

Además de la adecuación teórica del contenido del cuestionario, deberemos comprobar que existe validez convergente y validez discriminante. La validez convergente implica que ítems que se refieran a conceptos relacionados deben obtener respuestas con cierta correlación, y en el caso opuesto, no debe haber una correlación significativa entre las respuestas $^{7}$ de aquellos ítems cuyos contenidos no guarden relación. Atendiendo a esta idea, lo lógico es que deba existir una correlación mayor entre las respuestas dadas a las parejas de cuestiones 1-2, 1-10, 2-6, 2-9, y 4-5, que al resto.

\begin{tabular}{|c|c|c|}
\hline $\begin{array}{c}\text { Pareja } \\
\text { de ítems }\end{array}$ & Estadístico empleado & Valor \\
\hline $1-2$ & $\begin{array}{l}\text { Coeficiente de contingencia (basado en } \mathrm{x}^{2} \text { ) } \\
\text { Gamma de Goodman } \\
\mathrm{R} \text { de Pearson }\end{array}$ & $\begin{array}{l}0,387 \\
0,795 \\
0,370^{\star *}\end{array}$ \\
\hline $1-10$ & $\begin{array}{l}\text { Coeficiente de contingencia (basado en } x^{2} \text { ) } \\
\text { Gamma de Goodman } \\
\text { R de Pearson }\end{array}$ & $\begin{array}{l}0,423 \\
0,835 \\
0,350^{\star *}\end{array}$ \\
\hline $2-6$ & $\begin{array}{l}\text { Coeficiente de contingencia (basado en } \mathrm{x}^{2} \text { ) } \\
\text { Gamma de Goodman } \\
\mathrm{R} \text { de Pearson }\end{array}$ & $\begin{array}{l}0,267 \\
0,419 \\
0,215\end{array}$ \\
\hline $2-9$ & $\begin{array}{l}\text { Coeficiente de contingencia (basado en } \mathrm{X}^{2} \text { ) } \\
\text { Gamma de Goodman } \\
\mathrm{R} \text { de Pearson }\end{array}$ & $\begin{array}{l}0,451 \\
0,551 \\
0,416^{*}\end{array}$ \\
\hline $4-5$ & $\begin{array}{l}\text { Coeficiente de contingencia (basado en } \mathrm{x}^{2} \text { ) } \\
\text { Gamma de Goodman } \\
\mathrm{R} \text { de Pearson }\end{array}$ & $\begin{array}{l}0,467 \\
0,562 \\
0,415^{\star}\end{array}$ \\
\hline $3-4$ & $\begin{array}{l}\text { Coeficiente de contingencia (basado en } \mathrm{x}^{2} \text { ) } \\
\text { Gamma de Goodman } \\
\mathrm{R} \text { de Pearson }\end{array}$ & $\begin{array}{l}0,185 \\
0,141 \\
0,113\end{array}$ \\
\hline $3-10$ & $\begin{array}{l}\text { Coeficiente de contingencia (basado en } \mathrm{X}^{2} \text { ) } \\
\text { Gamma de Goodman } \\
\mathrm{R} \text { de Pearson }\end{array}$ & $\begin{array}{l}0,184 \\
0,107 \\
0,071\end{array}$ \\
\hline & \multicolumn{2}{|c|}{ *Asociación de variables significativas con $p<0,05 ;{ }^{* * i d e m}$ con $p<0,1$} \\
\hline
\end{tabular}

Tabla 7.15.- Correlación entre respuestas de diferentes ítems del Pre-BAC.

\footnotetext{
${ }^{7}$ Las puntuaciones atribuidas a cada cuestión se detallan en el anexo VIII
} 
La fiabilidad de la prueba respecto a la puntuación, queda constatada al observar la elevada correlación existente en todos los ítems entre las puntuaciones otorgadas por dos investigadores diferentes.

\begin{tabular}{|l|c|c|c|c|c|c|c|c|c|c|c|}
\hline \multicolumn{1}{|c|}{ Ítem n $^{\mathbf{0}}$} & $\mathbf{1}$ & $\mathbf{2}$ & $\mathbf{3}$ & $\mathbf{4}$ & $\mathbf{5}$ & $\mathbf{6}$ & $\mathbf{7}$ & $\mathbf{8}$ & $\mathbf{9}$ & $\mathbf{1 0}$ & Total \\
\hline $\begin{array}{l}\text { Coef. De } \\
\text { correlación }\end{array}$ & 1,000 & 0,795 & 0,765 & 0,598 & 0,835 & 0,812 & 0,658 & 0,807 & 0,894 & 0,647 & 0,888 \\
\hline $\begin{array}{l}\text { Coef. De } \\
\text { contingencia }\end{array}$ & 0,707 & 0,743 & 0,716 & 0,585 & 0,668 & 0,752 & 0,576 & 0,768 & 0,779 & 0,743 & 0,926 \\
\hline
\end{tabular}

Tabla 7.16.- Correlación entre las puntuaciones otorgadas por dos investigadores diferentes

Por último vamos a comparar, la nota obtenida en este cuestionario con la nota media del curso en la asignatura de física y química, para tratar de concretar la validez convergente, ya que como se ha apuntado anteriormente es la nota más genérica de cada alumno.

\begin{tabular}{|l|c|c|c|c|c|}
\hline \multicolumn{1}{|c|}{ Grupo } & $\begin{array}{c}\mathbf{N}^{\mathbf{0}} \text { de } \\
\text { alumnos }\end{array}$ & $\begin{array}{c}\text { Media } \\
\text { intervención }\end{array}$ & Media curso & correlación \\
\hline Experimental & 47 & 3,92 & 4,64 & 0,528 \\
\hline Control & 16 & 4,22 & 7,44 & 0,872 \\
\hline Total & 63 & 4,08 & 5,35 & 0,685 \\
\hline
\end{tabular}

Tabla 7.17.- Correlación entre las puntuaciones del Pre-BAC y las del curso.

De igual modo obtenemos unos resultados razonables y con un coeficiente de correlación bastante elevado, por lo que también contamos con esta condición y auque las medias de la intervención en ambos grupos es más baja que la media del curso, no supone falta de vinculación entre ambas variables.

Por tanto para este cuestionario también queda contrastada su validez, y por tanto queda justificada su utilización. 


\subsubsection{Validez y fiabilidad del Post-BAC}

Por último realizaremos las mismas pruebas que en los cuestionarios anteriores, considerando también que este cuestionario es el que nos indicará el máximo de lo aprendido por el alumno previo a su paso por las PAU y/o acceso a la universidad.

\begin{tabular}{|c|c|c|}
\hline $\begin{array}{c}\text { Pareja } \\
\text { de ítems }\end{array}$ & Estadístico empleado & Valor \\
\hline $1-5$ & $\begin{array}{l}\text { Coeficiente de contingencia (basado en } x^{2} \text { ) } \\
\text { Gamma de Goodman } \\
\text { R de Pearson }\end{array}$ & $\begin{array}{l}0,465 \\
0,600 \\
0,416^{*}\end{array}$ \\
\hline $8-9$ & $\begin{array}{l}\text { Coeficiente de contingencia (basado en } x^{2} \text { ) } \\
\text { Gamma de Goodman } \\
\text { R de Pearson }\end{array}$ & $\begin{array}{l}0,283 \\
0,326 \\
0,189\end{array}$ \\
\hline $1-6$ & $\begin{array}{l}\text { Coeficiente de contingencia (basado en } x^{2} \text { ) } \\
\text { Gamma de Goodman } \\
\text { R de Pearson }\end{array}$ & $\begin{array}{l}0,423 \\
0,630 \\
0,449^{*}\end{array}$ \\
\hline $6-9$ & $\begin{array}{l}\text { Coeficiente de contingencia (basado en } x^{2} \text { ) } \\
\text { Gamma de Goodman } \\
\text { R de Pearson }\end{array}$ & $\begin{array}{l}0,359 \\
0,324 \\
0,252\end{array}$ \\
\hline $4-7$ & $\begin{array}{l}\text { Coeficiente de contingencia (basado en } x^{2} \text { ) } \\
\text { Gamma de Goodman } \\
\text { R de Pearson }\end{array}$ & $\begin{array}{l}0,393 \\
0,508 \\
0,348^{*}\end{array}$ \\
\hline $1-2$ & $\begin{array}{l}\text { Coeficiente de contingencia (basado en } x^{2} \text { ) } \\
\text { Gamma de Goodman } \\
\text { R de Pearson }\end{array}$ & $\begin{array}{l}0,480 \\
0,684 \\
0,426^{\star *}\end{array}$ \\
\hline $6-7$ & $\begin{array}{l}\text { Coeficiente de contingencia (basado en } x^{2} \text { ) } \\
\text { Gamma de Goodman } \\
\text { R de Pearson }\end{array}$ & $\begin{array}{l}0,571 \\
0,703 \\
0,546^{\star *}\end{array}$ \\
\hline $9-10$ & $\begin{array}{l}\text { Coeficiente de contingencia (basado en } x^{2} \text { ) } \\
\text { Gamma de Goodman } \\
\text { R de Pearson }\end{array}$ & $\begin{array}{l}0,333 \\
0,504 \\
0,332^{\star *}\end{array}$ \\
\hline $4-10$ & $\begin{array}{l}\text { Coeficiente de contingencia (basado en } x^{2} \text { ) } \\
\text { Gamma de Goodman } \\
\text { R de Pearson }\end{array}$ & $\begin{array}{l}0,296 \\
0,363 \\
0,209\end{array}$ \\
\hline & \multicolumn{2}{|c|}{${ }^{*}$ Asociación de variables significativas con $p<0,05 ;{ }^{* \star i d e m ~ c o n ~} p<0,1$} \\
\hline
\end{tabular}

Tabla 7.18.- Correlación entre las respuestas de diferentes ítems

En esta ocasión hay bastantes parejas de ítems que guardan relación, no obstante, hay una mayor correlación entre los ítems 1-2 y 1-5, ambas muy relacionadas o entre las parejas 1-6, 6-7 y 4-7. Por lo que queda constatada la validez convergente.

En cuanto a la estabilidad de la calificación, se obtienen resultados muy satisfactorios en cuanto a la correlación, sobre todo en lo referido a la calificación total, que se aproxima mucho a la unidad. 


\begin{tabular}{|l|c|c|c|c|c|c|c|c|c|c|c|}
\hline \multicolumn{1}{|c|}{ Ítem no } & $\mathbf{1}$ & $\mathbf{2}$ & $\mathbf{3}$ & $\mathbf{4}$ & $\mathbf{5}$ & $\mathbf{6}$ & $\mathbf{7}$ & $\mathbf{8}$ & $\mathbf{9}$ & $\mathbf{1 0}$ & Total \\
\hline $\begin{array}{l}\text { Coef. De } \\
\text { correlación }\end{array}$ & 0,891 & 0,777 & 0,918 & 0,324 & 0,908 & 0,970 & 0,868 & 0,994 & 0,959 & 0,932 & 0,975 \\
\hline $\begin{array}{l}\text { Coef. De } \\
\text { contingencia }\end{array}$ & 0,793 & 0,785 & 0,803 & 0,653 & 0,798 & 0,816 & 0,758 & 0,707 & 0,816 & 0,816 & 0,953 \\
\hline
\end{tabular}

Tabla 7.19.- Correlación entre las puntuaciones otorgadas por dos investigadores diferentes

Y por último, respecto a la validez concurrente, también obtenemos buenos resultados en cuanto a la correlación entre las dos variables, aunque en el grupo de control la media del curso es muy superior a la de la intervención, pero este valor en absoluto muestra falta de concurrencia, sino mas bien un bajo resultado en la calificación por parte del grupo de control.

\begin{tabular}{|l|c|c|c|c|c|}
\hline \multicolumn{1}{|c|}{ Grupo } & $\begin{array}{c}\mathbf{N}^{\mathbf{0}} \text { de } \\
\text { alumnos }\end{array}$ & $\begin{array}{c}\text { Media } \\
\text { intervención }\end{array}$ & Media curso & correlación \\
\hline Experimental & 47 & 4,74 & 4,64 & 0,843 \\
\hline Control & 16 & 4,75 & 7,44 & 0,854 \\
\hline Total & 63 & 4,75 & 5,35 & 0,715 \\
\hline
\end{tabular}

Tabla 7.20.- Correlación entre las puntuaciones del Post-Bac y las del curso.

Tras haber realizado el tratamiento estadístico propuesto para validar los cuestionarios llegamos a la conclusión de que son correctos, puesto que en los cuatro se han cumplido los requisitos necesarios. 


\subsection{Análisis de los resultados de las pruebas diagnósticas.}

\subsubsection{Síntesis del planteamiento experimental}

\subsubsection{Síntesis metodológica}

Después de haber preparado y propuesto una intervención didáctica para tercer curso de ESO, y segundo de bachillerato, se ha llevado a cabo una intervención cuyo objetivo ha sido medir su influencia en el aprendizaje del enlace químico. La cuestión planteada se relaciona con la posibilidad de que una metodología basada en un acercamiento a las propuestas del aprendizaje basado en problemas, pueda tener efectos positivos en el desarrollo ordinario de un curso en enseñanza obligatoria.

Este planteamiento ha dado lugar a la emisión de la primera hipótesis de trabajo, cuya verificación se ha intentado probar a lo largo del proceso de experimentación en el aula, y constatar de forma tanto cualitativa como cualitativa mediante la realización de cuestionarios previos y finales a cada intervención. El desarrollo de este proceso se ha visto especificado con la ayuda de otras hipótesis en que puede desglosarse la primera.

Previamente en el curso 2005/2006, se hizo un estudio exploratorio con alumnos de segundo de bachillerato y alumnos de primer curso universitario para detectar y confirmar la conveniencia o no de este trabajo. A lo largo del proceso se han realizado cuestionarios de para detectar los conocimientos de los alumnos previos al estudio del enlace químico en ESO y en bachillerato (Pre-ESO y Pre-Bac, respectivamente, Anexos III y VII) y cuestionarios finales para comprobar el nivel de competencias adquirido (post-ESO y Post-Bac. Anexos V y IX). Estos cuestionarios se han pasado tanto a los alumnos que han realizado la intervención como a otros grupos de control, que no la han hecho, así como a grupos de control externo (Tabla 7.1).

Tras la utilización de estos elementos de control, vamos a proceder al análisis estadístico de los resultados y con ello tratar de verificar, o no, las hipótesis de partida. 


\subsubsection{Equivalencia de los grupos experimentales y de control}

En tercero de ESO, de un total de 10 grupos (7 experimentales, 2 de control y uno de control externo) de cuatro centros diferentes, tratamos de establecer la máxima rigurosidad en la investigación a partir de la homogeneidad de todos ellos.

Para ello se han tomado las notas del curso anterior a la intervención de cada alumno y se han tabulado de forma que se dispone de la nota media del curso de cada uno de los alumnos. Con esta nota individual se ha calculado la media de las notas globales de los alumnos que forman cada uno de los grupos. Con ello vamos a disponer para cada uno de los 10 grupos, de la nota media del curso anterior y de la nota media obtenida en el área de ciencias naturales de segundo curso. Además como dato de interés hallaremos las varianzas y asimetrías de dichas puntuaciones.

\begin{tabular}{|l|c|c|c|c|c|}
\hline Grupo & $\mathbf{n}^{\mathbf{0}}$ alumnos & Nota media & Varianza & Curtosis & Asimetría \\
\hline E1 & 18 & 6,45 & 1,225 & $-1,281$ & 0,581 \\
\hline E2 & 14 & 6,65 & 1,713 & $-0,916$ & 0,669 \\
\hline E3 & 12 & 7,55 & 1,831 & $-1,036$ & 0,402 \\
\hline E4 & 13 & 6,75 & 1,259 & 2,432 & 1,210 \\
\hline E5 & 19 & 6,73 & 1,547 & $-1,336$ & 0,010 \\
\hline E6 & 11 & 5,79 & 6,018 & 0,920 & $-0,553$ \\
\hline E7 & 8 & 7,40 & 2,400 & $-1,801$ & 0,414 \\
\hline C1 & 13 & 6,52 & 1,782 & $-1,280$ & 0,254 \\
\hline C2 & 10 & 5,16 & 0,378 & $-0,963$ & $-0,420$ \\
\hline Ce & 17 & 6,43 & 1,274 & 0,061 & 0,774 \\
\hline Total & 135 & 6,57 & 1,912 & 1,011 & $-0,055$ \\
\hline
\end{tabular}

Tabla 7.21.- Notas medias del curso anterior en los alumnos de ESO.

La nota media de todos los alumnos está cerca de 6,5 puntos. Excepto dos de los grupos experimentales y uno de los de control todos están muy próximos a este valor. En el caso del grupo E3, el valor es casi un punto superior a la media, pero presenta una asimetría positiva debido a unos pocos alumnos con nota alta y un número mayor que 
obtiene una nota más baja. Por el contrario en el caso de los grupos E6 y C2, la nota es inferior pero ambas presentan una asimetría negativa, implicando pues la presencia de unos pocos alumnos con nota muy baja frente a una mayoría con una nota más cercana a la media. Podemos observar los dos efectos contrarios en esta serie de grupos, traduciéndose en diferencias que, aunque significativas, consideramos que no van a ser inconvenientes a considerar en la investigación.

A continuación realizamos la misma operación con los alumnos de segundo de bachillerato, tomando la media aritmética de las nueve asignaturas cursadas en el año anterior, obteniendo:

\begin{tabular}{|c|c|c|c|c|c|c|}
\hline Grupo & $\mathbf{n}^{\mathbf{0}}$ alumnos & Nota media & Varianza & Curtosis & Asimetría \\
\hline E1 & 9 & 6,80 & 1,179 & $-1,199$ & $-0,790$ \\
\hline E2 & 22 & 6,32 & 0,609 & 4,794 & 1,670 \\
\hline E3 & 16 & 6,95 & 2,075 & $-1,448$ & 0,255 \\
\hline C1 & 16 & 7,21 & 2,472 & $-1,048$ & 0,001 \\
\hline Total & 63 & 6,79 & 1,626 & $-0,562$ & 0,547 \\
\hline
\end{tabular}

Tabla 7.22.- Notas medias del curso anterior en los alumnos de Bachillerato.

En cuanto a estos alumnos, la nota media se sitúa alrededor de los 6,8 puntos. La desviación respecto de este valor, no excede de los 0,5 puntos en ningún grupo y aunque la diferencia máxima se de entre el E2 y el $\mathrm{C} 1$, no es demasiado grande y por tanto dentro de los límites lógicos de estudio.

Para aproximarnos más a la situación de estudio nos centraremos en la materia concreta de interés y del mismo modo, hallaremos la nota media del área de ciencias de la naturaleza en segundo curso de ESO y de Física y química en primero de bachillerato, en los mismos cursos: 


\begin{tabular}{|l|c|c|c|c|c|}
\hline Grupo & $\mathbf{n}^{\mathbf{0}}$ alumnos & Nota media & Varianza & Curtosis & Asimetría \\
\hline E1 & 18 & 6.00 & 1,500 & 0,714 & 1,157 \\
\hline E2 & 14 & 7,27 & 2,018 & 0,187 & 0,438 \\
\hline E3 & 12 & 8,38 & 1,411 & $-1,746$ & $-0,288$ \\
\hline E4 & 13 & 6,73 & 2,418 & 0,450 & 0,748 \\
\hline E5 & 19 & 7,07 & 3,302 & $-1,154$ & $-0,326$ \\
\hline E6 & 11 & 5,75 & 6,786 & 0,580 & $-0,412$ \\
\hline E7 & 8 & 6,50 & 1,900 & 2,355 & 1,375 \\
\hline C1 & 13 & 6,33 & 5,697 & 0,690 & $-0,956$ \\
\hline C2 & 10 & 5,40 & 0,800 & 5,000 & 2,236 \\
\hline Ce & 17 & 6,56 & 1,996 & $-0,973$ & 0,422 \\
\hline Total & 135 & 6,60 & 3,083 & 0,405 & $-0,183$ \\
\hline
\end{tabular}

Tabla 7.23.- Notas medias en Ciencias Naturales en el curso anterior de los alumnos de ESO.

En este caso la nota media es de 6,60 puntos y al igual que ocurría en el caso de la media del curso obtenemos que el grupo C3, mantiene una nota bastante superior al resto de grupos, mientras que el E6 y el C2, lo hacen en sentido contrario, por tanto podemos considerar que la nota en la materia de física y química es un parámetro fiel para caracterizar a los grupos que han sido objeto de la investigación. Así mismo tendremos en cuenta estos valores a la hora de analizar los resultados pero resultan aptos para trabajar con todos ellos.

En los grupos de segundo de bachillerato, se han buscado las notas correspondientes a la física y química de primero, y se han obtenido los valores:

\begin{tabular}{|c|c|c|c|c|c|c|}
\hline Grupo & $\mathbf{n}^{\mathbf{0}}$ alumnos & Nota media & Varianza & Curtosis & Asimetría \\
\hline E1 & 9 & 5,71 & 0,238 & $-0,840$ & $-1,230$ \\
\hline E2 & 22 & 5,79 & 3,287 & 0,687 & 0,850 \\
\hline E3 & 16 & 6,86 & 3,824 & $-0,469$ & $-0,272$ \\
\hline C1 & 16 & 7,25 & 2,333 & $-0,684$ & 0,032 \\
\hline Total & 63 & 6,46 & 3,090 & $-0,479$ & 0,270 \\
\hline
\end{tabular}

Tabla 7.24.- Notas medias en Física y Química en el curso anterior de los alumnos de Bachillerato. 
Al igual que en el caso de ESO, encontramos que los grupos con mayor nota media en el curso, también presentan esta virtud en la asignatura que nos ocupa, Siendo de nuevo los grupos E3 y C1 los mejor situados. No obstante la diferencia en ninguno de los casos supera los 0,8 puntos de desviación respecto de la media.

Por tanto, como conclusión a esta cuestión podemos alegar que los grupos de estudio nos parecen correctamente distribuidos y con niveles que si no iguales, son bastante semejantes, y que salvando las consideraciones oportunas en el tratamiento estadístico de los resultados, nos van a permitir llevar a cabo el estudio previsto. 


\subsubsection{Resultados de los cuestionarios}

\subsubsection{Resultados obtenidos en el Pre-ESO}

Tras haber realizado los cuestionarios los resultados han sido los siguientes

\begin{tabular}{|l|c|c|c|c|}
\hline Grupo & Alumnos & Media & $\begin{array}{c}\text { Desviación } \\
\text { típica }\end{array}$ & Curtosis \\
\hline E1 & 18 & 4,15 & 1,5328 & $-1,438$ \\
\hline E2 & 14 & 5,23 & 3,0250 & $-1,266$ \\
\hline E3 & 12 & 6,04 & 1,0104 & 0,603 \\
\hline E4 & 13 & 4,83 & 1,3200 & $-0,490$ \\
\hline E5 & 18 & 5,73 & 1,4567 & 0,436 \\
\hline E6 & 11 & 4,78 & 1,5854 & 0,543 \\
\hline E7 & 8 & 5,64 & 1,4438 & 0,297 \\
\hline C1 & 13 & 5,38 & 2,6348 & 0,764 \\
\hline C2 & 10 & 5,16 & 1,6538 & 0,543 \\
\hline Ce & 17 & 4,33 & 1,1146 & $-0,616$ \\
\hline Total & 135 & 5,03 & 1,9426 & 0,180 \\
\hline
\end{tabular}

Tabla 7.25. Resultados obtenidos en el Pre-ESO.

\section{Porcentaje de respuestas correctas en el} Pre-ESO

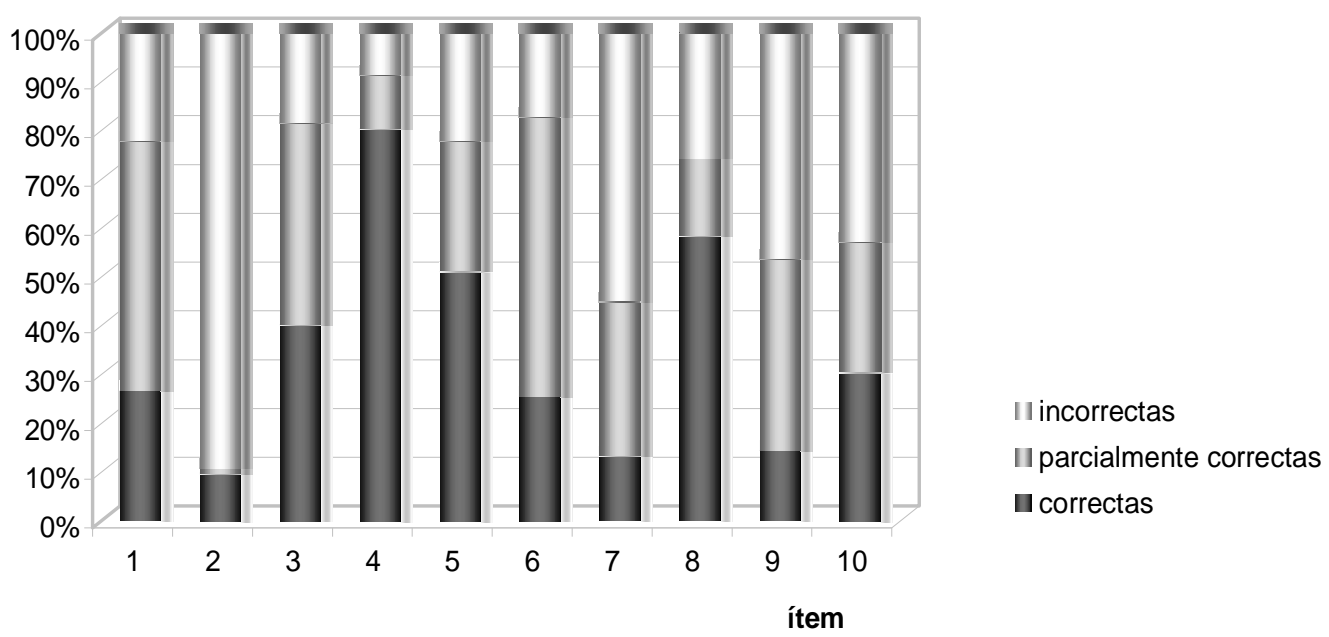

Figura 7.3. Porcentajes de respuestas correctas, parcialmente correctas e incorrectas en el Pre-ESO 
Tras revisar post-cuestionarios iniciales pasados a los alumnos:

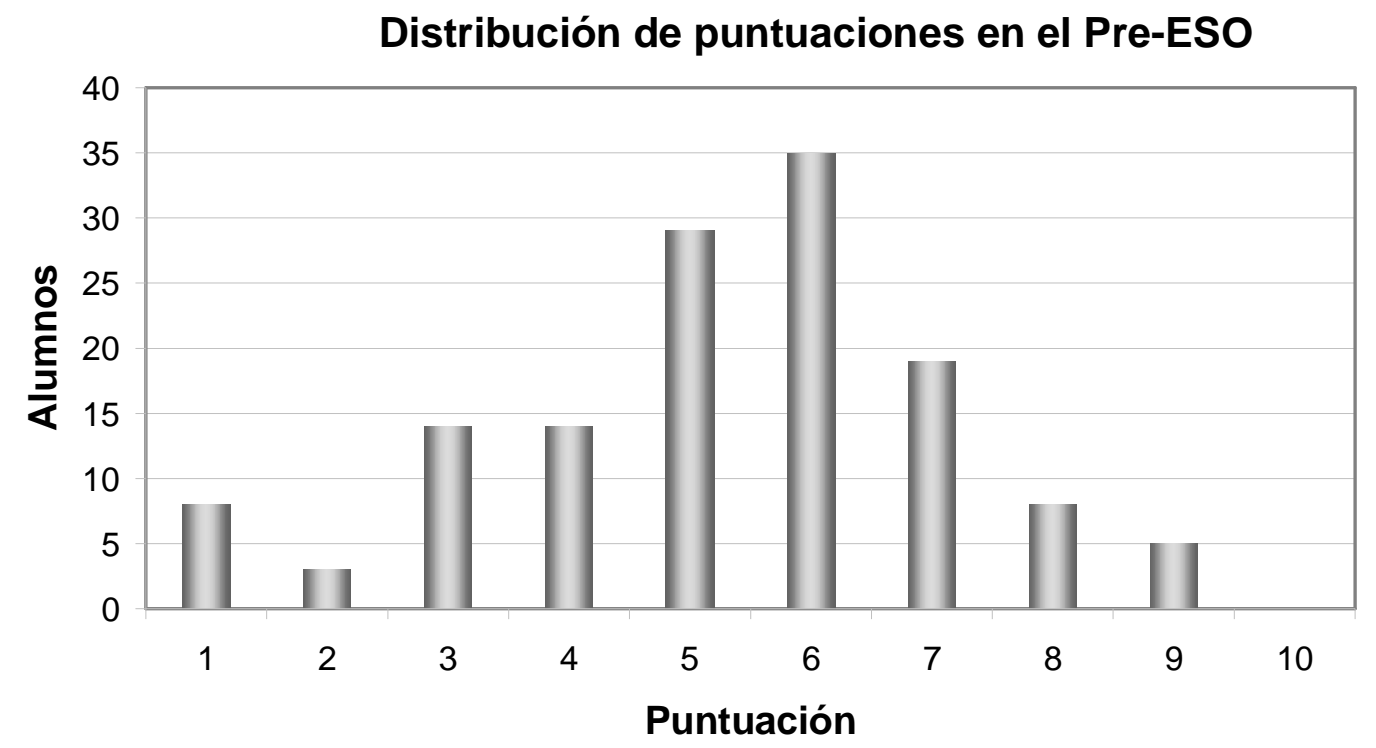

Figura 7.4. Distribución de puntuaciones en el Pre-ESO

\section{Ítem 1. El átomo. Partículas constituyentes}

La primera cuestión que se presenta, trata sencillamente de indagar en la imagen que tiene cada alumno de qué es un átomo. Se ha considerado conveniente esta pregunta puesto que en el curso anterior se han estudiado algunos átomos y, además el estudio del enlace químico, cronológicamente se sitúa inmediatamente después de conocer la estructura atómica, incluyendo los modelos de Thompson y Rutherford, así como la ley de Dalton. También han estudiado la tabla periódica y sus principales propiedades.

Sin embargo, aunque cerca de la mitad de los alumnos han indicado que el dibujo representaba a un átomo, ni uno sólo de los participantes ha apuntado que se trataba de un átomo de carbono, Siendo uno de los más conocidos por ellos desde el curso anterior. Un $79 \%$ ha sido capaz de interpretar todos los elementos que allí se mostraban, indicando el papel del núcleo y de los electrones en sus órbitas. Cuando han tratado de explicar la forma del átomo la mayor parte ha apuntado correctamente que la carga positiva estaba concentrada en el núcleo mientras que la negativa lo hacía en órbitas alrededor de este. 
Por regla general, los alumnos no han cometido errores conceptuales en este apartado, los que no lo han hacho bien, ha sido por dejarlo en blanco, lo que indica que esta modelo de átomo es muy atractivo para esta edad.

\section{¿Indica de qué elemento se trata?}

\begin{tabular}{l|l}
$\mathrm{Si} \rightarrow \mathrm{0} \%$ & $\mathrm{No} \rightarrow \mathbf{1 0 0} \%$
\end{tabular}

- Ninguno de los alumnos ha indicado que se trataba de un

- El átomo de carbono debe resultar átomo de carbono.

- Unos pocos alumnos pese a no decirlo han respondido que se trata del elemento “ $z=6 "$. minimanente conocido por los alumnos, pues es uno de los elementos vistos en segundo curso de ESO. Pese a ello ninguno de los estudiantes lo ha advertido, aunque ciertamente no se pedía de forma explícita este dato y, dada la poca familiaridad con el sistema periódico es lógico este dato.

\begin{tabular}{|c|c|}
\hline \multicolumn{2}{|l|}{ ¿Describe su forma? } \\
\hline $\mathrm{Si} \rightarrow 79 \%$ & $\mathrm{No} \rightarrow 21 \%$ \\
\hline $\begin{array}{l}\text { - El } 79 \% \text { de los alumnos ha distinguido } \\
\text { entre un núcleo donde se encuentran } \\
\text { los protones y neutrones, y una corteza } \\
\text { con electrones. } \\
\text { - Un } 21 \% \text { indica que los electrones se } \\
\text { encuentran describiendo órbitas (la } \\
\text { mitad de ellos elípticas). } \\
\text { - Un } 5 \% \text { apunta que los electrones se } \\
\text { encuentran en capas. } \\
\text { Un } 2,3 \% \text { indica que la posición de los } \\
\text { electrones se encuentran en orbitas "no } \\
\text { definidas". }\end{array}$ & $\begin{array}{l}\text { - Un } 21 \% \text { de los alumnos no ha } \\
\text { indicado nada o bien no lo } \\
\text { relacionan en absoluto con un } \\
\text { átomo. }\end{array}$ \\
\hline
\end{tabular}

\section{¿Explica que se trata de un átomo?}

$$
\begin{array}{l|l}
\mathrm{Si} \rightarrow \mathbf{4 7 , 7} \% & \text { No } \rightarrow \mathbf{5 2 , 3} \%
\end{array}
$$

- Un 47,7 \% de los alumnos indica explícitamente que se trata de un átomo.
- Aproximadamente un $20 \%$ de los alumnos no explican de que se trata el esquema.

- Hay un elevado porcentaje de alumnos que pese a explicar la forma del átomo, no indican que están hablando de ello.

Tabla 7.26. Porcentaje de alumnos que responden correctamente al ítem 1 del Pre-ESO. 


\section{Ítem 2. Estructura de la materia}

Este ítem es el más representativo de cara al problema planteado en la intervención. Tras presentar tres objetos diferentes, todos formados por, o conteniendo hierro, se les pregunta si creen que los átomos de hierro que allí se encuentran son del mismo tipo. Tan sólo un $20 \%$ cree que así es, mientras que el resto opina otras cosas.

Los alumnos no creen que la diferencia entre uno u otros cuerpos resida en el tipo de estructura que formen ni en la proporción en que allí se encuentren. El error más común es atribuir a la cuchara formada por hierro metálico, mientras que a las verduras les atribuyen "el hierro de las vitaminas"o "hiero nutritivo" y en el caso de la sangre hablan del "hierro de las proteínas".

En algunos casos han considerado que el hierro de las verduras si que es el mismo que el de la sangre y que ha pasado allí en el proceso de nutrición.

\section{¿Cree que se trata del mismo tipo de átomos?}

\begin{tabular}{|c|c|}
\hline $\mathrm{Si} \rightarrow 19,8 \%$ & $\mathrm{No} \rightarrow \mathbf{8 0 , 2} \%$ \\
\hline $\begin{array}{l}\text { - Casi una quinta parte de los } \\
\text { alumnos confirma que todos } \\
\text { los átomos de hierro son } \\
\text { iguales independientemente } \\
\text { de la sustancia en la que se } \\
\text { encuentren. }\end{array}$ & $\begin{array}{l}\text { - Un } 16,3 \% \text { no responde a la cuestión. } \\
\text { - Un } 17 \% \text { de los que si han contestado explica } \\
\text { que el hierro de las verduras y la sangre es el } \\
\text { mismo. } \\
\text { - Hay alumnos que indican que el hierro de la } \\
\text { cuchara es el elemento de la tabla periódica, } \\
\text { atribuyéndole propiedades como metálico, } \\
\text { duro, firme, mineral... ( } 45,3 \%) \text {. } \\
\text { - Otros afirman que el hierro de la lechuga es el } \\
\text { de las vitaminas o proteínas ( } 33 \%) \text {. } \\
\text { - Otros indican que el hierro de la sangre } \\
\text { proviene de los alimentos. }\end{array}$ \\
\hline
\end{tabular}

\section{¿Cree que difieren en su ordenación o estructura?}

\begin{tabular}{|l|l|}
\hline $\mathbf{S i} \rightarrow \mathbf{4 2} \%$ & No $\rightarrow \mathbf{5 8} \%$ \\
\hline \begin{tabular}{l|l|}
\hline Del total de los alumnos que \\
contestan correctamente, el
\end{tabular} & $\begin{array}{l}\text { La mayoría de los alumnos consideran que } \\
\text { hay otros motivos, como que son un } \\
\text { diferente tipo de átomos, o directamente, no }\end{array}$ \\
$\begin{array}{ll}\text { diferencian en la forma en } \\
\text { que se ordenan o estructuran. }\end{array}$ & han respondido. \\
\hline
\end{tabular}




\section{¿Cree que difiere en su cantidad?}

\section{\begin{tabular}{l|l}
$\mathrm{Si} \rightarrow 29,4 \%$ & $\mathrm{No} \rightarrow \mathbf{7 0 , 6} \%$
\end{tabular}}

- El 29,4\% de los alumnos que responden correctamente indican que un de las diferencias entre unos cuerpos y otros es la proporción en que se encuentra en ellos el

- En la misma línea que las cuestiones anteriores, la mayoría de los alumnos, no atribuye la diferencia de las propiedades a las diferentes estructuras, ni por tanto a la mayor o menor presencia del hierro en cada sustancia. hierro.

Figura.- 7.27. Porcentaje de alumnos que responden correctamente al ítem 2 del Pre-ESO.

\section{Ítem 3. Teoría cinético-molecular}

En esta cuestión se trata de conocer su imagen de las partículas gaseosas según la teoría cinético-molecular, con la intención de ver hasta qué punto ellos entienden que una sustancia formada por partículas puede ocupar un espació u otro, y si estas partículas pueden estar más o menos cerca, sin variar su naturaleza.

El $80 \%$ dibujan correctamente puntos representando partículas gaseosas distribuidas en todo el recipiente, y el 65\% dibuja en el segundo caso la mitad de las que había dibujado inicialmente. El resto dibuja una proporción mucho menor.

El principal error cometido ha sido dibujar pequeñas circunferencias juntas en la parte inferior del recipiente en ambos casos, como si de un sólido o líquido se tratase. Por otro lado sólo el $47 \%$ ha representado a las partículas gaseosas separadas entre si, lo que lleva a deducir que conocen la teoría pero con importantes carencias.

\begin{tabular}{|c|c|}
\hline \multicolumn{2}{|c|}{$\begin{array}{l}\text { ¿Dibuja correctamente las partículas, distribuidas en todo el espacio } \\
\text { disponible? }\end{array}$} \\
\hline $\mathrm{Si} \rightarrow \mathbf{8 0} \%$ & $\mathrm{No} \rightarrow 20 \%$ \\
\hline $\begin{array}{l}\text { - El } 80 \% \text { de los alumnos ha } \\
\text { dibujado las partículas en el estado } \\
\text { final distribuidas por el espacio } \\
\text { disponible. } \\
\text { - El } 91,8 \% \text { ha dibujado las } \\
\text { partículas de este modo en el estado } \\
\text { inicial. }\end{array}$ & $\begin{array}{l}\text { - Un } 11,8 \% \text { ha dibujado las partículas } \\
\text { en el estado final agrupadas en la mitad } \\
\text { del recipiente (unos bajo y, otros } \\
\text { arriba) } \\
\text { - Un 8,2 \% no ha respondido a la } \\
\text { cuestión. }\end{array}$ \\
\hline
\end{tabular}




\section{¿En el segundo caso, dibuja la cantidad adecuada?}

\begin{tabular}{|l|l|}
\hline $\mathbf{S i} \rightarrow \mathbf{6 5} \%$ & $\mathbf{N o} \rightarrow \mathbf{3 5} \%$ \\
\hline \begin{tabular}{l|l} 
- Del total de los alumnos que \\
han respondido la cuestión, el
\end{tabular} & $\begin{array}{c}\text { El } 35 \% \text { dibuja una cantidad muy inferior a } \\
\text { la mitad. }\end{array}$ \\
$\begin{array}{l}\text { 65\% dibuja la mitad de las } \\
\text { partículas en el estado final } \\
\text { que en el inicial. }\end{array}$ & \\
\hline
\end{tabular}

\section{¿Deja espacios entre las partículas aún cuando se trata de un gas?}

\begin{tabular}{|l|l|l|}
\hline Si $\rightarrow \mathbf{4 7} \%$ & No $\rightarrow \mathbf{5 3} \%$ \\
\hline - De los alumnos que han & - El 53 \% de los que han respondido ha \\
respondido a la cuestión en & $\begin{array}{l}\text { dibujado las partículas en el estado inicial } \\
\text { completamente pegadas. }\end{array}$ \\
$91,3 \%$ ha dejado espacio & \\
entre las partículas en el & \\
estado final. & \\
- Sólo el 47 \% ha dejado & \\
espacio vacío entre las \\
partículas en el estado inicial.
\end{tabular}

Figura 7.28. Porcentaje de alumnos que responden correctamente al ítem 3 del Pre-ESO.

\section{Ítem 4. Clasificación de la materia}

La principal intención de este ítem es ver si los alumnos diferencian entre los conceptos de elemento, compuesto y mezcla. Para ello se ha dispuesto de tres esquemas en los que se han representado átomos de diferentes elementos utilizando círculos de diferentes colores.

El resultado ha sido muy satisfactorio en cuanto que la gran mayoría discierne bien entre unos y otros. Sólo un pequeño porcentaje, un $6 \%$ no indica correctamente que átomos iguales representan un elemento. En cuanto a distinguir entre mezclas y compuestos, aparece un $18 \%$ de los alumnos que además de no identificar los átomos, tampoco lo hace. 


\section{¿Distingue los elementos?}

\begin{tabular}{l|l}
$\mathrm{Si} \rightarrow 94 \%$ & No $\rightarrow 6 \%$
\end{tabular}

- El 94\% de los alumnos - Un 6\% no responde a la pregunta o lo hace identifica que el grupo de átomos iguales representa a un determinado elemento.

\begin{tabular}{|c|c|}
\hline ¿Distingue los compuestos? & \\
\hline $\mathrm{Si} \rightarrow 82,4 \%$ & $\mathrm{No} \rightarrow 17,6 \%$ \\
\hline 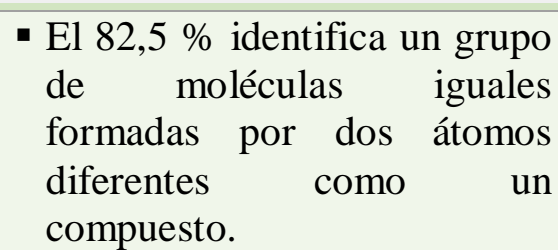 & - Un 17,6 \% lo identifica como una mezcla. \\
\hline
\end{tabular}

\begin{tabular}{|l|l|}
\hline \multicolumn{2}{|l|}{ ¿Distingue las mezclas? } \\
\hline $\mathbf{S i} \rightarrow \mathbf{8 3 , 5} \%$ & $\mathbf{N o} \rightarrow \mathbf{1 6 , 5} \%$ \\
\hline \begin{tabular}{|l|l|} 
- Un 83,5 \% la reconoce \\
correctamente.
\end{tabular} & \begin{tabular}{|l|} 
- Un $12,5 \%$ identifican el compuesto como \\
mezcla. \\
- Un 6,5 \% identifica como mezclas tanto al \\
ejemplo de la mezcla como el del compuesto.
\end{tabular} \\
\hline
\end{tabular}

Tabla 7.29.- Porcentaje de alumnos que responden correctamente al ítem 4 del Pre-ESO.

\section{Ítem 5. Estructura de la materia}

Con este ítem se pretende averiguar si los alumnos, pueden relacionar moléculas o redes con la sustancia que la forma. Ha sido así hasta el punto que el error más común ha sido formular correctamente las sustancias moleculares y formular como tales a las redes, es decir como " $\mathrm{Na}_{4} \mathrm{Cl}_{4}$ " y "Fe" ${ }_{9}$ " al cloruro sódico y al hierro respectivamente.

En esta cuestión se presenta cuatro estructuras formadas por elementos en los cuales figura su símbolo, por tanto, como cabría esperar a los alumnos les resulta más sencillo indicar la fórmula que el nombre y, además les resulta más fácil trabajar con elementos que con sustancias compuestas. 


\section{¿Formula las sustancias compuestas?}

\begin{tabular}{l|l}
$\mathrm{Si} \rightarrow 8,2 \%$ & No $\rightarrow 91,8 \%$
\end{tabular}

- El 64,7 \% en el caso de sustancias moleculares.

- El 8,2 \% en el caso de sustancias iónicas.
- El 45,6 \% formula una red de cloruro sódico como $\mathrm{Na}_{4} \mathrm{Cl}_{4}$ (el número de átomos representados).

- Hay un 91,8 \% que no formula correctamente las sustancias iónicas, dando como su fórmula empírica la unidad representada en el dibujo.

\section{¿Nombra las sustancias compuestas?}

$\mathrm{Si} \rightarrow \%$

No $\rightarrow \%$

- El 56,5 \% lo hace correctamente en el caso del

- Igual que en el caso anterior hay un mejor agua.

- Sólo el 5,9 \% lo hace en el caso del cloruro sódico. resultado cuando se trata de sustancias moleculares siendo un $94,1 \%$, el porcentaje de alumnos que cometen este error.

- Un 43,5\% consigue hacerlo correctamente en el caso de las moléculas.

\section{¿Formula los elementos?}

\begin{tabular}{l|l}
$\mathrm{Si} \rightarrow \mathbf{1 4 , 1} \%$ & No $\rightarrow \mathbf{8 5 , 9} \%$
\end{tabular}

- El 61,2 \% lo hace

- El 45,9 \% ha formulado el hierro como $\mathrm{Fe}_{9}$. correctamente en el caso del hidrogeno.

- Pero únicamente $14,1 \%$ en el caso del hierro.

- Hay un $40 \%$ de los alumnos que no ha contestado a la pregunta, en el caso del hierro.

- En el caso del hidrógeno un $28,8 \%$ no ha contestado, y un $10 \%$ lo ha hecho erróneamente.

\section{¿Nombra los elementos?}

$\mathrm{Si} \rightarrow \mathbf{5 7 , 7} \%$

- El $62,4 \%$ lo hace correctamente en el caso del hidrógeno.

- El 57,7 \% lo hace correctamente en el caso del hierro.
No $\rightarrow 42,3 \%$

- En este caso la diferencia entre ambos elementos se reduce y son un $42,3 \%$ los alumnos que no nombran al hierro como tal, prácticamente todos ellos no han contestado nada.

Figura 7.30.- Porcentaje de alumnos que responden correctamente al ítem 5 del Pre-ESO. 


\section{Ítem 6. Estructura atómica}

Gran parte de los alumnos responden bastante bien a esta cuestión, razonan que el color de las sustancias no es debido al color de los átomos, admiten la presencia del vacío y conocen que el electrón es una partícula constituyente del átomo. Sin embargo alrededor de un tercio de lo alumnos incurren en errores, demostrando carencias importantes en su formación inicial.

Como era de prever, los errores más comunes han sido atribuir los sucesos contrarios a los reales, aunque el más relevante es pensar que entre el núcleo y los electrones hay aire, ya que esto evidencia falta de razonamiento, al igual que no indicar que el electrón es menor que el átomo.

\section{¿Distingue las propiedades macro y microscópicas?}

\section{\begin{tabular}{l|l}
$\mathrm{Si} \rightarrow \mathbf{8 3 , 9 \%}$ & No $\rightarrow \mathbf{1 6 , 1} \%$
\end{tabular}}

- El 83,9 \% de los alumnos indica que es falso que los átomos presentes propiedades físicas macroscópicas.

- La mayoría de ellos explicitan que el color de los átomos no puede verse y por ello no puede ser acumulativo.
- El 16,1\% indica que si el oro es amarillo es por que los átomos también lo son.

\section{¿Admite la presencia del vacío?}

\section{$\mathrm{Si} \rightarrow 64,1 \%$ \\ No $\rightarrow 33,9 \%$}

- El 64,1\% de los alumnos indican que no hay nada.

- Muchos de ellos indican que si hubiese otra sustancia también tendrían núcleo y electrones y volverían a estar en la misma situación de forma indefinida.
- Prácticamente un tercio de los alumnos indican que existe aire en el espacio interatómico.

- La mayoría de los alumnos indican que debe existir "algo".

\section{¿Conoce la relación átomo-electrón?}

\section{\begin{tabular}{l|l}
$\mathrm{Si} \rightarrow \mathbf{8 3 , 3} \%$ & $\mathrm{No} \rightarrow \mathbf{1 6 , 7} \%$
\end{tabular}}

- El 83,3 \% indica que el electrón debe ser más pequeño que el átomo.

- La mitad de estos alumnos indica que debe ser así puesto que el electrón es una parte constituyente del átomo.
- El 16,7 \% responde que el electrón no es menor que el átomo.

- Un 4,2 \% lo justifica diciendo que "el átomo es la partícula de menor tamaño que se puede encontrar".

Tabla 7.31.- Porcentaje de alumnos que responden correctamente al ítem 6 del Pre-ESO. 


\section{Ítem 7. Capacidad de abstracción numérica}

Este ítem trata de establecer si los alumnos tienen un grado de abstracción matemática necesario para comprender las dimensiones microscópicas con las que trabajan. El resultado es bastante pobre sólo la mitad de ellos expresa un cantidad razonable comprendiendo entre $10^{10}$ y $10^{25}$ al número de átomos, y tan sólo un $14 \%$ lo cifra en $10^{20}$, que atendiendo a la distribución de los resultados, semeja atender a razones de casualidad.

Teniendo en cuenta que, según el programa oficial, los alumnos han estudiado en el primer trimestre, los aspectos relacionados con el método científico, magnitudes, notación, etc..., no parece razonable un resultado tan bajo.

\section{¿Concibe la idea de $n^{o}$ exponencial?}

\begin{tabular}{l|l}
$\mathbf{S i} \rightarrow \mathbf{5 0} \%$ & $\mathbf{N o} \rightarrow \mathbf{5 0} \%$
\end{tabular}

- Un $50 \%$ de los alumnos da - Otro $50 \%$ da valores inferiores a $10^{2}$. un valor comprendido entre - Un 18,6\% da valores iguales o inferiores a la $10^{5}$ y $10^{30}$. unidad.

\section{¿Cuantifica correctamente el $n^{\circ}$ de átomos?}

\begin{tabular}{l|l}
$\mathrm{Si} \rightarrow \mathbf{2 9 , 7} \%$ & $\mathrm{No} \rightarrow \mathbf{7 0 , 3 \%}$
\end{tabular}

- Un $29,7 \%$, da resultados asequibles comprendidos entre $10^{10}$ y $10^{25}$.

- Un $10,4 \%$ da un valor correcto de $10^{20}$.
- La mayoría de alumnos no da resultados aceptables y aproximadamente un $20 \%$ de ellos no contesta a la cuestión.

Tabla 7.32.- Porcentaje de alumnos que responden correctamente al ítem 7 del Pre-ESO.

\section{Ítem 8. Clasificación de la materia}

La mayoría de los alumnos pone ejemplos de sustancias puras, un 70\%, y de mezclas homogéneas. En el primer caso hasta un 30\%, recurre utilizar elementos como sustancias puras y en el caso de mezclas normalmente, se nombran disoluciones acuosas de sal o azúcar. 


\section{¿Es capaz de poner ejemplos de sustancias puras?}

\begin{tabular}{l|l}
$\mathrm{Si} \rightarrow 72 \%$ & No $\rightarrow 28 \%$
\end{tabular}

- Un de $72 \%$ de los alumnos pone estos ejemplos.

Normalmente se recurre a sustancias de la vida común como azúcar, agua, sal o elementos químicos.
- Un $20 \%$ no contesta la cuestión.

- Un $8 \%$ indican otros tipos de sustancias, como tierra u otras mezclas.

\section{¿Es capaz de poner ejemplos de mezclas homogéneas?}

\section{\begin{tabular}{l|l}
$\mathrm{Si} \rightarrow \mathbf{7 0} \%$ & $\mathrm{No} \rightarrow \mathbf{3 0} \%$
\end{tabular}}

- La mayoría de estos alumnos ponen ejemplos cotidianos de disoluciones como el agua con sal o azúcar, leche con Cola cao, café con leche, vino, etc.
- Un $14 \%$ no contestan a la cuestión.

- Un $16 \%$ pone ejemplos de mezclas de sustancias, sobre todo de comidas, por ejemplo se repite en muchas ocasiones, la paella, macarrones, ensalada o lentejas.

\section{¿Identifica sustancias puras con elementos?}

\begin{tabular}{l|l}
$\mathrm{Si} \rightarrow \mathbf{5 2 , 5 \%}$ & No $\rightarrow \mathbf{4 7 , 5 \%}$
\end{tabular}

- En la mayoría de casos los alumnos relacionan las sustancias puras con los elementos de la tabla periódica.

- En un 22,5\% de los casos se ha puesto como ejemplo el hierro, en un $16,3 \%$ el oro, en un $13,6 \%$ el oxígeno y en un 6,3 $\%$ la plata.
- Un 19,5\% de los alumnos pone ejemplos validos como el agua, el hielo o la sal.

- Un $18 \%$ no ha contestado a la cuestión.

Tabla 7.33.- Porcentaje de alumnos que responden correctamente al ítem 8 del Pre-ESO.

\section{Ítem 9. Imagen de la química}

Buscando información acerca de la predisposición del alumno frente a la química, nos sorprendemos negativamente cuando encontramos que sólo un $22 \%$ de los alumnos opinaba que las industrias químicas tenían consecuencias positivas para las personas, mientras que la cifra se elevaba hasta $49 \%$ en el caso de pensar que eran negativas. 
En el primer caso se han apuntado ideas como que la industria química sirve para fabricar medicamentos, permite avanzar a la sociedad y crear objetos nuevos.

En el otro sentido mayoritariamente se concluye que contaminan el medio ambiente, e incluso bastantes personas afirman que sirve para hacer bombas y drogas.

\section{¿Cree que las industrias químicas tienen consecuencias positivas?}

\begin{tabular}{|l|l|}
\hline Si $\rightarrow \mathbf{2 2} \%$ & $\mathbf{N o ~} \rightarrow \mathbf{7 8} \%$ \\
\hline \begin{tabular}{l|l|} 
- Todos los alumnos que han apuntado \\
que hay consecuencias positivas
\end{tabular} & $\begin{array}{l}\text { - Un } 41,2 \% \text { de los alumnos no ha } \\
\text { contestado a la cuestión. }\end{array}$ \\
$\begin{array}{l}\text { apuntan al desarrollo de } \\
\text { medicamentos. }\end{array}$ & $\begin{array}{l}\text { El resto no ha hecho referencia a este } \\
\text { aspecto. }\end{array}$ \\
\hline
\end{tabular}

- Además un $12,7 \%$ añade que gracias a la química se consigue avanzar en la tecnología.

- Un 1,4\% aporta que la industria química permite conocer el porqué de las cosas.

\section{¿Cree que las industrias químicas tienen consecuencias negativas?}

\begin{tabular}{|c|c|}
\hline $\mathrm{Si} \rightarrow 53,6 \%$ & $\mathrm{No} \rightarrow 46,4 \%$ \\
\hline $\begin{array}{l}\text { - Un 53,6\% aporta una visión negativa } \\
\text { acerca de estas industrias. } \\
\text { - Un } 35,7 \% \text { de los alumnos indica que } \\
\text { produce contaminación. } \\
\text { - Un } 27,5 \% \text { de ellos indica que es malo } \\
\text { para la salud, o provoca infecciones o } \\
\text { es nocivo. } \\
\text { Un 7,6\% expresa que sirven para } \\
\text { fabricar armamento. }\end{array}$ & $\begin{array}{l}\text { - Un } 41,2 \% \text { de los alumnos no ha } \\
\text { contestado a la cuestión. } \\
\text { - El resto no ha explicado el porqué } \\
\text { tiene consecuencias negativas. }\end{array}$ \\
\hline
\end{tabular}

Tabla 7.34.- Porcentaje de alumnos que responden correctamente al ítem 9 del Pre-ESO

\section{Ítem 10. Estructura de la materia}

A partir de un mapa conceptual mudo de intenta ver si los alumnos conocen la relación entre átomos, moléculas, elementos, sistema periódico, y símbolos.

La respuesta es baja y sólo alrededor de un 50\% concluyen que la materia está formada por átomos y que esos se clasifican según sus propiedades el sistema periódico. 


\section{¿Concluye que la materia está formada por átomos?}

\begin{tabular}{l|l}
$\mathrm{Si} \rightarrow \mathbf{5 6 , 3} \%$ & No $\rightarrow \mathbf{4 5 , 7} \%$
\end{tabular}

- El 56,3\% de los alumnos han

- Prácticamente todos los que no han sabido contestado que esta formada por átomos, aunque dada su responder lo han dejado en blanco.

facilidad cabría haber

- Un 3,7\% ha indicado que la materia está esperado un mejor resultado.

\section{¿Los átomos de agrupan en moléculas?}

\begin{tabular}{l|l}
$\mathrm{Si} \rightarrow 38,8 \%$ & $\mathrm{No} \rightarrow 61,2 \%$
\end{tabular}

- El 17,5\% de los estudiantes indican que los átomos se agrupan en moléculas.

- El 21,3\% indican que se agrupan en sustancias compuestas, que aunque no es siempre así también es una opción.
- Un 11,1 \% ha indicado que se agrupan en sustancias o isótopos.

- Un 50,1 \% n ha sabido contestar a la cuestión.

\section{¿Los elementos de clasifican según el SP y se representan con símbolos?}

\section{\begin{tabular}{l|l}
$\mathrm{Si} \rightarrow \mathbf{5 3 , 8} \%$ & $\mathrm{No} \rightarrow \mathbf{4 6 , 2} \%$
\end{tabular}}

- EL 53,8 \% reconoce la silueta

- Un 16,7 \% ha indicado que los elementos se del sistema periódico e indica que allí se representa.

- El 50 \% hace lo propio con los símbolos. representan con abreviaturas, siglas o letras.

- Un 33,3 \% ha dejado en blanco la cuestión.

- El 46,2 \% no indica que los elementos se clasifican en el SP.

Tabla 7.35.- Porcentaje de alumnos que responden correctamente al ítem 10 del Pre-ESO 


\subsubsection{Resultados obtenidos en el Post-ESO}

Tras haber realizado los cuestionarios los resultados han sido los siguientes

\begin{tabular}{|l|c|c|c|c|}
\hline Grupo & Alumnos & Media & $\begin{array}{c}\text { Desviación } \\
\text { típica }\end{array}$ & Curtosis \\
\hline E1 & 18 & 3,19 & 1,621 & $-0,658$ \\
\hline E2 & 14 & 4,79 & 2,723 & $-1,120$ \\
\hline E3 & 12 & 4,30 & 1,764 & 0,479 \\
\hline E4 & 13 & 2,35 & 1,473 & 0,106 \\
\hline E5 & 18 & 6,21 & 2,463 & $-0,359$ \\
\hline E6 & 11 & 5,50 & 1,987 & 0,091 \\
\hline E7 & 8 & 5,18 & 1,822 & $-0,260$ \\
\hline C1 & 13 & 2,68 & 1,834 & 1,279 \\
\hline C2 & 10 & 5,55 & 2,466 & $-1,757$ \\
\hline Ce & 17 & 2,87 & 1,356 & 1,291 \\
\hline Total & 135 & 4,28 & 2,372 & $-0,836$ \\
\hline
\end{tabular}

Tabla 7.36.- Resultados obtenidos en el Post-ESO.

En la gráfica podemos observar los resultados obtenidos en cada uno de los ítems

\section{Porcentaje de respuestas correctas en el Post-ESO}

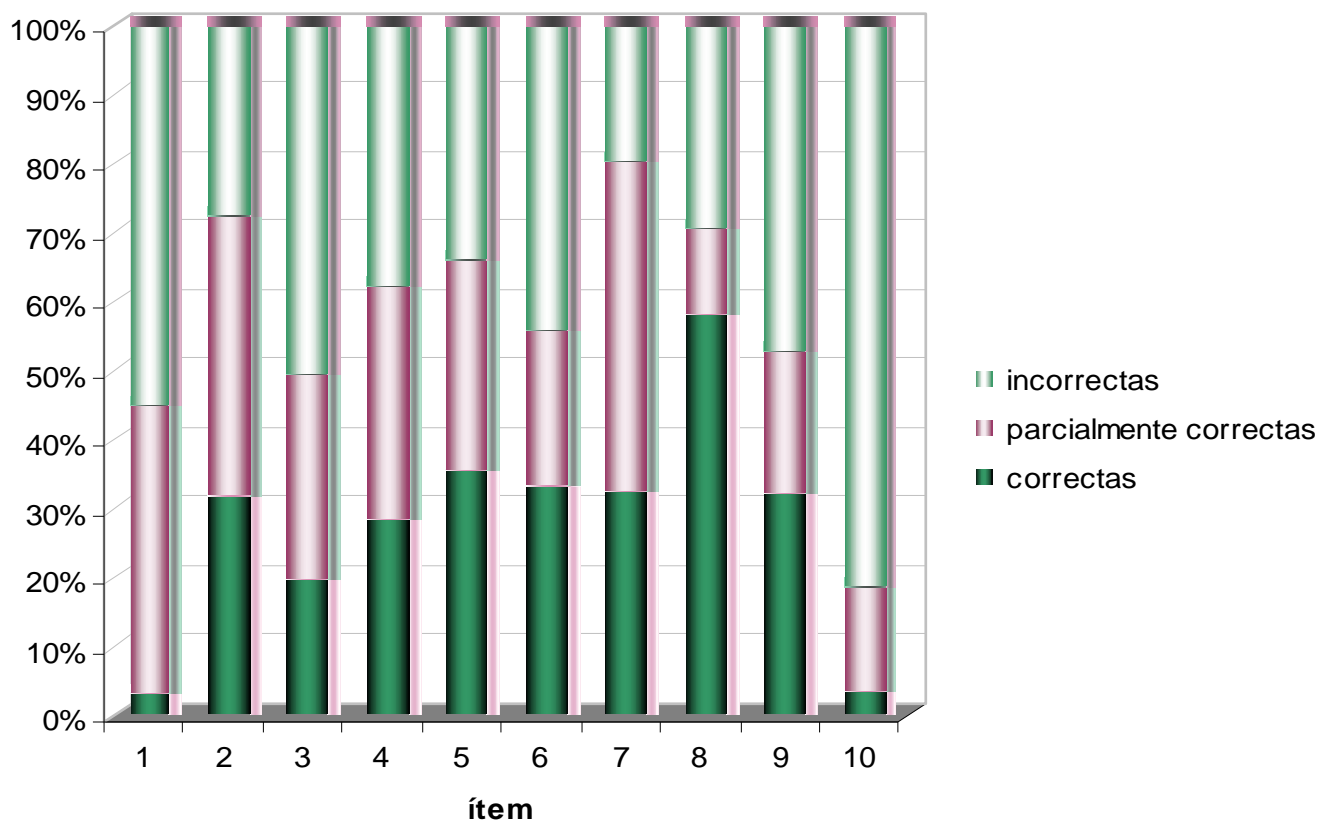

Figura 7.5.- Porcentajes de respuestas correctas, parcialmente correctas e incorrectas en el Post-ESO. 
En gráfica siguiente podemos observar el histograma correspondiente a la distribución de puntuaciones de los alumnos:

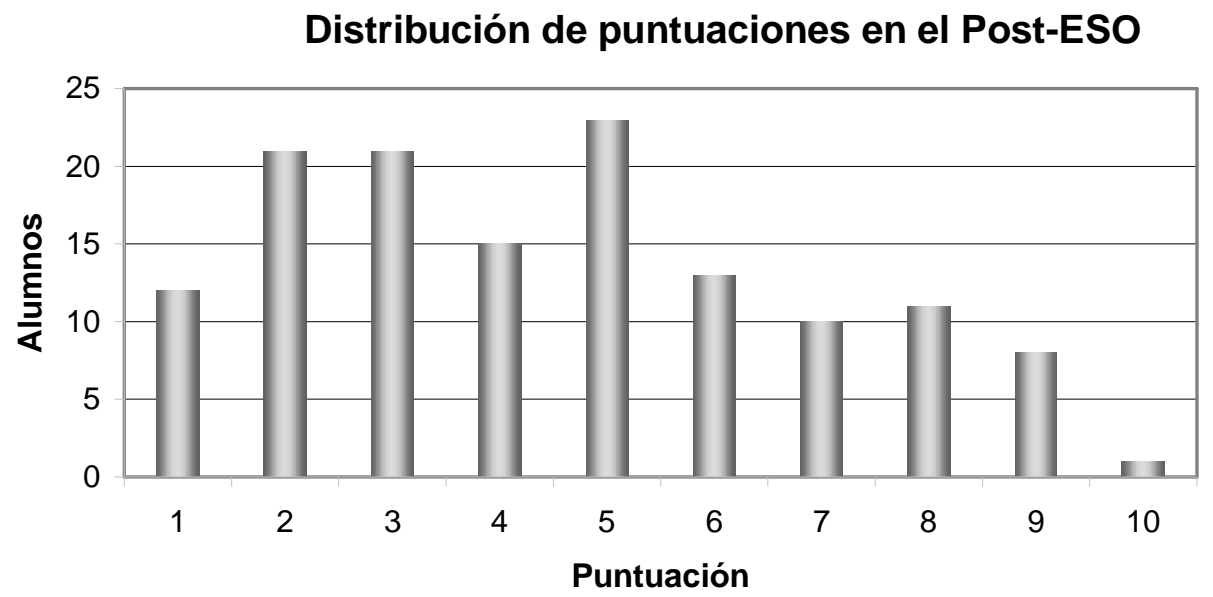

Figura 7.6.- Distribución de puntuaciones en el Post-ESO.

Con objeto de estudiar con profundidad cual ha sido el resultado de la intervención vamos a analizar las respuestas dadas por los alumnos en cada ítem, para ello se ha dispuesto de una red de análisis (Tabla 8.7) en la que se extraen las ideas de los alumnos, y a partir de la cual se tratará de obtener la mayor información posible.

\section{Ítem 1: Definición de molécula y su por qué.}

En la mayoría de los cuestionarios muchos de los alumnos no contestan a este ítem, o bien lo hacen de forma muy escueta, con frases como: "es lo más pequeño de los compuestos", "la unión de varios átomos" (esta última, mayoritariamente), no obstante a partir de las respuestas dadas en los ítems 4,7 y 8 se desprende que sí conocen el significado de esta partícula, pero no tiene seguridad a la hora de definirla.

Concretamente sólo un $44 \%$ de los alumnos da una respuesta satisfactoria cuando se les pregunta que es una molécula. De todos ellos solamente un 18,9\% indica algo lógico sobre el tipo de unión. Generalmente se alude a la compartición de 
electrones, pero casi ninguno, un 3\%, menciona que se produce por cuestión de estabilidad.

\section{¿Explica qué es una molécula?}

\begin{tabular}{l|l}
$\mathrm{Si} \rightarrow \mathbf{4 4 \%}$ & $\mathrm{No} \rightarrow \mathbf{5 6} \%$
\end{tabular}

- Un $18,1 \%$ de los alumnos lo

- Un $46 \%$ de los alumnos ha dejado ha justificado como una unión completamente en blanco la cuestión.

de átomos.

- Un 5,7\% lo ha hecho como una unión de elementos.

- Un 10,2\% como un conjunto de átomos.

- Un 4\% indica que son "una parte del átomo".

- Un $12,5 \%$ resuelve la cuestión indicando que es un tipo de partículas que lo forma todo.

\section{¿Indica la forma de unión?}

\section{\begin{tabular}{l|l}
$\mathrm{Si} \rightarrow \mathbf{1 9 \%}$ & $\mathrm{No} \rightarrow \mathbf{8 1 \%}$
\end{tabular}}

- Un $10 \%$ indica que es el resultado de un enlace covalente

- Un 6\% indica que es lo que se obtiene al unir dos elementos no metálicos.
- La gran mayoría no han hecho referencia al tipo de unión entre los átomos que forman la molécula.

\section{¿Menciona la estabilidad?}

\section{$\mathrm{Si} \rightarrow \mathbf{3 \%}$ \\ No $\rightarrow 97 \%$}

- Únicamente un $3,4 \%$ de los alumnos explica que los átomos comparten electrones para obtener una estructura de gas noble.
- Mayoritariamente no dan ninguna respuesta a este aspecto.

Tabla 7.37.- Porcentaje de alumnos que responden correctamente al ítem 1 del Post-ESO.

\section{Ítem 2: Clasificación de la materia}

Esta cuestión es respondida prácticamente por todos los alumnos. En ella se han incluido sustancias muy conocidas por ellos como la Coca cola o la sangre, y otras muy poco, como la cal o el aguarrás. La mayoría de ellos, un $80,3 \%$ ha detectado sin problemas que el hierro y el cobre eran elementos, sin embargo hasta un $40 \%$ han identificado como tales al ácido sulfúrico o el amoniaco, lo que lleva a pensar que no conocen a los elementos como parte integradora de la tabla, si no como sustancias mas sencillas o habituales. 
En cuanto a distinguir si se trata de una mezcla o un compuesto también ha habido bastante dificultad, no sólo en sustancias más extrañas a ellos, si no también en otras como el vino o la sangre. Sólo un $37 \%$ los distingue con relativa solvencia.

\begin{tabular}{|l|c|c|c|c|}
\hline \multicolumn{1}{|c|}{$\mid$} & Elemento & Mezcla & Compuesto & ns/nc \\
\hline Madera & $35,2 \%$ & $20,5 \%$ & $31,8 \%$ & $12,5 \%$ \\
\hline Hierro & $81,8 \%$ & $1,1 \%$ & $7,9 \%$ & $9,2 \%$ \\
\hline Agua destilada & $37,5 \%$ & $26,1 \%$ & $26,1 \%$ & $10,3 \%$ \\
\hline Tierra & $14,8 \%$ & $43,2 \%$ & $35,2 \%$ & $6,8 \%$ \\
\hline Coca cola & $0 \%$ & $69,3 \%$ & $23,9 \%$ & $6,8 \%$ \\
\hline Sangre & $5,7 \%$ & $52,3 \%$ & $34,1 \%$ & $7,9 \%$ \\
\hline Azúcar & $31,8 \%$ & $19,3 \%$ & $38,6 \%$ & $10,3 \%$ \\
\hline Humo & $6,8 \%$ & $39,8 \%$ & $39,8 \%$ & $13,6 \%$ \\
\hline Cal viva & $23,9 \%$ & $28,4 \%$ & $34,1 \%$ & $13,6 \%$ \\
\hline Amoniaco & $17 \%$ & $30,7 \%$ & $40,9 \%$ & $11,4 \%$ \\
\hline Ácido sulfúrico & $30,1 \%$ & $19,3 \%$ & $40,9 \%$ & $9,7 \%$ \\
\hline Aguarrás & $4,5 \%$ & $39,8 \%$ & $43,2 \%$ & $12,5 \%$ \\
\hline Cobre & $73,9 \%$ & $2,3 \%$ & $11,4 \%$ & $12,5 \%$ \\
\hline Vino & $4,5 \%$ & $68,2 \%$ & $19,3 \%$ & $6,8 \%$ \\
\hline Agua mineral & $19,3 \%$ & $40,9 \%$ & $28,4 \%$ & $13,6 \%$ \\
\hline
\end{tabular}

Tabla 7.38.- Porcentajes de respuestas dadas al ítem 2 del Post- ESO.

\begin{tabular}{|c|c|}
\hline \multicolumn{2}{|c|}{ ¿Reconoce qué sustancias son elementos químicos? } \\
\hline $\mathrm{Si} \rightarrow \mathbf{8 0 \%}$ & $\mathrm{No} \rightarrow \mathbf{2 0 \%}$ \\
\hline $\begin{array}{l}\text { - Tanto el hierro }(81,8 \%) \text { como } \\
\text { el cobre }(73,9 \%) \text { son } \\
\text { reconocidos como elementos } \\
\text { por los alumnos. }\end{array}$ & $\begin{array}{l}\text { - Raramente los confunden con una mezcla, } \\
\text { en su caso lo hacen con un compuesto o } \\
\text { dejan la pregunta en blanco. }\end{array}$ \\
\hline
\end{tabular}

\section{¿Distingue cuando se trata de mezclas o compuestos?}
$\mathrm{Si} \rightarrow 37 \%$
$\mathrm{No} \rightarrow 63 \%$

- Tiene bastante claros los

- Confunden la madera o el agua destilada con ejemplos de la coca cola, la un elemento. sangre el vino o la tierra, pero no otros como la madera o el humo. 


\section{¿Identifica los compuestos más comunes como tales en lugar de cómo} elementos?

\begin{tabular}{|c|c|}
\hline $\mathrm{Si} \rightarrow 60 \%$ & $\mathrm{No} \rightarrow 40 \%$ \\
\hline $\begin{array}{l}\text { - Aunque la mayoría los distinguen, } \\
\text { no se observa una buena definición, } \\
\text { puesto que sustancias como el } \\
\text { ácido sulfúrico la cal o el amoniaco } \\
\text { son reconocidos como tales } \\
\text { aproximadamente por un } 40 \% \text { de } \\
\text { los alumnos. }\end{array}$ & $\begin{array}{l}\text { - Un } 37,5 \% \text { de los alumnos identifica el } \\
\text { agua destilada como un elemento, } \\
\text { mientras que en el ejemplo del ácido } \\
\text { sulfúrico ocurre en un } 30,1 \% \text {, un } \\
31,8 \% \text { en el azúcar y un } 17 \% \text { para el } \\
\text { amoniaco. }\end{array}$ \\
\hline
\end{tabular}

Tabla 7.39.- Porcentaje de alumnos que responden correctamente al ítem 2 del Post-ESO.

\section{Ítem 3: Sistema periódico.}

Se hacen tres preguntas de respuesta abierta para que se explique la idea fundamental del sistema periódico, y además de forma muy explicita se intenta que se responda a que se trata de una clasificación según sus propiedades. La mayoría de ellos, un $61 \%$, no da respuesta o bien indican que la diferencia entre grupos se encuentra en que son o no metales. Esta respuesta resulta comprensible puesto que es la primera de las propiedades que se les presenta. Un 39\% indica claramente que los elementos de un mismo grupo tienen propiedades similares.

En cambio, cuando se trata de buscar la relación entre los elementos de un mismo periodo, el porcentaje de alumnos que indica que se trata de un mismo nivel energético o elementos con número atómico consecutivo, o simplemente que no tienen las mismas propiedades químicas, se reduce a un $27 \%$.

Pese a todo ello hay un $45 \%$ de los alumnos que no contestan nada o su respuesta indica que al preguntarles por grupos o periodos no aluden al sistema periódico. 


\section{¿Conoce que los elementos de un mismo grupo tienen propiedades similares?}

\begin{tabular}{|c|c|}
\hline $\mathrm{Si} \rightarrow \mathbf{3 9 \%}$ & $\mathrm{No} \rightarrow 61 \%$ \\
\hline $\begin{array}{l}\text { - De esta cantidad la gran } \\
\text { mayoría (un } 88 \% \text { ) contesta que } \\
\text { tienen características físicas y } \\
\text { químicas parecidas, mientras } \\
\text { que el resto apunta que forman } \\
\text { los mismos tipos de } \\
\text { compuestos. }\end{array}$ & $\begin{array}{l}\text { - Muchos de los alumnos no han respondido } \\
\text { a la cuestión o bien no lo han hecho en el } \\
\text { sentido propuesto. }\end{array}$ \\
\hline
\end{tabular}

\section{¿Conoce que esta relación no se da en un mismo periodo?}

\begin{tabular}{|l|l|}
\hline $\mathbf{S i} \rightarrow \mathbf{2 7 \%}$ & No $\rightarrow \mathbf{7 3 \%}$ \\
\hline $\begin{array}{c}\text { - Unánimemente han } \\
\text { contestado que los elementos } \\
\text { se ordenan en un periodo por } \\
\text { números atómicos crecientes. }\end{array}$ & $\begin{array}{c}\text { - En este caso la dificultad para contestar aun } \\
\text { ha sido mayor. }\end{array}$ \\
\hline
\end{tabular}

\section{¿Conoce algo del SP?}

\begin{tabular}{|l|l|}
\hline $\mathbf{S i} \rightarrow \mathbf{5 5 \%}$ & $\mathbf{N o} \rightarrow \mathbf{4 5 \%}$ \\
\hline \begin{tabular}{l|l|}
\hline Algunos alumnos han apuntado que tanto periodos \\
como grupos sirven para clasificar a los \\
elementos.
\end{tabular} & $\begin{array}{l}\text { Casi la mitad de los } \\
\text { alumnos no describen } \\
\text { ninguna relación entre }\end{array}$ \\
- Aproximadamente un 30\% de los alumnos pese a \\
$\begin{array}{l}\text { no indicar nada acerca de grupos o periodos han } \\
\text { aportado que sirve para clasificar a los elementos }\end{array}$ & periódica. \\
$\begin{array}{l}\text { apolabla } \\
\text { en metales y no metales. }\end{array}$ & \\
\hline
\end{tabular}

Tabla 7.40.- Porcentaje de alumnos que responden correctamente al ítem 3 del Post-ESO.

\section{Ítem 4: Transformaciones químicas.}

La pregunta en cuestión trata de reconocer en cual de los esquemas se está representando una reacción química. Un $62 \%$ de ellos reconoce correctamente que cuando hay un grupo de átomos unidos de una forma, se encuentran luego de otra, ha habido una reacción química, aunque algunos de ellos no lo consideren cuando varias moléculas se unen formando una mayor sin que se rompa ningún enlace.

En el caso de tratarse de sustancias que no están en proporción, el número de alumnos que lo entiende como reacción química disminuye hasta un $57 \%$.

Otro error cometido con gran frecuencia, hasta un $66 \%$ de los alumnos, han apuntado que se había producido un cambio químico en situaciones donde solamente se 
había cambiado la posición de las partículas, o bien se ha cambiado el tipo de estas, lo que supondría un cambio de posición o una reacción nuclear.

\section{¿Reconoce los cambios químicos?}

\begin{tabular}{l|l}
$\mathrm{Si} \rightarrow 62 \%$ & $\mathrm{No} \rightarrow 38 \%$
\end{tabular}

- Los tres casos en los que se describía un cambio químico(a, d y e)

- En el primer ejemplo (el más claro) un $67 \%$ lo indica como cambio químico

- En el ejemplo "e" se trata de una agrupación de moléculas para formar otra mayor y sólo lo reconoce un 48,9\%.

\section{¿Los reconoce aún cuando es parcial?}

$$
\begin{array}{l|l}
\mathrm{Si} \rightarrow \mathbf{5 7 \%} & \text { No } \rightarrow \mathbf{4 3 \%}
\end{array}
$$

- Hablamos del ejemplo "d" donde varios de los átomos quedan sin reaccionar. En este caso el $57 \%$ indica correctamente que se trata de una reacción química.
- Un $22 \%$ de los alumnos ha dejado directamente la cuestión en blanco.
- Además del $21 \%$ que ha dejado en blanco la cuestión hay un $22 \%$ que han interpretado que en este caso no tiene lugar una reacción.

\section{¿Distingue entre cambio de posición y reacción química?}
$\mathrm{Si} \rightarrow \mathbf{3 4 \%}$
No $\rightarrow 66 \%$

- Del total de los alumnos un $34 \%$ no ha identificado los ejemplos "b", "c" o "f" como cambios químicos puesto que se trataba de un cambio de posición o de partículas, pero no de ruptura o formación de moléculas.

-
- Un $48 \%$ de los alumnos que han respondido a la cuestión han atribuido un cambio químico al ejemplo "f" donde se representaba un cambio de unos átomos por otros.

- Un $11 \%$ ha atribuido una reacción al ejemplo "c" donde sólo se ha cambiado la ordenación espacial de las moléculas representadas.

Tabla 7.41.- Porcentaje de alumnos que responden correctamente al ítem 4 del Post-ESO. 


\section{Ítem 5: Estructura de la materia.}

En este ítem los alumnos ven con claridad la diferencia entre un cristal y unas moléculas, era bastante sencillo puesto que se parte de un dibujo y no del nombre de una sustancia, por tanto intuitivamente se puede contestar. No obstante hay un $36 \%$ de los alumnos que no responden correctamente a esta cuestión, y la mayoría de ellos por haberla dejado en blanco.

En otro sentido una vez determinado el tipo de estructura, un $62 \%$ de los alumnos identifica correctamente el tipo de enlace, y en bastantes casos no hay coincidencia, es decir contestan correctamente de que tipo de enlace se trata pero no indican si es una red o moléculas.

\section{¿Distingue entre moléculas y redes?}

\begin{tabular}{l|l}
$\mathrm{Si} \rightarrow 64 \%$ & $\mathrm{No} \rightarrow 36 \%$
\end{tabular}

- Atribuyen al primer y tercer ejemplo la estructura de red y

- La mayoría de estos dejan en blanco la cuestión.

al segundo y cuarto la de

- Un 8,8 \% llama átomo a la molécula.

molécula.

- Un 15,5\% reconoce las redes iónicas, pero no las metálicas.

\section{¿Identifica correctamente los tres tipos de enlace?}

\begin{tabular}{|c|c|}
\hline $\mathrm{Si} \rightarrow 62 \%$ & $\mathrm{No} \rightarrow \mathbf{3 8 \%}$ \\
\hline $\begin{array}{l}\text { - En el caso de la red iónica, el } 76 \% \text { la reconoce como tal. } \\
\text { - En el caso de la molécula representada por dos átomos } \\
\text { compartiendo electrones un } 62 \% \text { la reconoce como una } \\
\text { unión covalente, mientras que un } 31 \% \text { lo hace como } \\
\text { iónico. Este error se atribuye claramente al ejemplo } \\
\text { gráfico utilizado por los libros de texto para introducir } \\
\text { este último tipo de enlace. } \\
\text { - Un } 46 \% \text { de los alumnos identifica correctamente la } \\
\text { estructura metálica, aunque un } 24 \% \text { la asocia a una red } \\
\text { iónica, y un } 30 \% \text { lo hace a una estructura covalente } \\
\text { (que también se corresponde con este gráfico). }\end{array}$ & $\begin{array}{ll}\text { - Hay un } 24 \% \text { de } \\
\text { los alumnos que } \\
\text { no reconoce la } \\
\text { estructura } \\
\text { cristalina como } \\
\text { una conión } \\
\text { covalente. }\end{array}$ \\
\hline
\end{tabular}

Tabla 7.42.- Porcentaje de alumnos que responden correctamente al ítem 5 del Post-ESO. 


\section{Ítem 6: Tipos de enlace químico.}

Este ítem es el más determinante de la prueba y trata de medir si los alumnos son capaces de reconocer el tipo de enlace dada una sustancia. Un 51\% de los alumnos indica explícitamente que responde en base a que la unión entre un no metal y un metal supone un enlace iónico, entre un no metal y otro no metal supone un enlace covalente y que entre metales tiene lugar un enlace metálico.

Sin embargo dado este razonamiento el $61 \%$ de los estudiantes reconoce como metal o no metal a los elementos de forma incorrecta, lo que lleva a una determinación equivocada del tipo de enlace. Este error se resolvería fácilmente con un mínimo conocimiento de la tabla periódica.

\begin{tabular}{|l|c|c|c|}
\hline \multicolumn{1}{|l|}{} & Covalente & Iónico & Metálico \\
\hline $\mathbf{K I}$ & $17 \%$ & $83 \%$ & $0 \%$ \\
\hline $\mathbf{C u O}$ & $20,8 \%$ & $78,1 \%$ & $1 \%$ \\
\hline $\mathbf{N H}_{3}$ & $65,3 \%$ & $31,6 \%$ & $3,1 \%$ \\
\hline $\mathbf{M g H}_{2}$ & $25,6 \%$ & $64 \%$ & $10,4 \%$ \\
\hline $\mathbf{C O}$ & $71,4 \%$ & $24,5 \%$ & $4,1 \%$ \\
\hline $\mathbf{H C l}$ & $57,4 \%$ & $39,4 \%$ & $3,2 \%$ \\
\hline $\mathbf{B a F}_{2}$ & $25,9 \%$ & $70,4 \%$ & $3,7 \%$ \\
\hline $\mathbf{H}_{2} \mathbf{O}$ & $61,5 \%$ & $36,9 \%$ & $1,5 \%$ \\
\hline $\mathbf{P H}_{3}$ & $53,1 \%$ & $44,9 \%$ & $2 \%$ \\
\hline $\mathbf{H}_{2} \mathbf{S}$ & $52,9 \%$ & $44,8 \%$ & $2,3 \%$ \\
\hline $\mathbf{L i}_{3} \mathbf{N}$ & $20,5 \%$ & $78,3 \%$ & $1,2 \%$ \\
\hline $\mathbf{N}_{\mathbf{2}} \mathbf{O}_{3}$ & $70,5 \%$ & $26,3 \%$ & $3,2 \%$ \\
\hline
\end{tabular}

Tabla 7.43.- Porcentajes de respuestas dadas al ítem 6 del Post-ESO. 


\section{¿Conoce qué elementos son metálicos y cuales no?}

\begin{tabular}{|l|l|}
\hline $\mathbf{S i} \rightarrow \mathbf{3 9 \%}$ & No $\rightarrow \mathbf{6 1 \%}$ \\
\hline $\begin{array}{l}\text { - El 39\% de los alumnos } \\
\text { cuando justifica el por qué de }\end{array}$ & $\begin{array}{c}\text { - La mayoría de alumnos no indica el por que } \\
\text { de la elección de uno u otro tipo de enlace. }\end{array}$ \\
$\begin{array}{l}\text { uno u otro tipo de enlace } \\
\text { distingue correctamente a los }\end{array}$ & \\
$\begin{array}{l}\text { átomos como metálicos o no } \\
\text { metálicos. }\end{array}$ & \\
\hline
\end{tabular}

\begin{tabular}{|c|c|}
\hline \multicolumn{2}{|c|}{$\begin{array}{c}\text { ¿Asume que "no metal + no metal" supone enlace covalente } \\
\text { y" no metal + metal" supone enlace iónico? }\end{array}$} \\
\hline $\mathrm{Si} \rightarrow 51 \%$ & No $\rightarrow 49 \%$ \\
\hline $\begin{array}{l}\text { - El } 51 \% \text { de los alumnos } \\
\text { responde el tipo de enlace que } \\
\text { considera, a partir del } \\
\text { razonamiento del tipo de } \\
\text { elemento implicado. }\end{array}$ & $\begin{array}{l}\text { - Estos alumnos no asignan correctamente el } \\
\text { tipo de enlace. } \\
\text { - En muy pocos casos, incluso recociendo que } \\
\text { se trata de metales o no metales también } \\
\text { equivocan el tipo de enlace. }\end{array}$ \\
\hline
\end{tabular}

\section{¿Asigna correctamente el tipo de enlace?}

\begin{tabular}{|l|l|}
\hline Si $\rightarrow \mathbf{6 7 , 2 \%}$ & No $\rightarrow \mathbf{3 2 , 8 \%}$ \\
\hline $\begin{array}{l}\text { - Mayoritariamente, responden } \\
\text { alumnos los }\end{array}$ & $\begin{array}{l}\text { - Los ejemplos donde los alumnos han } \\
\text { equivocado la respuesta han sido aquellos en } \\
\text { correctamente a esta cuestión. } \\
\text { los que esta implicado el hidrógeno }\end{array}$ \\
$\begin{array}{l}\text { En todos los ejemplos hay un } \\
\text { elevado porcentaje de } \\
\text { repuestas correctas. }\end{array}$ & $\begin{array}{l}\text { En base a las justificaciones, los errores se } \\
\text { han debido a no saber como ubicar al } \\
\text { hidrógeno como metal o no metal en la regla } \\
\text { - En todos ellos la respuesta } \\
\text { más repetida ha sido la }\end{array}$ \\
$\begin{array}{ll}\text { nemotécnica. } \\
\text { correcta. }\end{array}$
\end{tabular}

Tabla 7.44.- Porcentaje de alumnos que responden correctamente al ítem 6 del Post-ESO.

\section{Ítem 7: Enlace químico y estructura de la materia}

Los alumnos no han prestado mucha dedicación a explicar el por que de las respuestas dadas a estas preguntas pero han sido bastante satisfactorias.

La mitad de ellos han confirmado que el enlace iónico no conlleva la formación de moléculas, pero además mayoritariamente han apuntado que se producen cristales o redes iónicas. En el caso del enlace covalente son un $71 \%$ los que apuntan que no debe siempre formarse moléculas y también indican que pueden formarse redes. 
En último lugar y bastante en concordancia con el ítem anterior, hay un $76 \%$ de los alumnos que indican que la unión entre elementos no metálicos conlleva la formación de un enlace covalente.

\section{¿Conoce que el enlace iónico no conlleva la formación de moléculas?}

\begin{tabular}{|l|l|}
\hline $\mathbf{S i} \rightarrow \mathbf{5 0 \%}$ & $\mathbf{N o} \rightarrow \mathbf{5 0 \%}$ \\
\hline \begin{tabular}{l|l|} 
- Un 55,5\% de los alumnos explica \\
que con el enlace iónico no se
\end{tabular} & $\begin{array}{l}\text { - Un 9,8\% de los alumnos no ha } \\
\text { contestado a esta cuestión. }\end{array}$ \\
$\begin{array}{l}\text { pueden formar } \\
\text { - el 65,3\% de ellos además indica } \\
\text { que con el enlace iónico se obtiene } \\
\text { redes cristalinas o iónicas. }\end{array}$ & $\begin{array}{l}\text { un } 44,5 \% \text { ha indicado que era cierto } \\
\text { que las moléculas podían formarse a } \\
\text { partir de enlaces iónicos. }\end{array}$ \\
$\begin{array}{l}\text { - El 12,7\% de este grupo apunta que } \\
\text { las moléculas sólo se forman } \\
\text { mediante un enlace covalente. }\end{array}$ & \\
\hline
\end{tabular}

\section{¿Conoce que el enlace covalente no se forma con metales?}

\begin{tabular}{|c|c|}
\hline $\mathrm{Si} \rightarrow 76 \%$ & No $\rightarrow 24 \%$ \\
\hline $\begin{array}{l}\text { - Los alumnos conocen con } \\
\text { claridad que los metales forman } \\
\text { entre si enlaces metálicos. } \\
\text { - Aproximadamente un } 50 \% \text { de los } \\
\text { que aportan esta respuesta la } \\
\text { justifican añadiendo que el enlace } \\
\text { covalente se forma por la unión } \\
\text { de dos elementos no metálicos. }\end{array}$ & $\begin{array}{l}\text { - Hay un porcentaje minoritario que indica } \\
\text { que si pueden formarse enlaces } \\
\text { covalentes con metales. } \\
\text { - Un } 11,7 \% \text { de los alumnos no ha } \\
\text { contestado esta cuestión. }\end{array}$ \\
\hline
\end{tabular}

\section{¿Conoce que el enlace covalente no siempre forma moléculas?}

\begin{tabular}{|l|l|}
\hline $\mathbf{S i} \rightarrow \mathbf{7 0 , 6} \%$ & No $\rightarrow \mathbf{2 9 , 4} \%$ \\
\hline $\begin{array}{l}\text { - Los alumnos responden } \\
\text { mayoritariamente que los }\end{array}$ & $\begin{array}{c}\text { - Los alumnos que han contestado que si las } \\
\text { forman no han explicado el por qué. }\end{array}$ \\
$\begin{array}{l}\text { enlaces covalentes no siempre } \\
\text { forman moléculas. }\end{array}$ \\
$\begin{array}{l}\text { - Únicamente un 15,5\% indica } \\
\text { que también pueden formarse } \\
\text { redes covalentes. }\end{array}$ \\
\hline
\end{tabular}

Tabla 7.45.- Porcentaje de alumnos que responden correctamente al ítem 7 del Post-ESO. 


\section{Ítem 8: Masas moleculares. Enlace covalente}

Este ítem queda curricularmente englobado dentro del concepto de molécula, pero a efectos de diferenciar entre el tipo de enlace o las propiedades que se derivan, no va a ser representativo. Más bien se trata de un algoritmo que resulta bastante sencillo para alumnos de 14 ó 15 años. Sin embargo va a ser útil buscar la relación en cuanto a concordancia, que hay entre los alumnos en cuanto a su capacidad para realizar este cálculo y distinguir entre un tipo u otro de estructura o su capacidad para definir qué es una molécula.

Claramente observamos que un 55,8\% de los alumnos han resuelto el cálculo sin problemas, y que solamente hay un 9,1\% que comete errores en la utilización de los subíndices.

Además un $56 \%$, lo que supone que prácticamente todos los que lo han realizado correctamente, utilizan como unidades la letra u. o ninguna unidad. Los datos que se les facilitaban eran masas relativas y por tanto los que colocado a los gramos como unidad han incurrido en un error de unidades, bastante común.

\begin{tabular}{|c|c|}
\hline \multicolumn{2}{|c|}{ ¿Calcula correctamente la masa molecular? } \\
\hline $\mathrm{Si} \rightarrow \mathbf{5 5 , 8} \%$ & $\mathrm{No} \rightarrow \mathbf{4 4 , 2} \%$ \\
\hline $\begin{array}{l}\text { - Más de la mitad } \begin{array}{l}\text { de los } \\
\text { alumnos } \\
\text { correctamente } \\
\text { solizan } \\
\text { cálculo }\end{array} \\
\end{array}$ & $\begin{array}{l}\text { - El } 31,2 \% \text { de los alumnos no ha contestado } \\
\text { la cuestión o bien ha hecho algún cálculo } \\
\text { diferente al indicado. } \\
\text { - El } 13 \% \text { de los alumnos aunque sigue el } \\
\text { procedimiento adecuado se equivocan al } \\
\text { hacer operaciones. }\end{array}$ \\
\hline
\end{tabular}

\section{¿Utiliza correctamente los subíndices?}

\begin{tabular}{|l|l|}
\hline $\mathbf{S i} \rightarrow \mathbf{5 9 , 7} \%$ & $\mathbf{N o} \rightarrow \mathbf{4 0 , 3 \%}$ \\
\hline \begin{tabular}{|l|l|} 
- Aunque hayan cometido \\
algún otro error, si utilizan \\
correctamente los subíndices.
\end{tabular} & $\begin{array}{r}\text { El } 9,1 \% \text { de los alumnos hace los cálculos, } \\
\text { pero no tienen en cuenta los subíndices y por } \\
\text { tanto, simplemente suman la masa atómica } \\
\text { de cada elemento. } \\
\text { - El resto no han contestado o no lo han hecho } \\
\text { de forma minimamente correcta. }\end{array}$ \\
\hline
\end{tabular}




\section{¿Asigna la unidad correcta?}

\section{\begin{tabular}{l|l}
$\mathrm{Si} \rightarrow 56 \%$ & $\mathrm{No} \rightarrow \mathbf{4 0 \%}$
\end{tabular}}

- Un 29,9 \% de los alumnos no coloca ninguna unidad para la masa molecular relativa

- Un 11,7 \% atribuye como unidad los gramos.

- Un 1,4\% indica que son moléculas.

- Un $26 \%$ utiliza como unidad la letra "u" en referencia a la unidad de masa.

Tabla 7.46.- Porcentaje de alumnos que responden correctamente al ítem 8 del Post-ESO

\section{Ítem 9: Formulación y nomenclatura químicas}

En este ítem se buscaba conocer la facilidad de los alumnos para relacionar las fórmulas químicas con sus nombres. La intención es conocer de forma objetiva si los alumnos conocen la tabla periódica y en concordancia con el ítem 6 concluir si hay relación o no entre los alumnos que conocen el sistema periódico y distinguen correctamente el tipo de enlace.

\section{¿Relaciona correctamente las formulas químicas con los nombres?}

\begin{tabular}{l|l}
$\mathrm{Si} \rightarrow \mathbf{5 2 , 6} \%$ & No $\rightarrow \mathbf{4 7 , 4} \%$
\end{tabular}

- El 52,6 \% hace la relación correctamente.

- En el caso de los óxidos los alumnos responden mejor $\left(\mathrm{Li}_{2} \mathrm{O}, 88,5 \%\right.$; $\mathrm{FeO}, 80,3 \%$; $\mathrm{PbO}, 60,7 \%)$.
- Un 29,1 \% ha relacionado al hidruro de calcio con el $\mathrm{HCl}$.

- Un $12,7 \%$ ha relacionado el ácido clorhídrico con el ácido carbónico, y en la misma proporción con el trióxido de dicloro.

Tabla 7.47.- Porcentaje de alumnos que responden correctamente al ítem 9 del Post-ESO.

\section{Ítem 10: Reacciones químicas. Estructura de la materia. Estados de agregación.}

Esta cuestión está pensada para que los alumnos concluyan que en una reacción química no hay más que una reordenación de los átomos debida a una ruptura y formación de enlaces y que además existen los mismos átomos sea cual sea el momento de la reacción. 
Se trata pues de concluir la propuesta inicial en la que se planteaba un problema donde un niño se pregunta si un mismo tipo de átomos que forma un elemento puede encontrarse en diferentes tipos de estructura. La respuesta ha sido bastante corta y sólo un 34,2\% ha indicado que los mismos átomos han cambiado su distribución y se han marchado en forma de otras sustancias, y tan solo un $16,5 \%$ ha indicado que la sustancia "madera" se ha transformado en "humo y cenizas" y finalmente un $4 \%$ ha expresado que la masa es la misma pero que se encuentra en el humo y las cenizas. Esto es lo que realmente se preguntaba.

\section{¿Explica que en una reacción se conserva la masa?}

\section{$\mathrm{Si} \rightarrow 34,2 \%$ \\ No $\rightarrow 65,8 \%$}

- El 34,2 \% de los alumnos da alguna explicación razonable, siendo la más frecuente que la materia ha pasado a estado gaseoso o que había gran parte de agua que se ha evaporado.

- La respuestas han sido del orden:

La madera se descompone.

La materia cambia de forma.

Se van desprendiendo moléculas.

Las moléculas se separan.

- La ceniza tiene una estructura diferente a la madera.
- El 48,1\% de los alumnos no da respuesta a la cuestión

- El 17,7 \% da respuestas que llevan a pensar que la materia no se conserva, del tipo:

Las moléculas se queman

Las moléculas se destruyen

La madera se consume

Las moléculas se hacen más pequeñas.

El fuego se come la madera.

- La masa se desintegra.

\section{¿Identifica al humo como parte de la materia?}

\section{\begin{tabular}{l|l}
$\mathrm{Si} \rightarrow \mathbf{1 6 , 5} \%$ & $\mathrm{No} \rightarrow \mathbf{8 3 , 5 \%}$
\end{tabular}}

- Un 12,6\% de los alumnos o lo que es lo mismo un $31,2 \%$ de los que han respondido a la cuestión, indican que la materia se ha separado en forma de humo o gas.
- Gran parte de los alumnos, o bien no ha contestado o no identifica al humo como una sustancia material.

\section{¿Admite que el humo tiene masa?}

\section{$\mathrm{Si} \rightarrow \mathbf{3 , 8 \%}$

$$
\text { No } \rightarrow \mathbf{9 7 , 2 \%}
$$

- Únicamente un 3,8 \% ha indicado explícitamente que el humo tiene masa y que corresponde a partículas que provienen de la madera.
- El la misma situación que la pregunta anterior, al no identificarlo como materia en mayor proporción se le deja de atribuir masa.

Tabla 7.48.- Porcentaje de alumnos que responden correctamente al ítem 10 del Post-ESO. 


\subsubsection{Resultados obtenidos en el Pre-Bac}

\begin{tabular}{|l|c|c|c|c|}
\hline Grupo & Alumnos & Media & $\begin{array}{c}\text { Desviación } \\
\text { típica }\end{array}$ & Curtosis \\
\hline E1 & 9 & 3,389 & 1,5161 & $-1,109$ \\
\hline E2 & 22 & 4,114 & 1,1436 & 2,480 \\
\hline E3 & 16 & 3,967 & 1,0933 & 0,229 \\
\hline C1 & 16 & 5,227 & 2,6492 & 0,143 \\
\hline Total & 63 & 4,175 & 1,6434 & 1,552 \\
\hline
\end{tabular}

Tabla 7.49.- Resultados obtenidos en el Pre-Bac.

\section{Porcentaje de respuestas correctas en el Pre-Bac}

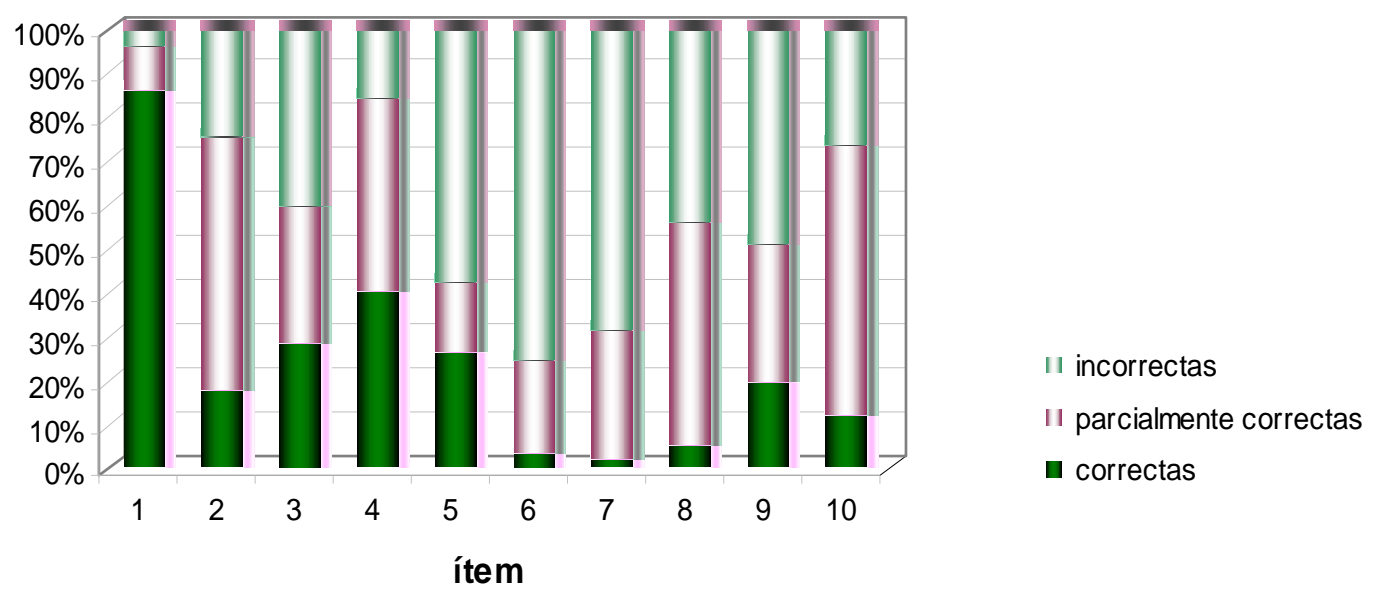

Figura 7.7. Porcentajes de respuestas correctas, parcialmente correctas e incorrectas en el Pre-Bac.

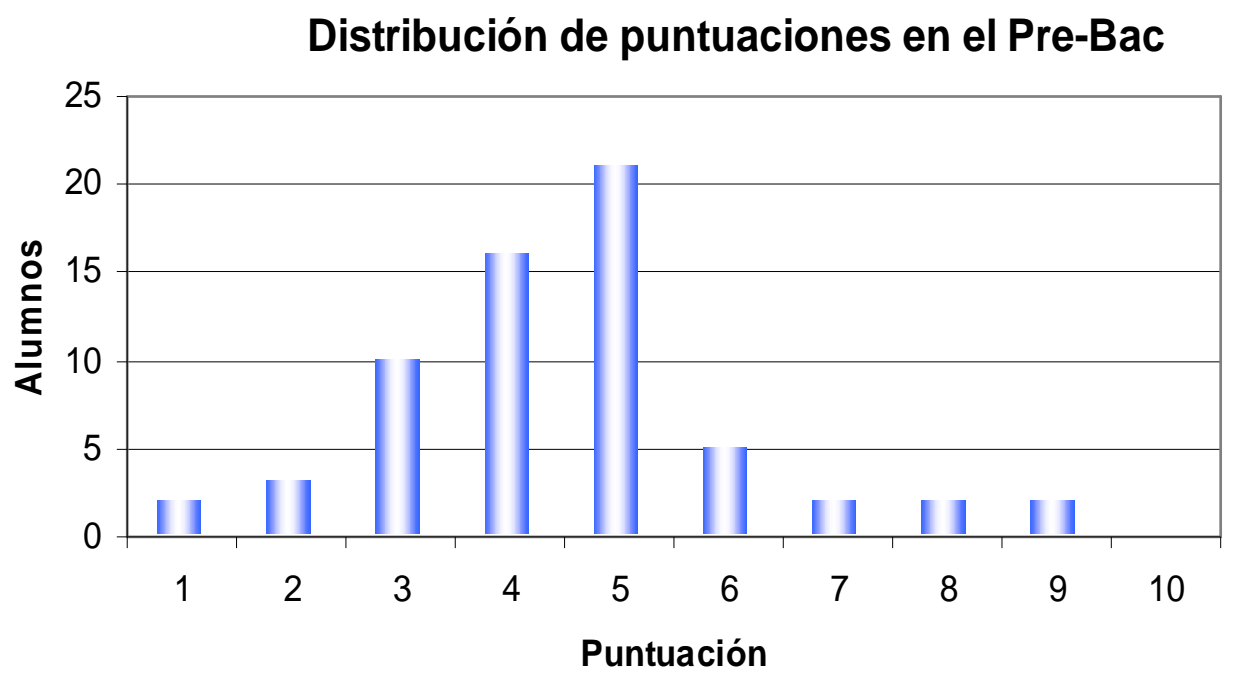

Figura 7.8.- Distribución de puntuaciones en el Pre-Bac. 


\section{Ítem 1. Símbolos y nombres de los elementos químicos}

Este primer ítem a priori parece trivial, pero en entramos que hay cerca de un $40 \%$ de los alumnos que se equivocan al reconocer los símbolos de algunos elementos. Este error no se da en ejemplos como el calcio, cobre o niquel, pero si en otros cono el antimonio, el mercurio o cobre, siendo sobre todo estos dos últimos muy frecuentes en las clases de física y química.

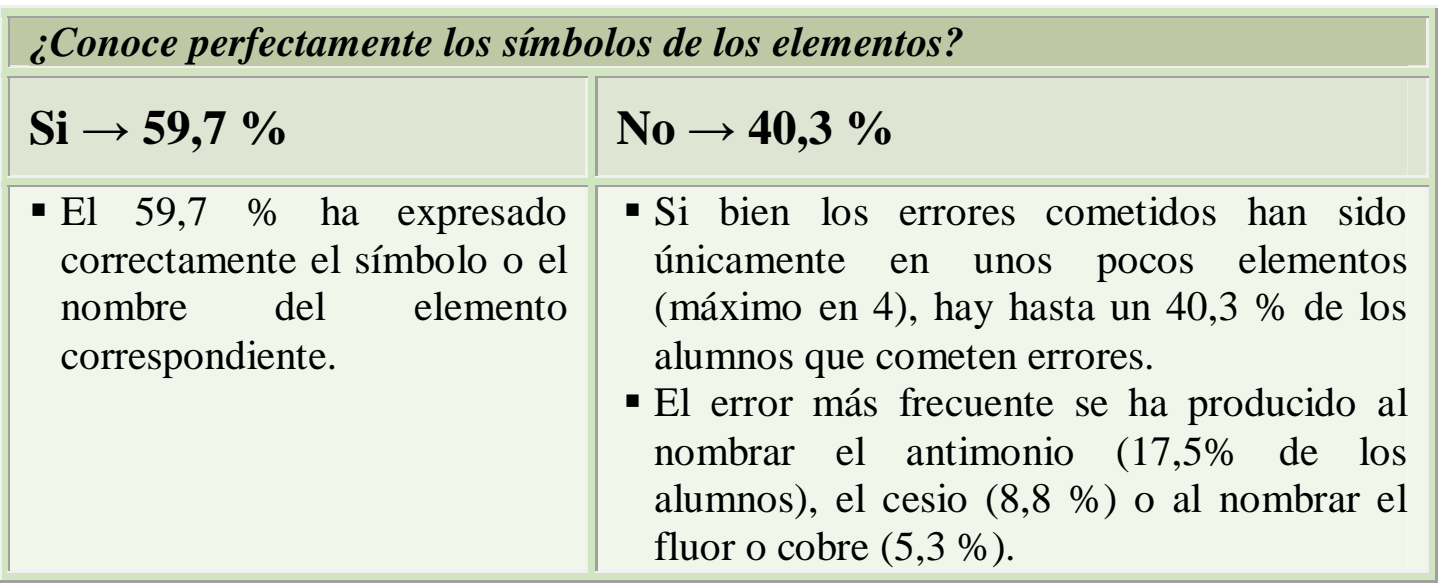

Tabla 7.50.- Porcentaje de alumnos que responden correctamente al ítem 1 del Pre-Bac.

\section{Ítem 2. Bloques, grupos y periodos en la tabla periódica. Propiedades periódicas}

Este ítem trata de analizar si los alumnos tienen un conocimiento suficientemente amplio del sistema periódico como para abordar el estudio del enlace químico. Para ello comenzamos preguntando a los alumnos sobre cuales de una serie de elementos son conductores, con la intención de ver si discriminan correctamente entre metales y no metales. El 52,6\% responde correctamente, aunque cuando se pregunta sobre una clasificación más detallada, son sólo un 45,6\% los que ubican correctamente por ejemplo a los halógenos o a los elementos gaseosos en condiciones normales.

Respecto a las propiedades periódicas, tema estudiado anteriormente a este por su parte, el 75\% saben situar a los elementos, y en concreto en el caso de la electronegatividad, todos estos indican que es '"el que está más arriba y más a la derecha". 
Respecto a la tabla periódica

\begin{tabular}{|l|l|l|}
\hline \multicolumn{2}{|l|}{ ¿Sitúa los metales $y$ los no metales? } \\
\hline Si $\rightarrow \mathbf{5 2 , 6} \%$ & No $\rightarrow \mathbf{4 7 , 4} \%$ \\
\hline $\begin{array}{l}\text { - El 52,6 \% indica } \\
\text { correctamente cuales de los } \\
\text { elementos son conductores. }\end{array}$ & $\begin{array}{l}\text { - El } 47,4 \% \text { no distingue con claridad qué } \\
\text { elementos son metales. } \\
\text { - El } 21 \% \text { de los alumnos no ha contestado la } \\
\text { cuestión. } \\
\text { - El } 26,4 \% \text { ha respondido de forma incorrecta } \\
\text { aportando como metales a cualquiera de los } \\
\text { propuestos. }\end{array}$ \\
\hline
\end{tabular}

\section{¿Distingue cuales son los grupos?}
$\mathrm{Si} \rightarrow 45,6 \%$
No $\rightarrow \mathbf{5 4 , 4} \%$

- El 45,6 \% conoce cual es el grupo de los halógenos y, qué elementos son representativos.

- Más de la mitad de los alumnos no identifican los grupos de la tabla periódica.

\section{¿Ubica los elementos respecto a su EN?}

\begin{tabular}{|l|l|l|l|}
\hline Si $\rightarrow \mathbf{7 5 , 4} \%$ & $\mathbf{N o} \rightarrow \mathbf{2 4 , 6} \%$ & \\
\hline $\begin{array}{l}\text { - Conocen que el elemento más } \\
\text { electronegativo es el situado en la tabla, }\end{array}$ & - Un $8,8 \%$ no responde la \\
más hacia arriba y hacia la derecha, & - Un 15,8 \% responde de forma \\
explicitándolo en la explicación. & incorrecta. & \\
$\begin{array}{l}\text { - Un porcentaje similar (70,2 \%) indica } \\
\text { que es posible la unión entre un elemento } \\
\text { alcalino y otro halógeno. }\end{array}$ & &
\end{tabular}

Tabla 7.51.- Porcentaje de alumnos que responden correctamente al ítem 2 del Pre-Bac.

\section{Ítem 3. Estructura atómica. Partículas subatómicas}

Este ítem debería haber resultado muy sencillo puesto que la idea de átomo es conocida desde hace tiempo por estos alumnos. Sin embargo sólo un 67,9\% de los alumnos lo representa con cierta corrección.

Únicamente el 35,7\% expresa correctamente el lugar donde se encuentran protones, neutrones y electrones. Y tan solo el $11 \%$ dibuja a los electrones de forma 
deslocalizada, mientras que el resto lo hace dibujándolos en órbitas alrededor del núcleo obedeciendo al modelo de Rutherford. Este problema sería comprensible, dada su utilización en situaciones de la vida ordinaria, pero no es el caso puesto que en el tema anterior se han estudiado con profundidad los modelos atómicos.

Respecto a estructura atómica:

¿Es capaz de dibujar un átomo?

\begin{tabular}{l|l}
$\mathrm{Si} \rightarrow 67,9 \%$ & $\mathrm{No} \rightarrow 32,1 \%$
\end{tabular}

- Un 67,9 \% de los alumnos

- Una tercera parte de los alumnos deja en dibuja el esquema de un átomo, de una u otra forma. blanco la cuestión o dibuja cosas carentes de sentido.

- La gran mayoría dibuja el modelo de Borh.

\section{¿Coloca cada componente en su lugar?}

\begin{tabular}{l|l}
$\mathrm{Si} \rightarrow 35,7 \%$ & No $\rightarrow 64,3 \%$
\end{tabular}

- El 35,7 \% de los alumnos dibuja correctamente los protones y neutrones indicados en el núcleo

- Además de del 32,1 \% de los que no contestan la cuestión hay otro $32,2 \%$ que no lo hace correctamente.

atómico, y los electrones

- Los errores cometidos con mayor frecuencia han sido dibujar únicamente protones en el alrededor. núcleo $(13,8 \%)$, dibujar el núcleo sólo con

- Es decir, poco más de la mitad de los que hacen el un círculo $(10,8 \%)$ o no dibujar ningún electrón $(12,3 \%)$. dibujo con cierta corrección colocan las partículas en el lugar adecuado.

\section{¿Dibuja a los electrones dispersos en lugar de hacerlo en órbitas?}

\begin{tabular}{|c|c|}
\hline $\mathrm{Si} \rightarrow 10,8 \%$ & $\mathrm{No} \rightarrow \mathbf{8 9 , 1} \%$ \\
\hline $\begin{array}{l}\text { - Únicamente el } 10,8 \% \text { de los } \\
\text { alumnos ha dibujado a los } \\
\text { electrones dispersos alrededor } \\
\text { del núcleo. }\end{array}$ & $\begin{array}{l}\text { - De los alumnos que han dibujado } \\
\text { correctamente el átomo con sus partículas, la } \\
\text { tercera parte ha utilizado un modelo con los } \\
\text { electrones dispersos alrededor del núcleo. } \\
\text { - El } 52 \% \text { de todos los alumnos ha hecho un } \\
\text { dibujo el que los electrones describían } \\
\text { orbitas circulares. }\end{array}$ \\
\hline
\end{tabular}

Tabla 7.52.- Porcentaje de alumnos que responden correctamente al ítem 3 del Pre-Bac 


\section{Ítem 4. Configuración electrónica}

Dado el carácter algorítmico de la respuesta a esta cuestión, la respuesta ha sido contestada correctamente por un $75,4 \%$ de los alumnos. Ha habido un pequeño porcentaje alrededor del 15\% que ha confundido el número másico con el atómico. En cambio hay una cantidad importante de alumnos, alrededor del 69,1\%, que no resuelve correctamente la situación en el caso de un ión y que directamente identifica el número de electrones con el número atómico.

Respecto a la configuración electrónica:

\begin{tabular}{|c|c|}
\hline \multicolumn{2}{|l|}{ ¿La escribe correctamente? } \\
\hline $\mathrm{Si} \rightarrow 75,4 \%$ & $\mathrm{No} \rightarrow 24,6 \%$ \\
\hline $\begin{array}{l}\text { - El 75,4 \% de los alumnos sabe } \\
\text { utilizar el algoritmo que permite } \\
\text { el cálculo de la configuración } \\
\text { electrónica en el caso de átomos } \\
\text { de con número atómico bajo. }\end{array}$ & $\begin{array}{l}\text { - Una cuarta parte de los alumnos no hace } \\
\text { este cálculo correctamente. } \\
\text { - Sólo un } 4,6 \% \text { de los alumnos no ha } \\
\text { contestado la cuestión. }\end{array}$ \\
\hline
\end{tabular}

\section{¿Distingue correctamente entre A y Z?}
$\mathrm{Si} \rightarrow \mathbf{8 4 , 6} \%$
No $\rightarrow 15,4 \%$

- El 84,6 \% busca una

- El 15,4 \% de los alumnos ha buscado la configuración cuyo número de electrones coincida con la coincidencia de la suma de los exponentes suma de los exponentes.

\begin{tabular}{|l|l|}
\hline \multicolumn{2}{|c|}{ ¿Conoce el número de $e^{-}$en el caso de un ión? } \\
\hline Si $\rightarrow \mathbf{3 0 , 8} \%$ & No $\rightarrow \mathbf{6 9 , 1} \%$ \\
\hline \begin{tabular}{l|l|} 
- El $30,8 \%$ resuelve \\
correctamente el \\
caso del ión $\mathrm{Cl}^{-}$.
\end{tabular} & $\begin{array}{l}\text { - El } 69,1 \% \text { no lo hace. } \\
\text { - El } 35,8 \% \text { de los alumnos no ha tenido en cuenta el } \\
\text { electrón adicional que supone la carga negativa, } \\
\text { obteniendo una configuración en 3p }\end{array}$ \\
$\begin{array}{l}\text { - Un } 7,7 \% \text { ha considerado que debía rebajar en una } \\
\text { unidad el número atómico obteniendo una } \\
\text { terminación } 3 p^{4} .\end{array}$ \\
\hline
\end{tabular}

Tabla 7.53.- Porcentaje de alumnos que responden correctamente al ítem 4 del Pre-Bac. 


\section{Ítem 5. Valencias de los elementos químicos.}

El 43,5\% de los alumnos conoce cual es la valencia iónica de los elementos propuestos y, dada la frecuencia con la que aparecen tanto oxígeno, fluor o potasio, es evidente y preocupante el hecho de la mayoría no tenga claro este dato.

\section{¿Conoce la valencia iónica del elemento?}

\begin{tabular}{|c|c|}
\hline $\mathrm{Si} \rightarrow 43,5 \%$ & $\mathrm{No} \rightarrow 56,5 \%$ \\
\hline $\begin{array}{l}\text { - } \begin{array}{l}\text { El } 23,0 \% \\
\text { correctamente el }\end{array} \text { valor } \\
\text { correcto. } \\
\text { - Hay un 18,5 \% que } \\
\text { equivoca el valor del Sb, } \\
\text { respondiendo correctamente } \\
\text { en el resto de ejemplos. }\end{array}$ & $\begin{array}{l}\text { - Un } 56,5 \% \text { de los alumnos comete números } \\
\text { errores en esta cuestión. } \\
\text { - Un } 35,4 \% \text { no atribuye al oxígeno la valencia - } \\
2 \text {. } \\
\text { - Un } 46,2 \% \text { no atribuye al fluor la valencia }-1 \text {. } \\
\text { - Un } 43,1 \text { no lo hace con el potasio }(+1) \\
\text { - Y un } 67,9 \% \text { no lo hace con el antimonio }(-3) \\
\text { asignando valores como el }+3 \text { en la mayoría } \\
\text { de los casos }\end{array}$ \\
\hline
\end{tabular}

Figura 7.54.- Porcentaje de alumnos que responden correctamente al ítem 5 del Pre-Bac.

\section{Ítem 6. Configuración electrónica y sus consecuencias}

Dado el poco tiempo transcurrido entre el tema anterior y éste cabría esperar mejores respuestas en este apartado. Tan sólo un 41,4\% de los alumnos observan que el hecho de tener un electrón en el último nivel va a determinar su ubicación en la tabla periódica y su actividad química.

Solo un $2 \%$ indica que se trata de un elemento alcalino y que es este último electrón el que le confiere su reactividad.

\begin{tabular}{|c|c|}
\hline \multicolumn{2}{|c|}{ ¿Relaciona el comportamiento químico con la configuración electrónica? } \\
\hline $\mathrm{Si} \rightarrow \mathbf{4 1 , 4 \%}$ & $\mathrm{No} \rightarrow \mathbf{5 8 , 6} \%$ \\
\hline $\begin{array}{l}\text { - El } 41,4 \% \text { de los alumnos indican que a } \\
\text { la vista de la configuración propuesta } \\
\text { el átomo presenta un electrón } \\
\text { desapareado y que por tanto tendera a } \\
\text { cederlo. }\end{array}$ & $\begin{array}{l}\text { - El resto de alumnos no indica nada } \\
\text { acerca de su posible } \\
\text { comportamiento. }\end{array}$ \\
\hline
\end{tabular}




\section{¿Obtiene alguna información?}

\begin{tabular}{l|l}
$\mathrm{Si} \rightarrow 20,7 \%$ & No $\rightarrow 79,3 \%$
\end{tabular}

- El 20,7 \% aporta alguna idea a la cuestión.

- El 10,3 \% de los alumnos expresa que el electrón presente en la última capa le confiere una baja energía de ionización, baja electronegatividad y baja electroafinidad.

- El 3,5\% indica que se trata de un elemento con $Z=19$.

- El 11,6 \% responde que el elemento en cuestión se encuentra en el cuarto periodo y en el grupo de los alcalinos.

Tabla 7.55.- Porcentaje de alumnos que responden correctamente al ítem 6 del Pre-Bac.

\section{Ítem 7. Orbital atómico}

Dada la configuración electrónica de un átomo el 66\% de los alumnos conoce el significado de cajas que representan a los orbitales.

\section{¿Interpreta correctamente los diagramas de cajas?}

\section{\begin{tabular}{l|l}
$\mathrm{Si} \rightarrow 66,1 \%$ & $\mathrm{No} \rightarrow 33,9 \%$
\end{tabular}}

- El 32,1 \% de los alumnos indica que el último electrón se encuentra en la última

- El $25 \%$ no responde nada a la cuestión. capa.

- El 7,2 \% indica que se encuentra en el último orbital.

- El 21,4 \% indica que se encuentra en el orbital $4 \mathrm{~s}$.

- El $12,5 \%$ indica que se encuentra en la cuarta capa.

- Un 5,4 \% indica que se encuentra en un orbital s.

Tabla 7.56.- Porcentaje de alumnos que responden correctamente al ítem 7 del Pre-Bac. 


\section{Ítem 8.Átomos, iones y moléculas}

Un $60 \%$ de los alumnos da una explicación correcta a la diferencia entre un átomo y un ión, aunque son un 50,9\% los que consiguen razonar, en el caso de los iones, que se trata de átomos que han ganado o perdido electrones. El resto alude a que son átomos con carga eléctrica.

Por otro lado hay un $72,7 \%$ de alumnos que opinan que un elemento no puede estar formado por moléculas, si no por átomos, y que por tanto las moléculas son el resultado de la unión de átomos deferentes.

\section{¿Distingue correctamente entre átomo e ión?}

\begin{tabular}{|c|c|}
\hline $\mathrm{Si} \rightarrow 60 \%$ & $\mathrm{No} \rightarrow 40 \%$ \\
\hline $\begin{array}{l}\text { - Un } 60 \% \text { de los alumnos } \\
\text { distingue claramente ente lo } \\
\text { que es un átomo y lo que es } \\
\text { un ión. }\end{array}$ & $\begin{array}{l}\text { - Un } 16,4 \% \text { no responde a la cuestión. } \\
\text { - Un } 23,6 \% \text { indica que se trata de un átomo } \\
\text { diferente o que uno es una parte } \\
\text { constituyente del otro. }\end{array}$ \\
\hline
\end{tabular}

\section{¿Razona correctamente la diferencia?}

\begin{tabular}{l|l}
$\mathrm{Si} \rightarrow \mathbf{5 0 , 9} \%$ & No $\rightarrow$ 49,1 \%
\end{tabular}

- El $20 \%$ de los alumnos indica que la

- El 10,9 \% de los alumnos alegan diferencia entre átomos e iones de un mismo elemento reside en el número de electrones.

- El 9,1\% indica que la diferencia se encuentra en que los iones tienen carga.

- El 32,7\% de los alumnos razona que un que la diferencia entre átomo e ión es que el primero es estable y el segundo no.

- El 38,2 \% de los alumnos no justifica la cuestión. ión se produce cuando un átomo gana $o$ pierde electrones.

\section{¿Admite que un elemento puede estar formado por moléculas?}

\begin{tabular}{|l|l|}
\hline Si $\rightarrow \mathbf{2 7 , 3} \%$ & No $\rightarrow \mathbf{7 2 , 7 \%}$ \\
\hline \begin{tabular}{l|l|} 
- El 27,3 \% de los alumnos \\
indica que si puede darse esta \\
situación.
\end{tabular} & $\begin{array}{l}\text { - La mayoría de los alumnos piensa que un } \\
\text { elemento no puede estar formado por } \\
\text { moléculas. }\end{array}$ \\
$\begin{array}{l}\text { - La mayoría lo justifica } \\
\text { poniendo como ejemplos las } \\
\text { moléculas biatómicas de los } \\
\text { elementos halógenos. }\end{array}$ & $\begin{array}{l}\text { - El } 21,8 \% \text { no responde a esta cuestión. } \\
\text { - El } 12,7 \% \text { de los alumnos indica que los } \\
\text { elementos están formados por átomos. } \\
\text { - El resto de alumnos no justifica la repuesta } \\
\text { negativa. }\end{array}$ \\
\hline
\end{tabular}

Tabla 7.57.- Porcentaje de alumnos que responden correctamente al ítem 8 del Pre-Bac. 


\section{Ítem 9. Propiedades periódicas}

Como ejemplo de propiedad periódica, hemos hecho referencia a la energía de ionización, y un 49,1\% han sido capaces de definirla aunque la práctica totalidad ha omitido detalles como que se ha de partir de átomos gaseosos, o que se trata de un solo electrón. No obstante, parecen tener claro que se trata de la energía necesaria para el proceso en cuestión.

El porcentaje se reduce hasta un 41,8 \% cuando se trata de relacionar la energía necesaria con la configuración electrónica, quedando un 58,2 \% que no consigue explicar su variación dentro de un mismo grupo.

\section{¿Es capaz de definir la energía de ionización?}

\begin{tabular}{l|l}
$\mathrm{Si} \rightarrow \mathbf{4 9}, \mathbf{1 \%}$ & $\mathrm{No} \rightarrow \mathbf{5 0 , 9 \%}$
\end{tabular}

- Prácticamente la mitad de los alumnos han definido la energía de ionización.

- Todos ellos han indicado que se trata de la energía necesaria para "arrancar un electrón a un átomo".

- Únicamente el 18,5\% de estos últimos indica que se habla de un átomo aislado en estado gaseoso.
- El 36,4\% de los alumnos no responde a la cuestión.

- El 14,5\% responde incorrectamente alegando que se trata de la energía que tiene el átomo en estado fundamental o la energía necesaria para pasar un electrón de un nivel a otro.

\section{¿La relaciona con la configuración electrónica?}

\begin{tabular}{|c|c|}
\hline $\mathrm{Si} \rightarrow 41,8 \%$ & $\mathrm{No} \rightarrow \mathbf{5 8 , 2 \%}$ \\
\hline $\begin{array}{l}\text { - El 41,8\% indica que la } \\
\text { energía de ionización está } \\
\text { relacionada con la } \\
\text { distribución electrónica en el } \\
\text { átomo. } \\
\text { - El 32,7\% indica que la } \\
\text { diferencia se encuentra en que } \\
\text { en los átomos de litio y cesio, } \\
\text { el nivel energético del último } \\
\text { electrón es diferente. }\end{array}$ & $\begin{array}{l}\text { - El } 25,5 \% \text { de los alumnos no explica la } \\
\text { diferencia de energías de ionización entre } \\
\text { estos átomos. } \\
\text { - El } 38,2 \% \text { de los alumnos indica que el litio } \\
\text { tiene mayor esta energía por encontrarse más } \\
\text { arriba en la tabla periódica. } \\
\text { - Estos últimos generalmente no la han } \\
\text { definido y responden algorítmicamente la } \\
\text { cuestión. }\end{array}$ \\
\hline
\end{tabular}

Tabla 7.58.- Porcentaje de alumnos que responden correctamente al ítem 9 del Pre-Bac. 


\section{Ítem 10. Formulación y nomenclatura química}

Por último pretendemos conocer la habilidad de los alumnos en algo tan elemental como la formulación. Como ha ocurrido en el caso de otros cuestionarios, a los alumnos les resulta más fácil nombrar a los compuestos que formularlos. Y como parece normal, también es más sencillo trabajar con compuestos binarios que con ternarios.

En términos porcentuales, un $74,1 \%$ nombra correctamente a los compuestos binarios, pero la cifra se reduce hasta un $53,2 \%$ en el caso de los ternarios, y si hablamos de formular y nombrar en general, tenemos un $29,1 \%$ de los alumnos que lo hacen correctamente.

\section{¿Nombra correctamente los compuestos binarios?}

\begin{tabular}{l|l}
$\mathrm{Si} \rightarrow \mathbf{7 4 , 1 \%}$ & No $\rightarrow \mathbf{2 5 , 9 \%}$
\end{tabular}

- En el 74,1\% de los casos los alumnos

- Los alumnos tienen mayor nombran correctamente los compuestos dificultad a la hora de nombrar la binarios. molécula de cloro.

- Normalmente utilizan la nomenclatura sistemática.

\begin{tabular}{|c|c|}
\hline \multicolumn{2}{|l|}{ ¿Nombra correctamente los compuestos ternarios? } \\
\hline $\mathrm{Si} \rightarrow \mathbf{5 3 , 2 \%}$ & $\mathrm{No} \rightarrow \mathbf{4 6 , 8 \%}$ \\
\hline $\begin{array}{l}\text { - El 53,2\% nombra correctamente los } \\
\text { compuestos ternarios. } \\
\text { - En el caso del hidróxido, contesta } \\
\text { correctamente un } 63,6 \% \text { de los alumnos. }\end{array}$ & $\begin{array}{l}\text { - Generalmente se opta por } \\
\text { dejar en blanco la cuestión } \\
\text { antes de hacerlo mal. } \\
\text { - El principal error cometido se } \\
\text { refiere a la utilización de los } \\
\text { prefijos y sufijos. }\end{array}$ \\
\hline
\end{tabular}

\section{¿Formula correctamente los compuestos binarios?}
$\mathrm{Si} \rightarrow \mathbf{4 8 , 2 \%}$
$\mathrm{No} \rightarrow \mathbf{5 1 , 8 \%}$

- Prácticamente la mitad de los

- La principal dificultad ha residido en alumnos los formula correctamente. formular los ácidos hidrácidos.

- El $80 \%$ formula correctamente el

- Además una cuarta parte de los hidruro de litio. alumnos no ha contestado en varios de los ejemplos. 


\section{¿Formula correctamente los compuestos ternarios?}

\begin{tabular}{|l|l|}
\hline $\mathbf{S i} \rightarrow \mathbf{2 9 , 1 \%}$ & $\mathbf{N o} \rightarrow \mathbf{7 0 , 9 \%}$ \\
\hline \begin{tabular}{l|l|}
\hline El 29,1\% de los alumnos \\
formula correctamente los \\
compuestos ternarios.
\end{tabular} & $\begin{array}{l}\text { - La principal dificultad de presenta en el caso } \\
\text { del fosfato cálcico y sales ternarias en } \\
\text { general. }\end{array}$ \\
\hline
\end{tabular}

Tabla 7.59.- Porcentaje de alumnos que responden correctamente al ítem 10 del Pre-Bac. 


\subsubsection{Resultados obtenidos en el Post-Bac}

\begin{tabular}{|l|c|c|c|c|}
\hline Grupo & Alumnos & Media & $\begin{array}{c}\text { Desviación } \\
\text { típica }\end{array}$ & Curtosis \\
\hline E1 & 9 & 4,22 & 1,9703 & $-0,663$ \\
\hline E2 & 22 & 5,18 & 1,9306 & $-0,413$ \\
\hline E3 & 16 & 4,44 & 2,4622 & 0,027 \\
\hline C1 & 16 & 4,75 & 3,0277 & $-1,505$ \\
\hline Total & 63 & 4,75 & 2,3621 & $-0,763$ \\
\hline
\end{tabular}

Tabla 7.60.- Resultados obtenidos en el Post-Bac.

\section{Porcentaje de respuestas correctas en el Post-Bac}

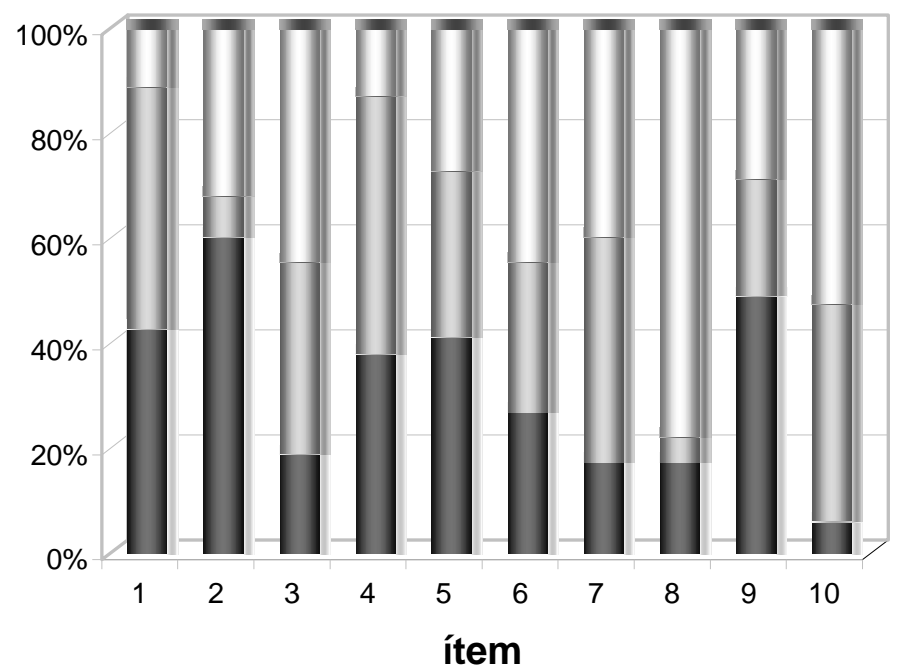

I incorrectas
$\square$ parcialmente correctas
$\square$ correctas

Figura 7.9.- Porcentajes de respuestas correctas, parcialmente correctas e incorrectas en el Post-Bac.

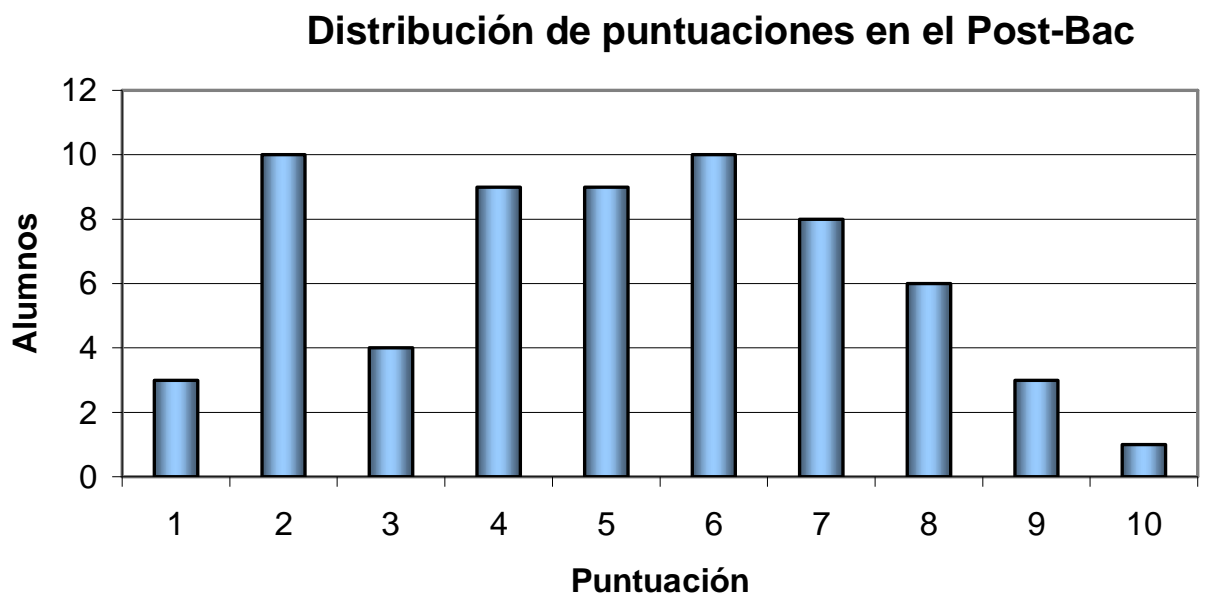

Figura 7.10.- Distribución de puntuaciones en el Post-Bac. 


\section{Ítem 1. Estructuras de Lewis}

En este primer ítem se pretende conocer si los alumnos saben utilizar los símbolos de Lewis para representar la unión de átomos en las moléculas. Esta es una cuestión que tradicionalmente se pregunta en cada examen y que, es representativa de si al menos un alumno ha aprendido algo del tema. Se trata de un trabajo bastante mecánico que suele ser bien asimilado por los alumnos. Aquellos que no realizan bien este ejercicio, no suelen hacerlo en el resto del tema.

El resultado obtenido es que un $95 \%$ de los alumnos sabe construir correctamente estas estructuras. Incluso en el caso de expansión del octeto, como ocurre en el $\mathrm{PBr}_{5}$, o contracción del mismo, $\mathrm{AlF}_{3}$, el $63,4 \%$ de ellos resuelve satisfactoriamente la cuestión.

\begin{tabular}{|c|c|}
\hline \\
\hline \multicolumn{2}{|c|}{\begin{tabular}{l|l}
\multicolumn{2}{l}{ ¿Utiliza correctamente los símbolos de Lewis? } \\
$\mathrm{Si} \rightarrow 95,2 \%$ & No $\rightarrow 4,8 \%$
\end{tabular}} \\
\hline $\begin{array}{l}\text { - La gran mayoría de los } \\
\text { alumnos } \quad \text { los } \\
\text { correctamente. }\end{array}$ & $\begin{array}{l}\text { - Este bajo porcentaje de alumnos no representa } \\
\text { a los electrones alrededor del átomo, ni los } \\
\text { enlaces como pares compartidos. }\end{array}$ \\
\hline
\end{tabular}

\section{¿Calcula correctamente el número de enlaces?}

\begin{tabular}{|c|c|}
\hline $\mathrm{Si} \longrightarrow 36,6 \%$ & No $\rightarrow 63,4 \%$ \\
\hline $\begin{array}{l}\text { - El } 36,6 \% \text { plantea y } \\
\text { resuelve correctamente el } \\
\text { algoritmo de cálculo para } \\
\text { el número de enlaces. }\end{array}$ & $\begin{array}{l}\text { - Casi dos tercios de los alumnos presentan } \\
\text { alguna dificultad en este cálculo. } \\
\text { - El } 24,4 \% \text {, tratan de componer el ión clorato con } \\
\text { tres enlaces. } \\
\text { - El } 31,7 \% \text {, lo hace con el carbonato. } \\
\text { - El } 22 \% \text { presenta problemas con la molécula del } \\
\text { HCN. }\end{array}$ \\
\hline
\end{tabular}

\section{¿En el caso de expansión y contracción del octeto?}

$$
\begin{array}{l|l}
\mathrm{Si} \rightarrow \mathbf{6 3 , 4 \%} & \text { No } \rightarrow \mathbf{3 6 , 6 \%}
\end{array}
$$

- El 63,4\% de los alumnos calcula correctamente el número de enlaces en el caso de que haya expansión o contracción del octeto.
- El 36,6\% no lo ha hecho.

- El 29,3 de los alumnos no conoce el hecho de que el aluminio promociona un electrón del nivel $2 \mathrm{~s}$ al $2 \mathrm{p}$ quedando 3 electrones en la capa de valencia y que se rodea de otros 3 provenientes de los respectivos átomos de fluor.

- El 7,3\% no amplia el octeto en el caso del $\mathrm{PBr}_{5}$. 


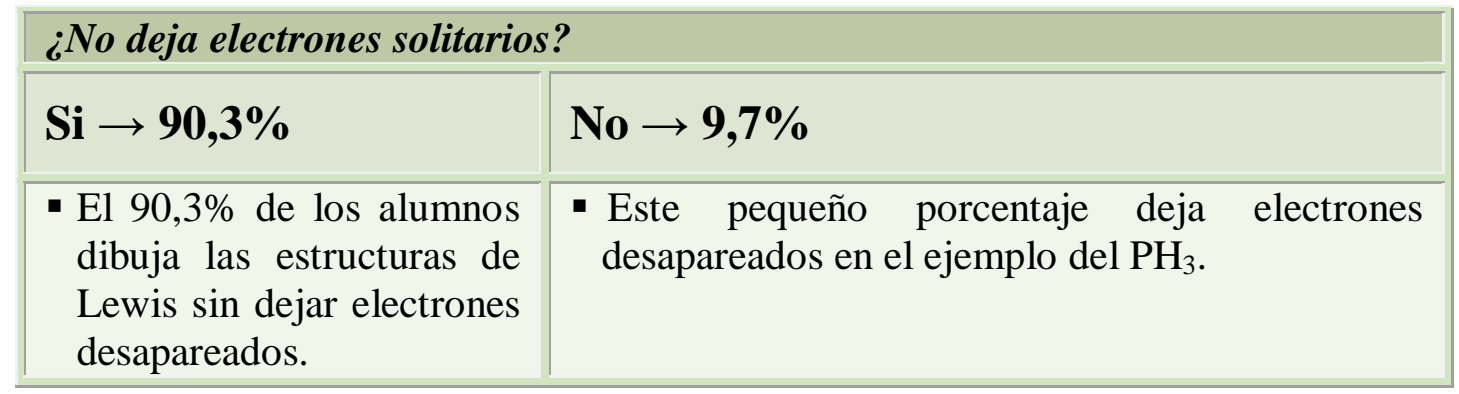

\section{¿Dibuja los pares no compartidos?}

\begin{tabular}{|c|c|}
\hline $\mathrm{Si} \rightarrow 58,6 \%$ & No $\rightarrow 41,4 \%$ \\
\hline $\begin{array}{l}\text { - El } 58,6 \% \text { de los alumnos } \\
\text { dibuja todos los pares } \\
\text { solitarios en todos los } \\
\text { ejemplos. }\end{array}$ & $\begin{array}{l}\text { - Hay un elevado porcentaje de alumnos que no lo } \\
\text { hace. } \\
\text { - El } 26,8 \% \text { de los alumnos no dibuja el par } \\
\text { solitario que le queda al nitrógeno en el caso del } \\
\text { HCN. } \\
\text { - El } 22 \% \text { no lo hacen en el caso de los átomos de } \\
\text { bromo del PBr } \text { PB. }^{\text {. }} \\
\text { - El } 17,1 \% \text { no lo hace en el átomo de aluminio del } \\
\mathrm{AlF}_{3} \text {. }\end{array}$ \\
\hline
\end{tabular}

Tabla 7.61.- Porcentaje de alumnos que responden correctamente al ítem 1 del Post-Bac.

\section{Ítem 2. Estructuras de Lewis. Geometría molecular. Polaridad}

En esta cuestión la mayoría de los alumnos, un 71,4 \%, antes de responder al hecho de que una molécula sea polar o no, han recurrido a buscar su geometría, lo cual indica que sí saben de que están hablando, exactamente los mismos recurren previamente a dibujar las estructuras de Lewis, por lo que puede deducirse que normalmente no razonan que el átomo central no tiene cuatro átomos con quien compartir electrones y quedará asimétrico. No obstante, es satisfactorio que se recurra al camino más seguro para resolver el problema. De esta forma confirmamos lo apuntado anteriormente, al indicar que los alumnos que no son capaces de dibujar las estructuras de Lewis presentan problemas en los contenidos posteriores.

Por otro lado, una vez representada la molécula, un porcentaje similar, un $67 \%$, distingue con claridad que en el caso del $\mathrm{PF}_{3}$, los enlaces son polares y el conjunto de la molécula también, sin embargo en el caso del $\mathrm{SiF}_{4}$, aún siendo estos polares de neutralizan por la simetría de la molécula quedando esta apolar. 


\section{¿Relaciona la polaridad con la geometría?}

\begin{tabular}{l|l}
$\mathrm{Si} \rightarrow \mathbf{7 1 , 4 \%}$ & No $\rightarrow \mathbf{2 8 , 6 \%}$
\end{tabular}

- El $71,6 \%$ de los alumnos indica que el hecho ser polar

- El 13,3\% de los alumnos no ha respondido a la cuestión.

o no una molécula está

- El 9,5\% indica que la polaridad es una relacionado con la geometría de la molécula. propiedad periódica y que el $\mathrm{PF}_{3}$ es polar por encontrarse más arriba en la tabla, mientras que el $\mathrm{SiF}_{4}$ no lo es por estar más abajo.

- El 6,3\% indica que el PF3 es polar por ser más fuerte su tipo de enlace.

\section{¿Busca previamente las estructuras de Lewis?}

\begin{tabular}{|c|c|}
\hline $\mathrm{Si} \rightarrow 63,4 \%$ & $\mathrm{No} \rightarrow 36,6 \%$ \\
\hline $\begin{array}{l}\text { - El } 63,4 \% \text { de los alumnos } \\
\text { dibuja previamente a la } \\
\text { respuesta las estructuras de } \\
\text { Lewis. }\end{array}$ & $\begin{array}{l}\text { - El resto de alumnos, o bien no han } \\
\text { respondido, o bien han indicado } \\
\text { directamente la estructura correspondiente. }\end{array}$ \\
\hline
\end{tabular}

\section{¿Distingue entre polaridad de enlace o molécula?}

\begin{tabular}{|l|l|}
\hline $\mathbf{S i} \rightarrow \mathbf{3 6 , 7 \%}$ & $\mathbf{N o} \rightarrow \mathbf{6 3 , 3 \%}$ \\
\hline \begin{tabular}{|l|l|} 
- Únicamente un 36,7\% de los \\
alumnos, tras escribir la
\end{tabular} & $\begin{array}{l}\text { El } 63,3 \% \text { no busca la polaridad total de la } \\
\text { molécula a partir de la individual de cada }\end{array}$ \\
\begin{tabular}{|l|l|} 
estructura de la molécula \\
busca la polaridad de los \\
enlaces y con ella, define la \\
polaridad total de la molécula.
\end{tabular} & $\begin{array}{l}\text { El } 26,8 \% \text { de los alumnos pese a no buscar } \\
\text { esta relación responde correctamente a la } \\
\text { cuestión al indicar que la molécula no es } \\
\text { polar si es simétrica. }\end{array}$ \\
\hline
\end{tabular}

Tabla 7.62.- Porcentaje de alumnos que responden correctamente al ítem 2 del Post-Bac.

\section{Ítem 3. Estructuras de Lewis. Formas resonantes}

En esta cuestión la mayoría de los alumnos resuelve fácilmente el caso del $\mathrm{NO}_{2}{ }^{-}$, no así en el caso del $\mathrm{HNO}_{3}$. Atendiendo a su habilidad en ambos casos podemos concluir que un 58,7\% de los alumnos sabe dibujar las estructuras resonantes, aunque otros muchos tienen problemas cuando hay más de dos tipos de átomos. 
Saben que en el caso de no coincidir el número de enlaces con el de átomos alrededor del central hay varias combinaciones válidas y así lo proponen. En el caso del $\mathrm{HNO}_{3}$, se añade la dificultad de tener dos tipos de átomos además del central, y muchos de los alumnos tratan de rodear al átomo de nitrógeno con los cuatro restantes.

\section{¿Dibuja correctamente las fórmulas resonantes?}

\begin{tabular}{|c|c|}
\hline $\mathrm{Si} \rightarrow 58,7 \%$ & No $\rightarrow 41,3 \%$ \\
\hline $\begin{array}{l}\text { - El 58,7\% de los alumnos } \\
\text { dibuja correctamente las } \\
\text { estructuras resonantes para el } \\
\mathrm{NO}_{2}^{-} \text {. } \\
\text { - En el caso del } \mathrm{HNO}_{3} \\
\text { únicamente lo han dibujado } \\
\text { correctamente un } 6,4 \% \text {. } \\
\text { - Tan sólo un } 4,8 \% \text { dibuja las } \\
\text { cagas formales de la } \\
\text { molécula. }\end{array}$ & $\begin{array}{l}\text { - El 30,2\% de los alumnos no responde a esta } \\
\text { cuestión. } \\
\text { - En el caso del } \mathrm{HNO}_{3} \text {, el } 63,5 \% \text { responde } \\
\text { incorrectamente. } \\
\text { - La mayoría de estos (un } 77,5 \% \text { de ellos) } \\
\text { trata de rodear al átomo central con los otros } \\
\text { cuatro, lo que les obliga a ampliar el octeto } \\
\text { alrededor del nitrógeno. } \\
\text { - Otros (un } 13,3 \% \text { ) cambia la posición de la } \\
\text { molécula, que sigue siendo la misma. }\end{array}$ \\
\hline
\end{tabular}

Tabla 7. 63.- Porcentaje de alumnos que responden correctamente al ítem 3 del Post-Bac.

\section{Ítem 4. Tipo de enlace químico.}

La propuesta realizada es este ítem es de muy sencilla explicación, y obedece a una simple clasificación de las sustancias según se trate de enlaces iónicos, covalentes o metálicos, para ello es necesario previamente conocer si estas están formadas por elementos metálicos o no.

El 84,1\% de los participantes hace esta clasificación correctamente, y aunque no se pide explícitamente, un $8,5 \%$ de ellos indica en que casos se encuentran enlaces intermoleculares.

Por otro lado solamente un $24 \%$ de los alumnos justifica, tal y como se pedía en el enunciado, el por qué de su respuesta. Todos los que lo han hecho han alegado que la unión de dos elementos no metálicos conlleva la formación de un enlace covalente, mientras que un metal unido a un no metal suponía un enlace iónico, del mismo modo que un metal consigo mismo debería presentar un enlace metálico. 


\begin{tabular}{|c|c|c|c|c|c|}
\hline & Iónico & Metálico & Covalente & ns/nc & \\
\hline $\begin{array}{l}\text { Bromuro de } \\
\text { cesio }\end{array}$ & $92 \%$ & $1,6 \%$ & $4,8 \%$ & $1,6 \%$ & Forma redes, $3,2 \%$ \\
\hline Cloro & $3,2 \%$ & $3,2 \%$ & $90,5 \%$ & $3,2 \%$ & Forma moléculas, $19 \%$ \\
\hline $\begin{array}{l}\text { Ioduro } \\
\text { cálcico }\end{array}$ & $84,1 \%$ & $0 \%$ & $12,7 \%$ & $3,2 \%$ & Forma redes, $3,2 \%$ \\
\hline $\begin{array}{l}\text { Dióxido de } \\
\text { nitrógeno }\end{array}$ & $3,2 \%$ & $1,6 \%$ & $88,9 \%$ & $6,3 \%$ & $\begin{array}{l}\text { Forma moléculas, } \\
20,6 \% \\
\text { Fuerzas de van der } \\
\text { Walls, } 3,2 \%\end{array}$ \\
\hline Sodio & $4,8 \%$ & $85,7 \%$ & $1,6 \%$ & $7,9 \%$ & Forma redes $1,6 \%$ \\
\hline Agua & $11,1 \%$ & $0 \%$ & $77,8 \%$ & $11,1 \%$ & $\begin{array}{l}\text { Forma moléculas, } \\
14,3 \% \\
\text { Puentes de hidrógeno, } \\
15,9 \%\end{array}$ \\
\hline $\begin{array}{l}\text { Cloruro de } \\
\text { sodio }\end{array}$ & $79,4 \%$ & $0 \%$ & $11,1 \%$ & $9,5 \%$ & Forma redes, $3,2 \%$ \\
\hline $\begin{array}{l}\text { Óxido de } \\
\text { sodio }\end{array}$ & $84,1 \%$ & $0 \%$ & $9,5 \%$ & $6,3 \%$ & Forma redes, $1,6 \%$ \\
\hline Octano & $7,9 \%$ & $0 \%$ & $74,6 \%$ & $19 \%$ & $\begin{array}{l}\text { Forma moléculas, } 7,9 \% \\
\text { Fuerzas de van der } \\
\text { Walls, } 1,6 \% \\
\text { Puentes de hidrógeno, } \\
4,8 \%\end{array}$ \\
\hline
\end{tabular}

Tabla 7.64.- Porcentajes de respuestas dadas al ítem n³ del Post-Bac

\section{¿Discrimina entre todos los tipos de enlace?}

$$
\begin{array}{l|l}
\mathrm{Si} \rightarrow \mathbf{8 4 , 1 \%} & \text { No } \rightarrow \mathbf{1 5 , 9 \%}
\end{array}
$$

- La mayoría de los alumnos

- Un elevado porcentaje de alumnos no reconoce fácilmente el tipo de enlaces en cada caso. responde la cuestión o lo hace incorrectamente.

- El caso más acusado es el del octano, aunque sorprenden los datos del agua y del cloruro de sodio. 


\section{¿Tiene en cuenta los enlaces intermoleculares?}

\begin{tabular}{|c|c|}
\hline $\mathrm{Si} \rightarrow \mathbf{8 , 5} \%$ & No $\rightarrow 91,5 \%$ \\
\hline $\begin{array}{l}\text { - Tan sólo es un } 8,5 \% \text { de los casos se } \\
\text { han tenido en cuenta las interacciones } \\
\text { intermoleculares o el tipo de estructura } \\
\text { que se ha formado. } \\
\text { - En los casos del cloro, del dióxido de } \\
\text { nitrógeno y del agua, alrededor de un } \\
20 \% \text { de los alumnos ha indicado que } \\
\text { son estructuras moleculares. } \\
\text { - En el caso del agua, un } 15,9 \% \text { ha } \\
\text { apuntado la formación de puentes de } \\
\text { hidrógeno. }\end{array}$ & $\begin{array}{l}\text { - La gran mayoría de los alumnos se } \\
\text { ha limitado a clasificar las } \\
\text { sustancias en iónicas covalentes o } \\
\text { metálicas. } \\
\text { - Tan sólo en un } 7,6 \% \text { se han dejado } \\
\text { de contestar las propuestas. }\end{array}$ \\
\hline
\end{tabular}

\section{¿Justifica las respuestas?}

\begin{tabular}{|c|c|}
\hline $\mathrm{Si} \rightarrow 23,8 \%$ & $\mathrm{No} \rightarrow 76,2 \%$ \\
\hline $\begin{array}{l}\text { - el } 23,8 \% \text { de los alumnos justifica el } \\
\text { tipo de enlace adjudicado. } \\
\text { - Todos ellos lo han hecho clasificando } \\
\text { los elementos implicados en metales o } \\
\text { no metales y utilizando la regla: }\end{array}$ & $\begin{array}{l}\text { - La mayoría de los alumnos no ha } \\
\text { justificado la respuesta. No } \\
\text { obstante el lógico que no lo hayan } \\
\text { hecho puesto que no se les pedía } \\
\text { explícitamente. }\end{array}$ \\
\hline $\begin{array}{l}\text { Metal + no metal = iónico } \\
\text { No metal + no metal }=\text { covalente } \\
\text { Metal + metal = metálico }\end{array}$ & \\
\hline
\end{tabular}

\section{¿Localiza a los enlaces de mayor polaridad?}

\section{\begin{tabular}{l|l}
$\mathrm{Si} \rightarrow \mathbf{1 1 , 1 \%}$ & No $\rightarrow \mathbf{8 8 , 9 \%}$
\end{tabular}}

- Muy pocos alumnos apuntan al óxido de magnesio, al bromuro de cesio o al cloruro de sodio como sustancias con enlaces más polares.

- El 57,2\% de los alumnos no responde a esta cuestión.

- El 25,4 apuntan al dióxido de nitrógeno como sustancia con mayor polaridad en sus enlaces.

Tabla 7.65.- Porcentaje de alumnos que responden correctamente al ítem 4 del Post-Bac. 


\section{Ítem 5. Geometría molecular. Polaridad.}

Esta pregunta se ha presentado como una tabla en la que los alumnos deberían representar aspectos del enlace covalente relacionados con la geometría y la polaridad. Para ello se ha presentado el nombre y la fórmula de cinco sustancias moleculares, y se les pide que dibujen la molécula, a lo cual el 49,2\% responde correctamente y en la práctica totalidad de los casos, lo justifica correctamente utilizando los símbolos de Lewis. Un 34,9 \%, nombre correctamente la forma geométrica y sobre ella son los mismos los que sitúan correctamente los momentos bipolares de cada enlace. Además sólo un 19\% advierte que todos los enlaces no son igual de polares.

Sin embargo un $61,9 \%$ reconoce correctamente la polaridad de la molécula, lo que sólo puede explicarse si la respuesta ha sido espontánea y basada en la estructura de Lewis y no deducida de forma lógica a partir de la geometría.

\section{¿Escribe correctamente la estructura de Lewis?}
$\mathrm{Si} \rightarrow 49,2 \%$
No $\rightarrow \mathbf{5 0 , 8 \%}$

- Prácticamente la mitad de los alumnos escribe correctamente todas las estructuras de Lewis.
- La otra mitad no lo hace.

- El $46 \%$ ha escrito mal la estructura del $\mathrm{SO}_{2}$, en la mayoría de los casos han dibujado directamente dos enlaces entre el átomo de azufre y los de oxígeno.

- El $11.1 \%$ ha dibujado mal la molécula de $\mathrm{CH}_{3} \mathrm{Cl}$, situando al $\mathrm{Cl}$ como átomo central.

- Otros han escrito mal la del $\mathrm{Br}_{2}(12,7 \%)$, o la de $\mathrm{PCl}_{5}(9,5 \%)$.

\section{¿Conoce su geometría?}
$\mathrm{Si} \rightarrow \mathbf{3 4 , 9 \%}$
$\mathrm{No} \rightarrow 65,1 \%$

- Tan sólo una tercera parte de los alumnos indica correctamente la geometría de todas las moléculas.
- El 36,5\% no indica correctamente la geometría del $\mathrm{SO}_{2}$, casi todos responden que es lineal en base a haber dibujado dos dobles enlaces en ella.

- El 44,4\% de los alumnos responde que la geometría del $\mathrm{CH}_{3} \mathrm{Cl}$ es tetraédrica, haciendo iguales a todos los enlaces.

- El 25,4\% equivoca la respuesta en el caso del $\mathrm{PCl}_{5}$, indicando nombres como, pirámide irregular, pentaédrica, o dejándola en blanco. 


\section{¿Dibuja correctamente los momentos dipolares?}

\begin{tabular}{|c|c|}
\hline $\mathrm{Si} \rightarrow 34,9 \%$ & No $\rightarrow 45,1 \%$ \\
\hline $\begin{array}{l}\text { - El } 34,9 \% \text { de los alumnos } \\
\text { dibuja los momentos } \\
\text { dipolares sobre la molécula. }\end{array}$ & $\begin{array}{l}\text { - El } 31,7 \% \text { no dibuja ningún momento } \\
\text { dipolar. } \\
\text { - El } 13,4 \% \text { indica si los enlaces son polares o } \\
\text { apolares pero no lo refleja en la molécula. }\end{array}$ \\
\hline
\end{tabular}

\begin{tabular}{|l|l|}
\hline \multicolumn{2}{|c|}{ ¿Advierte que todos los enlaces no son igual de polares? } \\
\hline $\mathbf{S i} \rightarrow \mathbf{1 9 \%}$ & $\mathbf{N o} \rightarrow \mathbf{8 1 \%}$ \\
\hline $\begin{array}{l}\text { - El 19\% explicita que en el caso del } \\
\mathrm{CH}_{3} \mathrm{Cl} \text {, el enlace entre el átomo de cloro }\end{array}$ & $\begin{array}{c}\text { - El resto de alumnos no responde } \\
\text { nada a este respecto. }\end{array}$ \\
$\begin{array}{l}\text { y el de carbono es más polar que el } \\
\text { existente entre el carbono y el hidrógeno. }\end{array}$ & \\
\hline
\end{tabular}

\begin{tabular}{|c|c|}
\hline \multicolumn{2}{|l|}{ ¿Reconoce la polaridad de la molécula? } \\
\hline $\mathrm{Si} \rightarrow 61,9 \%$ & No $\rightarrow 32,1 \%$ \\
\hline $\begin{array}{l}\text { - El } 61,9 \% \text { reconoce correctamente la } \\
\text { polaridad de la molécula. } \\
\text { - La mayoría de los alumnos han } \\
\text { respondido correctamente pesa a no } \\
\text { haberlo hecho con la polaridad de los } \\
\text { enlaces, basándose en la simetría de la } \\
\text { molécula. }\end{array}$ & $\begin{array}{l}\text { - El } 32,1 \% \text { ha respondido } \\
\text { incorrectamente debido a que ha } \\
\text { dibujado mal la molécula. }\end{array}$ \\
\hline
\end{tabular}

Tabla 7.66.- Porcentaje de alumnos que responden correctamente al ítem 5 del Post-Bac.

\section{Ítem 6. Propiedades del enlace.}

Con tal de indagar en el conocimiento de las propiedades de las sustancias se les pregunta sobre la situación de los electrones dentro de una red metálica y el 52,4\% responde satisfactoriamente explicando que se encuentran formando una nube alrededor del conjunto de los núcleos y capas completas.

En otro sentido cuando se pregunta sobre la solubilidad de las sustancias un 50,8 $\%$ conoce y así lo justifica que las sustancias se disuelven en otras semejantes y que por tanto las sustancias, tanto polares, apolares o metálicas se disuelven entre las de su misma condición. 


\section{¿Entiende el concepto de deslocalización electrónica en las redes metálicas?}

\begin{tabular}{l|l}
$\mathrm{Si} \rightarrow \mathbf{5 2 , 4 \%}$ & $\mathrm{No} \rightarrow \mathbf{4 7 , 6 \%}$
\end{tabular}

- Aproximadamente la mitad de los alumnos explican la existencia de una nube

- El 23,8\% de los alumnos indica que los electrones se desprenden debido a la conductividad de los metales electrónica en el interior de la

- El 19\% habla de electrones sueltos, no estructura metálica. deslocalizados.

- El 9\% lo justifica por el "elevado punto de fusión de los metales".

\section{¿Conoce qué sustancias se disuelven entre si?}

\begin{tabular}{|l|l|l|}
\hline $\mathbf{S i} \rightarrow \mathbf{5 0 , 8 \%}$ & $\mathbf{N o} \rightarrow \mathbf{4 9 , 2 \%}$ \\
\hline $\begin{array}{l}\text { - La mitad de los alumnos } \\
\text { explican que sustancias }\end{array}$ & $\begin{array}{l}\text { - La mayoría de los alumnos que no dan una } \\
\text { rimilares se disuelven entre si. }\end{array}$ \\
$\begin{array}{l}\text { questa correcta indican que se debe a } \\
\text { - Algunos dicen que se debe a que el oro y } \\
\text { el mercurio están cerca en la tabla } \\
\text { periódica. }\end{array}$ \\
\hline
\end{tabular}

Tabla 7.67.- Porcentaje de alumnos que responden correctamente al ítem 6 del Post-Bac.

\section{Ítem 7. Propiedades del enlace.}

En este ítem la mayoría de alumnos han optado por indicar si las sustancias propuestas son o no conductoras, cuando la propuesta era razonar el porqué de que lo fuesen, indicando que ya lo eran.

Prácticamente todos han indicado que el cobre era conductor y que el gafito no lo era, pero sin justificarlo. En el caso del $\mathrm{NaCl}$ disuelto o fundido un 36,5\% ha indicado que en estas circunstancias los iones formados tenían movilidad y que por tanto eran conductores. 


\section{¿Relaciona correctamente la conductividad con los iones en disolución?}
$\mathbf{S i} \rightarrow \mathbf{3 6 , 5 \%}$
No $\rightarrow 63,5 \%$

- El 36,5\% de los alumnos justifican relativamente el porque de la conductividad del $\mathrm{NaCl}$ tanto fundido como en disolución.

- No obstante el 78,3\% de estos alumnos hablan de la movilidad de los electrones por el hecho de estar la sustancia fundida o disuelta.

- Tan sólo un 21,7 habla de separación de la sustancia en iones positivos y negativos.

- El 27\% de los alumnos justifica la conductividad del grafito.

- Un 52,4 justifica correctamente la conductividad del cobre.
- El 63,5\% aunque admite que el $\mathrm{NaCl}$ es conductor en estas condiciones, no lo justifica correctamente.

- El 43,6\% de estos alumnos indica que la conductividad se debe a que está disuelto en agua.

- El 53,8\% simplemente indica que el hecho de ser conductor en disolución o fundido en una propiedad característica de las sustancias iónicas.

- El 52,4\% de todos los alumnos no solo no justifica la conductividad sino que afirman que el grafito no es conductor.

- El 47,6\% de los alumnos pese a indicar que el cobre es conductor, lo justifican alegando que los metales son buenos conductores.

Tabla 7.68.- Porcentaje de alumnos que responden correctamente al ítem 7 del Post-Bac.

\section{Ítem 8. Consecuencias del enlace intermolecular y Ítem 9. Enlaces interatómicos e intermoleculares}

Estas dos cuestiones versan sobre similares conceptos, basados en las uniones intermoleculares.

Al presentar varias sustancias un 28,6 \% advierte que existen fuerzas de unión entre las moléculas, pero solo un $12,7 \%$ explica correctamente el porqué de estos enlaces, tal y como se pedía explícitamente en el enunciado. En una posición intermedia entre ambos extremos tenemos que un 33,3 \% sitúa ambos tipos de enlace al mismo tiempo, lo que demuestra que comprende lo que hace, y un $31,7 \%$ de los alumnos es capaz de concretar que en primer lugar existe una unión entre átomos, y como consecuencia hay una posterior organización que a que las nuevas partículas formas se atraigan entre si. 


\section{¿Conoce los tipos de interacciones intermoleculares?}

\begin{tabular}{l|l}
$\mathrm{Si} \rightarrow \mathbf{2 8 , 6 \%}$ & No $\rightarrow \mathbf{7 1 , 4 \%}$
\end{tabular}

- El 28,6\% indica que se debe a que las interacciones entre las moléculas son diferentes en

- El 7,9\% de los alumnos no responde a la cuestión.

ambos casos.

- El 63,5\% de los alumnos aporta otras explicaciones no relacionadas con el enlace intermolecular.

\begin{tabular}{|c|c|}
\hline \multicolumn{2}{|l|}{ ¿Razona el porque de estas interacciones? } \\
\hline $\mathrm{Si} \rightarrow 60,3 \%$ & No $\rightarrow 39,7 \%$ \\
\hline $\begin{array}{l}\text { - El } 60,3 \% \text { intenta buscar una explicación del motivo de la } \\
\text { diferencia de estado físico entre una y otra sustancia. } \\
\text { - El } 12,7 \% \text { razona correctamente la diferencia de } \\
\text { polarizabilidad entre ambas moléculas consecuencia de su } \\
\text { volumen, y el consiguiente aumento de las fuerzas } \\
\text { electrostáticas entre ellas. } \\
\text { - El } 14,3 \% \text { indica que se debe a que "tienen puntos de } \\
\text { fusión diferentes". } \\
\text { - El } 25,4 \% \text { de los alumnos indica que se debe a que el cloro } \\
\text { es más electronegativo que el yodo. } \\
\text { - El } 7,9 \% \text { viene a indicar que el cloro es una excepción. }\end{array}$ & $\begin{array}{l}\text { - El 39,7\% no da } \\
\text { ninguna } \\
\text { justificación. }\end{array}$ \\
\hline
\end{tabular}

\section{¿Relativiza los enlaces interatómicos?}

\begin{tabular}{l|l}
$\mathrm{Si} \rightarrow \mathbf{3 3 , 3 \%}$ & $\mathrm{No} \rightarrow \mathbf{6 6 , 7 \%}$
\end{tabular}

- Una tercera parte de los alumnos expresa el tipo de enlace existente entre los átomos $\mathrm{y}$, tras razonar la polaridad resultante expresa el tipo de unión entre las moléculas.

- El 66,7\% de los alumnos no expresa ninguna relación entre los enlaces interatómicos y los intermoleculares.

\section{¿Reconoce enlaces interatómicos e intermoleculares?}

\begin{tabular}{|l|l|}
\hline $\mathbf{S i} \rightarrow \mathbf{3 1 , 7 \%}$ & $\mathbf{N o} \rightarrow \mathbf{6 8 , 3 \%}$ \\
\hline \begin{tabular}{|l|l|} 
- Un porcentaje similar \\
sitúa en el mismo
\end{tabular} & $\begin{array}{l}\text { El resto únicamente expresa los enlaces } \\
\text { intermoleculares. }\end{array}$ \\
$\begin{array}{l}\text { ejemplo los enlaces } \\
\text { interatómicos y los } \\
\text { intermoleculares. }\end{array}$ & $\begin{array}{l}\text { Hay un } 12,7 \% \text { de los alumnos que pese a no indicar } \\
\text { el tipo de enlace intermolecular existente, apuntan al } \\
\text { enlace por puente de hidrógeno en el agua. }\end{array}$ \\
\hline
\end{tabular}

Tabla 7.69.- Porcentaje de alumnos que responden correctamente a los ítems 8 y 9 del Post-Bac. 


\section{Ítem 10. Enlaces interatómicos e intermoleculares}

Este ítem pretende conocer si los alumnos son capaces de conocer propiedades macroscópicas derivadas del enlace, al tiempo que predecir cual va a ser la estabilidad de las sustancias, en tanto que conozcan si el tipo de unión es fuerte o débil.

Un 41,3\% indica correctamente el tipo de enlaces que deben vencerse para llevar a cabo el proceso. El error más común es suponer que para fundir, sublimar o vaporizar hay que romper uno u otro tipo de enlaces interatómicos. Por otro lado son un $12,7 \%$ de los alumnos, los que identifican enlaces tanto entre átomos como entre moléculas, menor que el ejercicio anterior, pero lógico porque aquí el hecho de averiguar el tipo de enlace estaba implícito en la pregunta.

\section{¿Distingue qué enlaces hay que romper?}

\begin{tabular}{|c|c|}
\hline $\mathrm{Si} \rightarrow 41,3 \%$ & No $\rightarrow \mathbf{5 8 , 7 \%}$ \\
\hline $\begin{array}{l}\text { - En el } 41,3 \% \text { de los casos los alumnos indican } \\
\text { correctamente la interacción que debe vencerse } \\
\text { en cada caso. } \\
\text { - El } 55,6 \% \text { de los alumnos indican que para fundir } \\
\text { el cloruro sódico deben vencerse las fuerzas } \\
\text { electrostáticas características de las redes } \\
\text { iónicas. } \\
\text { - El } 31,8 \% \text { de los alumnos indica que en los } \\
\text { ejemplos de la naftalina y el bromo deben }\end{array}$ & $\begin{array}{l}\text { - En un } 18,9 \% \text { de los casos } \\
\text { los alumnos no responden } \\
\text { a las cuestiones. } \\
\text { - El } 13,3 \% \text { de los alumnos } \\
\text { indica que en el caso de } \\
\text { las sustancias moleculares } \\
\text { las interacciones que } \\
\text { deben vencerse son los } \\
\text { enlaces covalentes. }\end{array}$ \\
\hline
\end{tabular}
vencerse fuerzas de atracción entre las moléculas que los forman.

- El 39,7\% indica que para fundir el oro debe vencerse un enlace metálico.

- El 63,5\% de los alumnos apunta al enlace por puente de hidrógeno como responsable de la vaporización del agua.

- El 49,2\% de ellos indica que para vaporizar el diamante deben vencerse las un iones covalentes entre todos los átomos de carbono.

- El 27\% de los alumnos responde que la vaporización del alcohol depende de los enlaces por puente de hidrógeno. 


\section{¿Sitúa enlaces interatómicos e intermoleculares en un mismo ejemplo?}

\begin{tabular}{l|l}
$\mathrm{Si} \rightarrow \mathbf{1 2 , 7 \%}$ & $\mathrm{No} \rightarrow \mathbf{8 7 , 3 \%}$
\end{tabular}

- Un $12,7 \%$ de los alumnos indica en los ejemplos cuales son los enlaces existentes y cuales deben vencerse.

- Este matiz tiene sentido en los casos en que hay sustancias moleculares y deben vencerse los enlaces entre ellas.

Tabla 7.70.- Porcentaje de alumnos que responden correctamente al ítem 10 del Post-Bac 


\subsubsection{Análisis de la relación entre los cuestionarios}

Tras haber registrado los resultados de los cuestionarios podemos obtener por simple diferencia el aumento de competencias adquiridas. Pero además podemos buscar una información adicional sobre la situación inicial y final de los alumnos, que nos permita asociar problemas iniciales con otros finales.

Por tanto para poder analizar las dificultades que han encontrado los alumnos va a resultar muy interesante poder relacionar ambos estados de forma que podamos conocer si hay alguna correlación entre determinados conceptos preinstruccionales y otros postinstruccionales. Con ello podremos concluir si es necesario o no exigir a los alumnos que previamente al inicio del tema tengan dominados otros conceptos y predecir las consecuencias de no haberlo hecho. Estableceremos como variables algunos de los ítems corregidos en los cuestionarios y buscaremos las posibles dependencias o no entre ellos.

Para llevar a cabo este estudio realizaremos un análisis de la correlación entre las respuestas dadas por los alumnos en los pre-test y en los post-test, de forma que obtendremos un apartado para la ESO y otro para Bachillerato. Utilizaremos varios parámetros estadísticos y posteriormente, estableceremos las relaciones existentes entre conceptos previos y conceptos estudiados en cada tema. 


\subsubsection{Relación entre el Pre-ESO y el Post-ESO}

En tercero de ESO se han pasado los cuestionarios Pre-ESO anterior a la intervención y el Post-ESO posterior a la misma. Al margen de que los resultados hayan sido mejores o no en los grupos experimentales o en los grupos de control, vamos a buscar correlaciones que nos permitan extraer conclusiones sobre cual es el estado óptimo de los alumnos al iniciar un tema como el que nos ocupa.

Para ello vamos a tomar algunos de los ítems de cada cuestionario, cuyos contenidos consideremos que puedan influir entre si, y a partir de un estudio estadístico basado en la prueba de $\chi^{2}$, estableceremos si existe dependencia ente ellos. En principio vamos a tomar los ítems según se han planteado en los cuestionarios para posteriormente, hacerlo de forma más detallada en los aspectos que se ubican en cada uno de ellos. Para cada uno de las ítems se ha valorado la respuesta en 0, 0.5 ó 1 puntos dependiendo de si la respuesta era incorrecta o en blanco, incompleta o correcta. A partir de estos valores se crean las tablas de contingencia donde se recogen los datos, en el menú "analizar/estadísticos descriptivos/tablas de contingencia" del programa estadístico.

Para tratar de asociar variables entre si o buscar la posible relación entre ellas, dentro de las posibilidades hemos decidido utilizar:

El coeficiente de contingencia, que basado en la prueba de $\chi^{2,}$ toma valores entre 0 y 1 según sea su grado de asociación, que puede considerarse bastante bueno para valores mayores de 0,3. Es decir, a partir de este valor consideraremos que las variables tienen relación entre si, mientras que por debajo de él consideraremos que no la hay.

La Gamma de Goodman que nos da una media del número de pares de valores concordantes respecto del número de pares discordantes, y cuyo valor máximo de 1 y teniendo en cuenta que se trata de tablas con tres valores por variable y por tanto 4 grados de libertad, su valor positivo será suficiente. 
En concreto vamos a estudiar la relación entre los conceptos e ítems que se indican en la siguiente tabla.

\begin{tabular}{|c|c|c|c|}
\hline \multicolumn{2}{|l|}{ Pre-ESO } & \multicolumn{2}{|r|}{ Post-ESO } \\
\hline Concepto & ítem & ítem & Concepto \\
\hline El átomo. Partículas constituyentes & 1 & 1 & Moléculas. Su necesidad \\
\hline Identificación de sustancias & 5 & 1 & Moléculas. Su necesidad \\
\hline Identificación de sustancias & 5 & 5 & Enlace y estructuras \\
\hline Identificación de sustancias & 5 & 6 & Clasificación de enlaces \\
\hline Identificación de sustancias & 5 & 7 & Enlace y estructuras \\
\hline Capacidad de abstracción numérica & 7 & 1 & Moléculas. Su necesidad \\
\hline Clasificación de las sustancias & 8 & 2 & $\begin{array}{l}\text { Clasificación de las } \\
\text { sustancias }\end{array}$ \\
\hline Clasificación de las partículas & 10 & 1 & Moléculas. Su necesidad \\
\hline Clasificación de las partículas & 10 & 2 & $\begin{array}{l}\text { Clasificación de las } \\
\text { sustancias }\end{array}$ \\
\hline Clasificación de las partículas & 10 & 5 & Enlace y estructuras \\
\hline Clasificación de las partículas & 10 & 6 & Clasificación de enlaces \\
\hline Clasificación de las partículas & 10 & 7 & Enlace y estructuras \\
\hline
\end{tabular}

Tabla 7.71.- conceptos implicados en los ítems del Pre-ESO y el Post-ESO

Los resultados obtenidos tras el cálculo realizado con el programa informático SSPS han sido muy variados dependiendo de la pareja seleccionada. En la tabla siguiente se recogen los resultados más característicos de los que se han encontrado. 


\begin{tabular}{|c|c|c|}
\hline $\begin{array}{l}\text { Pareja } \\
\text { de ítems }\end{array}$ & Estadístico & Valor \\
\hline $1-1$ & $\begin{array}{l}\text { Coeficiente de contingencia (basado en } x^{2} \text { ) } \\
\text { Gamma } \\
\text { Pearson }\end{array}$ & $\begin{array}{l}0,312 \\
0,414 \\
0,268^{* *}\end{array}$ \\
\hline $5-1$ & $\begin{array}{l}\text { Coeficiente de contingencia (basado en } x^{2} \text { ) } \\
\text { Gamma } \\
\text { Pearson }\end{array}$ & $\begin{array}{l}0,323 \\
0,551 \\
0,300^{*}\end{array}$ \\
\hline $5-5$ & $\begin{array}{l}\text { Coeficiente de contingencia (basado en } x^{2} \text { ) } \\
\text { Gamma } \\
\text { Pearson }\end{array}$ & $\begin{array}{l}0,357 \\
0,303 \\
0,153\end{array}$ \\
\hline $5-6$ & $\begin{array}{l}\text { Coeficiente de contingencia (basado en } x^{2} \text { ) } \\
\text { Gamma } \\
\text { Pearson }\end{array}$ & $\begin{array}{l}0,303 \\
0,402 \\
0,220^{* *}\end{array}$ \\
\hline $5-7$ & $\begin{array}{l}\text { Coeficiente de contingencia (basado en } x^{2} \text { ) } \\
\text { Gamma } \\
\text { Pearson }\end{array}$ & $\begin{array}{l}0,386 \\
0,192 \\
0,152\end{array}$ \\
\hline $7-1$ & $\begin{array}{l}\text { Coeficiente de contingencia (basado en } x^{2} \text { ) } \\
\text { Gamma } \\
\text { Pearson }\end{array}$ & $\begin{array}{l}0,363 \\
0,224 \\
0,175\end{array}$ \\
\hline $8-2$ & $\begin{array}{l}\text { Coeficiente de contingencia (basado en } x^{2} \text { ) } \\
\text { Gamma } \\
\text { Pearson }\end{array}$ & $\begin{array}{l}0,395 \\
0,585 \\
0,387^{*}\end{array}$ \\
\hline $10-1$ & $\begin{array}{l}\text { Coeficiente de contingencia (basado en } x^{2} \text { ) } \\
\text { Gamma } \\
\text { Pearson }\end{array}$ & $\begin{array}{l}0,370 \\
0,533 \\
0,359^{*}\end{array}$ \\
\hline $10-2$ & $\begin{array}{l}\text { Coeficiente de contingencia (basado en } x^{2} \text { ) } \\
\text { Gamma } \\
\text { Pearson }\end{array}$ & $\begin{array}{l}0,323 \\
0,269 \\
0,193^{\star *}\end{array}$ \\
\hline $10-5$ & $\begin{array}{l}\text { Coeficiente de contingencia (basado en } x^{2} \text { ) } \\
\text { Gamma } \\
\text { Pearson }\end{array}$ & $\begin{array}{l}0,380 \\
0,281 \\
0,189^{* *}\end{array}$ \\
\hline $10-6$ & $\begin{array}{l}\text { Coeficiente de contingencia (basado en } x^{2} \text { ) } \\
\text { Gamma } \\
\text { Pearson }\end{array}$ & $\begin{array}{l}0,410 \\
0,469 \\
0,367^{*}\end{array}$ \\
\hline \multirow[t]{2}{*}{$10-7$} & $\begin{array}{l}\text { Coeficiente de contingencia (basado en } x^{2} \text { ) } \\
\text { Gamma } \\
\text { Pearson }\end{array}$ & $\begin{array}{l}0,376 \\
0,157 \\
0,123\end{array}$ \\
\hline & $\begin{array}{l}{ }^{*} \text { Asociación de variables significativas con } \\
p<0,001 ; \text { **idem con } p<0,05\end{array}$ & \\
\hline
\end{tabular}

Tabla 7.72.- correlación entre las repuestas a ítems relacionados en el Pre-ESO y el Post-ESO.

Tras realizar el análisis estadístico se evidencia que hay relaciones importantes entre algunas parejas de ítems, mientras que en otras no la hay, además algunos de los contenidos del Pre-ESO guardan relación con otros del Post-ESO, por tanto es interesante comentar estos aspectos.

Los ítems del Pre-ESO con mayor influencia posterior son el 1, 5, 7 y 10. Podemos obviar que este razonamiento no es trivial, puesto que el hecho de obtener 
mejor resultado inicialmente, no conduce a un mejor resultado posterior, ya que en este caso se daría en todos los ítems. Lógicamente si es probable que se produzca en el conjunto de la prueba. Esta concordancia no se da en la gran mayoría de las posibles combinaciones entre parejas de ítems debido a la fuerte restricción impuesta (coeficiente de contingencia $\geq 0,3$ ).

Estos ítems implicados hacen referencia al significado y partes del átomo, a la identificación de sustancias, a la clasificación de sustancias y a la abstracción numérica. En definitiva podemos observar que corresponde a la capacidad de razonamiento abstracto de la química, es decir al entendimiento del nivel microscópico, hecho que se explicita de forma contundente en el ítem 7, pero sobre todo en el mapa conceptual que se propone en el ítem 10, y que además podemos observar en la tabla, mantiene los mayores valores para el coeficiente de contingencia. Este hecho pone de manifiesto la importancia de saber relacionar todas las partículas (átomos, moléculas, iones, partículas subatómicas, elementos...) así como conocer su papel dentro del sistema periódico.

Para concretar las relaciones existentes hemos decidido compararlas entre si a partir de parejas de ítems que hemos considerado que presentaban interés, encontrando:

\begin{tabular}{|c|c|c|}
\hline \multicolumn{3}{|c|}{ Relación entre los resultados de los cuestionarios } \\
\hline Pre - ESO & Correlación entre los resultados & Post-ESO \\
\hline $\begin{array}{l}\text { ¿Conoce que los elementos se } \\
\text { clasifican según el SP y se } \\
\text { representan con símbolos? }\end{array}$ & $\begin{array}{l}\text { Coef. Conting }=0,394 \\
\text { Gamma de Goodman }= \\
\text { V de Cramer }=0,429\end{array}$ & $\begin{array}{l}\text { Razona que: } \\
\qquad \begin{array}{c}\mathrm{M}+\mathrm{nM}=\text { iónico } \\
\mathrm{nM}+\mathrm{nM}=\text { covalente }\end{array}\end{array}$ \\
\hline $\begin{array}{l}\text { ¿Reconoce el dibujo de un } \\
\text { átomo? }\end{array}$ & $\begin{array}{l}\text { Coef. Conting }=0,146 \\
\text { Gamma de Goodman }= \\
\text { V de Cramer }=0,150\end{array}$ & $\begin{array}{l}\text { ¿Sabe explicar qué es } \\
\text { una molécula? }\end{array}$ \\
\hline $\begin{array}{l}\text { ¿Dibuja correctamente las } \\
\text { partículas gaseosas, según la } \\
\text { teoría cinético- molecular? }\end{array}$ & $\begin{array}{l}\text { Coef. Conting }=0,162 \\
\text { Gamma de Goodman }= \\
\text { V de Cramer }=0,165\end{array}$ & $\begin{array}{c}\text { ¿Sabe explicar qué es } \\
\text { una molécula? }\end{array}$ \\
\hline $\begin{array}{l}\text { ¿Distingue qué sustancias del } \\
\text { entorno son elementos, } \\
\text { compuestos o mezclas? }\end{array}$ & $\begin{array}{l}\text { Coef. Conting }=0,143 \\
\text { Gamma de Goodman }= \\
\text { V de Cramer }=0,208\end{array}$ & $\begin{array}{l}\text { ¿Distingue } \\
\text { simbólicamente entre } \\
\text { elementos compuestos } \\
\text { o mezclas? }\end{array}$ \\
\hline
\end{tabular}




\begin{tabular}{|c|c|c|}
\hline $\begin{array}{l}\text { ¿Concluye que la materia está } \\
\text { formada por átomos? }\end{array}$ & $\begin{array}{l}\text { Coef. Conting }=0,403 \\
\text { Gamma de Goodman }=0,364 \\
\text { V de Cramer }=0,407\end{array}$ & $\begin{array}{l}\text { ¿Razona que el enlace } \\
\text { covalente se forma } \\
\text { entre no metales y el } \\
\text { iónico entre metal y } \\
\text { no metal? }\end{array}$ \\
\hline $\begin{array}{l}\text { ¿Dibuja correctamente las } \\
\text { partículas gaseosas, según la } \\
\text { teoría cinético- molecular? }\end{array}$ & $\begin{array}{l}\text { Coef. Conting }=0,210 \\
\text { Gamma de Goodman }=0,5 \\
\text { V de Cramer }=0,217\end{array}$ & $\begin{array}{l}\text { ¿Distingue entre } \\
\text { moléculas y redes? }\end{array}$ \\
\hline $\begin{array}{l}\text { ¿Contempla la posibilidad de } \\
\text { la existencia de un mismo } \\
\text { átomo en diferentes } \\
\text { sustancias? }\end{array}$ & $\begin{array}{l}\text { Coef. Conting }=0,387 \\
\text { Gamma de Goodman }=0 \\
\text { V de Cramer }=0,408\end{array}$ & $\begin{array}{c}\text { ¿Explica la } \\
\text { conservación de la } \\
\text { masa? }\end{array}$ \\
\hline $\begin{array}{l}\text { ¿Dibuja correctamente el } \\
\text { esquema de un átomo? }\end{array}$ & $\begin{array}{l}\text { Coef. Conting }=0,158 \\
\text { Gamma de Goodman }=( \\
\text { V de Cramer }=0,160\end{array}$ & $\begin{array}{c}\text { ¿Explica la } \\
\text { conservación de la } \\
\text { masa? }\end{array}$ \\
\hline $\begin{array}{l}\text { ¿Dibuja correctamente las } \\
\text { partículas gaseosas en un } \\
\text { recipiente? }\end{array}$ & $\begin{array}{l}\text { Coef. Conting }=0,159 \\
\text { Gamma de Goodman }=0,34 \\
\text { V de Cramer }=0,161\end{array}$ & $\begin{array}{c}\text { ¿Explica la } \\
\text { conservación de la } \\
\text { masa? }\end{array}$ \\
\hline
\end{tabular}

Figura 7.11.- Correlaciones entre conceptos relacionados en los cuestionarios Pre-ESO y Post-ESO.

Tras haber hecho estas comparaciones podremos obtener conclusiones acerca de la relación que hay entre las competencias de los alumnos previas a la intervención y el estado resultante tras ella. No obstante para obtener una mejor valoración del trabajo desarrollado vamos a buscar también relaciones entre los conceptos adquiridos por los alumnos, es decir trataremos de encontrar posibles relaciones entre los conceptos incluidos es el cuestionario final.

\begin{tabular}{|c|c|c|}
\hline \multicolumn{3}{|c|}{ Relación entre los resultados de los cuestionarios } \\
\hline Pre - ESO & Correlación entre los resultados & Pre-ESO \\
\hline $\begin{array}{c}\text { ¿Pone correctamente } \\
\text { ejemplos de sustancias puras? }\end{array}$ & $\begin{array}{l}\text { Coef. Conting }=0,373 \\
\text { Gamma de Goodman }=0 \\
\text { V de Cramer }=0,404\end{array}$ & $\begin{array}{c}\text { ¿Distingue claramente } \\
\text { entre elementos y } \\
\text { compuestos químicos? }\end{array}$ \\
\hline
\end{tabular}

Figura 7.12.- Correlaciones entre conceptos relacionados en el cuestionario Pre-ESO. 


\begin{tabular}{|c|c|c|}
\hline \multicolumn{3}{|c|}{ Relación entre los resultados de los cuestionarios } \\
\hline Post - ESO & Correlación entre los resultados & Post - ESO \\
\hline $\begin{array}{l}\text { ¿Conoce qué elementos son } \\
\text { metálicos y cuales no? }\end{array}$ & $\begin{array}{l}\text { Coef. Conting }=0,738 \\
\text { Gamma de Goodman }=0 \\
\text { V de Cramer }=0,800\end{array}$ & $\begin{array}{c}\text { ¿Razona que: } \\
\mathrm{M}+\mathrm{nM}=\text { iónico } \\
\mathrm{nM}+\mathrm{nM}=\text { covalente }\end{array}$ \\
\hline $\begin{array}{c}\text { ¿Razona que: } \\
\mathrm{M}+\mathrm{nM}=\text { iónico } \\
\mathrm{nM}+\mathrm{nM}=\text { covalente }\end{array}$ & $\begin{array}{l}\text { Coef. Conting }=0,734 \\
\text { Gamma de Goodman }= \\
\text { V de Cramer }=0,763\end{array}$ & $\begin{array}{l}\text { ¿Conoce que el enlace } \\
\text { iónico no conlleva la } \\
\text { formación de } \\
\text { moléculas? }\end{array}$ \\
\hline $\begin{array}{c}\text { ¿Razona que: } \\
\mathrm{M}+\mathrm{Nm}=\text { iónico } \\
\mathrm{Nm}+\mathrm{Nm}=\text { covalente }\end{array}$ & $\begin{array}{l}\text { Coef. Conting }=0,716 \\
\text { Gamma de Goodman }= \\
\text { V de Cramer }=0,726\end{array}$ & $\begin{array}{l}\text { ¿Advierte que el } \\
\text { enlace covalente no } \\
\text { tienen lugar con } \\
\text { metales? }\end{array}$ \\
\hline $\begin{array}{c}\text { ¿Razona que: } \\
\mathrm{M}+\mathrm{nM}=\text { iónico } \\
\mathrm{nM}+\mathrm{nM}=\text { covalente }\end{array}$ & $\begin{array}{l}\text { Coef. Conting }=0,740 \\
\text { Gamma de Goodman }= \\
\text { V de Cramer }=0,789\end{array}$ & $\begin{array}{l}\text { ¿Distingue entre } \\
\text { moléculas y redes? }\end{array}$ \\
\hline $\begin{array}{c}\text { ¿Distingue entre moléculas y } \\
\text { redes? }\end{array}$ & \begin{tabular}{|l} 
Coef. Conting $=0,721$ \\
Gamma de Goodman $=$ \\
V de Cramer $=0,735$ \\
\end{tabular} & $\begin{array}{l}\text { ¿Conoce que el enlace } \\
\text { iónico no conlleva la } \\
\text { formación de } \\
\text { moléculas? }\end{array}$ \\
\hline $\begin{array}{c}\text { ¿Distingue entre moléculas y } \\
\text { redes? }\end{array}$ & $\begin{array}{l}\text { Coef. Conting }=0,731 \\
\text { Gamma de Goodman }= \\
\text { V de Cramer }=0,758\end{array}$ & $\begin{array}{c}\text { ¿Ve que el enlace } \\
\text { covalente no se forma } \\
\text { con metales? }\end{array}$ \\
\hline $\begin{array}{c}\text { ¿Distingue entre moléculas y } \\
\text { redes? }\end{array}$ & \begin{tabular}{|l} 
Coef. Conting $=0,738$ \\
Gamma de Goodman $=($ \\
V de Cramer $=0,775$
\end{tabular} & $\begin{array}{l}\text { ¿Ve que el enlace } \\
\text { covalente, no siempre } \\
\text { forma moléculas? }\end{array}$ \\
\hline $\begin{array}{c}\text { ¿Distingue entre moléculas y } \\
\text { redes? }\end{array}$ & $\begin{array}{l}\text { Coef. Conting }=0,611 \\
\text { Gamma de Goodman }=0, \\
\text { V de Cramer }=0,566\end{array}$ & $\begin{array}{c}\text { ¿Explica la } \\
\text { conservación de la } \\
\text { masa? }\end{array}$ \\
\hline
\end{tabular}

Figura 7.13.- Correlaciones entre conceptos relacionados en el cuestionario Post-ESO.

Por tanto tras haber analizado las relaciones existentes entre las respuestas dadas a cada ítem por cada alumno obtenemos varias conclusiones: 


\section{¿Conoce los grupos de la} tabla periódica?

\section{Post - ESO}

Coef. Conting $=0,738$

Gamma de Godman $=0,849$

$\mathrm{V}$ de Cramer $=0,800$

\section{¿Discrimina entre todos los} tipos de enlace?

\section{Post-ESO}

Coef. Conting $=0,740$

Gamma de Godman $=0,901$

$\mathrm{V}$ de Cramer $=0,789$

Distingue correctamente entre moléculas y redes

\section{Post-ESO}

Coef. Conting $=0,738$

Gamma de Godman $=0,802$

$\mathrm{V}$ de Cramer $=0,775$

Conocen las consecuencias de los enlaces y estructuras

\section{Post-ESO}

Figura 7.14.- Síntesis de las correlaciones positivas halladas en el Pre-ESO y Post-ESO.

Tras hacer este análisis, podemos concluir que existe una elevada correlación entre los ítems tratados, lo que hace suponer que los alumnos que conocen correctamente la tabla periódica, serán capaces de asignar un tipo de enlace a cada sustancia, que a su vez también será capaz de distinguir las estructuras de la sustancia.

Por tanto, Como conclusión podremos emitir una secuencia de núcleos de contenido que presentan una secuencia jerárquica que, además de resultar lógica, se ha demostrado necesaria. 


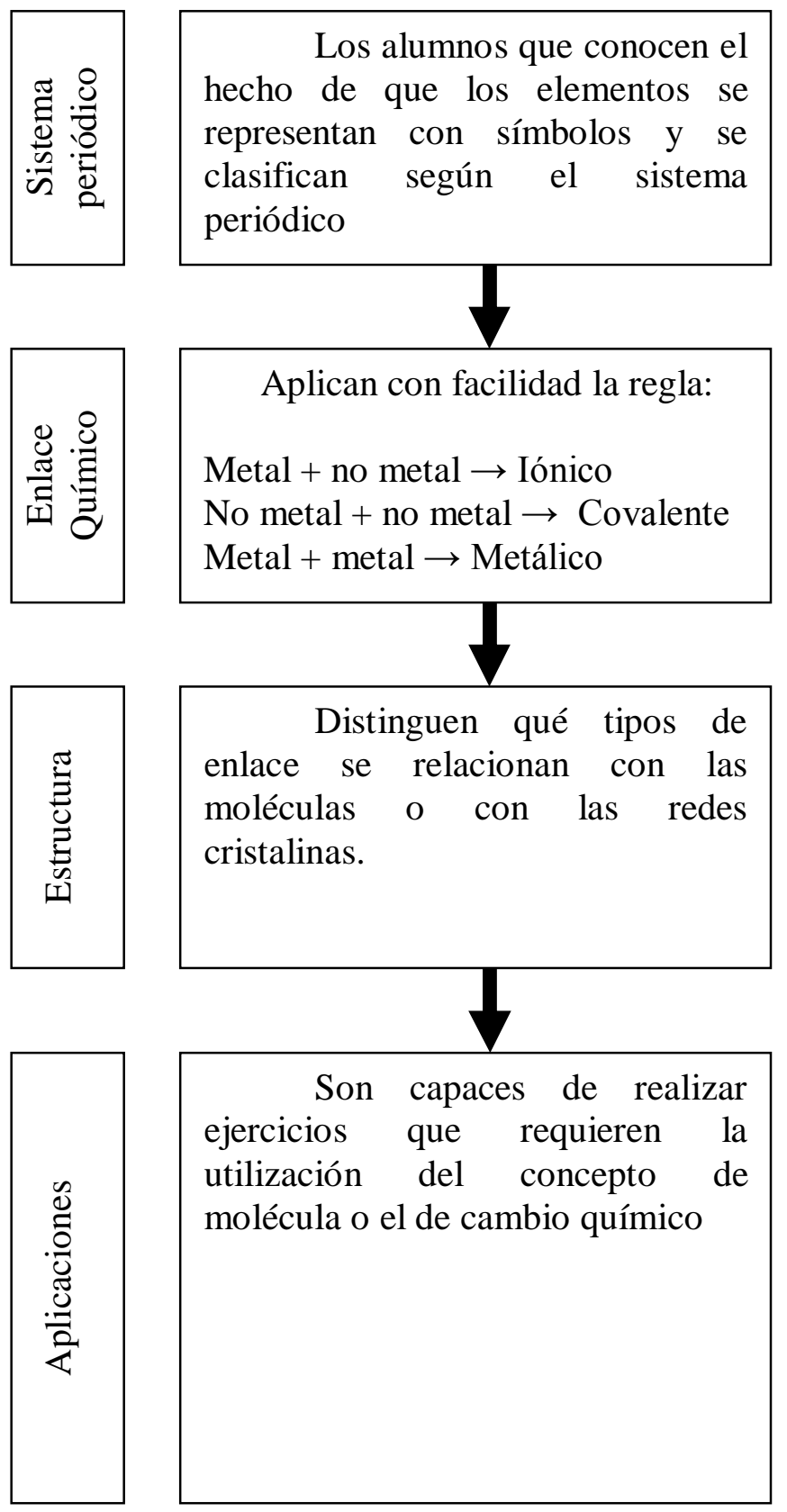

Son capaces de distinguir entre metales y no metales, así como comprender que existe relación entre los elementos de un mismo grupo o periodo, y no entre el resto.

Identifican correctamente el tipo de enlace a partir de la fórmula del compuesto

Afirman que el enlace covalente conlleva la formación tanto de moléculas como de redes $\mathrm{y}$, que los enlaces metálicos e iónicos únicamente a redes.

Conoce que mediante un enlace iónico no pueden formarse moléculas, que los metales no pueden participar en un enlace covalente, que estos además no forman moléculas, calculan correctamente la masa molecular e incluso razonan la conservación de la masa en reacciones químicas.

Figura 7.15.- Conclusiones extraídas tras relacionar las cuestiones del Pre-ESO y Post-ESO. 


\section{Comprende que un mismo tipo átomos} se puede encontrar en diferentes

Coef. Conting $=0,378$

Gamma de Godman $=0,201$

$\mathrm{V}$ de Cramer $=0,408$

\section{Explica la conservación de la masa}

\section{Post-ESO}

Figura 7.16.- Síntesis de las correlaciones positivas halladas en el Pre-ESO y Post-ESO.

Esta pareja de ítems resulta muy significativa en cuanto a la intención de la investigación, puesto que dada la elevada correlación podemos concluir que si un alumno es capaz de entender que los átomos que forman parte de un determinado elemento pueden encontrarse en diferentes sustancias, es capaz también de interpretar la reordenación de átomos que supone una reacción química. Esto es de especial interés puesto que implica que el alumno conoce el nivel atómico de la estructura de la materia.

Luego:

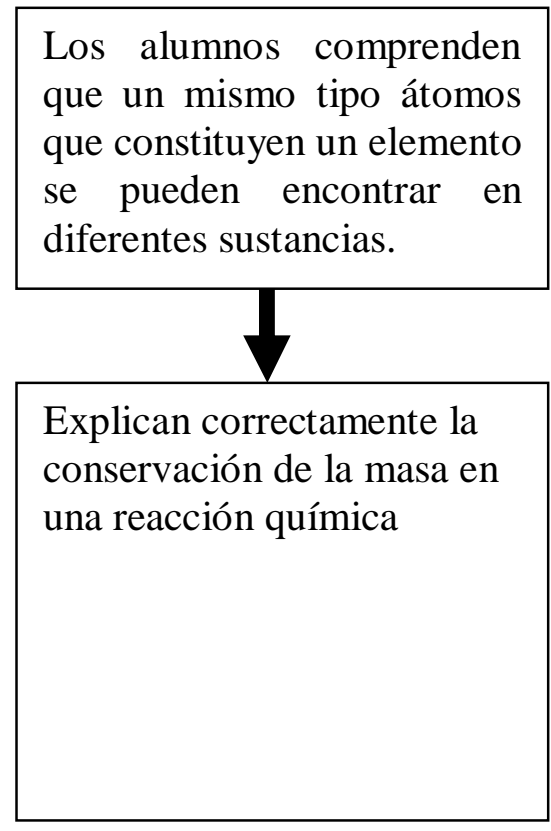

\begin{tabular}{|c|}
\hline $\begin{array}{l}\text { Estos alumnos han alegado que } \\
\text { los átomos de hierro se } \\
\text { encuentran presentes en las tres } \\
\text { sustancias propuestas }\end{array}$ \\
\hline $\begin{array}{l}\text { Justifican una reacción de } \\
\text { combustión } \\
\text { indicando que lo que ha ocurrido es } \\
\text { una reordenación atómica. Es decir } \\
\text { la masa que inicialmente se } \\
\text { encontraba en la madera se combina } \\
\text { con el oxígeno formando sustancias } \\
\text { gaseosas con la masa }\end{array}$ \\
\hline
\end{tabular}

Figura 7.17.- Conclusiones extraídas tras relacionar las cuestiones del Pre-ESO y Post-ESO. 
Es capaz de poner ejemplos de sustancias puras y de mezclas homogéneas

Coef. Conting $=0,373$

Gamma de Godman $=0,481$

$\mathrm{V}$ de Cramer $=0,404$

Distinguen claramente entre elementos y compuestos

Figura 7.18.- Síntesis de las correlaciones positivas halladas en el Pre-ESO y Pre-ESO.

La conclusión que extraemos al comparar este par de ítems es que los alumnos que son capaces de poner ejemplos de sustancias puras y de mezclas homogéneas, posteriormente distinguen claramente entre elementos y compuestos, tanto si han participado en la intervención propuesta como si no lo han hecho.

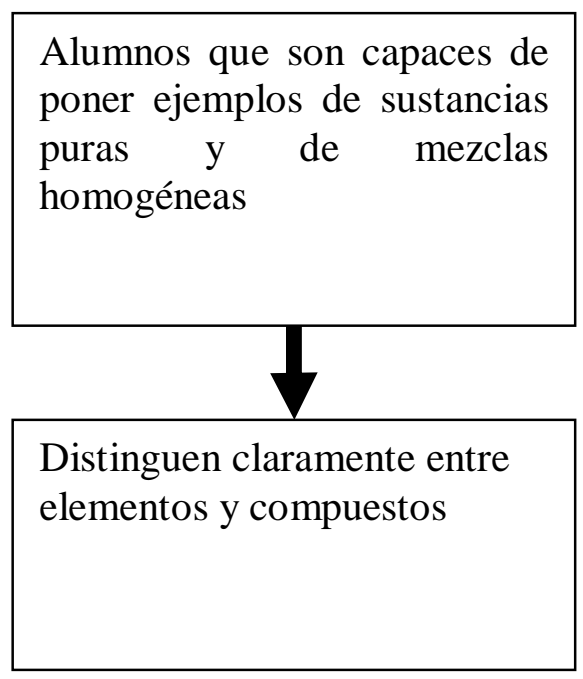

Generalmente los alumnos recurren a elementos para sustancias puras, y a disoluciones como ejemplos de mezclas homogéneas.

Son capaces de clasificar sustancias de la vida cotidiana como elementos mezclas $\mathrm{o}$ compuestos

Figura 7.19.- Conclusiones extraídas tras relacionar las cuestiones del Pre-ESO y Post-ESO. 


\section{Explican que es una molécula}

Coef. Conting $=0,146$

Gamma de Godman = 0,235

$\mathrm{V}$ de Cramer $=0,150$

Describen correctamente el esquema de un átomo

Coef. Conting $=0,162$

Gamma de Godman $=0,325$

$\mathrm{V}$ de Cramer $=0,165$

\section{Dibuja correctamente} las partículas gaseosas

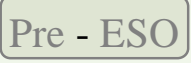

Coef. Conting $=0,158$

Gamma de Godman $=0,268$

$\mathrm{V}$ de Cramer $=0,160$

Coef. Conting $=0,159$

Gamma de Godman $=0,340$

V de Cramer $=0,161$

\section{Explica la conservación de la masa}

Post-ESO

Figura 7.20.- Síntesis de las correlaciones positivas halladas en el Pre-ESO y Post-ESO.

En esta secuencia no hemos encontrado una correlación entre los conceptos, lo que nos lleva a deducir que el hecho de realizar correctamente ciertas representaciones gráficas no conlleva la comprensión de los mismos.

\begin{tabular}{l}
\hline Los alumnos \\
que describen \\
correctamente \\
el esquema de \\
un átomo
\end{tabular}

\begin{tabular}{|l|}
\hline Representan el \\
modelo de \\
Bohr, con sus \\
partículas \\
constituyentes
\end{tabular}

Los alumnos que
dibujan correctamente
las partículas gaseosas
en un recipiente

Dibujan las partículas según marca la teoría cinética

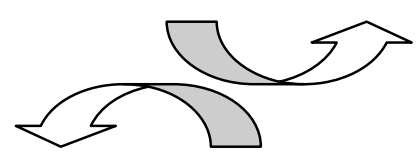

Explican correctamente la conservación de la masa en una reacción química

Explican que es una molécula, que tipo de enlace supone y a que se debe su formación.

Figura 7.21.- Conclusiones extraídas tras relacionar las cuestiones del Pre-ESO y Post-ESO. 
Tras este análisis de las respuestas y posterior extracción de conclusiones nos ha parecido interesante prestan atención al ítem n ${ }^{\circ} 9$ del cuestionario Pre-ESO.

Esta cuestión tal como se indica en el apartado 7.2.2.1, se encuentra al margen de los contenidos académicos y pretende conocer la imagen que tienen los alumnos acerca de la química. Llegados a este punto vamos a analizar la relación existente entre dicha imagen y los resultados tanto escolares como en los cuestionarios utilizados en esta intervención.

Para ello hemos de considerar que a los alumnos se les preguntaba por "las consecuencias que se derivaban de la industria química”. Hemos utilizado la palabra industria para dar una dimensión social y económica a la pregunta y no limitarla a la química como materia escolar. Para realizar el estudio hemos clasificado las respuestas, y a continuación se han catalogado a los alumnos según aporten consecuencias positivas o no, y según aporten consecuencias negativas o no lo hagan, de forma que podremos establecer puntuaciones características de los alumnos que aportan cosas positivas acerca de la química, de los que las aportan negativas, de los que no lo hacen en alguno o en ninguno de ambos, etc.

El análisis, al igual que en el resto del trabajo se ha realizado a través del programa informático SPSS. Hemos procedido a separar a los alumnos en grupos según sus respuestas:

a) según muestren una opinión positiva o no:

Hemos realizado dos grupos, uno con los que tienen opiniones positivas acerca de la química, y otro con los que simplemente no las presentan para, a continuación indagar en los resultados de los dos grupos obtenidos. Los resultados han sido: 
Alumnos que si apuntan cosas positivas sobre la química

\begin{tabular}{|l|c|c|c|c|}
\hline \multicolumn{1}{|c|}{} & Media & Desv. tip. & Asimetría & Curtosis \\
\hline Nota del curso anterior & 7,07 & 1,363 & 0,614 & $-0,676$ \\
\hline Pre-ESO & 6,18 & 1,635 & $-0,047$ & $-1,092$ \\
\hline Post-ESO & 4,09 & 2,230 & 0,193 & $-1,019$ \\
\hline (Post-ESO) - (Pre-ESO) & $-2,28$ & 1,966 & 0,520 & 0,301 \\
\hline Nota final de curso & 6,10 & 1,574 & 0,937 & 0,795 \\
\hline
\end{tabular}

Tabla 7.73.- Parámetros de los alumnos con una imagen positiva de la Química.

Alumnos que no apuntan cosas positivas

\begin{tabular}{|l|c|c|c|c|}
\hline \multicolumn{1}{|c|}{} & Media & Desv. tip. & Asimetría & Curtosis \\
\hline Nota del curso anterior & 6,49 & 1,191 & 0,660 & $-0,612$ \\
\hline Pre-ESO & 4,68 & 1,904 & $-0,796$ & $-0,072$ \\
\hline Post-ESO & 3,63 & 2,322 & 0,653 & $-0,456$ \\
\hline (Post-ESO) - (Pre-ESO) & $-1,59$ & 2,106 & 0,545 & 1,460 \\
\hline Nota final de curso & 5,30 & 2,285 & $-0,487$ & $-0,339$ \\
\hline
\end{tabular}

Tabla 7.74.- Parámetros de los alumnos sin una imagen positiva de la Química.

b) según muestren una opinión negativa o no:

Hemos realizado una clasificación al margen de la anterior clasificando a los alumnos según expresen opiniones negativas o no.

Alumnos que si apuntan cosas negativas

\begin{tabular}{|l|c|c|c|c|}
\hline \multicolumn{1}{|c|}{} & Media & Desv. tip. & Asimetría & Curtosis \\
\hline Nota del curso anterior & 6,77 & 1,276 & 0,444 & $-0,992$ \\
\hline Pre-ESO & 5,69 & 1,542 & $-0,354$ & $-0,523$ \\
\hline Post-ESO & 3,86 & 2,434 & 0,794 & $-0,472$ \\
\hline (Post-ESO) - (Pre-ESO) & $-2,30$ & 1,917 & 0,234 & 0,328 \\
\hline Nota final de curso & 5,65 & 1,802 & $-0,406$ & 0,637 \\
\hline
\end{tabular}

Tabla 7.75.- Parámetros de los alumnos con una imagen negativa de la Química.

Alumnos que no apuntan cosas negativas

\begin{tabular}{|l|c|c|c|c|}
\hline \multicolumn{1}{|l|}{} & Media & Desv. tip. & Asimetría & Curtosis \\
\hline Nota del curso anterior & 6,48 & 1,216 & 0,911 & 0,221 \\
\hline Pre-ESO & 4,40 & 2,086 & $-0,495$ & $-0,217$ \\
\hline Post-ESO & 3,58 & 2,167 & 0,158 & $-1,186$ \\
\hline (Post-ESO) - (Pre-ESO) & $-1,19$ & 2,119 & 0,751 & 1,638 \\
\hline Nota final de curso & 5,34 & 2,451 & $-0,418$ & $-0,366$ \\
\hline
\end{tabular}

Tabla 7.76.- Parámetros de los alumnos sin una imagen negativa de la Química. 
c) en último lugar hemos buscado estos mismos resultados en alumnos, que presente ambas opiniones o ninguna de ellas.

Alumnos que apuntan cosas positivas y negativas

\begin{tabular}{|l|c|c|c|c|}
\hline \multicolumn{1}{|l|}{} & Media & Desv. tip. & Asimetría & Curtosis \\
\hline Nota del curso anterior & 6,68 & 1,139 & 0,771 & $-0,600$ \\
\hline Pre-ESO & 5,96 & 1,616 & 0,380 & $-0,855$ \\
\hline Post-ESO & 3,36 & 2,169 & 0,918 & 0,490 \\
\hline (Post-ESO) - (Pre-ESO) & $-2,68$ & 1,966 & 1,105 & 2,901 \\
\hline Nota final de curso & 5,83 & 1,411 & 0,840 & 0,467 \\
\hline
\end{tabular}

Tabla 7.77.- Parámetros de los alumnos con una imagen positiva y negativa de la Química.

Alumnos que no aportan cosas positivas ni negativas

\begin{tabular}{|l|c|c|c|c|}
\hline \multicolumn{1}{|c|}{} & Media & Desv. tip. & Asimetría & Curtosis \\
\hline Nota del curso anterior & 6,25 & 1,010 & 0,740 & $-0,507$ \\
\hline Pre-ESO & 4,01 & 1,903 & $-0,800$ & $-0,529$ \\
\hline Post-ESO & 3,26 & 2,085 & 0,338 & $-1,038$ \\
\hline (Post-ESO) - (Pre-ESO) & $-1,16$ & 2,183 & 0,816 & 1,697 \\
\hline Nota final de curso & 5,10 & 2,504 & $-0,392$ & $-0,693$ \\
\hline
\end{tabular}

Tabla 7.78.- Parámetros de los alumnos sin una imagen positiva ni negativa de la Química.

A continuación tomando como única variable la media de los resultados anteriores hemos resumido los resultados de los casos anteriores:

\begin{tabular}{|c|c|c|c|c|c|c|}
\hline & 1 & 4 & 2 & 5 & 3 & 6 \\
\hline & $\begin{array}{l}0 \\
: \\
: \\
0 \\
0 \\
0\end{array}$ & 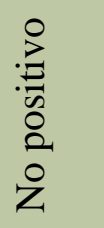 & 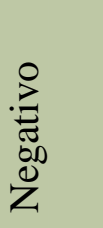 & Z & 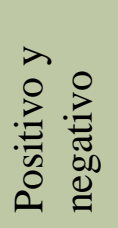 & 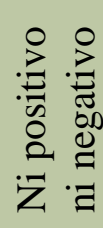 \\
\hline Nota del curso anterior & 7,07 & 6,49 & 6,77 & 6,48 & 6,68 & 6,25 \\
\hline Pre-ESO & 6,18 & 4,68 & 5,69 & 4,40 & 5,96 & 4,01 \\
\hline Post-ESO & 4,09 & 3,63 & 3,86 & 3,58 & 3,36 & 3,26 \\
\hline (Post-ESO) - (Pre-ESO) & $-2,28$ & $-1,59$ & $-2,30$ & $-1,19$ & $-2,68$ & $-1,16$ \\
\hline Nota final de curso & 6,10 & 5,30 & 5,65 & 5,34 & 5,83 & 5,10 \\
\hline
\end{tabular}

Tabla 7.79.- Síntesis de los parámetros de los alumnos según su imagen acerca de la Química. 
Podemos observar que los alumnos que aportaron una imagen positiva de la química fueron los que mejores resultados obtuvieron tanto en el curso anterior como en el de la intervención, por lo que podemos concretar que esta postura conlleva una predisposición favorable al estudio de esta materia.

En otro plano los alumnos que aportan ideas tanto positivas como negativas, también obtienen mejores resultados que aquellos que no las aportan en todos los casos, lo que supone un mejor rendimiento en aquellos alumnos que son capaces de expresar una opinión crítica del entorno tanto en un sentido como en otro.

Obtenemos la siguiente secuencia para los resultados:
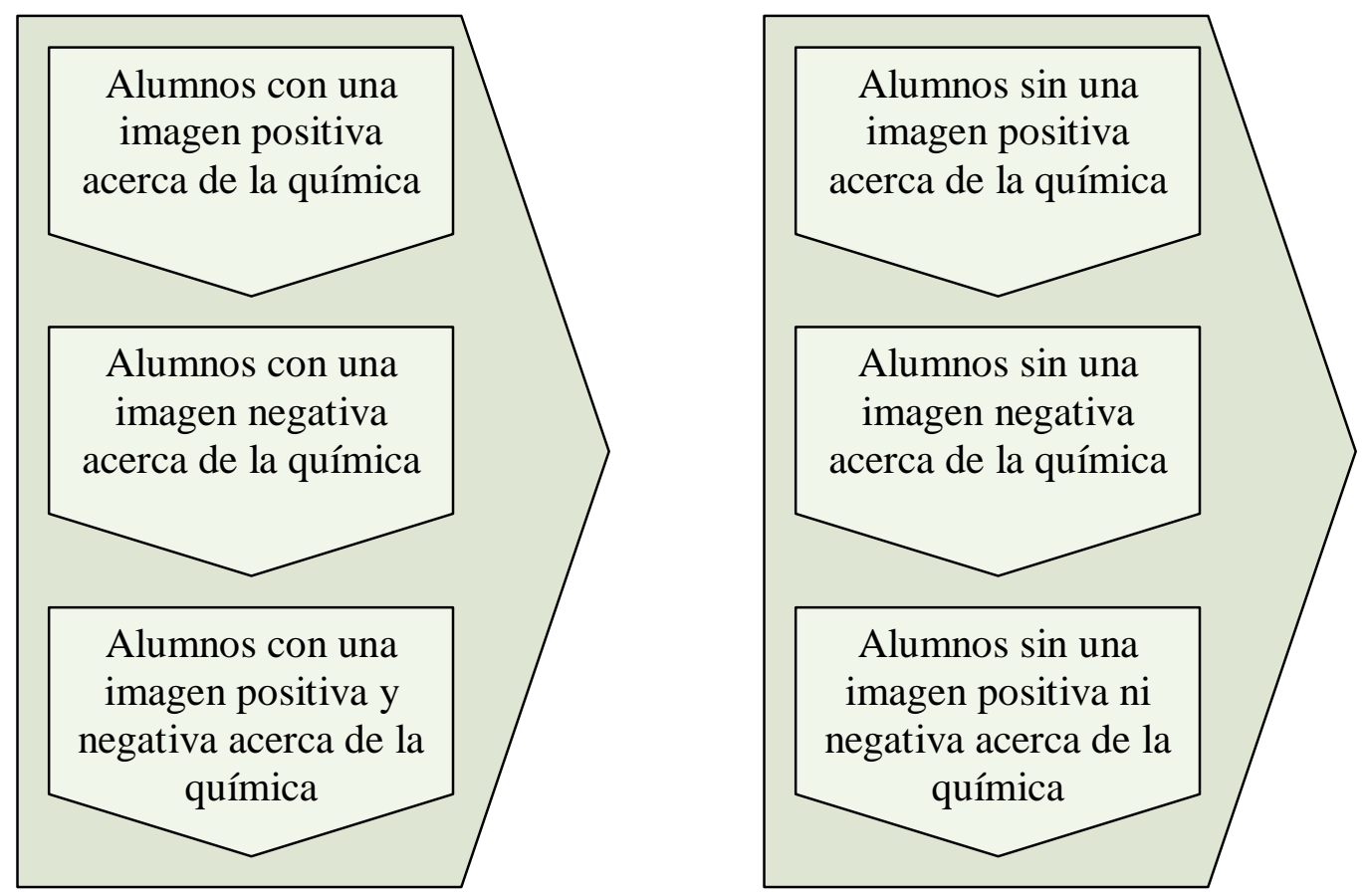

Figura 7.22.- Gradiente de notas obtenidas por los alumnos según su imagen de la Química. 


\subsubsection{Relación entre el Pre-BAC y el Post-BAC}

En segundo de bachillerato se ha pasado inicialmente el cuestionario Pre-BAC y finalmente el Post-BAC, de forma análoga al curso anterior, seguidamente se ha buscado posibles correlaciones entre los ítems propuestos:

\begin{tabular}{|c|c|c|c|}
\hline \multicolumn{2}{|l|}{ Pre-BAC } & \multicolumn{2}{|r|}{ Post-BAC } \\
\hline Concepto & Ítem & ítem & concepto \\
\hline Tabla periódica & 2 & 5 & Geometría molecular. Polaridad \\
\hline Tabla periódica & 2 & 6 & Propiedades macroscópicas \\
\hline Estructura atómica & 3 & 3 & Formas resonantes \\
\hline Estructura atómica & 3 & 4 & Tipo de enlace \\
\hline Estructura atómica & 3 & 10 & Enlace interatómico-intermolec. \\
\hline Configuración electrónica & 4 & 4 & Tipo de enlace \\
\hline Configuración electrónica & 4 & 8 & Enlace intermolecular \\
\hline Configuración electrónica & 6 & 5 & Geometría molecular. Polaridad \\
\hline Orbital atómico & 7 & 4 & Tipo de enlace \\
\hline Orbital atómico & 7 & 5 & Geometría molecular. Polaridad \\
\hline Orbital atómico & 7 & 8 & Enlace intermolecular \\
\hline Orbital atómico & 7 & 10 & Enlace interatómico-intermolec. \\
\hline Propiedades periódicas & 9 & 5 & Geometría molecular. Polaridad \\
\hline Propiedades periódicas & 9 & 7 & Propiedades macroscópicas \\
\hline Propiedades periódicas & 9 & 10 & Enlace interatómico-intermolec. \\
\hline Formulación y nomenclatura & 10 & 5 & Geometría molecular. Polaridad \\
\hline Formulación y nomenclatura & 10 & 6 & Propiedades macroscópicas \\
\hline Formulación y nomenclatura & 10 & 9 & Enlace interatómico-intermolec. \\
\hline Formulación y nomenclatura & 10 & 10 & Enlace interatómico-intermolec. \\
\hline
\end{tabular}

Tabla 7.80.- Conceptos implicados en los ítems del Pre-Bac y el Post-Bac

Los aspectos que mayor correlación tienen con los posteriores son los reflejados en los ítems 2, 7, 9 y 10. 


\begin{tabular}{|c|c|c|}
\hline $\begin{array}{l}\text { Pareja } \\
\text { de ítems }\end{array}$ & Estadístico & Valor \\
\hline $1-5$ & $\begin{array}{l}\text { Coeficiente de contingencia (basado en } x^{2} \text { ) } \\
\text { Gamma } \\
\text { Pearson }\end{array}$ & $\begin{array}{l}0,346 \\
0,507 \\
0,293\end{array}$ \\
\hline $2-5$ & $\begin{array}{l}\text { Coeficiente de contingencia (basado en } x^{2} \text { ) } \\
\text { Gamma } \\
\text { Pearson }\end{array}$ & $\begin{array}{l}0,368 \\
0,550 \\
0,374^{* *}\end{array}$ \\
\hline $2-6$ & $\begin{array}{l}\text { Coeficiente de contingencia (basado en } x^{2} \text { ) } \\
\text { Gamma } \\
\text { Pearson }\end{array}$ & $\begin{array}{l}0,430 \\
0,344 \\
0,271\end{array}$ \\
\hline $3-3$ & $\begin{array}{l}\text { Coeficiente de contingencia (basado en } x^{2} \text { ) } \\
\text { Gamma } \\
\text { Pearson }\end{array}$ & $\begin{array}{l}0,374 \\
0,131 \\
0,150\end{array}$ \\
\hline $3-4$ & $\begin{array}{l}\text { Coeficiente de contingencia (basado en } x^{2} \text { ) } \\
\text { Gamma } \\
\text { Pearson }\end{array}$ & $\begin{array}{l}0,343 \\
0,194 \\
0,152\end{array}$ \\
\hline $3-10$ & $\begin{array}{l}\text { Coeficiente de contingencia (basado en } x^{2} \text { ) } \\
\text { Gamma } \\
\text { Pearson }\end{array}$ & $\begin{array}{l}0,305 \\
0,281 \\
0,205\end{array}$ \\
\hline $4-8$ & $\begin{array}{l}\text { Coeficiente de contingencia (basado en } x^{2} \text { ) } \\
\text { Gamma } \\
\text { Pearson }\end{array}$ & $\begin{array}{l}0,314 \\
0,475 \\
0,196\end{array}$ \\
\hline $6-5$ & $\begin{array}{l}\text { Coeficiente de contingencia (basado en } x^{2} \text { ) } \\
\text { Gamma } \\
\text { Pearson }\end{array}$ & $\begin{array}{l}0,397 \\
0,793 \\
0,411^{*}\end{array}$ \\
\hline $7-5$ & $\begin{array}{l}\text { Coeficiente de contingencia (basado en } x^{2} \text { ) } \\
\text { Gamma } \\
\text { Pearson }\end{array}$ & $\begin{array}{l}0,314 \\
0,299 \\
0,175\end{array}$ \\
\hline $7-8$ & $\begin{array}{l}\text { Coeficiente de contingencia (basado en } x^{2} \text { ) } \\
\text { Gamma } \\
\text { Pearson }\end{array}$ & $\begin{array}{l}0,301 \\
0,309 \\
0,187\end{array}$ \\
\hline $7-10$ & $\begin{array}{l}\text { Coeficiente de contingencia (basado en } x^{2} \text { ) } \\
\text { Gamma } \\
\text { Pearson }\end{array}$ & $\begin{array}{l}0,323 \\
0,477 \\
0,232\end{array}$ \\
\hline $9-5$ & $\begin{array}{l}\text { Coeficiente de contingencia (basado en } x^{2} \text { ) } \\
\text { Gamma } \\
\text { Pearson }\end{array}$ & $\begin{array}{l}0,336 \\
0,414 \\
0,276\end{array}$ \\
\hline $9-7$ & $\begin{array}{l}\text { Coeficiente de contingencia (basado en } x^{2} \text { ) } \\
\text { Gamma } \\
\text { Pearson }\end{array}$ & $\begin{array}{l}0,393 \\
0,538 \\
0,406^{*}\end{array}$ \\
\hline $9-10$ & $\begin{array}{l}\text { Coeficiente de contingencia (basado en } x^{2} \text { ) } \\
\text { Gamma } \\
\text { Pearson }\end{array}$ & $\begin{array}{l}0,308 \\
0,352 \\
0,265\end{array}$ \\
\hline $10-5$ & $\begin{array}{l}\text { Coeficiente de contingencia (basado en } x^{2} \text { ) } \\
\text { Gamma } \\
\text { Pearson }\end{array}$ & $\begin{array}{l}0,360 \\
0,520 \\
0,356^{\star *}\end{array}$ \\
\hline $10-6$ & $\begin{array}{l}\text { Coeficiente de contingencia (basado en } x^{2} \text { ) } \\
\text { Gamma } \\
\text { Pearson }\end{array}$ & $\begin{array}{l}0,389 \\
0,426 \\
0,297\end{array}$ \\
\hline & \multicolumn{2}{|c|}{$\begin{array}{l}{ }^{*} \text { Asociación de variables significativas con } p<0,05 \\
\star \star * i d e m \text { con } p<0,1\end{array}$} \\
\hline
\end{tabular}

Tabla 7.81.- Correlación entre las respuestas a ítems relacionados en el Pre-Bac y el Post-Bac. 
En estos grupos el resultado es mucho más contundente y localizado que en tercero de ESO. Los ítems con mayor influencia en el tema del enlace son el 2, 3, 4, 7, 9 y 10, que son los referidos a la tabla periódica, estructura atómica, configuración electrónica, orbitales atómicos y la tabla periódica.

Esto nos lleva a la conclusión de que para abordar este tema con garantías es necesario conocer con mayor profundidad y extensión la tabla periódica. Otro dato destacable es que el ítem con mayor interés es el número 10 donde se propone formular y nombrar compuestos.

De la misma forma que en los resultados obtenidos en los cuestionarios de ESO, vamos a buscar las posibles relaciones en los de bachillerato, comenzando en primer lugar por la relación entre el cuestionario inicial y el final.

\begin{tabular}{|c|c|c|}
\hline \multicolumn{3}{|c|}{ Relación entre los resultados de los cuestionarios } \\
\hline Pre - BAC & Correlación entre los resultados & Post-BAC \\
\hline $\begin{array}{l}\text { ¿Sitúa correctamente a los } \\
\text { metales y no metales en la } \\
\text { tabla periódica? }\end{array}$ & $\begin{array}{l}\text { Coef. Conting }=0,153 \\
\text { Gamma de Goodman }= \\
\text { V de Cramer }=0,156\end{array}$ & $\begin{array}{l}\text { ¿Discrimina entre } \\
\text { todos los tipos de } \\
\text { enlace? }\end{array}$ \\
\hline $\begin{array}{c}\text { ¿Conoce los grupos de la } \\
\text { tabla periódica? }\end{array}$ & $\begin{array}{l}\text { Coef. Conting }=0,301 \\
\text { Gamma de Goodman }= \\
\text { V de Cramer }=0,319\end{array}$ & $\begin{array}{l}\text { ¿Discrimina entre } \\
\text { todos los tipos de } \\
\text { enlace? }\end{array}$ \\
\hline $\begin{array}{l}\text { ¿Dibuja correctamente un } \\
\text { átomo con sus componentes? }\end{array}$ & $\begin{array}{l}\text { Coef. Conting }=0,262 \\
\text { Gamma de Goodman }= \\
\text { V de Cramer }=0,640\end{array}$ & $\begin{array}{c}\text { ¿Utiliza correctamente } \\
\text { los símbolos de } \\
\text { Lewis? }\end{array}$ \\
\hline $\begin{array}{l}\text { ¿Formula correctamente los } \\
\text { compuestos químicos? }\end{array}$ & $\begin{array}{l}\text { Coef. Conting }=0,520 \\
\text { Gamma de Goodman }= \\
\text { V de Cramer = 0,519 }\end{array}$ & $\begin{array}{l}\text { ¿Conoce y asigna } \\
\text { correctamente los } \\
\text { tipos de enlace a las } \\
\text { sustancias? }\end{array}$ \\
\hline $\begin{array}{l}\text { ¿Dibuja correctamente un } \\
\text { átomo con sus componentes? }\end{array}$ & $\begin{array}{l}\text { Coef. Conting }=0,262 \\
\text { Gamma de Godman }=0 \\
\text { V de Cramer }=0,289\end{array}$ & $\begin{array}{l}\text { ¿Discrimina entre } \\
\text { todos los tipos de } \\
\text { enlace? }\end{array}$ \\
\hline $\begin{array}{l}\text { ¿Escribe correctamente la } \\
\text { configuración electrónica? }\end{array}$ & $\begin{array}{l}\text { Coef. Conting =0,223 } \\
\text { Gamma de Godman }=-1 \\
\text { V de Cramer }=0,231\end{array}$ & $\begin{array}{l}\text { ¿Conoce y asigna } \\
\text { correctamente los } \\
\text { tipos de enlace a las } \\
\text { sustancias? }\end{array}$ \\
\hline
\end{tabular}


Figura 7.23.- Correlaciones entre conceptos relacionados en los cuestionarios Pre-Bac y Post-Bac.

A continuación vamos a buscar relaciones entre los ítems del cuestionario inicial. Puesto que se ha comprobado la homogeneidad de los grupos, y todavía no se ha realizado ninguna intervención diferenciadora entre los grupos experimentales y de control, es de esperar que los resultados sean similares.

\begin{tabular}{|c|c|c|}
\hline \multicolumn{1}{|c|}{ Relación entre los resultados de los cuestionarios } & \multicolumn{1}{|c|}{ Pre-BAC } \\
\hline \begin{tabular}{c|c|c|}
\hline Pre - BAC \\
¿Conoce suficientemente el \\
sistema periódico?
\end{tabular} & $\begin{array}{l}\text { Correlación entre los resultados } \\
\text { Gamma de Goodman }=0,868 \\
\text { V de Cramer }=0,498\end{array}$ & $\begin{array}{c}\text { ¿Escribe } \\
\text { correctamente la } \\
\text { configuración } \\
\text { electrónica? }\end{array}$ \\
\hline \begin{tabular}{|l|l|} 
¿Escribe correctamente la \\
configuración electrónica?
\end{tabular} & $\begin{array}{l}\text { Coef. Conting }=0,635 \\
\text { Gamma de Goodman }=0,861 \\
\text { V de Cramer }=0,691\end{array}$ & $\begin{array}{c}\text { ¿Conoce la valencia } \\
\text { iónica del elemento? }\end{array}$ \\
\hline $\begin{array}{c}\text { ¿Conoce correctamente el } \\
\text { sistema periódico? }\end{array}$ & $\begin{array}{l}\text { Coef. Conting }=0,545 \\
\text { Gamma de Godman }=0,487 \\
\text { V de Cramer }=0,562\end{array}$ & $\begin{array}{c}\text { ¿Formula } \\
\text { compuestos químicos? }\end{array}$ \\
\hline
\end{tabular}

Figura 7.24.- Correlaciones entre conceptos relacionados en el cuestionario Pre-Bac.

\begin{tabular}{|c|c|c|}
\hline \multicolumn{3}{|c|}{ Relación entre los resultados de los cuestionarios } \\
\hline Post - BAC & Correlación entre los resultados & Post-BAC \\
\hline $\begin{array}{c}\text { ¿Conoce la geometría de las } \\
\text { moléculas? }\end{array}$ & $\begin{array}{l}\text { Coef. Conting }=0,459 \\
\text { Gamma de Goodman }= \\
\text { V de Cramer =0,521 }\end{array}$ & $\begin{array}{l}\text { ¿Relaciona la } \\
\text { polaridad con la } \\
\text { geometría? }\end{array}$ \\
\hline $\begin{array}{c}\text { ¿Conoce la polaridad de las } \\
\text { moléculas? }\end{array}$ & $\begin{array}{l}\text { Coef. Conting }=0,346 \\
\text { Gamma de Godman }=( \\
\text { V de Cramer }=0,369\end{array}$ & $\begin{array}{l}\text { ¿Conoce las } \\
\text { interacciones } \\
\text { moleculares? }\end{array}$ \\
\hline $\begin{array}{c}\text { ¿Conoce y asigna } \\
\text { correctamente los tipos de } \\
\text { enlace a las sustancias? }\end{array}$ & $\begin{array}{l}\text { Coef. Conting }=0,266 \\
\text { Gamma de Godman }=( \\
\text { V de Cramer }=0,262\end{array}$ & $\begin{array}{c}\text { ¿Entiende el concepto } \\
\text { de deslocalización } \\
\text { electrónica en redes } \\
\text { metálicas? }\end{array}$ \\
\hline $\begin{array}{c}\text { ¿Conoce y asigna } \\
\text { correctamente los tipos de } \\
\text { enlace a las sustancias? }\end{array}$ & $\begin{array}{l}\text { Coef. Conting }=0,144 \\
\text { Gamma de Goodman }= \\
\text { V de Cramer }=0,148\end{array}$ & $\begin{array}{c}\text { ¿Conoce el } \\
\text { comportamiento de los } \\
\text { iones? }\end{array}$ \\
\hline
\end{tabular}




\begin{tabular}{|c|c|c|}
\hline $\begin{array}{c}\text { ¿Conoce y asigna } \\
\text { correctamente los tipos de } \\
\text { enlace a las sustancias? }\end{array}$ & $\begin{array}{l}\text { Coef. Conting }=0,294 \\
\text { Gamma de Goodman }=0,632 \\
\text { V de Cramer }=0,339\end{array}$ & $\begin{array}{l}\text { ¿Reconoce la } \\
\text { polaridad de la } \\
\text { molécula? }\end{array}$ \\
\hline $\begin{array}{l}\text { ¿Entiende el concepto de } \\
\text { deslocalización electrónica en } \\
\text { redes metálicas? }\end{array}$ & $\begin{array}{l}\text { Coef. Conting }=0,454 \\
\text { Gamma de Goodman }= \\
\text { V de Cramer }=0,513\end{array}$ & $\begin{array}{l}\text { ¿Distingue qué tipo de } \\
\text { interacciones deben } \\
\text { vencerse en un cambio } \\
\text { físico o químico? }\end{array}$ \\
\hline $\begin{array}{c}\text { ¿Conoce el comportamiento } \\
\text { de los iones? }\end{array}$ & $\begin{array}{l}\text { Coef. Conting }=0,431 \\
\text { Gamma de Goodman }= \\
\text { V de Cramer }=0,480\end{array}$ & $\begin{array}{l}\text { ¿Distingue qué tipo de } \\
\text { interacciones deben } \\
\text { vencerse en un cambio } \\
\text { físico o químico? }\end{array}$ \\
\hline $\begin{array}{c}\text { ¿Conoce la geometría de las } \\
\text { moléculas? }\end{array}$ & $\begin{array}{l}\text { Coef. Conting }=0,512 \\
\text { Gamma de Goodman }= \\
\text { V de Cramer }=0,667\end{array}$ & $\begin{array}{l}\text { ¿Conoce los tipos de } \\
\text { interacciones } \\
\text { moleculares? }\end{array}$ \\
\hline $\begin{array}{c}\text { ¿Conoce los tipos de } \\
\text { interacciones moleculares? }\end{array}$ & $\begin{array}{l}\text { Coef. Conting }=0,236 \\
\text { Gamma de Goodman }= \\
\text { V de Cramer }=0,251\end{array}$ & $\begin{array}{l}\text { ¿Distingue qué tipo de } \\
\text { interacciones deben } \\
\text { vencerse en un cambio } \\
\text { físico o químico? }\end{array}$ \\
\hline $\begin{array}{l}\text { ¿Reconoce enlaces } \\
\text { interatómicos e } \\
\text { intermoleculares en una } \\
\text { misma sustancia? }\end{array}$ & $\begin{array}{l}\text { Coef. Conting }=0,544 \\
\text { Gamma de Goodman }= \\
\text { V de Cramer = 0,664 }\end{array}$ & $\begin{array}{l}\text { ¿Distingue qué tipo de } \\
\text { interacciones deben } \\
\text { vencerse en un cambio } \\
\text { físico o químico? }\end{array}$ \\
\hline $\begin{array}{l}\text { ¿Escribe correctamente la } \\
\text { configuración electrónica? }\end{array}$ & $\begin{array}{l}\text { Coef. Conting }=0,156 \\
\text { Gamma de Goodman }= \\
\text { V de Cramer }=0,334 \\
\end{array}$ & $\begin{array}{l}\text { ¿Utiliza correctamente } \\
\text { los símbolos de } \\
\text { Lewis? }\end{array}$ \\
\hline $\begin{array}{l}\text { ¿Utiliza correctamente los } \\
\text { símbolos de Lewis? }\end{array}$ & $\begin{array}{l}\text { Coef. Conting }=0,084 \\
\text { Gamma de Goodman }=0 \\
\text { V de Cramer }=0,084\end{array}$ & $\begin{array}{l}\text { ¿Reconoce la } \\
\text { polaridad de la } \\
\text { molécula? }\end{array}$ \\
\hline
\end{tabular}

Figura 7.25.- Correlaciones entre conceptos relacionados en el cuestionario Post-Bac. 
Conoce correctamente el Sistema Periódico

\begin{tabular}{|l|l|}
\hline Cont. $=0,545$ \\
$\mathrm{G}=0,487$ \\
$\mathrm{~V}=0,562$
\end{tabular}$\quad \begin{aligned} & \text { Cont }=0,489 \\
& \mathrm{G}=0,868 \\
& \mathrm{~V}=0,498\end{aligned}$

Formula los compuestos químicos

$$
\begin{aligned}
& \text { Cont }=0,520 \\
& G=552 \\
& V=0,519
\end{aligned}
$$

Asigna correctamente los tipos de enlace
Escribe correctamente la configuración electrónica

$$
\begin{aligned}
& \text { Cont }=0,223 \\
& G=-0,200 \\
& \mathrm{~V}=0,231
\end{aligned}
$$
Cont $=0,294$
$\mathrm{G}=0,632$
$\mathrm{V}=0,339$
Conoce el efecto de los iones

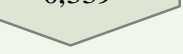

$$
\begin{aligned}
& \text { Cont }=0,144 \\
& G=0,592 \\
& V=0,148
\end{aligned}
$$

$$
\begin{aligned}
& \text { Cont }=0,266 \\
& \mathrm{G}=0,651 \\
& \mathrm{~V}=0,262
\end{aligned}
$$

Entiende la deslocalización de $\mathrm{e}^{-}$en el enlace metálico

Reconoce la polaridad de la molécula

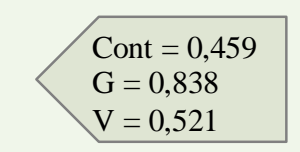

\section{Conoce la geometría de la molécula}

$$
\begin{aligned}
& \text { Cont }=0,346 \\
& G=0,758 \\
& V=0,369
\end{aligned}
$$

Conoce las interacciones moleculares

Cont $=0,414$

$\mathrm{G}=0,770$

$\mathrm{V}=0,465$

Reconoce enlaces interatómicos

e intermoleculares en una misma sustancia
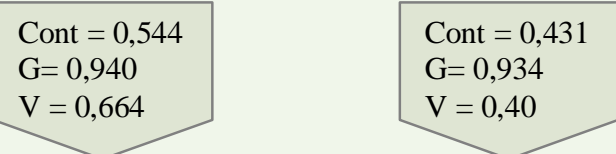

Cont $=0,454$

$\mathrm{G}=0,878$

$\mathrm{V}=0,573$

Distingue qué tipo de interacciones deben vencerse en un cambio físico o químico

Figura 7.26.- Síntesis de las correlaciones positivas halladas en el Pre-Bac y Post-Bac. 
Tras el análisis de este esquema, salta a la vista una clara relación entre los conceptos implicados:

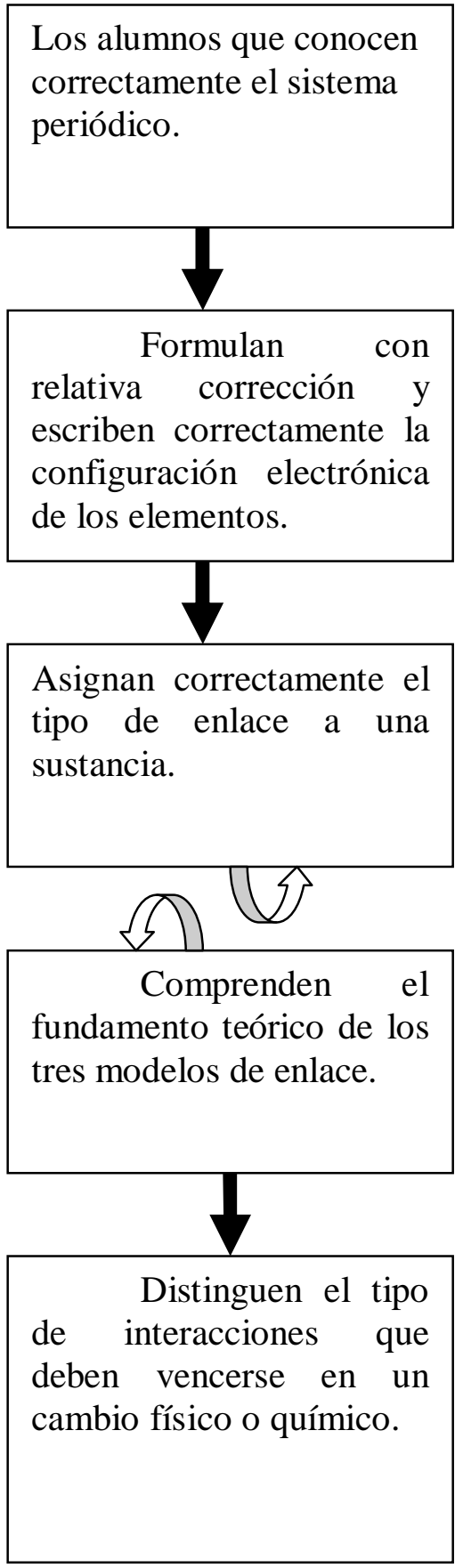

Distinguen correctamente entre metales y no metales, conocen los grupos y los periodos, así como las propiedades periódicas. Asignan correctamente el modelo de enlace que elementos son metales y no metales.

Formulan compuestos binarios y ternarios, conocen las valencias de los elementos, y obtienen las configuraciones. Todo ello correcta y mecánicamente.
$\mathrm{Al}$ igual que los alumnos de ESO, aplican con facilidad la regla:
Metal + no metal $\rightarrow$ Iónico
No metal + no metal $\rightarrow$ Covalente
Metal + metal $\rightarrow$ Metálico

Explican la formación y el comportamiento de los iones, la deslocalización electrónica en un enlace metálico o la estructura de una molécula.

Son capaces de distinguir la estructura de la materia, indicar de qué tipo de enlace se trata, y en su caso, distinguir las fuerzas intermoleculares. Por lo que según el proceso distinguen si hay que vencer fuerzas interatómicas, intermoleculares o ambas.

Figura 7.27.- Conclusiones extraídas tras relacionar las cuestiones del Pre-Bac y Post-Bac.

Encontramos pues en esta secuencia, la única salvedad de que no hay una correlación entre los alumnos que asignan (de forma mecánica) el tipo de enlace a una sustancia y los que razonan las características y consecuencias de ellos. 


\section{Dibuja un átomo Escribe la configuración electrónica}

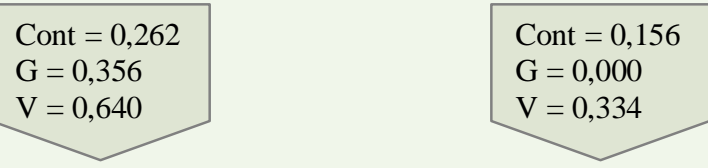

Escribe correctamente las estructuras de Lewis

$$
\text { Cont }=0,084
$$$$
\mathrm{G}=0,257
$$

$\mathrm{V}=0,084$

\section{Reconoce la polaridad de la molécula}

Figura 7.28.- Síntesis de las correlaciones positivas halladas en el Pre-Bac y Post-Bac.

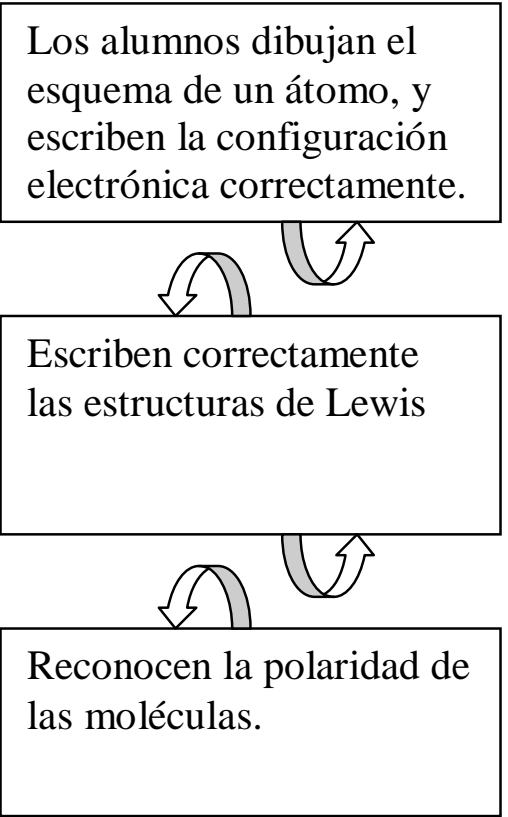
Ambas tareas son propias del aspecto procedimental de la materia. Son capaces de reproducir una tarea que se les ha explicado.

Es también una tarea mecánica que los alumnos realizan a partir del cálculo del número de enlaces y la distribución de electrones.

Esta cuestión requiere emplear varios conceptos, como la geometría y la polaridad del enlace.

Figura 7.29.- Conclusiones extraídas tras relacionar las cuestiones del Pre-Bac y Post-Bac.

Con esto concluimos que entre los alumnos que realizan correctamente estas actividades de tipo mecánico no hay una correlación aceptable, por lo que no hay una relación que justifique su secuenciación como si ha ocurrido en otros casos anteriores. 


\subsubsection{Influencia de la intervención}

\subsubsection{Resultados cuantitativos de la intervención}

Este es el punto crucial de la investigación. En este apartado vamos a comparar los resultados obtenidos tras la intervención en los grupos experimentales y de control, con lo que obtendremos un valor cuantitativo del efecto conseguido.

Tras la intervención, podremos afirmar que el grupo que mejor nota media obtenga en los cuestionarios finales, es el que mejor rendimiento ha obtenido tras estudiar el tema, y por tanto el que mejor método que el profesor ha seguido a la hora de plantearlo, no obstante hay que tener en cuenta que el nivel inicial de todos los grupos no era el mismo y por tanto deberemos obtener conclusiones a partir de la mejora experimentada durante el proceso más que de el estado final.

Por simple diferencia entre los resultados medios obtenidos entre los grupos experimentales y de control encontraremos para cada uno de ellos un valor que expresará cual ha obtenido mejores resultados.

Diferencias encontradas en el Post-ESO

\begin{tabular}{|l|c|c|c|}
\hline \multicolumn{1}{|l|}{} & $\begin{array}{c}\text { Nota media } \\
\text { Pre-ESO }\end{array}$ & $\begin{array}{c}\text { Nota media } \\
\text { Post-ESO }\end{array}$ & Post-ESO - Pre-ESO \\
\hline Grupos experimentales & 5,12 & 4,58 & $-0,55$ \\
\hline Grupos control & 5,27 & 4,05 & $-1,22$ \\
\hline Grupo control externo & 4,33 & 2,87 & $-1,46$ \\
\hline Total & 5,03 & 4,28 & $-0,75$ \\
\hline
\end{tabular}

Tabla 7.82.- Notas medias de los cuestionaros en ESO.

En nuestro caso las notas medias del cuestionario final son inferiores a las del cuestionario inicial en el grupo de control externo, pero esto carece de importancia, puesto que ambas pruebas estaban referidas a momentos, contextos y niveles diferentes. Es decir las pruebas iniciales versaban sobre contenidos de temas anteriores ya estudiados y sobre cuestiones de cultura general, de cálculo, de sentido común o de opiniones sobre la materia, mientras que las finales hacían referencia implícita a los contenidos curriculares del tema. Por ello hablaremos siempre de mejores o peores 
resultados de forma relativa, tomando como nota de referencia la nota media final de todos los grupos de estudio.

En el caso de la intervención llevada a cabo en tercer curso de ESO, calcularemos el porcentaje de mejora del grupo experimental respecto tanto del grupo de control como del grupo de control externo:

$$
\begin{aligned}
& \% \text { mejora }=\frac{\Delta \text { nota } G \exp -\Delta \text { nota Gcont }}{\text { nota } \text { media final total }} \cdot 100=\frac{-0,55-(-1,22)}{4,28} \cdot 100 \approx 16 \% \\
& \% \text { mejora }=\frac{\Delta \text { nota } G \exp -\Delta \text { nota Gcont } \text { ext }}{\text { nota media final total }} \cdot 100=\frac{-0,55-(-1,47)}{4,28} \cdot 100 \approx 22 \%
\end{aligned}
$$

Diferencias encontradas en el Post-Bac

\begin{tabular}{|l|c|c|c|}
\hline \multicolumn{1}{|l|}{} & $\begin{array}{c}\text { Nota media } \\
\text { Pre-BAC }\end{array}$ & $\begin{array}{c}\text { Nota media } \\
\text { Post-BAC }\end{array}$ & Post-BAC - Pre-BAC \\
\hline Grupos experimentales & 3,92 & 4,74 & 0,82 \\
\hline Grupos control & 4,23 & 4,75 & 0,52 \\
\hline Total & 4,08 & 4,75 & 0,57 \\
\hline
\end{tabular}

Tabla 7.83.- Notas medias de los cuestionarios en Bachillerato.

En el caso de la intervención llevada a cabo en bachillerato, las notas finales son muy parecidas, pero la diferencia reside en el los mejores valores obtenidos inicialmente por el grupo de control. Nuevamente realizaremos los cálculos en términos porcentuales de mejora del grupo experimental respecto del grupo de control:

$\%$ mejora $=\frac{\Delta \text { nota } G \exp -\Delta \text { nota Gcont }}{\text { nota media final total }} \cdot 100=\frac{0,82-(0,53)}{4,75} \cdot 100 \approx 6 \%$ 


\subsubsection{Resultados cualitativos de la intervención}

\section{Conclusión diagnosis I}

La intervención propuesta conducirá a que los alumnos sean capaces de comprender mejor la estructura de la materia, interpretar mejor sus características, y en consecuencia serán capaces de predecir la estabilidad y propiedades de las sustancias

Esta hipótesis ha sido contrastada en los dos grupos de trabajo, obteniendo sendos resultados en ambos. Tanto en tercero de ESO como en segundo de bachillerato, los grupos experimentales, han obtenido resultados (tablas 7.82 y 7.83) en los que se comprueba que las calificaciones finales son mejores en términos absolutos y relativos que los de los grupos de control. Obteniéndose en el caso de tercero de ESO una mejora por parte del grupo que ha llevado a cabo la intervención alternativa del 16\% respecto al grupo de control y de un $22 \%$ respecto al grupo de control externo. Mientras que en los grupos de bachillerato, aunque ha sido menor, se ha obtenido un mejora del $6 \%$.

\section{Conclusión diagnosis II}

La correcta adquisición de los conceptos previos al estudio de los modelos de enlace químico, tales como la nomenclatura y formulación química, el sistema periódico o modelos atómicos resulta determinante para el correcto desarrollo de este nuevo tema.

En todos los grupos y niveles hemos podido comprobar que tanto en los grupos experimentales como en los de control se confirma este hecho.

En los grupos de tercero de la ESO hemos constatado (figura 7.15) que hay una elevada correlación $(\approx 0,7)$ entre los alumnos que conocen los grupos de la tabla periódica, en consecuencia discriminan entre los tipos de enlace, con ello distinguen correctamente entre moléculas y redes y, conocen las consecuencias del enlace. Esta estrecha relación se explicita tanto en los grupos experimentales como en los de control, manifestando la conveniencia de un desarrollo constructivista en la didáctica de nuestra materia. 
Esta hipótesis ha quedado contrastada en tanto y cuanto se ha analizado la correlación existente entre los conocimientos iniciales de los alumnos y los posteriores relacionados con ellos, así como los que se van sucediendo entre sí.

En el caso del bachillerato se ha encontrado mayor correlación (figura 7.27) entre los grupos experimentales, que en los de control, para los alumnos que conociendo correctamente el sistema periódico son capaces de expresar correctamente la configuración electrónica, conocer las valencias y formular los compuestos químicos y, asignar correctamente los tipos de enlace existentes en cada compuesto.

En los grupos de ESO la diferencia no es tan notoria, en general aun cuando si lo es en algunos contenidos puntuales (figura 7.16).

\section{Conclusión diagnosis III}

Una buena actitud y una visión positiva de la química frente a la sociedad por parte de los alumnos favorecerán el estudio de esta materia.

Se ha constatado, a lo largo de esta investigación, que atendiendo a la imagen que presentan los alumnos puede establecerse una secuencia de los resultados obtenidos por los alumnos en las diferentes pruebas realizadas (cuestionarios, cursos anteriores, curso actual). Esta secuencia se manifiesta como un gradiente de resultados y, que muestra una mejor posición para aquellos que mostraron una opinión positiva, frente a los que contemplan opiniones negativas.

En cualquier caso, son mejores los resultados en los casos en que los alumnos manifiestan su opinión, tanto en sentido positivo como negativo, siendo peores en aquellos casos en que muestran indiferencia. Esto justifica la idea presente en los objetivos generales de la ESO y el Bachillerato de utilizar críticamente las fuentes de información (MEC, 2006; MEC, 2007a), que aunque a priori semeja un contenido transversal sin una implicación clara con la materia, el hecho de que los alumnos manifiesten su opinión respecto el entorno resulta beneficiosa sea cual sea el signo de esta expresión. 


\section{Conclusión diagnosis IV}

Es más sencillo realizar este tipo de experiencias en tercero de la ESO que es segundo de Bachillerato.

Efectivamente, a la hora de llevar a cabo la intervención ha sido bastante más sencillo en el caso de la ESO que en el de bachillerato, no obstante son los datos los que reflejan que el nivel final que han conseguido los alumnos tras la intervención, son más significativos en la enseñanza obligatoria que en la postobligatoria como cabría esperar dado el fuerte carácter conceptual que impone la prueba de acceso a la universidad en este curso.

Con ello se han conseguido en tercero de ESO, valores superiores en más de medio punto en los grupos experimentales que en los de control (tabla 7.82) y en casi dos puntos respecto al de control externo. Mientras que en los cursos de segundo de bachillerato las calificaciones finales han sido muy similares en todos los casos (tabla 7.84), si bien el nivel inicial era superior en el grupo de control

\subsubsection{Conclusiones generales respecto a la intervención diagnostica.}

Respecto a la intervención en tercero de la ESO

Todos los profesores que han participado en la experiencia consideran que resulta interesante el hecho de experimentar con cualquier tipo de propuesta y que resulta necesario buscar alternativas que motiven a los alumnos en clase, por lo que la aceptación ha sido muy buena a la hora de llevarla a cabo.

Así mismo también entienden que este tema resulta adecuado para llevar a cabo este proceso, ya que en este curso, el estudio de los modelos de enlace es un puente necesario entre el sistema periódico y la estructura de la materia y la estequiometría.

Respecto al desarrollo de la propuesta la totalidad de los participantes se ha ajustado a la temporización indicada, no obstante el aspecto que mayoritariamente han destacado ha sido la facilidad por parte de los alumnos para seguir el hilo conductor del tema. Aspecto que ha destacado en los alumnos que habitualmente les cuesta más seguir el ritmo de las clases. 
En cuanto a la parte metodológica, los profesores han destacado la dificultad inicial para centrar a los alumnos en el problema, puesto que la idea de que un mismo elemento este formando parte de estructuras tan diferentes como las propuestas no fue fácil de asimilar. No obstante, tras ello ha resultado más sencillo el trabajo diario.

La realización de la experiencia propuesta no ha presentado ninguna dificultad, puesto que la primera parte, es un ejercicio de reconocimiento de las propiedades de los elementos, que casi todos los profesores suelen realizar en este tema. En cuanto a la oxidación del hierro han destacado la facilidad para realizarla, lo evidente del resultado y lo fácil que ha sido para los alumnos interpretar el fenómeno observado como una como una combinación del oxígeno atmosférico con el hierro metálico.

Los profesores que han colaborado han mostrado su agrado con la propuesta y dos de ellos han sugerido desarrollar el resto del temario de esta forma, tanto por lo que supone una contextualización de los contenidos como por la utilización de un dossier personal que ayuda a muchos alumnos a mantener la atención sobre el tema a lo largo de los días.

Respecto a la intervención en segundo de bachillerato.

Los profesores han aceptado la propuesta sin demasiado entusiasmo, aunque admitiendo que es necesario buscar alternativas que mejoren los resultados obtenidos en los cursos actuales y a título de favor personal. La propuesta supone un contratiempo más, en un curso cargado con un extenso temario que está perfectamente repartido para llegar a tiempo a las pruebas de acceso a la Universidad. De hecho uno de los participantes explicitó que no se veía capaz de llevarlo a cabo, por la distorsión que le suponía y se ofreció como grupo de control.

Todos ellos han coincidido en lo relevante de este tema en el curso, y de lo necesario que es asimilar los conceptos relacionados, sobre todo la formación de iones para los temas posteriores de equilibrios y la idea ruptura y formación de enlaces en todos los temas en general.

Normalmente en este curso se suele seguir el texto con bastante fidelidad sin hacer muchas aportaciones personales y con la referencia externa que marcan las colecciones de exámenes de selectividad de años anteriores. 
Respeto al desarrollo de las actividades, todos los participantes han necesitado una sesión para discutir el proceso que deberían seguir. Todos ellos han realizado la parte experimental propuesta de forma demostrativa en la mesa del profesor, teniendo todo lo necesario preparado para evitar en lo posible la perdida de tiempo, aunque no es posible en la destilación ni en la cristalización. Esta última se ha realizado a posteriori.

En la opinión de los profesores esta parte supone un obstáculo importante, en cuanto a tiempo invertido, pero en cambio se traduce en una mayor participación de los alumnos en las clases.

En cuanto al desarrollo teórico del tema y corrección de actividades el tiempo empleado ha sido muy superior al estimado, habiendo sido necesarios en algunos casos 5 ó 6 sesiones para trabajar la teoría del enlace covalente o el enlace iónico.

\section{Respecto a profesores y alumnos}

La aceptación por parte del profesorado ha sido muy buena en tercer curso de la ESO, sobre todo por la utilización de un dossier que al tiempo que proporcionaba un hilo conductor al tema, permitía dar un carácter abierto a su desarrollo. Por el contrario en el segundo de bachillerato ha supuesto un contratiempo ya que la presión temporizadora del programa no permite extenderse más de lo estrictamente necesario en cada tema.

En cuanto al desarrollo del tema, los alumnos de segundo han expresado insatisfacción en cuanto que ha supuesto una dificultad añadida el hecho de cambiar la forma de trabajar que están manteniendo desde el principio de curso. Ellos explican que prefieren aprender el máximo de contenidos de forma memorística o algorítmica, pero no desviar la atención en otros aspectos, aunque admiten que es más ameno.

En cambio por parte de los alumnos de tercero de ESO, lejos de mostrar indiferencia han expresado satisfacción, que unida a la mejora de los resultados, invita a reproducir este método en temas posteriores. 


\section{Respecto al desarrollo de la intervención}

Al igual que han manifestado profesores y alumnos, todo el proceso ha sido más sencillo en ESO que en Bachillerato.

Por parte del profesorado de este último, se plantea que los contenidos del tema son fuertemente teóricos y que pese a que se trata de contextualizar el tema, cuando se trata de abordar el estudio de los diferentes enlaces, estructuras de Lewis, resonancia, hibridación, geometría, ciclo de Born-Haber, etc. no cabe otra posibilidad que la transmisión directa de información y que por tanto el desarrollo de las clases sigue siendo el mismo excepto la introducción que se realiza de forma práctica, y que repetimos, hace más amena la clase pero no cambia su planteamiento. Por el contrario la parte de reflexión y cálculos asociados a la intervención se realizan en casa lo que no repercute en aumentar el tiempo empleado en el tema, pero si en las tareas diarias del alumno.

En cambio en ESO se trata de una materia de dos horas semanales, que permite más flexibilidad tanto en el aula como en casa, los contenidos son más limitados y permite seguir el tema con relativa facilidad incluso a alumnos que habitualmente encuentran mayores dificultades y que generalmente no siguen el curso.

\section{Respecto a los resultados obtenidos}

Observando los resultados de forma estrictamente cuantitativa, la conclusión es que claramente son mejores en los grupos donde se ha llevado a cabo la investigación, que en los grupos de control, por lo que esta resulta provechosa, dándose esta circunstancia en los dos niveles implicados.

No obstante la diferencia ha sido mayor en el tercer curso de eso tal y como se esperaba dado el mayor peso de la dinámica empleada. 


\section{Respecto la enseñanza de la química en general}

- En cuanto al tercer curso de ESO

Los alumnos no conocen suficientemente la tabla periódica, es necesario profundizar en el conocimiento de los elementos, al menos conocer los aspectos más sencillos de los más habituales. Este hecho se explicita de forma contundente sobre todo a la hora de expresar los conocimientos en un mapa conceptual y que además podemos observar los elevados valores para el coeficiente de contingencia cuando se relaciona conceptos adquiridos con los conceptos aprendidos anteriormente.

En definitiva podemos observar que la dificultad reside principalmente en la capacidad de razonamiento abstracto de la química, es decir al entendimiento del nivel microscópico. Los alumnos aunque conocen el modelo de Rutherford no tienen minimamente claro el comportamiento de cada partícula

Aunque si conocen bastante bien la teoría cinética, no asimilan correctamente la teoría atómica de Dalton, por lo que no tienen clara la composición ni la estructura de la materia. Este hecho se pone de manifiesto cuando presenta dificultad para relacionar todas las partículas (átomos, moléculas, iones, partículas subatómicas, elementos...) así como conocer su papel dentro del sistema periódico.

En cuanto a la formulación, los resultados han sido muy pobres. Esto asociado a un bajo conocimiento de la tabla periódica hace que no se consiga distinguir fácilmente el tipo de enlace implicado en cada sustancia.

- En cuanto al segundo curso de bachillerato

Tras la experiencia llegamos a la conclusión de que para abordar este tema con garantías es necesario conocer con mayor profundidad y extensión la tabla periódica, así como el resto de contenidos, formulación, estructura atómica y leyes de los gases, poniendo de manifiesto la necesidad de una correcta asimilación de los conceptos básicos de química antes de abordar temas de mayor complejidad como es en nuestro caso el del enlace. 
En este sentido hemos encontrado importantes correlaciones entre los alumnos que conociendo el sistema periódico relativamente bien, son capaces de asignar el tipo de enlace a una sustancia, conocer su estructura y explicar sus propiedades.

Los alumnos presentan bastante facilidad para realizar ejercicios algorítmicos o sistemáticos como escribir la estructura electrónica o las estructuras de Lewis, pero no extraen correctamente la información que les proporcionan. Existe además una baja correlación entre los alumnos que son capaces de hacer estos ejercicios o dibujos y los que conocen su significado o aplicación en los problemas.

El principal problema encontrado en la dificultad para asignar el tipo de enlace y propiedades de sustancias cuando coexistes varios tipos de enlace. Los alumnos no relacionan las fuerzas intermoleculares con un tipo más de enlace, que puede darse entre átomos, moléculas o iones.

Por tanto en la intervención propuesta para el primer curso de bachillerato se va a tratar de estructurar los modelos de enlace de forma que no se recurra a la simple clasificación en iónico, covalente y metálico. 
7.- Metodología, desarrollo y resultado de las investigaciones diagnósticas 


\section{PLANTEAMIENTO DE UNA INTERVENCIÓN COOPERATIVA CON UNA FINALIDAD REGULADORA}

\subsection{Introducción}

Tal como se esta indicando a lo largo del desarrollo de la presente investigación tratamos de establecer un mecanismo de regulación para optimizar el trabajo colectivo. La herramienta pretendida debe permitir una dinámica del tipo:

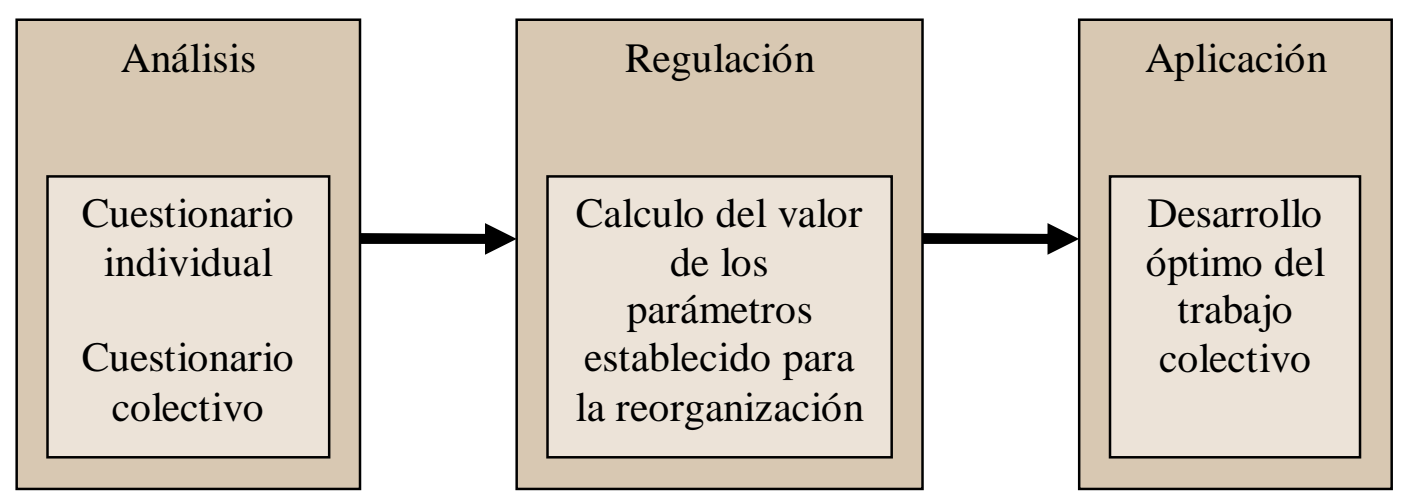

Figura 8.1.- División de los objetivos perseguidos en la intervención.

El objetivo es diseñar un método que permita a un profesor establecer una organización óptima de forma rápida y eficaz de grupos de trabajo, a partir del análisis estadístico de una prueba inicial.

Para ello vamos a establecer variables que permitan caracterizar a los alumnos y poder establecer una tipología de grupos de trabajo. Con ello pretendemos mejorar el rendimiento escolar de los alumnos. 


\subsection{Modelo y propuesta de trabajo cooperativo}

\section{Intervención en $1^{\circ}$ de bachillerato}

\section{Leyes de la química}

El tema se desarrollará de forma tradicional a partir de clases basadas en la explicación de los conceptos detallados en el currículo de la materia (punto 1.1.2) y apoyadas tanto en la parte teórica, como en la propuesta y resolución de ejercicios en el libro de texto de la editorial Anaya. La única novedad que se introducirá en este tema es que la prueba de evaluación se realizará de forma escrita tanto individual como en grupo.

Para ello se utilizará un cuestionario (anexo XIII) que se realizará por los alumnos de forma individual, tal como seria de esperar por su parte y acto seguido se volverá a realizar de forma conjunta utilizando grupos formados por orden alfabético.

\section{Estructura atómica y sistema periódico}

El tema se desarrollara del mismo modo.

\section{Enlace químico}

Aquí toma lugar la dinámica de grupo.

\section{Intervención en primer curso de bachillerato, para abordar el estudio del enlace químico:}

Cuando se trata de explicar un cambio físico o químico en una determinada sustancia, los alumnos presentan dificultades para distinguir cuales son las interacciones que se deben vencer (según se ha podido constatar en la intervención previa/diagnóstica descrita en el punto 6.4, resultados obtenidos en el punto y 7.3.2.4 y reflejados en la figura 7.9 , tablas 7.69 y 7.70 ).

Curricularmente, el estudio del enlace químico se aborda desde una perspectiva en la que se clasifican las sustancias según posean enlaces iónicos covalentes o metálicos. A continuación se trata el enlace intermolecular, donde se agrupan puentes de 
hidrógeno, interacciones entre moléculas polares o apolares, y átomos aislados. Desde una perspectiva constructivista, tal y como hemos podido comprobar en el apartado 7.3.3.2 y cuantificado en la figura 7.24 Los alumnos que poseen un conocimiento básico de la tabla periódica y conocen que elementos son metálicos o no, identifican con facilidad si un compuesto binario es iónico, covalente o metálico. Sin embargo, cuando intervienen mayor número de elementos o varios tipos de enlace en una misma sustancia cambia la situación (figuras 7.26 y 7.27).

Sustancias como el diamante presenta enlaces covalentes y son muy duros, con un elevado punto de fusión. El nitrógeno también presenta enlaces covalentes pero a temperatura ambiente es un gas, mientras que el agua en su misma situación es un líquido. Esto se debe a que en las sustancias moleculares, coexisten enlaces entre los átomos que constituyen la propia molécula y las interacciones entre moléculas vecinas.

Los enlaces intermoleculares reciben una menor importancia curricular, mientras que si se le da al enlace covalente cuando este se esta estudiando para formar las partículas (moléculas), no las sustancias. Realmente las redes covalentes estudiadas en bachillerato se reducen al carbono y la sílice.

Los libros de texto siguen una estructura en la que según los sucesivos Reales Decretos de mínimos se aborda el enlace interatómico (covalente, iónico y metálico), y a continuación el enlace intermolecular. Cuando se introducen los tres modelos de enlace interatómico existe un conjunto de contenidos que le confieren a cada uno de ellos una entidad propia y que acumula varias sesiones. Al trabajar el enlace covalente se incide en las estructuras de Lewis y geometría molecular. Se hace lo propio con el enlace iónico y las estructuras reticulares y ciclo de Born-Habber. En el caso del enlace metálico se explica, el modelo de mar de electrones y la teoría de bandas. Con ello se construye un sistema en el que el alumno ubicará fácilmente a cada una de las sustancias. Sin embargo las interacciones entre partículas formadas por varios átomos reciben un tratamiento más simplificado y en último lugar.

La estabilidad de las sustancias depende de las fuerzas que mantienen unidas a las partículas. Las partículas de las que habla la teoría cinética, que es la utilizada en secundaria para interpretar los cambios de estado, pueden ser átomos, moléculas o iones 
(monoatómicos o poliatómicos). En sustancias como el nitrato potásico coexisten enlaces covalentes e iónicos.

Sería interesante tratar por un lado las uniones discretas en una cantidad definida para formar moléculas, neutras o con carga (mediante enlaces covalentes). Y por otro lado tratar la unión masiva entre las partículas, átomos no metálicos en enlaces covalentes, aniones y cationes en enlaces iónicos, átomos de metales en enlaces metálicos y del mismo modo la unión entre moléculas o átomos aislados mediante puentes de hidrogeno, fuerzas de orientación, dirección o dispersión, o bien atracción entre átomos estables.

De este modo se puede interpretar los procesos de fusión o vaporización (cambios físicos) como la ruptura de estas últimas uniones. Las rupturas de los enlaces que forman las moléculas no suponen cambios es los estados de la materia sino cambios en la naturaleza de las mismas (cambios químicos)

En definitiva pasaríamos de una estructura, a otra ligeramente diferente:

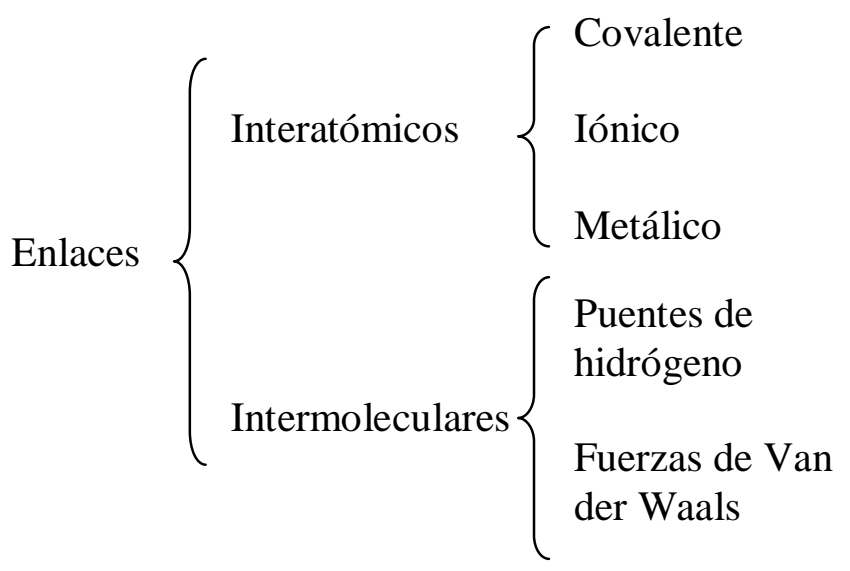

Figura 8.2.- Clasificación habitual de los tipos de enlace. 
Estructuras $\begin{cases}\text { Atómicas } \rightarrow & \text { Covalente molecular } \\ \text { Multiatómicas } & \left\{\begin{array}{l}\text { Covalente } \\ \text { Iónico } \\ \text { Metálico } \\ \text { Interacciones intermoleculares }\end{array}\right.\end{cases}$

Figura 8.3.- Enlaces implicados en las agrupaciones de átomos.

En nuestro trabajo vamos a desarrollar una intervención en el primero de los cursos, en la cual se pretende aunar el estudio de todos los modelos de enlace. Como se puede ver en los contenidos oficiales a tratar, los dos cursos presentan una estructura semejante. A nuestro entender y con alguna excepción, los contenidos pueden asumirse perfectamente por un alumno de primer curso.

Por tanto trataremos de elaborar un método de trabajo que permita a los alumnos tener una visión global del tema del enlace químico y su relación con la estructura y propiedades de la materia. No obstante en este nivel educativo no vamos a tratar los conceptos que consideramos propiamente de segundo curso como son la formación de los compuestos iónicos, hibridación, leyes de Hess, o algunos aspectos termodinámicos avanzados.

- La teoría cinética nos permite explicar como están constituidas las sustancias sólidas, líquidas y gaseosas.

- Como están constituidas estas partículas es una cuestión que va a determinar dicha unión.
Átomos
Moléculas
Iones (mono o poliatómicos)

- Conceptos previos. (necesarios según se explica en el punto 5.2.2, se analiza en el punto 7.3.3 y se confirma en las figuras 7.15, 716 y 7.27), Estados de agregación de la materia, Repaso de las teorías atómica y cinética, Repaso del SP, Cambios de estado.

- Contextualización de las actividades (indicado en el punto 3.3 y justificado con los resultados de la intervención previa) 
Se persigue que los alumnos asimilen una ordenación de los modelos de enlace como la siguiente:

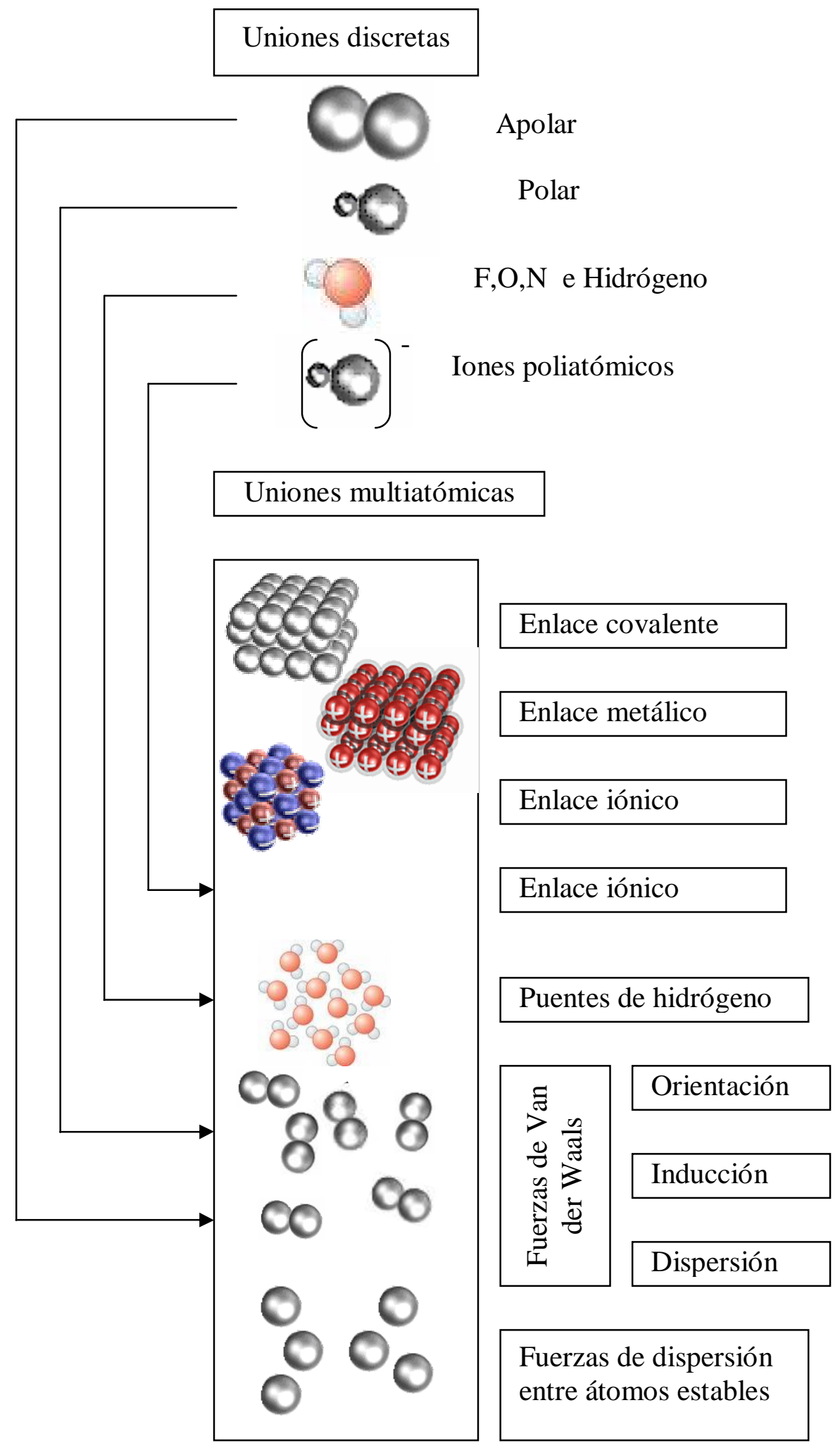

Figura 8.4.- Organización de los modelos de enlace. 


\section{Enlace químico - Actividades}

A-1.- Indicad si las sustancias representadas en los dibujos se corresponden con sustancias puras o sustancias compuestas.
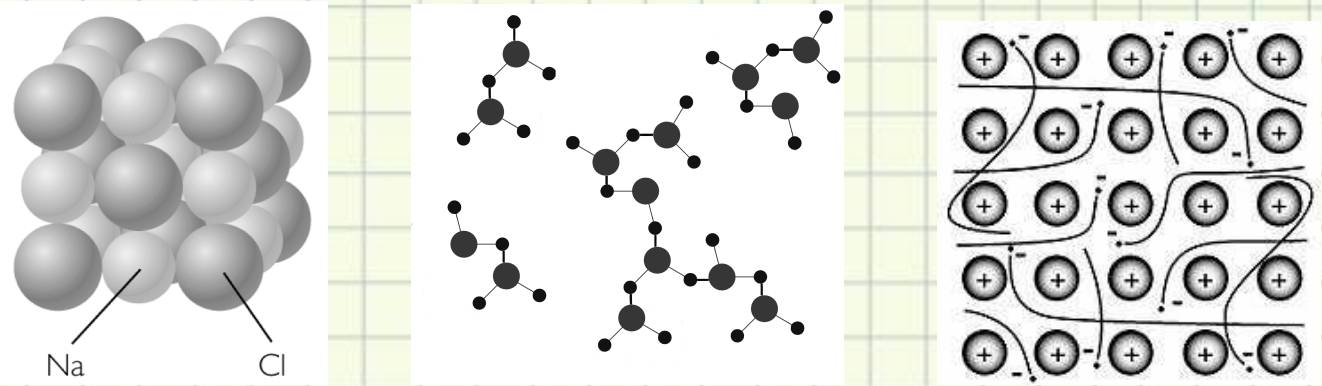

A-2.- Indicad y justificad el estado de agregación que se representa en las siguientes sustancias.
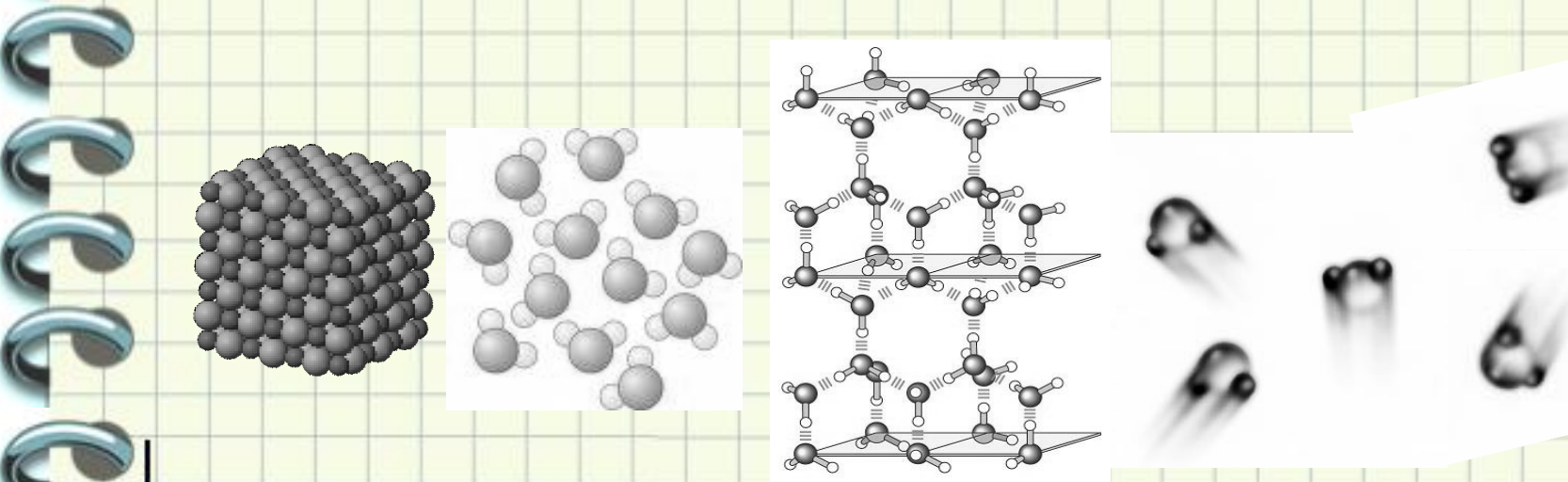

A-3.- Dibujad posibles estructuras para las sustancias:

Cobre sólido

$\mathrm{NH}_{3}$ (líquido)

$\mathrm{Cl}_{2}$ (gas)

$\mathrm{NaCl}$ disuelto en agua 


\section{A-4.- Práctica TCM}

\section{Introducción:}

La teoría cinética de la materia se basa en dos ideas fundamentales:

1. La materia está formada por partículas muy pequeñas que no podemos ver, que están en continuo movimiento de manera aleatoria.

2. La velocidad de las partículas aumenta al elevar la temperatura y disminuye al disminuir la temperatura.

\section{Objetivos:}

- Investigar la estructura de la materia.

- Justificar con la teoría cinética el comportamiento de la materia.

\section{Material y recursos necesarios:}

- Vaso de precipitados pinzas, nuez y soporte

- Embudo pequeño

- Papel de celofán

- Permanganato de potasio

\section{Procedimiento:}

1. Coge un embudo de vidrio y tapa la boca amplia con papel de celofán.

2. Introduce por el agujero pequeño del embudo unos granos de permanganato de potasio.

3. Sujeta el embudo con una pinza.

4. Ahora sumerge el embudo parcialmente (por la parte más amplia) en un vaso de precipitados que contenga agua, y ANOTA LO QUE OBSERVAS.

Nota: Unos grupos realizarán la experiencia en agua fría y otros en agua caliente.

\section{Cuestiones:}

1. Haced un dibujo donde se esquematicen las partículas tanto de permanganato potásico como de agua, antes y después de sumergir el embudo en el agua.

2. ¿Cómo explicaríais que el permanganato pase a través del celofán sin que este se vea afectado?

3. ¿Qué puede aclararte la experiencia anterior sobre la estructura de la materia?

4. Explica utilizando la teoría cinética de la materia como:

a) El permanganato se disuelve.

b) Se difunde por todo el vaso.

5. ¿Qué diferencia se observa al realizar la experiencia en agua caliente? Justifícala utilizando la teoría cinética de la materia. 
A-5.- A partir de muestras y nombres de varias sustancias y compuestos, tratad de identificar su estructura y propiedades. Para ello utilizad la siguiente plantilla.

\begin{tabular}{|c|c|c|c|c|c|c|c|}
\hline Sustancia & Fórmula & \multirow{3}{*}{$\begin{array}{l}\text { Forma } \\
\text { Sólido } \\
\text { rígido }\end{array}$} & Color & Partículas & \multirow{2}{*}{$\begin{array}{c}\text { SP } \\
\text { Metal }\end{array}$} & \multirow{2}{*}{$\begin{array}{c}\mathbf{T}^{\mathbf{a}} \mathbf{f u}_{\mathbf{u}}(\mathbf{K}) \\
1808\end{array}$} & \multirow{2}{*}{$\frac{\mathbf{T}_{\mathbf{~} \mathbf{a b}}(\mathbf{K})}{3023}$} \\
\hline Hierro & $\mathrm{Fe}$ & & Gris & Fo) & & & \\
\hline насно & & & & & & & \\
\hline \multirow{2}{*}{$\begin{array}{l}\text { Cloruro } \\
\text { sódico }\end{array}$} & \multirow{3}{*}{$\mathrm{NaCl}$} & Cristales & Blanco & & \multirow{3}{*}{$\begin{array}{l}\text { Metal } \\
+ \text { No } \\
\text { metal }\end{array}$} & & \\
\hline & & & & & & & \\
\hline & & & & & & & \\
\hline Cobre & $\mathrm{Cu}$ & & & & & & \\
\hline & & & & & & & \\
\hline Aluminio & $\mathrm{Al}$ & & & & & & \\
\hline & & & & & & & \\
\hline \multirow{2}{*}{ Azufre } & \multirow{2}{*}{$S$} & & & & & & \\
\hline & & & & & & & \\
\hline \multirow{2}{*}{ Cinc } & $\mathrm{Zn}$ & & & & & & \\
\hline & & & & & & & \\
\hline \multirow{3}{*}{$\begin{array}{l}\text { Nitrato } \\
\text { potásico }\end{array}$} & \multirow{2}{*}{$\mathrm{KNO}_{3}$} & & & & & & \\
\hline & & & & & & & \\
\hline & & & & & & & \\
\hline \multirow{2}{*}{$\begin{array}{l}\text { Dicromato } \\
\text { potásico }\end{array}$} & $\mathrm{K}_{2} \mathrm{Cr}_{2} \mathrm{O}_{7}$ & & & & & & \\
\hline & & & & & & & \\
\hline \multirow{2}{*}{$\begin{array}{l}\text { Cloruro } \\
\text { amónico }\end{array}$} & $\mathrm{NH}_{4} \mathrm{Cl}$ & & & & & & \\
\hline & & & & & & & \\
\hline 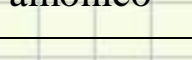 & & & & & & & \\
\hline Hidrógeno & $\mathrm{H}_{2}$ & & & & & & \\
\hline & & & & & & & \\
\hline Carbono & $\mathrm{C}$ & & & & & & \\
\hline & & & & & & & \\
\hline Azúcar & $\mathrm{C}_{12} \mathrm{H}_{22} \mathrm{O}_{11}$ & & & & & & \\
\hline & & & & & & & \\
\hline Agua & $\mathrm{H}_{2} \mathrm{O}$ & & & & & & \\
\hline Agua & & & & & & & \\
\hline Aceite & $\mathrm{C}_{1} \mathrm{H}_{2} \mathrm{O}_{2}$ & & $t^{2}$ & & 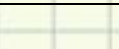 & $=$ & \\
\hline & $C_{18} \Pi_{34}$ & & & & & & \\
\hline Dióxido & $\mathrm{SiO}_{2}$ & & +2 & & & 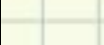 & \\
\hline de silicio & $\mathrm{SIO}_{2}$ & & 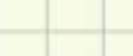 & & & 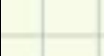 & \\
\hline & & & & & & & \\
\hline Yodo & $\mathrm{I}_{2}$ & & - & 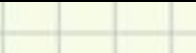 & 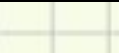 & 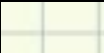 & \\
\hline 1000 & $\mathbf{I}_{2}$ & & & & & & \\
\hline
\end{tabular}


A-6.- A partir de las diferentes partículas que se acaban de describir tratad de esquematizar los posibles tipos de uniones entre ellas.

A-7.- Determinar la fórmula de Lewis de:

Fluor $\left(\mathrm{F}_{2}\right)$, Oxígeno $\left(\mathrm{O}_{2}\right)$, Metano $\left(\mathrm{CH}_{4}\right)$, Agua $\left(\mathrm{H}_{2} \mathrm{O}\right)$, tetracloruro de carbono $\left(\mathrm{CCl}_{4}\right)$

A-8.- Determinar la fórmula de Lewis de:

Nitrógeno $\left(\mathrm{N}_{2}\right)$, dióxido de carbono $\left(\mathrm{CO}_{2}\right)$, monóxido de dicloro $\left(\mathrm{Cl}_{2} \mathrm{O}\right)$

A-9.- Determinad las estructuras de Lewis para el ión nitrato $\left(\mathrm{NO}_{3}{ }^{-}\right)$

A-10.- ¿Por qué en general los gases nobles, salvo en unos pocos compuestos, no forman enlaces?

A-11.- Determina las estructuras de Lewis para:

amoniaco $\left(\mathrm{NH}_{3}\right)$ y difluoruro de oxígeno $\left(\mathrm{F}_{2} \mathrm{O}\right)$ trifluoruro de nitrógeno $\left(\mathrm{NF}_{3}\right)$

A-12.- Escribir las fórmulas de Lewis del: $\mathrm{O}_{2}{ }^{-}, \mathrm{OH}^{-}, \mathrm{H}_{3} \mathrm{O}^{+}, \mathrm{N}_{3}{ }^{-}, \mathrm{NH}_{2}{ }^{-}, \mathrm{NH}_{3}, \mathrm{NH}_{4}{ }^{+}$

A-13.- Como ejemplo de ampliación del octeto para reducir las cargas formales, escribid la estructura de Lewis del ión Sulfato $\left(\mathrm{SO}_{4}{ }^{2-}\right)$

A-14.- Dibuja las estructuras de Lewis para los oxiones: $\mathrm{IO}_{3}^{-}$y $\mathrm{IO}_{4}{ }^{-}$

A-15.- Representar las fórmulas de Lewis de dos moléculas que no cumplen la regla del octeto: $\mathrm{PCl}_{5}$ y $\mathrm{SF}_{4}$

A-16.- Representar las estructuras de Lewis de las siguientes especies químicas:

$\mathrm{H}_{3} \mathrm{O}^{+}, \mathrm{SCl}_{2}, \mathrm{SO}_{2}, \mathrm{NO}_{3}, \mathrm{CO}_{3}{ }^{2-}, \mathrm{SO}_{2} \mathrm{~F}_{2}, \mathrm{XeF}_{2}, \mathrm{XeF}_{4}, \mathrm{XeF}_{6}, \mathrm{BrF}_{4}^{-}, \mathrm{ICl}_{2}^{-}, \mathrm{XeOF}_{4}$

A-17.- Representar las estructuras de Lewis de las siguientes especies:

\begin{tabular}{|l|l|l|l|l|l|l|}
\hline Grupo & 1 & 2 & 3 & 4 & 5 & 6 \\
\hline & $\mathrm{N}_{2}$ & $\mathrm{~F}_{2}$ & $\mathrm{O}_{2}$ & $\mathrm{Cl}_{2}$ & $\mathrm{HCl}$ & $\mathrm{H}_{2} \mathrm{O}$ \\
\hline & $\mathrm{CH}_{4}$ & $\mathrm{HCN}$ & $\mathrm{CS}_{2}$ & $\mathrm{NH}_{3}$ & $\mathrm{SO}_{2}$ & $\mathrm{BF}_{3}$ \\
\hline & $\mathrm{HCCl}_{3}$ & $\mathrm{PCl}_{5}$ & $\mathrm{SF}_{6}$ & $\mathrm{NO}_{3}{ }^{-}$ & $\mathrm{ClO}_{4}{ }^{-}$ & $\mathrm{CO}_{3}{ }^{2-}$ \\
\hline
\end{tabular}

A-18.- Utilizar el modelo VSERP para predecir la forma geométrica para cada una de las moléculas o iones siguientes. Representar primero la fórmula electrónica de cada molécula o ión por puntos (Lewis)

$\mathrm{CH}_{4}$

$\mathrm{CS}_{2}$

$\mathrm{H}_{2} \mathrm{O}$

$\mathrm{NH}_{3}$

$\mathrm{CO}_{2}$

$\mathrm{NH}_{4}^{+}$

$\mathrm{OF}_{2}$

$\mathrm{SiH}_{4}$

$\mathrm{NO}_{3}^{-}$

$\mathrm{CO}_{3}{ }^{2-}$

$\mathrm{ClO}_{4}$ 
A-19.- Discutir los ángulos de enlace de $\mathrm{NH}_{3}\left(107^{\circ}\right)$ y $\mathrm{PH}_{3}\left(93^{\circ}\right)$ por las repulsiones electrónicas de los electrones de enlace y de los pares solitarios.

A-20.- Estudiar por el modelo de repulsión electrónica de pares de electrones de la capa de valencia, las formas de las moléculas y los ángulos de enlace de:

$\mathrm{PF}_{5}, \mathrm{SF}_{4}$ y $\mathrm{ClF}_{3}$

A-21.- Dibujar la estructura de Lewis del $\mathrm{SF}_{6}$ ¿Cuál debe ser la geometría de esta molécula?

A-22.- Predecir la geometría de las moléculas: $\mathrm{HCN}, \mathrm{BF}_{4}^{-}, \mathrm{TeCl}_{4}, \mathrm{PF}_{6}^{-}$,

A-23.- ¿qué quiere decir que una molécula es polar? ¿Qué molécula será más polar el $\mathrm{CH}_{4}$ o el $\mathrm{NH}_{3}$ ?

A-24.- Indica si las siguientes moléculas son o no polares:

$\mathrm{CH}_{4}, \mathrm{SF}_{4}, \mathrm{ClF}_{3}$ y $\mathrm{CO}_{2}$

A-25.- Escribid las estructuras de Lewis de los siguientes compuestos: $\mathrm{NF}_{3}, \mathrm{SO}_{2}$ y $\mathrm{SF}_{4}$.

a) determinad la forma geométrica en cada caso.

b) determinad si en estas moléculas existen enlaces polarizados, en cuyo caso, indica que átomo estará cargado positivamente y cuál negativamente.

c) estableced cuáles de estas moléculas tienen momento dipolar.

A-26.- Escribid las estructuras de Lewis de los siguientes compuestos: $\mathrm{SiCl}_{4}, \mathrm{CO}_{2}$ y $\mathrm{NO}_{2}$.

a) determinad la forma geométrica en cada caso.

b) determinad si en estas moléculas existen enlaces polarizados, en cuyo caso, indica que átomo estará cargado positivamente y cuál negativamente.

c) estableced cuáles de estas moléculas tienen momento dipolar.

A-27.a) escribid las estructuras de Lewis del tricloruro de fósforo y el tricloruro de boro.

b) Proponed una estructura para cada uno de ellos

c) justificad el diferente comportamiento polar de ambas especies.

A-28.- Definir propiedades elásticas y plásticas de los metales ¿Qué significa tenacidad, ductilidad y maleabilidad de un metal?

A-29- Ordenar la temperatura de fusión y la dureza de los siguientes metales: $\mathrm{Ca}, \mathrm{Ba}$ y Co y explicar porqué.

A-30.- Dados los siguientes aniones poliatómicos $\mathrm{ClO}_{3}{ }^{-}, \mathrm{CH}_{3} \mathrm{COO}^{-}, \mathrm{SO}_{4}{ }^{2-}$ y $\mathrm{PO}_{4}{ }^{3-}$, y los cationes $\mathrm{Na}^{+}, \mathrm{Sr}^{2+} \mathrm{y} \mathrm{Al}^{3+}$. Escribir las fórmulas de los correspondientes compuestos y nombrarlos correctamente.

A-31.- Teniendo presente el concepto de enlace iónico:

a) justificar la conductividad de las sales iónicas

b) explicar sus elevados puntos de fusión

c) explicar su dureza

d) explicar su fragilidad 
A-32.- Interpretar de forma cualitativa la siguiente tabla:

\begin{tabular}{|l|c|c|c|c|}
\hline Compuesto & $\mathrm{NaF}$ & $\mathrm{NaCl}$ & $\mathrm{NaBr}$ & $\mathrm{NaI}$ \\
\hline $\mathrm{T}^{\mathrm{a}}$ de fusión $\left({ }^{\circ} \mathrm{C}\right)$ & 1000 & 800 & 750 & 670 \\
\hline
\end{tabular}

A-33.- Sabiendo que tanto el $\mathrm{NaF}$, como el $\mathrm{CaO}$ tienen la misma estructura cristalina y radios atómicos similares, ¿Cuál de ellos tendrá mayor temperatura de fusión?

A-34.- Dados los tres compuestos y temperaturas de ebullición siguientes:

\begin{tabular}{l|l|}
$\mathrm{CaO}$ & $1280^{\circ} \mathrm{C}$ \\
$\mathrm{KF}$ & $1505^{\circ} \mathrm{C}$ \\
$\mathrm{CsI}$ & $2850^{\circ} \mathrm{C}$.
\end{tabular}

Asignar y justificar a cada sustancia la temperatura correspondiente.

A-35.- ¿Qué sólido fundirá antes: el Argón sólido o el helio sólido? Justifícalo

A.36.- Explicar la siguiente serie de puntos de ebullición en función de los enlaces intermoleculares:

\begin{tabular}{|c|c|}
\hline $\mathrm{H}_{2} \mathrm{O}$ & $100^{\circ} \mathrm{C}$ \\
\hline $\mathrm{H}_{2} \mathrm{~S}$ & $-60^{\circ} \mathrm{C}$ \\
\hline $\mathrm{H}_{2} \mathrm{Se}$ & $-40^{\circ} \mathrm{C}$ \\
\hline $\mathrm{H}_{2} \mathrm{Te}$ & $-5^{\circ} \mathrm{C}$ \\
\hline
\end{tabular}

A-37.- Indica en qué sustancias de las siguientes existen enlaces de hidrógeno

\begin{tabular}{|l|l|}
\hline Compuesto & T$^{\text {a }}$ de ebullición $\left({ }^{\circ} \mathrm{C}\right)$ \\
\hline $\mathrm{CH}_{4}$ & $-161,4$ \\
\hline $\mathrm{NH}_{3}$ & -33 \\
\hline $\mathrm{H}_{2} \mathrm{O}$ & 100 \\
\hline $\mathrm{CH}_{3}-\mathrm{CH}_{3}$ & -88 \\
\hline $\mathrm{CH}_{3}-\mathrm{NH}_{2}$ & -67 \\
\hline $\mathrm{CH}_{3}-\mathrm{OH}$ & 65 \\
\hline
\end{tabular}

A-38.- Escribid las estructuras de Lewis para el $\mathrm{CH}_{4}$ y el $\mathrm{NH}_{3}$. ¿Cuáles son los tipos de fuerzas intermoleculares que mantienen unidas a las moléculas de ambos compuestos en estado sólido? ¿Cuál de las dos tendrá un punto de fusión más elevado? ¿Por qué?

A-39.- Seguidamente se dan los siguientes puntos de ebullición que corresponden a los gases nobles: $\mathrm{Ne}, \mathrm{Ar}$ y $\mathrm{Kr}:-152,30^{\circ} \mathrm{C},-246,048^{\circ} \mathrm{C} \mathrm{y}-185,7^{\circ} \mathrm{C}$. Indicad a que gas noble corresponde cada punto de ebullición justificando su respuesta.

A-40.- predecir para cada uno de los compuestos siguientes si el tipo de atracción molecular se debe a fuerzas polares, a enlaces por puente de hidrógeno o a interacciones de Van der Walls.
a) $\mathrm{CCl}_{4}$
d) $\mathrm{CO}_{2}$
b) $\mathrm{HCN}$
e) $\mathrm{CH}-\mathrm{OH}$
c) $\mathrm{C}_{2} \mathrm{H}_{4}$
f) $\mathrm{NH}_{3}$ 
A-41.- Clasificar las siguientes sustancias según orden creciente de sus puntos de fusión:

$\mathrm{HCl}, \mathrm{Cl}_{2}, \mathrm{CCl}_{4}$ y justificar dicha ordenación.

A-42.- Dad una explicación a los siguientes hechos:
a) el cloruro de sodio tiene un punto de fusión de $800^{\circ} \mathrm{C}$, en cambio el cloro es un gas a temperatura ambiente.
b) El diamante no conduce la corriente eléctrica, mientras que el níquel si lo hace.
c) El flúor es una molécula covalente, mientras que el CsF es iónico.

A-43.-Indicad que fuerzas atractivas han de ser vencidas para que se verifiquen los siguientes procesos:
a) disolución de $\mathrm{NaNO}_{3}$ en agua.
b) fusión de un cristal de hielo.
c) ebullición de hidrógeno líquido.

A-44.- Clasificad como: covalente puro, covalente polar, o iónico, el enlace químico que se formará entre los siguientes pares de elementos, justificándolo:
a) Li y $\mathrm{O}$; b)
b) Bry I;
c) $\mathrm{Mg}$ e $\mathrm{H}$;
d) $\mathrm{O}$ y $\mathrm{O}$;
e) $\mathrm{Rb}$ y $\mathrm{F}$.

A-45.- clasificad como metálico, covalente, iónico o molecular.

a) un sólido que funde por debajo de $100^{\circ} \mathrm{C}$ dando un líquido no conductor de la electricidad.

b) un sólido que conduce la corriente eléctrica.

c) un sólido que no es conductor, pero si lo es cuando se funde.

d) un sólido aislante que no se disuelve en agua y que funde a $2000^{\circ} \mathrm{C}$.

e) un sólido aislante que se disuelve en agua dando una disolución conductora de la electricidad.

A-46.- Indicar el tipo de enlace interatómico e intermolecular de las siguientes sustancias:
a) $\mathrm{NaCl}(\mathrm{s})$
e) $\mathrm{H}_{2}(\mathrm{~g})$
b) $\mathrm{NaCl}(\mathrm{aq})$
f) $\mathrm{NH}_{3}(\mathrm{~g})$
c) $\mathrm{NaCl}(\mathrm{g})$
g) $\mathrm{NH}_{3}(\mathrm{aq})$
d) $\mathrm{H} 2(\mathrm{~s})$

A-47.- Considerad las siguientes sustancias: a) sodio, b) diamante, c) cloruro potásico y d) butano. De todas ellas elige de forma justificada:
a) Una sustancia cuyas moléculas estén ligadas por fuerzas de Van der Waals.
b) Una sustancia de gran conductividad eléctrica en su estado normal.
c) Una sustancia de punto de fusión muy elevado.
d) Una sustancia aislante que se hace conductora al fundir. 


\begin{tabular}{|c|c|c|}
\hline Sesión & Actividades & Tareas \\
\hline 1 & Actividad inicial - (Test previo) & Test I \\
\hline 2 & $\begin{array}{l}\text { Estados de agregación de la materia. } \\
\text { Cambios de estado TCM }\end{array}$ & A1-A3 \\
\hline 3 & Práctica TCM & A4 \\
\hline $4-5$ & $\begin{array}{l}\text { Actividad - (Clasificación de las sustancias) } \\
\text { Elaboración del póster }\end{array}$ & A5-A6 \\
\hline 6 & $\begin{array}{l}\text { Enlace covalente } \\
\text { - Teoría de Lewis del enlace covalente } \\
\text { - Diagramas de Lewis. } \\
\text { - Regla del octeto y limitaciones } \\
\text { - Enlaces múltiples. } \\
\text { - Iones poliatómicos. }\end{array}$ & A8-A13 \\
\hline 7 & $\begin{array}{l}\text { - Octetos incompletos o ampliados. } \\
\text { - Enlace covalente dativo. } \\
\text { - Estructuras de resonancia. }\end{array}$ & A14-A17 \\
\hline 8 & $\begin{array}{l}\text { - Modelo VSERP } \\
\text { - Geometría. }\end{array}$ & $\mathrm{A} 17-\mathrm{A} 22$ \\
\hline 9 & $\begin{array}{l}\text { - Polaridad. } \\
\text { - Propiedades de las sustancias moleculares }\end{array}$ & A23-27 \\
\hline 10 & Actividad - (uniones atómicas) & $\begin{array}{l}\text { Modelos globos, bolas, } \\
\text { plastilina-pajitas }\end{array}$ \\
\hline 11 & $\begin{array}{l}\text { Sólidos covalentes } \\
\text { - Redes covalentes } \\
\text { - Propiedades de las sustancias covalentes } \\
\text { Enlaces metálicos } \\
\text { - Teoría del enlace de valencia o teoría de } \\
\quad \text { deslocalización. } \\
\text { - Redes metálicas } \\
\text { Propiedades de los metales }\end{array}$ & A28-A29 \\
\hline 12 & $\begin{array}{l}\text { Enlace iónico } \\
\text { - Teoría de Lewis sobre el enlace iónico } \\
\text { - Formación de los cristales iónicos. } \\
\text { - Redes cristalinas. } \\
\text { - Energía reticular. } \\
\text { - Propiedades de los compuestos iónicos. }\end{array}$ & A30-A34 \\
\hline 13 & $\begin{array}{l}\text { Fuerzas intermoleculares. } \\
\text { - Enlaces de hidrógeno. } \\
\text { - Fuerzas de Van der Waals } \\
\text { Interacciones dip. Perm.-dip. Perm. } \\
\text { Enlaces dip. Perm.-dip. ind. } \\
\text { Enlaces dipolo instan.- dipolo ind. } \\
\text { Sustancias moleculares polares y apolares. }\end{array}$ & A35-A39 \\
\hline 14 & Actividad - (uniones multiatómicas) & $\begin{array}{l}\text { Construcción de estructuras } \\
\text { covalentes, metálicas e iónicas. } \\
\text { A40-A47. }\end{array}$ \\
\hline 15 & Actividad final - (Test final) & Test III \\
\hline
\end{tabular}

Tabla 8.1.- Distribución de actividades y tareas. 


\section{Formulación}

El tema de la formulación se hace necesario en los primeros temas de Química, ya que como se detecta en la fase exploratoria (punto 5.2.2) y en la diagnóstica (punto 7.3.4.3) en las que los alumnos presentan grandes dificultades por lo que se trabajará la formulación de forma integra.

Para ello se utiliza un colección de ejercicios en los que se clasifican los compuestos por orden de complejidad (óxidos, hidruros, hidróxidos, oxácidos, sales...) en todos ellos se trabaja la formulación y la nomenclatura,

La dinámica seguida en clase se basará en un modelo tradicional de transmisión de contenidos por parte del profesor (reglas de nomenclatura y formulación) y un trabajo posterior basado en la realización de los ejercicios propuestos. Es en este punto donde los alumnos realizaran las tareas distribuidos en los grupos de trabajo formados y reordenados según las conclusiones de la investigación anterior.

Con esta metodología se persigue que los miembros de cada grupo compartan sus conocimientos y que la habilidad que se adquiere con la realización de estas tareas, quede potenciada en tanto y cuanto es el fruto de la interacción entre individuos con un mismo objetivo, es decir acercarse en lo posible al nivel descrito por Vygotsky.

\section{Estequiometría}

Este tema se trabajará de forma análoga al de formulación pero utilizando como base tanto para la introducción de compuestos como para la propuesta de actividades, el libro de texto de la editorial Anaya.

Los ejercicios se realizarán en los grupos propuestos y durante las sesiones de clase. 


\subsection{Diseño experimental}

Se ha preparado una intervención según la directriz establecida en el anterior apartado, en la que los tres pasos indicados permitirán obtener conclusiones al respecto.

\subsubsection{Procedimiento}

La intervención se lleva a cabo en la segunda mitad del curso y se tratan cinco temas con la intención de ensayar estos tres aspectos:

a) Efecto del trabajo cooperativo sobre grupos aleatorios, donde se desarrollaran las clases de forma ordinaria y se realizarán los cuestionarios de forma individual y conjunta, pero que se han formado aleatoriamente.

b) Aplicación del mecanismo de regulación basado en la ZDP. En este apartado de desarrolla todo el tema mediante trabajos organizados en los mismos grupos que en los temas anteriores y siguiendo el guión expuesto en el punto 6.4.2, donde se distribuyen los contenidos y actividades.

A partir de los resultados obtenidos en los cuestionarios referentes a estos tres temas se reordenan los alumnos formando nuevos grupos de trabajo en base a la influencia que ejerce cada miembro sobre el grupo. Concretamente se van a ordenar de forma que estén juntos aquellos alumnos que tienen grados de influencia similares.

c) Efecto del trabajo cooperativo sobre grupos organizados según la ZDP. En el desarrollo de los dos últimos temas los alumnos se han reordenado de la forma especificada y se mantiene el desarrollo de las actividades en grupo.

El último paso es analizar el resultado de este proceso para ver cuales han sido las consecuencias de esta nueva distribución. 


\subsubsection{Población}

En esta fase de la investigación, el grupo sobre el que se ha trabajado está formado por 22 estudiantes de primero de Bachillerato, del IES "La Marxadella" de Torrent, Valencia.

\subsubsection{Variables}

Las variables a la que nos podemos enfrentar en este apartado de la investigación son las mismas que las descritas en la investigación diagnóstica y razonadas en el punto 7.1.2, no obstante aquí aparecen unas variables nuevas que hacen referencia al comportamiento de los alumnos frente a un trabajo colectivo.

Por ello, consideraremos dos tipos de datos, los anteriormente descritos como referencia a la actuación cuantitativa frente a la puntuación de las pruebas, y los referidos a la interacción grupal y que vamos a fijar en el punto 8.3.5 en términos de parámetros estadísticos.

\subsubsection{Instrumentos de medida}

Los instrumentos de medida han sido:

Cuestionarios: un total de cinco, realizados por duplicado, y que contienen entre 20 y 25 ítems, la mayoría de ellos de elección múltiple y otros en forma de cuestión abierta o problemas.

Secuencias de video: grabadas durante el desarrollo de las clases y la realización de ejercicios y experiencias, así como en la realización de los cuestionarios.

Fotos: tomadas en estas mismas condiciones

Cuadernos: donde los alumnos han ido tomando notas de las explicaciones y realizando los ejercicios propuestos, tanto individuales como colectivos. 


\subsubsection{Análisis de datos}

Para el análisis de de los datos se han establecido varios parámetros cuantificadores del trabajo cooperativo en grupo (Llorens, 2008).

Los parámetros estadísticos utilizados son:

\section{Influencia del trabajo cooperativo}

Establecida para cada grupo, es la diferencia entre la calificación obtenida por el grupo y la media de las calificaciones individuales

$$
\Delta x=x_{g}-\bar{x}_{i}
$$

Este parámetro nos indica la mejoría experimentada en una actividad al ser realizada de forma individual o en grupo.

\section{Influencia relativa del trabajo cooperativo}

Es el cociente entre la mejora relativa y la media de las calificaciones individuales

$$
\frac{\Delta x}{\bar{x}_{i}} \cdot 100=\frac{x_{g}-\bar{x}_{i}}{\bar{x}_{i}} \cdot 100
$$

\section{Grado de coincidencia}

Es el cociente entre número total de coincidencias (tanto correctas como incorrectas) de todos los alumnos con el grupo, y máximo posible de estas (producto de número de alumnos por número de ítems)

$$
L A=\frac{n}{S \cdot N} \quad S=n^{\mathrm{o}} \text { de alumnos, } \quad N=n^{\mathrm{o}} \text { de ítems }
$$

Puede expresarse el grado de coincidencia referido a las respuestas correctas o a las incorrectas:

$$
L A_{R}=\frac{n_{R}}{S \cdot N_{R}}
$$


Este parámetro es el cociente entre el número de coincidencias correctas totales de los alumnos y el producto del número de alumnos por el número de respuestas correctas del grupo.

$$
L A_{W}=\frac{n_{W}}{S \cdot N_{W}}
$$

Este es análogo al anterior pero referido a las coincidencias incorrectas.

\section{Grado de coincidencia entre cada estudiante y su grupo}

Está referido a cada individuo y es el cociente entre las coincidencias de cada alumno (correctas e incorrectas) y el número total de ítems.

$$
L A_{i}=\frac{n_{i}}{N}
$$

Y que también puede expresarse referido a las respuestas correctas e incorrectas:

$$
L A_{R i}=\frac{n_{R i}}{N_{R}}
$$

Es decir el cociente entre las coincidencias correctas del alumno con el grupo y las respuestas correctas del grupo.

$$
L A_{W i}=\frac{n_{W i}}{N_{W}}
$$

análogo al anterior para el caso de respuestas incorrectas.

\section{Coeficiente de variación}

Define la homogeneidad del grupo y es el cociente de la varianza de las puntuaciones de los componentes del grupo y la media de todas ellas.

Coeficente de variación $=\frac{\sigma}{\bar{x}_{i}}$ 
Para llevar a cabo el cálculo de estos parámetros se ha empleado una hoja de cálculo, realizada con el programa informático Excel, sobre la que se refleja:

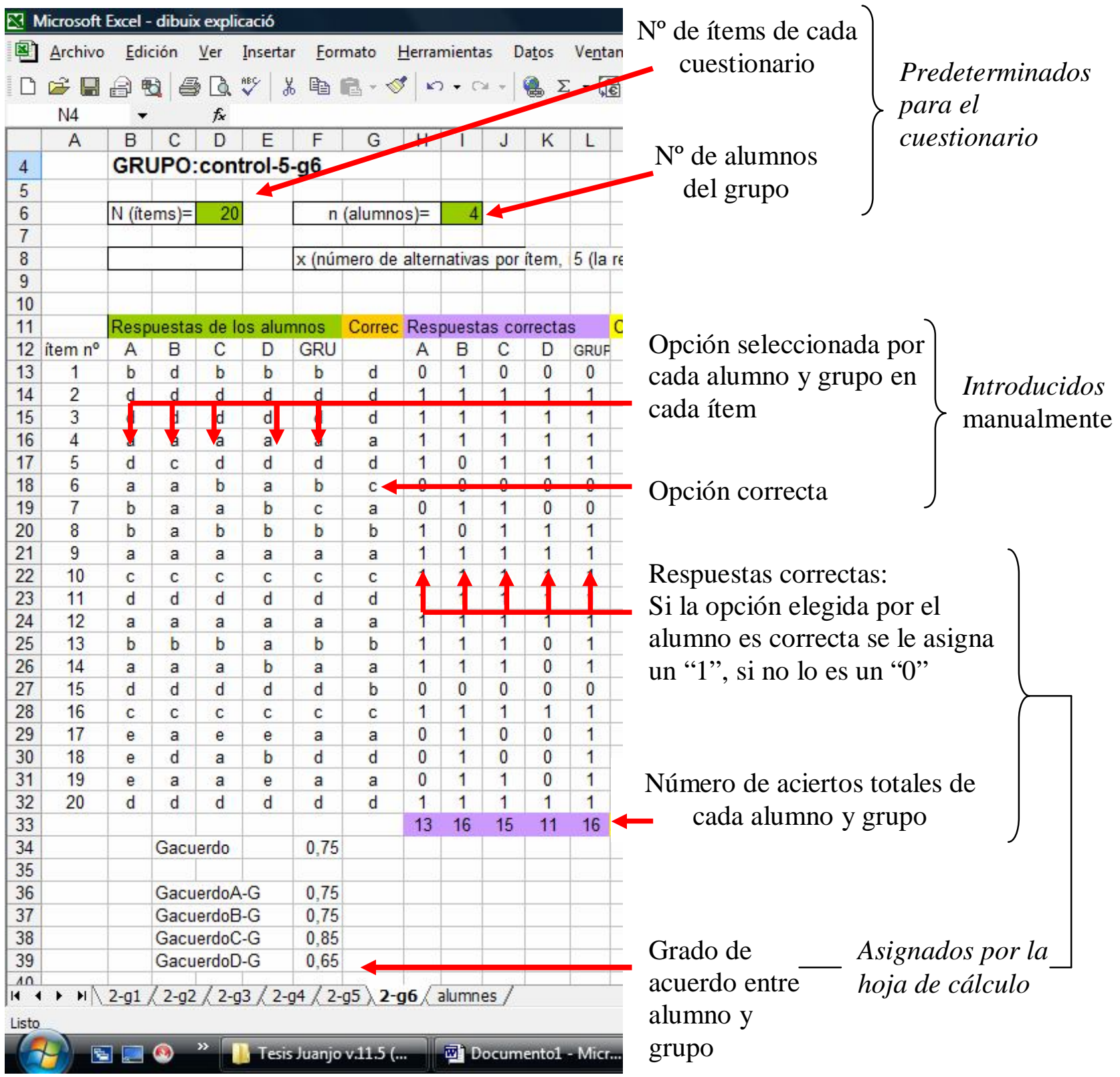




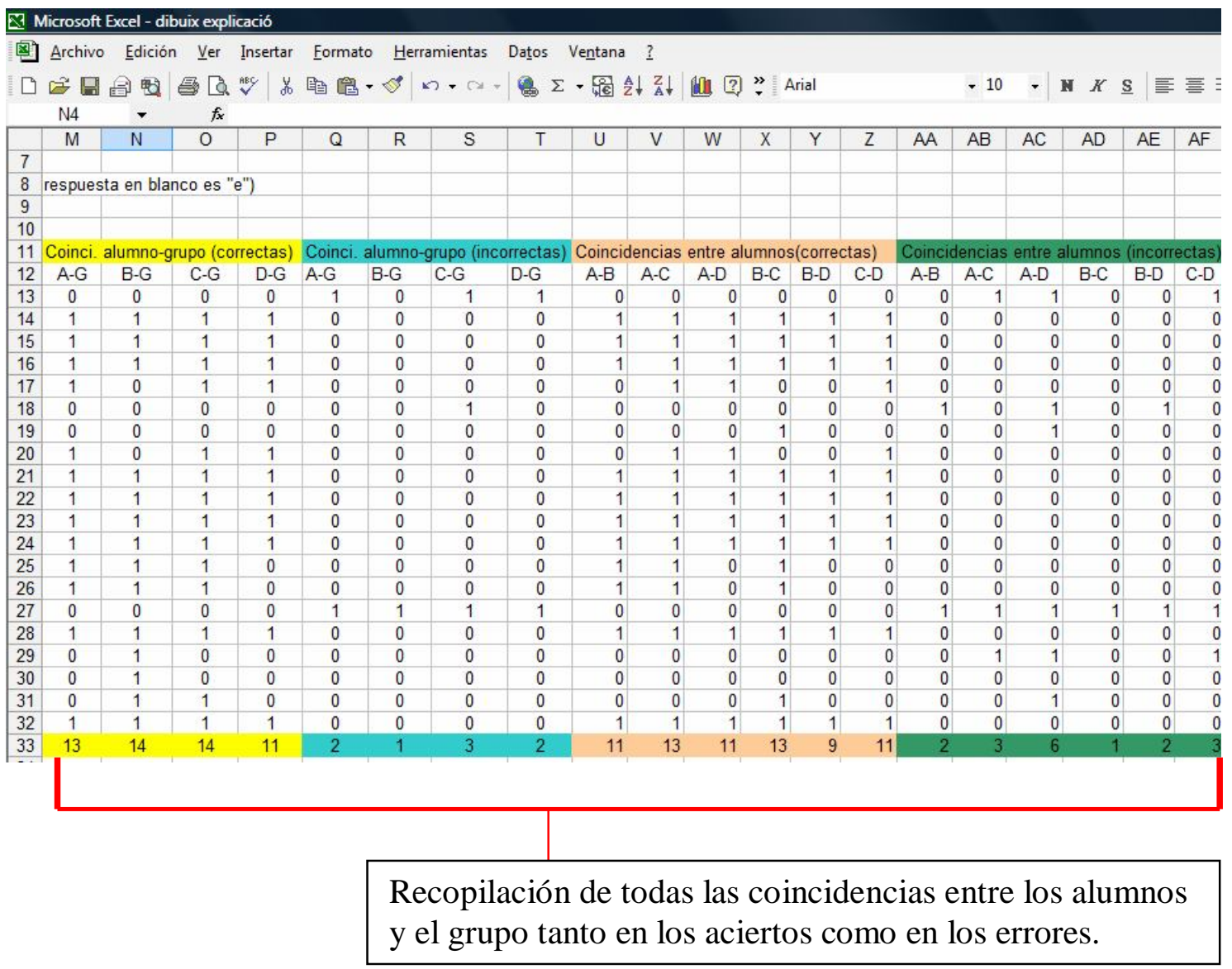

Grado de coincidencia con el grupo (número de coincidencias de cada alumno con el grupo, tanto correctas como incorrectas, dividido por el número de ítems)

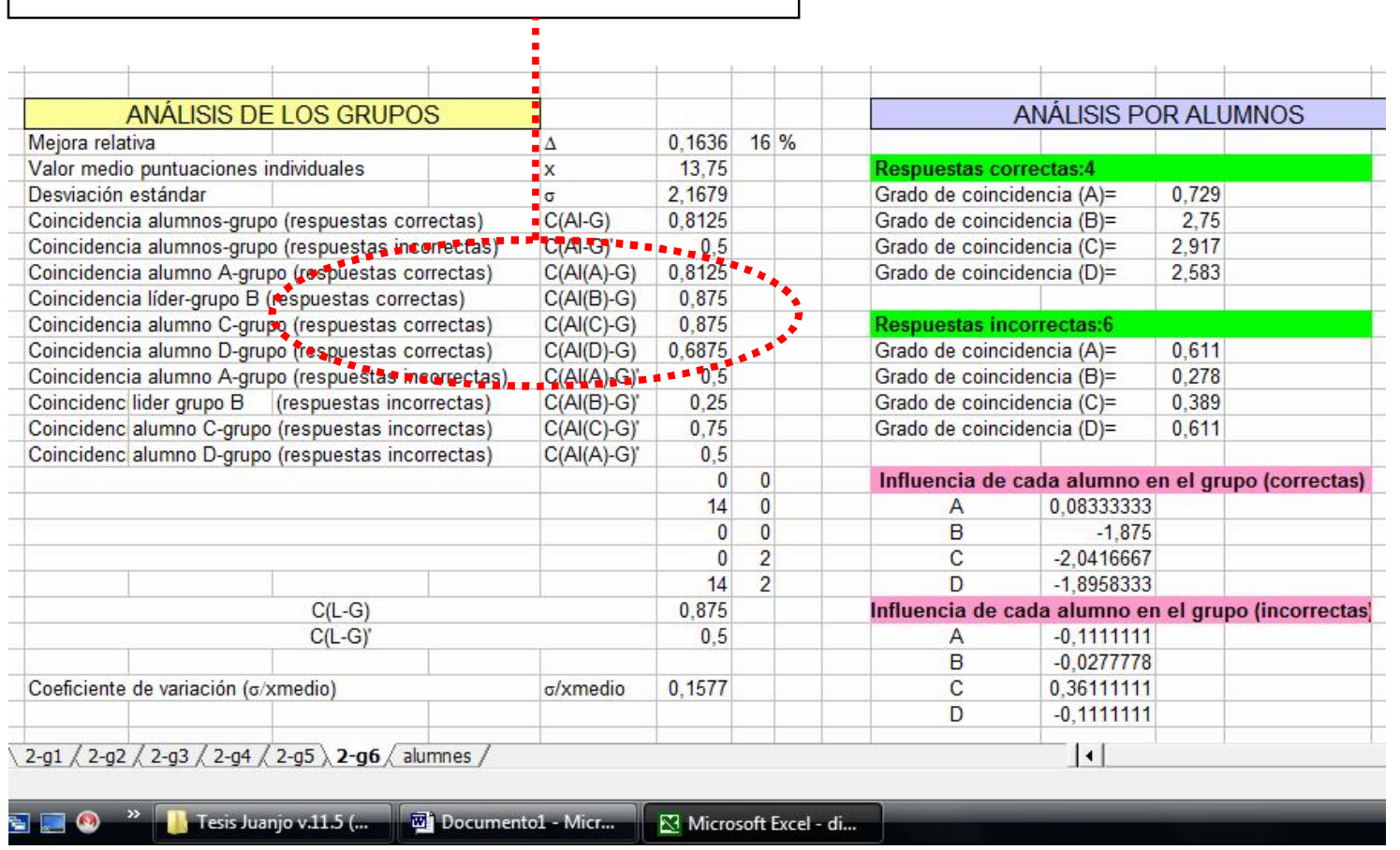




\subsection{Diseño y validación de cuestionarios}

Los test se han formado, en su mayoría, a partir de un banco de ítems de la ACS

Para validar los cinco test propuestos se siguen los mismos pasos que se dieron en la validación de los cuestionarios de la intervención diagnóstica ${ }^{36}$ (figura 7.2)

a) Validez de contenido

Todas las cuestiones incluidas en estas pruebas están enmarcadas dentro del currículo de la asignatura "Física y Química" de primer curso de bachillerato por lo que esta condición queda cumplida.

b) Validez convergente

Para conocer si las preguntas están bien planteadas, en cada cuestionario hemos de comprobar si existe una correlación clara entre ítems relacionados.

\section{Test 1}

\begin{tabular}{|c|c|c|}
\hline $\begin{array}{l}\text { Pareja } \\
\text { de ítems }\end{array}$ & Estadístico empleado & valor \\
\hline $2-3^{*}$ & $\begin{array}{l}\text { Coeficiente de contingencia (basado en } \mathrm{x}^{2} \text { ) } \\
\text { Gamma de Goodman } \\
\mathrm{R} \text { de Pearson }\end{array}$ & $\begin{array}{l}0,369 \\
1,000 \\
0,397\end{array}$ \\
\hline $2-15^{*}$ & $\begin{array}{l}\text { Coeficiente de contingencia (basado en } \mathrm{x}^{2} \text { ) } \\
\text { Gamma de Goodman } \\
\mathrm{R} \text { de Pearson }\end{array}$ & $\begin{array}{l}0,385 \\
0,829 \\
0,417\end{array}$ \\
\hline $10-15^{\star}$ & $\begin{array}{l}\text { Coeficiente de contingencia (basado en } \mathrm{x}^{2} \text { ) } \\
\text { Gamma de Goodman } \\
\mathrm{R} \text { de Pearson }\end{array}$ & $\begin{array}{l}0,312 \\
0,660 \\
0,328\end{array}$ \\
\hline $18-19^{*}$ & $\begin{array}{l}\text { Coeficiente de contingencia (basado en } \mathrm{x}^{2} \text { ) } \\
\text { Gamma de Goodman } \\
\mathrm{R} \text { de Pearson }\end{array}$ & $\begin{array}{l}0,362 \\
0,778 \\
0,389\end{array}$ \\
\hline $5-15^{*}$ & $\begin{array}{l}\text { Coeficiente de contingencia (basado en } \mathrm{x}^{2} \text { ) } \\
\text { Gamma de Goodman } \\
\mathrm{R} \text { de Pearson }\end{array}$ & $\begin{array}{l}0,591 \\
1,000 \\
0,733\end{array}$ \\
\hline $7-9$ & $\begin{array}{l}\text { Coeficiente de contingencia (basado en } \mathrm{x}^{2} \text { ) } \\
\text { Gamma de Goodman } \\
\mathrm{R} \text { de Pearson }\end{array}$ & $\begin{array}{l}0,097 \\
0,208 \\
0,098\end{array}$ \\
\hline $11-20$ & $\begin{array}{l}\text { Coeficiente de contingencia (basado en } \mathrm{x}^{2} \text { ) } \\
\text { Gamma de Goodman } \\
\mathrm{R} \text { de Pearson }\end{array}$ & $\begin{array}{l}0,243 \\
0,625 \\
0,250\end{array}$ \\
\hline $4-13$ & $\begin{array}{l}\text { Coeficiente de contingencia (basado en } \mathrm{x}^{2} \text { ) } \\
\text { Gamma de Goodman } \\
\mathrm{R} \text { de Pearson }\end{array}$ & $\begin{array}{l}0,277 \\
1,000 \\
0,289\end{array}$ \\
\hline
\end{tabular}

Tabla 8.2.- Correlación entre diferentes ítems en el test $\mathrm{n}^{\mathrm{o}} 1$

\footnotetext{
${ }^{36}$ Capítulo 7.2
} 
Test 2

\begin{tabular}{|c|c|c|}
\hline $\begin{array}{l}\text { Pareja } \\
\text { de ítems }\end{array}$ & Estadístico empleado & valor \\
\hline $4-21^{*}$ & $\begin{array}{l}\text { Coeficiente de contingencia (basado en } \mathrm{x}^{2} \text { ) } \\
\text { Gamma de Goodman } \\
\mathrm{R} \text { de Pearson }\end{array}$ & $\begin{array}{l}0,347 \\
0,745 \\
0,370\end{array}$ \\
\hline $7-8^{*}$ & $\begin{array}{l}\text { Coeficiente de contingencia (basado en } x^{2} \text { ) } \\
\text { Gamma de Goodman } \\
\text { R de Pearson }\end{array}$ & $\begin{array}{l}0,334 \\
0,731 \\
0,354\end{array}$ \\
\hline $6-21^{*}$ & $\begin{array}{l}\text { Coeficiente de contingencia (basado en } x^{2} \text { ) } \\
\text { Gamma de Goodman } \\
\text { R de Pearson }\end{array}$ & $\begin{array}{l}0,450 \\
0,855 \\
0,504\end{array}$ \\
\hline $10-24^{*}$ & $\begin{array}{l}\text { Coeficiente de contingencia (basado en } \mathrm{x}^{2} \text { ) } \\
\text { Gamma de Goodman } \\
\mathrm{R} \text { de Pearson }\end{array}$ & $\begin{array}{l}0,354 \\
0,688 \\
0,378\end{array}$ \\
\hline $15-16^{*}$ & $\begin{array}{l}\text { Coeficiente de contingencia (basado en } \mathrm{x}^{2} \text { ) } \\
\text { Gamma de Goodman } \\
\mathrm{R} \text { de Pearson }\end{array}$ & $\begin{array}{l}0,446 \\
0,818 \\
0,498\end{array}$ \\
\hline $1-19$ & $\begin{array}{l}\text { Coeficiente de contingencia (basado en } x^{2} \text { ) } \\
\text { Gamma de Goodman } \\
\text { R de Pearson }\end{array}$ & $\begin{array}{l}0,061 \\
0,185 \\
0,061\end{array}$ \\
\hline $3-4$ & $\begin{array}{l}\text { Coeficiente de contingencia (basado en } \mathrm{x}^{2} \text { ) } \\
\text { Gamma de Goodman } \\
\mathrm{R} \text { de Pearson }\end{array}$ & $\begin{array}{l}0,299 \\
0,680 \\
0,314\end{array}$ \\
\hline $6-14$ & $\begin{array}{l}\text { Coeficiente de contingencia (basado en } \mathrm{x}^{2} \text { ) } \\
\text { Gamma de Goodman } \\
\mathrm{R} \text { de Pearson }\end{array}$ & $\begin{array}{l}0,017 \\
0,034 \\
0,017\end{array}$ \\
\hline
\end{tabular}

Tabla 8.3.- Correlación entre diferentes ítems en el test $\mathrm{n}^{\mathrm{o}} 2$

Test 3

\begin{tabular}{|c|c|c|}
\hline $\begin{array}{c}\text { Pareja } \\
\text { de ítems }\end{array}$ & Estadístico empleado & valor \\
\hline $5-16^{*}$ & $\begin{array}{l}\text { Coeficiente de contingencia (basado en } x^{2} \text { ) } \\
\text { Gamma de Goodman } \\
\mathrm{R} \text { de Pearson }\end{array}$ & $\begin{array}{l}0,327 \\
1,000 \\
0,346\end{array}$ \\
\hline $7-12^{*}$ & $\begin{array}{l}\text { Coeficiente de contingencia (basado en } x^{2} \text { ) } \\
\text { Gamma de Goodman } \\
\mathrm{R} \text { de Pearson }\end{array}$ & $\begin{array}{l}0,523 \\
0,946 \\
0,614\end{array}$ \\
\hline $12-14^{*}$ & $\begin{array}{l}\text { Coeficiente de contingencia (basado en } x^{2} \text { ) } \\
\text { Gamma de Goodman } \\
\mathrm{R} \text { de Pearson }\end{array}$ & $\begin{array}{l}0,399 \\
1,000 \\
0,435\end{array}$ \\
\hline $20-24^{*}$ & $\begin{array}{l}\text { Coeficiente de contingencia (basado en } x^{2} \text { ) } \\
\text { Gamma de Goodman } \\
\text { R de Pearson }\end{array}$ & $\begin{array}{l}0,341 \\
1,000 \\
0,363\end{array}$ \\
\hline $24-25^{\star}$ & $\begin{array}{l}\text { Coeficiente de contingencia (basado en } x^{2} \text { ) } \\
\text { Gamma de Goodman } \\
\text { R de Pearson }\end{array}$ & $\begin{array}{l}0,332 \\
0,765 \\
0,351\end{array}$ \\
\hline $15-20$ & $\begin{array}{l}\text { Coeficiente de contingencia (basado en } x^{2} \text { ) } \\
\text { Gamma de Goodman } \\
\text { R de Pearson }\end{array}$ & $\begin{array}{l}0,167 \\
0,467 \\
0,169\end{array}$ \\
\hline
\end{tabular}

Tabla 8.4.- Correlación entre diferentes ítems en el test $n^{\circ} 3$ 
Test 4

\begin{tabular}{|c|c|c|}
\hline $\begin{array}{l}\text { Pareja } \\
\text { de ítems }\end{array}$ & Estadístico empleado & valor \\
\hline $1-12^{*}$ & $\begin{array}{l}\text { Coeficiente de contingencia (basado en } x^{2} \text { ) } \\
\text { Gamma de Goodman } \\
\mathrm{R} \text { de Pearson }\end{array}$ & $\begin{array}{l}0,332 \\
0,765 \\
0,251\end{array}$ \\
\hline $10-11^{*}$ & $\begin{array}{l}\text { Coeficiente de contingencia (basado en } x^{2} \text { ) } \\
\text { Gamma de Goodman } \\
\mathrm{R} \text { de Pearson }\end{array}$ & $\begin{array}{l}0,623 \\
1,000 \\
0,796\end{array}$ \\
\hline $6,13^{*}$ & $\begin{array}{l}\text { Coeficiente de contingencia (basado en } x^{2} \text { ) } \\
\text { Gamma de Goodman } \\
\mathrm{R} \text { de Pearson }\end{array}$ & $\begin{array}{l}0,447 \\
0,889 \\
0,500\end{array}$ \\
\hline $17-22^{*}$ & $\begin{array}{l}\text { Coeficiente de contingencia (basado en } x^{2} \text { ) } \\
\text { Gamma de Goodman } \\
\mathrm{R} \text { de Pearson }\end{array}$ & $\begin{array}{l}0,476 \\
0,867 \\
0,542\end{array}$ \\
\hline $4-9$ & $\begin{array}{l}\text { Coeficiente de contingencia (basado en } x^{2} \text { ) } \\
\text { Gamma de Goodman } \\
\mathrm{R} \text { de Pearson }\end{array}$ & $\begin{array}{l}0,100 \\
0,304 \\
0,101\end{array}$ \\
\hline $4-16$ & $\begin{array}{l}\text { Coeficiente de contingencia (basado en } x^{2} \text { ) } \\
\text { Gamma de Goodman } \\
\mathrm{R} \text { de Pearson }\end{array}$ & $\begin{array}{l}0,153 \\
0,368 \\
0,155\end{array}$ \\
\hline $7-12$ & $\begin{array}{l}\text { Coeficiente de contingencia (basado en } x^{2} \text { ) } \\
\text { Gamma de Goodman } \\
\mathrm{R} \text { de Pearson }\end{array}$ & $\begin{array}{l}0,234 \\
0,556 \\
0,241\end{array}$ \\
\hline
\end{tabular}

Tabla 8.5.- Correlación entre diferentes ítems en el test $n^{\circ} 4$

Test 5

\begin{tabular}{|c|c|c|}
\hline $\begin{array}{c}\text { Pareja } \\
\text { de ítems }\end{array}$ & Estadístico empleado & valor \\
\hline $5-8$ & $\begin{array}{l}\text { Coeficiente de contingencia (basado en } x^{2} \text { ) } \\
\text { Gamma de Goodman } \\
\text { R de Pearson }\end{array}$ & $\begin{array}{l}0,348 \\
0,684 \\
0,371\end{array}$ \\
\hline $10-11$ & $\begin{array}{l}\text { Coeficiente de contingencia (basado en } x^{2} \text { ) } \\
\text { Gamma de Goodman } \\
\text { R de Pearson }\end{array}$ & $\begin{array}{l}0,523 \\
0,946 \\
0,614\end{array}$ \\
\hline $17-19$ & $\begin{array}{l}\text { Coeficiente de contingencia (basado en } x^{2} \text { ) } \\
\text { Gamma de Goodman } \\
\text { R de Pearson }\end{array}$ & $\begin{array}{l}0,475 \\
0,842 \\
0,540\end{array}$ \\
\hline $4-19$ & $\begin{array}{l}\text { Coeficiente de contingencia (basado en } x^{2} \text { ) } \\
\text { Gamma de Goodman } \\
\text { R de Pearson }\end{array}$ & $\begin{array}{l}0,061 \\
0,185 \\
0,061\end{array}$ \\
\hline $5-18$ & $\begin{array}{l}\text { Coeficiente de contingencia (basado en } x^{2} \text { ) } \\
\text { Gamma de Goodman } \\
\text { R de Pearson }\end{array}$ & $\begin{array}{l}0,048 \\
0,111 \\
0,048\end{array}$ \\
\hline $4-12$ & $\begin{array}{l}\text { Coeficiente de contingencia (basado en } x^{2} \text { ) } \\
\text { Gamma de Goodman } \\
\text { R de Pearson }\end{array}$ & $\begin{array}{l}0,054 \\
0,167 \\
0,054\end{array}$ \\
\hline
\end{tabular}

Tabla 8.6.- Correlación entre diferentes ítems en el test $\mathrm{n}^{\circ} 5$ 
c) Validez concurrente

Ha de haber una relación entre las notas de los cuestionarios y las notas obtenidas en otras pruebas. Aquí buscamos la correlación entre las notas de cada alumno en cada cuestionario y las obtenidas en las materias de ciencias, letras o comunes y el curso global.

\begin{tabular}{|c|c|c|c|c|c|c|c|}
\hline \multirow{2}{*}{ Test } & $\begin{array}{c}\text { Media del } \\
\text { cuestionario }\end{array}$ & \multicolumn{2}{|c|}{$\begin{array}{c}\text { Corr. con materias } \\
\text { de ciencias }\end{array}$} & \multicolumn{2}{c|}{$\begin{array}{c}\text { Corr. con otras } \\
\text { materias }\end{array}$} & \multicolumn{2}{c|}{$\begin{array}{c}\text { Correlación con el } \\
\text { curso }\end{array}$} \\
\hline & Pearson & Spearman & Pearson & Spearman & Pearson & Spearman \\
\hline 1 & 6,73 & 0,410 & 0,506 & 0,462 & 0,549 & 0,452 & 0,515 \\
\hline 2 & 5,69 & 0,582 & 0,529 & 0,504 & 0,454 & 0,552 & 0,476 \\
\hline 3 & 6,6 & 0,500 & 0,449 & 0,417 & 0,399 & 0,465 & 0,455 \\
\hline 4 & 7,4 & 0,675 & 0,706 & 0,707 & 0,745 & 0,712 & 0,753 \\
\hline 5 & 6,98 & 0,668 & 0,674 & 0,674 & 0,685 & 0,690 & 0,710 \\
\hline
\end{tabular}

Tabla 8.7.- Correlación entre las calificaciones en los cuestionarios y otras pruebas.

d) Estabilidad

Esta condición queda resuelta por la propia naturaleza de la prueba, ya que un cuestionario de tipo test no es susceptible de una posible subjetividad por parte del corrector, por lo que no se ha procedido a este análisis y se da por cumplida esta premisa. No obstante la correlación entre las notas de los test y la nota media del curso en la materia de Física y Química es la siguiente.

\begin{tabular}{|c|c|c|c|c|c|c|}
\hline \multicolumn{2}{|c|}{ Test $\mathbf{n}^{\mathbf{0}}$} & 1 & 2 & 3 & 4 & 5 \\
\hline \multicolumn{2}{|c|}{$\begin{array}{l}\text { Coeficiente de } \\
\text { contingencia }\end{array}$} & 0,839 & 0,855 & 0,865 & 0,855 & 0,837 \\
\hline \multirow{2}{*}{ Correlación } & Pearson & 0,467 & 0,688 & 0,489 & 0,646 & 0,654 \\
\hline & Sperman & 0,509 & 0,613 & 0,441 & 0,700 & 0,675 \\
\hline
\end{tabular}

Tabla 8.8.- Correlación entre las calificaciones y la nota media del curso de cada alumno. 


\subsection{Desarrollo de la intervención.}

El temario de Física y Química de primero de Bachillerato, consta a partes iguales de ambas disciplinas, que se distribuyen en las dos mitades del curso.

La primera mitad del curso se estudia física y la segunda mitad del curso se dedica íntegramente a la química.

Como ya se ha razonado anteriormente (Apartado 6.3), vamos a abordar con mayor extensión el tema del enlace a costa, en este caso de no introducir la química orgánica. Los temas que se han trabajado son:

Las leyes de la química

Estructura atómica y sistema periódico

Enlace químico

Formulación

Estequiometría 


\section{Primer tema: Las leyes de la química}

El primer tema se ha trabajado de forma individual y con la utilización del libro de texto propuesto por el centro, "Física y Química, Bachillerato 1". Editorial Anaya. En él se han realizado las explicaciones correspondientes, los ejercicios y las actividades propuestas.

Se han empleado un total de 12 sesiones en las que se han trabajado los siguientes contenidos:

a) Clasificación y transformaciones de la materia.

b) Leyes ponderales.

c) Teoría atómica de Dalton.

d) Hipótesis de Avogadro.

e) Cantidades y fórmulas en química.

f) Estados de agregación de la materia.

g) Leyes de los gases.

h) Disoluciones.

Y se ha realizado la prueba de evaluación por duplicado:

En primer lugar de forma individual, y a continuación y sin ningún tipo de interrupción se ha procedido a volverlo a rellenar de forma conjunta. 
Segundo tema: Estructura atómica y sistema periódico

El desarrollo del tema ha sido análogo al primer tema. Se han trabajado los contenidos:
a) Partículas subatómicas
b) Modelos atómicos
c) Modelo mecanocuántico del átomo
d) Sistema periódico
e) Propiedades atómicas periódicas 


\section{Tercer tema: Enlace químico}

En el tercer tema ya se ha procedido a realizar todas las actividades utilizando dinámicas de grupo, siguiendo el guión (apartado 8.2)

Los alumnos presentan buena predisposición ante la propuesta, lo que permite en un momento dado recurrir a horas extraescolares de forma voluntaria.

1.- En la primera sesión del tema tras recodar a los alumnos la teoría cinética de la materia, y su implicación en los estados de agregación, se propuso a los alumnos que realizaran las actividades A-1, A-2, A-3. Estas actividades versaban sobre estos conceptos, y las realizaron separados en grupos de tres o cuatro. Los alumnos se distribuyeron por orden alfabético como método objetivo de separación y la medida fue bien acogida por su parte.

En la segunda sesión, utilizando los mismos grupos de trabajo se realizó la experiencia propuesta en el guión y descrita en el anexo XIII. Se pretendía que los alumnos razonasen que a mayor temperatura, más rápida era la difusión de la sustancia a través del papel de celofán. Para ello cada uno de los seis grupos utilizó agua a diferente temperatura, obteniendo el resultado esperado. 


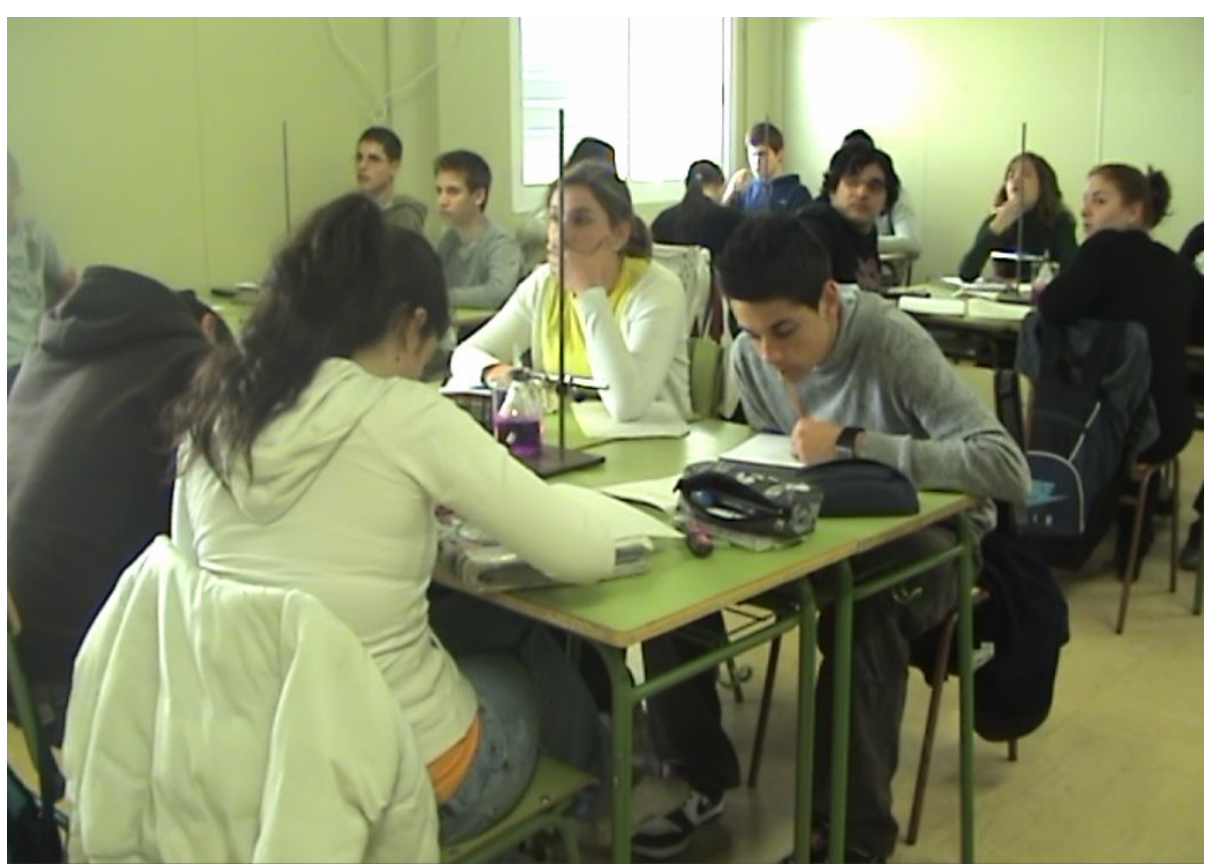

Imagen 8.1.- Alumnos realizando la actividad A-4.

2.- En la siguiente sesión se procede a tratar de relacionar las propiedades macroscópicas de la materia con su estructura interna. Se propone la actividad A-5, en la que a partir de una seria de sustancias, ellos deben ir rellenando la tabla que se les indica.

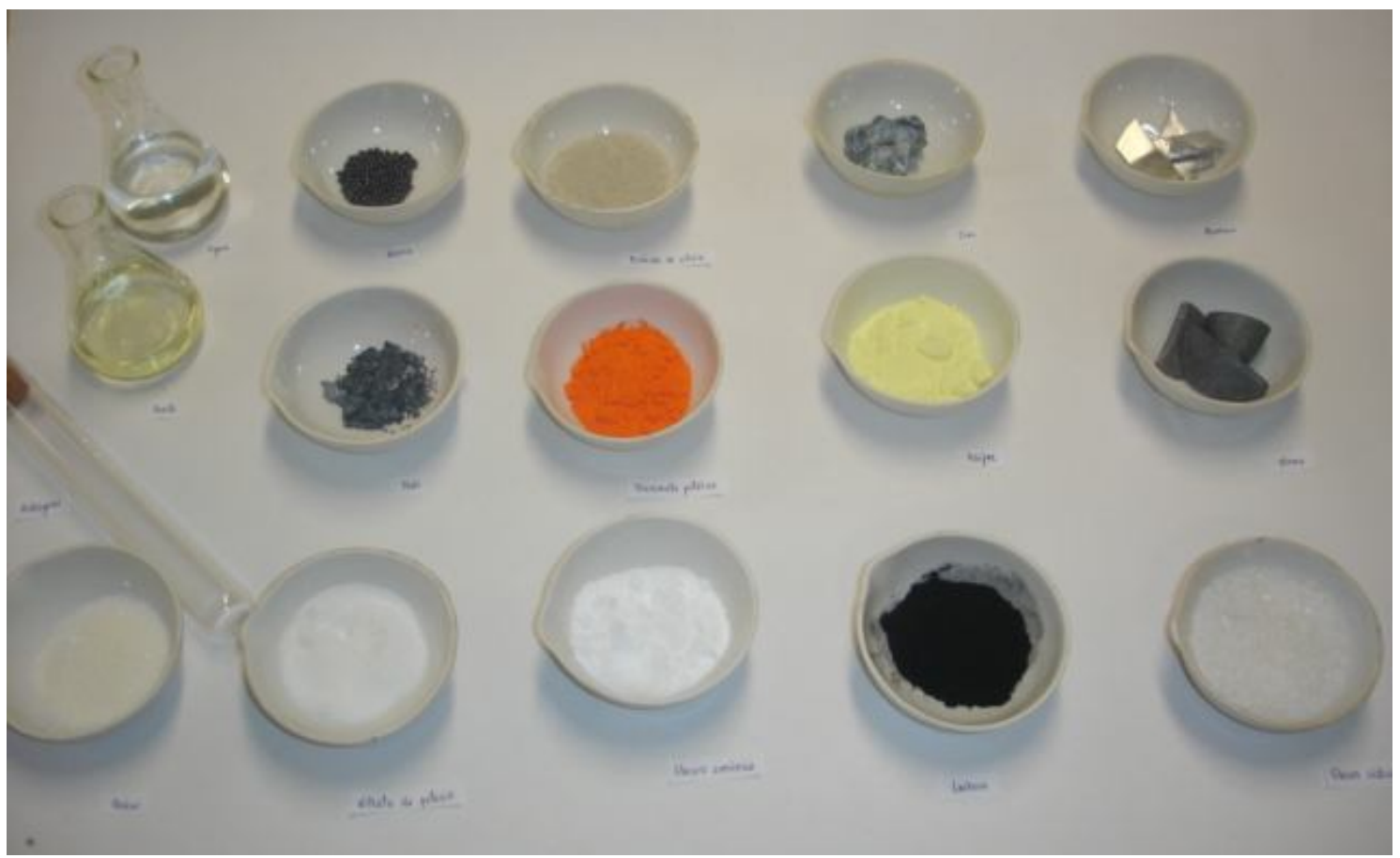

Imagen 8.2.- Sustancias utilizadas en la actividad A-5. 
3.- La siguiente actividad es el paso central del tema. A partir de las estructuras internas de las sustancias anteriores, se les distribuye a cada grupo la tarea de componer una parte de un mural, que esquematice los tipos de uniones y que quedará ubicado en el aula durante todo el tema.
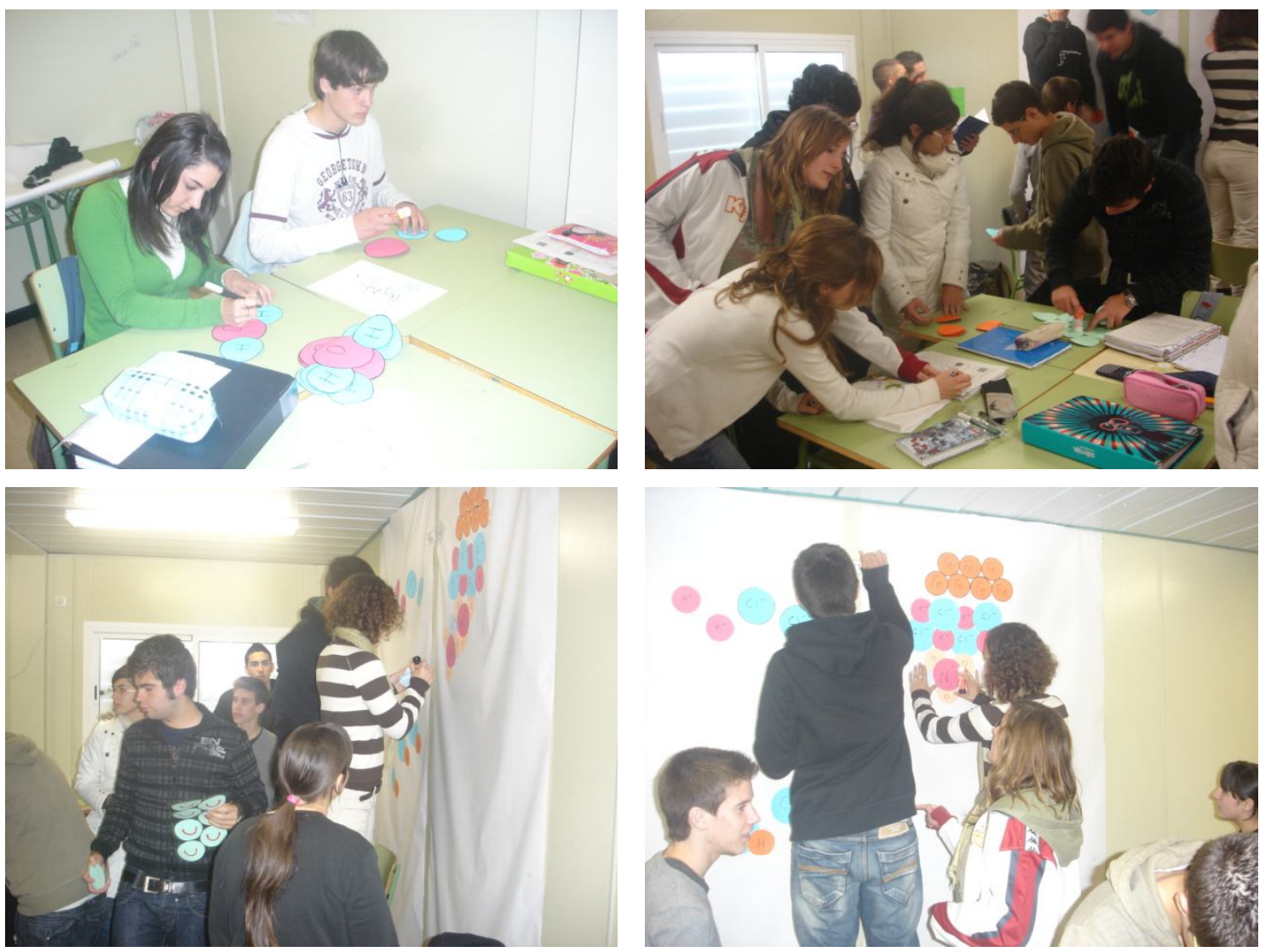

Imagen 8.3.- Alumnos realizando la actividad A-6. 


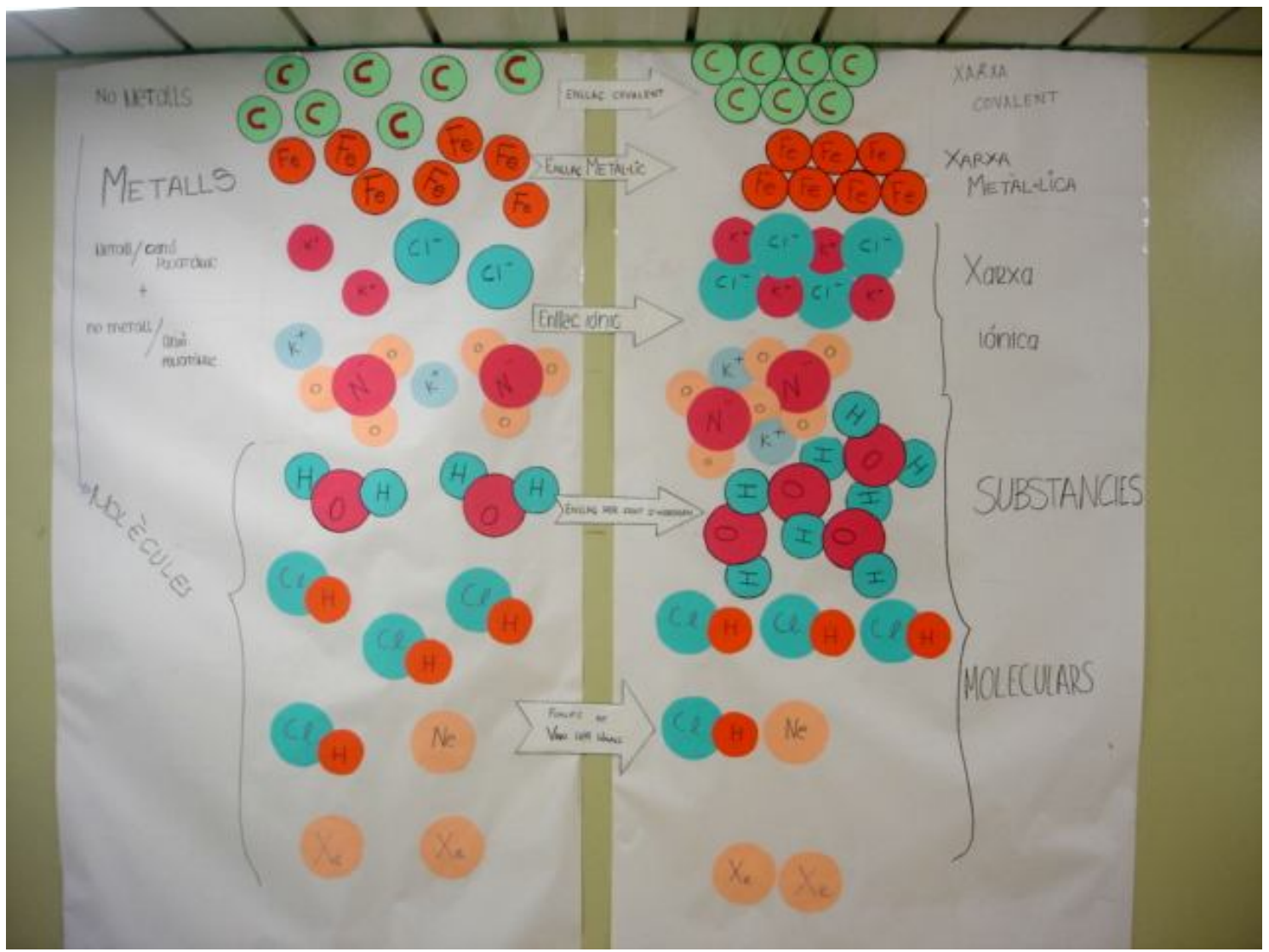

Imagen 8.4.- Mural donde los alumnos han esquematizado los tipos de enlace.

Construcción de modelos de plastilina-pajitas, modelo de globos
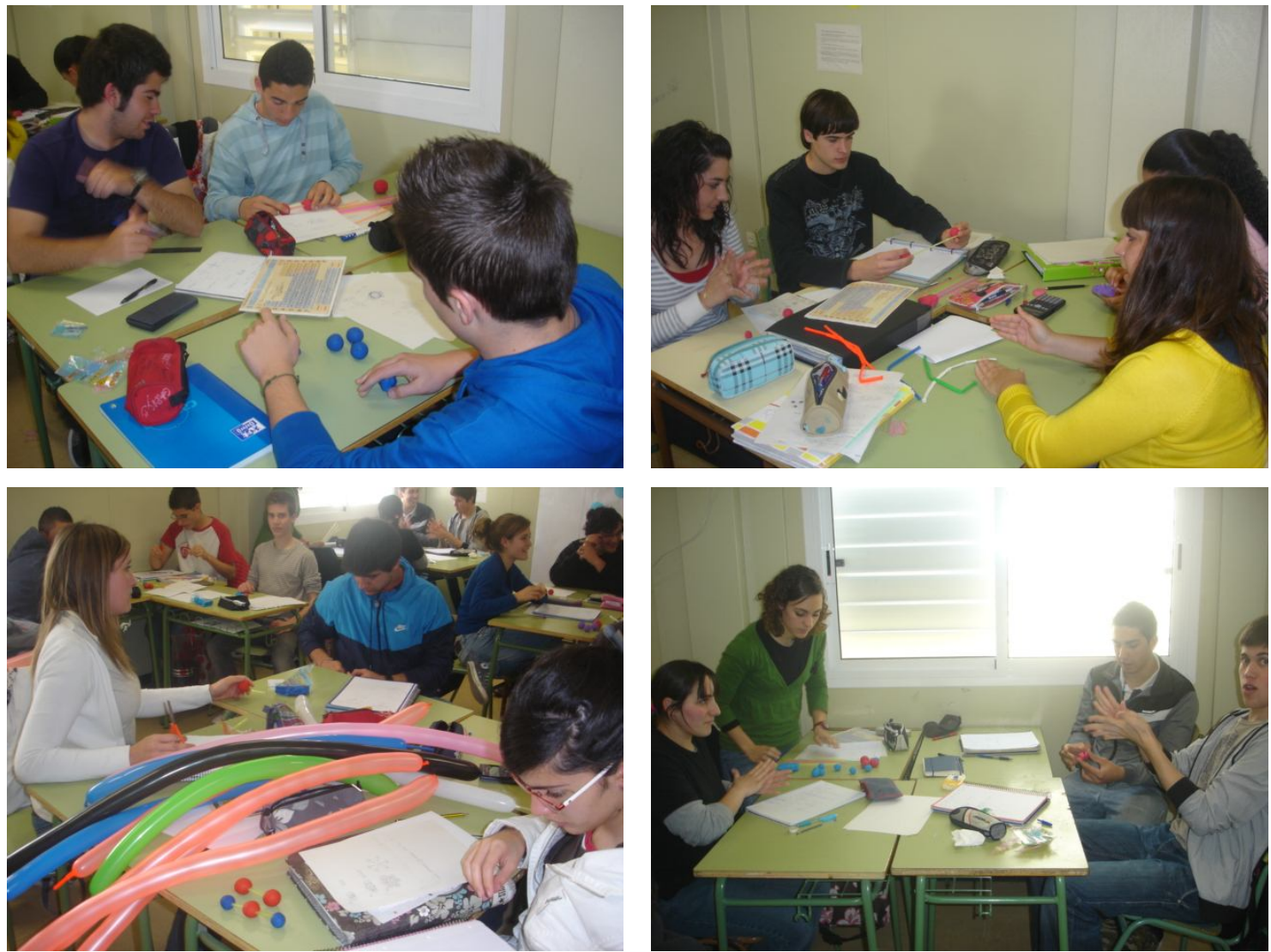

Imagen 8.5.- Alumnos construyendo modelos moleculares. 

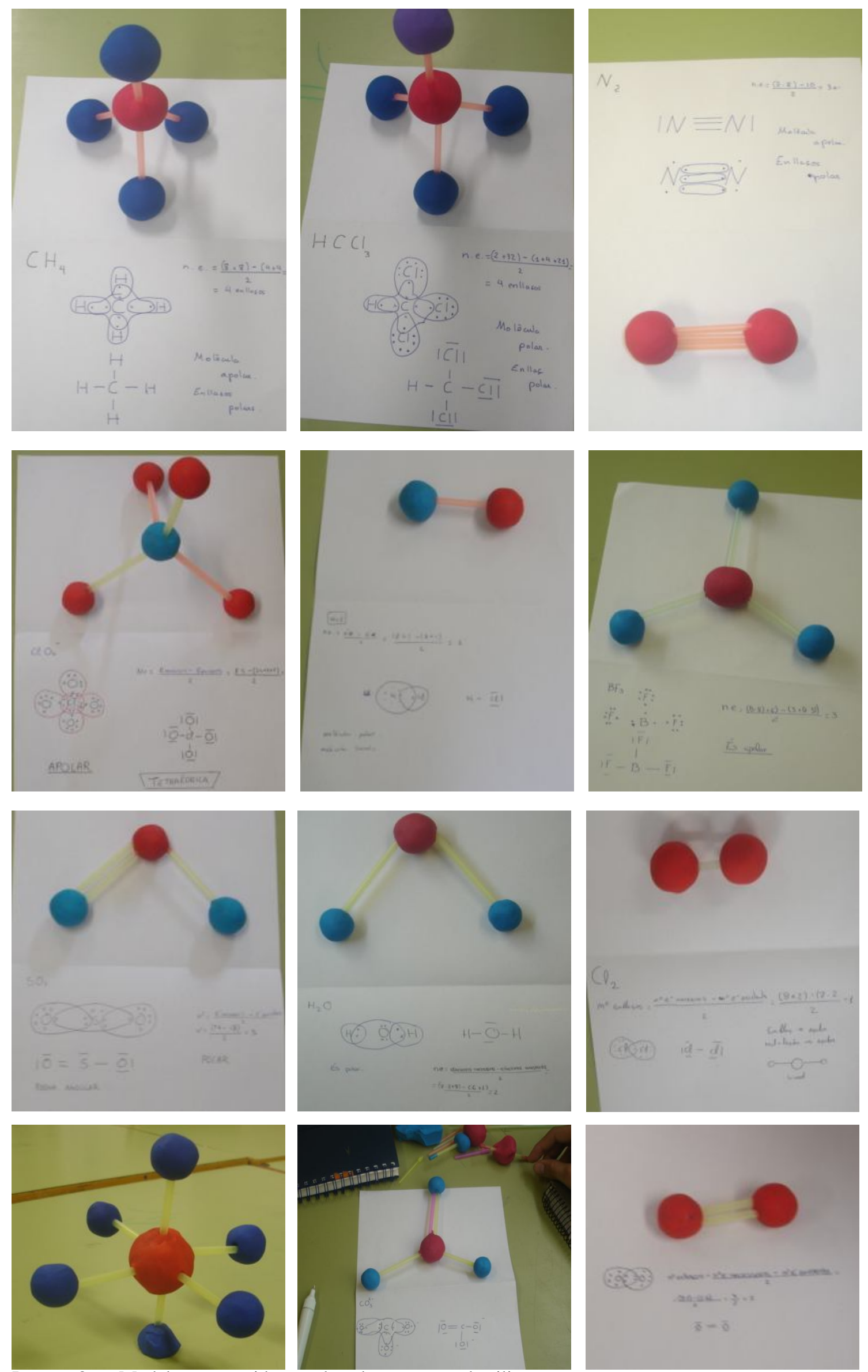

Imagen 8.6.- Modelos construidos por los alumnos con plastilina. 

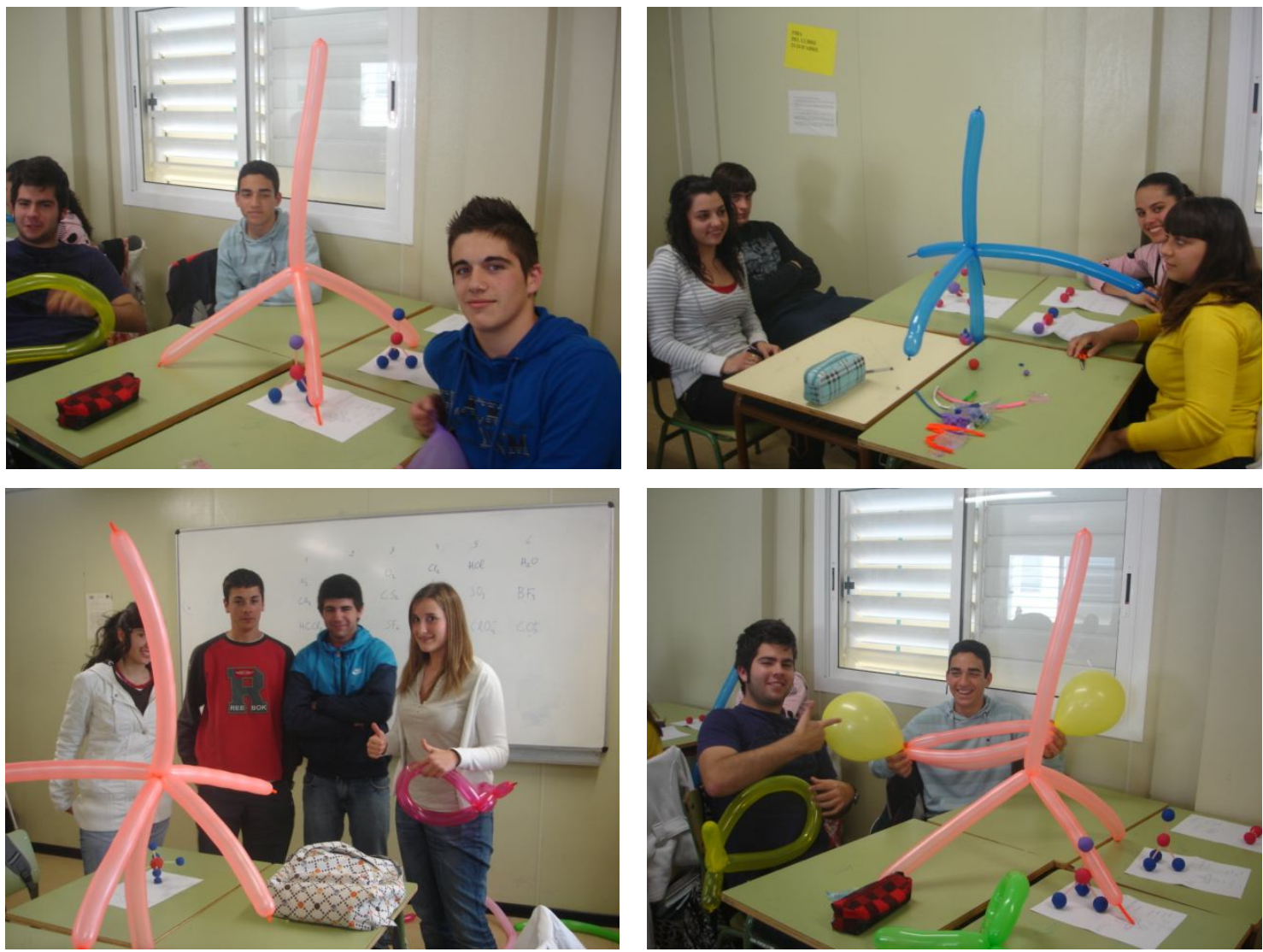

Imagen 8.7.- Modelos propuestos por Gillespie y construidos por los alumnos.

Una vez se establecieron las posibles uniones entre átomos para formar moléculas, se pasó al estudio de cómo podían unirse las partículas formadas, es decir, sólidos covalentes, enlaces iónicos, y sustancias moleculares. 


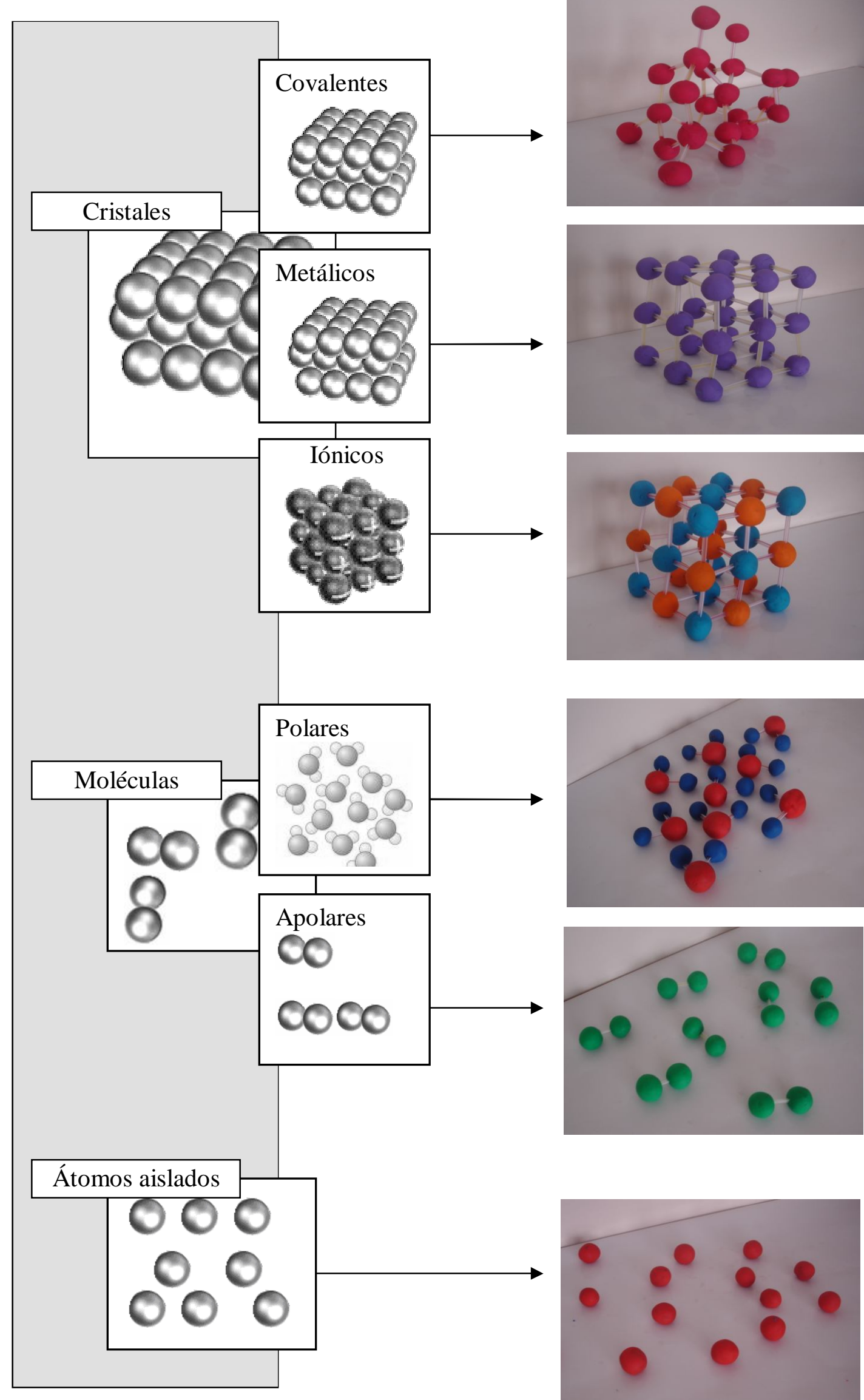

Figura 8.5.- Modelos de plastilina para relacionar los estados de agregación de la materia y los tipos de enlace 


\section{Cuarto tema}

Tras el estudio del tema del enlace químico se han reorganizado los grupos y con la nueva configuración se ha procedido a tratar la formulación y la estequiometría.

En ambos casos se ha mantenido la estructura de trabajo similar a la del tema anterior, no obstante se ha reducido la parte de trabajo manipulativo. Mayoritariamente se han realizado ejercicios escritos (sobre todo en la parte de formulación).

Se han trabajado los compuestos:
a) Compuestos binarios del oxígeno.
b) Compuestos binarios del hidrógeno.
c) Combinaciones binarias de no metales con metales.
d) Combinaciones binarias de no metales con no metales.
e) Hidróxidos.
f) Oxácidos.
g) Oxosales.

En el tema de formulación se ha procedido a indicar cual es forma de nombrar y de formula cada tipo de compuestos, tal y como podríamos considerar la forma habitual. Sin embargo de cada uno de estos grupos de sustancias, se ha propuesto un bloque de ejercicios que se han realizado en clase y en grupo.

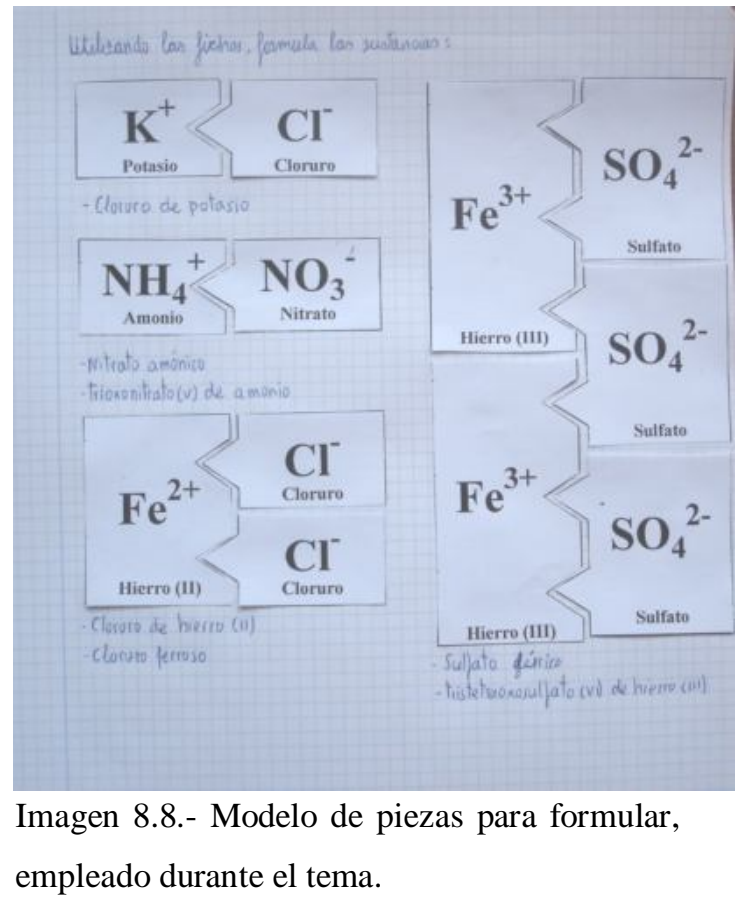




\section{Quinto tema}

En el tema de estequiometría se ha recuperado la utilización del libro de texto, como herramienta para introducir conceptos, pero los ejercicios propuestos en el mismo se han realizado de forma conjunta y con la configuración obtenida tras la reorganización de los grupos de trabajo.

Los contenidos trabajados han sido:

a) Reacciones químicas.

b) Tipos de reacciones químicas.

c) Estequiometría.

d) Cálculos estequiométricos.

e) Cálculos con volúmenes de gases.

f) Cálculos con reactivos en disolución.

g) Cálculos con reactivo limitante.

h) Cálculos con impurezas en los reactivos y rendimiento de la reacción.

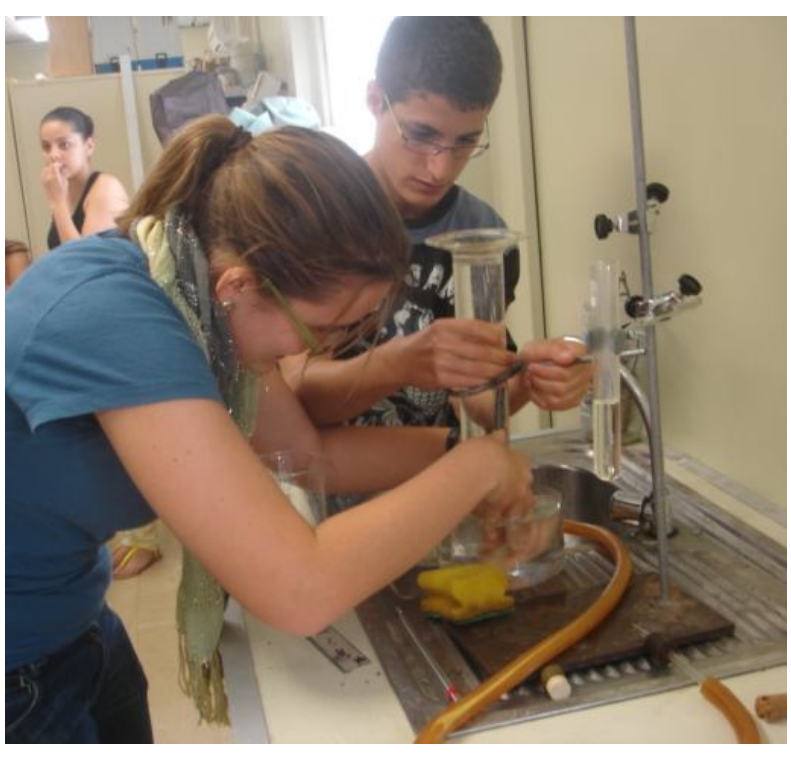

Entre las actividades realizadas ha destacado una sesión de laboratorio en la que debían obtener la masa de una muestra de cinc a partir del volumen de hidrógeno obtenido tras su reacción con ácido clorhídrico.

Imagen 8.9.-Alumnos montando un dispositivo para recoger hidrógeno sobre agua. 
8.- Planteamiento de una intervención cooperativa con una finalidad reguladora 


\section{TERCERA PARTE}

ANALISIS DE RESULTADOS, CONCLUSIONES Y PERSPECTIVAS 


\section{EL MODELO DE TRABAJO COOPERATIVO Y SU ORGANIZACIÓN}

\subsection{Síntesis del procedimiento experimental}

Los pasos dados a lo largo de este estudio han sido:

a) investigación exploratoria.

Realizada con alumnos de segundo de bachillerato y primer curso universitario con la intención de analizar la adquisición de conceptos básicos de química tanto a lo largo de un trimestre en educación secundaria o en los cursos de nivelación preuniversitarios.

b) investigación diagnóstica.

Realizada con alumnos de tercer curso de ESO y segundo de Bachillerato para ubicar un punto de inflexión en el currículo de secundaria, dada su importancia como concepto inclusor, y con la intención de utilizarlo como referencia en la intervención didáctica.

c) intervención didáctica.

Llevada a cabo con alumnos de primer curso de bachillerato y desarrollando el temario de química del curso. Ha supuesto el cuerpo de la investigación, en ella se ha realizado el estudio sobre el trabajo cooperativo y en ella se ha realizado aplicado el mecanismo de regulación que se espera permita mejorar el proceso de aprendizaje.

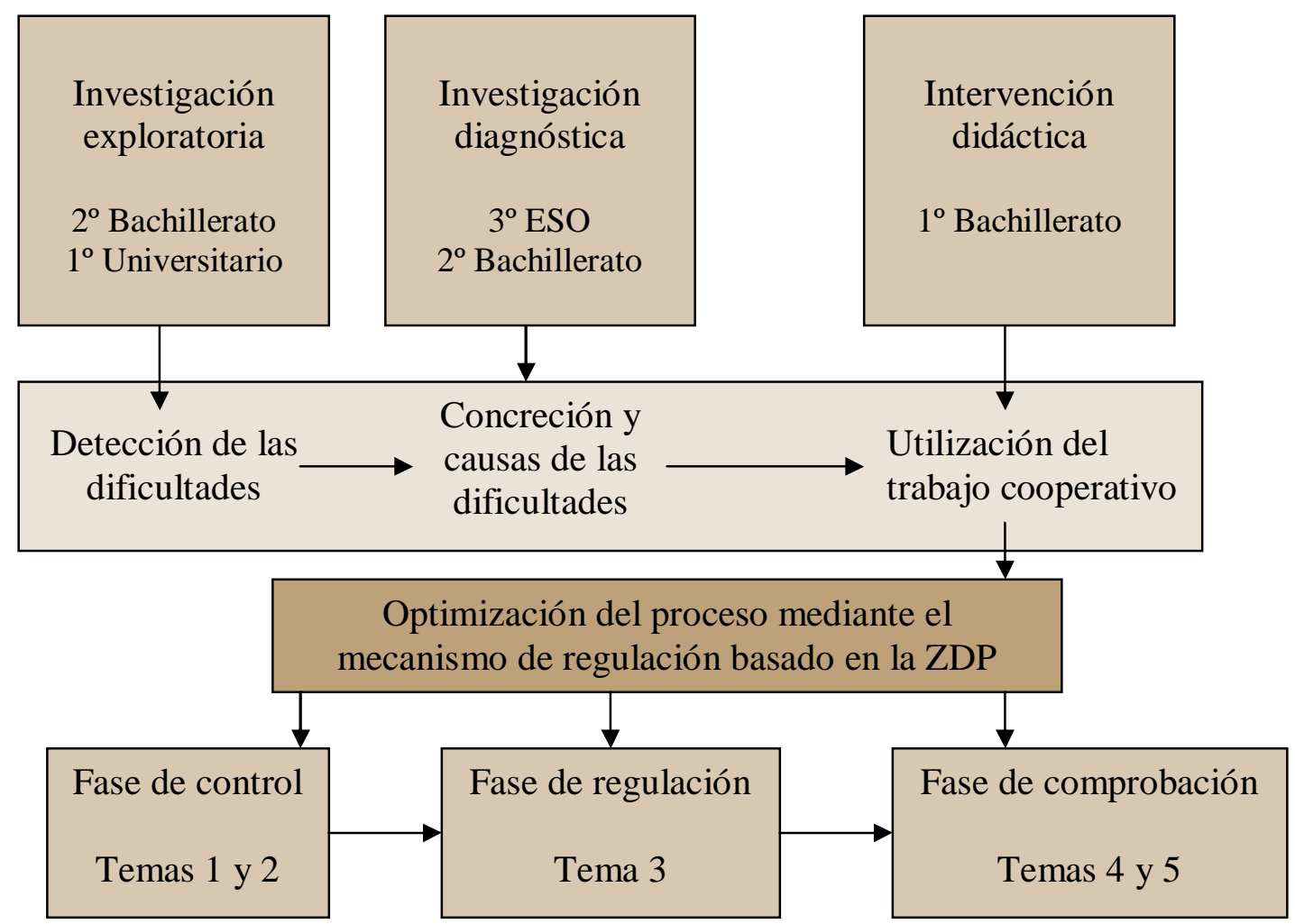

Figura 9.1.- Síntesis del procedimiento experimental 


\subsection{Resultados de la intervención.}

En todos los casos hemos empleado los parámetros indicados en el punto 8.3.5

\begin{tabular}{|c||l|}
\hline \multicolumn{2}{|c|}{ Calificación } \\
\hline$x_{i}$ & Calificación individual \\
\hline$x_{g}$ & Calificación del grupo \\
\hline $\bar{x}_{i}$ & Media de las calificaciones individuales dentro de un grupo \\
\hline
\end{tabular}

\begin{tabular}{|c|c|}
\hline \multicolumn{2}{|c|}{ Medidas de la influencia del grupo sobre el alumno } \\
\hline$\Delta x$ & Influencia del trabajo cooperativo \\
\hline$\Delta x / \bar{x}_{i}$ & Influencia relativa del trabajo cooperativo \\
\hline
\end{tabular}

\begin{tabular}{|c|l|l|}
\hline \multicolumn{2}{|c|}{ Medidas de cohesión del grupo } \\
\hline$L A$ & \multicolumn{2}{|c|}{ Grado de coincidencia (de todo el grupo) } \\
\hline & $L A_{R}$ & Coincidencia en las repuestas correctas \\
\hline & $L A_{W}$ & Coincidencia en las repuestas incorrectas \\
\hline$\sigma / \bar{x}$ & Coeficiente de variación \\
\hline
\end{tabular}

Medidas de la influencia del alumno sobre el grupo

\begin{tabular}{|l|l|l|}
\hline$L A_{i}$ & \multicolumn{2}{|l}{ Grado de coincidencia entre cada estudiante y el grupo } \\
\cline { 2 - 2 } & $L A_{R i}$ & Coincidencia entre estudiante y grupo en las respuestas correctas \\
\hline$L A_{W i}$ & Coincidencia entre cada y grupo en las respuestas correctas \\
\hline
\end{tabular}

Tabla 9.1.- Clasificación de los parámetros utilizados es el procedimiento estadístico 
Los resultados de la intervención se van a presentar en dos apartados, según dependan del cuestionario empleado o según el tipo de ítem implicado.

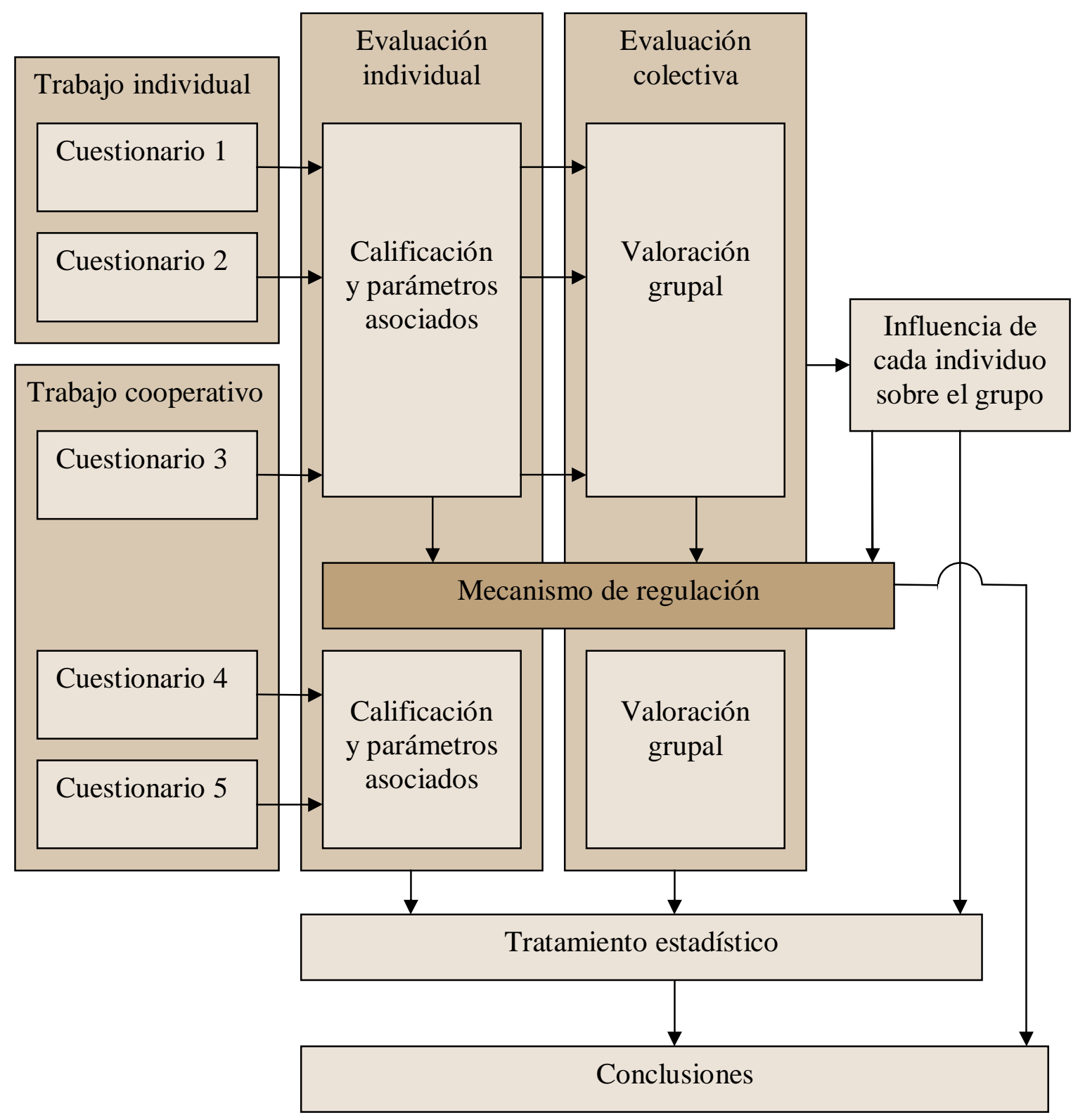

Figura 9.2.- Síntesis de los trabajos y pruebas realizados durante la intervención didáctica. 


\subsubsection{Efecto del trabajo cooperativo sobre grupos aleatorios}

\section{a) Análisis de la intervención en el tema de las Leyes de la Química}

En este tema y en los sucesivos mostraremos los resultados obtenidos desde un punto de vista puramente estadístico, como medida de los resultados obtenidos tanto en el trabajo individual como en el trabajo en equipo y, a continuación analizaremos los datos desde la perspectiva de la interacción a que se han sometido los alumnos.

Parámetros cuantitativos del proceso de calificación

\begin{tabular}{|c|c|c|c|}
\hline \multicolumn{4}{|c|}{ Test $\mathrm{n}^{0} 1 \rightarrow$ Leyes de la química } \\
\hline Alumno & $\begin{array}{c}\text { Calificación } \\
\text { individual }\end{array}$ & $\begin{array}{c}\text { Calificación } \\
\text { grupal }\end{array}$ & Dif. \\
\hline $1-a$ & 7,0 & 8,5 & 1,5 \\
\hline $1-b$ & 2,5 & 8,5 & 6,0 \\
\hline $1-c$ & 5,5 & 8,5 & 3,0 \\
\hline 2-a & 8,5 & 9,0 & 0,5 \\
\hline $2-b$ & 5,0 & 9,0 & 4,0 \\
\hline $2-c$ & 7,5 & 9,0 & 1,5 \\
\hline $2-d$ & 6,5 & 9,0 & 2,5 \\
\hline $3-a$ & 6,5 & 9,5 & 3,0 \\
\hline $3-b$ & 7,0 & 9,5 & 2,5 \\
\hline $3-c$ & 9,0 & 9,5 & 0,5 \\
\hline $3-d$ & 9,5 & 9,5 & 0,0 \\
\hline $4-a$ & 5,0 & 7,5 & 2,5 \\
\hline $4-b$ & 4,0 & 7,5 & 3,5 \\
\hline $4-c$ & 6,0 & 7,5 & 1,5 \\
\hline $4-d$ & 7,0 & 7,5 & 0,5 \\
\hline $5-a$ & 9,5 & 9,5 & 0,0 \\
\hline $5-b$ & 7,5 & 9,5 & 2,0 \\
\hline 5-c & 6,5 & 9,5 & 3,0 \\
\hline $6-a$ & 4,0 & 9,0 & 5,0 \\
\hline $6-b$ & 8,0 & 9,0 & 1,0 \\
\hline 6-c & 8,5 & 9,0 & 0,5 \\
\hline 6-d & 7,5 & 9,0 & 1,5 \\
\hline & 6,73 & 8,82 & 2,09 \\
\hline
\end{tabular}

\begin{tabular}{|l|r|r|}
\hline \multicolumn{1}{|c|}{ parámetros estadísticos } \\
\hline \multicolumn{1}{|l|}{} & Individual & \multicolumn{1}{c|}{ Grupo } \\
\hline Media & 6,73 & 8,82 \\
\hline Desv. Típ. & 1,843 & 0,716 \\
\hline Varianza & 3,398 & 0,513 \\
\hline Asimetría & $-0,499$ & $-0,997$ \\
\hline Curtosis & $-0,084$ & $-0,198$ \\
\hline
\end{tabular}

Tabla 9.2. Parámetros estadísticos asociados al test $\mathrm{n}^{\mathrm{o}} 1$

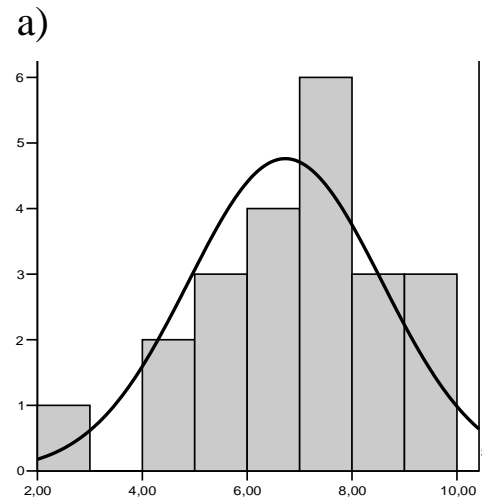

b)

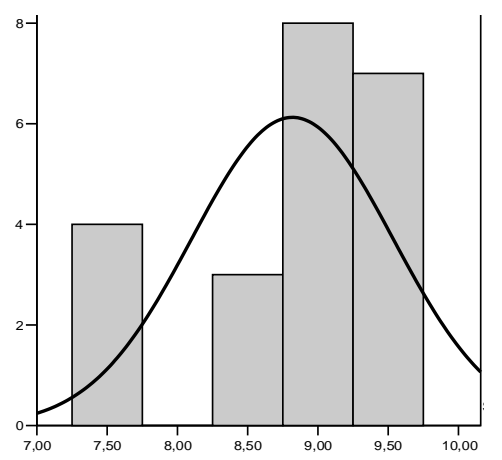

Figura 9.2.- Calificaciones individuales (a) y en grupo (b) en el test $\mathrm{n}^{\mathrm{o}} 1$. 
En los histogramas podemos observar con claridad como la media es muy superior en el caso del trabajo en grupo, al tiempo que una menor desviación típica en el segundo caso nos muestra una homogeneización resultados.

Parámetros cuantificadores del trabajo en grupo

Valoración grupal

\begin{tabular}{|c|c|c|c|c|c|c|c|c|}
\hline Grupo & $x_{g}$ & $\bar{x}_{i}$ & $\Delta x$ & $\Delta x / \bar{x}_{i}$ & $L A$ & $L A_{R}$ & $L A_{W}$ & $\sigma / \bar{x}$ \\
\hline 1 & 8,5 & 5,00 & 3,50 & 0,70 & 0,55 & 0,569 & 0,44 & 0,46 \\
\hline 2 & 9,0 & 6,88 & 2,12 & 0,31 & 0,69 & 0,722 & 0,38 & 0,22 \\
\hline 3 & 9,5 & 8,00 & 1,50 & 0,19 & 0,84 & 0,842 & 0,75 & 0,18 \\
\hline 4 & 7,5 & 5,50 & 2,00 & 0,37 & 0,51 & 0,583 & 0,30 & 0,23 \\
\hline 5 & 9,5 & 7,83 & 1,67 & 0,21 & 0,59 & 0,605 & 0,25 & 0,20 \\
\hline 6 & 9,0 & 7,00 & 2,00 & 0,29 & 0,68 & 0,722 & 0,38 & 0,29 \\
\hline Media & & & & 0,35 & & & & 0,26 \\
\hline
\end{tabular}

Tabla 9.3.- Parámetros cuantificadores del grupo en el test $\mathrm{n}^{\circ} 1$.

Coeficiente de variación $\rightarrow 0,26 \quad$ Mejora relativa $\rightarrow 0,345$

Valoración individual

\begin{tabular}{|c|c|c|c|c|}
\hline Alumno & $\begin{array}{c}\text { Calificación } \\
\text { individual }\end{array}$ & $L A_{i}$ & $L A_{R i}$ & $L A_{W i}$ \\
\hline $1-a$ & 7,0 & 0,80 & 0,824 & 0,667 \\
\hline $1-b$ & 2,5 & 0,30 & 0,294 & 0,333 \\
\hline $1-c$ & 5,5 & 0,55 & 0,588 & 0,333 \\
\hline $2-a$ & 8,5 & 0,85 & 0,889 & 0,500 \\
\hline $2-b$ & 5,0 & 0,55 & 0,556 & 0,500 \\
\hline $2-c$ & 7,5 & 0,80 & 0,833 & 0,500 \\
\hline $2-d$ & 6,5 & 0,55 & 0,611 & 0,000 \\
\hline 3-a & 6,5 & 0,65 & 0,684 & 0,000 \\
\hline $3-b$ & 7,0 & 0,75 & 0,737 & 1,000 \\
\hline 3-c & 9,0 & 0,95 & 0,947 & 1,000 \\
\hline $3-d$ & 9,5 & 1,00 & 1,000 & 1,000 \\
\hline $4-a$ & 5,0 & 0,35 & 0,467 & 0,000 \\
\hline $4-b$ & 4,0 & 0,50 & 0,467 & 0,600 \\
\hline 4-c & 6,0 & 0,60 & 0,667 & 0,400 \\
\hline 4-d & 7,0 & 0,60 & 0,733 & 0,400 \\
\hline 5-a & 9,5 & 0,90 & 0,947 & 0,000 \\
\hline $5-b$ & 7,5 & 0,75 & 0,789 & 0,000 \\
\hline 5-c & 6,5 & 0,70 & 0,684 & 1,000 \\
\hline $6-a$ & 4,0 & 0,45 & 0,444 & 0,500 \\
\hline $6-b$ & 8,0 & 0,80 & 0,833 & 0,500 \\
\hline 6-c & 8,5 & 0,85 & 0,889 & 0,500 \\
\hline \multirow[t]{2}{*}{$6-d$} & 7,5 & 0,65 & 0,722 & 0,000 \\
\hline & 6,73 & & & \\
\hline
\end{tabular}

Tabla 9.4.- Parámetros cuantificadores individuales en el test $\mathrm{n}^{\circ} 1$. 


\section{b) Análisis de la intervención en el tema de la estructura atómica y sistema periódico}

En este segundo tema se mantiene la misma estructura que en el anterior. Los alumnos han trabajado el tema de forma individual, pero han realizado la prueba escrita tanto de forma individual como colectiva.

Parámetros cuantitativos del proceso de calificación

\begin{tabular}{|c|c|c|c|}
\hline \multicolumn{4}{|c|}{ 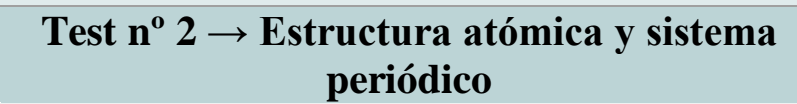 } \\
\hline Alumno & $\begin{array}{l}\text { Calificación } \\
\text { individual }\end{array}$ & $\begin{array}{l}\text { Calificación } \\
\text { grupal }\end{array}$ & Dif. \\
\hline $1-a$ & 5,2 & 6,8 & 1,6 \\
\hline $1-b$ & 4,0 & 6,8 & 2,8 \\
\hline $1-c$ & 4,0 & 6,8 & 2,8 \\
\hline $2-a$ & 7,2 & 9,2 & 2,0 \\
\hline $2-b$ & 3,2 & 9,2 & 6,0 \\
\hline $2-c$ & 8,0 & 9,2 & 1,2 \\
\hline $2-d$ & 4,0 & 9,2 & 5,2 \\
\hline $3-a$ & 5,2 & 6,4 & 1,2 \\
\hline $3-b$ & 4,0 & 6,4 & 2,4 \\
\hline $3-c$ & 4,8 & 6,4 & 1,6 \\
\hline $3-d$ & 5,2 & 6,4 & 1,2 \\
\hline $4-a$ & 7,2 & 8,4 & 1,2 \\
\hline $4-b$ & 6,4 & 8,4 & 2,0 \\
\hline $4-c$ & 6,8 & 8,4 & 1,6 \\
\hline $4-d$ & 4,8 & 8,4 & 3,6 \\
\hline $5-a$ & 8,8 & 9,6 & 0,8 \\
\hline $5-b$ & 9,2 & 9,6 & 0,4 \\
\hline $5-c$ & 5,2 & 9,6 & 4,4 \\
\hline $6-a$ & 6,8 & 8,4 & 1,6 \\
\hline $6-b$ & 4,4 & 8,4 & 4,0 \\
\hline 6-c & 5,2 & 8,4 & 3,2 \\
\hline \multirow[t]{2}{*}{$6-d$} & 5,6 & 8,4 & 2,8 \\
\hline & 5,69 & 8,13 & 2,44 \\
\hline
\end{tabular}

\begin{tabular}{|l|c|c|}
\hline \multicolumn{2}{|c|}{ parámetros estadísticos } \\
\hline \multicolumn{1}{|c|}{} & individual & Grupo \\
\hline Media & 5,69 & 8,13 \\
\hline Desv. típ. & 1,646 & 1,173 \\
\hline Varianza & 2,711 & 1,377 \\
\hline Asimetría & 0,664 & $\begin{array}{c}- \\
0,419\end{array}$ \\
\hline Curtosis & $-0,353$ & \begin{tabular}{c}
- \\
\hline
\end{tabular} \\
\hline
\end{tabular}

Tabla 9.6.- Parámetros estadísticos asociados al test $\mathrm{n}^{\circ} 2$

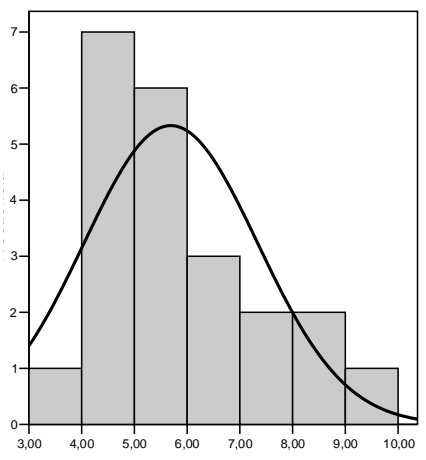

Tabla 9.5.- Calificaciones en el test $\mathrm{n}^{\circ} 2$

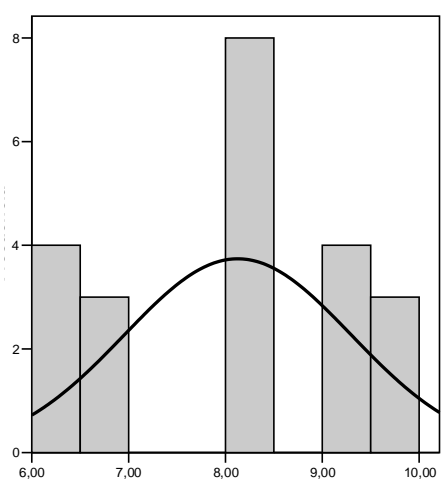

Figura 9.4.- Calificaciones individuales (a) y en grupo (b) en el test 2. 
b) Parámetros cuantificadores del trabajo en grupo

Valoración grupal

\begin{tabular}{|c|c|c|c|c|c|c|c|c|}
\hline Grupo & $x_{g}$ & $\bar{x}_{i}$ & $\Delta x$ & $\Delta x / \bar{x}_{i}$ & $L A$ & $L A_{R}$ & $L A_{W}$ & $\sigma / \bar{x}$ \\
\hline 1 & 6,8 & 4,4 & 2,4 & 0,55 & 0,55 & 0,569 & 0,5 & 0,16 \\
\hline 2 & 9,2 & 5,6 & 3,6 & 0,64 & 0,58 & 0,598 & 0,375 & 0,42 \\
\hline 3 & 6,4 & 4,8 & 1,6 & 0,33 & 0,59 & 0,609 & 0,556 & 0,12 \\
\hline 4 & 8,4 & 6,3 & 2,1 & 0,33 & 0,65 & 0,702 & 0,375 & 0,17 \\
\hline 5 & 9,6 & 7,7 & 1,9 & 0,24 & 0,77 & 0,792 & 0,333 & 0,28 \\
\hline 6 & 8,4 & 5,5 & 2,9 & 0,53 & 0,6 & 0,563 & 0,524 & 0,18 \\
\hline
\end{tabular}

Tabla 9.7.- Parámetros cuantificadores del grupo en el test 2.

Coeficiente de variación $\rightarrow 0,22$

Mejora relativa $\rightarrow 0,437$

Valoración individual

\begin{tabular}{|c|c|c|c|c|}
\hline Alumno & $\begin{array}{c}\text { Calificación } \\
\text { individual }\end{array}$ & $L A_{i}$ & $L A_{R i}$ & $L A_{W i}$ \\
\hline $1-a$ & 5,2 & 0,72 & 0,765 & 0,625 \\
\hline $1-b$ & 4,0 & 0,56 & 0,529 & 0,625 \\
\hline $1-c$ & 4,0 & 0,36 & 0,412 & 0,250 \\
\hline $2-a$ & 7,2 & 0,72 & 0,739 & 0,500 \\
\hline $2-b$ & 3,2 & 0,36 & 0,348 & 0,500 \\
\hline $2-c$ & 8,0 & 0,80 & 0,870 & 0,000 \\
\hline $2-d$ & 4,0 & 0,44 & 0,435 & 0,500 \\
\hline $3-a$ & 5,2 & 0,56 & 0,688 & 0,333 \\
\hline $3-b$ & 4,0 & 0,44 & 0,438 & 0,444 \\
\hline $3-c$ & 4,8 & 0,56 & 0,563 & 0,556 \\
\hline $3-d$ & 5,2 & 0,80 & 0,750 & 0,889 \\
\hline $4-a$ & 7,2 & 0,84 & 0,857 & 0,750 \\
\hline $4-b$ & 6,4 & 0,76 & 0,762 & 0,750 \\
\hline 4-c & 6,8 & 0,64 & 0,762 & 0,000 \\
\hline $4-d$ & 4,8 & 0,36 & 0,429 & 0,000 \\
\hline $5-a$ & 8,8 & 0,84 & 0,875 & 0,000 \\
\hline $5-b$ & 9,2 & 0,96 & 0,958 & 1,000 \\
\hline $5-c$ & 5,2 & 0,52 & 0,542 & 0,000 \\
\hline $6-a$ & 6,8 & 0,64 & 0,714 & 0,250 \\
\hline $6-b$ & 4,4 & 0,56 & 0,524 & 0,750 \\
\hline 6-c & 5,2 & 0,68 & 0,619 & 1,000 \\
\hline $6-d$ & 5,6 & 0,52 & 0,571 & 0,250 \\
\hline & & & & \\
\hline
\end{tabular}

Tabla 9.8.- Parámetros cuantificadores individuales en el test 2. 


\subsubsection{Aplicación del mecanismo de regulación basado en la ZDP}

\section{Análisis de la intervención en el tema del enlace químico}

Test aplicado sobre el tema del enlace químico, que se ha desarrollado íntegramente utilizando actividades de cooperación en grupo.

Parámetros cuantitativos del proceso de calificación

\begin{tabular}{|c|c|c|c|}
\hline \multicolumn{4}{|c|}{ Test $\mathbf{n}^{0} \mathbf{3} \rightarrow$ Enlace químico } \\
\hline Alumno & $\begin{array}{c}\text { Calificación } \\
\text { individual }\end{array}$ & $\begin{array}{c}\text { Calificación } \\
\text { grupal }\end{array}$ & Dif. \\
\hline $1-\mathrm{a}$ & 6,8 & 8,8 & 2,0 \\
\hline $1-b$ & 6,4 & 8,8 & 2,4 \\
\hline $1-c$ & 7,6 & 8,8 & 1,2 \\
\hline $2-a$ & 8,8 & 8,8 & 0,0 \\
\hline $2-b$ & 5,6 & 8,8 & 3,2 \\
\hline 2-c & 7,2 & 8,8 & 1,6 \\
\hline $2-d$ & 5,2 & 8,8 & 3,6 \\
\hline $3-a$ & 6,4 & 8,4 & 2,0 \\
\hline $3-b$ & 6,4 & 8,4 & 2,0 \\
\hline $3-c$ & 8,4 & 8,4 & 0,0 \\
\hline $3-d$ & 6,8 & 8,4 & 1,6 \\
\hline $4-a$ & 5,2 & 7,2 & 2,0 \\
\hline $4-b$ & 4,4 & 7,2 & 2,8 \\
\hline 4-c & 5,2 & 7,2 & 2,0 \\
\hline $4-d$ & 7,2 & 7,2 & 0,0 \\
\hline $5-a$ & 9,2 & 9,6 & 0,4 \\
\hline $5-b$ & 8,8 & 9,6 & 0,8 \\
\hline 5-c & 7,6 & 9,6 & 2,0 \\
\hline 6-a & 6,0 & 7,6 & 1,6 \\
\hline 6-b & 5,6 & 7,6 & 2,0 \\
\hline 6-c & 4,8 & 7,6 & 2,8 \\
\hline 6-d & 5,6 & 7,6 & 2,0 \\
\hline & 6,6 & 8,33 & 1,73 \\
\hline
\end{tabular}

\begin{tabular}{|c|c|c|}
\hline \multicolumn{3}{|c|}{ parámetros estadísticos } \\
\hline & Individual & Grupo \\
\hline Media & 6,60 & 8,33 \\
\hline Desv. típ. & 1,379 & 0,806 \\
\hline Varianza & 1,901 & 0,650 \\
\hline Asimetría & 0,384 & $-0,034$ \\
\hline Curtosis & $-0,781$ & $-1,108$ \\
\hline
\end{tabular}

Tabla 9.10. Parámetros estadísticos asociados al test $\mathrm{n}^{\circ} 3$.

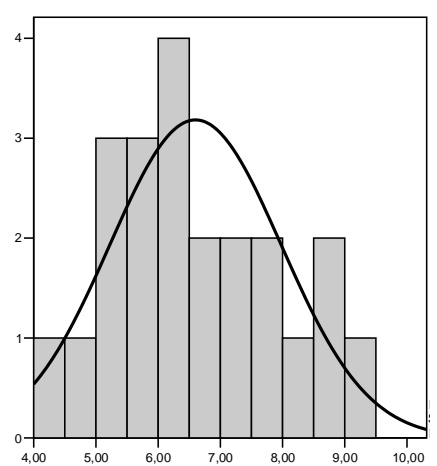

Tabla 9.9.- Calificaciones en el test $n^{\circ} 3$

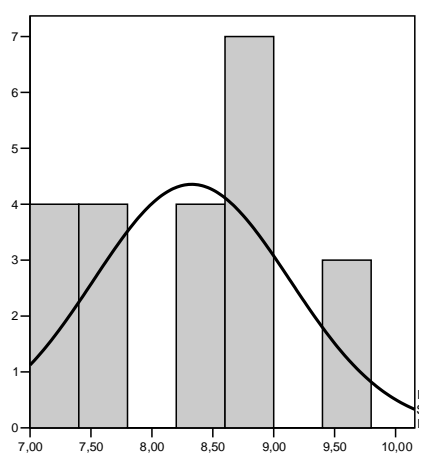

Figura 9.6.- Calificaciones individuales (a) y en grupo (b) en el test $n^{\circ} 3$. 
b) Parámetros cuantificadores del trabajo en grupo

Valoración grupal

\begin{tabular}{|c|c|c|c|c|c|c|c|c|}
\hline Grupo & $x_{g}$ & $\bar{x}_{i}$ & $\Delta x$ & $\Delta x / \bar{x}_{i}$ & $L A$ & $L A_{R}$ & $L A_{W}$ & $\sigma / \bar{x}$ \\
\hline 1 & 8,8 & 6,9 & 1,9 & 0,27 & 0,71 & 0,742 & 0,444 & 0,09 \\
\hline 2 & 8,8 & 6,7 & 2,1 & 0,31 & 0,70 & 0,739 & 0,417 & 0,25 \\
\hline 3 & 8,4 & 7,0 & 1,4 & 0,20 & 0,74 & 0,798 & 0,438 & 0,14 \\
\hline 4 & 7,2 & 5,5 & 1,7 & 0,31 & 0,63 & 0,694 & 0,464 & 0,22 \\
\hline 5 & 9,6 & 8,5 & 1,1 & 0,13 & 0,67 & 0,667 & 0,75 & 0,10 \\
\hline 6 & 7,6 & 5,5 & 2,1 & 0,38 & 0,60 & 0,684 & 0,333 & 0,09 \\
\hline
\end{tabular}

Tabla 9.11.- Parámetros cuantificadores del grupo en el test $\mathrm{n}^{\circ} 3$.

Coeficiente de variación $\rightarrow 0,15$

Mejora relativa $\rightarrow 0,267$

Valoración individual

\begin{tabular}{|c|c|c|c|c|}
\hline Alumno & $\begin{array}{c}\text { Calificación } \\
\text { individual }\end{array}$ & $L A_{i}$ & $L A_{R i}$ & $L A_{W i}$ \\
\hline $1-a$ & 6,8 & 0,80 & 0,773 & 1,000 \\
\hline $1-b$ & 6,4 & 0,56 & 0,636 & 0,000 \\
\hline $1-c$ & 7,6 & 0,76 & 0,818 & 0,333 \\
\hline $2-a$ & 8,8 & 0,88 & 0,955 & 0,333 \\
\hline $2-b$ & 5,6 & 0,64 & 0,636 & 0,667 \\
\hline $2-c$ & 7,2 & 0,76 & 0,818 & 0,333 \\
\hline $2-d$ & 5,2 & 0,52 & 0,545 & 0,333 \\
\hline 3-a & 6,4 & 0,64 & 0,714 & 0,250 \\
\hline $3-b$ & 6,4 & 0,76 & 0,762 & 0,750 \\
\hline 3-c & 8,4 & 0,84 & 0,952 & 0,250 \\
\hline $3-d$ & 6,8 & 0,72 & 0,762 & 0,500 \\
\hline $4-a$ & 5,2 & 0,64 & 0,722 & 0,429 \\
\hline $4-b$ & 4,4 & 0,52 & 0,556 & 0,429 \\
\hline 4-c & 5,2 & 0,56 & 0,611 & 0,429 \\
\hline $4-d$ & 7,2 & 0,80 & 0,889 & 0,571 \\
\hline 5-a & 9,2 & 0,96 & 0,958 & 1,000 \\
\hline $5-b$ & 8,8 & 0,92 & 0,917 & 1,000 \\
\hline 5-c & 7,6 & 0,80 & 0,792 & 1,000 \\
\hline 6-a & 6,0 & 0,64 & 0,737 & 0,333 \\
\hline $6-b$ & 5,6 & 0,72 & 0,737 & 0,667 \\
\hline 6-c & 4,8 & 0,48 & 0,579 & 0,167 \\
\hline \multirow[t]{2}{*}{$6-d$} & 5,6 & 0,56 & 0,684 & 0,167 \\
\hline & 6,6 & & & \\
\hline
\end{tabular}

Tabla 9.12.- Parámetros cuantificadores individuales en el test $n^{\circ} 3$. 
Tras haber analizado la influencia de cada alumno dentro de su grupo, se reordenan de modo que en cada grupo se encuentren alumnos con similar grado de influencia $\left(L A_{R i}\right)$, a partir del la media de este valor en los tres primeros controles realizados:

En la tabla siguiente se muestran los valores del parámetro $L A_{R i}$ para cada alumno y control, así como su valor medio y la ubicación de cada alumno en cada uno de los nuevos grupos.

\begin{tabular}{|c|c|c|c|c|c|c|c|c|c|c|}
\hline & Control-1 & Control-2 & Control-3 & & 1 & 2 & 3 & 4 & 5 & 6 \\
\hline $1-a$ & 0,824 & 0,765 & 0,773 & 0,787 & & & & & & \\
\hline $1-b$ & 0,294 & 0,529 & 0,636 & 0,486 & & & & & & \\
\hline $1-c$ & 0,588 & 0,412 & 0,818 & 0,606 & & & & & & \\
\hline $2-a$ & 0,889 & 0,739 & 0,955 & 0,861 & & & & & & \\
\hline $2-b$ & 0,556 & 0,348 & 0,636 & 0,513 & & & & & & \\
\hline $2-c$ & 0,833 & 0,870 & 0,818 & 0,840 & & & & & & \\
\hline $2-d$ & 0,611 & 0,435 & 0,545 & 0,530 & & & & & & \\
\hline $3-a$ & 0,684 & 0,688 & 0,714 & 0,695 & & & & & & \\
\hline $3-b$ & 0,737 & 0,438 & 0,762 & 0,646 & & & & & & \\
\hline $3-c$ & 0,947 & 0,563 & 0,952 & 0,821 & & & & & & \\
\hline $3-d$ & 1,000 & 0,750 & 0,762 & 0,837 & & & & & & \\
\hline $4-a$ & 0,467 & 0,857 & 0,722 & 0,682 & & & & & & \\
\hline $4-b$ & 0,467 & 0,762 & 0,556 & 0,595 & & & & & & \\
\hline $4-c$ & 0,667 & 0,762 & 0,611 & 0,680 & & & & & & \\
\hline 4-d & 0,733 & 0,429 & 0,889 & 0,684 & & & & & & \\
\hline $5-a$ & 0,947 & 0,875 & 0,958 & 0,927 & & & & & & \\
\hline $5-b$ & 0,789 & 0,958 & 0,917 & 0,888 & & & & & & \\
\hline $5-c$ & 0,684 & 0,542 & 0,792 & 0,673 & & & & & & \\
\hline 6-a & 0,444 & 0,714 & 0,737 & 0,632 & & & & & & \\
\hline $6-b$ & 0,833 & 0,524 & 0,737 & 0,698 & & & & & & \\
\hline $6-c$ & 0,889 & 0,619 & 0,579 & 0,696 & & & & & & \\
\hline $6-d$ & 0,722 & 0,571 & 0,684 & 0,659 & & & & & & \\
\hline
\end{tabular}

Tabla 9. .- Valores del parámetro $L A_{R i}$ para cada alumno y posterior reordenación en los nuevos grupos. 
Por tanto los nuevos grupos estarán compuestos por los alumnos de la siguiente forma:

\begin{tabular}{|c|c|}
\hline $\begin{array}{c}\text { Nueva } \\
\text { ordenación }\end{array}$ & $\begin{array}{c}\text { Anterior } \\
\text { ordenación }\end{array}$ \\
\hline $01-a$ & $1-a$ \\
\hline $01-b$ & $3-c$ \\
\hline $01-c$ & $3-d$ \\
\hline $02-a$ & $1-b$ \\
\hline $02-b$ & $2-b$ \\
\hline $02-c$ & $2-d$ \\
\hline $02-d$ & $4-b$ \\
\hline $03-a$ & $1-c$ \\
\hline $03-b$ & $3-b$ \\
\hline $03-c$ & $6-a$ \\
\hline $03-d$ & $6-d$ \\
\hline $04-a$ & $2-a$ \\
\hline $04-b$ & $2-c$ \\
\hline $04-c$ & $5-a$ \\
\hline $04-d$ & $5-b$ \\
\hline $05-a$ & $4-a$ \\
\hline $05-b$ & $4-c$ \\
\hline $05-c$ & $5-c$ \\
\hline $06-a$ & $3-a$ \\
\hline $06-b$ & $4-d$ \\
\hline $06-c$ & $6-b$ \\
\hline $06-d$ & $6-c$ \\
\hline
\end{tabular}

Tabla 9.13.- Relación entre los grupos aleatorios y los grupos ordenados según la propuesta. 


\subsubsection{Efecto del trabajo cooperativo sobre grupos organizados según la ZDP}

\section{a) Análisis de la intervención en el tema de formulación}

Parámetros cuantitativos del proceso de calificación

\begin{tabular}{|c|c|c|c|}
\hline \multicolumn{4}{|c|}{ Test $n^{\circ} 4 \rightarrow$ Formulación } \\
\hline Alumno & $\begin{array}{c}\text { Calificación } \\
\text { individual }\end{array}$ & $\begin{array}{c}\text { Calificación } \\
\text { grupal }\end{array}$ & Dif. \\
\hline $01-a$ & 7,6 & 10,0 & 2,4 \\
\hline $01-b$ & 7,6 & 10,0 & 2,4 \\
\hline 01-c & 9,6 & 10,0 & 0,4 \\
\hline $02-a$ & 7,6 & 8,8 & 1,2 \\
\hline $02-b$ & 6,0 & 8,8 & 2,8 \\
\hline 02-c & 6,8 & 8,8 & 2,0 \\
\hline 02-d & 3,2 & 8,8 & 5,6 \\
\hline 03-a & 6,0 & 8,4 & 2,4 \\
\hline 03-b & 7,6 & 8,4 & 0,8 \\
\hline 03-c & 8,0 & 8,4 & 0,4 \\
\hline 03-d & 6,0 & 8,4 & 2,4 \\
\hline 04-a & 10,0 & 10,0 & 0,0 \\
\hline 04-b & 9,2 & 10,0 & 0,8 \\
\hline 04-c & 10,0 & 10,0 & 0,0 \\
\hline 04-d & 9,2 & 10,0 & 0,8 \\
\hline 05-a & 5,2 & 7,6 & 2,4 \\
\hline 05-b & 6,4 & 7,6 & 1,2 \\
\hline 05-c & 7,6 & 7,6 & 0,0 \\
\hline $06-a$ & 6,0 & 8,8 & 2,8 \\
\hline $06-b$ & 7,6 & 8,8 & 1,2 \\
\hline 06-c & 8,0 & 8,8 & 0,8 \\
\hline \multirow[t]{2}{*}{ 06-d } & 7,6 & 8,8 & 1,2 \\
\hline & 7,4 & 8,95 & 1,55 \\
\hline
\end{tabular}

Tabla 9.14.- Calificaciones en el test $n^{\circ} 4$

\begin{tabular}{|l|c|c|}
\multicolumn{2}{c|}{ parámetros estadísticos } \\
\hline & Individual & Grupo \\
\hline Media & 7,40 & 8,95 \\
\hline Desv. típ. & 1,655 & 0,833 \\
\hline Varianza & 2,793 & 0,694 \\
\hline Asimetría & $-0,450$ & 0,021 \\
\hline Curtosis & 0,636 & $-1,001$ \\
\hline
\end{tabular}

Tabla 9.15. Parámetros estadísticos asociados al test $\mathrm{n}^{\circ} 4$.
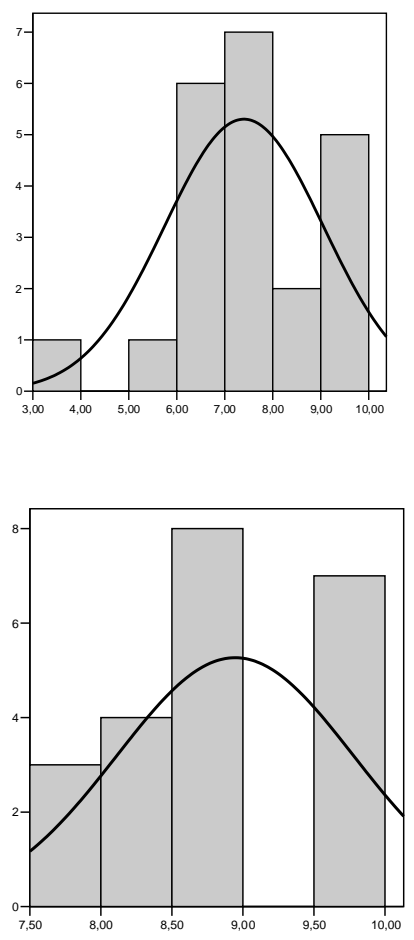

Figura 9.8.- Calificaciones individuales (a) y en grupo (b) en el test $n^{\circ} 4$. 
b) Parámetros cuantificadores del trabajo en grupo

Valoración grupal

\begin{tabular}{|c|c|c|c|c|c|c|c|c|}
\hline Grupo & $x_{g}$ & $\overline{x_{i}}$ & $\Delta x$ & $\Delta x / \overline{x_{i}}$ & $L A$ & $L A_{R}$ & $L A_{W}$ & $\sigma / \bar{x}$ \\
\hline 1 & 10 & 8,3 & 1,7 & 0,21 & 0,83 & 0,827 & ------ & 0,14 \\
\hline 2 & 8,8 & 5,9 & 2,9 & 0,49 & 0,64 & 0,659 & 0,5 & 0,32 \\
\hline 3 & 8,4 & 6,9 & 1,5 & 0,22 & 0,71 & 0,774 & 0,375 & 0,15 \\
\hline 4 & 10 & 9,6 & 0,4 & 0,04 & 0,96 & 0,96 & ------ & 0,05 \\
\hline 5 & 7,6 & 6,4 & 1,2 & 0,19 & 0,59 & 0,702 & 0,222 & 0,19 \\
\hline 6 & 8,8 & 7,3 & 1,5 & 0,21 & 0,72 & 0,773 & 0,333 & 0,12 \\
\hline
\end{tabular}

Tabla 9.16.- Parámetros cuantificadores del grupo en el test $n^{\circ} 4$.

Coeficiente de variación $\rightarrow 0,16$

Mejora relativa $\rightarrow 0,227$

Valoración individual

\begin{tabular}{|c|c|c|c|c|}
\hline Alumno & $\begin{array}{c}\text { Calificación } \\
\text { individual }\end{array}$ & $L A_{i}$ & $L A_{R i}$ & $L A_{W i}$ \\
\hline $01-a$ & 7,6 & 0,76 & 0,760 & ---- \\
\hline $01-b$ & 7,6 & 0,76 & 0,760 & ----- \\
\hline 01-c & 9,6 & 0,96 & 0,960 & ---- \\
\hline $02-a$ & 7,6 & 0,84 & 0,864 & 0,667 \\
\hline $02-b$ & 6,0 & 0,64 & 0,682 & 0,333 \\
\hline 02-c & 6,8 & 0,72 & 0,773 & 0,333 \\
\hline $02-d$ & 3,2 & 0,36 & 0,318 & 0,667 \\
\hline 03-a & 6,0 & 0,64 & 0,667 & 0,500 \\
\hline 03-b & 7,6 & 0,76 & 0,857 & 0,250 \\
\hline 03-c & 8,0 & 0,76 & 0,857 & 0,250 \\
\hline 03-d & 6,0 & 0,68 & 0,714 & 0,500 \\
\hline $04-a$ & 10,0 & 1,00 & 1,000 & ---- \\
\hline $04-b$ & 9,2 & 0,92 & 0,920 & ---- \\
\hline 04-c & 10,0 & 1,00 & 1,000 & ---- \\
\hline $04-d$ & 9,2 & 0,92 & 0,920 & ----- \\
\hline $05-a$ & 5,2 & 0,56 & 0,579 & 0,500 \\
\hline $05-b$ & 6,4 & 0,52 & 0,684 & 0,000 \\
\hline 05-c & 7,6 & 0,68 & 0,842 & 0,167 \\
\hline $06-a$ & 6,0 & 0,52 & 0,591 & 0,000 \\
\hline $06-b$ & 7,6 & 0,68 & 0,773 & 0,000 \\
\hline 06-c & 8,0 & 0,80 & 0,864 & 0,333 \\
\hline \multirow[t]{2}{*}{$06-d$} & 7,6 & 0,88 & 0,864 & 1,000 \\
\hline & 7,4 & & & \\
\hline
\end{tabular}

Tabla 9.17.- Parámetros cuantificadores individuales en el test $n^{\circ} 4$. 


\section{b) Análisis de la intervención en el tema de la estequiometría}

Parámetros cuantitativos del proceso de calificación

\begin{tabular}{|c|c|c|c|}
\hline \multicolumn{4}{|c|}{ Tema $n^{\circ} 5 \rightarrow$ Estequiometría } \\
\hline Alumno & $\begin{array}{c}\text { Calificación } \\
\text { individual }\end{array}$ & $\begin{array}{c}\text { Calificación } \\
\text { grupal }\end{array}$ & Dif. \\
\hline $01-a$ & 8,0 & 10,0 & 2,0 \\
\hline $01-b$ & 6,5 & 10,0 & 3,5 \\
\hline 01-c & 8,5 & 10,0 & 1,5 \\
\hline $02-a$ & 6,5 & 9,0 & 2,5 \\
\hline $02-b$ & 6,5 & 9,0 & 2,5 \\
\hline 02-c & 5,0 & 9,0 & 4,0 \\
\hline $02-d$ & 3,5 & 9,0 & 5,5 \\
\hline 03-a & 6,5 & 8,5 & 2,0 \\
\hline 03-b & 6,0 & 8,5 & 2,5 \\
\hline 03-c & 8,5 & 8,5 & 0,0 \\
\hline 03-d & 4,5 & 8,5 & 4,0 \\
\hline $04-a$ & 9,5 & 10,0 & 0,5 \\
\hline $04-b$ & 9,0 & 10,0 & 1,0 \\
\hline 04-c & 9,5 & 10,0 & 0,5 \\
\hline 04-d & 9,0 & 10,0 & 1,0 \\
\hline $05-a$ & 6,5 & 8,0 & 1,5 \\
\hline 05-b & 5,0 & 8,0 & 3,0 \\
\hline 05-c & 7,5 & 8,0 & 0,5 \\
\hline $06-a$ & 6,5 & 8,0 & 1,5 \\
\hline $06-b$ & 8,0 & 8,0 & 0,0 \\
\hline $06-c$ & 7,5 & 8,0 & 0,5 \\
\hline \multirow[t]{2}{*}{$06-d$} & 5,5 & 8,0 & 2,5 \\
\hline & 6,98 & 8,91 & 1,93 \\
\hline
\end{tabular}

\begin{tabular}{|l|r|r|}
\hline \multicolumn{2}{|c|}{ parámetros estadísticos } \\
\hline & Individual & \multicolumn{1}{|c|}{ Grupo } \\
\hline Media & 6,98 & 8,91 \\
\hline Desv. típ. & 1,672 & 0,840 \\
\hline Varianza & 2,797 & 0,706 \\
\hline Asimetría & $-0,217$ & 0,314 \\
\hline Curtosis & $-0,661$ & $-1,596$ \\
\hline
\end{tabular}

Tabla 9.19. Parámetros estadísticos asociados al test $\mathrm{n}^{\circ} 5$.

a)

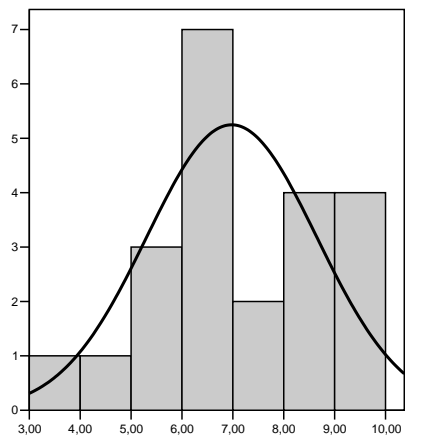

b)

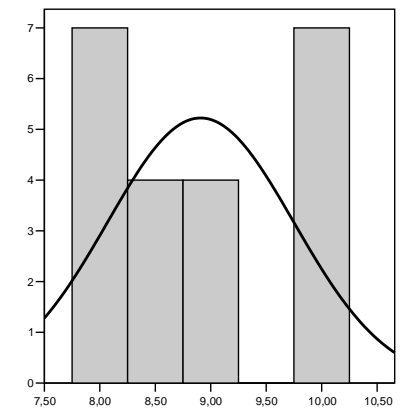

Figura 9.10.- Calificaciones individuales (a) y en grupo (b) en el test $n^{\circ} 5$. 
b) Parámetros cuantificadores del trabajo en grupo

Valoración grupal

\begin{tabular}{|c|c|c|c|c|c|c|c|c|}
\hline Grupo & $x_{g}$ & $\bar{x}_{i}$ & $\Delta x$ & $\Delta x / \bar{x}_{i}$ & $L A$ & $L A_{R}$ & $L A_{W}$ & $\sigma / \bar{x}$ \\
\hline 1 & 10,0 & 7,7 & 2,3 & 0,30 & 0,77 & 0,767 & ----- & 0,18 \\
\hline 2 & 9,0 & 5,4 & 3,6 & 0,67 & 0,60 & 0,597 & 0,625 & 0,27 \\
\hline 3 & 8,5 & 6,4 & 2,1 & 0,33 & 0,63 & 0,691 & 0,250 & 0,26 \\
\hline 4 & 10,0 & 9,3 & 0,7 & 0,08 & 0,93 & 0,925 & ----- & 0,03 \\
\hline 5 & 8,0 & 6,3 & 1,7 & 0,26 & 0,58 & 0,688 & 0,813 & 0,20 \\
\hline 6 & 8,0 & 6,9 & 1,1 & 0,16 & 0,75 & 0,813 & 0,500 & 0,16 \\
\hline
\end{tabular}

Tabla 9.20.- Parámetros cuantificadores del grupo en el test $\mathrm{n}^{\circ} 5$.

Coeficiente de variación $\rightarrow 0,15$

Mejora relativa $\rightarrow 0,300$

Valoración individual

\begin{tabular}{|c|c|c|c|c|}
\hline Alumno & $\begin{array}{c}\text { Calificación } \\
\text { individual }\end{array}$ & $L A_{i}$ & $L A_{R i}$ & $L A_{W i}$ \\
\hline $01-a$ & 7,6 & 0,80 & 0,800 & ---- \\
\hline $01-b$ & 7,6 & 0,65 & 0,650 & ----- \\
\hline 01-c & 9,6 & 0,85 & 0,850 & ---- \\
\hline $02-a$ & 7,6 & 0,75 & 0,722 & 1,00 \\
\hline $02-b$ & 6,0 & 0,70 & 0,722 & 0,50 \\
\hline $02-c$ & 6,8 & 0,55 & 0,556 & 0,50 \\
\hline $02-d$ & 3,2 & 0,40 & 0,389 & 0,50 \\
\hline 03-a & 6,0 & 0,60 & 0,706 & 0,00 \\
\hline 03-b & 7,6 & 0,55 & 0,647 & 0,00 \\
\hline 03-c & 8,0 & 0,90 & 0,941 & 0,67 \\
\hline 03-d & 6,0 & 0,45 & 0,471 & 0,33 \\
\hline $04-a$ & 10,0 & 0,95 & 0,950 & ---- \\
\hline $04-b$ & 9,2 & 0,90 & 0,900 & ---- \\
\hline 04-c & 10,0 & 0,95 & 0,950 & ---- \\
\hline $04-d$ & 9,2 & 0,90 & 0,900 & ----- \\
\hline $05-a$ & 5,2 & 0,70 & 0,813 & 0,25 \\
\hline $05-b$ & 6,4 & 0,40 & 0,500 & 0,00 \\
\hline 05-c & 7,6 & 0,65 & 0,750 & 0,25 \\
\hline $06-a$ & 6,0 & 0,75 & 0,813 & 0,50 \\
\hline $06-b$ & 7,6 & 0,75 & 0,875 & 0,25 \\
\hline 06-c & 8,0 & 0,85 & 0,875 & 0,75 \\
\hline \multirow[t]{2}{*}{$06-d$} & 7,6 & 0,65 & 0,688 & 0,50 \\
\hline & 7,4 & & & \\
\hline
\end{tabular}

Tabla 9.21.- Parámetros cuantificadores individuales en el test $\mathrm{n}^{\circ} 5$. 
Unificando los incrementos en las calificaciones obtenidos en todas las pruebas obtenemos:

\begin{tabular}{|c|c|c|c|c|c|c|c|c|c|c|}
\hline \multirow{2}{*}{ Grupo } & \multicolumn{2}{|c|}{ control-1 } & \multicolumn{2}{|c|}{ control-2 } & \multicolumn{2}{|c|}{ control-3 } & \multicolumn{2}{|c|}{ control-4 } & \multicolumn{2}{|c|}{ control-5 } \\
\hline & Indiv. & Grup. & Indiv. & Grup. & Indiv. & Grup. & Indiv. & Grup. & Indiv. & Grup. \\
\hline$g-1$ & 5,00 & 8,50 & 4,4 & 6,8 & 6,9 & 8,8 & 8,3 & 10 & 7,7 & 10,0 \\
\hline$g-2$ & 6,88 & 9,00 & 5,6 & 9,2 & 6,7 & 8,8 & 5,9 & 8,8 & 5,4 & 9,0 \\
\hline$g-3$ & 8,00 & 9,50 & 4,8 & 6,4 & 7,0 & 8,4 & 6,9 & 8,4 & 6,4 & 8,5 \\
\hline$g-4$ & 5,50 & 7,50 & 6,3 & 8,4 & 5,5 & 7,2 & 9,6 & 10,0 & 9,3 & 10,0 \\
\hline$g-5$ & 7,83 & 9,50 & 7,7 & 9,6 & 8,5 & 9,6 & 6,4 & 7,6 & 6,3 & 8,0 \\
\hline \multirow[t]{5}{*}{$g-6$} & 7,00 & 9,00 & 5,5 & 8,4 & 5,5 & 7,6 & 7,3 & 8,8 & 6,9 & 8,0 \\
\hline & 6,73 & 8,82 & 5,69 & 8,13 & 6,6 & 8,13 & 7,4 & 8,95 & 6,98 & 8,91 \\
\hline & \multicolumn{2}{|c|}{$\Delta c=2,09$} & \multicolumn{2}{|c|}{$\Delta c=2,44$} & \multicolumn{2}{|c|}{$\Delta c=1,53$} & \multicolumn{2}{|c|}{$\Delta c=1,55$} & \multicolumn{2}{|c|}{$\Delta c=1,93$} \\
\hline & \multicolumn{4}{|c|}{$\Delta \mathrm{c}(\mathrm{a})=2,27$} & \multicolumn{2}{|c|}{$\Delta c(b)=1,53$} & \multicolumn{4}{|c|}{$\Delta \mathrm{c}(\mathrm{c})=1,80$} \\
\hline & \multicolumn{10}{|c|}{$\Delta c(t)=1,91$} \\
\hline
\end{tabular}

Tabla 9.22.- Media de las notas de cada test.

\section{Índices de mejora (\%)}

\begin{tabular}{|c|c|c|c|c|c|}
\hline Grupo & control-1 & control-2 & Control-3 & control-4 & control-5 \\
\hline$g-1$ & 70,00 & 54,54 & 26,92 & 20,97 & 30,43 \\
\hline$g-2$ & 30,91 & 64,29 & 31,34 & 49,15 & 67,44 \\
\hline$g-3$ & 18,75 & 33,33 & 20,00 & 21,74 & 33,33 \\
\hline $\mathrm{g}-4$ & 36,37 & 33,33 & 30,91 & 4,17 & 8,11 \\
\hline$g-5$ & 21,27 & 24,14 & 12,50 & 18,75 & 26,32 \\
\hline $\mathrm{q}-6$ & 28,57 & 52,73 & 38,18 & 20.55 & 16,36 \\
\hline & 34,31 & 43,73 & 26,64 & 22,56 & 30,33 \\
\hline
\end{tabular}

Tabla 9.23.- índices de mejora en cada cuestionario y grupo.

\begin{tabular}{|l|c|c|}
\hline \multicolumn{1}{|l|}{} & $\sigma / \bar{x}$ & $\Delta x / \bar{x}_{i}$ \\
\hline Test 1 & 0,26 & 0,345 \\
\hline Test 2 & 0,22 & 0,437 \\
\hline Test 3 & 0,15 & 0,267 \\
\hline Test 4 & 0,16 & 0,227 \\
\hline Test 5 & 0,15 & 0,300 \\
\hline
\end{tabular}

Tabla 9.24.- Valores medios de los coeficientes de variación y mejora relativa en cada test. 


\subsection{Establecimiento de las variables significativas}

Para tratar de cuantificar el trabajo cooperativo se han utilizado las variables descritas en el punto 8.2.5.

En el análisis se pretende establecer una tipología de grupos donde puedan encuadrarse los grupos estudiados en la intervención. Se han estudiando un total de 30 grupos posibles, que corresponden a los seis grupos que han realizado cada uno de los cinco cuestionarios. Estos grupos no están formados por los mismos grupos puesto que se han redistribuido durante su estudio.

Para hacer este estudio se ha realizado un análisis de conglomerados jerárquico utilizando todos los parámetros descritos y estandarizados y utilizando como método de conglomeración el de la vinculación promedio o vinculación inter-grupos y la distancia euclídea como medida de disimilaridad. Se ha ido aplicando este método a diferentes combinaciones de parámetros con intención de identificar, a partir de los dendrogramas correspondientes, los conjuntos de variables que proporcionan los conglomerados más definidos. Se ha determinado el conglomerado de pertenencia para cada caso para un intervalo de 4 a 6 conglomerados, y a continuación se ha analizado en cada caso los estadísticos de grupo para determinar qué número de conglomerados proporciona una caracterización más significativa de los grupos. 
Los valores de los parámetros utilizados en el análisis de los grupos son:

\begin{tabular}{|c|c|c|c|c|c|c|c|c|c|c|c|}
\hline & $\bar{x}_{i}$ & $x_{g}$ & $\Delta x$ & $\Delta x / \bar{x}_{i}$ & $L A$ & $L A_{R}$ & $L A_{W}$ & $L A_{1}$ & $L A_{1 R}$ & $L A_{1 W}$ & $\sigma / \bar{x}_{i}$ \\
\hline 1 & 0,500 & 0,850 & 0,350 & 0,700 & 0,550 & 0,569 & 0,444 & 0,800 & 0,824 & 0,667 & 0,460 \\
\hline 2 & 0,688 & 0,900 & 0,212 & 0,308 & 0,690 & 0,722 & 0,375 & 0,850 & 0,889 & 0,500 & 0,220 \\
\hline 3 & 0,800 & 0,950 & 0,150 & 0,188 & 0,840 & 0,842 & 0,750 & 1,000 & 1,000 & 1,000 & 0,180 \\
\hline 4 & 0,550 & 0,750 & 0,200 & 0,364 & 0,510 & 0,583 & 0,300 & 0,600 & 0,733 & 0,400 & 0,230 \\
\hline 5 & 0,783 & 0,950 & 0,167 & 0,213 & 0,590 & 0,605 & 0,250 & 0,900 & 0,947 & 0,000 & 0,200 \\
\hline 6 & 0,700 & 0,900 & 0,200 & 0,286 & 0,680 & 0,722 & 0,375 & 0,850 & 0,889 & 0,500 & 0,290 \\
\hline 7 & 0,440 & 0,680 & 0,240 & 0,545 & 0,550 & 0,569 & 0,500 & 0,720 & 0,765 & 0,625 & 0,160 \\
\hline 8 & 0,560 & 0,920 & 0,360 & 0,643 & 0,580 & 0,598 & 0,375 & 0,800 & 0,870 & 0,000 & 0,420 \\
\hline 9 & 0,480 & 0,640 & 0,160 & 0,333 & 0,590 & 0,609 & 0,556 & 0,800 & 0,750 & 0,889 & 0,120 \\
\hline 10 & 0,630 & 0,840 & 0,210 & 0,333 & 0,650 & 0,702 & 0,375 & 0,640 & 0,762 & 0,000 & 0,170 \\
\hline 11 & 0,773 & 0,960 & 0,187 & 0,242 & 0,770 & 0,792 & 0,333 & 0,960 & 0,958 & 1,000 & 0,280 \\
\hline 12 & 0,550 & 0,840 & 0,290 & 0,527 & 0,600 & 0,563 & 0,524 & 0,640 & 0,714 & 0,250 & 0,180 \\
\hline 13 & 0,693 & 0,880 & 0,187 & 0,270 & 0,710 & 0,742 & 0,444 & 0,760 & 0,818 & 0,333 & 0,090 \\
\hline 14 & 0,670 & 0,880 & 0,210 & 0,313 & 0,700 & 0,739 & 0,417 & 0,880 & 0,880 & 0,955 & 0,250 \\
\hline 15 & 0,700 & 0,840 & 0,140 & 0,200 & 0,740 & 0,798 & 0,438 & 0,840 & 0,952 & 0,250 & 0,140 \\
\hline 16 & 0,550 & 0,720 & 0,170 & 0,309 & 0,630 & 0,694 & 0,464 & 0,800 & 0,889 & 0,571 & 0,220 \\
\hline 17 & 0,853 & 0,960 & 0,107 & 0,125 & 0,670 & 0,667 & 0,750 & 0,960 & 0,958 & 1,000 & 0,100 \\
\hline 18 & 0,550 & 0,760 & 0,210 & 0,382 & 0,600 & 0,684 & 0,333 & 0,640 & 0,737 & 0,333 & 0,090 \\
\hline 19 & 0,827 & 1,000 & 0,173 & 0,209 & 0,830 & 0,827 & ------ & 0,960 & 0,960 & ------ & 0,140 \\
\hline 20 & 0,590 & 0,880 & 0,290 & 0,492 & 0,640 & 0,659 & 0,500 & 0,840 & 0,864 & 0,667 & 0,320 \\
\hline 21 & 0,690 & 0,840 & 0,150 & 0,217 & 0,710 & 0,774 & 0,375 & 0,760 & 0,857 & 0,250 & 0,150 \\
\hline 22 & 0,960 & 1,000 & 0,040 & 0,042 & 0,960 & 0,960 & ------ & 1,000 & 1,000 & ------ & 0,050 \\
\hline 23 & 0,640 & 0,760 & 0,120 & 0,188 & 0,590 & 0,702 & 0,222 & 0,680 & 0,842 & 0,167 & 0,190 \\
\hline 24 & 0,730 & 0,880 & 0,150 & 0,205 & 0,720 & 0,773 & 0,333 & 0,800 & 0,864 & 0,333 & 0,120 \\
\hline 25 & 0,750 & 1,000 & 0,250 & 0,333 & 0,770 & 0,767 & ------ & 0,850 & 0,850 & ------ & 0,180 \\
\hline 26 & 0,538 & 0,900 & 0,362 & 0,673 & 0,600 & 0,597 & 0,625 & 0,750 & 0,722 & 1,000 & 0,270 \\
\hline 27 & 0,638 & 0,850 & 0,212 & 0,332 & 0,630 & 0,691 & 0,250 & 0,900 & 0,941 & 0,667 & 0,260 \\
\hline 28 & 0,925 & 1,000 & 0,075 & 0,081 & 0,930 & 0,925 & ------ & 0,950 & 0,950 & ------ & 0,030 \\
\hline 29 & 0,633 & 0,800 & 0,167 & 0,264 & 0,580 & 0,688 & 0,813 & 0,650 & 0,750 & 0,250 & 0,200 \\
\hline 30 & 0,688 & 0,800 & 0,112 & 0,163 & 0,750 & 0,813 & 0,500 & 0,850 & 0,875 & 0,750 & 0,160 \\
\hline
\end{tabular}

Tabla 9.25.- valores de los parámetros utilizados. 
Con la intención de establecer la tipología de grupos se han utilizado dendrogramas, obtenidos a partir de la combinación de las variables empleadas. El que mejor ha clasificado a los grupos de trabajo ha sido el obtenido a partir de la combinación de cuatro variables: $\bar{x}_{i}, \Delta x / \bar{x}_{i}, L A, L A_{R i}$ Con las que se ha obtenido el dendrograma:

Rescaled Distance Cluster Combine

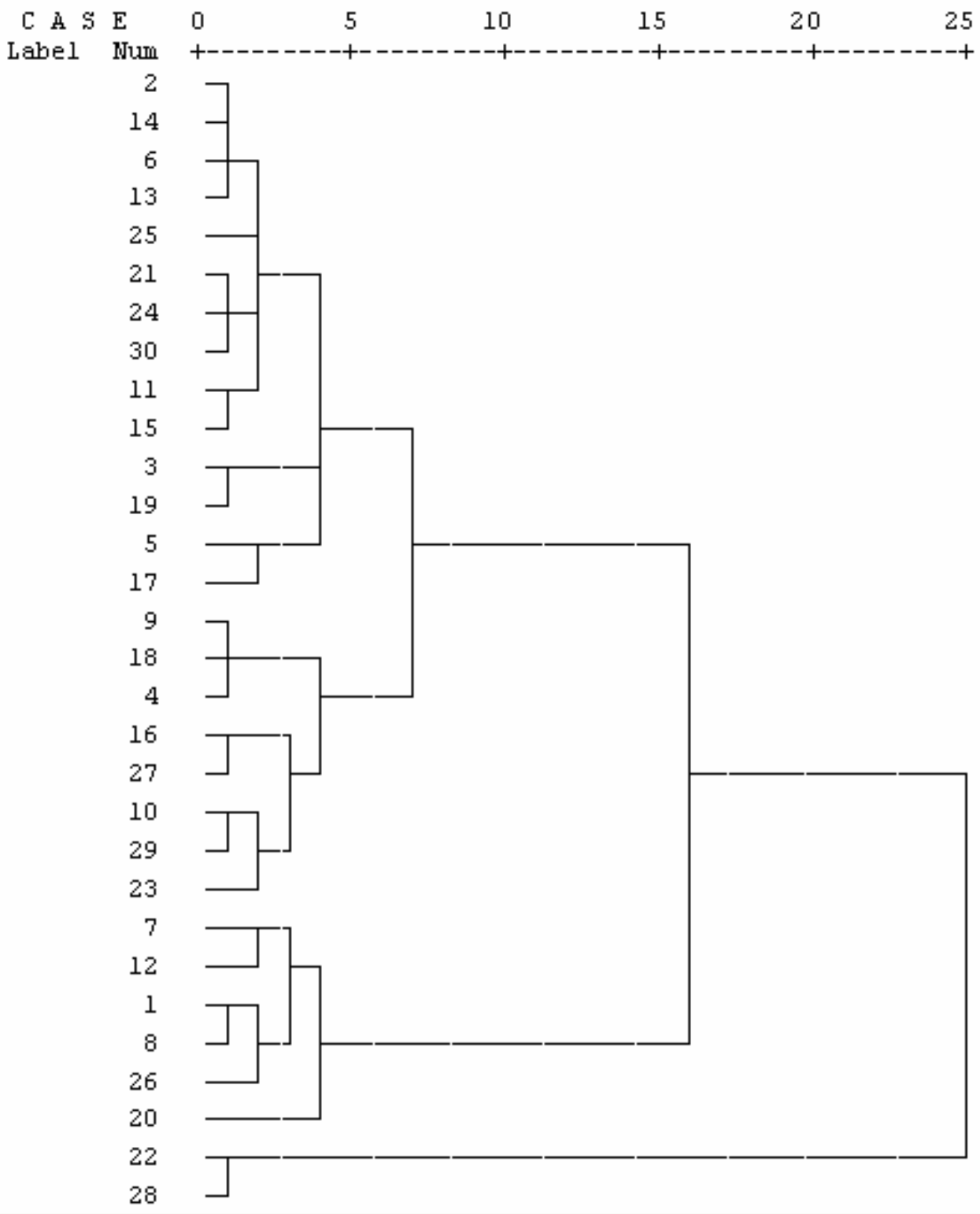

Figura 9.12.- Dendrograma obtenido a partir de las variables $\bar{x}_{i}, \Delta x / \bar{x}_{i}, L A, L A_{R i}$ 
Estadísticos de los cuatro conglomerados definidos

\begin{tabular}{|c|c|c|c|}
\hline & & Media & Desv. Típica \\
\hline \multirow{4}{*}{14 casos } & $\bar{x}_{i}$ & 0,7389 & 0,0590 \\
\hline & $\Delta x / \overline{x_{i}}$ & 0,2371 & 0,0607 \\
\hline & $L A$ & 0,7264 & 0,0649 \\
\hline & $L A_{R i}$ & 0,9069 & 0,0542 \\
\hline \multirow{4}{*}{8 casos } & $\bar{x}_{i}$ & 0,5839 & 0,5959 \\
\hline & $\Delta x / \bar{x}_{i}$ & 0,3131 & 0,6160 \\
\hline & $L A$ & 0,5975 & 0,0430 \\
\hline & $L A_{R i}$ & 0,8005 & 0,0797 \\
\hline \multirow{4}{*}{6 casos } & $\bar{x}_{i}$ & 0,5297 & 0,0528 \\
\hline & $\Delta x / \bar{x}_{i}$ & 0,5967 & 0,0862 \\
\hline & $L A$ & 0,5867 & 0,0344 \\
\hline & $L A_{R i}$ & 0,7932 & 0,0693 \\
\hline \multirow{4}{*}{2 casos } & $\bar{x}_{i}$ & 0,9425 & 0,0247 \\
\hline & $\Delta x / \overline{x_{i}}$ & 0,0615 & 0,0276 \\
\hline & $L A$ & 0,9450 & 0,0212 \\
\hline & $L A_{R i}$ & 0,9750 & 0,354 \\
\hline \multirow{4}{*}{ Total } & $\bar{x}_{i}$ & 0,6693 & 0,1283 \\
\hline & $\Delta x / \overline{x_{i}}$ & 0,3160 & 0,1671 \\
\hline & $L A$ & 0,6787 & 0,1101 \\
\hline & $L A_{R i}$ & 0,8603 & 0,0872 \\
\hline
\end{tabular}

Tabla 9.26.- Caracterización de los conglomerados obtenidos.

Se observa claramente que a lo largo de la intervención se produce un aumento del rendimiento en las actividades realizadas. No obstante podemos hacer una clasificación de los resultados obtenidos en base a los conglomerados obtenidos: 
En el modelo 1, que supone un $46 \%$ de los casos, se caracteriza por un aumento moderado del rendimiento en alumnos que ya partían de una buena nota individual. Así mismo los valores de LA y $L A_{R i}$ son elevados, lo que supone una baja interacción entre los alumnos y una situación más próxima a la mejora por suma de contribuciones individuales que a la aportación de trabajo colectivo.

El modelo 2, supone un $27 \%$ de los casos y refleja un mayor rendimiento que el grupo anterior pero partiendo de una mota individual bastante inferior. Muestra un bajo valor de la correlación con el grupo, pero elevada respecto del alumno de mejor rendimiento, lo que pone de manifiesto una fuerte relación de liderazgo dentro del grupo, que ha tenido un importante efecto positivo en el reste de compañeros.

El tercer modelo (20\% de los casos) es el grupo más interesante. Es el que supone un mayor aumento del rendimiento a partir de una nota individual moderada. Estos grupos tienen asociados valores bajos, tanto de la concordancia entre los miembros del grupo (LA) como, entre el grupo y el alumno con mejores resultados $\left(\mathrm{LA}_{1}\right)$. Por tanto esta mejora en el rendimiento es atribuible a la interacción de los miembros del grupo y la reflexión colectiva, por tanto este tipo de grupos son los que están desarrollando un trabajo cooperativo con mayor eficiencia.

Por último el cuarto modelo (7\% de los casos) supone una situación muy concreta en la que alumnos con un elevado rendimiento individual, experimentan una baja mejoría en su trabajo colectivo. No obstante el resultado final es el mejor de todos los grupos lo que claramente indica que el margen de mejora era muy reducido y pese a ello se ha producido. 


\subsection{Estudio de la influencia del tipo de ítem}

Para completar la investigación se ha optado por estudiar si la influencia del trabajo cooperativo se produce de igual forma en todos los aspectos educativos o si existe una dependencia del objetivo cognitivo que se persigue.

Por ello a continuación vamos a establecer una clasificación de los ítems de cada cuestionario a partir de un criterio basado en la taxonomía de dominios cosgnoscitivos de Bloom-Anderson ${ }^{37}$. En esta se establecen seis niveles sobre lo que los educadores quieren que aprendan los alumnos, pero dadas las características de las pruebas realizadas se ha simplificado en tres únicos niveles, de la forma:

$\mathrm{A} \rightarrow$ Conocimiento/Comprensión (recordar información, reproducir, etiquetar, nombrar, definir...)

$\mathrm{B} \rightarrow$ Cálculo/Aplicación (utilización de datos y leyes para completar un problema., aplicar, resolver...)

$\mathrm{C} \rightarrow$ Relacionar/Analizar (Resolver problemas que impliquen relacionar varios conceptos, categorizar, distinguir, comparar...)

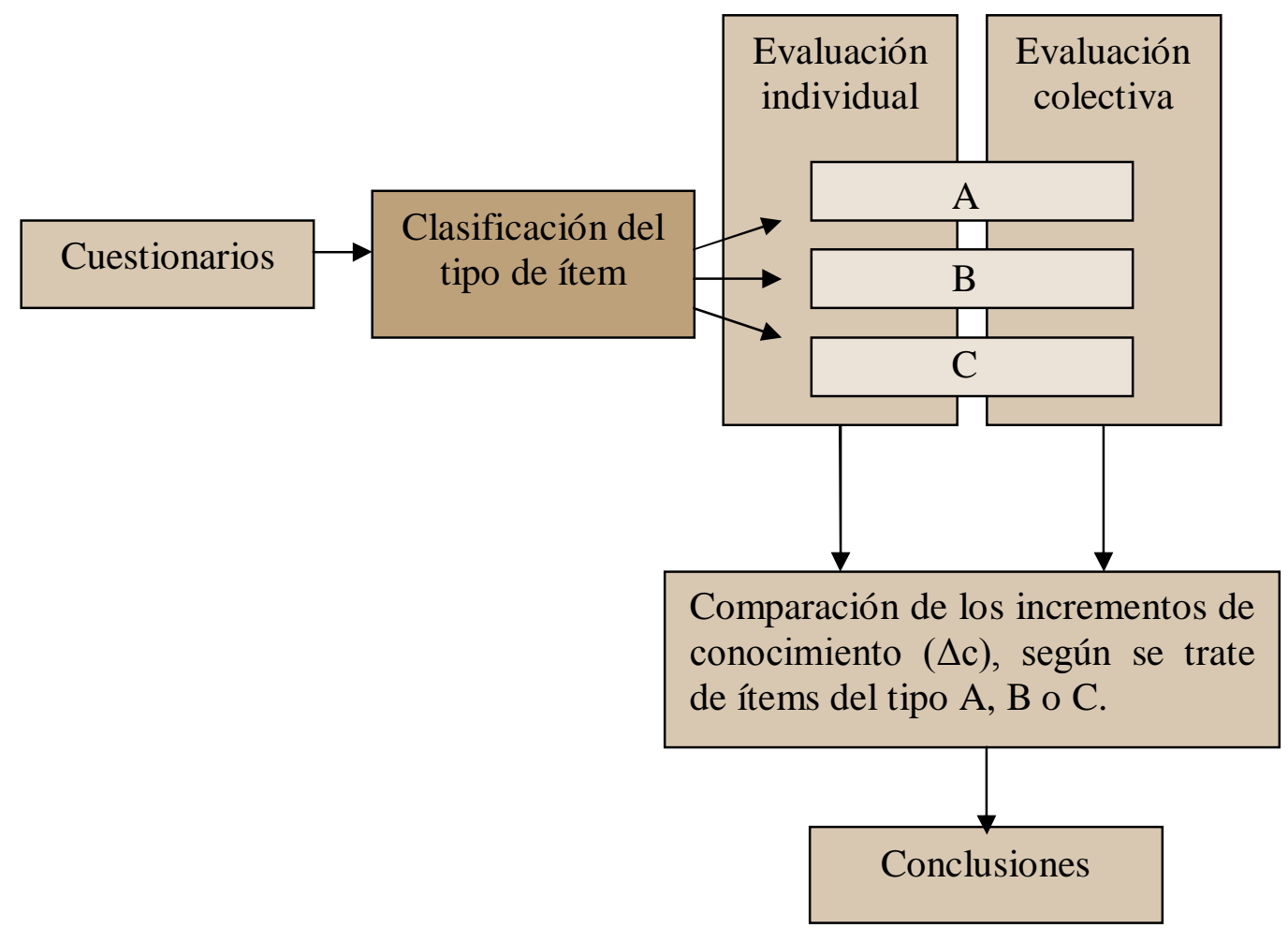

Figura 9. .- Esquema del análisis llevado a cabo para comprobar la influencia del tipo de ítem.

\footnotetext{
${ }^{37}$ Propuesta por Bloom en 1956 y revisada por Anderson en 2001
} 
Se ha aplicado este criterio sobre los ítems propuestos en la intervención (anexos XIII-XXIII), quedando de la forma:

\begin{tabular}{|c|c|c|c|c|c|}
\hline & \multicolumn{5}{|c|}{ Cuestionario } \\
\hline Ítem & 1 & 2 & 3 & 4 & 5 \\
\hline 1 & A & A & A & B & $\mathrm{C}$ \\
\hline 2 & $\mathrm{C}$ & A & A & A & B \\
\hline 3 & $\mathrm{C}$ & A & A & A & B \\
\hline 4 & $\mathrm{~B}$ & A & $\mathrm{C}$ & A & B \\
\hline 5 & $\mathrm{C}$ & $\mathrm{C}$ & A & B & B \\
\hline 6 & $\mathrm{C}$ & $\mathrm{C}$ & A & B & B \\
\hline 7 & B & $\mathrm{C}$ & $\mathrm{C}$ & B & $\mathrm{C}$ \\
\hline 8 & B & A & A & B & B \\
\hline 9 & $\mathrm{C}$ & A & A & A & B \\
\hline 10 & $\mathrm{C}$ & A & $\mathrm{C}$ & A & B \\
\hline 11 & $\mathrm{C}$ & A & $\mathrm{C}$ & A & B \\
\hline 12 & $\mathrm{C}$ & $\mathrm{C}$ & A & A & B \\
\hline 13 & B & $\mathrm{C}$ & A & B & B \\
\hline 14 & $\mathrm{C}$ & $\mathrm{C}$ & $\mathrm{C}$ & B & B \\
\hline 15 & $\mathrm{C}$ & $\mathrm{C}$ & $\mathrm{C}$ & A & B \\
\hline 16 & A & $\mathrm{C}$ & $\mathrm{C}$ & A & B \\
\hline 17 & $\mathrm{~B}$ & $\mathrm{C}$ & $\mathrm{C}$ & B & B \\
\hline 18 & B & $\mathrm{C}$ & $\mathrm{C}$ & A & B \\
\hline 19 & $\mathrm{~B}$ & $\mathrm{C}$ & $\mathrm{C}$ & $\mathrm{C}$ & B \\
\hline 20 & $\mathrm{C}$ & A & $\mathrm{C}$ & $\mathrm{C}$ & B \\
\hline 21 & --- & $\mathrm{C}$ & B & B & --- \\
\hline 22 & --- & A & $\mathrm{C}$ & B & --- \\
\hline 23 & --- & $\mathrm{C}$ & $\mathrm{C}$ & B & --- \\
\hline 24 & --- & B & $\mathrm{C}$ & B & --- \\
\hline 25 & --- & B & $\mathrm{C}$ & B & --- \\
\hline
\end{tabular}

Tabla 9.27.- Clasificación de cada uno de los ítems propuestos en los test.

Una vez clasificados los ítems de cada cuestionario vamos a analizar los conjuntos formados para encontrar su relación con el trabajo cooperativo. 
Test 1

Parámetros cuantitativos del proceso de calificación

\begin{tabular}{|c|c|c|c|c|c|c|c|c|c|}
\hline \multicolumn{10}{|c|}{ Tema $1 \rightarrow$ Leyes de la química } \\
\hline & \multicolumn{3}{|c|}{ A } & \multicolumn{3}{|c|}{ B } & \multicolumn{3}{|c|}{$\mathrm{C}$} \\
\hline Alumno & $\chi_{\mathrm{i}}$ & $\chi_{g}$ & $\Delta \chi$ & $\chi_{\mathrm{i}}$ & $\chi_{\mathrm{g}}$ & $\Delta \chi$ & $\chi_{\mathrm{i}}$ & $\chi_{\mathrm{g}}$ & $\Delta \chi$ \\
\hline $1-a$ & 0 & 5 & 5 & 10,0 & 10 & 0,00 & 6,36 & 8,18 & 1,82 \\
\hline $1-b$ & 0 & 5 & 5 & 5,71 & 10 & 4,29 & 0,91 & 8,18 & 7,27 \\
\hline $1-c$ & 5 & 5 & 0 & 4,29 & 10 & 5,71 & 6,36 & 8,18 & 1,82 \\
\hline $2-a$ & 5 & 10 & 5 & 10,0 & 8,6 & $-1,40$ & 8,18 & 9,09 & 0,91 \\
\hline $2-b$ & 5 & 10 & 5 & 7,14 & 8,6 & 1,43 & 3,64 & 9,09 & 5,45 \\
\hline 2-c & 5 & 10 & 5 & 8,57 & 8,6 & 0,00 & 7,27 & 9,09 & 1,82 \\
\hline 2-d & 10 & 10 & 0 & 7,14 & 8,6 & 1,43 & 5,45 & 9,09 & 3,64 \\
\hline 3-a & 0 & 5 & 5 & 8,57 & 10,0 & 1,43 & 6,36 & 10,0 & 3,64 \\
\hline $3-b$ & 0 & 5 & 5 & 8,57 & 10,0 & 1,43 & 7,27 & 10,0 & 2,73 \\
\hline 3-c & 5 & 5 & 0 & 10,0 & 10,0 & 0,00 & 9,09 & 10,0 & 0,91 \\
\hline 3-d & 5 & 5 & 0 & 10,0 & 10,0 & 0,00 & 10,0 & 10,0 & 0,00 \\
\hline 4-a & 5 & 5 & 0 & 2,86 & 8,6 & 5,71 & 6,36 & 7,27 & 0,91 \\
\hline $4-b$ & 0 & 5 & 5 & 5,71 & 8,6 & 2,86 & 3,64 & 7,27 & 3,64 \\
\hline 4-c & 0 & 5 & 5 & 7,14 & 8,6 & 1,43 & 6,36 & 7,27 & 0,91 \\
\hline 4-d & 5 & 5 & 0 & 10,0 & 8,6 & $-1,40$ & 5,45 & 7,27 & 1,82 \\
\hline $5-a$ & 10 & 10 & 0 & 10,0 & 10,0 & 0,00 & 9,09 & 9,09 & 0,00 \\
\hline $5-b$ & 0 & 10 & 10 & 10,0 & 10,0 & 0,00 & 7,27 & 9,09 & 1,82 \\
\hline 5-c & 5 & 10 & 5 & 8,57 & 10,0 & 1,43 & 5,45 & 9,09 & 3,64 \\
\hline $6-a$ & 0 & 10 & 10 & 7,14 & 8,6 & 1,43 & 2,73 & 9,09 & 6,36 \\
\hline $6-b$ & 0 & 10 & 10 & 10,0 & 8,6 & $-1,40$ & 8,18 & 9,09 & 0,91 \\
\hline 6-c & 10 & 10 & 0 & 10,0 & 8,6 & $-1,40$ & 7,27 & 9,09 & 1,82 \\
\hline $6-d$ & 5 & 10 & 5 & 7,14 & 8,6 & 1,43 & 8,18 & 9,09 & 0,91 \\
\hline & 3,64 & 7,50 & 3,86 & 8,12 & 9,24 & 1,11 & 6,40 & 8,80 & 2,40 \\
\hline
\end{tabular}

Tabla 9.28.- Calificaciones en el test $\mathrm{n}^{\circ} 1$

\begin{tabular}{|l||r|r|r|r|r|r|}
\hline \multicolumn{7}{|c|}{ Tipo de ítem } \\
\hline \multicolumn{1}{|c|}{} & \multicolumn{7}{|c|}{} \\
\hline Indiv. & \multicolumn{1}{|c|}{ Grupo } & Indiv. & \multicolumn{1}{|c|}{ Grupo } & Indiv. & \multicolumn{1}{|c|}{ Grupo } \\
\hline Media & 3,64 & 7,50 & 8,12 & 9,24 & 6,40 & 8,80 \\
\hline Desv. Típ. & 3,512 & 2,559 & 2,086 & 0,714 & 2,199 & 0,905 \\
\hline Varianza & 12,338 & 6,548 & 4,351 & 0,509 & 4,834 & 0,819 \\
\hline Asimetría & 0,442 & 0,000 & $-0,999$ & 0,196 & $-0,766$ & $-0,557$ \\
\hline Curtosis & $-0,762$ & $-2,211$ & 0,412 & $-2,168$ & 0,630 & $-0,576$ \\
\hline
\end{tabular}

Tabla 9.29.- Parámetros estadísticos asociados al test $\mathrm{n}^{\circ} 1$ 
Representando los resultados en un histograma:

A

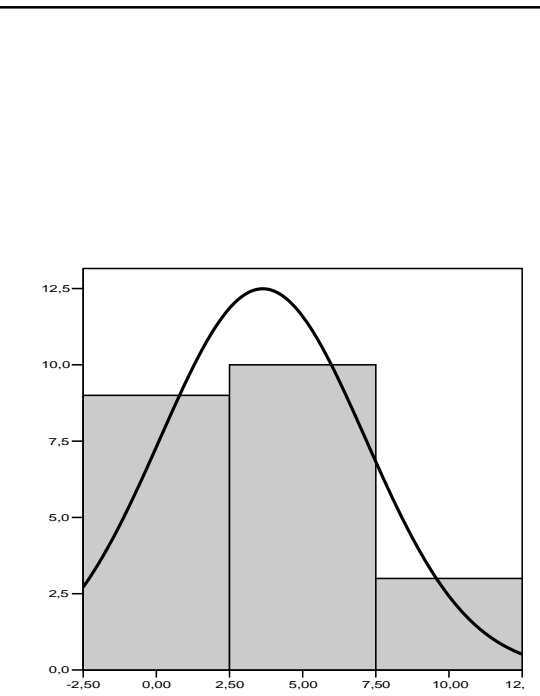

B

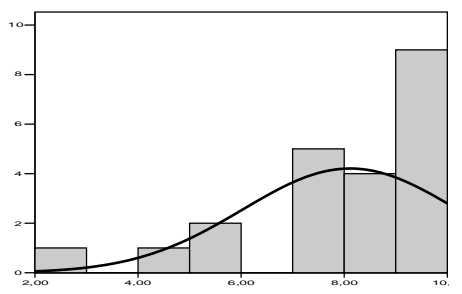

$\mathrm{C}$
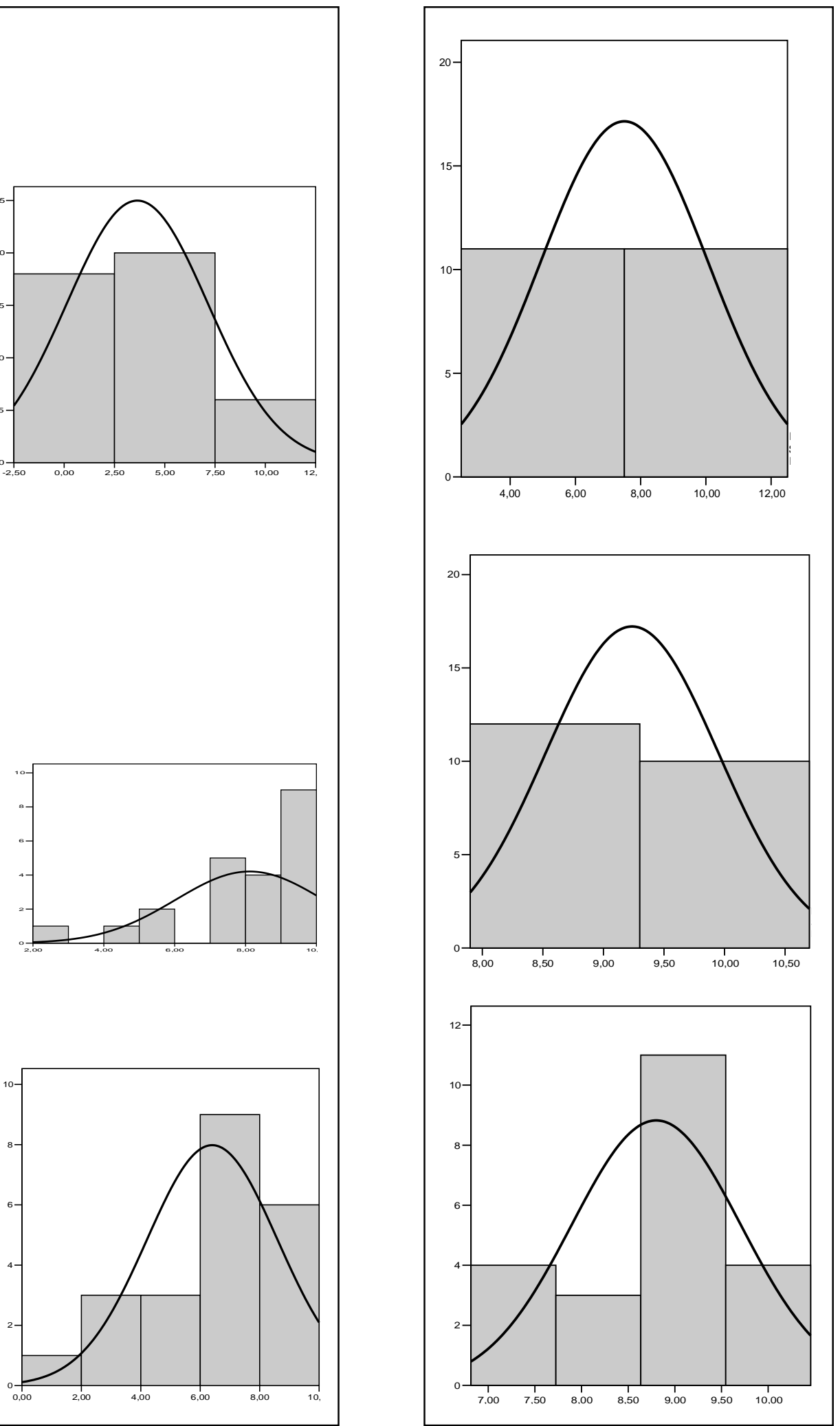

Figura 9.13.- Calificaciones individuales en el test 1. Figura 9.14.- Calificaciones en grupo en el test 1. 


\section{b) Parámetros cuantificadores del trabajo en grupo}

Valoración grupal

\begin{tabular}{|c|c|c|c|c|c|c|c|c|c|c|c|c|}
\hline Ítem & \multicolumn{4}{|c|}{ A } & \multicolumn{4}{|c|}{ B } & \multicolumn{4}{|c|}{ C } \\
\hline Grupo & $\Delta x / \bar{x}_{i}$ & $L A$ & $L A_{R}$ & $\sigma / \bar{x}$ & $\Delta x / \bar{x}_{i}$ & $L A$ & $L A_{R}$ & $\sigma / \bar{x}$ & $\Delta x / \bar{x}_{i}$ & $L A$ & $L A_{R}$ & $\sigma / \bar{x}$ \\
\hline 1 & 2,00 & 0,50 & 0,33 & 1,732 & 0,50 & 0,67 & 0,67 & 0,446 & 0,80 & 0,49 & 0,52 & 0,693 \\
\hline 2 & 0,60 & 0,63 & 0,63 & 0,400 & 0,04 & 0,75 & 0,88 & 0,167 & 0,48 & 0,66 & 0,65 & 0,328 \\
\hline 3 & 1,00 & 0,63 & 0,50 & 1,155 & 0,08 & 0,93 & 0,93 & 0,089 & 0,22 & 0,82 & 0,82 & 0,203 \\
\hline 4 & 1,00 & 0,25 & 0,00 & 1,155 & 0,33 & 0,58 & 0,63 & 0,463 & 0,33 & 0,52 & 0,63 & 0,235 \\
\hline 5 & 1,00 & 0,50 & 0,50 & 1.000 & 0,05 & 0,95 & 0,95 & 0,087 & 0,25 & 0,73 & 0,77 & 0,25 \\
\hline 6 & 1,67 & 0,38 & 0,38 & 1,277 & 0,00 & 0,75 & 0,88 & 0,193 & 0,38 & 0,71 & 0,70 & 0,396 \\
\hline
\end{tabular}

Tabla 9.30.- Parámetros cuantificadores del grupo en el test 1.

\begin{tabular}{|l|c|c|c|c|}
\hline \multicolumn{1}{|c|}{} & A & B & C \\
\hline Coeficiente de variación & 1,103 & 0,256 & 0,351 \\
\hline Mejora relativa & 1,212 & 0,167 & 0,410 \\
\hline
\end{tabular}

Tabla 9.31.- Coeficientes de variación y mejora relativa medios en el test $\mathrm{n}^{\circ} 1$ en función del tipo de ítem.

Valoración individual

\begin{tabular}{|c|c|c|c|c|c|c|c|c|c|}
\hline \multirow[b]{2}{*}{ Alumno } & \multicolumn{3}{|c|}{$\mathbf{A}$} & \multicolumn{3}{|c|}{ B } & \multicolumn{3}{|c|}{ C } \\
\hline & $L A_{i}$ & $L A_{R i}$ & $L A_{W i}$ & $L A_{i}$ & $L A_{R i}$ & $L A_{W i}$ & $L A_{i}$ & $L A_{R i}$ & $L A_{W i}$ \\
\hline $1-a$ & 0,0 & 0,0 & 0,0 & 1,000 & 1,000 & --- & 0,818 & 0,778 & 1,000 \\
\hline $1-b$ & 0,5 & 0,0 & 1,0 & 0,571 & 0,571 & --- & 0,091 & 0,111 & 0,000 \\
\hline $1-c$ & 1,0 & 1,0 & 1,0 & 0,429 & 0,429 & --- & 0,545 & 0,667 & 0,000 \\
\hline $2-a$ & 0,5 & 0,5 & --- & 0,857 & 1,000 & 0 & 0,909 & 0,900 & 1,000 \\
\hline $2-b$ & 0,5 & 0,5 & --- & 0,714 & 0,833 & 0 & 0,455 & 0,400 & 1,000 \\
\hline $2-c$ & 0,5 & 0,5 & --- & 0,857 & 1,000 & 0 & 0,818 & 0,800 & 1,000 \\
\hline $2-d$ & 1,0 & 1,0 & --- & 0,571 & 0,667 & 0 & 0,455 & 0,500 & 0,000 \\
\hline 3-a & 0,0 & 0,0 & 0,0 & 0,857 & 0,857 & --- & 0,636 & 0,636 & -- \\
\hline $3-b$ & 0,5 & 0,0 & 1,0 & 0,857 & 0,857 & --- & 0,727 & 0,727 & --- \\
\hline $3-c$ & 1,0 & 1,0 & 1,0 & 1,000 & 1,000 & --- & 0,909 & 0,909 & --- \\
\hline $3-d$ & 1,0 & 1,0 & 1,0 & 1,000 & 1,000 & --- & 1,000 & 1.000 & --- \\
\hline $4-a$ & 0,0 & 0,0 & 0,0 & 0,143 & 0,167 & 0 & 0,545 & 0,750 & 0,000 \\
\hline $4-b$ & 0,5 & 0,0 & 1,0 & 0,429 & 0,500 & 0 & 0,545 & 0,500 & 0,667 \\
\hline 4-c & 0,5 & 0,0 & 1,0 & 0,857 & 0,833 & 1 & 0.455 & 0,625 & 0,000 \\
\hline $4-d$ & 0,0 & 0,0 & 0,0 & 0,857 & 1,000 & 0 & 0,545 & 0,625 & 0,333 \\
\hline $5-a$ & 1,0 & 1,0 & --- & 1,000 & 1,000 & --- & 0,818 & 0,900 & 0,000 \\
\hline $5-b$ & 0,0 & 0,0 & --- & 1,000 & 1,000 & --- & 0,727 & 0,800 & 0,000 \\
\hline $5-c$ & 0,5 & 0,5 & --- & 0,875 & 0,875 & --- & 0,636 & 0,600 & 1,000 \\
\hline $6-a$ & 0,0 & 0,0 & --- & 0,714 & 0,833 & 0 & 0,636 & 0,300 & 1,000 \\
\hline $6-b$ & 0,0 & 0,0 & --- & 0,857 & 1,000 & 0 & 0,909 & 0,900 & 1,000 \\
\hline 6-c & 1,0 & 1,0 & --- & 0,857 & 1,000 & 0 & 0,818 & 0,800 & 1,000 \\
\hline $6-d$ & 0,5 & 0,5 & --- & 0,571 & 0,667 & 0 & 0,727 & 0,800 & 0,000 \\
\hline
\end{tabular}

Tabla 9.32.- Parámetros cuantificadores individuales en el test 1. 
Test 2

Parámetros cuantitativos del proceso de calificación

\begin{tabular}{|c|c|c|c|c|c|c|c|c|c|}
\hline \multicolumn{10}{|c|}{ Tema $2 \rightarrow$ Estructura atómica y sistema periódico } \\
\hline & \multicolumn{3}{|c|}{ A } & \multicolumn{3}{|c|}{ B } & \multicolumn{3}{|c|}{$\mathrm{C}$} \\
\hline Alumno & $\chi_{\mathrm{i}}$ & $\chi_{g}$ & $\Delta \chi$ & $\chi_{\mathrm{i}}$ & $\chi_{\mathrm{g}}$ & $\Delta \chi$ & $\chi_{\mathrm{i}}$ & $\chi_{g}$ & $\Delta \chi$ \\
\hline $1-\mathrm{a}$ & 7 & 7 & 0 & 5 & 10 & 5 & 3,85 & 6,15 & 2,31 \\
\hline $1-b$ & 3 & 7 & 4 & 5 & 10 & 5 & 4,62 & 6,15 & 1,54 \\
\hline $1-c$ & 2 & 7 & 5 & 5 & 10 & 5 & 5,38 & 6,15 & 0,77 \\
\hline $2-a$ & 6 & 9 & 3 & 10 & 10 & 0 & 7,69 & 9,23 & 1,54 \\
\hline $2-b$ & 3 & 9 & 6 & 5 & 10 & 5 & 3,08 & 9,23 & 6,15 \\
\hline 2-c & 8 & 9 & 1 & 5 & 10 & 5 & 8,46 & 9,23 & 0,77 \\
\hline 2-d & 3 & 9 & 6 & 10 & 10 & 0 & 3,85 & 9,23 & 5,38 \\
\hline $3-a$ & 6 & 9 & 3 & 10 & 10 & 0 & 3,85 & 3,85 & 0,00 \\
\hline $3-b$ & 3 & 9 & 6 & 5 & 10 & 5 & 4,62 & 3,85 & $-0,80$ \\
\hline 3-c & 5 & 9 & 4 & 10 & 10 & 0 & 3,85 & 3,85 & 0,00 \\
\hline $3-d$ & 6 & 9 & 3 & 10 & 10 & 0 & 3,85 & 3,85 & 0,00 \\
\hline 4-a & 8 & 10 & 2 & 10 & 10 & 0 & 6,15 & 6,92 & 0,77 \\
\hline $4-b$ & 7 & 10 & 3 & 5 & 10 & 5 & 6,15 & 6,92 & 0,77 \\
\hline 4-c & 8 & 10 & 2 & 0 & 10 & 10 & 6,92 & 6,92 & 0,00 \\
\hline $4-d$ & 5 & 10 & 5 & 5 & 10 & 5 & 4,62 & 6,92 & 2,31 \\
\hline $5-a$ & 7 & 10 & 3 & 10 & 10 & 0 & 10,0 & 9,23 & $-0,80$ \\
\hline $5-b$ & 10 & 10 & 0 & 10 & 10 & 0 & 8,46 & 9,23 & 0,77 \\
\hline 5-c & 3 & 10 & 7 & 10 & 10 & 0 & 6,15 & 9,23 & 3,08 \\
\hline $6-a$ & 8 & 9 & 1 & 10 & 10 & 0 & 5,38 & 7,69 & 2,31 \\
\hline $6-b$ & 5 & 9 & 4 & 5 & 10 & 5 & 3,85 & 7,69 & 3,85 \\
\hline 6-c & 6 & 9 & 3 & 5 & 10 & 5 & 4,62 & 7,69 & 3,08 \\
\hline $6-d$ & 4 & 9 & 5 & 5 & 10 & 5 & 6,92 & 7,69 & 0,77 \\
\hline & 5,59 & 9,05 & 3,45 & 7,05 & 10,00 & 2,95 & 5,56 & 7,13 & 1,57 \\
\hline
\end{tabular}

Tabla 9.33.- Calificaciones en el test $\mathrm{n}^{\circ} 2$

\begin{tabular}{|c|c|c|c|c|c|c|}
\hline \multicolumn{7}{|c|}{ Tipo de ítem } \\
\hline & \multicolumn{2}{|c|}{$A$} & \multicolumn{2}{|c|}{$B$} & \multicolumn{2}{|c|}{ C } \\
\hline & Indiv. & Grupo & Indiv. & Grupo & Indiv. & Grupo \\
\hline Media & 5,59 & 9,05 & 7,05 & 10,00 & 5,56 & 7,13 \\
\hline Desv. Típ. & 2,175 & 0,950 & 2,952 & 0,000 & 1,866 & 1,930 \\
\hline Varianza & 4,729 & 0,903 & 8,712 & 0,000 & 3,481 & 3,725 \\
\hline Asimetría & 0,063 & $-1,196$ & $-0,379$ & & 0,831 & $-0,575$ \\
\hline Curtosis & $-0,865$ & 1,058 & $-0,626$ & & $-0,080$ & $-0,726$ \\
\hline
\end{tabular}

Tabla 9.34.- Parámetros estadísticos asociados al test $\mathrm{n}^{\circ} 2$ 
Que representados en histogramas:
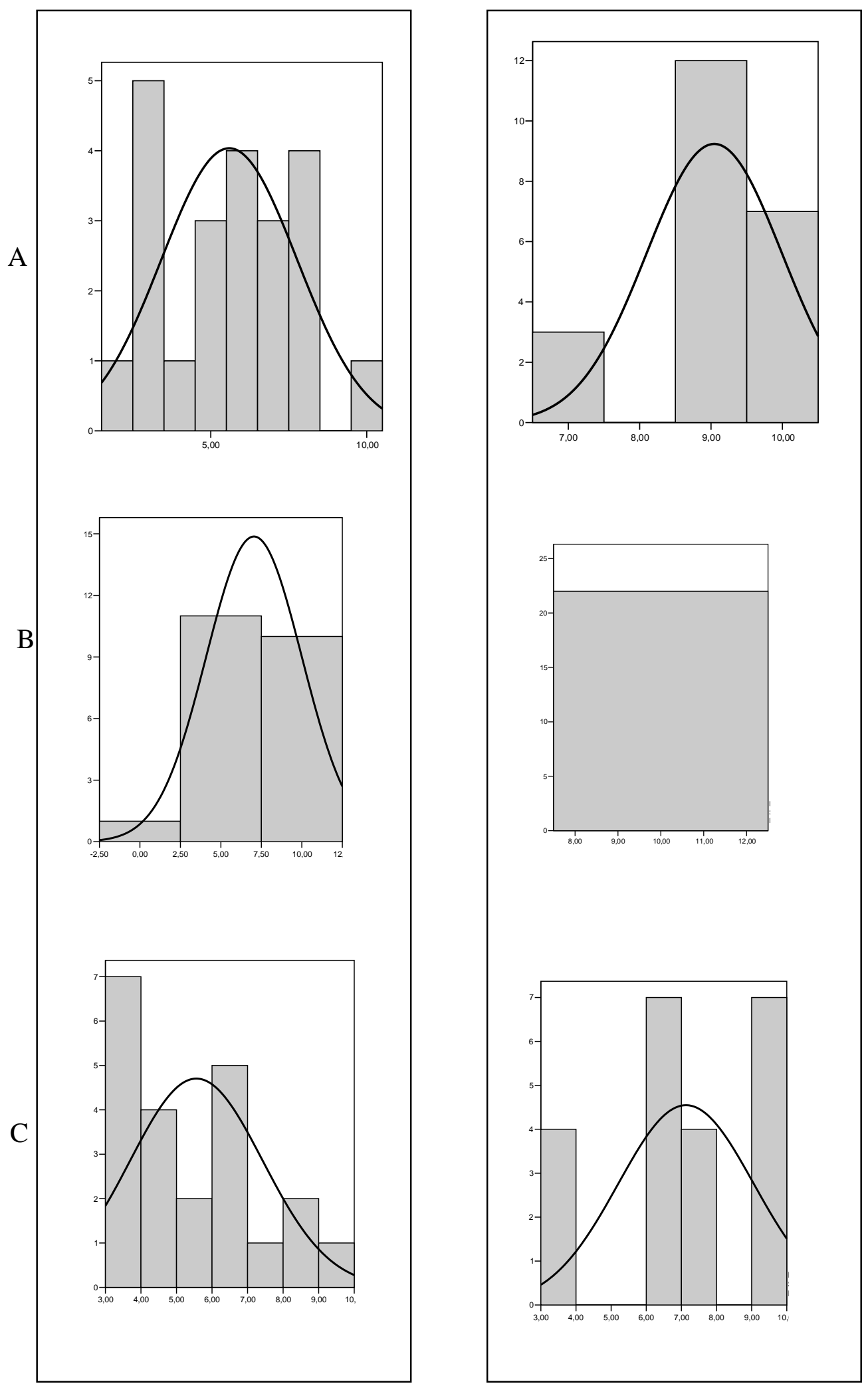

Figura 9.15.- Calificaciones individuales en el test 2. Figura 9.16.- Calificaciones en grupo en el test 2. 
b) Parámetros cuantificadores del trabajo en grupo

Valoración grupal

\begin{tabular}{|c|c|c|c|c|c|c|c|c|c|c|c|c|}
\hline Ítem & \multicolumn{4}{|c|}{ A } & \multicolumn{4}{|c|}{ B } & \multicolumn{4}{|c|}{ C } \\
\hline Grupo & $\Delta x / \bar{x}_{i}$ & $L A$ & $L A_{R}$ & $\sigma / \bar{x}$ & $\Delta x / \bar{x}_{i}$ & $L A$ & $L A_{R}$ & $\sigma / \bar{x}$ & $\Delta x / \bar{x}_{i}$ & $L A$ & $L A_{R}$ & $\sigma / \bar{x}$ \\
\hline 1 & 0,75 & 0,500 & 0,524 & 0,661 & 1,00 & 0,500 & 0,500 & 0,000 & 0,33 & 0,590 & 0,625 & 0,166 \\
\hline 2 & 0,80 & 0,550 & 0,556 & 0,490 & 0,33 & 0,750 & 0,750 & 0,385 & 0,60 & 0,577 & 0,604 & 0,468 \\
\hline 3 & 0,80 & 0,500 & 0,528 & 0,283 & 0,40 & 0,875 & 0,875 & 0,286 & $-0,05$ & 0,615 & 0,650 & 0,095 \\
\hline 4 & 0,43 & 0,700 & 0,700 & 0,202 & 1,00 & 0,500 & 0,500 & 0,766 & 0,16 & 0,635 & 0,750 & 0,162 \\
\hline 5 & 0,50 & 0,667 & 0,667 & 0,527 & 0,00 & 1,000 & 1,000 & 0,000 & 0,13 & 0,821 & 0,861 & 0,236 \\
\hline 6 & 0,57 & 0,625 & 0,639 & 0,297 & 0,60 & 0,625 & 0,625 & 0,400 & 0,48 & 0,577 & 0,575 & 0,252 \\
\hline
\end{tabular}

Tabla 9.35.- Parámetros cuantificadores del grupo en el test $\mathrm{n}^{\circ} 2$.

\begin{tabular}{|l|c|c|c|}
\hline \multicolumn{1}{|c|}{} & A & B & C \\
\hline Coeficiente de variación & 0,410 & 0,306 & 0,230 \\
\hline Mejora relativa & 0,642 & 0,556 & 0,275 \\
\hline
\end{tabular}

Tabla 9.36.- Coeficientes de variación y mejora relativa medios en el test $\mathrm{n}^{\circ} 2$ en función del tipo de ítem. Valoración individual

\begin{tabular}{|c|c|c|c|c|c|c|c|c|c|}
\hline \multirow[b]{2}{*}{ Alumno } & \multicolumn{3}{|c|}{ A } & \multicolumn{3}{|c|}{ B } & \multicolumn{3}{|c|}{ C } \\
\hline & $L A_{i}$ & $L A_{R i}$ & $L A_{W i}$ & $L A_{i}$ & $L A_{R i}$ & $L A_{W i}$ & $L A_{i}$ & $L A_{R i}$ & $L A_{W i}$ \\
\hline $1-a$ & 0,8 & 1,000 & 0,333 & 0,5 & 0,5 & -- & 0,692 & 0,625 & 0,800 \\
\hline $1-b$ & 0,5 & 0,429 & 0,667 & 0,5 & 0,5 & -- & 0,615 & 0,625 & 0,600 \\
\hline $1-c$ & 0,2 & 0,143 & 0,333 & 0,5 & 0,5 & --- & 0,461 & 0,625 & 0,200 \\
\hline $2-a$ & 0,7 & 0,667 & 1,000 & 1,0 & 1,0 & -- & 0,692 & 0,750 & 0,000 \\
\hline $2-b$ & 0,4 & 0,333 & 1,000 & 0,5 & 0,5 & --- & 0,308 & 0,333 & 0,000 \\
\hline $2-c$ & 0,8 & 0,889 & 0,000 & 0,5 & 0,5 & -- & 0,846 & 0,917 & 0,000 \\
\hline $2-d$ & 0,3 & 0,333 & 0,000 & 1,0 & 1,0 & -- & 0,462 & 0,417 & 1,000 \\
\hline $3-a$ & 0,5 & 0,556 & 0,000 & 1,0 & 1,0 & -- & 0,538 & 0,800 & 0,375 \\
\hline $3-b$ & 0,3 & 0,333 & 0,000 & 0,5 & 0,5 & -- & 0,538 & 0,600 & 0,500 \\
\hline $3-c$ & 0,5 & 0,556 & 0,000 & 1,0 & 1,0 & --- & 0,538 & 0,400 & 0,625 \\
\hline $3-d$ & 0,7 & 0,667 & 1,000 & 1,0 & 1,0 & -- & 0,846 & 0,800 & 0,875 \\
\hline 4-a & 0,8 & 0,800 & -- & 1,0 & 1,0 & -- & 0,846 & 0,889 & 0,750 \\
\hline $4-b$ & 0,7 & 0,700 & -- & 0,5 & 0,5 & -- & 0,846 & 0,889 & 0,750 \\
\hline $4-c$ & 0,8 & 0,800 & --- & 0,0 & 0,0 & -- & 0,615 & 0,889 & 0,000 \\
\hline $4-d$ & 0,5 & 0,500 & -- & 0,5 & 0,5 & -- & 0,231 & 0,333 & 0,000 \\
\hline $5-a$ & 0,7 & 0,700 & --- & 1,0 & 1,0 & --- & 0,923 & 1,000 & 0,000 \\
\hline $5-b$ & 1,0 & 1,000 & -- & 1,0 & 1,0 & -- & 0,923 & 0,917 & 1,000 \\
\hline $5-c$ & 0,3 & 0,300 & --- & 1,0 & 1,0 & -- & 0,615 & 0,667 & 0,000 \\
\hline $6-a$ & 0,9 & 0,889 & 1,000 & 1,0 & 1,0 & -- & 0,385 & 0,500 & 0,000 \\
\hline $6-b$ & 0,5 & 0,556 & 0,000 & 0,5 & 0,5 & --- & 0,615 & 0,500 & 1,000 \\
\hline 6-c & 0,7 & 0,667 & 1,000 & 0,5 & 0,5 & -- & 0,692 & 0,600 & 1,000 \\
\hline $6-d$ & 0,4 & 0,444 & 0,000 & 0,5 & 0,5 & -- & 0,615 & 0,700 & 0,333 \\
\hline
\end{tabular}

Tabla 9.37.- Parámetros cuantificadores individuales en el test $\mathrm{n}^{\circ} 2$. 
Test 3

a) Parámetros cuantitativos del proceso de calificación

Tema $3 \rightarrow$ El enlace químico

\begin{tabular}{|c|c|c|c|c|c|c|c|c|c|}
\hline & \multicolumn{3}{|c|}{ A } & \multicolumn{3}{|c|}{ B } & \multicolumn{3}{|c|}{$\mathrm{C}$} \\
\hline Alumno & $\chi_{\mathrm{i}}$ & $\chi_{g}$ & $\Delta \chi$ & $\chi_{i}$ & $\chi_{g}$ & $\Delta \chi$ & $\chi_{i}$ & $\chi_{g}$ & $\Delta \chi$ \\
\hline $1-a$ & 7,78 & 10 & 2,2 & 0 & 0 & 0 & 6,67 & 8,67 & 2,00 \\
\hline $1-b$ & 8,89 & 10 & 1,1 & 10 & 0 & -10 & 4,67 & 8,67 & 4,00 \\
\hline $1-c$ & 10,0 & 10 & 0,0 & 0 & 0 & 0 & 6,67 & 8,67 & 2,00 \\
\hline $2-a$ & 10,0 & 10 & 0,0 & 0 & 10 & 10 & 8,67 & 8,00 & $-0,7$ \\
\hline $2-b$ & 8,89 & 10 & 1,1 & 0 & 10 & 10 & 4,00 & 8,00 & 4,00 \\
\hline $2-c$ & 10,0 & 10 & 0,0 & 0 & 10 & 10 & 6,00 & 8,00 & 2,00 \\
\hline $2-d$ & 6,67 & 10 & 3,3 & 10 & 10 & 0 & 4,00 & 8,00 & 4,00 \\
\hline $3-a$ & 8,89 & 10 & 1,1 & 0 & 10 & 10 & 5,33 & 7,33 & 2,00 \\
\hline $3-b$ & 7,78 & 10 & 2,2 & 0 & 10 & 10 & 6,00 & 7,33 & 1,33 \\
\hline $3-c$ & 10,0 & 10 & 0,0 & 10 & 10 & 0 & 7,33 & 7,33 & 0,00 \\
\hline $3-d$ & 8,89 & 10 & 1,1 & 0 & 10 & 10 & 6,00 & 7,33 & 1,33 \\
\hline $4-a$ & 8,89 & 8,89 & 0,0 & 0 & 10 & 10 & 3,33 & 6,00 & 2,67 \\
\hline $4-b$ & 6,67 & 8,89 & 2,2 & 10 & 10 & 0 & 2,67 & 6,00 & 3,33 \\
\hline 4-c & 7,78 & 8,89 & 1,1 & 0 & 10 & 10 & 4,00 & 6,00 & 2,00 \\
\hline $4-d$ & 10,0 & 8,89 & $-1,0$ & 10 & 10 & 0 & 5,33 & 6,00 & 0,67 \\
\hline $5-a$ & 10,0 & 10 & 0,0 & 10 & 10 & 0 & 8,67 & 9,33 & 0,67 \\
\hline $5-b$ & 8,89 & 10 & 1,1 & 10 & 10 & 0 & 8,67 & 9,33 & 0,67 \\
\hline 5-c & 10,0 & 10 & 0,0 & 0 & 10 & 10 & 6,67 & 9,33 & 2,67 \\
\hline $6-a$ & 10,0 & 8,89 & $-1,0$ & 0 & 10 & 10 & 4,00 & 6,67 & 2,67 \\
\hline $6-b$ & 7,78 & 8,89 & 1,1 & 0 & 10 & 10 & 4,67 & 6,67 & 2,00 \\
\hline 6-c & 7,78 & 8,89 & 1,1 & 0 & 10 & 10 & 3,33 & 6,67 & 3,33 \\
\hline 6-d & 6,67 & 8,89 & 2,2 & 0 & 10 & 10 & 5,33 & 6,67 & 1,33 \\
\hline & 8,74 & 9,60 & 0,86 & 3,18 & 8,64 & 5,45 & 5,55 & 7,55 & 2,00 \\
\hline
\end{tabular}

Tabla 9.38.- Calificaciones en el test $\mathrm{n}^{\circ} 3$

\begin{tabular}{|c|c|c|c|c|c|c|}
\hline \multicolumn{7}{|c|}{ Tipo de ítem } \\
\hline & \multicolumn{2}{|c|}{ A } & \multicolumn{2}{|c|}{ B } & \multicolumn{2}{|c|}{ C } \\
\hline & Indiv. & Grupo & Indiv. & Grupo & Indiv. & Grupo \\
\hline Media & 8,74 & 9,60 & 3,18 & 8,64 & 5,55 & 7,55 \\
\hline Desv. Típ. & 1,201 & 0,547 & 4,767 & 3,513 & 1,775 & 1,133 \\
\hline Varianza & 1,443 & 0,299 & 22,727 & 12,338 & 3,152 & 1,285 \\
\hline Asimetría & $-0,450$ & $-0,609$ & 0,839 & $-2,278$ & 0,374 & 0,151 \\
\hline Curtosis & $-1,063$ & $-1,802$ & $-1,436$ & 3,498 & $-0,664$ & $-1,155$ \\
\hline
\end{tabular}

Tabla 9.39.- Parámetros estadísticos asociados al test $n^{\circ} 3$ 
La representación en histogramas quedará:

A

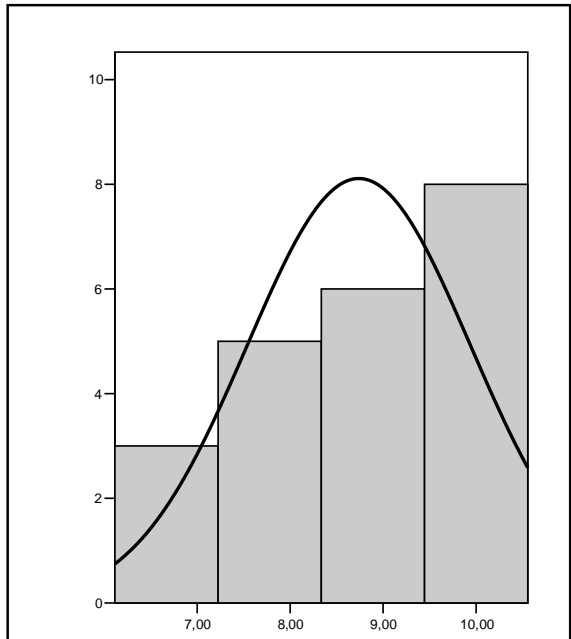

$\mathrm{B}$

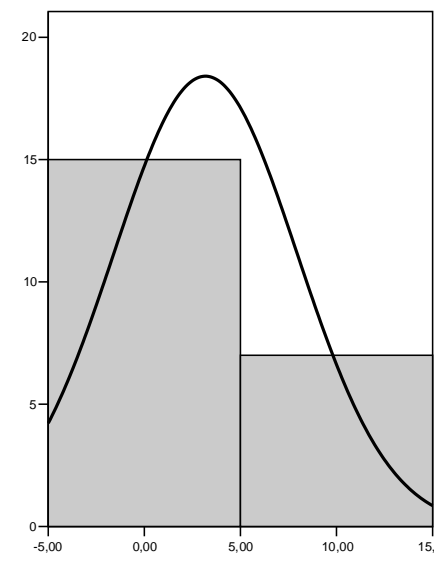

$\mathrm{C}$

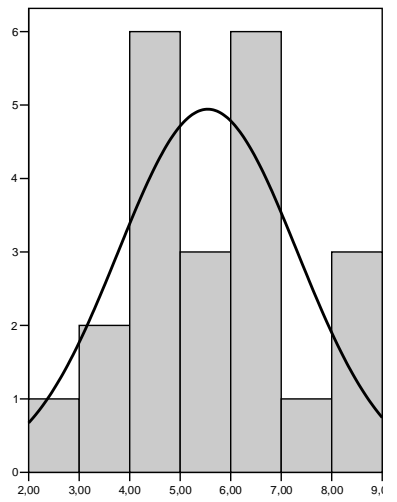

Figura 9.17.- Calificaciones individuales en el test $n^{\circ} 3$. Figura 9.18.- Calificaciones en grupo en el test $\mathrm{n}^{\circ} 3$. 
b) Parámetros cuantificadores del trabajo en grupo

Valoración grupal

\begin{tabular}{|c|c|c|c|c|c|c|c|c|c|c|c|c|}
\hline Ítem & \multicolumn{4}{|c|}{ A } & \multicolumn{4}{|c|}{ B } & \multicolumn{4}{|c|}{$\mathrm{C}$} \\
\hline Grupo & $\Delta x / \bar{x}_{i}$ & $L A$ & $L A_{R}$ & $\sigma / \bar{x}$ & $\Delta x / \bar{x}_{i}$ & $L A$ & $L A_{R}$ & $\sigma / \bar{x}$ & $\Delta x / \bar{x}_{i}$ & $L A$ & $L A_{R}$ & $\sigma / \bar{x}$ \\
\hline 1 & 0,13 & 0,889 & 0,889 & 0,125 & $-1,0$ & 0,667 & --- & 1,732 & 0,44 & 0,600 & 0,641 & 0,192 \\
\hline 2 & 0,13 & 0,889 & 0,889 & 0,177 & 3,0 & 0,250 & 0,250 & 2,000 & 0,41 & 0,617 & 0,667 & 0,390 \\
\hline 3 & 0,13 & 0,889 & 0,889 & 0,102 & 3,0 & 0,250 & 0,250 & 2,000 & 0,19 & 0,683 & 0,773 & 0,136 \\
\hline 4 & 0,07 & 0,750 & 0,844 & 0,172 & 1,0 & 0,500 & 0,500 & 1,155 & 0,57 & 0,567 & 0,583 & 0,297 \\
\hline 5 & 0,04 & 0,963 & 0,963 & 0,067 & 0,5 & 0,667 & 0,667 & 0,866 & 0,17 & 0,867 & 0,857 & 0,144 \\
\hline 6 & 0,10 & 0,806 & 0,875 & 0,173 & --- & 0,000 & 0 & \#\#\#\#\# & 0,538 & 0,517 & 0,600 & 0,199 \\
\hline
\end{tabular}

Tabla 9.40.- Parámetros cuantificadores del grupo en el test 3.

\begin{tabular}{|l|c|c|c|c|}
\hline \multicolumn{1}{|c|}{} & A & B & C \\
\hline Coeficiente de variación & 0,136 & 1,551 & 0,226 \\
\hline Mejora relativa & 0,100 & 1,300 & 0,386 \\
\hline
\end{tabular}

Tabla 9.41.- Coeficientes de variación y mejora relativa medios en el test $\mathrm{n}^{\circ} 3$ en función del tipo de ítem.

Valoración individual

\begin{tabular}{|c|c|c|c|c|c|c|c|c|c|}
\hline \multirow[b]{2}{*}{ Alumno } & \multicolumn{3}{|c|}{$\mathbf{A}$} & \multicolumn{3}{|c|}{ B } & \multicolumn{3}{|c|}{ C } \\
\hline & $L A_{i}$ & $L A_{R i}$ & $L A_{W i}$ & $L A_{i}$ & $L A_{R i}$ & $L A_{W i}$ & $L A_{i}$ & $L A_{R i}$ & $L A_{W i}$ \\
\hline $1-a$ & 0,778 & 0,778 & --- & 1 & & 1 & 0,800 & 0,769 & 1,000 \\
\hline $1-b$ & 0,889 & 0,889 & --- & 0 & & 0 & 0,400 & 0,462 & 0,000 \\
\hline $1-c$ & 1,000 & 1,000 & --- & 1 & & 1 & 0,600 & 0,692 & 0,000 \\
\hline $2-a$ & 1,000 & 1,000 & --- & 0 & 0 & --- & 0,867 & 1,000 & 0,333 \\
\hline $2-b$ & 0,889 & 0,889 & --- & 0 & 0 & --- & 0,533 & 0,500 & 0,667 \\
\hline $2-c$ & 1,000 & 1,000 & --- & 0 & 0 & --- & 0,667 & 0,750 & 0,333 \\
\hline $2-d$ & 0,667 & 0,667 & --- & 1 & 1 & --- & 0,400 & 0,417 & 0,333 \\
\hline $3-a$ & 0,889 & 0,889 & --- & 0 & 0 & --- & 0,533 & 0,636 & 0,250 \\
\hline $3-b$ & 0,778 & 0,778 & --- & 0 & 0 & --- & 0,800 & 0,818 & 0,750 \\
\hline $3-c$ & 1,000 & 1,000 & --- & 1 & 1 & --- & 0,733 & 0,909 & 0,250 \\
\hline $3-d$ & 0,889 & 0,889 & --- & 0 & 0 & --- & 0,667 & 0,727 & 0,500 \\
\hline $4-a$ & 0,889 & 1,000 & 0 & 0 & 0 & --- & 0,533 & 0,556 & 0,500 \\
\hline $4-b$ & 0,556 & 0,625 & 0 & 1 & 1 & --- & 0,467 & 0,444 & 0,500 \\
\hline $4-c$ & 0,667 & 0,750 & 0 & 0 & 0 & --- & 0,533 & 0,556 & 0,500 \\
\hline $4-d$ & 0,889 & 1,000 & 0 & 1 & 1 & --- & 0,733 & 0,778 & 0,667 \\
\hline $5-a$ & 1,000 & 1,000 & --- & 1 & 1 & --- & 0,933 & 0,929 & 1,000 \\
\hline $5-b$ & 0,889 & 0,889 & --- & 1 & 1 & --- & 0,933 & 0,929 & 1,000 \\
\hline 5-c & 1,000 & 1,000 & --- & 0 & 0 & --- & 0,733 & 0,714 & 1,000 \\
\hline $6-a$ & 0,889 & 1,000 & 0 & 0 & 0 & --- & 0,533 & 0,600 & 0,400 \\
\hline $6-b$ & 0,889 & 0,875 & 1 & 0 & 0 & --- & 0,667 & 0,700 & 0,600 \\
\hline 6-c & 0,778 & 0,875 & 0 & 0 & 0 & --- & 0,333 & 0,400 & 0,200 \\
\hline $6-d$ & 0,667 & 0,750 & 0 & 0 & 0 & --- & 0,533 & 0,700 & 0,200 \\
\hline
\end{tabular}

Tabla 9.42.- Parámetros cuantificadores individuales en el test $\mathrm{n}^{\circ} 3$. 
Test 4

a) Parámetros cuantitativos del proceso de calificación

\begin{tabular}{|c|c|c|c|c|c|c|c|c|c|}
\hline \multicolumn{10}{|c|}{ Tema $\mathrm{n}^{\circ} 4 \rightarrow$ Formulación } \\
\hline & \multicolumn{3}{|c|}{ A } & \multicolumn{3}{|c|}{ B } & \multicolumn{3}{|c|}{$\mathrm{C}$} \\
\hline Alumno & $\chi_{\mathrm{i}}$ & $\chi_{g}$ & $\Delta \chi$ & $\chi_{\mathrm{i}}$ & $\chi_{g}$ & $\Delta \chi$ & $\chi_{\mathrm{i}}$ & $\chi_{g}$ & $\Delta \chi$ \\
\hline 01-a & 9 & 10 & 1 & 6,92 & 10,0 & 3,08 & 5 & 10 & 5 \\
\hline $01-b$ & 7 & 10 & 3 & 7,69 & 10,0 & 2,31 & 10 & 10 & 0 \\
\hline 01-c & 10 & 10 & 0 & 9,23 & 10,0 & 0,77 & 10 & 10 & 0 \\
\hline $02-a$ & 9 & 10 & 1 & 6,92 & 7,69 & 0,77 & 5 & 10 & 5 \\
\hline $02-b$ & 9 & 10 & 1 & 3,85 & 7,69 & 3,85 & 5 & 10 & 5 \\
\hline 02-c & 8 & 10 & 2 & 5,38 & 7,69 & 2,31 & 10 & 10 & 0 \\
\hline $02-d$ & 4 & 10 & 6 & 3,08 & 7,69 & 4,62 & 0 & 10 & 10 \\
\hline 03-a & 6 & 10 & 4 & 5,38 & 6,92 & 1,54 & 10 & 10 & 0 \\
\hline 03-b & 8 & 10 & 2 & 4,62 & 6,92 & 2,31 & 10 & 10 & 0 \\
\hline 03-c & 10 & 10 & 0 & 6,92 & 6,92 & 0,00 & 5 & 10 & 5 \\
\hline 03-d & 7 & 10 & 3 & 4,62 & 6,92 & 2,31 & 10 & 10 & 0 \\
\hline 04-a & 10 & 10 & 0 & 10,0 & 10,0 & 0,00 & 10 & 10 & 0 \\
\hline 04-b & 9 & 10 & 1 & 10,0 & 10,0 & 0,00 & 5 & 10 & 5 \\
\hline 04-c & 10 & 10 & 0 & 10,0 & 10,0 & 0,00 & 10 & 10 & 0 \\
\hline 04-d & 10 & 10 & 0 & 8,46 & 10,0 & 1,54 & 10 & 10 & 0 \\
\hline 05-a & 6 & 8 & 2 & 4,62 & 6,92 & 2,31 & 5 & 10 & 5 \\
\hline 05-b & 7 & 8 & 1 & 6,15 & 6,92 & 0,77 & 5 & 10 & 5 \\
\hline 05-c & 8 & 8 & 0 & 6,92 & 6,92 & 0,00 & 10 & 10 & 0 \\
\hline $06-a$ & 9 & 10 & 1 & 3,08 & 8,46 & 5,38 & 10 & 5 & -5 \\
\hline $06-b$ & 8 & 10 & 2 & 7,69 & 8,46 & 0,77 & 5 & 5 & 0 \\
\hline 06-c & 10 & 10 & 0 & 6,92 & 8,46 & 1,54 & 5 & 5 & 0 \\
\hline $06-d$ & 10 & 10 & 0 & 6,15 & 8,46 & 2,31 & 5 & 5 & 0 \\
\hline & 8,36 & 9,73 & 1,36 & 6,57 & 8,32 & 1,75 & 7,27 & 9,09 & 1,82 \\
\hline
\end{tabular}

Tabla 9.43.- Calificaciones en el test $n^{\circ} 4$

\begin{tabular}{|c|c|c|c|c|c|c|}
\hline \multicolumn{7}{|c|}{ Tipo de ítem } \\
\hline & \multicolumn{2}{|c|}{ A } & \multicolumn{2}{|c|}{ B } & \multicolumn{2}{|c|}{ C } \\
\hline & Indiv. & Grupo & Indiv. & Grupo & Indiv. & Grupo \\
\hline Media & 8,36 & 9,73 & 6,57 & 8,32 & 7,27 & 9,09 \\
\hline Desv. Típ. & 1,649 & 0,703 & 2,132 & 1,294 & 2,979 & 1,974 \\
\hline Varianza & 2,719 & 0,494 & 4,544 & 1,673 & 8,874 & 3,896 \\
\hline Asimetría & $-0,997$ & $-2,278$ & 0,097 & 0,314 & $-0,553$ & $-1,773$ \\
\hline Curtosis & 0,692 & 3,498 & $-0,779$ & $-1,596$ & $-0,524$ & 1,250 \\
\hline
\end{tabular}

Tabla 9.44.- Parámetros estadísticos asociados al test $n^{\circ} 4$ 
En los histogramas:
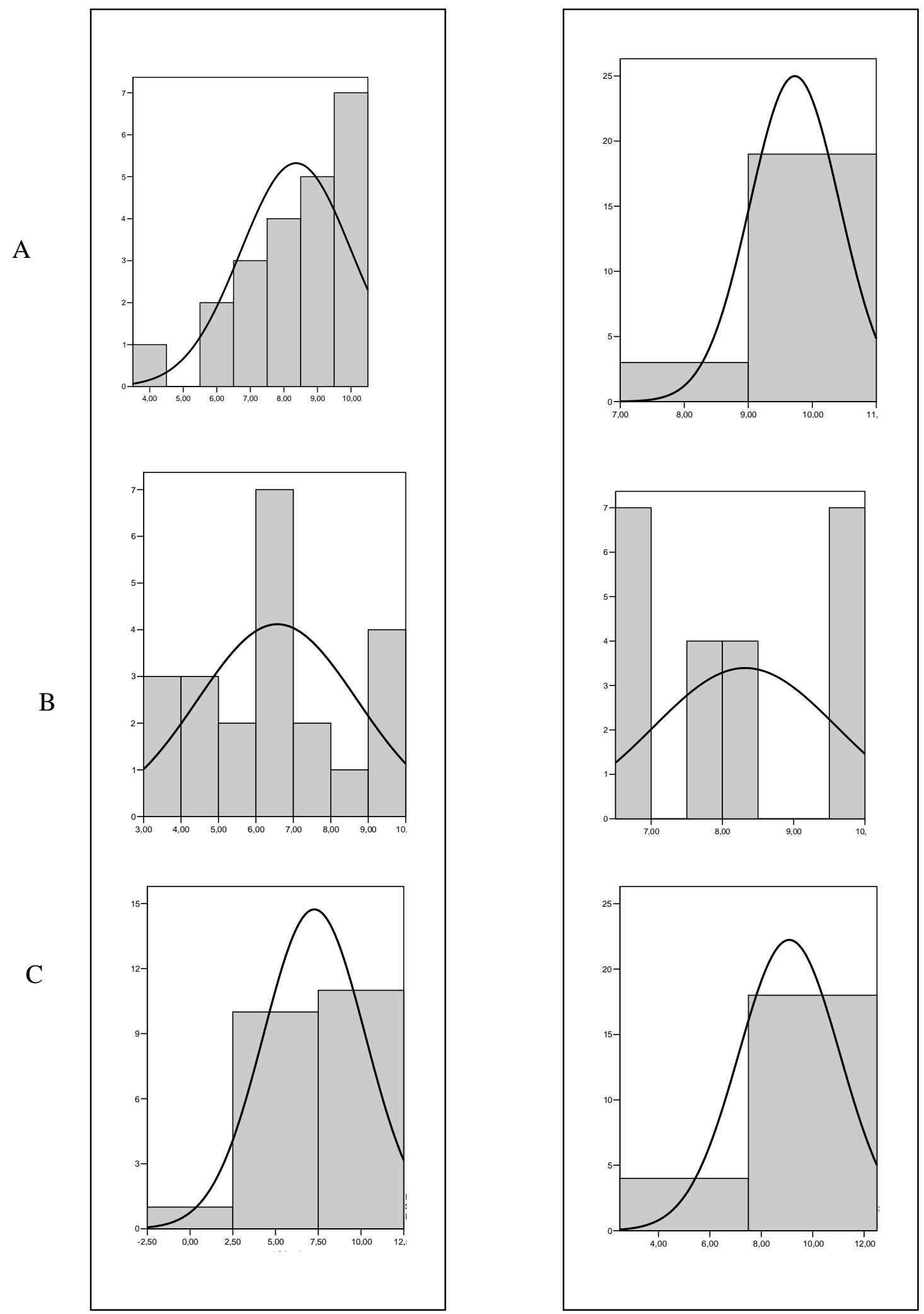

Figura 9.19.- Calificaciones individuales en el test $\mathrm{n}^{\circ} 4 . \quad$ Figura 9.20.- Calificaciones en grupo en el test $\mathrm{n}^{\circ} 4$. 
b) Parámetros cuantificadores del trabajo en grupo

Valoración grupal

\begin{tabular}{|c|c|c|c|c|c|c|c|c|c|c|c|c|}
\hline Ítem & \multicolumn{4}{|c|}{ A } & \multicolumn{4}{|c|}{ B } & \multicolumn{4}{|c|}{$\mathrm{C}$} \\
\hline Grupo & $\Delta x / \bar{x}_{i}$ & $L A$ & $L A_{R}$ & $\sigma / \bar{x}$ & $\Delta x / \bar{x}_{i}$ & $L A$ & $L A_{R}$ & $\sigma / \bar{x}$ & $\Delta x / \bar{x}_{i}$ & $L A$ & $L A_{R}$ & $\sigma / \bar{x}$ \\
\hline 1 & 0,15 & 0,867 & 0,867 & 0,18 & 0,26 & 0,795 & 0,795 & 0,15 & 0,20 & 0,833 & 0,833 & 0,35 \\
\hline 2 & 0,33 & 0,750 & 0,750 & 0,32 & 0,60 & 0,577 & 0,600 & 0,35 & 1,00 & 0,500 & 0,500 & 0,82 \\
\hline 3 & 0,29 & 0,775 & 0,775 & 0,22 & 0,16 & 0,635 & 0,750 & 0,20 & 0,14 & 0,875 & 0,875 & 0,29 \\
\hline 4 & 0,03 & 0,975 & 0,975 & 0,05 & 0,04 & 0,962 & 0,962 & 0,08 & 0,14 & 0,875 & 0,875 & 0,29 \\
\hline 5 & 0,14 & 0,567 & 0,667 & 0,14 & 0,17 & 0,590 & 0,741 & 0,20 & 0,50 & 0,667 & 0,667 & 0,43 \\
\hline 6 & 0,08 & 0,925 & 0,925 & 0,10 & 0,42 & 0,577 & 0,614 & 0,34 & $-0,20$ & 1,000 & 0,625 & 0,40 \\
\hline
\end{tabular}

Tabla 9.45.- Parámetros cuantificadores del grupo en el test $\mathrm{n}^{\circ} 4$.

\begin{tabular}{|l|c|c|c|c|}
\hline \multicolumn{1}{|c|}{} & A & B & C \\
\hline Coeficiente de variación & 0,168 & 0,220 & 0,430 \\
\hline Mejora relativa & 0,170 & 0,275 & 0,297 \\
\hline
\end{tabular}

Tabla 9.46.- Coeficientes de variación y mejora relativa medios en el test $\mathrm{n}^{\circ} 4$ en función del tipo de ítem.

Valoración individual

\begin{tabular}{|c|c|c|c|c|c|c|c|c|c|}
\hline \multirow[b]{2}{*}{ Alumno } & \multicolumn{3}{|c|}{ A } & \multicolumn{3}{|c|}{ B } & \multicolumn{3}{|c|}{ C } \\
\hline & $L A_{i}$ & $L A_{R i}$ & $L A_{W i}$ & $L A_{i}$ & $L A_{R i}$ & $L A_{W i}$ & $L A_{i}$ & $L A_{R i}$ & $L A_{W i}$ \\
\hline $01-a$ & 0,9 & 0,900 & --- & 0,692 & 0,692 & --- & 0,5 & 0,5 & --- \\
\hline $01-b$ & 0,7 & 0,700 & --- & 0,769 & 0,769 & --- & 1,0 & 1,0 & -- \\
\hline 01-c & 1,0 & 1,000 & --- & 0,923 & 0,923 & --- & 1,0 & 1,0 & --- \\
\hline $02-a$ & 0,9 & 0,900 & --- & 0,846 & 0,900 & 0,667 & 0,5 & 0,5 & --- \\
\hline $02-b$ & 0,9 & 0,900 & --- & 0,462 & 0,500 & 0,333 & 0,5 & 0,5 & --- \\
\hline 02-c & 0,8 & 0,800 & --- & 0,615 & 0,700 & 0,333 & 1,0 & 1,0 & --- \\
\hline $02-d$ & 0,4 & 0,400 & --- & 0,385 & 0,300 & 0,667 & 0,0 & 0,0 & --- \\
\hline 03-a & 0,6 & 0,600 & --- & 0,615 & 0,667 & 0,500 & 1,0 & 1,0 & --- \\
\hline 03-b & 0,8 & 0,800 & --- & 0,692 & 0,889 & 0,250 & 1,0 & 1,0 & --- \\
\hline 03-c & 1,0 & 1,000 & --- & 0,615 & 0,778 & 0,250 & 0,5 & 0,5 & --- \\
\hline 03-d & 0,7 & 0,700 & --- & 0,615 & 0,667 & 0,500 & 1,0 & 1,0 & --- \\
\hline $04-a$ & 1,0 & 1,000 & --- & 1,000 & 1,000 & --- & 1,0 & 1,0 & --- \\
\hline 04-b & 0,9 & 0,900 & --- & 1,000 & 1,000 & --- & 0,5 & 0,5 & --- \\
\hline 04-c & 1,0 & 1,000 & --- & 1,000 & 1,000 & --- & 1,0 & 1,0 & --- \\
\hline 04-d & 1,0 & 1,000 & --- & 0,846 & 0,846 & --- & 1,0 & 1,0 & -- \\
\hline 05-a & 0,4 & 0,500 & 0,000 & 0,692 & 0,667 & 0,750 & 0,5 & 0,5 & --- \\
\hline 05-b & 0,5 & 0,625 & 0,000 & 0,538 & 0,778 & 0,000 & 0,5 & 0,5 & --- \\
\hline 05-c & 0,8 & 0,875 & 0,500 & 0,538 & 0,778 & 0,000 & 1,0 & 1,0 & --- \\
\hline $06-a$ & 0,9 & 0,900 & --- & 0,231 & 0,273 & 0,000 & 0,5 & 1,0 & 0,0 \\
\hline 06-b & 0,8 & 0,800 & --- & 0,615 & 0,727 & 0,000 & 0,5 & 1,0 & 0,0 \\
\hline 06-c & 1,0 & 1,000 & --- & 0,692 & 0,727 & 0,500 & 0,5 & 1,0 & 0,0 \\
\hline $06-d$ & 1,0 & 1,000 & --- & 0,769 & 0,727 & 1,000 & 1,0 & 1,0 & 1,0 \\
\hline
\end{tabular}

Tabla 9.47.- Parámetros cuantificadores individuales en el test $\mathrm{n}^{\circ} 4$. 


\section{Test 5}

a) Parámetros cuantitativos del proceso de calificación

\section{Tema $n^{0} 5 \rightarrow$ Estequiometría}

\begin{tabular}{|c|c|c|c|c|c|c|c|c|c|}
\hline & \multicolumn{3}{|c|}{ A } & \multicolumn{3}{|c|}{ B } & \multicolumn{3}{|c|}{$\mathrm{C}$} \\
\hline Alumno & $\chi_{\mathrm{i}}$ & $\chi_{g}$ & $\Delta \chi$ & $\chi_{\mathrm{i}}$ & $\chi_{g}$ & $\Delta \chi$ & $\chi_{i}$ & $\chi_{g}$ & $\Delta \chi$ \\
\hline $01-a$ & & & & 7,78 & 10,0 & 2,22 & 10 & 10 & 0 \\
\hline $01-b$ & & & & 6,11 & 10,0 & 3,89 & 10 & 10 & 0 \\
\hline 01-c & & & & 8,89 & 10,0 & 1,11 & 5 & 10 & 5 \\
\hline $02-a$ & & & & 6,67 & 8,89 & 2,22 & 5 & 10 & 5 \\
\hline $02-b$ & & & & 6,11 & 8,89 & 2,78 & 10 & 10 & 0 \\
\hline 02-c & & & & 5,00 & 8,89 & 3,89 & 5 & 10 & 5 \\
\hline $02-d$ & & & & 2,78 & 8,89 & 6,11 & 10 & 10 & 0 \\
\hline 03-a & & & & 6,67 & 8,89 & 2,22 & 5 & 5 & 0 \\
\hline 03-b & & & & 6,11 & 8,89 & 2,78 & 5 & 5 & 0 \\
\hline 03-c & & & & 8,33 & 8,89 & 0,56 & 10 & 5 & -5 \\
\hline 03-d & & & & 3,89 & 8,89 & 5,00 & 10 & 5 & -5 \\
\hline 04-a & & & & 9,44 & 10,0 & 0,56 & 10 & 10 & 0 \\
\hline $04-b$ & & & & 8,89 & 10,0 & 1,11 & 10 & 10 & 0 \\
\hline 04-c & & & & 10,0 & 10,0 & 0,00 & 5 & 10 & 5 \\
\hline 04-d & & & & 9,44 & 10,0 & 0,56 & 5 & 10 & 5 \\
\hline $05-a$ & & & & 6,11 & 7,78 & 1,67 & 10 & 10 & 0 \\
\hline $05-b$ & & & & 4,44 & 7,78 & 3,33 & 10 & 10 & 0 \\
\hline 05-c & & & & 7,78 & 7,78 & 0,00 & 5 & 10 & 5 \\
\hline $06-a$ & & & & 7,22 & 8,89 & 1,67 & 0 & 0 & 0 \\
\hline $06-b$ & & & & 7,78 & 8,89 & 1,11 & 10 & 0 & -10 \\
\hline $06-c$ & & & & 7,78 & 8,89 & 1,11 & 5 & 0 & -5 \\
\hline 06-d & & & & 6,11 & 8,89 & 2,78 & 0 & 0 & 0 \\
\hline & & & & 6,97 & 9,09 & 2,12 & 7,05 & 7,27 & 0,23 \\
\hline
\end{tabular}

Tabla 9.48.- Calificaciones en el test $\mathrm{n}^{\circ} 5$

\begin{tabular}{|l|r|r|r|r|r|r|}
\hline \multicolumn{7}{|c|}{ Tipo de ítem } \\
\hline & \multicolumn{2}{|c|}{ A } & B & & C \\
\hline & Indiv. & Grupo & Indiv. & Grupo & Indiv. & Grupo \\
\hline Media & 6,97 & 9,09 & 7,05 & 7,27 & 6,97 & 9,09 \\
\hline Desv. Típ. & 6,945 & 8,890 & 7,500 & 10,000 & 6,945 & 8,890 \\
\hline Varianza & 1,88344 & 0,73759 & 3,33063 & 4,00216 & 1,88344 & 0,73759 \\
\hline Asimetría & 3,547 & 0,544 & 11,093 & 16,017 & 3,547 & 0,544 \\
\hline Curtosis & 0,491 & 0,491 & 0,491 & 0,491 & 0,491 & 0,491 \\
\hline
\end{tabular}

Tabla 9.49.- Parámetros estadísticos asociados al test $n^{\circ} 5$ 
En los histogramas:

B
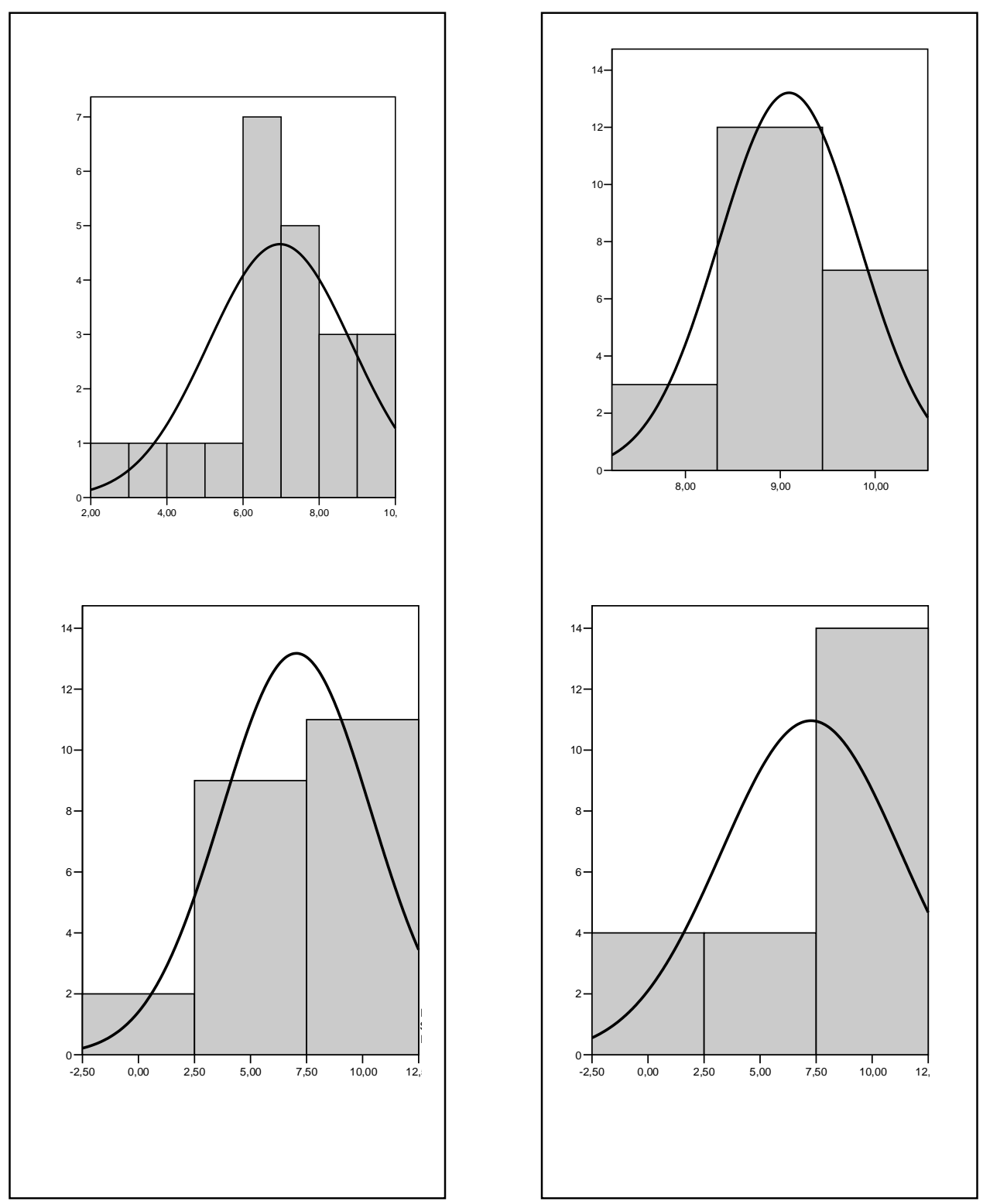

Figura 9.21.- Calificaciones individuales en el test $\mathrm{n}^{\circ} 5$. Figura 9.22.- Calificaciones en grupo en el test $\mathrm{n}^{\circ} 5$. 
b) Parámetros cuantificadores del trabajo en grupo

Valoración grupal

\begin{tabular}{|c|c|c|c|c|c|c|c|c|c|c|c|c|}
\hline Ítem & \multicolumn{4}{|c|}{ A } & \multicolumn{4}{|c|}{ B } & \multicolumn{4}{|c|}{ C } \\
\hline Grupo & $\Delta x / \bar{x}_{i}$ & $L A$ & $L A_{R}$ & $\sigma / \bar{x}$ & $\Delta x / \bar{x}_{i}$ & $L A$ & $L A_{R}$ & $\sigma / \bar{x}$ & $\Delta x / \bar{x}_{i}$ & $L A$ & $L A_{R}$ & $\sigma / \bar{x}$ \\
\hline 1 & & & & & 0,32 & 0,759 & 0,759 & 0,184 & 0,20 & 0,833 & 0,833 & 0,346 \\
\hline 2 & & & & & 0,73 & 0,583 & 0,578 & 0,335 & 0,33 & 0,750 & 0,750 & 0,385 \\
\hline 3 & & & & & 0,42 & 0,639 & 0,672 & 0,293 & $-0,33$ & 0,500 & 1,000 & 0,385 \\
\hline 4 & & & & & 0,06 & 0,944 & 0,944 & 0,048 & 0,33 & 0,750 & 0,750 & 0,385 \\
\hline 5 & & & & & 0,27 & 0,556 & 0,667 & 0,273 & 0,20 & 0,833 & 0,833 & 0,346 \\
\hline 6 & & & & & 0,23 & 0,792 & 0,813 & 0,109 & $-1,00$ & 0,375 & --- & 1,277 \\
\hline
\end{tabular}

Tabla 9.50.- Parámetros cuantificadores del grupo en el test $\mathrm{n}^{\circ} 5$.

\begin{tabular}{|l|l|l|l|l|}
\hline \multicolumn{1}{|c|}{} & A & B & C \\
\hline Coeficiente de variación & --- & 0,207 & 0,521 \\
\hline Mejora relativa & --- & & 0,338 & $-0,045$ \\
\hline
\end{tabular}

Tabla 9.51.- Coeficientes de variación y mejora relativa medios en el test $\mathrm{n}^{\circ} 5$ en función del tipo de ítem.

Valoración individual

\begin{tabular}{|c|c|c|c|c|c|c|c|c|c|}
\hline \multirow[b]{2}{*}{ Alumno } & \multicolumn{3}{|c|}{ A } & \multicolumn{3}{|c|}{ B } & \multicolumn{3}{|c|}{ C } \\
\hline & $L A_{i}$ & $L A_{R i}$ & $L A_{W i}$ & $L A_{i}$ & $L A_{R i}$ & $L A_{W i}$ & $L A_{i}$ & $L A_{R i}$ & $L A_{W i}$ \\
\hline $01-a$ & & & & 0,778 & 0,778 & --- & 1,00 & 1,00 & --- \\
\hline $01-b$ & & & & 0,611 & 0,611 & --- & 1,00 & 1,00 & --- \\
\hline 01-c & & & & 0,889 & 0,889 & --- & 0,50 & 0,50 & --- \\
\hline $02-a$ & & & & 0,778 & 0,750 & 1,00 & 0,50 & 0,50 & --- \\
\hline $02-b$ & & & & 0,667 & 0,688 & 0,50 & 1,00 & 1,00 & --- \\
\hline 02-c & & & & 0,556 & 0,563 & 0,50 & 0,50 & 0,50 & --- \\
\hline $02-d$ & & & & 0,333 & 0,313 & 0,50 & 1,00 & 1,00 & --- \\
\hline 03-a & & & & 0,611 & 0,688 & 0,00 & 0,50 & 1,00 & 0,00 \\
\hline 03-b & & & & 0,556 & 0,625 & 0,00 & 0,50 & 1,00 & 0,00 \\
\hline 03-c & & & & 0,944 & 0,938 & 1,00 & 0,50 & 1,00 & 0,00 \\
\hline 03-d & & & & 0,444 & 0,438 & 0,50 & 0,50 & 1,00 & 0,00 \\
\hline $04-a$ & & & & 0,944 & 0,944 & --- & 1,00 & 1,00 & --- \\
\hline $04-b$ & & & & 0,889 & 0,889 & --- & 1,00 & 1,00 & --- \\
\hline 04-c & & & & 1,000 & 1,000 & --- & 0,50 & 0,50 & --- \\
\hline 04-d & & & & 0,944 & 0,944 & --- & 0,50 & 0,50 & --- \\
\hline $05-a$ & & & & 0,667 & 0,786 & 0,25 & 1,00 & 1,00 & --- \\
\hline 05-b & & & & 0,333 & 0,429 & 0,00 & 1,00 & 1,00 & -- \\
\hline 05-c & & & & 0,667 & 0,786 & 0,25 & 0,50 & 0,50 & --- \\
\hline $06-a$ & & & & 0,778 & 0,813 & 0,50 & 0,50 & --- & 0,50 \\
\hline $06-b$ & & & & 0,833 & 0,875 & 0,50 & 0,00 & --- & 0,00 \\
\hline 06-c & & & & 0,889 & 0,875 & 1,00 & 0,50 & --- & 0,50 \\
\hline $06-d$ & & & & 0,667 & 0,688 & 0,50 & 0,50 & --- & 0,50 \\
\hline
\end{tabular}

Tabla 9.52.- Parámetros cuantificadores individuales en el test $\mathrm{n}^{\circ} 5$. 


\begin{tabular}{|c|c|c|c|c|c|c|c|c|c|c|}
\hline \multirow{2}{*}{$\mathbf{A}$} & \multirow{2}{*}{\multicolumn{2}{|c|}{ control-1 }} & \multirow{2}{*}{\multicolumn{2}{|c|}{ control-2 }} & \multirow{2}{*}{\multicolumn{2}{|c|}{ control-3 }} & \multirow{2}{*}{\multicolumn{2}{|c|}{ control-4 }} & \multirow{2}{*}{\multicolumn{2}{|c|}{ control-5 }} \\
\hline & & & & & & & & & & \\
\hline Grupo & Indiv. & Grup. & Indiv. & Grup. & Indiv. & Grup. & Indiv. & Grup. & Indiv. & Grup. \\
\hline$g-1$ & 1,7 & 5 & 4 & 7 & 8,9 & 10,0 & 8,67 & 10 & & \\
\hline$g-2$ & 6,3 & 10 & 5 & 9 & 8,9 & 10,0 & 7,50 & 10 & & \\
\hline$g-3$ & 2,5 & 5 & 5 & 9 & 8,9 & 10,0 & 7,75 & 10 & & \\
\hline$g-4$ & 2,5 & 5 & 7 & 10 & 8,3 & 8,89 & 9,75 & 10 & & \\
\hline$g-5$ & 5,0 & 10 & 6,7 & 10 & 9,6 & 10,0 & 7,00 & 10 & & \\
\hline \multirow[t]{5}{*}{$g-6$} & 3,8 & 10 & 5,8 & 9 & 8,1 & 8,89 & 9,25 & 10 & & \\
\hline & 3,63 & 7,50 & 5,58 & 9,00 & 8,78 & 9,63 & 8,32 & 10 & & \\
\hline & \multicolumn{2}{|c|}{$\Delta c=3,87$} & \multicolumn{2}{|c|}{$\Delta c=3,42$} & \multicolumn{2}{|c|}{$\Delta c=0,85$} & \multicolumn{2}{|c|}{$\Delta c=1,68$} & \multicolumn{2}{|c|}{$\Delta c=\#$} \\
\hline & \multicolumn{4}{|c|}{$\Delta c(a)=3,65$} & $\Delta \mathrm{c}(\mathrm{b}$ & $=0,85$ & \multicolumn{4}{|c|}{$\Delta c(c)=1,68$} \\
\hline & \multicolumn{10}{|c|}{$\Delta c(t)=2,06$} \\
\hline
\end{tabular}

\begin{tabular}{|c|c|c|c|c|c|c|c|c|c|c|}
\hline \multirow{3}{*}{$\begin{array}{l}\text { B } \\
\text { Grupo }\end{array}$} & \multirow{2}{*}{\multicolumn{2}{|c|}{ control-1 }} & \multirow{2}{*}{\multicolumn{2}{|c|}{ Control-2 }} & \multirow{2}{*}{\multicolumn{2}{|c|}{ control-3 }} & \multirow{2}{*}{\multicolumn{2}{|c|}{ control-4 }} & \multirow{2}{*}{\multicolumn{2}{|c|}{ control-5 }} \\
\hline & & & & & & & & & & \\
\hline & Indiv. & Grup. & Indiv. & Grup. & Indiv. & Grup. & Indiv. & Grup. & Indiv. & Grup. \\
\hline$g-1$ & 6,7 & 10,0 & 5,0 & 10 & & & 7,95 & 10,0 & 7,59 & 10,0 \\
\hline$g-2$ & 8,2 & 8,6 & 7,5 & 10 & & & 4,81 & 7,69 & 5,14 & 8,89 \\
\hline$g-3$ & 9,3 & 10,0 & 8,8 & 10 & & & 5,39 & 6,92 & 6,25 & 8,89 \\
\hline$g-4$ & 6,4 & 8,6 & 6,3 & 10 & & & 9,62 & 10,0 & 9,44 & 10,0 \\
\hline$g-5$ & 9,5 & 10,0 & 10,0 & 10 & & & 5,90 & 6,92 & 6,11 & 7,78 \\
\hline \multirow[t]{5}{*}{$g-6$} & 8,6 & 8,6 & 6,3 & 10 & & & 5,96 & 8,46 & 7,22 & 8,89 \\
\hline & 8,12 & 9,30 & 7,32 & 10,00 & & & 6,61 & 8,33 & 6,96 & 9,08 \\
\hline & \multicolumn{2}{|c|}{$\Delta c=1,18$} & \multicolumn{2}{|c|}{$\Delta c=2,68$} & & & \multicolumn{2}{|c|}{$\Delta c=1,72$} & \multicolumn{2}{|c|}{$\Delta c=2,12$} \\
\hline & \multicolumn{4}{|c|}{$\Delta \mathrm{c}(\mathrm{a})=1,93$} & \multicolumn{2}{|c|}{$\Delta \mathrm{c}(\mathrm{b})=\#$} & \multicolumn{4}{|c|}{$\Delta c(c)=1,92$} \\
\hline & \multicolumn{10}{|c|}{$\Delta c(t)=1,93$} \\
\hline
\end{tabular}

\section{C}

control-1

control-2

control-3

control-4

control-5

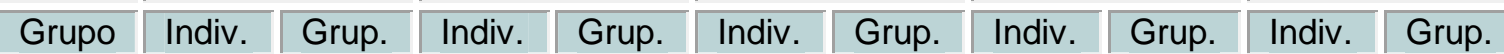

\begin{tabular}{|c|c|c|c|c|c|c|c|c|c|c|}
\hline$g-1$ & 4,5 & 8,18 & 4,6 & 6,15 & 6,0 & 8,67 & 8,33 & 10 & 8,33 & 10 \\
\hline$g-2$ & 6,1 & 9,09 & 5,8 & 9,23 & 5,7 & 8,00 & 5,00 & 10 & 7,50 & 10 \\
\hline$g-3$ & 8,2 & 10,0 & 4,0 & 3,85 & 6,2 & 7,33 & 8,75 & 10 & 7,50 & 5 \\
\hline$g-4$ & 5,5 & 7,27 & 6,0 & 6,92 & 3,8 & 6,00 & 8,75 & 10 & 7,50 & 10 \\
\hline$g-5$ & 7,3 & 9,09 & 8,2 & 9,23 & 8,0 & 9,33 & 6,67 & 10 & 8,33 & 10 \\
\hline \multirow[t]{5}{*}{$g-6$} & 6,6 & 9,09 & 5,2 & 7,69 & 4,3 & 6,67 & 6,25 & 5 & 3,75 & 0 \\
\hline & 6,37 & 8,79 & 5,63 & 7,18 & 5,67 & 7,67 & 7,29 & 9,17 & 7,15 & 7,50 \\
\hline & \multicolumn{2}{|c|}{$\Delta \mathrm{c}=2,42$} & \multicolumn{2}{|c|}{$\Delta c=1,55$} & \multicolumn{2}{|c|}{$\Delta c=2$} & $\Delta c=$ & & \multicolumn{2}{|c|}{$\Delta c=0,35$} \\
\hline & \multicolumn{4}{|c|}{$\Delta c(a)=1,99$} & \multicolumn{2}{|c|}{$\Delta c(b)=2$} & \multicolumn{4}{|c|}{$\Delta c(c)=1,12$} \\
\hline & \multicolumn{10}{|c|}{$\Delta c(t)=1,70$} \\
\hline
\end{tabular}

Tabla 9.53.- Media de las notas de cada test. 


\begin{tabular}{|c|c|c|c|c|c|}
\hline $\mathbf{A}$ & \multicolumn{5}{|c|}{ índice de mejora } \\
\hline Grupo & control-1 & control-2 & Control-3 & control-4 & control-5 \\
\hline$g-1$ & 2,00 & 0,75 & 0,13 & 0,15 & \\
\hline$g-2$ & 0,60 & 0,80 & 0,13 & 0,33 & \\
\hline$g-3$ & 1,00 & 0,80 & 0,13 & 0,29 & \\
\hline$g-4$ & 1,00 & 0,43 & 0,07 & 0,03 & \\
\hline$g-5$ & 1,00 & 0,50 & 0,04 & 0,14 & \\
\hline$g-6$ & 1,67 & 0,57 & 0,10 & 0,08 & \\
\hline 0,53 & 1,21 & 0,64 & 0,10 & 0,17 & \\
\hline
\end{tabular}

\begin{tabular}{|l|r|r|r|r|r|}
\hline \multicolumn{1}{|c|}{ B } & \multicolumn{5}{|c|}{ índice de mejora } \\
\hline Grupo & control-1 & control-2 & Control-3 & control-4 & control-5 \\
\hline g-1 & 0,50 & 1,00 & $-1,00$ & 0,26 & 0,32 \\
\hline g-2 & 0,04 & 0,33 & 3,00 & 0,60 & 0,73 \\
\hline g-3 & 0,08 & 0,40 & 3,00 & 0,16 & 0,42 \\
\hline g-4 & 0,33 & 1,00 & 1,00 & 0,04 & 0,06 \\
\hline g-5 & 0,05 & 0,00 & 0,50 & 0,17 & 0,27 \\
\hline g-6 & 0,00 & 0,60 & -- & 0,42 & 0,23 \\
\hline 0,53 & 0,17 & 0,56 & 1,30 & 0,28 & 0,34 \\
\hline
\end{tabular}

\begin{tabular}{|l||r|r|r|r|r|}
\hline \multicolumn{1}{|c|}{ C } & \multicolumn{5}{|c|}{ índice de mejora } \\
\hline Grupo & control-1 & control-2 & Control-3 & control-4 & control-5 \\
\hline g-1 & 0,80 & 0,33 & 0,44 & 0,20 & 0,20 \\
\hline g-2 & 0,48 & 0,60 & 0,41 & 1,00 & 0,33 \\
\hline g-3 & 0,22 & $-0,05$ & 0,19 & 0,14 & $-0,33$ \\
\hline g-4 & 0,33 & 0,16 & 0,57 & 0,14 & 0,33 \\
\hline g-5 & 0,25 & 0,13 & 0,17 & 0,50 & 0,20 \\
\hline g-6 & 0,38 & 0,48 & 0,54 & $-0,20$ & $-1,00$ \\
\hline 0,286 & 0,41 & 0,28 & 0,39 & 0,30 & $-0,05$ \\
\hline
\end{tabular}

Tabla 9.54.- índices de mejora en cada cuestionario y grupo. 


\begin{tabular}{|l|l|l|}
\hline A & $\sigma / \bar{x}$ & $\Delta x / \bar{x}_{i}$ \\
\hline Test 1 & 1,103 & 1,212 \\
\hline Test 2 & 0,410 & 0,642 \\
\hline Test 3 & 0,136 & 0,100 \\
\hline Test 4 & 0,168 & 0,170 \\
\hline Test 5 & & \\
\hline
\end{tabular}

\begin{tabular}{|l|l|l|}
\hline B & $\sigma / \bar{x}$ & $\Delta x / \bar{x}_{i}$ \\
\hline Test 1 & 0,256 & 0,167 \\
\hline Test 2 & 0,306 & 0,556 \\
\hline Test 3 & 1,551 & 1,300 \\
\hline Test 4 & 0,220 & 0,275 \\
\hline Test 5 & 0,207 & 0,338 \\
\hline
\end{tabular}

\begin{tabular}{|l|l|l|}
\hline \multicolumn{1}{|l|}{} & $\sigma / \bar{x}$ & $\Delta x / \bar{x}_{i}$ \\
\hline Test 1 & 0,351 & 0,410 \\
\hline Test 2 & 0,230 & 0,275 \\
\hline Test 3 & 0,226 & 0,386 \\
\hline Test 4 & 0,430 & 0,297 \\
\hline Test 5 & 0,521 & $-0,045$ \\
\hline
\end{tabular}

Tabla 9.55.- Coeficientes de variación media en cada test en función del tipo de ítem 


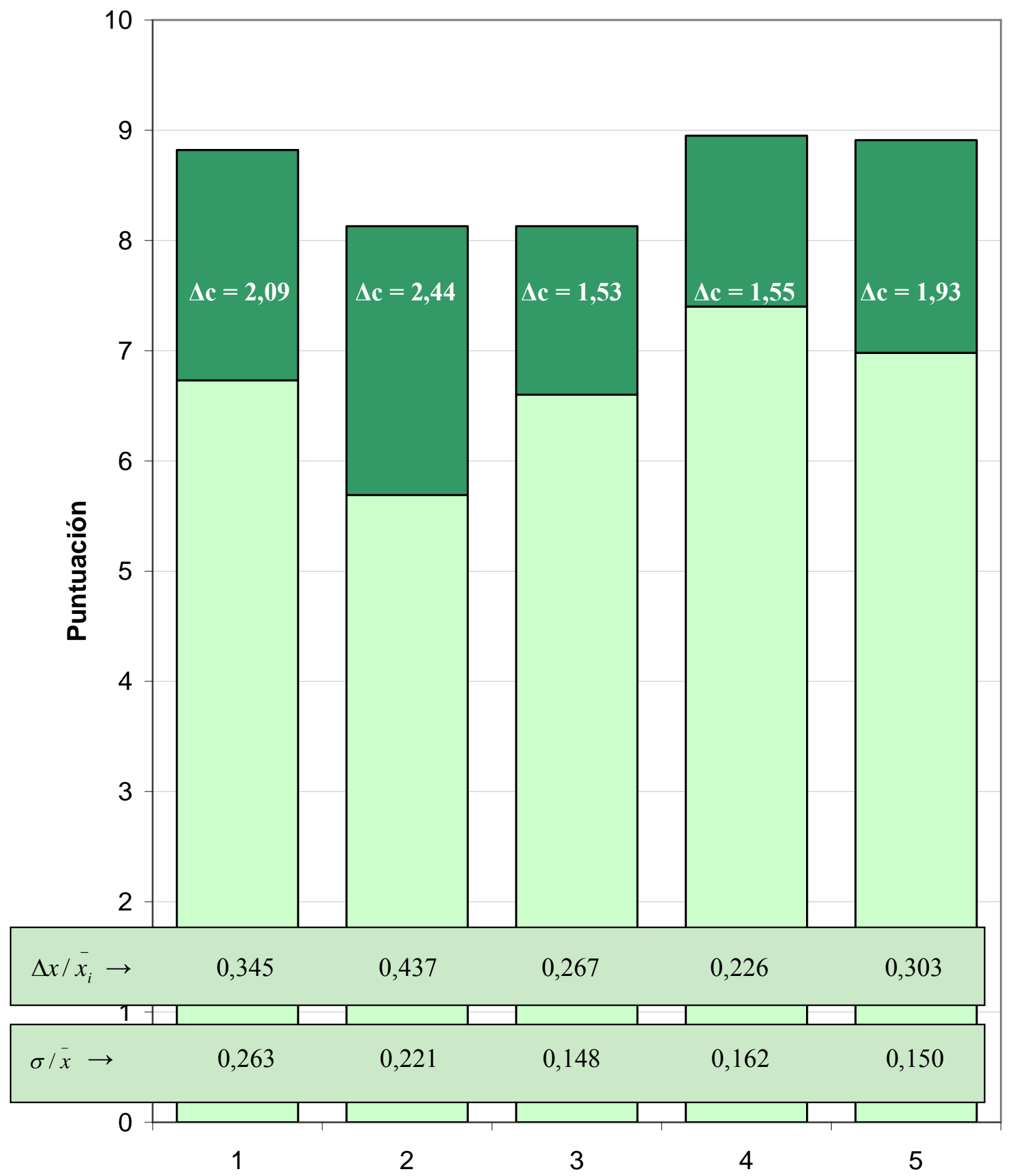

Figura 9.23.- Cuantificación de la ZDP registrada en cada test 


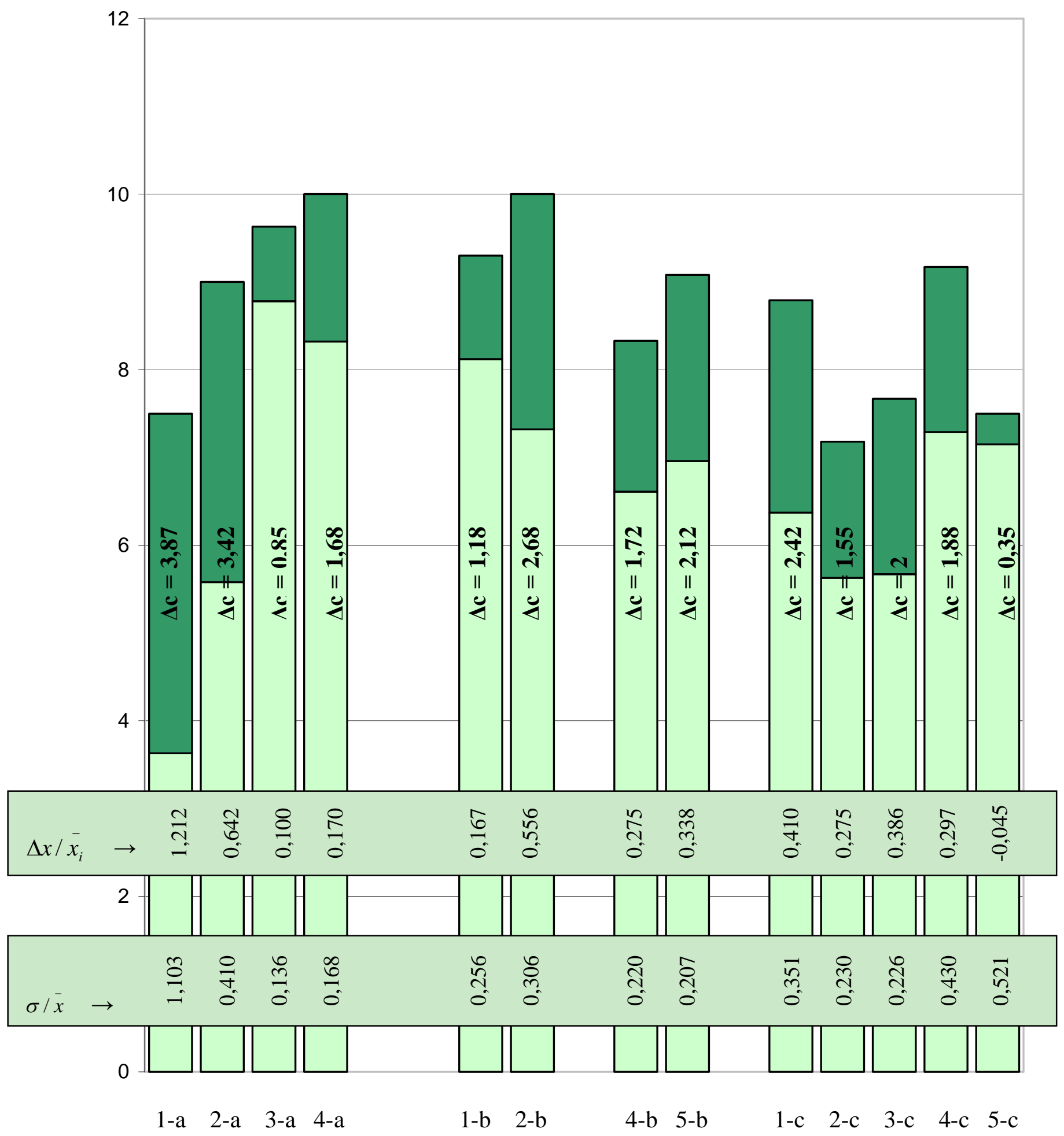

Figura 9.24.-Cuantificación de la ZDP en cada test según el tipo de ítem 


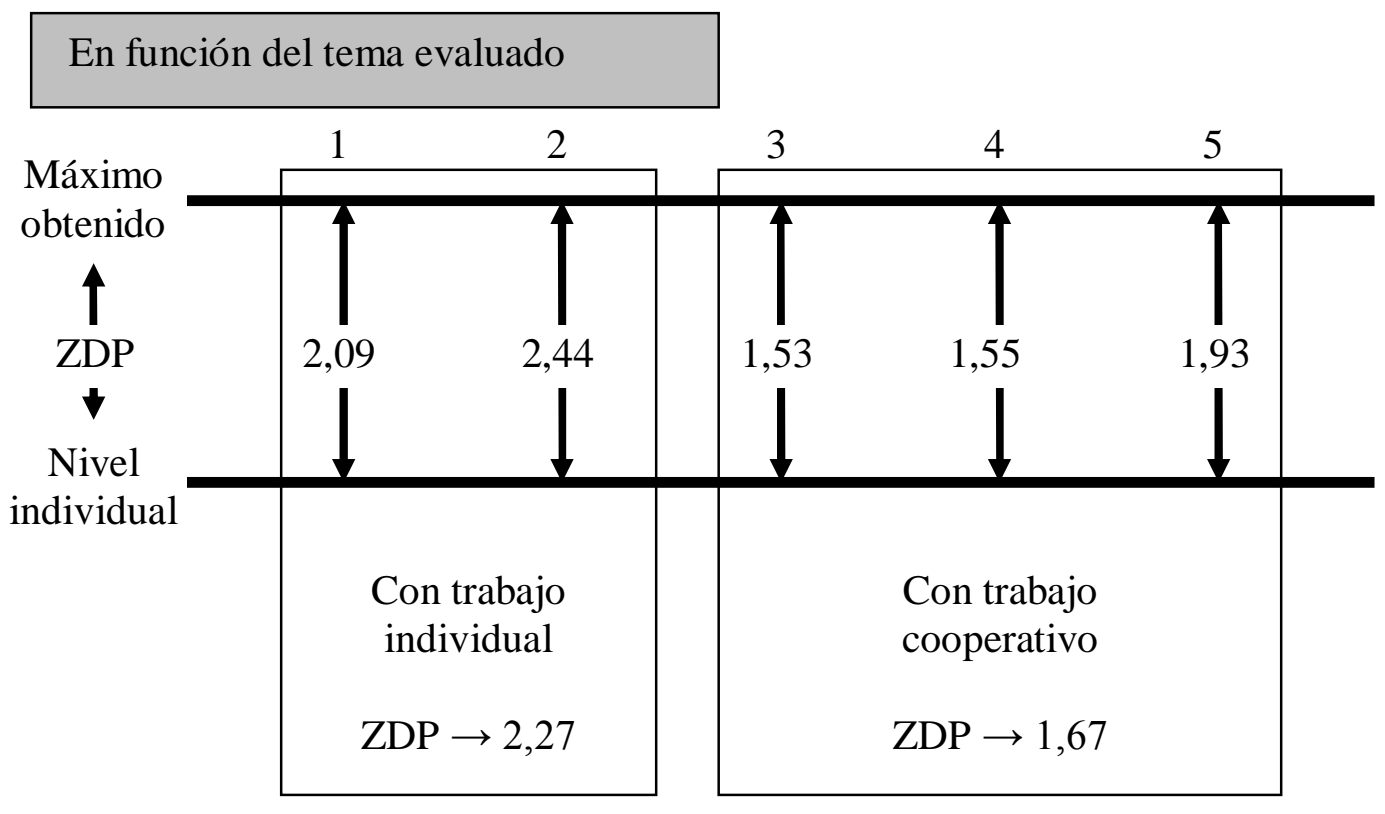

Re ducción de la $Z D P=\frac{2,27-1,67}{2,27} \cdot 100=26,27 \%$

Figura 9.25.- Variaciones de la ZDP en los test realizados

En función del tipo de ítem evaluado

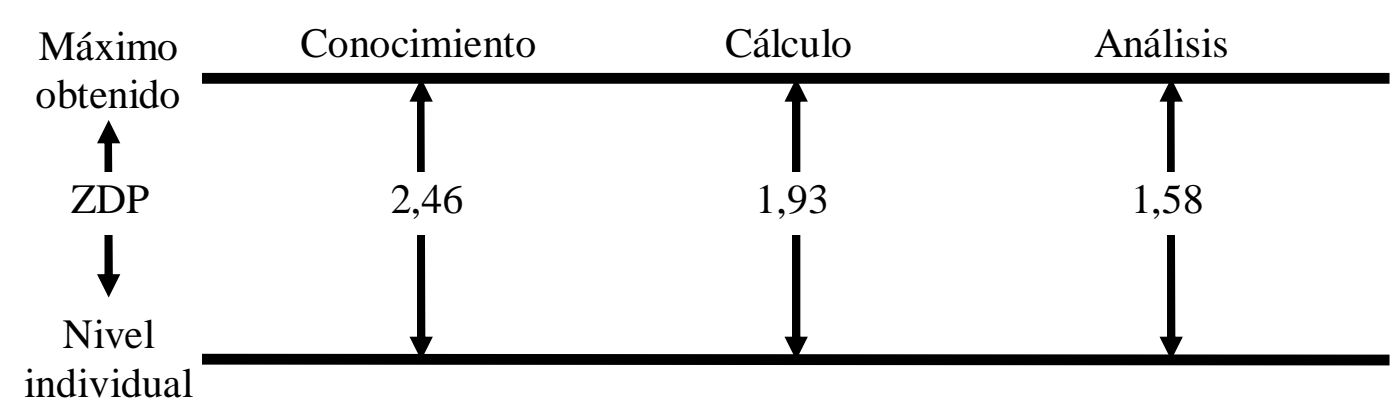

Re ducción de la $Z D P_{A-B}=\frac{2,46-1,93}{2,46} \cdot 100=21,54 \%$

Re ducción de la $Z D P_{B-C}=\frac{1,93-1,58}{1,93} \cdot 100=18,13 \%$

Re ducción de la $Z D P_{A-C}=\frac{2,46-1,58}{2,46} \cdot 100=35,77 \%$

Figura 9.26.- Variaciones de la ZDP obtenidos en función del ítem evaluado. 


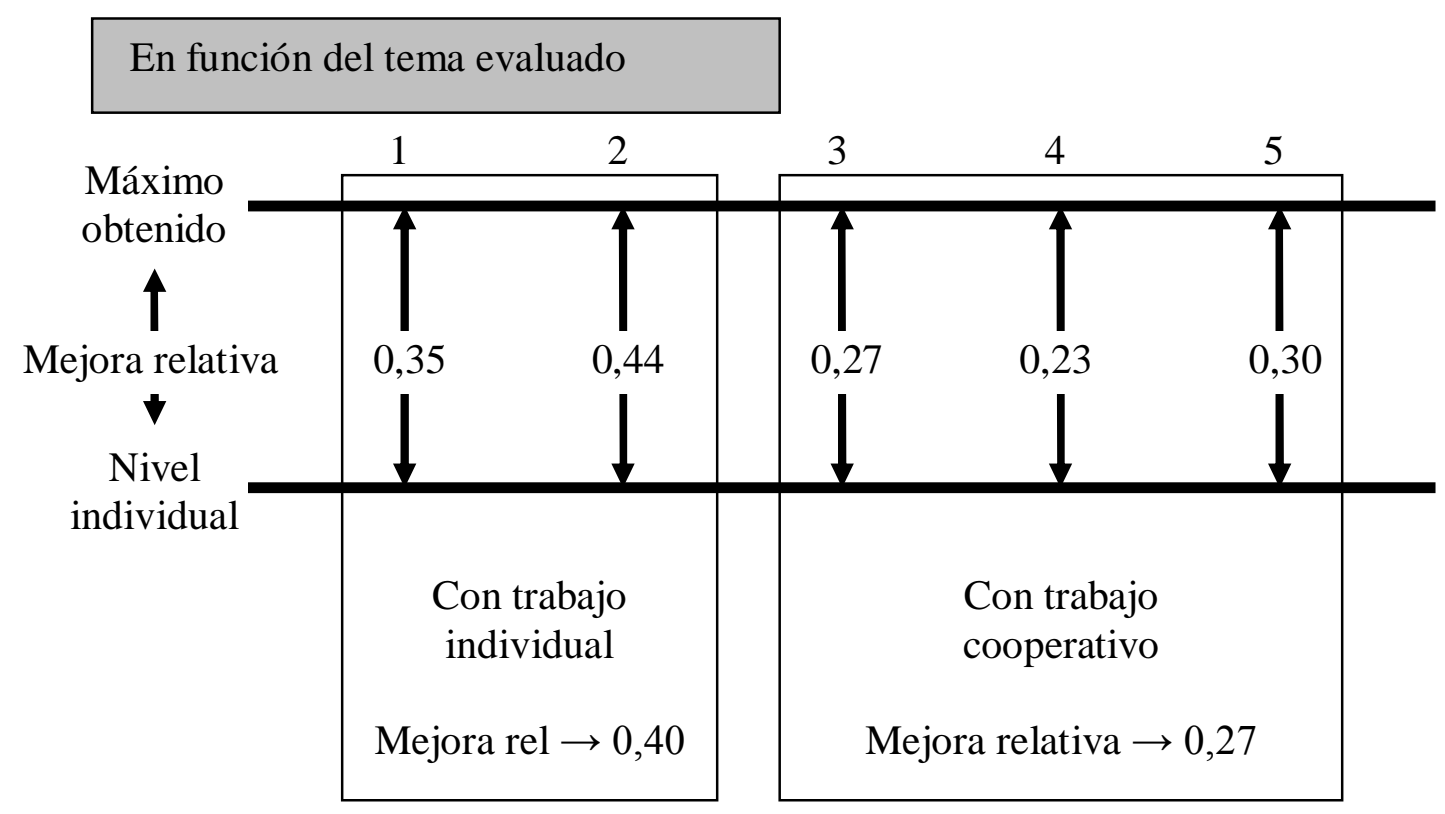

Re ducción de la mejora $=\frac{0,40-0,27}{0,40} \cdot 100=32,5 \%$

\section{En función del tipo de ítem evaluado}

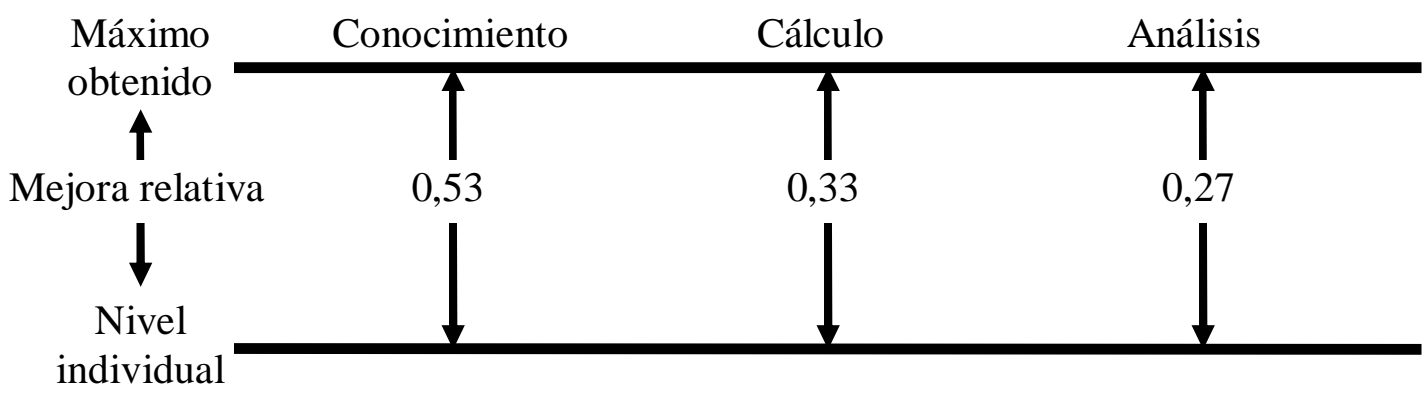

Re ducción de la mejora ${ }_{A-B}=\frac{0,53-0,33}{0,53} \cdot 100=37,63 \%$

Re ducción de la mejora ${ }_{B-C}=\frac{0,33-0,27}{0,33} \cdot 100=18,18 \%$

Re ducción de la mejora ${ }_{A-C}=\frac{0,53-0,27}{0,53} \cdot 100=49,06 \%$

Figura 9.27.- Variaciones relativas de la ZDP obtenidos en función del ítem evaluado. 
En estos esquemas se observa claramente que la diferencia entre el resultado obtenido por alumnos en la realización de las pruebas de forma colectiva e individual, es menor cuando estos han completado su formación mediante en trabajo cooperativo. Es decir, con esta metodología se reduce la ZDP o dicho de otro modo, el resultado de cada alumno se aproxima más al óptimo que supone el trabajo conjunto.

Las calificaciones finales, tanto individuales como colectivas, han sido más altas tras haber reorganizado los grupos a partir de los resultados obtenidos en las pruebas iniciales, por lo que concluimos que se ha cumplido el objetivo.

Por tanto podemos concluir todo este análisis definiendo el método ensayado:

Frente a un aula distribuida en grupos de trabajo, puede llevarse a cabo una reordenación de sus componentes realizando un sencillo procedimiento estadístico.

- Realizando una actividad de evaluación de forma individual, y seguidamente en grupo, se puede estimar la actividad de cada alumno en el grupo.

- Se puede calcular el valor del parámetro $L A_{\mathrm{Ri}}$. Está referido a cada individuo y es el cociente entre las coincidencias correctas del alumno con el grupo y las respuestas correctas del grupo.

$$
L A_{R i}=\frac{n_{R i}}{N_{R}}
$$

- Los alumnos pueden ordenarse de forma que dentro de un mismo grupo tengan éste valor lo más similar posible, es decir listarlos según este parámetro y hacer los grupos con él. 


\section{CONCLUSIONES}

\subsection{Verificación de las hipótesis}

Para obtener conclusiones definitivas $\mathrm{y}$, tras haber realizado el análisis estadístico, en primer lugar vamos a comparar las hipótesis que se plantearon inicialmente con los resultados obtenidos.

\section{Hipótesis 1}

La utilización del trabajo cooperativo como metodología favorecedora de las interrelaciones personales dará lugar a una mejora del rendimiento académico en el desarrollo de un curso ordinario de química en Educación Secundaria.

La hipótesis puede darse por verificada a partir de los resultados mostrados en la figura 9.23, puesto que, en todos los casos, se han obtenido mejores resultados cuando se ha trabajado en grupo que de forma individual. Asimismo, los resultados son mejores en el supuesto en que hemos considerado los dos últimos temas, que son los que se han trabajado con la distribución propuesta tras el análisis. El índice de mejora puede interpretarse como una magnitud que refleja, cualitativa y cuantitativamente, la zona de desarrollo próximo.

Al realizar las actividades de forma cooperativa, se ha experimentado una mejoría relativa importante en todas las pruebas realizadas (Tablas 9.3, 9.7, 9.11, 9,16 y 9,20). Pero el resultado obtenido por cada alumno de forma individual es mayor cuando la realización de actividades ha sido llevada a cabo de forma cooperativa (Tabla 9.23). La dinámica de la clase ha sido más fluida y, en general, se ha visto favorecida en la medida que ha aumentado el número de ejercicios que se han podido llevar a cabo.

\section{Hipótesis 2}

La realización de tareas de evaluación individualmente y en grupo, de manera consecutiva, mostrará la existencia de una mejora del rendimiento como consecuencia de la interacción entre los miembros del grupo 
En todos los cuestionarios que se han realizado a lo largo de la intervención, se ha podido constatar la diferencia de calificaciones obtenidas de ambos modos (tablas 9.1, 9.5, 9.9, 9.14 y 9.18). Es a partir de estos datos, cuando se trabaja estadísticamente y de forma sencilla, obteniendo la información necesaria para conocer la dinámica de cada grupo y actuar en consecuencia.

\section{Hipótesis 3}

A través del análisis comparativo de los resultados individuales y de grupo en tareas de evaluación ordinarias, puede establecerse un conjunto de parámetros mediante los cuales pueden caracterizarse algunos rasgos relevantes del trabajo cooperativo, principalmente, la relación entre cada una de las aportaciones individuales y la formulada por el grupo como tal, como aproximación a la identificación de las relaciones de liderazgo dentro del mismo.

Esta reordenación de los grupos ha sido la pieza clave en la investigación. A través del estudio estadístico de los resultados obtenidos se ha podido caracterizar a los alumnos en base a los parámetros $\left(\bar{x}_{i}\right.$, calificación media individual de los alumnos que forman un grupo, $\Delta x / \bar{x}_{i}$, mejora relativa experimentada al realizar evaluaciones en grupo, $L A$, grado de coincidencia entre los resultados individuales y los del grupo, $L A_{R i}$, ) establecidos a partir del dendrograma obtenido (figura 9.12).

En concreto, la que ha resultado más conveniente ha sido el grado de coincidencia de cada alumno con su grupo, referido a respuestas correctas $\left(L A_{R i}\right)$. A partir del valor de este parámetro, se ha realizado la reordenación de los grupos, de forma los alumnos que forman cada grupo fuesen lo más parecidos posible en ese sentido. Cuando se ha distribuido a los alumnos atendiendo a su similitud en relación con ese parámetro los resultados han sido mejores que con los grupos formados aleatoriamente al iniciar la investigación. 
Se ha estimado que, a partir de las cuatro variables establecidas, pueden caracterizarse los grupos de trabajo y que, a partir del grado de coincidencia entre un alumno y su grupo $\left(L A_{R i}\right)$, se puede conseguir una nueva reordenación. Por tanto, queda determinado un patrón de trabajo, consistente en la realización de un trabajo individual y un trabajo conjunto, que tras el conveniente tratamiento estadístico (apartado 9.2) nos proporciona unos nuevos grupos de trabajo (tabla 9.13) que mejorarán los resultados y el rendimiento.

\section{Hipótesis 4}

La reestructuración de los grupos llevada a cabo como consecuencia de la información obtenida a partir de los citados parámetros permitirá mejorar la eficacia del trabajo cooperativo en cuanto a los resultados del aprendizaje de los conceptos y procedimientos vinculados a los objetivos del curso en el que se aplica esta metodología.

Más que cuantificar los conocimientos finales, el propósito de la evaluación formativa es favorecer la mejora del aprendizaje de forma continua. Esta evaluación del aprendizaje precisa de una evaluación diagnóstica inicial y en una mejora tanto del proceso (profesor, medios...) como del resultado.

Así pues, podemos dar por comprobada esta hipótesis en la medida que se ha constatado que, a través de la intervención, se ha obtenido una mejora en el rendimiento de los alumnos.

El trabajo en grupo da siempre mejores resultados que el trabajo individual. Sin embargo, cuando los alumnos han sido reorganizados, la diferencia entre los resultados obtenidos de una evaluación individual habiendo trabajado en grupo y los obtenidos de la realizada de forma colectiva se reduce. Ello demuestra que el trabajo cooperativo da lugar a una mejora en el trabajo individual. 


\section{Hipótesis 5}

El enriquecimiento cognitivo referido en la hipótesis II será tanto más evidente en la medida en que las tareas implicadas correspondan a procesos cognitivos más complejos, que implican, principalmente, la aplicación de relacionales causales complejas.

Cuando se ha analizado el resultado de la intervención respecto al nivel cognitivo de las competencias implicadas (apartado 9.4) se ha constatado de forma clara un aumento del rendimiento del trabajo cooperativo en la mediada que este aumentaba (Tabla 9.53, figuras 9.24 y 9.26 )

En el desarrollo de la intervención se han conseguido resultados mucho más satisfactorios que los obtenidos en las fases exploratoria y diagnóstica, especialmente, en el los aspectos relacionados con la identificación de los tipos de enlace.

\subsection{Conclusiones Finales}

Tras haber completado las tres partes de la investigación podemos concluir:

Los alumnos que ingresan en la universidad presentan carencias importantes en los conceptos básicos de química que necesitan dominar para enfrentarse con garantías a un primer curso universitario. Los alumnos de segundo curso de bachillerato tampoco consiguen dominar suficientemente esos conceptos.

Los cursos de nivelación muestran esas carencias, pero no consiguen superarlas. Entre las principales dificultades a las que se enfrentan los alumnos, podemos destacar las siguientes:

a) No distinguen con claridad todos los tipos de enlace que pueden encontrarse en la materia.

b) No consiguen argumentar la estabilidad de las sustancias.

c) No relacionan los cambios físicos con enlaces intermoleculares y los químicos con enlaces interatómicos. 
Ni el desarrollo de los temas básicos a lo largo de un trimestre en segundo de bachillerato, ni el desarrollo de los mismos en un curso de nivelación al entrar a la universidad, resultan suficientemente efectivos para que los alumnos adquieran un nivel de conocimientos adecuado.

Utilizando una metodología que permita contextualizar estos conceptos se obtiene cierta mejora, pero no es suficiente. Los alumnos siguen manteniendo carencias, lo que hace necesario buscar un método más eficaz para lograr ese objetivo.

Con respecto al tema del enlace químico se ha observado que resulta más efectiva una clasificación de los tipos de enlace en la que se priorice la diferencia entre las estructuras moleculares, por una parte, y las multiatómicas por otra, frente a la tradicional distinción entre iónico, covalente o metálico. Lo que conseguimos con ello, principalmente, es igualar en importancia la uniones intermoleculares a las uniones entre átomos en las redes covalentes e iónicas, lo que permite explicar, desde un punto microscópico, los cambios físicos y químicos.

Al utilizar el trabajo cooperativo se comprueba que se puede mejorar el proceso de aprendizaje y que, utilizando mecanismos de regulación, se puede optimizar ese proceso.

En esta investigación hemos comprobado que el trabajo llevado a cabo de forma cooperativa permite a los alumnos alcanzar, de forma individual, un nivel más cercano al óptimo que establece la teoría de Vygotsky. Es decir, si fijamos el mayor nivel alcanzable por los alumnos como aquel que se obtiene cuando se trabaja de forma conjunta, la ZDP viene definida por la distancia que existe entre él y el nivel obtenido por cada alumno de forma individual.

Cuando el desarrollo del tema se ha llevado a cabo a través de una metodología cooperativa (temas 3, 4 y 5, de la intervención didáctica) la ZDP se ha reducido en un $26,27 \%$, lo que sitúa al alumno en un nivel más cercano al óptimo alcanzable que si hubiese trabajado de forma individual (figura 9.25). 
Quedando clara la conveniencia de este trabajo, hemos realizado una reordenación de los grupos de trabajo en función de la influencia de cada alumno en su grupo y se ha constado que, colocando juntos a los alumnos que la ejercen de forma similar, factor $L A_{R i}$, el nivel obtenido individualmente en el aprendizaje de las actividades es mayor. Con ello concluimos que el mecanismo de regulación que supone esta reordenación supone una mejora importante en el proceso de enseñanza y aprendizaje.

Atendiendo al tipo de contenidos trabajados también hemos podido concluir que el trabajo cooperativo supone un esfuerzo por parte de los componentes en forma de interacción que resulta más enriquecedora en la medida en que aumenta el grado de dificultad intelectual del trabajo propuesto. Esto se traduce en una reducción de la ZDP cuando las tareas propuestas requieren un análisis o una reflexión, reducción que no es tan significativa en aquellas tareas que necesiten un esfuerzo memorístico o de cálculo (figura 9.26).

El trabajo en el aula puede organizarse, por tanto, de forma que el trabajo cooperativo se emplee en aquellas cuestiones complejas que lo requieran y se utilice el trabajo individual en otras en las que no sea necesaria una interacción personal para favorecer su desarrollo.

Pese a la satisfacción por los resultados obtenidos, este trabajo presenta como mayor limitación las condiciones en que se ha desarrollado. Se ha trabajado en la fase experimental con un único grupo y en un contexto favorable, de modo que estos resultados deben ser considerados validadores de la metodología propuesta, pero no como un sistema que pueda ser aplicado en cualquier caso.

Desde un punto de vista operativo, queremos destacar que resulta difícil encajar la zona de desarrollo próximo dentro del sistema habitual de calificación, puesto que trabajamos con una escala entre cero y diez y no existe una proporcionalidad directa entre la consecución de objetivos y la nota obtenida que, en el mejor de los casos, tiende asintóticamente a ese valor máximo. A nivel práctico, ello supone que los alumnos con mejor rendimiento académico presenten una mejora inferior a la del resto, ya que su 
margen es menor. En otros ámbitos, donde se juzgue la productividad o la calidad de un trabajo determinado, no se presentará ese inconveniente.

\subsection{Implicaciones didácticas y perspectivas futuras}

En este trabajo de investigación se pueden encontrar varios puntos que pueden ser de interés, tanto práctico como teórico. Resulta necesario, por tanto, hacer una revisión de las implicaciones didácticas que conlleva y ofrecer posibles sugerencias.

Toda la investigación ha pivotado en torno a los contenidos a ofrecer, la forma en que podían ser asimilados por los alumnos y el modo de llevar a cabo todo ello, por lo que los resultados y conclusiones obtenidos, además de presentar situaciones reales que se dan en la enseñanza de la química, permite formular cuestiones de cara a investigaciones futuras.

\section{Implicaciones didácticas.}

En primer lugar, y desde un punto de vista teórico, hemos comprobado cómo se desarrollan, en nuestro entorno de trabajo, las ideas constructivistas, de gran influencia en la didáctica de la química. Sus fundamentos hacen referencia a la necesidad de estructurar los contenidos, el currículo y, dentro de él, las secuencias de aprendizaje. Sin embargo, hemos podido comprobar que existen muchas deficiencias en el trabajo habitual en el aula y que utilizando recursos, como ha sido en nuestro caso el trabajo cooperativo, se puede lograr un aprendizaje de mayor calidad, permitiendo alcanzar, además, otros objetivos.

Además de buscar un beneficio individual, en cuanto que la formación de cada alumno mejora con su aplicación, la metodología cooperativa supone un reto en su utilización, puesto que supone una vertiente formativa añadida al alumno. El trabajo en grupo es una herramienta en sí misma que prepara al alumno de cara a futuras situaciones, lo que es cada vez más habitual en las actuales circunstancias laborales. Por tanto, su utilización en nuestra materia resulta de gran interés, ya sea como objetivo o como elemento motivador y dinamizador de las clases. 
Dado que el interés por la metodología cooperativa es manifiesto, tanto desde el ámbito literario como del laboral y, por supuesto, del didáctico, el hecho de haber trabajado en busca de mejorar su utilización supone, en nuestra opinión, un paso hacia delante que puede colaborar a extender su uso por parte del profesorado, a la vez que se le ofrece una propuesta de trabajo claramente definida.

No perdemos de vista, sin embargo, que esta propuesta metodológica tan sólo intenta ser una herramienta orientativa para conseguir una mejora en el rendimiento mediante el uso del trabajo cooperativo; en ningún caso es la solución definitiva a los problemas que presenta hoy día enseñanza.

Por otra parte, uno de los objetivos principales del aprendizaje de las ciencias es el fomento de la autonomía del alumno en el aprendizaje. La utilización de esta metodología puede favorecer el aumento de las habilidades sociales del alumno, lo que puede permitirle desenvolverse en situaciones de conflicto en las que tenga que interaccionar con otros individuos. De ahí que el control de esas situaciones de trabajo, en lo que se refiere a la homogeneización de los grupos en busca del máximo rendimiento individual y grupal, haya servido para justificar todo el proceso.

\section{Perspectivas futuras de investigación.}

Ciertamente, la línea de trabajo que se abre al hablar de trabajo cooperativo es muy amplia. Pero, si nos centramos en elaborar mecanismos sencillos que permitan regularlo en el aula de forma rápida, convirtiéndolo en una herramienta de uso habitual, podemos acotar un campo de estudio de gran interés didáctico.

Podemos, por tanto, plantear una lista de propuestas que, sin ánimo de agotar el tema, puede contribuir a la formulación de nuevas investigaciones.

1. En este proyecto se ha planteado como objetivo el trabajo con un grupo acotado de estudiantes de una misma clase. Sería interesante hacer un estudio con una muestra mayor y, con ello, extender el uso del trabajo cooperativo, hasta convertirlo en una herramienta de uso habitual. 
2. En nuestra investigación se han fijado algunos de los principales problemas con que tropiezan los alumnos al estudiar el enlace químico. Seria de interés ampliar el estudio a otros o incluso todos los temas de Química que se tratan en enseñanza secundaria.

3. Se plantea la posibilidad de realizar la investigación en otros niveles educativos, dado que se ha llevado a cabo con alumnos de primero de bachillerato que son los que, básicamente, están completando la etapa de transición entre el periodo operacional concreto y el periodo operacional formal, ya que, en los primeros cursos de secundaria los alumnos se encuentran en una etapa operacional concreta. Por tanto, la utilización del trabajo cooperativo puede tener efectos muy diferentes, según la etapa educativa en que se aplique, siendo interesante, además, evaluar la posible interacción entre niveles.

4. El estudio de la influencia del trabajo cooperativo en el proceso de enseñanza y aprendizaje se ha llevado a cabo en el área de química. Sería conveniente ampliar este estudio a otras áreas de ciencias, como la física, las matemáticas o la biología.

5. También sería interesante estudiar el desarrollo esta metodología en el ámbito universitario, donde ya hay trabajos realizados y donde se puede abarcar un mayor campo de contenidos.

6. Desde un punto de vista más amplio sería de interés reproducir esta experiencia paralelamente a otra en la que se estudiasen las relaciones sociales y etnográficas, para comprobar si se mantienen las mismas caracterizaciones.

Así mismo, ofrecemos una lista de interrogantes susceptibles de ser estudiados en futuras investigaciones.

¿El trabajo cooperativo mejora la motivación de los alumnos en las áreas de ciencias?

¿Cómo influye el trabajo cooperativo en las interrelaciones personales de los alumnos? ¿Y entre alumnos y profesor?

En un mismo grupo, ¿cómo interpretan el trabajo cooperativo los alumnos aventajados y los alumnos rezagados que comparten conocimientos y, sobre todo, resultados? 
Desde un punto de vista didáctico, ¿puede considerarse útil la facilidad para relacionarse con otros compañeros, aun cuando no se asocie a un buen nivel de participación en el equipo de trabajo?

¿Podría incorporarse nuestro trabajo a otros campos dedicados a las relaciones sociales?

¿Suelen convertirse en líderes de los equipos de trabajo los alumnos de mayor rendimiento escolar dentro de un colectivo de jóvenes donde los valores del trabajo y esfuerzo están siendo desplazados por otros como la imagen física o las habilidades sociales? 


\section{REFERENCIAS BIBLIOGRÁFICAS}

ACAR, B. y TARHAN, L. (2008). Effects of Cooperative Learning on Students' Understanding of Metallic Bonding. Research in Science Education, v 38 n4, p401-420.

ACEVEDO, J.A. (1997). Ciencia, Tecnología y Sociedad (CTS). Un enfoque innovador para la enseñanza de las ciencias. Revista de Educación de la Universidad de Granada, 10, pp. 269-275.

ACEVEDO, P. y ACEVEDO, J. A. (2002). Proyectos y materiales curriculares para la educación CTS: enfoques, estructuras, contenidos y ejemplos. Bordón: Revista de Orientación Pedagógica. Vol. 54 (1) pp. 5-18.

ACS (2004). Química. Un proyecto de la ACS. Barcelona. Reverté.

ALMOND, R. J. (2009). Group assessment: comparing Group and individual untergradate module marks. Assessment \& Evaluation in Higher Education Vol. 34 (2), pp. 141-148.

ALONSO, M., GIL, D. y MARTÍNEZ TORREGROSA, J. (1995). Concepciones docentes sobre la evaluación. Alambique. nº 4, pp. 6-15.

ALONSO TAPIA, J. (1996). Condicionantes contextuales de la motivación por aprender. En Alonso Tapia, J. y Caturla Fita (Auts.). La motivación en el aula. Madrid: PPC, pp. 31-50.

ALONSO TAPIA, J. (1997). Evaluación del conocimiento y su adquisición. (Vol II. Ciencias Naturales y Experimentales). Universidad Autónoma de Madrid. CIDE. MEC.

ALVARADO, C. (2005). La estructura atómica y el enlace químico desde un punto de vista disciplinario. Enseñanza de las ciencias. Número extra. VII congreso.

AMERICAN CHEMICAL SOCIETY (2005) Química. Un proyecto de la ACS. Barcelona. Reverté.

AMETLlA, J. (2003). Las ciencias: la cenicienta del bachillerato. Alambique, 36, pp.15-18.

ANDERSON, O.R. (1976). The experience of science: a new prespective for laboratory teaching. Nueva York: Teachers College Press.

ANDERSON, W., MITCHELL, S. y OSGOOD M. (2005). Comparison of Student Perfomance in Cooperative Learning and Traditional Lecture-based Biochemistry 
Classes. Biochemistry and Molecular Biology Education. Vol.33, nº 6, pp. 387393.

AUSUBEL, D. P. (1978). Psicología educativa. Un punto de vista cognoscitivo. México: Trillas.

AUSUBEL, D. P., NOVAK, J. D. y HANESIAN, H. (1983). Psicología Educativa: Un punto de vista cognoscitivo. México: Trillas.

AZCONA, R., FURIÓ, C., INTXAUSTI, S. y ÁLVAREZ, A. (2004). ¿Es posible aprenderlos cambios químicos sin comprender qué es una sustancia? Importancia de los prerrequitos. Alambique, 40, pp. 7-17.

AYENSA, J. M. (2001). Instrumentos de regulación y modelo de evaluación en el aula de física. Tesis Doctoral. UNED-Madrid.

BALLESTEROS, M.E.(2002). Comprensión de conceptos de química general. Focus, I, 1, pp. 17-20.

BARBERÁ, O. y VALDÉS, P. (1996). El trabajo práctico en la enseñanza de las ciencias: Una revisión. Enseñanza de las ciencias, 14 (3), pp. 365-379.

BARBOSA, R.; JOFILI, Z. y WATTS, M. (2004). Cooperating in Constructing Knowledge: Case Studies from Chemistry and Citizenship. International Journal of Science Education, v26 n8 p935-949.

BARCO, B (2006). Elementos Mediadores en la Eficacia del Aprendizaje Cooperativo: Entrenamiento Previo en Habilidades Sociales y Dinámica de Grupos. Anales de Psicología. Volumen 22 Número 001. Universidad de Murcia, España.

BASILI, P. y SANFORD, J. (1991). Conceptual Change Strategies and cooperative Group Work in Chemistry. Journal of Research in Science Teaching. Vol. 28, $\mathrm{n}^{\mathbf{0}} 4$, pp. 293-304.

BAUMANN, M. R. y BONNER, B. L. (2004). The effects of variability and expectations on utilization of member expertise and group performance. Organizacional Behavior and Human Decision Processes. Vol. 93, n 2, pp. 89101.

BELLO, S. y GARCÍA, A. (2005). ¿Qué hay detrás de las ideas previas de estudiantes de química relacionadas con el enlace químico? Número extra. VII congreso.

BENNETT, J., GRÄSEL, C., PARCHMANN, I. y WADDINGTON, D. (2005). Context-based and Conventional Approaches to Teaching Chemistry: Comparing Teachers' views. International Journal of Science Education. Vol. 27, No 13, pp. $1521-1547$. 
BENNETT, J. and LUBBEN, F. (2006). Context-based Chemistry: The Salters approach. International Journal of Science Education. Vol. 28, № 9, pp. 999-1015. BILGIN, I. y GEBAN, O. (2006). The Effect of Cooperative Learning Approach Based on Conceptual Change Condition on Students' Understanding of Chemical Equilibrium. Journal of Science Education and Technology, Vol. 15, nº 1, pp. 3146.

BIRCH, W. (1986). Towards a model for problem-based learning. Studies in Higher Education, 11, pp.73-82.

BLACK, P.J. (1993). Formative and summative assessment by teachers. Studies in Science Education, 21, pp. 49-97.

BLOSSER, P. (1992). Using Coperative Learning in Science Education. http://www.stemworks.org/Bulletins/SEB92-1.html (13/06/05).

CAAMAÑO, A. (2001). Repensar el currículo de química en los inicios del siglo XXI. Alambique, 29, pp. 43-52.

CAAMAÑO, A. (2003). Las ciencias en el bachillerato: ¿una opción en declive? Alambique, 36, pp.5-10.

CAAMAÑO, A., COROMINAS, J., DÜLL, O., FURNÉMONT, J., MAUREL, J., MOUTON, R., RALLE, B., SCHWOB, M., SERAFINI, R. y TINNES, J. (2002). La enseñanza de las ciencias en secundaria en Europa: Francia, Bélgica, Italia, Alemania y España. Alambique. $n^{\circ} 31$, pp. 7-32.

CAAMAÑO, A. y IZQUIERDO, M. (2003). El currículo de química del bachillerato en Cataluña: todavía muy lejos de una química contextualizada. Alambique, 36, pp. 60-67

CAAMAÑO, A. y OÑORBE, A. (2004). La enseñanza de la química: Conceptos y teorías, dificultades de aprendizaje y replanteamientos curriculares. Alambique, 41, pp. 67-81.

CALATAYUD, M.L., GIL, D. y GIMENO, J.V. (1992). Cuestionado el pensamiento espontáneo docente del profesorado universitario: ¿Las deficiencias en la enseñanza como origen de las dificultades de los estudiantes? Revista Interuniversitaria de Formación del profesorado, 14, pp. 71-81.

CALATAYUD, M.LL. y HERNÁNDEZ, J.(2003). Currículo de química en la Comunidad Valenciana: una suma que resta. Alambique, 36, pp.55-59.

CAMACHO ROSALES, J. (1998). Estadística con SPSS para windows. Madrid. RAMA. 
CAMACHO ROSALES, J. (2000). Estadística con SPSS, versión 9 para windows. Madrid. RA-MA.

CARPENTER, S. R. y McMILLAN, T. (2003). Incorporation of a Cooperative Learning Technique in Organic Chemistry. Journal of Chemical Education, vol. 80, nº p. p. 330-32.

CARRASCOSA, J. y GIL, D. (1985). La "metodología de la superficialidad" y el aprendizaje de las ciencias. Enseñanza de las ciencias, 3, pp. 113-120.

CASA, L.G., CASQUETE DEL PRADO, A.M., CUBERO, R., HIDALGO, M.V. y LEMUS, S. (1986). Interacción social en el aula. Interacción entre iguales durante la resolución de una tarea. Actas de las IV Jornadas de Estudio sobre la Investigación en la Escuela. Sevilla.

CLACKSON, S.G. y WRIGHT, D.K. (1992). An Appraisal of practical work in science education. School Science Review, 74(266), pp. 39-42.

COOKE, R. A. y KERNAGHAN, J. A. (1987). Estimating the Diference Betweer Versus Individual Perfomance on Solving Tasks. Group and Organization Management. Vol. 12, no 3, pp. 319-342.

CRAIG, N. C. (2002). Correspondence with Sir Lawrence Bragg Regarding Evidence for the Ionic Bond. Journal of Chemical Education. Vol. 79, № 8, pp. 953-955.

CRISWELL, B. (2006). A Diaper a Day and What's Going on with Gaviscon?: Two Lab Activities Fucosing on Chemical Bonding Concepts. Journal of Chemical Education. Vol. 83, № 4, pp. 574-576.

DAHMS, M., GEONNOTTI, K. ; PASSALACQUA, D. ; SCHILK, J. N.; WETZEL, A. y ZULKOWSKY, M. (2008). The Educational Theory of Lev Vygotsky: an analysis. http://www.newfoundations.com/GALLERY/Vygotsky.html [consulta: enero de 2009]

DEAVOR, J. (1995). Cooperative learning in the analytical chemistry lab. http://www.cofc.edu/deavorj/posters/coop.htm (07/10/05).

DEMING, J. C. y CRACOLICE, M. S. ( 2004). Learning How to Think. Science Teacher, Vol. 71, nº 3 , pp. 42-47.

DINAN, F. J.(2006). Getting Started in a Cooperative Classroom. Journal of College Science Teaching, Vol. 35, nº 4 , pp. 12-14. 
DORAN, R.L., LAWRENZ, F. y HEGELSON, S. (1994). Research on assessment in science, en handbook of Research on Science Teaching and Learning, editado por Dorothy L. Gabel. Nueva York: Macmillan.

DOYMUS, K. (2007). Effects of a Cooperative Learning Strategy on Teaching and Learning Phases of Matter and One-Component Phase Diagrams. Journal of Chemical Education, Vol. 84 (11), pp. 1857-1860.

DREYFUS, A., JUNGWIRTH, E. y ELIOVITCH, R. (1990). Applying the "cognitive conflict" strategy for conceptual change-some implications, difficulties and problems. Science Education, 74, pp. 555-569.

DRIVER, R. (1988). Un enfoque constructivista para el desarrollo del currículo en ciencias. Enseñanza de las ciencias, 6(2), pp. 109-120.

DUIT, R. (1991). Students' conceptual framework consequences for learning science, en Glynn, S., Yeany, R. y Britton, B. (eds.). The Psychology of Learning Science. Hillsdal: Lawrence Erlbaum.

DURAN, M.A. (1988). De puertas adentro. Madrid. Instituto de la mujer.

EGERBLADH, T. (2006). A social decision scheme approach on group size, task difficulty and ability level. European Journal of Social Psychology. Vol. 11, n²2, pp.161-171.

FABRA, M. L. (1992). El trabajo cooperativo: Revisión y perspectivas. Aula. No 9, pp. 5-12.

FELDER, R. M. y BRENT, R. (2001). Efective strategies for cooperative learning. Journal of Cooperation and Collaboration in College Teaching. Vol. 10, $\mathrm{n}^{\mathrm{o}}$ 2, pp. 69-75.

FURIÓ, C. y otros (1993): Concepciones de los estudiantes sobre una magnitud “olvidada” en la enseñanza de la química: La cantidad de sustancia. Enseñanza de las Ciencias. 11 (2), 107-114.

FURIÓ, C. (1994). Tendencias actuales en la formación del profesorado de ciencias. Enseñanza de las Ciencias, 12, pp. 188-199.

FURIÓ, C y HERNÁNDEZ, J. (1983). Ideas sobre los gases en alumnos de 10 a 15 años. Enseñanza de las ciencias, 1 (2), 83-91.

FURIÓ, C., VILCHES, A., GUISASOLA, J. y ROMO, V. (2001). Finalidades de la enseñanza de las ciencias en la secundaria obligatoria. ¿alfabetización científica o preparación propedéutica? Enseñanza de las ciencias, 19 (3), 365-376. 
GALAGOVSKY, L. (1993). Redes conceptuales: Su base teórica e implicancias para el proceso de enseñanza-aprendizaje de las ciencias. Enseñanza de las ciencias, 11(2), pp.307-311.

GALAGOVSKY, L. y MUÑOZ, J.C. (2002). La distancia entre aprender palabras y aprehender conceptos. El entramado de palabras-concepto (EPC) como un instrumento para la investigación. Enseñanza de las Ciencias, 20 (1), pp. 29-45.

GALAGOVSKY, L., RODRÍGUEZ, M. A., STAMATI, N. y MORALES, L. (2003). Representaciones mentales, lenguajes y códigos en la enseñanza de ciencias naturales. Un ejemplo para el aprendizaje del concepto de reacción química a partir del concepto de mezcla. Enseñanza de las ciencias, 21 (1), 107-121.

GALAGOVSKY, L. (2004). Del aprendizaje significativo al aprendizaje sustentable. Parte 1: El modelo teórico. Enseñanza de las ciencias, 22 (2), 229-240.

GALBRAITH, J. M. (2007). On the Role of d Orbital Hybridization in the Chemistry Curriculum. Journal of Chemical Education. Vol. 84, No 5, pp. 783-787.

GALLUPE, R. (1990). Suppressing the contribution of the group's member appropriate for all group tasks? System Sciences, 1990, Proceedings of the Twenty Annual International Conference on. Vol. 3, pp. 13-22.

GARCÍA, F. ( ). Taller de estrategias didácticas para la enseñanza de la biología http://redescolar.ilce.edu.mx (15-04-08)

GARCÍA HOURCADE, J. L. y RODRIGUEZ DE AVILA, C. (1988). Ideas previas, esquemas alternativos, cambio conceptual y trabajo en el aula. Enseñanza de las ciencias. Vol. 6, nº 2, pp. 161-166.

GARRITZ, A., GASQUE, L., HERNÁNDEZ, G. y MARTÍNEZ, A. (2002). El mol: un concepto evasivo. Una estrategia didáctica para enseñarlo. Alambique, 33, pp. 99-109.

GENYEA, J. (1983). Improving Students’ Problem-Solving Skills. Journal of Chemical Education. Vol. 60, № 5, pp. 478-482.

GIJLERS, H. y JONG, T. (2005). The relation between prior knowledgeand students' collaborative discovery learning processes. Journal of Research in Science Teaching. Vol. 42, nº 3, pp. 264-282.

GIL, D. (1982). La investigación en el aula de física y química. Madrid: Anaya.

GIL, D. (1983). Tres paradigmas básicos en la enseñanza de las ciencias. Enseñanza de las ciencias, 1, pp. 26-33. 
GIL, D. (1993). Contribución de la historia y la filosofía de las ciencias al desarrollo de un modelo de enseñanza/aprendizaje como investigación. Enseñanza de las ciencias. 11 (2), pp. 197-212.

GIL, D. (1994). Relaciones entre conocimiento escolar y conocimiento científico. Investigación en la escuela, 23, pp. 17-32.

GIL, D. et al. (1999).¿¿Tiene sentido seguir distinguiendo entre el aprendizaje de conceptos, resolución de problemas de lápiz y papel y realización de prácticas de laboratorio? Enseñanza de las ciencias, 17 (2), pp. 311-320.

GIL, D., CARRASCOSA, J., FURIÓ, C. y MARTÍNEZ-TORREGROSA, J.(1991). La enseñanza de las ciencias en la educación secundaria. Barcelona: ICE. Universitat Autónoma de Barcelona.

GIL, D. y MARTÍNEZ-TORREGROSA, J.(1987). Los programas-guía de actividades: una concreción del modelo constructivista de aprendizaje de las ciencias. Investigación en la escuela, 3, pp. 3-12.

GIL, D. y VALDÉS, P. (1995). Contra la distinción clásica entre “teoría”, "prácticas experimentales" y "resolución de problemas": el estudio de las fuerzas elásticas como ejemplo ilustrativo. Didáctica de las Ciencias Experimentales y Sociales, 9, pp. 3-25.

GILMAN, J. J. (1999). In Defense of The Metallic Bond. Journal of Chemical Education. Vol. 76, No 10, pp. 1330-1331.

GLINZ, P. E. (2005). Un acercamiento al trabajo colaborativo, Revista Iberoamericana de Educación (ISSN: 1681-5653) Número 35/2. 10 - 02 - 05. http://www.campusoei.org/revista/rec_dist6.htm

GOIKOETXEA, J. (1988). Interacción por parejas en el aula y sus efectos en el aprendizaje escolar. Diseño experimental. Investigación en la escuela, nº 5, pp. 5361 .

GOMBA, F. J. (1999). A Comment on Molecular Geometry. Journal of Chemical Education. Vol. 76, $\mathrm{N}^{\mathrm{o}}$ 12, pp. 1732-1734.

GÓMEZ, A. y ACOSTA, H. (2003). Acerca del trabajo en grupos o equipos. Acimed. Vol. 11. $\mathrm{N}^{\mathrm{o}} 6$.

GÓMEZ, A. y ANDREA, A. DE. (2004). Las leyes de los gases y la teoría cinéticomolecular en educación secundaria. Alambique, 40, pp. 35-45. 
GÓMEZ CRESPO, M.A., GUTIÉRREZ, M. y MARTÍN-DÍAZ, M. J. (2002). La química en la ESO. Alambique, 33, pp. 69-78

GÓMEZ CRESPO, M.A., GUTIÉRREZ, M. y MARTÍN-DÍAZ, M. J. (2003). La química en el bachillerato. Pasado reciente, presente y futuro. Alambique, 36, pp. 48-54.

GRUP SALTERS (1999). Química Salters. Batxillerat. Barcelona. Generalitat de Catalunya. Departament d'Ensenyament.

GRUP SALTERS (2000a). Química Salters. Bachillerato. Centro de Investigación y Documentación Educativas (CIDE). Madrid.

GRUP SALTERS (2000b). Química Salters Bachillerato. Materiales Didácticos. Generalitat Valenciana. Consellería de Cultura i Educació.

GUILlESPIE, R. J. (2001). Electron Densities, Atomic Charges, and Ionic, Covalent, and Polar Bonds. Journal of Chemical Education. Vol. 78, No 12, pp. 1688-1690.

GUILLESPIE, R. J. (2004). Teaching Molecular Geometry with the VSERP Model. Journal of Chemical Education. Vol. 81, N 3, pp. 298-304.

GUILLESPIE, R., HUMPHREYS, D., BAIRD, C. y ROBINSON, E. (1990) Química. Barcelona. Reverté.

HAGER, P., SLEET, R., LOGAN, P. y HOOPER, M. (2003). Teaching Critical Thinking in Undergraduate Science Courses. Science and Education, Vol. 12, n⿳⺈冂3 pp. 303-313.

HALLER, C. R., GALLAGHER, V. J., WELDON, T. L. y FELDER, R. M. "Dynamics of peer interaction in cooperative learning workgroups". Journal of engineering education, Vol. 89, No. 3, 2000, pp. 285-293.

HEWSON, P.W. (1992). El cambio conceptual en la enseñanza de las ciencias y la formación de los profesores. Ponencia presentada en el encuentro sobre Investigación y Desarrollo del Currículo en la de las Ciencias. Madrid: CIDE.

HINDE, R. J. y KOVAC, J. (2001). Student Active Learning Methods in Physical Chemistry. Journal of Chemical Education, Vol. 78, nº1, pp. 93-99.

HOCKINGS, S. C.; De ANGELIS, K. J. y FREY, R. F. (2008). Peer-Led Team Learning in General Chemistry: Implementation and Evaluation. Journal of Chemical Education, Vol. 85, nº , pp. 990-996.

HODSON, D. (1992). Assesment of practical work. Some considerations in philosophy of science. Science and Education,1 pp. 115-144. 
HODSON, D. (1994). Hacia un enfoque más crítico del trabajo de laboratorio. Enseñanza de las ciencias, 12 (3), pp. 299-313.

HODSON, D. (1996). Practical work in school science: exploring some directions for change. International Journal of Science Education, 18, 755-760.

HODSON, D. (1998). Mini-Special Issue: Taking practical work beyond the laboratoru. International Journal of Science Education, 20, pp. 629-632.

HOFSTEIN, A. y LUNETA, V.N. (1982). The role of laboratory in science teaching: neglected aspects of research. Review of Educational Research, 52, pp. 201-217.

HOWE, C., TOLMIE, A., ThURSTON, A., TOPPING, K., CHRISTIE, D., LIVINGSTON, K., JESSIMAN, E. y DONALDSON, C. (2007). Group work in elementary science: Towards organisational principles for supporting pupil learning. Learning and Instruction, 17, pp. 549-563.

HURTS, M. O. (2002). How We Teach Molecular Structure to Freshmen. Journal of Chemical Education. Vol. 79, № 6, pp. 763-764.

IGELSRUD, D. y LEONARD, W.H. (1988). What research says about biology laboratory instruction. The American Biology Teacher, 50, pp. 303-306.

IZQUIERDO, M., SANMARTÍ, N. y ESPINET, M. (1999). Fundamentación y diseño de las prácticas escolares de ciencias experimentales. Enseñanza de las ciencias, 17 (1), pp. 45-59.

JACOBS, D. (2000). Cooperative Learning in General Chemistry. http://gallery.carnegiefoundation.org/djacobs/final report.pdf.(07/10/05)

JIMÉNEZ, M.R., SÁNCHEZ, M.A. y DE MANUEL, E. (2001). Aprender química de la vida cotidiana más allá de lo anecdótico. Alambique, 28, pp. 53-62.

JONHSON, R. y JOHNSON, D. (1978). Cooperative,competitive,, and individualistic learning. Journal of Research and Development in Education Vol. 12 (1), pp. 3-15.

JONHSON, D. W.; JOHNSON, R. T., y HOLUBEC, E. (1999a). Los nuevos círculos de aprendizaje. La cooperación en el aula y la escuela. Aique. Buenos Aires.

JONHSON, D. W.; JOHNSON, R. T., y HOLUBEC, E. (1999b). El aprendizaje cooperativo en el aula. Paidós. Buenos Aires.

JONHSTONE, A.H. (2006). Chemical education research in Glasgow in perspective. Chemistry Education Research and Practice, 7 (2), 49-63.

JORBA, J. y SANMARTÍN, N. (1996). Enseñar, aprender y evaluar: Un proceso de evaluación continúa. Madrid. CIDE. MEC. 
KAUFMAN, D., FELDER, R. y FULLER, H. (2000). Accounting for individual effort in cooperative learning teams. . Journal of Engineering Education. Vol. 89, $\mathrm{n}^{\mathbf{o}} 2$, pp. 133-140.

KEMPA, R. y AYOB, A. (1991). Learning interactions in group work in science. International journal of science education. Vol. 13, n³, pp.341-354.

KENNEDY, J. H. (1985). Poster Presentations for Evaluating Laboratory Coursework. Journal of Chemical Education. Vol. 62, No 12, pp. 1104-1107.

KITTLESON, J. y SOUTHERLAND, S. (2004). The role of discurse in group knowledge construction: A case study of engineering students. Journal of Research in Science Teaching. Vol. 41, nº 3, pp. 267-293.

KOVAC, J. (1999). Student active learning methods in general chemistry. Journal of chemical education. Vol. 76, n 1 pp. 120-124.

LAUGHLIN, P., CAREY, H. y KERR, N. (2008). Group-to-Individual ProblemSolving Transfer. http://gpi.sagepub.com (21/09/08).

LAUGHLIN, P. R., HATCH, E. C., SILVER, J.S. y BOH, L. (2006). Groups Perform Better Than the Best Individuals on Letters-to-Numbers Problems: Effects of Group Size. . Journal of Personality and Social Psychology. Vol. 90, nº 4, pp. 644651.

LAUGHLin, P. R.; VANDERSTOEP, S. W. y HOLlingShEAD, A. B. (1991). Collective Versus Individual Induction: Recognition of Truth, Rejection of Error, and Collective Information Processing. Journal of Personality and Social Psychology. Vol. 61, nº1, pp. 50-67.

LAZAROVITZ, R. y TAMIR, P. (1994). Research on using laboratory instruction in science, en handbook of research on Science Teaching and Learning, editado por Dorothy L. Gabel. Nueva York: Macmillan.

LEDERMAN, N.G. (1992). Students' and teachers' conceptions of the nature of science: a review of the research. Journal of Research in Science Teaching, 29, pp. 331-359.

LINN, M. (1987). Establishing a research base for Science Educación; challenges, trends and recomandations. Journal of research in science theaching, 24 (3), pp.215-223.

LINDER, C. (1993). A challenge to conceptual change. Science Education, 77,pp. 293300.

LIVAGE, J. (1982). El enlace químico, Mundo Científico, Vol. 1(1), pp. 54-63 
LLORENS, J. A. y DE JAIME, M. C.(1987). El medio cultural y la formación de los conceptos científicos: una aproximación lingüística. Infancia y aprendizaje. No $39-$ 40, pp. 47-55.

LLORENS, J. A., DE JAIME, M. C. y LLOPIS, R. (1987). El uso de la terminología científica en los alumnos que comienzan el estudio de la Química en la Enseñanza Media: una propuesta metodológica para su análisis. Enseñanza de las ciencias. Vol. $N^{\circ} 5, n^{\circ} 1$, pp.33-40.

LLORENS, J. A. (1988). La concepción corpuscular de la materia. Obstáculos epistemológicos y problemas de aprendizaje. Investigación en la escuela, 4, pp. $33-48$.

LLORENS, J. A. (1991). Comenzando a aprender química. Ideas para el diseño curricular. Madrid. Visor.

LLORENS, J. A. y otros. (1994). Aspectos didácticos de Física y Química (Química).5. ICE Universidad de Zaragoza.

LLORENS, J. A. (2007). Investigación sobre la evaluación en un curso universitario de química general. En Watts, F., García-Carbonell, A., (Eds.). La evaluación compartida: una investigación multidisciplinar. Universidad Politécnica de Valencia. Valencia.

LLORENS, J. A. (2008). Influencia del trabajo cooperativo en al mejora cualitativa del aprendizaje. Una aproximación basada en el concepto de "Zona de Desarrollo Próximo" de Vygotsky. V Congreso Iberoamericano de Docencia Universitaria.

LOBATO FRAILE, C. (1998). El trabajo en grupo. Aprendizaje cooperativo en secundaria. Bilbao: Universidad del País Vasco.

LOGAN, S. L. (2001). The Role of Lewis Structures in Teaching Covalent Bonding. Journal of Chemical Education. Vol. 78, № 11, pp. 1457-1458.

LOGSE. (1990). Ley Orgánica de Ordenación General del Sistema Educativo. Ley $1 / 990$ de 3 de octubre.

LOPES, B. y COSTA, N. (1996). Modelo de enseñanza-aprendizaje centrado en la resolución de problemas: Fundamentación, persentación e implicaciones educativas. Enseñanza de las Ciencias, 14, pp. 45-61.

MAGNASCO, V. (2004). A Model for the Chemical Bond. Journal of Chemical Education. Vol. 81, № 3, pp. 427-435. 
MAGNASCO, V. (2005). Correction (A Model for the Chemical Bond). Journal of Chemical Education. Vol. 82, № 9, pp. 1311.

McCLELLAND, J. A. G. (1984). Alternative Frameworks: Interpretation of Evidence. European Journal of Science Education. Vol. 7 (1), 1-6.

MAHALINGAM, M., SCHAFER, F. MORLINO, E. (2008). Promoting Student Learning through Group Problem Solving in General Chemistry Recitations. Journal of Chemical Education, Vol. 85, nº11, pp. 1577-1581.

MARTIN, M.T. y MARTIN, M. (2003). Trabajo experimental de la enseñanza de la química en niveles no universitarios. Química e industria. Quibal, 50 (5), nº 541, pp. 313-317.

MARTÍN, M. y SÁNCHEZ, P. J. (1999). Una propuesta didáctica para la enseñanza del concepto de enlace químico en secundaria. Universidade da Coruña. A Coruña MARTÍNEZ TORREGROSA, J., VERDÚ, R. y GIL, D. (1999). La evaluación en una enseñanza de la física como construcción de conocimientos. Educación abierta. Aspectos didácticos de Física y Química, ICE Universidad de Zaragoza $\mathrm{n}^{\circ} 8$, pp.147-176.

MEC (1992). Real Decreto 1178/1992, de 2 de octubre, (BOE, 21 de octubre de 1992), por el que se establecen las enseñanzas mínimas correspondientes a bachillerato.

MECD (2000). Real Decreto 3474/200, de 29 de diciembre, (BOE, 16 de enero de 2001) por el que se modifica el real decreto 1178/1992, de 2 de octubre, por el que se establecen las enseñanzas mínimas correspondientes a bachillerato.

MEC (2004). Aprender para el mundo de mañana. Resumen de resultados PISA 2003. OCDE.

MEC (2006). Real Decreto 1631/2006, de 29 de diciembre, (BOE, 5 de enero de 2007) por el que se establecen las enseñanzas mínimas correspondientes a la Educación Secundaria Obligatoria.

MEC (2007a). Real Decreto 1467/2007, de 2 de noviembre, (BOE, 6 de noviembre de 2007) por el que se establece la estructura del bachillerato y se fijan sus enseñanzas mínimas.

MEC (2007b). PISA 2006. Programa para la evaluación internacional de alumnos de la OCDE. Informe español.

MERGEL, B. (1998). Diseño instruccional y teoría del aprendizaje. Universidad de Saskatchewan (Canadá)http://www.usask.ca/education/coursework/802papers 
/mergel/espanol.pdf

MEEK, T. L. and GARNER, L. D. (2005). Electronegativity and the Bond Triangle. Journal of Chemical Education. Vol. 82, N² 2, pp. 325-333.

MICHAELSEN, L., WATSON, W. y BLACK, R.(1989). A Realistic Test of Individual Versus Group Consensus Decision Making. Journal of Applied Psychology. Vol. $74, \mathrm{n}^{\circ} 5$, pp. 834-839.

MORENO, M. (1994). Problemática científica y problemática social en la enseñanza. Aula de innovación educativa. n. 27, pp. 9-12.

MUNK, V. y GEORGE, A. V. (2003). Small group Learning in first year chemistry: Does it work? Australian Journal of Education Chemistry. Vol. 62, pp. 9-12.

MYERS, S. A. (2003). The Molecular Model Game. Journal of Chemical Education. Vol. 80, No 4, pp. 423-424.

NOVAK, J. (1982). Teoría y práctica de la educación. Madrid: Alianza

NOVAK, J. D. (1991) Ayuda a los alumnos a aprender a aprender. La opinión de un profesor investigador. Enseñanza de las Ciencias. 9 (3) pp. 225-228.

O'DONNELL, A. M. y DANSEREAU, D. F. (1992). Scripted cooperation in students dyads: a method for analyzinng and enhancing academic learning and performance. En Hertz-Lazarowitz, R. y Miller, N. (Eds.). Interaction in cooperative groups: the theoretical anatomy of group learning, pp. 120-141. New York: Cambridge University Press.

OLMOS, J. J. (2006). Cursos de nivelación como alternativa en el aprendizaje de conceptos básicos de química. Libro de actas Congreso CIES 2006. Universidad Politécnica de Valencia

OÑORBE, A. y SÁNCHEZ, J.M. (1996). Dificultades en la enseñanza-aprendizaje de los problemas de física y química. II. Opiniones del profesor. Enseñanza de las ciencias, 14(3), pp. 251-260.

OSBORNE, J., ERDURAN, S. y SIMON, S. (2004). Enhacing the quality of argumentation in school science. http://www3.interscience.wiley.com/cgibin/abstract/109746729/ABSTRACT (29/04/05).

OVEJERO, A. (1990). El aprendizaje cooperativo. Una alternativa eficaz a la enseñanza tradicional. Barcelona, P.P.U.

OVEJERO, B. (2005). Resumen-métodos de aprendizaje cooperativo. http//www.psi.uji.es/asignatura/obtener.php?letra=R\&codigo=26\&fichero=10655 33587R26 (18/02/05). 
PARKIN, G. (2006). Valence, Oxidation Number, and Formal Charge: Three Related but Fundamentally Different Concepts. Journal of Chemical Education. Vol. 83, No 5, pp. 791-799.

PAULSON, D. R. (1999). Active Learning and Cooperative Learning in the Organic Chemistry Lecture Class. Journal of Chemical Education. Vol. 76, № 8, pp. 11361140 .

PERALES, J. (2003). El nuevo Decreto de Mínimos con el bachillerato de ciencias: una mirada hacia el pasado. Alambique, 36, pp.11-14.

PFENNIG, B. W. and FROCK, R. L. (1999). The Use of Molecular Modeling and VSEPR Theory in the Undergraduate Curriculum to Predict the ThreeDimensional Structure of Molecules. Journal of Chemical Education. Vol. 76, $\mathrm{N}^{\mathrm{o}}$ 7, pp. 1018-1022.

PICKERING, M. (1980). Are lab courses a waste of time? Chronicle of Higher Education, 19, pp. 44-50.

PINTÓ, R., ALIBERAS, J. y GÓMEZ, R. (1996). Tres enfoques de la investigación sobre concepciones alternativas. Enseñanza de las Ciencias, 14, pp. 221-232.

POGACNIK, L. y CIGIC, B. (2006). How to Motivate Students to Study before They Enter the Lab. Journal of Chemical Education, Vol. 83, nº7, pp. 1094-1098.

POSADA, J.M. DE. (1993). Estudio de los constructor de los alumnos y análisis secuencial de libros de texto en los niveles BUP y COU en relación con la estructura de la materia y enlace químico. Tesis doctoral. Universidad de Málaga. España. Sao paulo , Brasil: Miguel de Cervantes. Resumen en Enseñanza de las Ciencias, 11(3), pp. 351-353.

POSADA, J.M. DE. (1993). Concepciones de los alumnos de 15-18 años sobre la estructura interna de la materia en el estado sólido. Enseñanza de las ciencias, 11(1), pp. 12-19.

POSADA, J.M. DE. (1996). Hacia una teoría sobre las ideas científicas de los alumnos: Influencia del contexto. Enseñanza de las Ciencias, 14(3), pp. 303-314.

POSADA, J.M. DE. (1999). Concepciones de los alumnos sobre el enlace químico antes, durante y después de la enseñanza formal. Problemas de aprendizaje. Enseñanza de las ciencias, 17 (2), 227-245. 
POSADA, J.M. DE. (2000). Problemas y soluciones didácticas para abordar el enlace químico. Alambique, 26, pp. 95-100.

POSNER, J.G., STRIKE, K.A., HEWSON, P.W. y GERTGOZ, W.A. (1982). Acomodation of a scientific conception: Toward a theory of a conceptual change. Science Education, 66, pp. 211-227.

POVEDA SERRA, P. (2007). Implicaciones del aprendizaje cooperativo en las relaciones interpersonales y en el rendimiento académico. Tesis Doctoral, Facultad de Educación, Universidad de Alicante (España).

http://www.cervantesvirtual.com/servlet/SirveObras/57972718101153509532279/ 025589.pdf

POZO, J. I. y otros. (1991). Procesos cognitivos en la comprensión de la ciencia: Las ideas de los adolescentes sobre la Química. CIDE. Madrid.

POZO, J. I. y GÓMEZ CRESPO, M. A. (1998).Aprender y enseñar ciencia. Morata. Madrid.

POZO, I., MARÍN, M. et al. (1999). Debates: Constructivismo y educación científica. Enseñanza de las ciencias, 17(3), pp.477-520.

POZO, J.L. y CARRETERO, M. (1987). Del pensamiento formal a las concepciones espontáneas: ¿Qué cambia en la enseñanza de la ciencia? Infancia y aprendizaje, 38 , pp.35-52.

PRATT, S. (2003). Cooperative Learning Strategies. Science Teacher, Vol. 70, nº4, pp. 25-29.

PRIEST, R. H. y STERLING, D. R. (2003). Team Science. Science Teacher, Vol. 70 no 4 , p. 38.

PURSEN, G. H. (1999). Lewis Structures Are Models for Predicting Molecular Structure, Not Electronic Structure. Journal of Chemical Education. Vol. 76, No 7, pp. 1013-1017.

PURSEN, G. H. (2001). Lewis Structures in General Chemistry: Agreement between Electron Density Calculations and Lewis Structures. Journal of Chemical Education. Vol. 78, № 7, pp. 981-983.

RAGHAVAN, K. y GLASER, R. (1995). Model-based analysis and reasoning in science: The MARS curriculum. Science Education, 79, pp. 37-61. 
RAIGOSA, C.E. y JIMÉNEZ, M.P. (2000). La cultura científica en la resolución de problemas en el laboratorio. Enseñanza de las ciencias. 18 (2), pp. 275-284.

RAO, S., COLLINS, H. y DICARLO, S. (2002). Collaborative testing enhaces student learnig. Advances in Physiology Education. No 26, pp. 37-41.

RAVINOVICH, D. (2003). Chemical Bonding and Molecular Geometry: From Lewis to Electron Densities. Journal of Chemical Education. Vol. 80, № 1, p. 31.

REIF, F. y ST. JOHN, M. (1979). Teachig physicists thinking skills in the laboratory. American Journal of Physics, 47, pp. 750-757.

RIBOLDI, L., PLIEGO, O. y ODETTI, H. (2004). El enlace químico: Una conceptualización poco comprendida. Enseñanza de las ciencias, 22(2), 195-212.

ROBINSON, W. R. (1998). An Alternative Framework for Chemical Bonding. Journal of Chemical Education. Vol. 75, $\mathrm{N}^{\mathrm{o}} \mathrm{xxxx}$, pp. 1074-1075.

RODRÍGUEZ, A. (2000). El proceso de aprendizaje y las teorías educativas. Departamento de lenguajes y sistemas informáticos. UNED. http://sensei.ieec. uned.es/ miguel/tesis/node14.html (10-04-08)

RODRIGUEZ, L. M. y ESCUDERO, T. (2000). Interacción entre iguales y aprendizaje de conceptos Científicos. Enseñanza de las Ciencias, Vol. 18, pp. 255-274.

RUÉ, J. (1991). El treball coperatiu. L'organització social d l'ensenyament i l'aprenentatge. Barcelona: Barcanova.

SCHRAY, K., RUSSO, M. J., EGOLF, R., LADERMAN, W. y GELORMO, D. (2009). Are In-Class Peer Leaders Effective in the Peer-Led Team-Learning Approach? Journal of College Science Teaching, Vol. 38 (4), pp. 62-67.

SHACHAR, H. y FISHER, S. (2004). Cooperative Learning and the Achievement of Motivation and Perceptions of Students in 11th Grade Chemistry Classes. Learning and Instruction, Vol. 14, nº 1, pp. 69-87.

SHARAN, S. (1980). Cooperative learning in small groups: Recent methods and effects on achievement, attitudes, and ethnic relations. Review of Educational Research, n 50 , pp. $241-272$

SHAYER, M. y ADEY, P. (1984). La ciencia de enseñar ciencias. Madrid. Narcea.

SHIBLEY, I. A. y ZIMMARO, D. M. (2002). The Influence of Collaborative Learning on Student Attitudes and Performance in an Introductory Chemistry Laboratory. Journal of Chemical Education. Vol. 79, pp. 745-748. 
SHUSTERMAN, G. P. and SHUSTERMAN, A. J. (1997). Teaching Chemistry with Electron Density Models. Journal of Chemical Education. Vol. 74, No 7, pp. 771776.

SLAVIN, R. (1990). Cooperative learning: theory research and practice. New York, Plenum.

SOLSONA, N. (2002a). La actividad científica en la cocina. Madrid. Instituto de la mujer.

SOLSONA, N. (2002b). La química de la cocina. Propuesta didáctica para la educación secundaria. Madrid. Instituto de la mujer.

SOLSONA, N. y MATÍN, R. (2004). Los cambios químicos: de los modelos del alumnado a los modelos escolares. Alambique, 42, pp. 19-28.

SOLVES, J. y otros. (1987). Model quàntic de l'àtom. Servei de formació permanent de la Universitat de València.

SOLVES, J. y VILCHES, A. (1991). Análisis de la introducción de la teoría de enlaces y bandas. Enseñanza de las Ciencias, 9(1), pp. 53-58.

SPROUL, G. (2001). Electronegativity and Bond Type: Predicting Bond Type. Journal of Chemical Education. Vol. 78, No 3, pp. 387-390.

SUTTON, R. y HARGADON, A. (2007). Brainstorming groups in context: effectiveness in a product design firm.

http://findarticles.com/p/articles/mi m4035/is n4 v41/ai 19137715/pg 2 $(26 / 12 / 07)$.

SYH-JONG, J. (2007). A Study of Students' Construction of Science Knowledge: Talk and Writing in a Collaborative Group. Educational Research, Vol. 49 n 1 , pp. 6581 .

TAMIR, P. (1974). An inquiry oriented laboratory examination. Journal of Educational Measurement, 11, pp. 25-33.

TAMIR, P. y LUNETA, V.N. (1978). An analysis of laboratory activities in the BSCS Yellow version. The American Biology Teacher, 40, pp. 353-357.

TANG, G., GALlO, P. B., JACOBS, G. M. y KIM-ENG, C. (1999). Using Cooperative Learning to Integrate Thinking and Information Technology in a Context-Based Writting Lesson. The Internet TESL Journal. Vol. 5, No8, 1999, http://iteslj.org/Techniques/Tan-Cooperative.html \{ref. 26/05/2005\} 
TOBIN, K. (1986). Secondary science laboratory activities. European Journal of Science Education, 8, pp. 199-211.

TOOTHACKER, W.S. (1983). A critical look at introductory laboratory instruction. American Journal of Physics, 51, pp. 516-520.

TRIBE, L. y KOSTKA, K. (2007). Peer-Developed and Peer-Led Labs in General Chemistry. Journal of Chemical Education, Vol. 84, nº, pp. 1031.

TRINIDAD-VELASCO, R. y GARRITZ, A. (2003). Revisión de las concepciones alternativas de los estudiantes de secundaria sobre la estructura de la materia. Educación química, $\mathrm{n}^{\circ} 14$ (2) pp. 92-105.

VALCÁRCEL, M. V., SÁNCHEZ, G. y RUIZ, M. (2000). El estudio del átomo en la educación secundaria. Alambique, 26, pp. 83-94.

VALCÁRCEL, M.V. y SÁNCHEZ, G. (2003). Los modelos en la enseñanza de la química: concepto de sustancia pura. Alambique, 35, pp. 45-52.

VAN ENGELEN, D. L., SUlJAK, S. W., HALl, J. P. y HOLMES, B. E. (2007). Undergraduate Introductory Quantitative Chemistry Laboratory Course: Interdisciplinary Group Projects in Phytoremediation. Journal of Chemical Education, Vol. 84, nº1, pp. 128-131.

VÁZQUEZ, A. (1999). Innovando la enseñanza de las ciencias: El movimiento cienciatecnología-sociedad. Revista del Col-legi Oficial de Doctors i Llicenciats de Balears, 8, pp. 25-35.

VYGOTSKY, L. S. (1980). Mind in society: The development of higher psychological processes. Cambridge, MA: Harvard University.

WANOUS, M., PROCTER, B. y MURSHID, K. (2009). Assessment for Learning and Skills Development: The Case of Large Classes. European Journal of Engineering Education, Vol. 34, nº1, pp. 77-85.

WATTS, F. y GARCÍA-CARBONELL, A. (2006). La evaluación compartida: Investigación multidisciplinar. IEMA. UPV.

WEINHOLD, F. and LANDIS, C. (2007). Valency and Bonding: A Natural Bond Orbital Donor-Acceptor Perspective. Journal of Chemical Education. Vol. 84, $\mathrm{n}^{\circ}$ 1, p. 43.

WHITE, R.T. (1979). Relevance of practical work to the comprehension of physics. Physics Education, 14, pp. 384-387. 


\section{ANEXO I}

CUESTIONARIO PARA LA COMPROBACIÓN DE CONOCIMIENTOS

REFERENTES A CONCEPTOS BÁSICOS DE QUÍMICA 


\section{CUESTIONARIO PARA LA COMPROBACIÓN DE CONOCIMIENTOS REFERENTES A CONCEPTOS BÁSICOS DE QUÍMICA.}

Nombre y apellidos

Curso...........................F echa....

1.- ¿Qué nombre es más correcto con la nomenclatura sistemática de la IUPAC para el compuesto, $\mathrm{Ni}_{2} \mathrm{O}_{3}$ ?
(A) óxido (III) de níquel.
(B) óxido de níquel (III).
(C) óxido de níquel (II).
(D) óxido (II) de níquel.

2.- Un compuesto con la fórmula $\mathrm{CaH}_{2}$ se denomina:
(A) hidruro de cadmio.
(B) carburo de hidrógeno.
(C) hidruro de calcio.
(D) hidrato de calcio.

3.- El nombre correcto según la IUPAC para el $\mathrm{N}_{2} \mathrm{O}_{3}$ es:
(A) óxido de nitrógeno.
(C) óxido de nitrógeno (II).
(B) óxido nitroso.
(D) trióxido de dinitrógeno.

4.- $\mathrm{El} \mathrm{NaBrO}_{3}$ es la fórmula correcta de:
(A) bromato de sodio.
(B) bromuro de sodio.
(C) bromito de sodio.
(D) hipobromito de sodio.

5.- ¿Cuál es la combinación correcta fórmula/nombre?
(A) $\mathrm{Al}_{2}\left(\mathrm{SO}_{4}\right)_{3} /$ sulfato de aluminio.
(B) $\mathrm{K}_{2} \mathrm{PO}_{3} /$ fosfato de potasio.
(C) $\mathrm{C}_{2} \mathrm{H}_{3} \mathrm{O}^{-} /$acetato.
(D) $\mathrm{PCl}_{3} /$ clorito de fósforo.

6.- La fórmula del nitrito de calcio es:
(A) $\mathrm{Ca}_{3} \mathrm{~N}_{2}$.
(B) $\mathrm{Ca}(\mathrm{NO})_{2}$
(C) $\mathrm{Ca}\left(\mathrm{NO}_{2}\right)_{2}$
(D) $\mathrm{Ca}\left(\mathrm{NO}_{3}\right)_{2}$

7.- ¿En qué caso la combinación fórmula-nombre es la correcta?
(A) $\mathrm{KNO}_{2} /$ nitrato de potasio.
(B) $\mathrm{FeCl}_{3} /$ cloruro de hierro (III).
(C) $\mathrm{FeS} /$ sulfito de hierro (II).
(D) $\mathrm{Mg}_{3} \mathrm{~N}_{2} /$ nitrito de magnesio.
(E) $\mathrm{HClO} /$ óxido hipoclorito. 
8.- La fórmula del vanadato de sodio es $\mathrm{Na}_{3} \mathrm{VO}_{4}$ y la del cloruro de calcio es $\mathrm{CaCl}_{2}$ ¿ ¿Cuál es la fórmula del vanadato de calcio?
(A) $\mathrm{CaVO}_{4}$
(B) $\mathrm{Ca}\left(\mathrm{VO}_{4}\right)_{2}$
(C) $\mathrm{Ca}\left(\mathrm{VO}_{4}\right)_{3}$
(D) $\mathrm{Ca}_{3}\left(\mathrm{VO}_{4}\right)_{2}$
(E) $\mathrm{Ca}_{2} \mathrm{VO}_{4}$

9.- Los iones presentes en el cromato de plata sólido, $\mathrm{Ag}_{2} \mathrm{CrO}_{4}$, son:
(A) $\mathrm{Ag}^{+} \mathrm{y} \mathrm{CrO}_{4}^{2-}$
(B) $\mathrm{Ag}^{2+} \mathrm{y} \mathrm{CrO}_{4}^{4-}$
(C) $\mathrm{Ag}+, \mathrm{Cr}^{6+} \mathrm{y} \mathrm{O}^{2-}$
(D) $\mathrm{Ag}^{+}, \mathrm{Cr}^{3+}, \mathrm{y} \mathrm{O}^{2-}$

10.- Según la teoría cinética molecular:

(A) Las moléculas gaseosas están continuamente en movimiento desordenado y sus colisiones son perfectamente elásticas.

(B) La temperatura absoluta de los gases depende de su masa molar.

(C) La presión que ejerce un gas afecta a la velocidad de sus moléculas.

(D) Las moléculas gaseosas pueden moverse en direcciones rectas o en caminos curvados.

(E) Todas las moléculas gaseosas son diatómicas.

11.- En condiciones normales, una masa molar de cualquier gas ocupa aproximadamente 22.4 L. Por lo tanto:

(A) La masa molecular de cualquier gas es siempre la misma.

(B) Todas las moléculas de todos los gases tienen la misma velocidad en condiciones estándar.

(C) Todos los gases son diatómicos.

(D) Existe el mismo número de moléculas en una masa molar de cualquier gas.

(E) Las moléculas de todos los gases se mueven a altas velocidades.

12.- Al cuadruplicar la temperatura absoluta de un gas ideal y duplicar la presión, ¿cuál es el efecto neto en el volumen del gas?
(A) El volumen permanece constante.
(B) El volumen se duplica.
(C) El volumen se cuadriplica.
(D) El volumen aumenta ocho veces. 
13.- Inflamos cuatro globos idénticos con la misma cantidad en masa con los gases indicados. ¿Cuál de los globos será el primero en explotar?
(A) $\mathrm{Ne}$
(B) $\mathrm{N}_{2}$
(C) $\mathrm{O}_{2}$
(D) $\mathrm{CH}_{4}$

14.- El mercurio en el tubo derecho está abierto a una presión de 1 atmósfera (760 $\mathrm{mm} \mathrm{Hg}$ ) y tiene una altura de $100 \mathrm{~mm}$ mientras que la altura del tubo izquierdo es de $120 \mathrm{~mm}$.

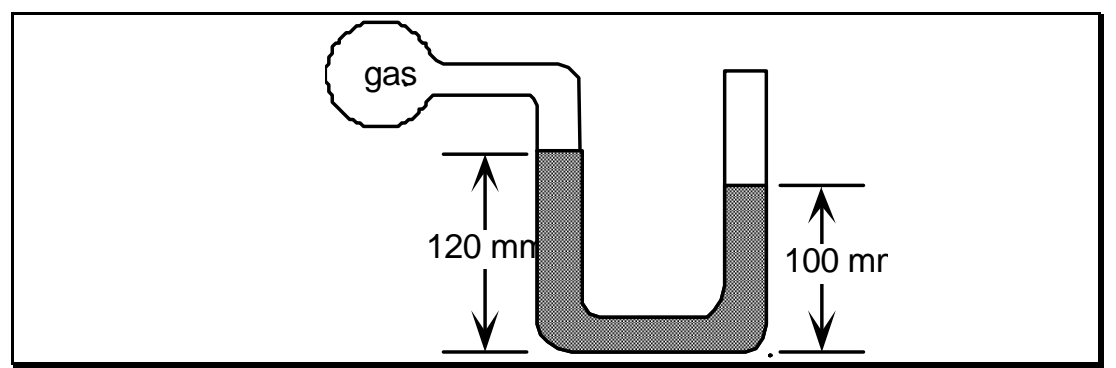

¿Cuál es la presión de gas del recipiente?
(A) $20 \mathrm{mmHg}$.
(B) $640 \mathrm{mmHg}$.
(C) $740 \mathrm{mmHg}$.
(D) $780 \mathrm{mmHg}$.

15.- Un mol de oxígeno gaseoso:
(A) Tiene una masa de $16 \mathrm{~g}$.
(B) Contiene dos átomos.
(C) Contiene aproximadamente $6,022 \cdot 10^{23}$ átomos.
(D) Ocupa 22.4 L a cualquier condición de temperatura y presión.
(E) Ocupa el mismo volumen que un mol de $\mathrm{Cl}_{2}$ en condiciones normales.

16.- El número aproximado de moléculas en un litro de oxígeno gas en condiciones normales es:
(A) $6 \cdot 10^{23}$
(B) $22,4 \cdot 6 \cdot 10^{23}$
(C) $\frac{6 \cdot 10^{23}}{22,4 \cdot 32}$
(D) $\frac{32 \cdot 6 \cdot 10^{23}}{22,4}$
(E) $\frac{6 \cdot 10^{23}}{22,4}$ 
17.- ¿Cuántos moles de un gas ideal se encuentran en una muestra que ocupa un volumen de $500 \mathrm{~mL}$ a $25^{\circ} \mathrm{C}$ y $0.460 \mathrm{~atm}$ ?
(A) 0.00941 moles
(B) 0.160 moles
(C) 10.2 moles
(D) 13.4 moles

18.- Cuando se añaden masas iguales de gas metano y oxígeno a un recipiente vacío a $25^{\circ} \mathrm{C}$, la fracción de la presión ejercida por el oxígeno es: $\quad \operatorname{Mr}\left(\mathrm{CH}_{4}\right)=16$; $\operatorname{Mr}\left(\mathbf{O}_{2}\right)=32$
(A) $\frac{1}{3}$ de la presión total.
(B) $\frac{1}{2}$ de la presión total.
(C) $\frac{2}{3}$ de la presión total.
(D) $\frac{1}{3}$ de la presión total $\frac{273}{298}$
(E) $\frac{2}{3}$ de la presión total $\frac{273}{298}$

19.- Dada la reacción $2 \mathrm{Al}+3 \mathrm{~S} \rightarrow \mathrm{Al}_{2} \mathrm{~S}_{3} \operatorname{Ar}(\mathrm{Al})=27$ y $\operatorname{Ar}(\mathrm{S})=32$. Hacemos reaccionar en un recipiente cerrado $20 \mathrm{~g}$ de aluminio con $20 \mathrm{~g}$ de azufre. ¿Cuál es la masa contenida en el recipiente después de la reacción? $\leftrightarrow$
A) más de $40 \mathrm{~g}$.
(B) $40 \mathrm{~g}$.
(C) menos de $40 \mathrm{~g}$.
(D) depende de las condiciones.

20.- A justa la ecuación:

$$
? \mathrm{~N}_{2} \mathrm{H}_{4}+? \mathrm{~N}_{2} \mathrm{O}_{4} \leftrightarrow ? \mathrm{~N}_{2}+? \mathrm{H}_{2} \mathrm{O}
$$

¿Cuántos moles de $\mathrm{N}_{2}$ se producirán por cada mol de $\mathrm{N}_{2} \mathrm{O}_{4}$ que reacciona?
(A) uno
(B) dos
(C) tres
(D) cuatro 
21.- La ecuación química: $\quad 2 \mathrm{CO}_{2} \leftrightarrow 2 \mathrm{CO}+\mathrm{O}_{2} \quad$ nos informa de que:

(A) cuando 2 moles de $\mathrm{CO}_{2}$ se descomponen, se formarán menos de 2 moles de $\mathrm{CO}$ y la cantidad de $\mathrm{O}_{2}$ formado será menos de $1 \mathrm{~mol}$.

(B) sólo bajo condiciones especiales se producirán 2 moles de $\mathrm{CO}_{2}, 2$ moles de $\mathrm{CO}$ y $1 \mathrm{~mol} \mathrm{de} \mathrm{O}_{2}$.

(C) el dióxido de carbono se descompone, pero la cantidad relativa de $\mathrm{CO}_{2}, \mathrm{CO}, \mathrm{y}$ $\mathrm{O}_{2}$ implicados en la reacción estará en función de las condiciones.

(D) en cualquier condición, la descomposición de 1 mol de $\mathrm{CO}_{2}$ producirá 1 mol de $\mathrm{CO}$ y $1 / 2 \mathrm{~mol}$ de $\mathrm{O}_{2}$.

(E) la tendencia del $\mathrm{CO}_{2}$ a descomponerse es igual a la tendencia del $\mathrm{CO}$ y el $\mathrm{O}_{2}$ a combinarse.

22.- Un compuesto gaseoso de carbono e hidrógeno contiene un $90 \% \mathrm{C}$ y $10 \% \mathrm{H}$ por masa. Si $45 \mathrm{~L}$ del gas, en condiciones normales, tiene una masa de aproximadamente $80 \mathrm{~g}$, ¿cuál es la fórmula molecular del gas? $\operatorname{Ar}(\mathrm{C})=12$; $\operatorname{Ar}(\mathbf{H})=1$.
(A) $\mathrm{C}_{6} \mathrm{H}_{8}$
(B) $\mathrm{C}_{3} \mathrm{H}_{4}$
(C) $\mathrm{C}_{7} \mathrm{H}_{14}$
(D) $\mathrm{C}_{3} \mathrm{H}_{8}$

23.- La fórmula para el metano es $\mathrm{CH}_{4}$. Ésto siginifica que en el metano, $\operatorname{Ar}(C)=12 ; \operatorname{Ar}(H)=1$

(A) por cada 100 átomos de hidrógeno hay 400 átomos de carbono.

(B) por cada átomo de carbono hay cuatro gramos de hidrógeno.

(C) por cada gramo de hidrógeno hay doce gramos de carbono.

(D) el compuesto posee un $25 \%$ de hidrógeno en masa.

(E) el compuesto posee un $80 \%$ de hidrógeno en masa.

24.- ¿Cuántos moles de Fe se necesitan para producir 10,0 moles de $\mathrm{H}_{2}$ ?

$$
4 \mathrm{H}_{2} \mathrm{O}(\mathrm{g})+3 \mathrm{Fe}(\mathrm{s}) \leftrightarrow \mathrm{Fe}_{3} \mathrm{O}_{4}(\mathrm{~s})+4 \mathrm{H}_{2}(\mathrm{~g})
$$
(A) 7.5 moles.
(B) 13.3 moles.
(C) 15.0 moles.
(D) 30.0 moles. 
25.- Admitiendo que se produce la oxidación completa en la reacción:

$$
\mathrm{C}(\mathrm{s})+\mathrm{O}_{2}(\mathrm{~g}) \leftrightarrow \mathrm{CO}_{2}(\mathrm{~g})
$$

¿Qué masa de $\mathrm{CO}_{2}$ producirán $15 \mathrm{~g}$ de carbono? $\mathrm{Ar}(\mathrm{C})=12 ; \mathrm{Mr}\left(\mathrm{O}_{2}\right)=32 ; \mathrm{Mr}$ $\left(\mathrm{CO}_{2}\right)=44$.
(A) $11 \mathrm{~g}$.
(B) $22 \mathrm{~g}$.
(C) $44 \mathrm{~g}$.
(D) $55 \mathrm{~g}$

26.- El sulfuro de cobre (II) es sólido a temperatura ambiente. ¿A qué masa corresponde "un mol de sulfuro de cobre (II)"?

(A) la masa de sulfuro de cobre (II) necesaria para ocupar un litro.

(B) la masa de sulfuro de cobre (II) sólido necesaria para ocupar 22,4 L en condiciones normales.

(C) la masa de cobre que se combina con azufre en una molécula.

(D) la masa de sulfuro de cobre (II) en gramos es igual a la masa de un mol obtenida mediante la fórmula.

(E) la masa en gramos de una molécula de sulfuro de cobre (II).

27.- Un volumen de $40 \mathrm{~mL}$ de una disolución de $\mathrm{MgSO}_{4} \mathrm{0.1} \mathrm{M}$, ¿cuántos gramos de $\mathrm{MgSO}_{4}$ contiene? $\operatorname{Ar}(\mathrm{Mg})=23 ; \operatorname{Ar}(\mathrm{O})=16 ; \operatorname{Ar}(\mathrm{S})=32,1 ;$
(A) $120 \mathrm{~g}$.
(B) $24 \mathrm{~g}$.
(C) $0,96 \mathrm{~g}$.
(D) $0,6 \mathrm{~g}$.
(E) $0,48 \mathrm{~g}$

28.-En la reacción $\quad \mathrm{N}_{2}(\mathrm{~g})+3 \mathrm{H}_{2}(\mathrm{~g}) \rightleftarrows 2 \mathrm{NH3}(\mathrm{g})$

¿qué volumen de nitrógeno se combinará con $12 \mathrm{~L}$ de hidrógeno, ambos medidos en condiciones normales?
(A) $4 \mathrm{~L}$
(B) $8 \mathrm{~L}$
(C) $12 \mathrm{~L}$
(D) $22.4 \mathrm{~L}$
(E) $28 \mathrm{~L}$

29.- ¿Cuántos moles de $\mathrm{NH}_{3}$ se pueden formar al reaccionar 0,50 moles de $\mathrm{NCl}_{3}$ con 0,40 moles de $\mathrm{H}_{2}$ ? $\quad 2 \mathrm{NCl}_{3}+3 \mathrm{H}_{2} \leftrightarrow 2 \mathrm{NH}_{3}+3 \mathrm{Cl}_{2}$
(A) 0,27 moles.
(B) 0,50 moles.
(C) 0,60 moles.
(D) 0,90 moles.

30.- El número de neutrones en el núcleo de un determinado átomo es igual a:
(A) la masa atómica.
(B) el número másico.
(C) el número atómico.
(D) el número másico menos el número atómico. 
31.- ¿Qué es la energía de ionización de un elemento?

(A) el potencial necesario para arrancar un electrón de un átomo o ión.

(B) el potencial necesario para conseguir que un electrolito débil se ionice.

(C) el mismo que el potencial de electrodo.

(D) el mismo que la constante de ionización.

(E) menor para los gases inertes que para todos los otros elementos.

32.- La masa atómica de un elemento es 32,07 y su número atómico es 16. El número de protones que existen en el núcleo de un átomo de éste elemento es:
(A) 16
(B) 31
(C) 32
(D) 48

33.- Un átomo tiene una configuración de la capa de valencia $n s^{1}$. ¿A qué grupo de elementos de la tabla periódica pertenece ésta configuración?
(A) metales de transición.
(B) tierras raras.
(C) metales alcalinotérreos.
(D) metales alcalinos.

34.-¿Cuál de las respuestas representa la estructura electrónica del elemento con número atómico 17?
(A) $1 s^{2} 2 p^{8} 3 d^{7}$
(C) $1 s^{2} 2 p^{2} 2 d^{6} 3 f^{7}$
(E) $1 s^{2} 2 s^{2} 2 p^{4} 2 d^{2} 3 s^{2} 3 p^{4} 3 d^{1}$
(B) $1 s^{2} 2 s^{8} 3 p^{7}$
(D) $1 s^{2} 2 s^{2} 2 p^{6} 3 s^{2} 3 p^{5}$

35.- ¿Qué par de los siguientes representan isótopos?
(A) ${ }_{24}^{58} \mathrm{Cr}$ y ${ }_{26}^{54} \mathrm{Fe}$
(B) ${ }_{92}^{235} \mathrm{U}$ y ${ }_{92}^{238} \mathrm{U}$
(C) ${ }_{48}^{116} \mathrm{Cd}$ y ${ }_{50}^{116} \mathrm{Sn}$
(D) ${ }_{93}^{239} \mathrm{~Np}$ y ${ }_{94}^{239} \mathrm{Pu}$ 
36.- ¿Qué cambio energético se produce cuando un electrón se mueve desde un nivel de energía en un átomo a otro nivel más externo del núcleo del mismo átomo?
(A) Se absorbe energía.
(B) Se libera energía.
(C) No hay cambio de energía.
(D) El átomo tendrá distinta valencia iónica (electrovalencia).
(E) Se emite luz de una longitud de onda definida.

37.- Considerando los estados de oxidación más comunes del $\mathrm{Rb}$ y $\mathrm{S}$, ¿qué compuesto se formaría al reaccionar el $\mathrm{Rb}$ con el $\mathrm{S}$ ?
(A) $\mathrm{Rb}_{2} \mathrm{~S}_{3}$
(B) $\mathrm{RbS}_{2}$
(C) $\mathrm{Rb}_{3} \mathrm{~S}_{2}$
(D) $\mathrm{Rb}_{2} \mathrm{~S}$

38.- ¿Cuál de estos iones isoelectrónicos es el más pequeño?
(A) $\mathrm{O}^{2-}$
(B) $\mathrm{F}^{-}$
(C) $\mathrm{Na}^{+}$
(D) $\mathrm{Mg}^{2+}$
(E) $\mathrm{Al}^{3+}$

39.- ¿Qué elemento presenta mayor electronegatividad?
(A) litio
(B) yodo
(C) cesio
(D) oxígeno

40.- ¿Qué par de elementos tienen las propiedades químicas más parecidas?
(A) $\mathrm{C}$ y F
(B) Py As
(C) Li y Be
(D) As y Se

41.- ¿Qué elemento gana electrones con mayor facilidad?
(A) flúor
(B) cloro
(C) bromo
(D) yodo
(E) astuto 
1.- $\mathrm{Si}$ 0,20 moles de $\mathrm{Na}_{3} \mathrm{PO}_{4}$ se mezclan con 0,4 moles de $\mathrm{BaCl}_{2}$, el máximo número de moles de fosfato de bario que se puede formar son:
(A) 0,10
(B) 0,15
(C) 0,30
(D) 0,50

2.- Ajusta la ecuación para la reacción sin utilizar coeficientes fraccionarios:

$$
\text { i } \mathrm{Na}_{2} \mathrm{CrO}_{4}+i \mathrm{AgNO}_{3} \rightarrow \text { i } \mathrm{Ag}_{2} \mathrm{CrO}_{4}+i \mathrm{NaNO}_{3}
$$

el coeficiente de $\mathrm{AgNO}_{3}$ en la ecuación ajustada es:
(A) 2
(B) 4
(C) 6
(D) 8
(E) 10

3.- Los iones presentes en el cromato de plata sólido, $\mathrm{Ag}_{2} \mathrm{CrO}_{4}$ son:
(A) $\mathrm{Ag}^{+}, \mathrm{Cr}^{3+}, \mathrm{y} \mathrm{O}^{2-}$
(B) $\mathrm{Ag}^{2+}, \mathrm{y} \mathrm{CrO}_{4}^{4-}$
(C) $\mathrm{Ag}^{+}, \mathrm{Cr}^{6+,} \mathrm{y} \mathrm{O}^{2-}$
(D) $\mathrm{Ag}^{+} \mathrm{y} \mathrm{CrO}_{4}{ }^{2-}$

4.- Llenamos un recipiente con oxígeno gaseoso $\mathrm{O}_{2}$ y otro recipiente del mismo volumen con gas neón, los dos a la misma temperatura y presión. Ambos cilindros contienen el/la mismo/a:
(A) Masa de gas
(B) Número de átomos
(C) Número de neutrones
(D) Número de moléculas

5.- La composición de un gas es carbono, $92,24 \%$ e hidrógeno, $7,76 \%$. La fórmula empírica del gas es:

$$
\operatorname{Ar}(H)=1,01 ; \operatorname{Ar}(C)=12
$$
(A) $\mathrm{CH}_{4}$
(B) $\mathrm{CH}$
(C) $\mathrm{C}_{2} \mathrm{H}_{4}$
(D) $\mathrm{C}_{3} \mathrm{H}_{6}$
(E) $\mathrm{C}_{4} \mathrm{H}_{10}$

6.- Se desprenden en un experimento, $5,6 \mathrm{~L}$ de cloro en condiciones normales de acuerdo con esta ecuación:

$$
4 \mathrm{HCl}+\mathrm{MnO}_{2} \rightarrow \mathrm{MnCl}_{2}+2 \mathrm{H}_{2} \mathrm{O}+\mathrm{Cl}_{2}
$$

La masa de cloruro de manganeso producida fue aproximadamente: $\operatorname{Ar}(\mathrm{Mn})=55 ; \operatorname{Ar}(\mathrm{Cl})=35,5$
(A) $12 \mathrm{~g}$
(B) $24 \mathrm{~g}$
(C) $32 \mathrm{~g}$
(D) $42 \mathrm{~g}$
(E) $84 \mathrm{~g}$ 
1.- Utilizando la siguiente ecuación:

$$
\mathrm{N}_{2}(\mathrm{~g})+3 \mathrm{H}_{2} \mathrm{O}(\mathrm{g}) \rightarrow 2 \mathrm{NH}_{3}(\mathrm{~g}) \quad \text { en c.n. } \quad \operatorname{Ar}(\mathrm{N})=14 ; \quad \operatorname{Ar}(\mathrm{H})=1
$$

a.- Si 2,0 moles de nitrógeno gas reaccionan completamente ¿Cuántos moles de amoniaco se producirán) Razona la respuesta

b.- ¿En c.n., qué volumen ocupa el amoniaco producido en (a)? Razona la respuesta

c.- Calcula el volumen molar y la masa molar del amoniaco

2.- Utilizando la siguiente ecuación:

$$
2 \mathrm{H}_{2}(\mathrm{~g})+\mathrm{O}_{2}(\mathrm{~g}) \rightarrow 2 \mathrm{H}_{2} \mathrm{O}(\mathrm{l}) \text { en c.n. } \quad \operatorname{Ar}(\mathrm{O})=16 ; \quad \operatorname{Ar}(\mathrm{H})=1
$$

a.- calcula los moles que hay en $3 \mathrm{dm}^{3}$ de hidrógeno

b.- $3 \mathrm{dm} 3$ de hidrógeno reaccionan completamente con exceso de oxígeno. ¿Cómo calculas el volumen de agua que se obtiene? Escribe todos los pasos y razona la respuesta.

3.- Utilizando la siguiente ecuación:

$$
2 \mathrm{CO}(\mathrm{g})+\mathrm{O}_{2}(\mathrm{~g}) \rightarrow 2 \mathrm{CO}_{2}(\mathrm{~g}) \quad \text { en c.n. } \operatorname{Ar}(\mathrm{O})=16 ; \quad \operatorname{Ar}(\mathrm{C})=12
$$

a.- Calcula la masa de dióxido de carbono gas que se producirá a partir de 22,4 $\mathrm{dm}^{3}$ de oxígeno gas. Escribe los pasos empleados

b.- Calcula los moles de dióxido de carbono producido en (a)

c.- Calcula la masa total de los reactivos utilizados para producir el número de moles de dióxido de carbono obtenido en (b)

4.- Utilizando la siguiente ecuación:

$$
2 \mathrm{CO}(\mathrm{g})+\mathrm{O}_{2}(\mathrm{~g}) \rightarrow 2 \mathrm{CO}_{2}(\mathrm{~g}) \quad \text { en c.n. } \operatorname{Ar}(\mathrm{O})=16 ; \quad \operatorname{Ar}(\mathrm{C})=12
$$

Un científico hace reaccionar en un recipiente cerrado $5 \mathrm{~g}$ de monóxido de carbono gas con 13 g de oxígeno gas para producir dióxido de carbono. ¿Cuál es la masa total del contenido del recipiente al acabar al reacción? 
a) Calcular los gramos de $\mathrm{NHO}_{3}$ necesarios para preparar $400 \mathrm{~mL}$ de disolución $1 \mathrm{M}$, sabiendo que la densidad del ácido nítrico concentrado es de $1,40 \mathrm{~g}^{\circ} \mathrm{cm}^{-3} \mathrm{y}$ el \% en masa es del $70 \% \quad \operatorname{Mr}\left(\mathrm{HNO}_{3}\right)=63 \mathrm{~g} \cdot \mathrm{mol}^{-1}$

b) Normalidad

c) Volumen en $\mathbf{m L}$ de $\mathrm{HNO}_{3}$ Concentrado necesario para preparar la disolución (a)

d) Al mezclar $200 \mathrm{~mL}$ de la disolución (a) con un gramo de $\mathrm{NaOH}$. Calcula la concentración de todos los iones resultantes $\mathrm{Mr}(\mathrm{NaOH})=40$ 


\section{ANEXO II}

CORRECCIÓN DEL CUESTIONARIO PARA LA COMPROBACIÓN DE CONOCIMIENTOS REFERENTES A CONCEPTOS BÁSICOS DE QUÍMICA 
Soluciones del primer test.

\begin{tabular}{|c|c|c|c|c|}
\hline $1 \rightarrow \mathrm{B}$ & $11 \rightarrow \mathrm{C}$ & $21 \rightarrow \mathrm{D}$ & $31 \rightarrow \mathrm{A}$ & $41 \rightarrow \mathrm{A}$ \\
\hline $2 \rightarrow \mathrm{C}$ & $12 \rightarrow \mathrm{B}$ & $22 \rightarrow B$ & $32 \rightarrow \mathrm{A}$ & \\
\hline $3 \rightarrow \mathrm{D}$ & $13 \rightarrow \mathrm{D}$ & $23 \rightarrow D$ & $33 \rightarrow \mathrm{D}$ & \\
\hline $4 \rightarrow \mathrm{A}$ & $14 \rightarrow \mathrm{C}$ & $24 \rightarrow \mathrm{A}$ & $34 \rightarrow \mathrm{D}$ & \\
\hline $5 \rightarrow A$ & $15 \rightarrow \mathrm{E}$ & $25 \rightarrow D$ & $35 \rightarrow \mathrm{B}$ & \\
\hline $6 \rightarrow C$ & $16 \rightarrow \mathrm{E}$ & $26 \rightarrow D$ & $36 \rightarrow \mathrm{A}$ & \\
\hline $7 \rightarrow \mathrm{B}$ & $17 \rightarrow \mathrm{A}$ & $27 \rightarrow E$ & $37 \rightarrow \mathrm{D}$ & \\
\hline $8 \rightarrow \mathrm{D}$ & $18 \rightarrow \mathrm{A}$ & $28 \rightarrow \mathrm{A}$ & $38 \rightarrow E$ & \\
\hline $9 \rightarrow \mathrm{A}$ & $19 \rightarrow \mathrm{B}$ & $29 \rightarrow A$ & $39 \rightarrow \mathrm{D}$ & \\
\hline $10 \rightarrow \mathrm{A}$ & $20 \rightarrow C$ & $30 \rightarrow \mathrm{D}$ & $40 \rightarrow B$ & \\
\hline
\end{tabular}

Soluciones del segundo test.

\begin{tabular}{|l|}
\hline $1 \rightarrow \mathrm{A}$ \\
\hline $2 \rightarrow \mathrm{A}$ \\
\hline $3 \rightarrow \mathrm{D}$ \\
\hline $4 \rightarrow \mathrm{D}$ \\
\hline $5 \rightarrow \mathrm{B}$ \\
\hline $6 \rightarrow \mathrm{C}$ \\
\hline
\end{tabular}


1.- Utilizando la siguiente ecuación:

$\mathrm{N}_{2}(\mathrm{~g})+3 \mathrm{H}_{2} \mathrm{O}(\mathrm{g}) \rightarrow 2 \mathrm{NH}_{3}(\mathrm{~g}) \quad$ en c.n. $\quad \operatorname{Ar}(\mathrm{N})=14 ; \quad \operatorname{Ar}(\mathrm{H})=1$

a.- Si 2,0 moles de nitrógeno gas reaccionan completamente ¿Cuántos moles de amoniaco se producirán) Razona la respuesta

4, ya que independientemente del estado en que se encuentren reactivos y productos, según la estequiometría de la reacción por cada mol de $\mathrm{N}_{2}$ que reacciona se forman dos de $\mathrm{NH}_{3}$

b.- ¿En c.n., qué volumen ocupa el amoniaco producido en (a)? Razona la respuesta

en c.n. el volumen de un mol de gas es $22,4 \mathrm{~L}$

$P \cdot V=n \cdot R \cdot T \rightarrow V=\frac{n \cdot R \cdot T}{P} \rightarrow V=\frac{1 \cdot 0,082 \cdot 273,15}{1}=22,4 L$,

Luego 4 moles de NH3 $\frac{22,4 \mathrm{~L}}{1 \mathrm{~mol}}=89,6 \mathrm{~L}$

c.- Calcula el volumen molar y la masa molar del amoniaco

El volumen molar es $22,4 \mathrm{~L} \cdot \mathrm{mol}^{-1}$, para cualquier gas en c.n.

$$
\mathrm{M}\left(\mathrm{NH}_{3}\right)=\mathrm{M}(\mathrm{N})+3 \cdot \mathrm{M}(\mathrm{H})=14+3 \cdot 1=17 \mathrm{~g} \cdot \mathrm{mol}^{-1}
$$

2.- Utilizando la siguiente ecuación:

$2 \mathrm{H}_{2}(\mathrm{~g})+\mathrm{O}_{2}(\mathrm{~g}) \rightarrow 2 \mathrm{H}_{2} \mathrm{O}(\mathrm{l})$ en c.n. $\operatorname{Ar}(\mathrm{O})=16 ; \quad \operatorname{Ar}(\mathrm{H})=1$

a.- calcula los moles que hay en $3 \mathrm{dm}^{3}$ de hidrógeno

$$
3 \mathrm{dm}^{3} \cdot \frac{1 \mathrm{~mol}}{22,4 \mathrm{dm}^{3}}=0,134 \text { moles }
$$

b.- $3 \mathrm{dm} 3$ de hidrógeno reaccionan completamente con exceso de oxígeno. ¿Cómo calculas el volumen de agua que se obtiene? Escribe todos los pasos y razona la respuesta.

$3 \mathrm{dm}^{3} \cdot \frac{1 \text { mol de } \mathrm{H}_{2}}{22,4 \mathrm{dm}^{3}} \cdot \frac{2 \text { moles de } \mathrm{H}_{2} \mathrm{O}}{2 \text { moles de } \mathrm{H}_{2}} \cdot \frac{18 \text { gramos de } \mathrm{H}_{2} \mathrm{O}}{1 \mathrm{~mol} \mathrm{de} \mathrm{H}_{2} \mathrm{O}}=2,41$ gramos $\approx 2,41 \mathrm{~cm}^{3}$ 
3.- Utilizando la siguiente ecuación:

$2 \mathrm{CO}(\mathrm{g})+\mathrm{O}_{2}(\mathrm{~g}) \rightarrow 2 \mathrm{CO}_{2}(\mathrm{~g}) \quad$ en c.n. $\operatorname{Ar}(\mathrm{O})=16 ; \quad \operatorname{Ar}(\mathrm{C})=12$

a.- Calcula la masa de dióxido de carbono gas que se producirá a partir de 22,4 $\mathrm{dm}^{3}$ de oxígeno gas. Escribe los pasos empleados

$22,4 \mathrm{dm}^{3} \mathrm{de} \mathrm{O}_{2} \cdot \frac{2 \mathrm{dm}^{3} \mathrm{de} \mathrm{CO}_{2}}{1 \mathrm{dm}^{3} \mathrm{deO}} \cdot \frac{1 \mathrm{~mol} \mathrm{de} \mathrm{CO}_{2}}{22,4 \mathrm{~L} \mathrm{de} \mathrm{CO}_{2}} \cdot \frac{44 \mathrm{~g} \mathrm{de} \mathrm{CO}_{2}}{1 \mathrm{~mol} \mathrm{de} \mathrm{CO}_{2}}=88 \mathrm{~g} \mathrm{de} \mathrm{CO}_{2}$

b.- Calcula los moles de dióxido de carbono producido en (a)

$22,4 \mathrm{dm}^{3}$ de $\mathrm{O}_{2} \cdot \frac{2 \mathrm{dm}^{3} \mathrm{de} \mathrm{CO}_{2}}{1 \mathrm{dm}^{3} \mathrm{deO}} \cdot \frac{1 \mathrm{~mol} \mathrm{de} \mathrm{CO}_{2}}{22,4 \mathrm{Lde} \mathrm{CO}_{2}}=2$ moles de $\mathrm{CO}_{2}$

c.- Calcula la masa total de los reactivos utilizados para producir el número de moles de dióxido de carbono obtenido en (b)

Dado que se han tomado un mol de $\mathrm{O} 2$ y dos moles de CO con masas 32 y 28 $\mathrm{g} \cdot \mathrm{mol}^{-1}$ respectivamente $(22,4 \mathrm{~L}=1 \mathrm{~mol}$ en c.n. $)$ la masa utilizada será:

$\mathrm{M}=1 \cdot 32+2 \cdot 28=88$ gramos, que coincide con la masa final

4.- Utilizando la siguiente ecuación:

$$
2 \mathrm{CO}(\mathrm{g})+\mathrm{O}_{2}(\mathrm{~g}) \rightarrow 2 \mathrm{CO}_{2}(\mathrm{~g}) \quad \text { en c.n. } \operatorname{Ar}(\mathrm{O})=16 ; \quad \operatorname{Ar}(\mathrm{C})=12
$$

Un científico hace reaccionar en un recipiente cerrado $5 \mathrm{~g}$ de monóxido de carbono gas con 13 g de oxígeno gas para producir dióxido de carbono. ¿Cuál es la masa total del contenido del recipiente al acabar al reacción?

Según la ley de conservación de masa de Lavoisier durante una reacción la masa total del no varia, por tanto al final de la reacción la suma de la masa de todas las sustancias presentes es la misma que al principio

$$
\mathrm{m}=5+13=18 \text { gramos }
$$


a) Calcular los gramos de $\mathrm{NHO}_{3}$ necesarios para preparar $400 \mathrm{~mL}$ de disolución $1 \mathrm{M}$, sabiendo que la densidad del ácido nítrico concentrado es $\mathrm{de} 1,40 \mathrm{~g} \cdot \mathrm{cm}^{-3} \mathrm{y}$ el \% en masa es del $70 \% \quad \operatorname{Mr}\left(\mathrm{HNO}_{3}\right)=63 \mathrm{~g} \cdot \mathrm{mol}^{-1}$

$400 \mathrm{~mL} \frac{1 \mathrm{~L}}{1000 \mathrm{~mL}} \cdot \frac{1 \mathrm{~mol} \mathrm{de} \mathrm{HNO}_{3}}{1 \mathrm{~L}} \cdot \frac{63 \text { gramos de } \mathrm{HNO}_{3}}{1 \mathrm{~mol} \mathrm{de} \mathrm{HNO}_{3}} \cdot \frac{100 \text { gramos de disolución comercial }}{70 \text { gramos de } \mathrm{HNO}_{3}}=36$ gramos

c) Normalidad

$$
N=M \cdot V=1 \cdot 1=1
$$

c) Volumen en $\mathrm{mL}$ de $\mathrm{HNO}_{3}$ Concentrado necesario para preparar la disolución (a)

36 gramos de $\mathrm{HNO}_{3}$ comercial $\cdot \frac{1 \mathrm{~mL} \text { de } \mathrm{HNO}_{3} \text { comercial }}{1,4 \text { gramos de } \mathrm{HNO}_{3} \text { comercial }}=25,7 \mathrm{~mL}$

d) Al mezclar $200 \mathrm{~mL}$ de la disolución (a) con un gramo de $\mathrm{NaOH}$. Calcula la concentración de todos los iones resultantes $\mathrm{Mr}(\mathrm{NaOH})=40$

1 gramo de $\mathrm{NaOH} \cdot \frac{1 \mathrm{~mol} \text { de } \mathrm{NaOH}}{40 \text { gramos de } \mathrm{NaOH}}=0,025$ moles de $\mathrm{NaOH}$

$200 \mathrm{~mL}$ de disolución $\cdot \frac{1 \mathrm{~L} \text { de disolución }}{1000 \mathrm{~mL}} \cdot \frac{1 \mathrm{~mol} \text { de } \mathrm{HNO}_{3}}{1 \mathrm{~L} \text { de disolución }}=0,2$ moles de $\mathrm{HNO}_{3}$

$\mathrm{HNO}_{3}+\mathrm{NaOH} \rightarrow \mathrm{NaNO}_{3}+\mathrm{H}_{2} \mathrm{O}$

En forma iónica:

$\mathrm{H}^{+}+\mathrm{NO}_{3}^{-}+\mathrm{Na}^{+}+\mathrm{OH}^{-} \rightarrow \mathrm{Na}^{+}+\mathrm{NO}_{3}^{-}+\mathrm{H}_{2} \mathrm{O}$

Habrá

0,2 moles de $\mathrm{NO}_{3}{ }^{-} \rightarrow\left[\mathrm{NO}_{3}{ }^{-}\right]=\frac{0,2}{0,2}=1 \mathrm{M}$

0,025 moles de $\mathrm{Na}^{+} \rightarrow\left[\mathrm{Na}^{+}\right]=\frac{0,025}{0,2}=0,125 \mathrm{M}$

0,2 moles de $\mathrm{H}^{+}$

0,025 moles de $\left.\mathrm{OH}^{-}\right\} 0,2-0,025=0,175 \rightarrow\left[H^{+}\right]=\frac{0,175}{0,2}=0,875 \mathrm{M}$ 


\section{ANEXO III}

CUESTIONARIO DE DETECCIÓN DE IDEAS PREVIAS EN $3^{\circ}$ DE ESO ACERCA DE LA ESTRUCTURA DE LA MATERIA 


\section{CUESTIONARIO DE DETECCIÓN DE IDEAS PREVIAS EN $3^{\circ}$ DE ESO ACERCA DE LA ESTRUCTURA DE LA MATERIA}

(Pre-ESO)

Centro:

Apellidos y nombre:

Curso y grupo:....

\section{INSTRUCCIONES}

El propósito de esta prueba es evaluar los conocimientos que posees acerca de la estructura de la materia. Los resultados obtenidos no serán considerados en tu calificación.

Por favor, responde a cada pregunta en el espacio reservado para ella, con letra clara e intentando explicar lo mejor posible las respuestas. Utiliza un folio para hacer todos los cálculos que necesites. 
1.- A partir del dibujo explica todo lo que puedas acerca de él
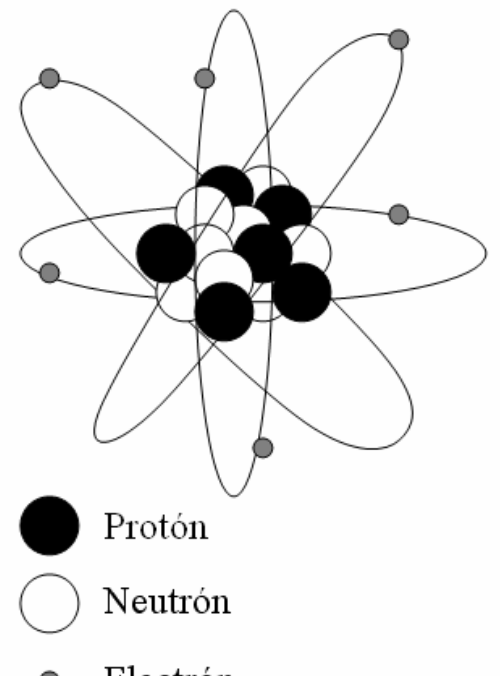

- Electrón

2.- Estos tres cuerpos contienen hierro. ¿Se trata del mismo tipo de átomos de hierro en los tres casos? En caso negativo indica por qué.

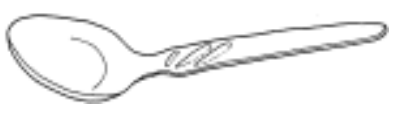

Cuchara

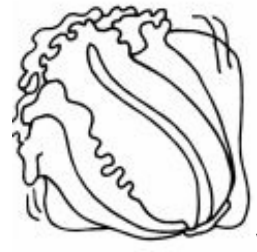

Verduras

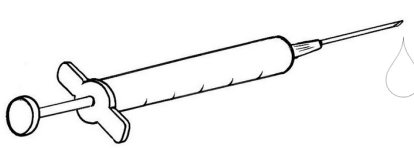

Sangre

3.- Dibuja de forma esquemática las partículas de oxigeno gaseoso en la botella de un buceador cuando está llena y cuando, después de utilizarla, le queda la mitad de este.
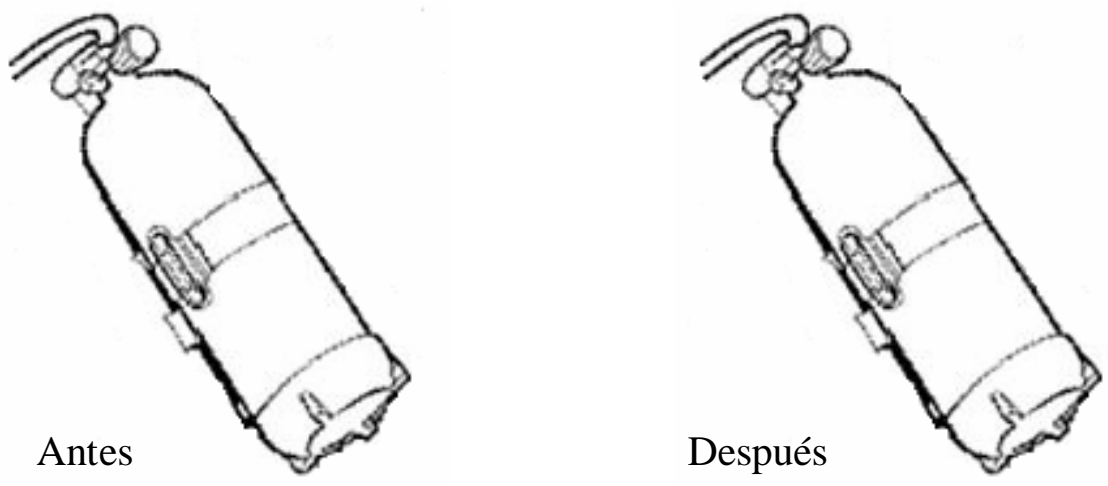
4.- ¿Qué recipiente contiene un solo elemento? ¿Y un compuesto? ¿En cuál o cuales hay una mezcla de elementos?
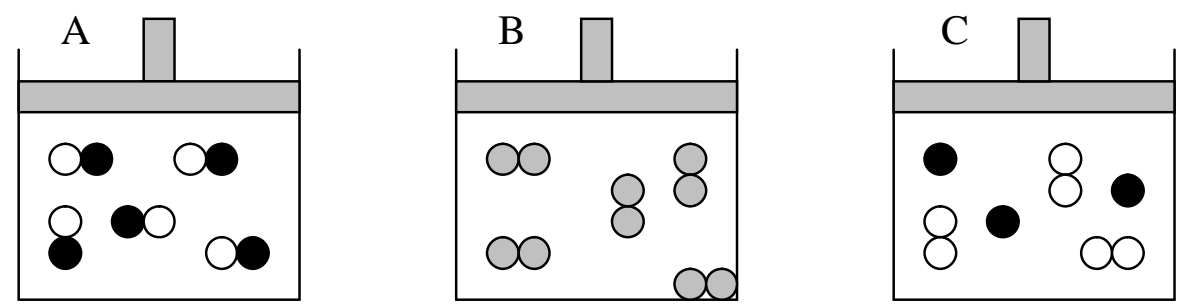

5.- Escribe la fórmula y el nombre de las sustancias representadas:
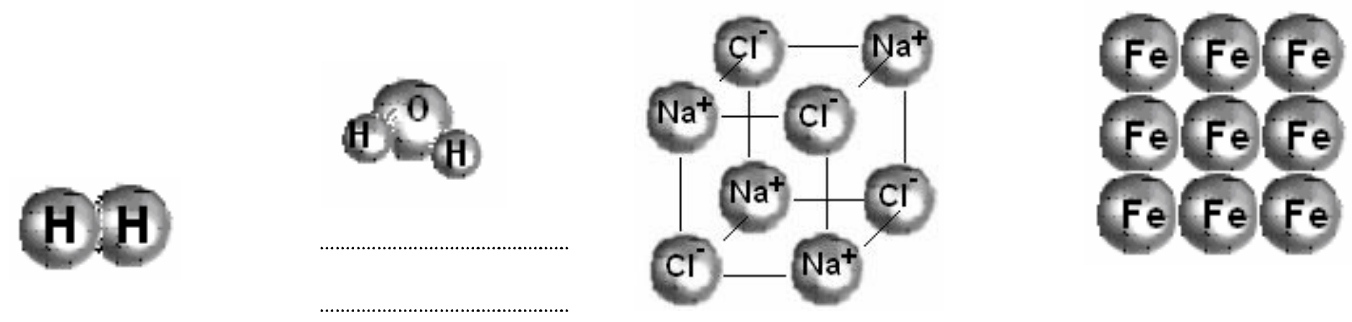

6.- Indica si las siguientes afirmaciones son ciertas o falsas. Justifícalo brevemente:

a) El oro es amarillo porque los átomos de oro son amarillos.

b) Entre el núcleo atómico y los electrones hay aire.

c) Los electrones son más pequeños que los átomos.

7.- Sabiendo que el átomo es la parte más pequeña de un elemento, y que es extraordinariamente pequeña, ¿cuántos átomos crees que pueden haber, aproximadamente en una gota de agua?

$$
\begin{array}{llllllllll}
10^{-10} & 10^{-5} & 10^{-2} & 1 & 10^{2} & 10^{5} & 10^{10} & 10^{20} & 10^{25} & 10^{30}
\end{array}
$$


8.- Pon dos ejemplos de sustancia pura y dos de mezcla homogénea.

9.- ¿Qué consecuencias tiene para la vida de las personas, la industria química?

10.- Rellena el siguiente mapa conceptual con los datos que conozcas.

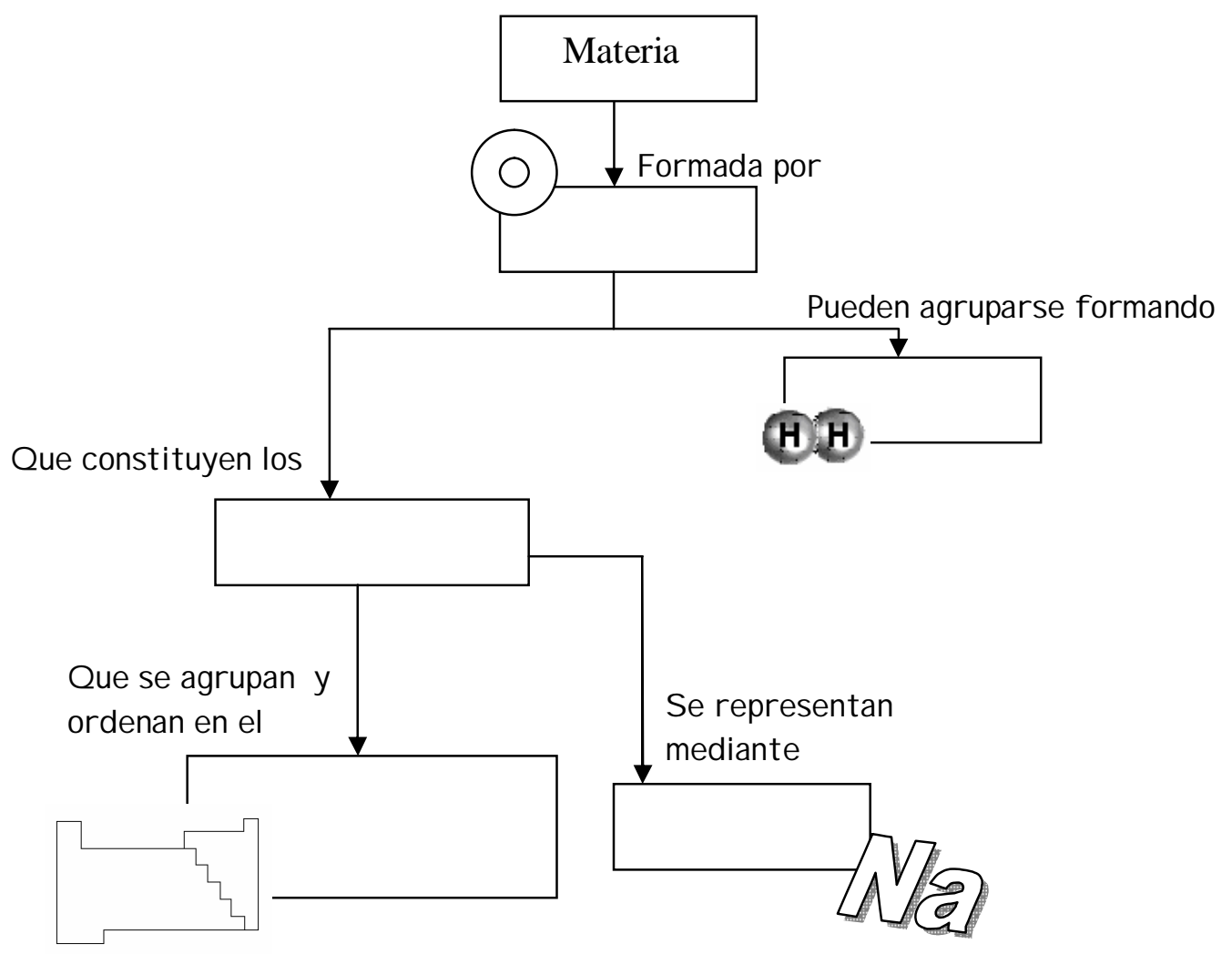




\section{ANEXO IV}

CORRECCIÓN DEL CUESTIONARIO Pre-ESO. CRITERIO DE PUNTUACIÓN 


\section{CORRECCIÓN DEL CUESTIONARIO Pre-ESO. CRITERIO DE PUNTUACIÓN}

En la plantilla de corrección del cuestionario se han establecido dos tablas de doble entrada, en ellas se ha recogido información cuantitativa, asignando una puntuación a la respuesta dada y otra cualitativa en la cual se han establecido unos ítems que no corresponden a la respuesta correcta o no, sino aspectos específicos que pueden extraerse de un ejercicio en concreto, tal como se ha expuesto en el apartado 7.1.5.

En primer lugar se ha cumplimentado una tabla de doble entrada en la que las filas, corresponden a cada uno de los alumnos y las columnas a cada uno de los diez ítems que constituyen el cuestionario. Para ello las respuestas dadas se han categorizado de la siguiente forma, atendiendo al criterio establecido:

- 0 puntos para las respuestas nulas o completamente erróneas.

- 0,5 puntos para las respuestas parcialmente correctas.

- 1 punto para las respuestas correctas

En la segunda tabla se ha realizado un registro por cada alumno de los aspectos expresados en la tabla..introduciendo:

- S en caso afirmativo

- $\mathrm{N}$ en caso negativo

A continuación exponemos el criterio para adjudicar una o otra puntuación en cada cuestión de la primera tabla. En el caso de la segunda no es necesario puesto que las preguntas planteadas son suficiente explicitas como para necesitar un modelo.

\section{Cuestión 1}

Se trata de una cuestión abierta respecto de un concepto estudiado de forma directa en el curso anterior,

1 punto para los alumnos que indiquen que se trata de un átomo, que está formado por un núcleo con 6 protones y 7 neutrones. Que posee 6 electrones orbitando a su alrededor. Incluso cabe esperar que algún alumno indique que se trata de un átomo de carbono. 
0,5 puntos para aquellos que indiquen como mínimo que se trata de un átomo y que está formado por protones, neutrones y electrones

0 puntos en el caso de dejarlo en blanco o no contestar al menos lo indicado anteriormente

\section{Cuestión 2}

Este ítem es el de mayor dificultad en cuanto a nivel de abstracción de conceptos de química, ya que hace referencia a la posibilidad de encontrar un tipo de átomos del mismo elemento (nivel microscópico) en sustancias con características físicas (nivel macroscópico) muy diferentes. Lo que conlleva al conflicto entre lo que es observable o no. Dada la dificultad que entraña se ha considerado:

1 punto para los alumnos que indiquen que efectivamente se trata del mismo elemento, pero que dada su unión a otras sustancias el resultado global es diferente.

0,5 puntos para los que indiquen en todos los casos es el mismo elemento, pero le atribuyan características diferentes, lo asignen a compuestos determinados, o no justifiquen la respuesta.

0 puntos para aquellos que no contesten, o bien indiquen que no se trata del mismo tipo de átomos.

\section{Cuestión 3}

Este ítem, se resuelve rápidamente dada la sencillez del modelo, que permite de forma muy gráfica representar las partículas, se otorgarán:

1 punto para los alumnos que dibujen algunas partículas dispersas en el interior de la botella en la etapa inicial, y aproximadamente la mitad de ellas en la etapa final, pero siempre ocupando todo el volumen disponible de la forma:
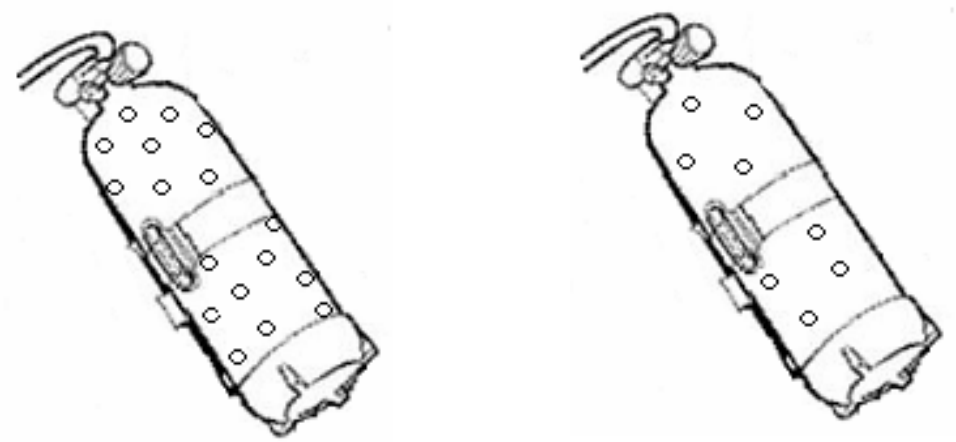
0,5 puntos en el caso de haber dibujado la botella llena de partículas sin dejar espacios libres, pero en la situación final dibujen la mitad de las partículas ocupando toda la botella.

0 puntos para aquellos alumnos que dibujen la mitad de las partículas sin ocupar la totalidad de la botella, o bien no dibujen la mitad de las partículas o no respondan la cuestión.

\section{Cuestión 4}

Dado que hay tres opciones para cada una de las tres preguntas, otorgaremos:

1 punto para los alumnos que indiquen que el recipiente que contiene un único elemento es el $\mathrm{B}$, que el que contiene un compuesto es el $\mathrm{A}$, y que el que contiene una mezcla es el C.

0,5 para los que acierten alguna de las respuestas, y lo justifique

0 puntos para aquellos que no contesten correctamente a ninguna pregunta o bien solo lo hagan a una de ellas y no lo justifiquen.

\section{Cuestión 5}

En este ítem se espera que los alumnos indiquen la fórmula molecular en los dos primeros casos y la fórmula empírica que represente a los otros dos compuestos iónicos, por lo que se otorgará:

1 punto a los alumnos que indiquen correctamente el nombre y la fórmula de cada una de las sustancias:
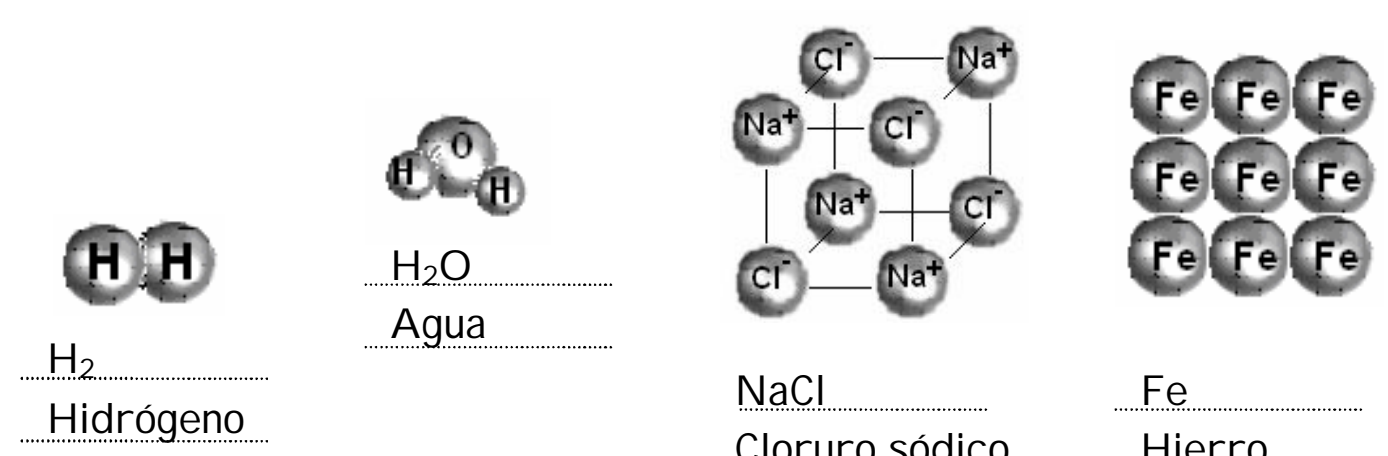

$\mathcal{N a C l}$

$\mathcal{F e}$

Cloruro sódico

Hierro

0,5 puntos para aquellos alumnos que contesten correctamente en al menos la mitad de los casos. 
0 puntos para aquellos alumnos que no contesten correctamente en al menos la mitad de los casos o dejen la cuestión en blanco.

\section{Cuestión 6}

En este ítem se considerará que la respuesta es correcta, si a la primera pregunta se contesta negativamente justificándolo con la diferencia existente entre las propiedades macroscópicas y microscópicas de la materia o bien directamente si alegan la imposibilidad de ver un átomo por su pequeño tamaño. En cuanto a la segunda pregunta se considerará correctamente contestada si explican que no hay aire por que en esa zona hay vacío, o bien que el propio aire está constituido al mismo tiempo también por átomos, lo que implicaría su existencia dentro de su mismo infinitas veces. Y respecto a la tercera deben indicar que es cierta puesto que el electrón forma parte del átomo y por tanto como constituyente suyo que es, obligatoriamente debe ser menor. Por tanto se otorgará:

1 punto a los alumnos que contesten y justifiquen correctamente a cada una de las tres propuestas

0,5 puntos a los que contesten correctamente, pero no las justifiquen o bien solo contesten y justifiquen a dos de ellas.

0 Puntos a los alumnos que sólo contesten a alguna de las tres o bien no realicen el ejercicio.

\section{Cuestión 7}

En este ítem se intenta averiguar si los alumnos tienen conciencia de lo pequeños que son loa átomos y lo enorme de la cantidad de ellos que pueden estar contenidos en una cantidad pequeña de materia.

Una gota de agua $\cdot \frac{1 \mathrm{ml} \text { de agua }}{20 \text { gotas de agua }} \cdot \frac{1 \mathrm{~g} \text { de agua }}{1 \mathrm{ml} \text { de agua }} \cdot \frac{1 \mathrm{~mol} \mathrm{de} \mathrm{agua}}{18 \mathrm{~g} \text { de agua }} \cdot \frac{3 \cdot 6,023 \cdot 10^{23} \text { átomos }}{1 \mathrm{~mol} \mathrm{de} \mathrm{agua}}=5 \cdot 10^{21}$ átomos

Por supuesto que no se espera que los alumnos hagan este razonamiento, pero se pretende conocer si son capaces de asignar un número aproximado. La puntuación que se asignará será: 
1 punto para los alumnos que indiquen que hay alrededor de $10^{20}$ átomos dentro de una gota de agua

0,5 puntos para aquellos que indiquen que existen alrededor de $10^{10}$ ó $10^{25}$ átomos puesto que sigue reflejando cantidades muy grandes y conceptualmente aproximadas.

0 puntos para cualquier otra respuesta, o en el caso de dejar en blanco la cuestión

\section{Cuestión 8}

Esta cuestión es completamente abierta y dado que deben dar un total de cuatro respuestas se otorgara la calificación:

1 punto para los alumnos queden correctamente el nombre dos sustancias puras y el de dos mezclas.

0,5 puntos en el caso de dar correctamente uno de cada grupo o bien los dos de uno de ellos.

0 puntos en el caso de indicar solamente una respuesta correcta o dejar la pregunta sin responder.

\section{Cuestión 9}

En esta cuestión no se puede hablar de respuesta correcta o incorrecta ya que se trata de una opinión personal que pretende ligarse posteriormente con los resultados obtenidos, por tanto asignaremos:

1 punto en el caso de que el alumno indique algunas consecuencias tanto positivas como negativas de la industria química o bien lo haga de una sola de ellas con una justificación razonada del porqué.

0,5 puntos en el caso de indicar solo consecuencias positivas, o negativas y no de una explicación del porqué.

0 puntos en el caso de no apuntar ninguna consecuencia.

La valoración de esta cuestión tiene su importancia al ser analizada cualitativamente según la red de análisis mostrada en la tabla $7 \ldots$ 


\section{Cuestión 10}

Este ítem consiste en rellenar un mapa conceptual relacionado con la estructura de la materia, que debe ser completado de la forma:

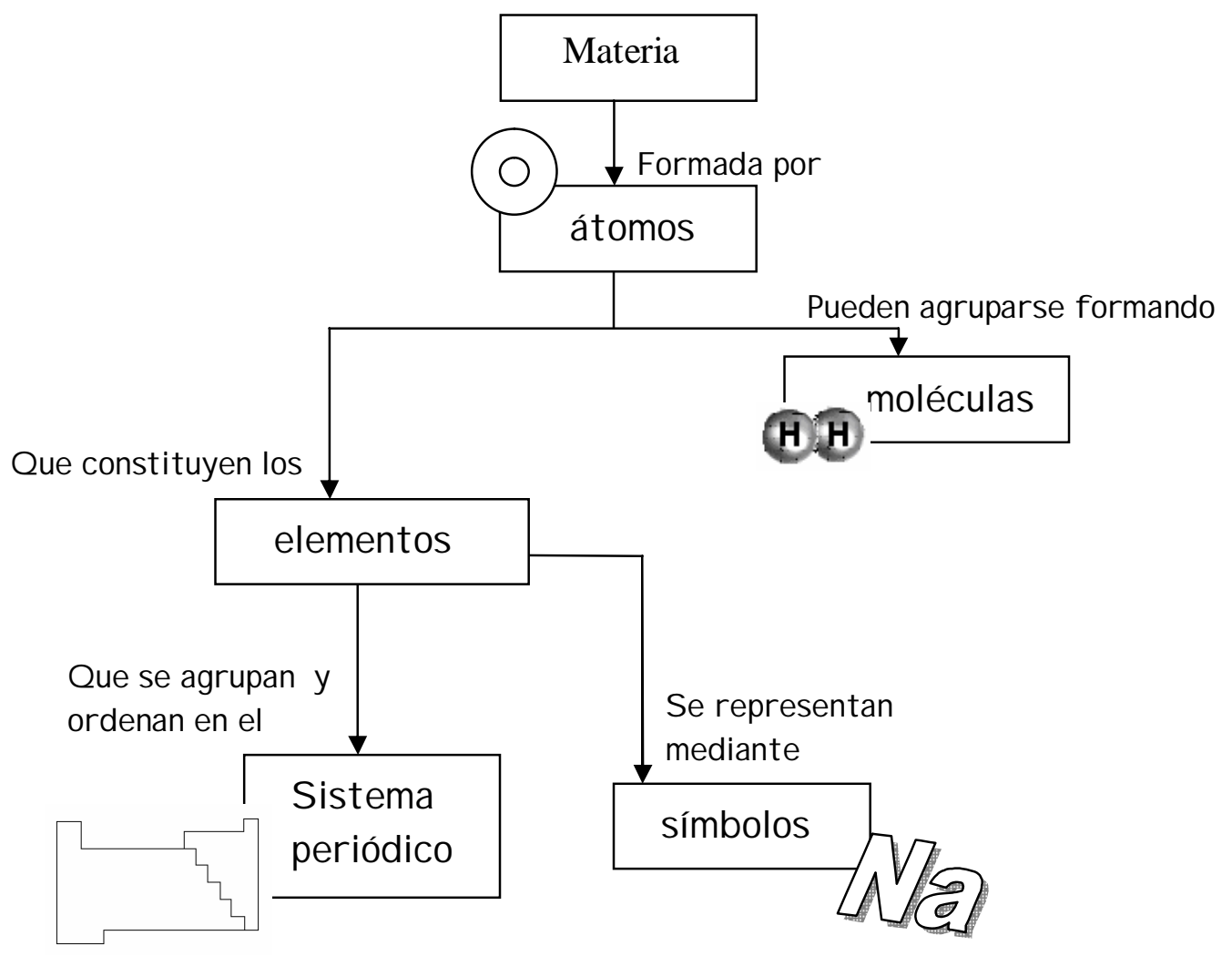

Se puntuará:

1 punto para los alumnos que coloquen correctamente las cinco expresiones en cada uno de los lugares correspondientes.

0,5 puntos para los que contesten correctamente al menos en dos ocasiones

0 puntos en el caso de contestar correctamente en solo una o ninguna ocasión. 


\section{ANEXO V}

CUESTIONARIO PARA ESTABLECER LOS CONOCIMIENTOS ACERCA DEL ENLACE QUÍMICO EN $3^{\circ}$ DE ESO 


\title{
CUESTIONARIO PARA ESTABLECER LOS CONOCIMIENTOS ACERCA DEL ENLACE QUÍMICO EN $3^{\circ}$ DE ESO
}

\author{
(Post-ESO)
}

Centro:

Apellidos y nombre:

Curso y grupo:

\section{INSTRUCCIONES}

El propósito de esta prueba es evaluar los conocimientos que posees acerca del enlace químico. Los resultados obtenidos serán considerados en tu calificación.

Por favor, responde a cada pregunta en el espacio reservado para ella, con letra clara e intentando explicar lo mejor posible las respuestas. Utiliza un folio para hacer todos los cálculos que necesites. 
1.- ¿Qué es una molécula? ¿A qué se debe su existencia en la naturaleza?

2.- Señala qué sustancias son elementos y cuales son mezclas o compuestos:

Madera

Hierro

Agua destilada

Tierra

Coca cola
Sangre

Azúcar

Humo

Cal viva

Amoniaco
Ácido sulfúrico

Aguarrás

Cobre

Vino

Agua mineral

3.- ¿Qué cosas tienen en común los elementos de un mismo grupo? ¿y los de un mismo periodo?

4.- Indica cuales de las siguientes representaciones de transformaciones de la materia corresponden a cambios químicos:

a)

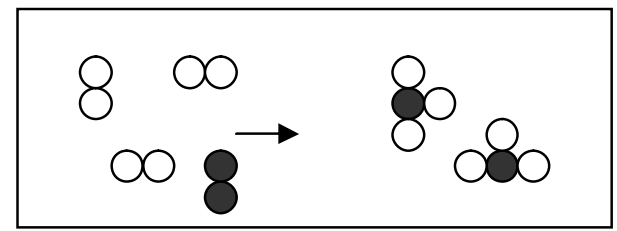

c)

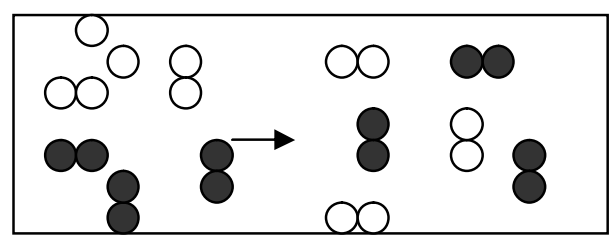

e)

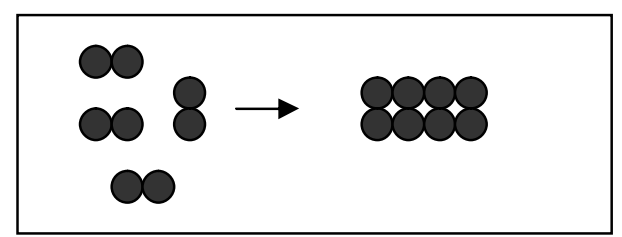

b)

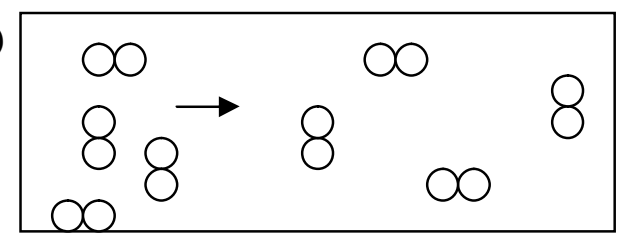

d)

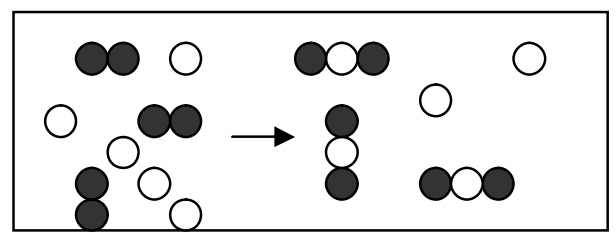

f)

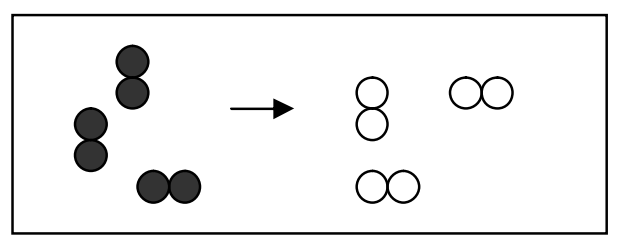

¿Por qué? 
5.- Asigna a cada estructura el tipo de enlace implicado:
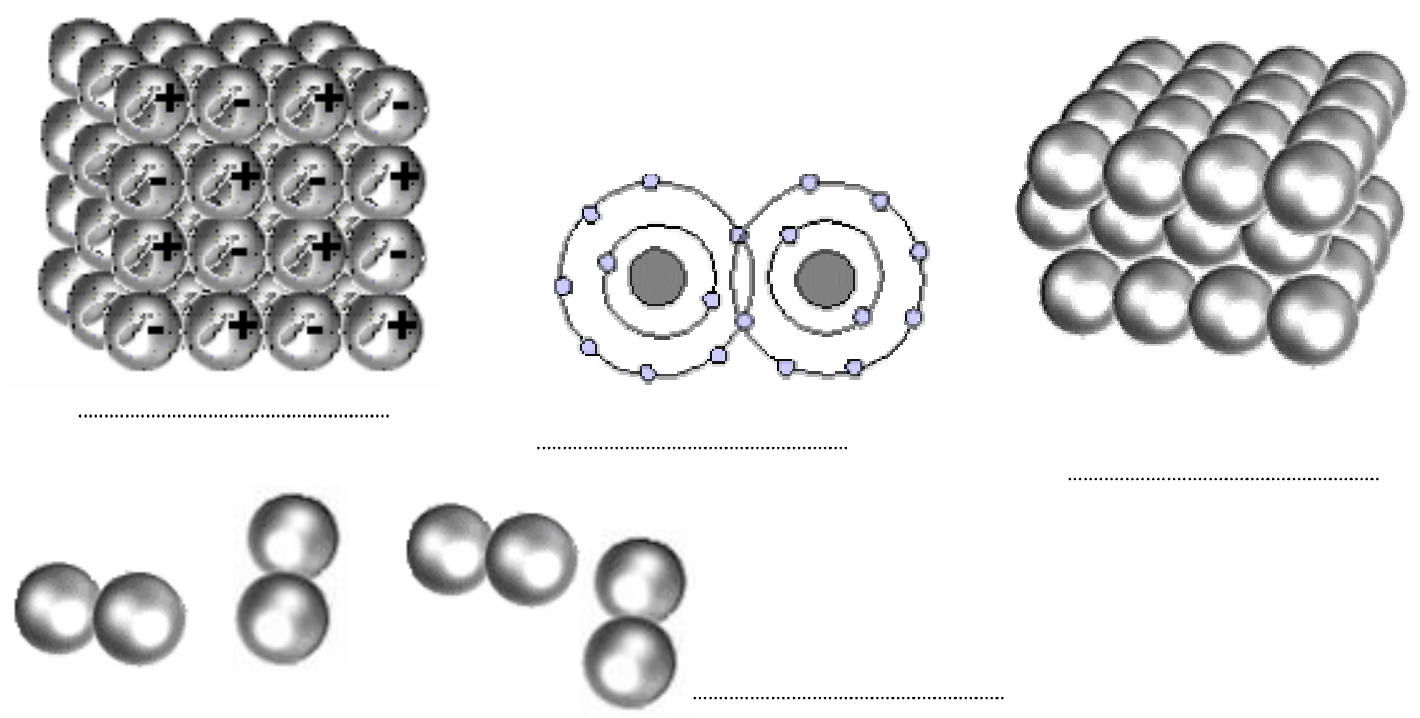

6.- Explica cuales de las siguientes sustancias son iónicas y cuales covalentes:

$\mathrm{KI}$

$\mathrm{CuO}$

$\mathrm{NH}_{3}$

$\mathrm{MgH}_{2}$

$\mathrm{CO}$

$\mathrm{HCl}$

$\mathrm{N}_{2} \mathrm{O}_{3}$

$\mathrm{BaF}_{2}$

$\mathrm{H}_{2} \mathrm{O}$

$\mathrm{PH}_{3}$

$\mathrm{H}_{2} \mathrm{~S}$

$\mathrm{Li}_{3} \mathrm{~N}$

7.- Explica su son verdaderas o falsas las afirmaciones siguientes:

a) El enlace iónico da lugar a la formación de moléculas

b) En el enlace covalente se unen átomos metálicos y comparten electrones

c) El enlace covalente puede producir la formación de moléculas, pero no siempre. 
8.- Conociendo las masas atómicas relativas siguientes:
$\operatorname{Ar}(\mathrm{Ag})=108$
$\operatorname{Ar}(\mathrm{O})=16$
$\operatorname{Ar}(\mathrm{S})=32$
$\operatorname{Ar}(\mathrm{N})=14$
$\operatorname{Ar}(\mathrm{K})=39$
$\operatorname{Ar}(\mathrm{Br})=80$

Calcula la masa molecular relativa de:

$\mathrm{AgBr}$

$\mathrm{Ag} \mathrm{NO}_{3}$

$\mathrm{K}_{2} \mathrm{SO}_{4}$

9.- Relaciona nombres y fórmulas:

Compuesto químico

- Óxido de litio

- Ácido carbónico

- Hidróxido de potasio

- Ácido Clorhídrico

- Ácido nítrico

- Trióxido de dicloro

- Óxido de hierro (II)

- Sulfato de sodio

- Óxido de plomo (II)

- Hidruro de calcio

\section{Fórmula}

- $\mathrm{H}_{2} \mathrm{CO}_{3}$

- $\mathrm{Na}_{2} \mathrm{SO}_{4}$

- $\mathrm{PbO}$

- $\mathrm{HNO}_{3}$

- $\mathrm{FeO}$

- $\mathrm{KOH}$

- $\mathrm{HCl}$

- $\mathrm{Li}_{2} \mathrm{O}$

- $\mathrm{CaH}_{2}$

- $\mathrm{Cl}_{2} \mathrm{O}$

10.- Como podrías explicar que tras quemar un tronco de madera la masa de las cenizas sea tan pequeña comparada con la inicial? 


\section{ANEXO VI}

CORRECCIÓN DEL CUESTIONARIO Post-ESO. CRITERIO DE PUNTUACIÓN 


\section{Cuestión 1}

Esta cuestión puede contestarse sencillamente con la afirmación:

Las moléculas son partículas con más de un átomo, que se han unido entre sí para formar una entidad con mayor estabilidad. Se puntuará de la forma:

1 punto para los alumno que expresen estas dos ideas, auque también consideraremos valida para la primera pregunta la utilización de ejemplos.

0,5 puntos para los alumnos que solo indiquen una de estas dos ideas.

0 puntos para los alumnos que no indiquen estas respuestas.

\section{Cuestión 2}

Se espera que los alumnos hagan la siguiente clasificación:

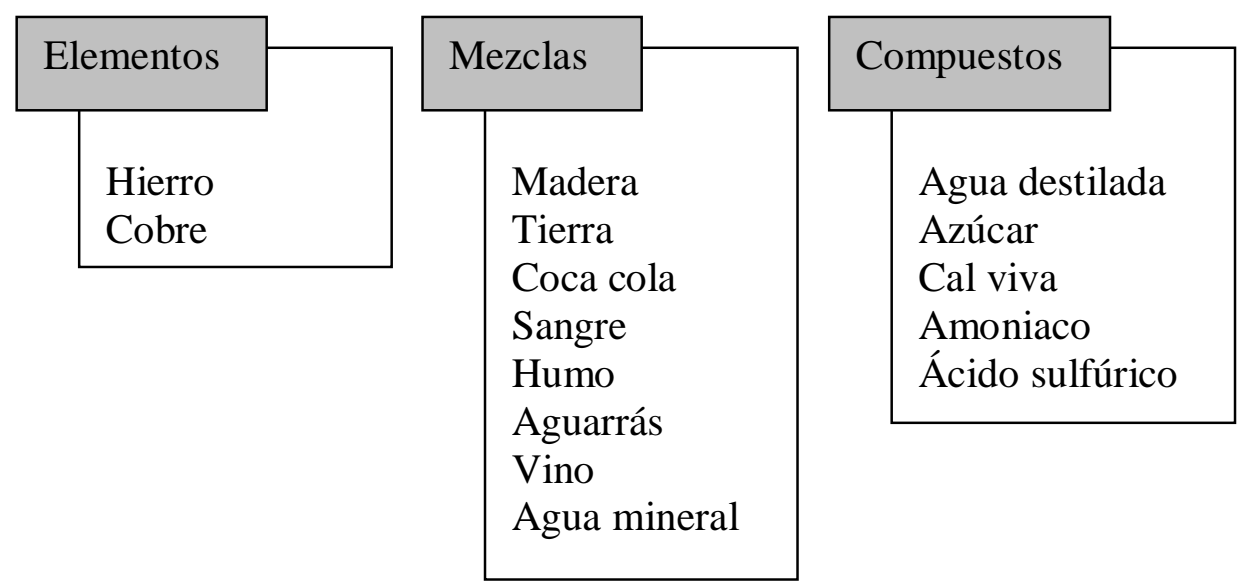

La puntuación que se utilizará será:

1 punto para los alumnos que clasifique correctamente todas las sustancias o bien se equivoquen en un máximo de tres ejemplos.

0,5 puntos para los alumnos que se equivoquen en un máximo de siete ejemplos

0 puntos para aquellos alumnos que no acierten al menos en ocho ocasiones o bien las dejen en blanco 


\section{Cuestión 3}

El criterio de corrección en esta cuestión será el siguiente:

1 punto para los alumnos que indique que los elementos de un mismo grupo poseen propiedades físicas y químicas parecidas, ya que tienen el mismo número de electrones en la última capa y que en un mismo periodo los átomos tienen el mismo número de capas de electrones aunque con diferente cantidad de estos

0,5 puntos para los alumnos indiquen solo una de las dos respuestas anteriores o bien lo hagan parcialmente

0 puntos a los alumnos que no contesten a ninguna pregunta o lo hagan de forma incorrecta.

\section{Cuestión 4}

De los ejemplos planteados en el ejercicio, el a), el d) y el e) corresponden a cambios químicos puesto que en ellos hay una reordenación de los átomos, mientras que en el b) y c) sólo hay un cambio de posición y en el $\mathrm{f}$ un absurdo cambio de unos átomos por otro, la calificación será:

1 punto para los alumnos que apunten correctamente a estos tres puntos y además justifiquen que lo hacen por que observan una reordenación de los átomos.

0,5 puntos para los alumnos que cometan algún error, bien no justifiquen la respuesta o ambas cosas.

0 puntos para los alumnos que se equivoquen en la mayoría de los casos y no justifiquen la respuesta, o lo hagan incorrectamente.

\section{Cuestión 5}

Se espera que los alumnos respondan:

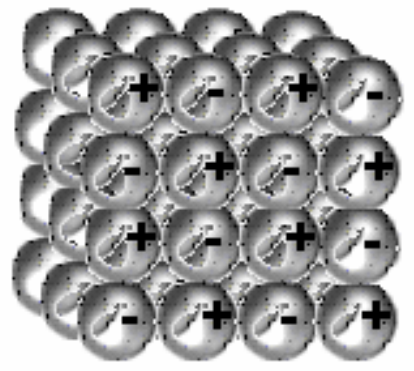

Enlace iónico

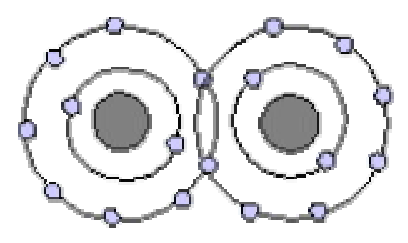

Enlace covale nte

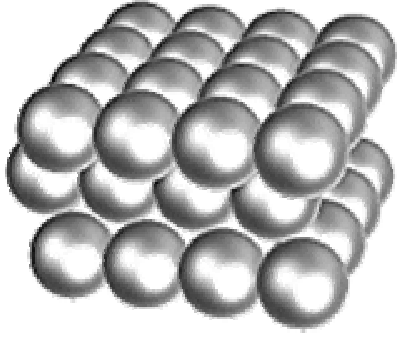

Enlace me tálico 
la identificación es sencilla en el caso del enlace iónico por observar rápidamente la alternancia de iones de signos positivo y negativo, así como metálico por observar átomos iguales unidos, auque también podría tratarse de una red covalente. En cambio en el segundo dibujo se incluyen las orbitas donde se comparten electrones, mientras en el cuarto no, lo que da pie a confusión por tratarse del mismo tipo de enlace. La puntuación que se concederá será:

1 punto para los alumnos que nombren correctamente a las cuatro especies, o bien confundan el segundo dibujo con un ejemplo de átomos unidos iónicamente, puesto que uno de los electrones de enlace podría provenir de la capa externa de uno de los átomos.

0,5 puntos para aquellos alumnos que indiquen la respuesta correcta en dos de los ejemplos.

0 puntos para los alumnos que acierten en uno solo o ninguno de los casos

\section{Cuestión 6}

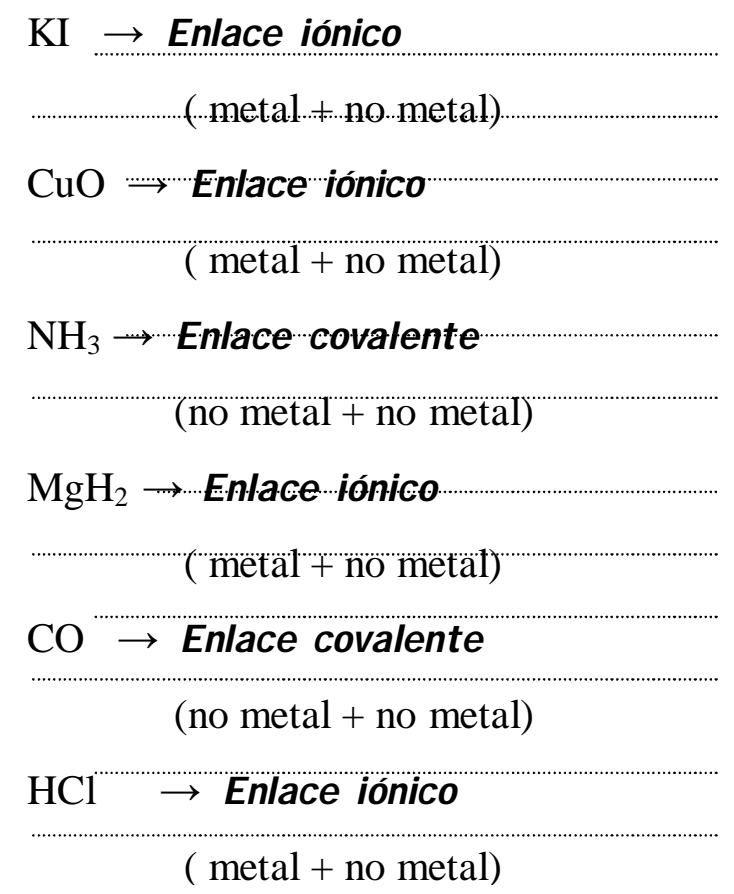

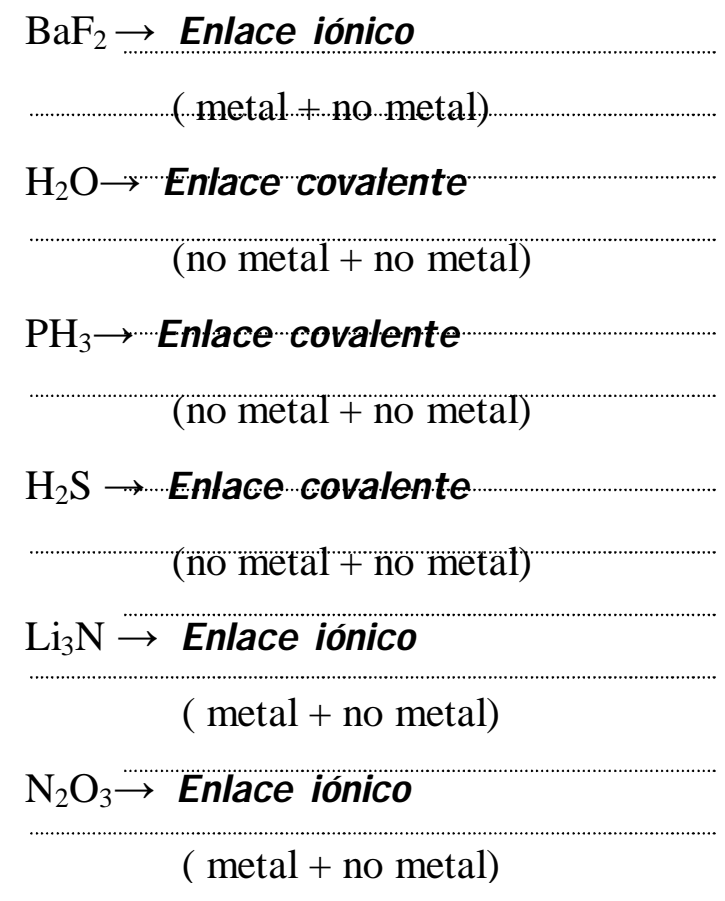


La explicación que deben dar los alumnos se limita a indicar si el compuesto es iónico o covalente, según se trate de la unión de elementos metálicos con no metálicos o de elementos no metálicos entre si. Se calificará:

1 punto para los alumnos que contesten correctamente y lo justifiquen en todos los caso o dejen de hacerlo en uno o dos de ellos, especialmente en los casos en que intervenga el hidrógeno puesto que puede llevar a confusión su aparición en compuestos tanto iónicos como covalentes.

0,5 puntos para los alumnos que contesten y justifiquen al menos la mitad de los casos o bien contesten correctamente a casi todos pero no lo justifiquen.

0 puntos para aquellos alumnos que acierten en menos de la mitad de los casos o bien lo hagan pero sin justificarlo.

\section{Cuestión 7}

Esta cuestión trata de establecer la una relación entre la capacidad de distinguir entre uno $\mathrm{u}$ otro tipo de enlace y las estructuras que son capaces de generar. Se puntuará:

1 punto a los alumnos que indiquen que:

a) es falso puesto que el enlace iónico sólo da lugar a redes, mientras que para que se formen moléculas debemos hablar de enlaces covalentes

b) Es falso pues en los enlaces covalentes se unen átomos no metálicos, aunque es cierto que se comparten electrones.

c) Es cierto puesto que el enlace covalente además de moléculas también pueda dar lugar a estructuras cristalinas, como en el caso del diamante o cuarzo

0,5 puntos para los alumnos que indiquen correctamente la veracidad o falsedad de las afirmaciones pero no lo justifiquen, o bien hagan ambas cosas en la mitad de los casos.

0 puntos para los alumnos que respondan correctamente en uno o ninguno de los casos. 


\section{Cuestión 8}

Utilizando los datos ofrecidos en el enunciado se calcula fácilmente la cuestión:

$\operatorname{Mr}(\mathrm{AgBr})=\operatorname{Ar}(\mathrm{Ag})+\operatorname{Ar}(\mathrm{Br})=108+80=188$

$\operatorname{Mr}\left(\mathrm{AgNO}_{3}\right)=\operatorname{Ar}(\mathrm{Ag})+\operatorname{Ar}(\mathrm{N})+3 \cdot \operatorname{Ar}(\mathrm{O})=108+14+3 \cdot 16=170$

$\operatorname{Mr}\left(\mathrm{K}_{2} \mathrm{SO}_{4}\right)=2 \cdot \operatorname{Ar}(\mathrm{K})+\operatorname{Ar}(\mathrm{S})+4 \cdot \operatorname{Ar}(\mathrm{O})=2 \cdot 39+32+4 \cdot 16=174$

La cuestión se puntuará de la forma:

1 punto para los alumnos que realicen las operaciones correctamente y obtengan estos resultados

0,5 puntos para los alumnos que cometan algún error en el cálculo o en la utilización de los datos, pero no en la utilización de subíndices

0 puntos para los alumnos que cometan algún error al no utilizar correctamente los subíndices o bien por no resolver de forma correcta este sencillo algoritmo.

\section{Cuestión 9}

La relación correcta es:

Compuesto químico

Fórmula

- Óxido de litio

- Ácido carbónico

- Hidróxido de potasio

- Ácido Clorhídrico

- Ácido nítrico

- Trióxido de dicloro

- Óxido de hierro (II)

- Sulfato de sodio

- Óxido de plomo (II)

- Hidruro de calcio

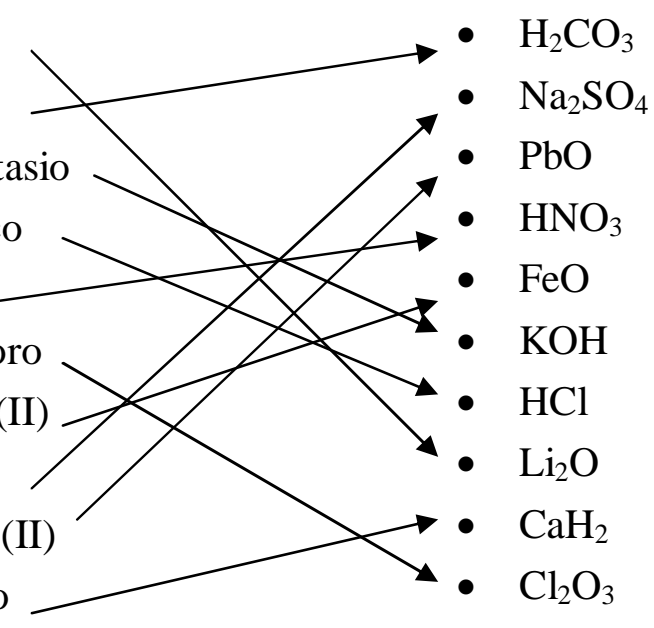

Se calificará con

1 punto a los alumnos que relacionen correctamente a todas las parejas o bien se equivoquen en una sola ocasión (lo que supone dos errores)

0,5 puntos para los alumnos que se equivoquen en un máximo de cuatro ocasiones

0 puntos para los alumnos que se equivoquen en cinco o más parejas. 


\section{Cuestión 10}

En esta cuestión se espera que los alumnos hagan referencia a la ley de conservación de masa con sus propias palabras atendiendo a la lógica de que una reordenación de átomos sólo conducir a una nueva distribución de la masa total. Por tanto se concederá:

1 punto a los alumnos que expliquen que durante la quema (combustión) de la madera, la mayor parte de su materia se combina con el oxígeno atmosférico y se produce vapor de agua y dióxido de carbono, estos dos gaseosos y que no quedan retenidos junto a las cenizas, de ahí que la masa sólida final sea menor que la masa sólida inicial.

0,5 puntos a los alumnos que den respuestas donde indiquen que se ha quemado y se ha formado humo, pero no hagan referencia a que ha habido una reacción, ni combinación de sustancias o algo que de a entender que ellos ven un cambio en la naturaleza de la sustancia.

0 puntos para los alumnos que no contesten o bien no indiquen ninguna explicación mínimamente razonable. 


\section{ANEXO VII}

CUESTIONARIO DE DETECCIÓN D

E CONOCIMIENTOS PREVIOS EN $2^{\circ}$ DE BACHILLERATO ACERCA DEL ENLACE QUÍMICO 


\title{
CUESTIONARIO DE DETECCIÓN DE CONOCIMIENTOS PREVIOS EN $2^{\circ}$ DE BACHILLERATO ACERCA DEL ENLACE QUÍMICO
}

\author{
(Pre-BAC)
}

Centro:

Apellidos y nombre:

Curso y grupo:....

\section{INSTRUCCIONES}

El propósito de esta prueba es evaluar los conocimientos que posees acerca de la química que se requieren para abordar satisfactoriamente el estudio del enlace químico. Los resultados obtenidos no serán considerados en tu calificación.

Por favor, responde a cada pregunta en el espacio reservado para ella, con letra clara e intentando explicar lo mejor posible las respuestas. Utiliza el folio para hacer todos los cálculos que necesites. 
1.- Completa la tabla siguiente:

\begin{tabular}{|l|l|}
\hline Ca & Fluor \\
\hline Cs & \\
\hline & Estaño \\
\hline Ba & \\
\hline & Cobre \\
\hline
\end{tabular}

\begin{tabular}{|l|l|}
\hline Ni & Plomo \\
\hline Cd & \\
\hline & Mercurio \\
\hline & Azufre \\
\hline Sb & \\
\hline
\end{tabular}

2.- En la siguiente tabla periódica, respecto a los elementos señalados, indica:
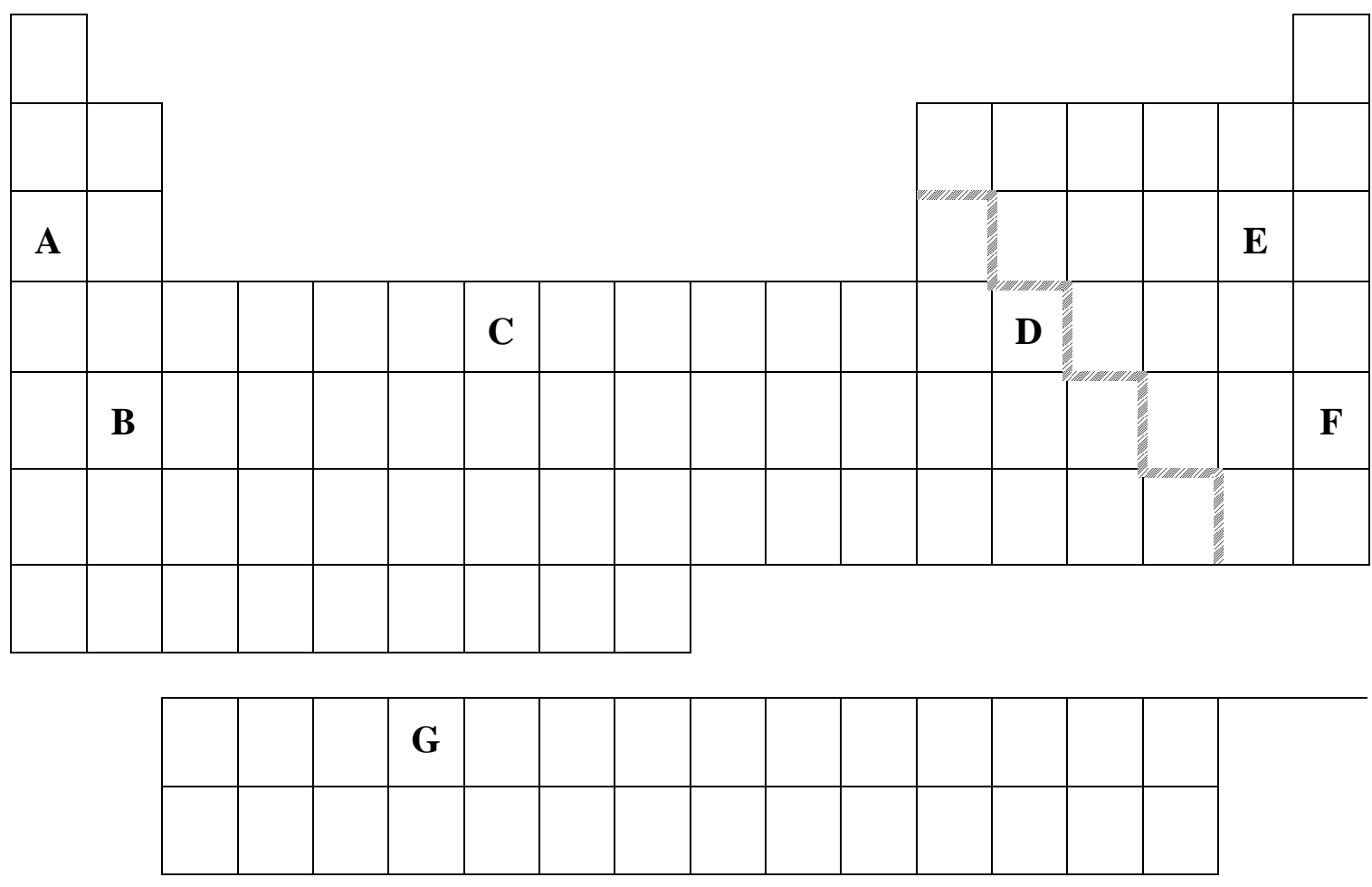

a) ¿Qué elementos son buenos conductores de la electricidad?

b) ¿Qué elementos se encuentran normalmente en estado gaseoso?

c) ¿Cuáles son, de ellos elementos representativos?

¿Cuáles son halógenos?

d) ¿Podrían unirse el elemento “A” y el elemento "E”?

e) ¿Cual es el elemento más electronegativo? 
3.- Dibuja esquemáticamente cómo tendría el átomo de fluor distribuidos sus:

9 protones

9 electrones

10 neutrones

4.- Escribe la configuración electrónica para el estado fundamental de los siguientes elementos:
${ }_{8}^{16} \mathrm{O}$
${ }_{17}^{35} \mathrm{Cl}^{-}$
${ }_{19}^{39} K$
${ }_{51}^{122} \mathrm{Sb}$

5.- ¿Cuál será la valencia iónica más probable de los siguientes elementos?

$\mathrm{O} \rightarrow$

$\mathrm{F} \rightarrow$

$\mathrm{K} \rightarrow$

$\mathrm{Sb} \rightarrow$

6.- La configuración electrónica del potasio puede representarse:

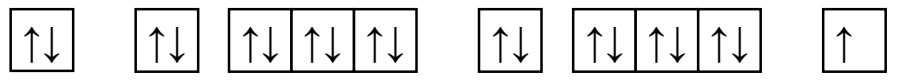

¿Qué información nos indica respecto a su comportamiento químico?

7.- La última casilla del ejercicio anterior representa la ubicación de un electrón en su átomo. Explica con tus palabras donde se encuentra dicho electrón. 
8.- ¿Cuál es la diferencia más importante entre un átomo y un ión de un mismo elemento?

¿Puede un elemento estar formado por moléculas?

9.- ¿Qué entiendes por energía de ionización?

Las primeras energías de ionización del litio y del cesio, siendo ambos metales alcalinos, son $520 \mathrm{~kJ} / \mathrm{mol}$ y $375 \mathrm{~kJ} / \mathrm{mol}$, respectivamente. ¿A qué se debe esta diferencia?

10.- Nombra y formula los siguientes compuestos químicos:

$\mathrm{HBr}$

Hidruro de litio

$\mathrm{FeCl}_{3}$

Óxido ferroso

$\mathrm{SO}_{2}$

Ácido carbónico

$\mathrm{Cl}_{2}$

Hidróxido estánnico

$\mathrm{Au}(\mathrm{OH})_{3}$

Ácido bromhídrico

$\mathrm{H}_{2} \mathrm{SO}_{3}$

Anhídrido sulfuroso

$\mathrm{HClO}$

Sulfito sódico

$\mathrm{K}_{2} \mathrm{SO}_{4}$

Fosfato cálcico 


\section{ANEXO VIII}

CORRECCIÓN DEL CUESTIONARIO Pre-BAC. CRITERIO DE PUNTUACIÓN 


\section{Cuestión 1}

Esta cuestión es cerrada y de gran sencillez, que debe ser contestada correctamente de la forma:

\begin{tabular}{|c|c|}
\hline Ca & Calcio \\
\hline $\mathcal{F}$ & Fluor \\
\hline Cs & Cesio \\
\hline$S_{n}$ & Estaño \\
\hline Ba & Bario \\
\hline$C u$ & Cobre \\
\hline
\end{tabular}

\begin{tabular}{|c|c|}
\hline Ni & Niquel \\
\hline Pb & Plomo \\
\hline Cd & Cadmio \\
\hline $\mathbf{H g}$ & Mercurio \\
\hline S & Azufre \\
\hline Sb & Antimonio \\
\hline
\end{tabular}

Se otorgará la puntuación siguiente:

1 punto para los alumnos que contesten correctamente en todas las casillas

0,5 puntos para los alumnos que se equivoquen en 1 ó 2 de las casillas, independientemente de cual sea

0 puntos para aquellos que se equivoquen en más de dos casillas o las dejen en blanco, situación que se antoja extraña dada su sencillez.

\section{Cuestión 2}

Se espera que los alumnos contesten a las cuestiones de la siguiente forma:

a) son buenos conductores los elementos A,B,C y G, puesto que son metales, en el caso del D hablaríamos de un semimetal

b) se encuentran normalmente en estado gaseoso el E y F, pos ser un halógeno de bajo peso molecular y un gas noble

c) son elementos representativos el A, B, D, E y F el E

d) si, puesto que trata de elementos de muy diferente electronegatividad y fácilmente se produciría un enlace iónico.

e) $\mathrm{El} \mathrm{E}$

Se calificará el ejercicio de la forma:

1 punto para los alumnos que contesten correctamente a las cuestiones o que en caso de fallar en alguno de ellos no sea muy desacertada la respuesta. 
0,5 puntos en el caso de responder correctamente en al menos tres de las cinco cuestiones

0 puntos para aquellos que no contesten al menos a tres de las preguntas o bien las dejen en blanco.

\section{Cuestión 3}

Se espera que los alumnos contesten la pregunta atendiendo a la representación heliocéntrica, ya que normalmente han estudiado los modelos atómicos de Rutherford y Bohr, aunque se aceptaría de buen grado una distribución de electrones desordenada en el espacio. Aproximadamente de la forma:

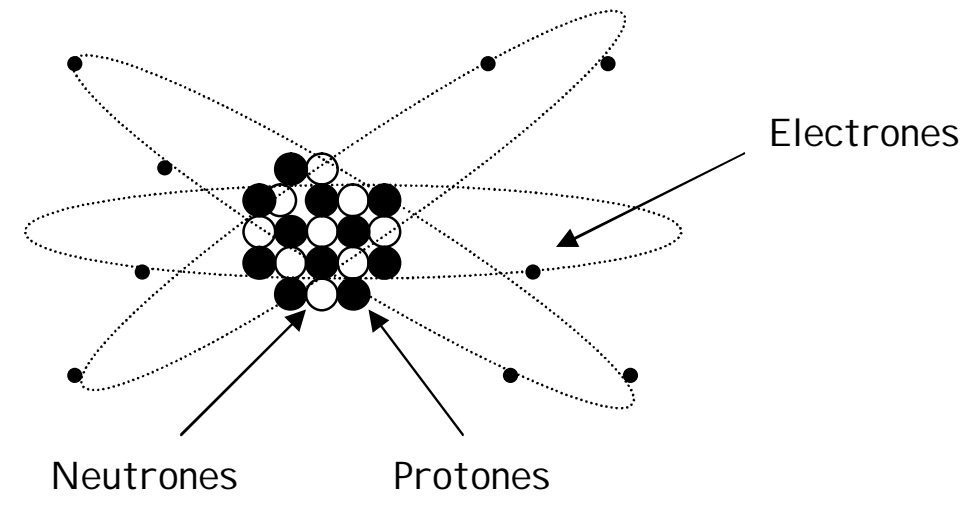

Por tanto se concederá:

1 punto a los alumnos que hagan una representación similar a la expuesta y que queden perfectamente diferenciados el núcleo y sus constituyentes de los electrones y que se encuentren todos ellos en el número correcto.

0,5 puntos para aquellos que se equivoquen en el número de partículas, pero mantengan a cada una en su lugar

0 puntos para los que dibujen las partículas en lugares equivocados, todas juntas, o bien no realicen ningún dibujo.

\section{Cuestión 4}

En este tercer ítem, la única dificultad que se pueden encontrar los alumnos es el hecho de no darse cuenta de la presencia del ión Cl-, y que supone considerar el electrón extra, se aceptará como correcta la respuesta: 


$$
\begin{aligned}
& { }_{8}^{16} O \rightarrow 1 \mathrm{~s}^{2} 2 \mathrm{~s}^{2} 2 \mathrm{p}^{4} \\
& { }_{17}^{35} \mathrm{l}^{-} \rightarrow 1 \mathrm{~s}^{2} 2 \mathrm{~s}^{2} 2 \mathrm{p}^{6} 3 \mathrm{~s}^{2} 3 \mathrm{p}^{6} \\
& { }_{19}^{39} K \rightarrow 1 \mathrm{~s}^{2} 2 \mathrm{~s}^{2} 2 \mathrm{p}^{6} 3 \mathrm{~s}^{2} 3 \mathrm{p}^{6} 4 \mathrm{~s} 1 \\
& { }_{51}^{122} S b \rightarrow 1 \mathrm{~s}^{2} 2 \mathrm{~s}^{2} 2 \mathrm{p}^{6} 3 \mathrm{~s}^{2} 3 \mathrm{p}^{6} 4 \mathrm{~s}^{2} 3 \mathrm{~d}^{10} 4 \mathrm{p}^{6} 5 \mathrm{~s}^{2} 4 \mathrm{~d}^{10} 5 \mathrm{p}^{3}
\end{aligned}
$$

Valorando las repuestas con:

1 punto en el caso de responder a todas ellas de forma correcta

0,5 puntos en el caso de equivocarse en una de ellas

0 puntos en el caso de equivocarse en dos o más ocasiones

\section{Cuestión 5}

Esta cuestión está relacionada con la segunda y únicamente se espera que expresen la valencia iónica del elemento, lo que se traduce en conocer su posición en la tabla y su consecuencia. La respuesta correcta quedará:

$$
\mathrm{O} \rightarrow-2, \quad \mathrm{~F} \rightarrow-1, \quad \mathrm{~K} \rightarrow+1, \quad \mathrm{Sb} \rightarrow-3
$$

Y se considerará:

1 punto para los alumnos que indiquen correctamente las cuatro valencias.

0,5 puntos para los alumnos que acierten al menos dos de ellas.

0 puntos para los que acierten una o ninguna de ellas.

\section{Cuestión 6}

En esta cuestión se espera que los alumnos, al menos indiquen que hay un electrón solitario la última capa, que se trata en concreto del electrón situado en el orbital 4s, y que esto le confiere gran reactividad, que se trata de un elemento alcalino y que con facilidad cederá este electrón adquiriendo una carga positiva.

También deberían saber que se trata del potasio y que como metal alcalino participará en gran número de compuestos iónicos y que es frecuente su aparición como ión $\mathrm{K}^{+}$en disoluciones acuosas. Por ello se asignará: 
1 punto para los alumnos que indiquen su elevada reactividad por la fácil formación del ión, y que esto se debe a la presencia de un único electrón en el nivel 4s.

0,5 puntos para los que únicamente indiquen que se trata de un elemento alcalino o muy reactivo, sin observar la facilidad de perder el electrón.

0 puntos para los alumnos que no contesten o que tampoco hayan expresado al menos la idea anterior.

\section{Cuestión 7}

Relacionada con la cuestión anterior, en esta se espera que los alumnos indiquen que el electrón se encuentra en el orbital $4 \mathrm{~s}$, con lo que se concluiría la respuesta. Además dado el carácter esférico de los orbitales de tipo s, también deberían contestar que se pueden encontrar en cualquier zona del espacio alrededor del núcleo. Las puntuaciones que se atribuirán serán:

1 punto para los alumnos que indiquen que el electrón se encuentra en un orbital 4s y, por tanto en cualquier dirección alrededor del núcleo 0,5 puntos para los que indique que se encuentra en el nivel 4 alrededor del núcleo 0 puntos para aquellos que no expresen ninguna de las ideas anteriores.

\section{Cuestión 8}

La respuesta que se pretende obtener en esa cuestión es que un ión es simplemente un átomo que a captado o cedido uno o varios electrones, quedando con carga neta negativa (anión) o positiva (catión) respectivamente.

En la segunda pregunta, naturalmente que puede estar un elemento formado por moléculas, ya que elementos habituales como el hidrógeno, oxígeno, cloro, etc. se encuentran de esta forma. Se atribuirán:

1 punto a los alumnos que contesten correctamente a las dos cuestiones, y las razonen mínimamente.

0,5 puntos a aquellos alumnos que contesten correctamente a una sola de ellas o bien a las dos pero no lo justifiquen.

0 puntos a los alumnos que no contesten el ejercicio o bien contesten a una de las preguntas y no lo justifiquen. 


\section{Cuestión 9}

Esta cuestión es estudiada en el curso anterior con amplitud y se espera sea contestada correctamente, atribuyendo:

1 punto a los alumnos que indiquen que se trata de la energía que debe suministrarse a un átomo gaseoso del elemento para arrancar el electrón más débilmente unido a él. Y que la diferencia de electronegatividades entre el litio y el cesio se debe al mayor tamaño del mismo, que hace que el electrón de valencia se encuentre más alejado del núcleo y en un estado energético superior.

0,5 puntos para los alumnos que contesten correctamente a una sola de las preguntas o bien no las razonen.

0 puntos en el caso de no contestar correctamente a ninguna de ellas.

\section{Cuestión 10}

Aunque alguno de estos compuestos aceptan varias nombre, daremos por válidos:

$$
\begin{array}{ll}
\mathrm{HBr} \rightarrow \text { Bromuro de hidrógrno } & \text { Hidruro de litio } \rightarrow \mathrm{LiH} \\
\mathrm{FeCl}_{3} \rightarrow \text { Tricloruro de hierro } & \text { Óxido ferroso } \rightarrow \mathrm{FeO} \\
\mathrm{SO}_{2} \rightarrow \text { Dióxido de azufre } & \text { Ácido carbónico } \rightarrow \mathrm{CO}_{2} \\
\mathrm{Cl}_{2} \rightarrow \text { Cloro } & \text { Hidróxido estánnico } \rightarrow \mathrm{Sn}(\mathrm{OH})_{4} \\
\mathrm{Au}(\mathrm{OH})_{3} \rightarrow \text { Trihidróxido de hierro } & \text { Bromuro de hidrógeno } \rightarrow \mathrm{HBr} \\
\mathrm{H}_{2} \mathrm{SO}_{3} \rightarrow \text { Ácido sulfuroso } & \text { Dióxido de azufre } \rightarrow \mathrm{SO}_{2} \\
\mathrm{HClO} \rightarrow \text { Ácido hipocloroso } & \text { Sulfito sódico } \rightarrow \mathrm{Na}_{2} \mathrm{SO}_{3} \\
\mathrm{~K}_{2} \mathrm{SO}_{4} \rightarrow \text { Sulfato potásico } & \text { Fosfato cálcico } \rightarrow \mathrm{Ca}_{3}\left(\mathrm{PO}_{4}\right)
\end{array}
$$

Y puntuaremos con:

1 punto a los alumnos que contesten correctamente en todos los casos o bien cometan un máximo de dos errores.

0,5 puntos a los alumnos que cometan un máximo de 6 fallos

0 puntos a los alumnos que cometan más de 6 fallos. 


\section{ANEXO IX}

CUESTIONARIO PARA ESTABLECER LOS CONOCIMIENTOS ACERCA DEL ENLACE QUÍMICO EN $2^{\circ}$ DE BACHILLERATO 


\section{CUESTIONARIO PARA ESTABLECER LOS CONOCIMIENTOS ACERCA DEL ENLACE QUÍMICO EN $2^{\circ}$ DE BACHILLERATO}

(Post-BAC)

Centro:

Apellidos y nombre:

Curso y grupo:

INSTRUCCIONES

El propósito de esta prueba es evaluar los conocimientos que posees acerca del enlace químico. Los resultados obtenidos serán considerados en tu calificación.

Por favor, responde a cada pregunta en el espacio reservado para ella, con letra clara e intentando explicar lo mejor posible las respuestas.

Utiliza el folio para hacer todos los cálculos que necesites. 
1.- Utilizando los símbolos de Lewis, muestra como se unen los átomos para formar los compuestos:
a) $\mathrm{PH}_{3}$
b) $\mathrm{CO}_{3}{ }^{2-}$

c) $\mathrm{AlF}_{3}$

d) $\mathrm{ClO}_{3}^{-}$
e) $\mathrm{HCN}$
f) $\mathrm{PBr}_{5}$

2.- Explica el hecho de que siendo el fósforo y silicio elementos próximos en la tabla periódica la molécula $\mathrm{PF}_{3}$ sea polar mientras que $\mathrm{SiF}_{4}$ no lo sea.

3.- Escribe las fórmulas resonantes para las especies $\mathrm{NO}_{2}{ }^{-}$y $\mathrm{HNO}_{3}$. ¿Cuál es el orden de cada enlace?

4.- Indica el tipo de enlace químico que predomina en cada una de las siguientes sustancias:
a) bromuro de cesio
b) cloro
c) yoduro cálcico
d) dióxido de nitrógeno
e) sodio metálico
f) agua
g) cloruro sódico
h) óxido de magnesio
i) octano

¿Cuáles serán los dos enlaces con mayor polaridad de todos ellos?

\begin{tabular}{|c|c|}
\hline Elemento & EN \\
\hline $\mathrm{Br}$ & 2.8 \\
\hline $\mathrm{Cs}$ & 0.8 \\
\hline $\mathrm{O}$ & 3.5 \\
\hline $\mathrm{N}$ & 3.0 \\
\hline $\mathrm{I}$ & 2.1 \\
\hline $\mathrm{Ca}$ & 1.0 \\
\hline $\mathrm{Na}$ & 1.0 \\
\hline $\mathrm{H}$ & 2.1 \\
\hline $\mathrm{Cl}$ & 3.0 \\
\hline $\mathrm{Mg}$ & 1.2 \\
\hline
\end{tabular}


5.- Completa

\begin{tabular}{|c|c|c|c|c|}
\hline Sustancia & Molécula & geometría & Momentos dipolares & polaridad \\
\hline $\mathrm{SO}_{2}$ & & & & \\
\hline $\begin{array}{r}\text { Dióxido de } \\
\text { azufre }\end{array}$ & & & & \\
\hline $\mathrm{CH}_{3} \mathrm{Cl}$ & & & & $\mu \neq 0$ \\
\hline Clorometano & & & & \\
\hline $\mathrm{Br}_{2}$ & & & & \\
\hline Bromo & & & & \\
\hline $\mathrm{CH}_{4}$ & & tetraédrica & & $\mu=0$ \\
\hline Metano & & & & \\
\hline $\mathrm{PCl}_{5}$ & & & & \\
\hline $\begin{array}{r}\text { Tetracloruro de } \\
\text { fósforo }\end{array}$ & & & & \\
\hline
\end{tabular}

6.- Da una explicación a los siguientes fenómenos:

a) al calentar un metal, este desprende electrones, mientras que al calentar una sustancia molecular o iónica esto no ocurre.

b) el oro se disuelve en mercurio a temperatura ambiente, mientras que no lo hace en agua, ni en benceno. 
7.- Razona la conductividad eléctrica de:

$\mathrm{NaCl}$ en disolución acuosa:

$\mathrm{NaCl}$ fundido

\section{Grafito}

Cobre

8.- Tanto las moléculas de cloro como las de yodo están formadas por enlaces covalentes entre dos átomos, a los que falta un electrón en su última capa. ¿por qué el primero es un gas en condiciones normales, mientras que el segundo es un sólido?

9.- ¿Qué tipos de fuerzas mantienen unidas a los siguientes átomos o moléculas?

a)

$$
\mathrm{Br} \mathrm{Br} \quad \mathrm{Br}
$$

b)

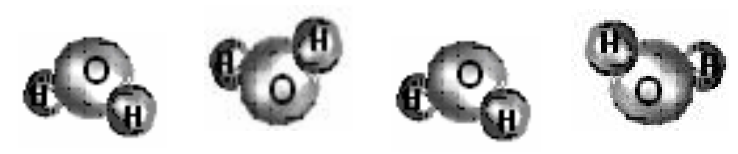

c) $x_{e} x_{e} x_{e}$

d)

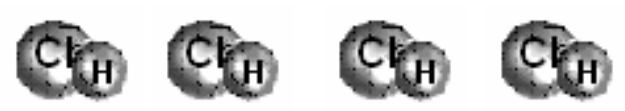

10.- Indica qué tipo de atracción o de enlace químico han de romperse para :
a) fundir cloruro sódico,
b) sublimar naftalina (naftaleno, $\mathrm{C} 10 \mathrm{H} 8$ ),
c) disolver bromo en agua,
d) disolver bromo en tetracloruro de carbono,
e) fundir oro,
f) vaporizar agua,
g) vaporizar C (diamante)
h) evaporar alcohol 
ANEXO X 


\section{Cuestión 1}

Las estructuras que se piden en la cuestión son las siguientes:

a) $\mathrm{PH}_{3}$

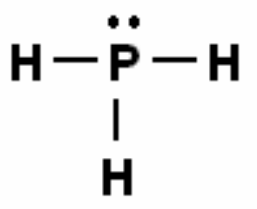

c) $\mathrm{AlF}_{3}$

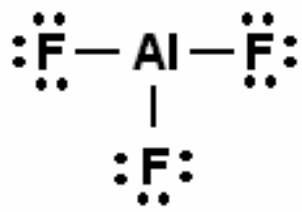

e) $\mathrm{HCN}$ b) $\mathrm{CO}_{3}{ }^{2-}$<smiles>O=C1O[C@H]2CO[C@H]1O2</smiles>

d) $\mathrm{ClO}_{3}{ }^{-}$

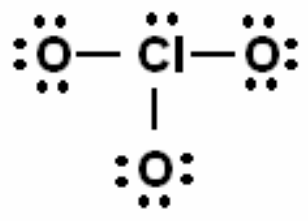

f) $\mathrm{PBr}_{5}$

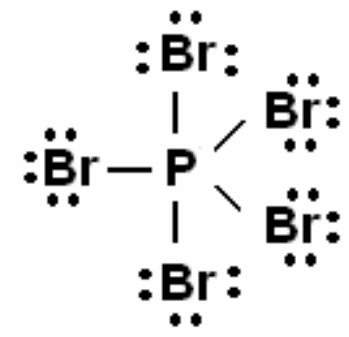

Para obtenerlas los alumnos realizaran los cálculos que consideren, pero deben llegar a este resultado. La calificación será la siguiente:

1 punto para los alumnos que escriban correctamente todas las estructuras o bien que hagan mal una de ellas, o bien cometan algún error como dejar sin colocar algún par de electrones solitarios.

0,5 puntos para los alumnos que hagan correctamente al menos tres de estas estructuras o cometan errores leves (no relacionados con el número de enlaces)

0 puntos para aquellos alumnos que no respondan a la cuestión o bien que no muestre un mínimo conociendo del proceso. 


\section{Cuestión 2}

En esta cuestión se conjuga la geometría molecular y la polaridad de las moléculas para obtener un momento bipolar neto. Por ello se calificará con:

1 punto a los alumnos que expresen la geometría de ambas moléculas y que concluyan que en el caso de tetrafuoruro de silicio, la simetría que resulta de la configuración tetraédrica conduce a un momento dipolar nulo, por compensarse la polaridad de los cuatro enlaces entre el átomo de silicio y los cuatro de fluor. En el caso del frifluoruro de fósforo, este último posee un par de electrones solitario y por tanto una geometría de pirámide trigonal, en la que hay una direccionalidad clara del momento dipolar. Por tanto aunque ambas moléculas son similares, el par solitario hace que sus propiedades sean
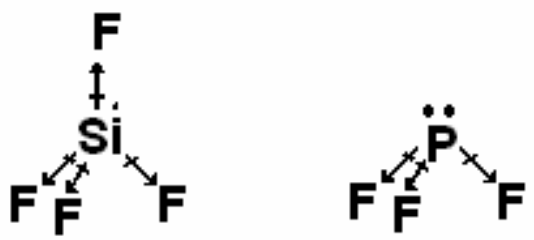
diferentes.

0,5 puntos para aquellos alumnos que indiquen que el PF3 es polar porque tiene un par de electrones solitarios pero que no relacione la geometría con el resultado de sumar los momentos dipolares de los enlaces.

0 puntos para los alumnos que no justifiquen la cuestión o lo hagan de forma errónea.

\section{Cuestión 3}

Tras buscar las estructuras de Lewis de ambos compuestos se debe llegar a la conclusión siguiente:

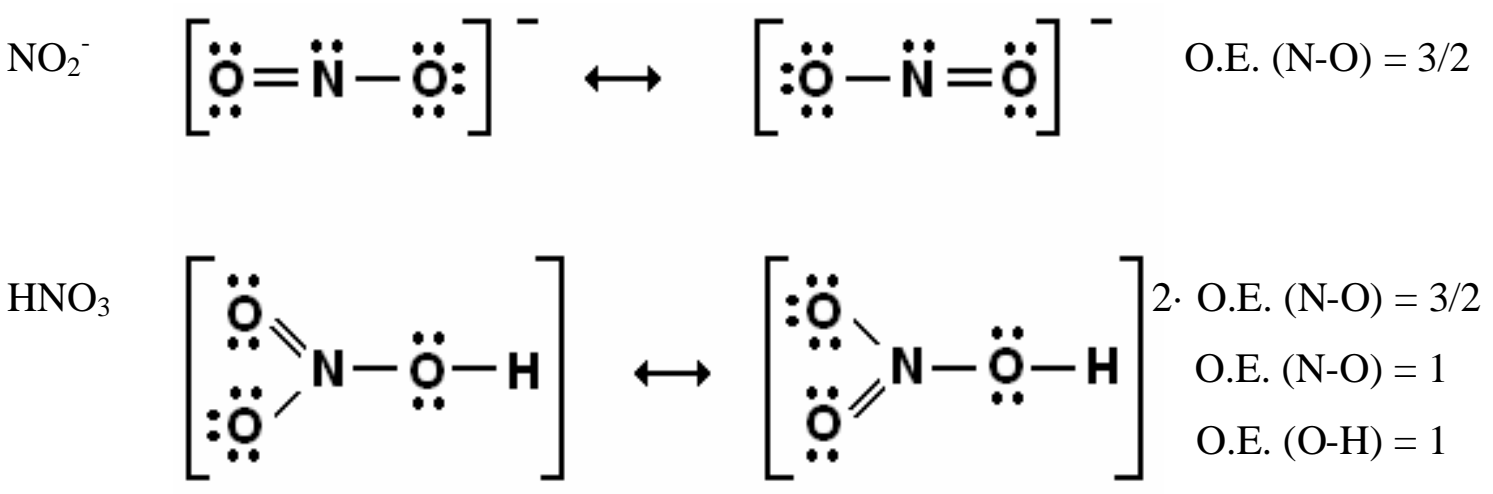

La cuestión se puntuará de la forma: 
1 punto para los alumnos que realicen correctamente las formas resonantes de ambas moléculas, aun cuando no expresen correctamente el orden de enlace ya que aunque sencillo no es un objetivo del curso.

0,5 puntos para aquellos alumnos que sólo realicen correctamente una de las estructuras 0 puntos para los que no dibujen correctamente ninguna de las dos.

\section{Cuestión 4}

Las respuestas correctas a la cuestión son:

a) bromuro de cesio $\rightarrow$ Enlace iónico

b) cloro $\rightarrow$ Enlace covalente

c) yoduro cálcico $\rightarrow$ Enlace iónico

d) dióxido de nitrógeno $\rightarrow$ Enlace covalente

e) sodio metálico $\rightarrow$ Enlace me tálico

f) agua $\rightarrow$ Enlace covalente

g) cloruro sódico $\rightarrow$ Enlace iónico

h) óxido de magnesio $\rightarrow$ Enlace iónico

i) octano $\rightarrow$ Enlace covalente

Y las sustancias cuyos enlaces estarán más polarizados serán el bromuro de cesio y el cloruro sódico, dada su elevada diferencia de electronegatividad. La puntuación asignada será:

1 punto para los alumnos que contesten correctamente en todos los casos o se equivoquen en uno solo de ellos.

0,5 puntos para los que se equivoquen en un máximo de dos casos o bien no contesten a la última pregunta.

0 puntos en el caso de equivocarse en más de cuatro ocasiones, o bien en dos de ellas y no contestar a la pregunta.

\section{Cuestión 5}

En esta cuestión se trata de rellenar la tabla según se indica para concluir con la polaridad de la molécula, de la forma: 


\begin{tabular}{|c|c|c|c|}
\hline Sustancia & Geometría & Momentos dipolares & polaridad \\
\hline Diónido de \\
azufre
\end{tabular}

Se calificará con:

1 punto a los alumnos que sitúen correctamente los aspectos solicitados, o bien tengan algún error en el conjunto.

0,5 puntos a aquellos alumnos que rellenen correctamente las casillas para al menos tres de las moléculas, aun cometiendo algún pequeño error.

0 puntos para aquellos alumnos que no lo hagan 


\section{Cuestión 6}

Los metales tienen una nube o mar de electrones casi libres que se mueven por todo el cristal metálico. Estos electrones son expulsados por el metal si reciben un aporte suficiente de energía en forma de calor o luz. En los sólidos iónicos y covalentes no hay electrones libres, sino que están firmemente ligados por enlaces iónicos o covalentes.

En el caso del oro, el agua es un disolvente polar y el benceno es apolar, pero no se disuelve en ninguno de ellos por que se trata de sustancias muy diferentes. Cada un o de ellos sólo disuelve a sustancias de su misma polaridad. Por tanto el oro se disolverá en sustancias similares a él como lo es el mercurio, presentando ambos enlaces metálicos. Para puntuar las cuestiones optaremos por:

1 punto a los alumnos que contesten razonablemente bien a las preguntas, demostrando que conoce el motivo.

0,5 puntos para los alumnos que contesten correctamente a una sola de las preguntas o bien que contesten a las dos pero su explicación no sea del todo clara.

0 puntos para los alumnos que no las contesten o no lo hagan con un mínimo de rigor.

\section{Cuestión 7}

a) el $\mathrm{NaCl}$ en disolución acuosa, es una mezcla en la que la sustancia iónica se ha disuelto en el agua de forma que los átomos de sodio y de cloro se has separado y cedido o captado un electrón con lo que hablamos de una disolución de iones $\mathrm{Na}^{+}$y $\mathrm{Cl}^{-}$por tanto, de cargas que pueden moverse libremente en el seno de la disolución siendo esta conductora de la corriente eléctrica.

b) Cuando se hala de $\mathrm{NaCl}$ fundido se trata igual que en el caso anterior de iones $\mathrm{Na}+$ y Cl-, pero ahora solos sin agua. De todos modos se trata de cargas con libertad de movimiento y por tanto de una sustancia conductora.

c) En el grafito los átomos de carbono presentan una hibridación sp2, formando tres enlaces covalentes en un mismo plano, donde se ubican tres de sus cuatro electrones de valencia. El último queda deslocalizado, permitiendo launión entre planos y la conductividad eléctrica. 
d) En el caso del cobre, se trata de un metal con un enlace cuya principal característica es la nube electrónica que envuelve a los núcleos y capas completas, y que confiere la conductividad gracias a la movilidad de los electrones en esta nube.

La calificación en esta cuestión será:

1 punto para los alumnos que razonen correcta o sensatamente las tres propuestas, o bien dejen alguna de ellas de forma incompleta.

0,5 puntos para aquellos alumnos que razonen correctamente dos de los supuestos, o lo hagan vagamente en todos ellos.

0 puntos para los alumnos que no den respuestas suficientemente claras.

\section{Cuestión 8}

Tanto las moléculas de yodo como la de cloro, están formadas por dos átomos unidos mediante enlaces covalentes, y sin carácter polar por ser los dos átomos iguales. Las causas que mantienen unidas a moléculas de un mismo elemento son un tipo de fuerzas de Van der Waals, denominadas fuerzas de London, en las que una molécula apolar sufre una distribución de carga asimétrica y con ello una débil polarización instantánea, que a su vez provoca el mismo efecto en las molécula vecinas. Resultando con ello una unión entre todas ellas.

Dado que las fuerzas se originan con la polarización, en la medida que se disponga de moléculas de mayor tamaño, y con una nube electrónica mayor, estas serán más fácilmente polarizables y el enlace de mayor fuerza, dentro de su debilidad relativa.

Por tanto este tipo de fuerzas de dará en mayor intensidad en el yodo que en el cloro, permitiendo su estado sólido. Esta cuestión se puntuará con:

1 punto en el caso de que el alumno de una respuesta correcta semejante a la explicación anterior.

0,5 puntos para los alumnos que indiquen que se debe a su mayor masa molecular pero no lo razone.

0 puntos para los alumnos que no den una respuesta en este sentido. 


\section{Cuestión 9}

a)

$$
\mathrm{Br} \mathrm{Br} \quad \mathrm{Br} \mathrm{Br}
$$

Enlace covalente entre los átomos de bromo que forman cada molécula y fuerzas de Van der Waals tipo London entre las moléculas.

b)

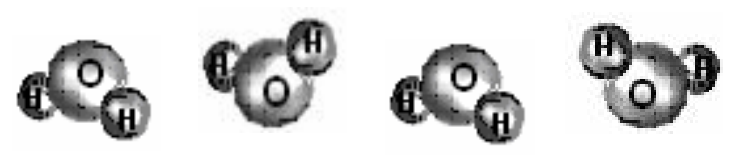

Enlaces covalentes entre los átomos de hidrógeno y oxígeno en cada molécula , y enlaces por puentes de hidrógeno entre las moléculas.

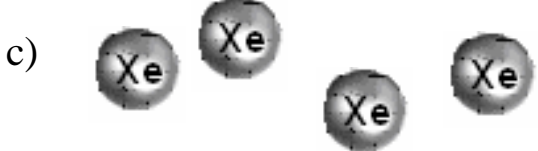

Fuerzas de atracción de Van der Waals entre los átomos

d)

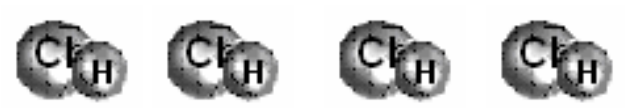

Enlace covalente entre los átomos de cloro e hidrógeno, y fuerzas de Van der Waals entre dipolos permanentes en el caso de las moléculas. La puntuación atribuida será:

1 punto para los alumnos que contesten correctamente a las cuatro propuestas o equivoquen alguno de los enlaces implicados

0,5 puntos para los alumnos que contesten correctamente en la mitad de los casos aproximadamente

0 puntos para los alumnos que no lo consigan.

\section{Cuestión 10}

La respuesta que se espera que aporten los alumnos es:

a) fundir cloruro sódico $\rightarrow$ romper los enlaces iónicos que forman la estructura cristalina

b) sublimar naftalina (naftaleno, $\mathrm{C}_{10} \mathrm{H}_{8}$ ) $\rightarrow$ vencer las fuerzas de Van der Waals que mantienen unidas a las moléculas de $\mathrm{C}_{10} \mathrm{H}_{8}$

c) disolver bromo en agua $\rightarrow$ vencer las fuerzas de Van der Waals que mantienen unidas a las moléculas de bromo entre si 
d) disolver bromo en tetracloruro de carbono $\rightarrow$ vencer las fuerzas de Van der Waals que mantienen unidas a las moléculas de bromo entre si

e) fundir oro $\rightarrow$ romper los enlaces metálicos que forman la red

f) vaporizar agua $\rightarrow$ romper los puentes de hidrógeno que hay entre las moléculas de agua

g) vaporizar $\mathrm{C}$ (diamante) $\rightarrow$ romper los enlaces covalentes que mantienen unidos entre si a los átomos de carbono

h) evaporar alcohol $\rightarrow$ romper los enlaces por puente de hidrógeno que mantienen unidas a las moléculas de alcohol.

El criterio de puntuación será:

1 punto a los alumnos que indiquen correctamente el tipo de enlaces a romper o se equivoquen en un máximo de dos.

0,5 puntos a los alumnos que acierten en al menos 4 de los casos

0 puntos para los alumnos que no alcancen esta cifra o no contesten a la pregunta. 


\section{ANEXO XI}

REDES DE ANÁLISIS EMPLEADAS EN LA CORRECCIÓN DE LOS CUESTONARIOS PREVIOS/DIAGNÓSTICOS 


\begin{tabular}{|c|c|c|c|}
\hline & Sí & No & Con dificultad \\
\hline \multicolumn{4}{|l|}{ Indica de qué elemento se trata } \\
\hline \multicolumn{4}{|l|}{ Describe su forma } \\
\hline \multicolumn{4}{|l|}{ Dice qué es un átomo } \\
\hline \multicolumn{4}{|l|}{ Cree que se trata del mismo tipo de átomos } \\
\hline \multicolumn{4}{|l|}{ Cree que difiere en su ordenación o estructura } \\
\hline \multicolumn{4}{|l|}{ Cree que difiere en su cantidad } \\
\hline \multicolumn{4}{|l|}{ Dibuja correctamente las partículas repartidas } \\
\hline \multicolumn{4}{|l|}{ En el segundo caso dibuja la cantidad adecuada } \\
\hline \multicolumn{4}{|l|}{ Deja espacios entre las partículas aunque es un gas } \\
\hline \multicolumn{4}{|l|}{ Distingue los elementos } \\
\hline \multicolumn{4}{|l|}{ Distingue los compuestos } \\
\hline \multicolumn{4}{|l|}{ Distingue las mezclas } \\
\hline \multicolumn{4}{|l|}{ Formula las sustancias compuestas } \\
\hline \multicolumn{4}{|l|}{ Nombra las sustancias compuestas } \\
\hline \multicolumn{4}{|l|}{ Formula los elementos } \\
\hline \multicolumn{4}{|l|}{ Nombra los elementos } \\
\hline \multicolumn{4}{|l|}{ Distingue las propiedades macro y microscópicas } \\
\hline \multicolumn{4}{|l|}{ Admite la presencia del vacío } \\
\hline \multicolumn{4}{|l|}{ Conoce la relación átomo-electrón } \\
\hline \multicolumn{4}{|l|}{ Concibe la idea de $\mathrm{n}^{\mathrm{o}}$ exponencial } \\
\hline \multicolumn{4}{|l|}{ Magnifica correctamente el $\mathrm{n}^{\mathrm{o}}$ de átomos } \\
\hline \multicolumn{4}{|l|}{ Es capaz de poner ejemplos de sustancias puras } \\
\hline \multicolumn{4}{|l|}{ Es capaz de poner ejemplos de mezclas homogéneas } \\
\hline \multicolumn{4}{|l|}{ Identifica sustancias puras con elementos } \\
\hline \multicolumn{4}{|l|}{$\begin{array}{l}\text { Cree que las industrias químicas tienen consecuencias } \\
\text { positivas }\end{array}$} \\
\hline \multicolumn{4}{|l|}{$\begin{array}{l}\text { Cree que las industrias químicas tienen consecuencias } \\
\text { negativas }\end{array}$} \\
\hline \multicolumn{4}{|l|}{ Concluye que la materia está formada por átomos } \\
\hline \multicolumn{4}{|l|}{ Los átomos de agrupan en moléculas } \\
\hline $\begin{array}{l}\text { Los elementos de clasifican según el SP y se } \\
\text { representan con símbolos }\end{array}$ & & & \\
\hline
\end{tabular}

Red de análisis utilizada en la corrección del Pre-ESO 


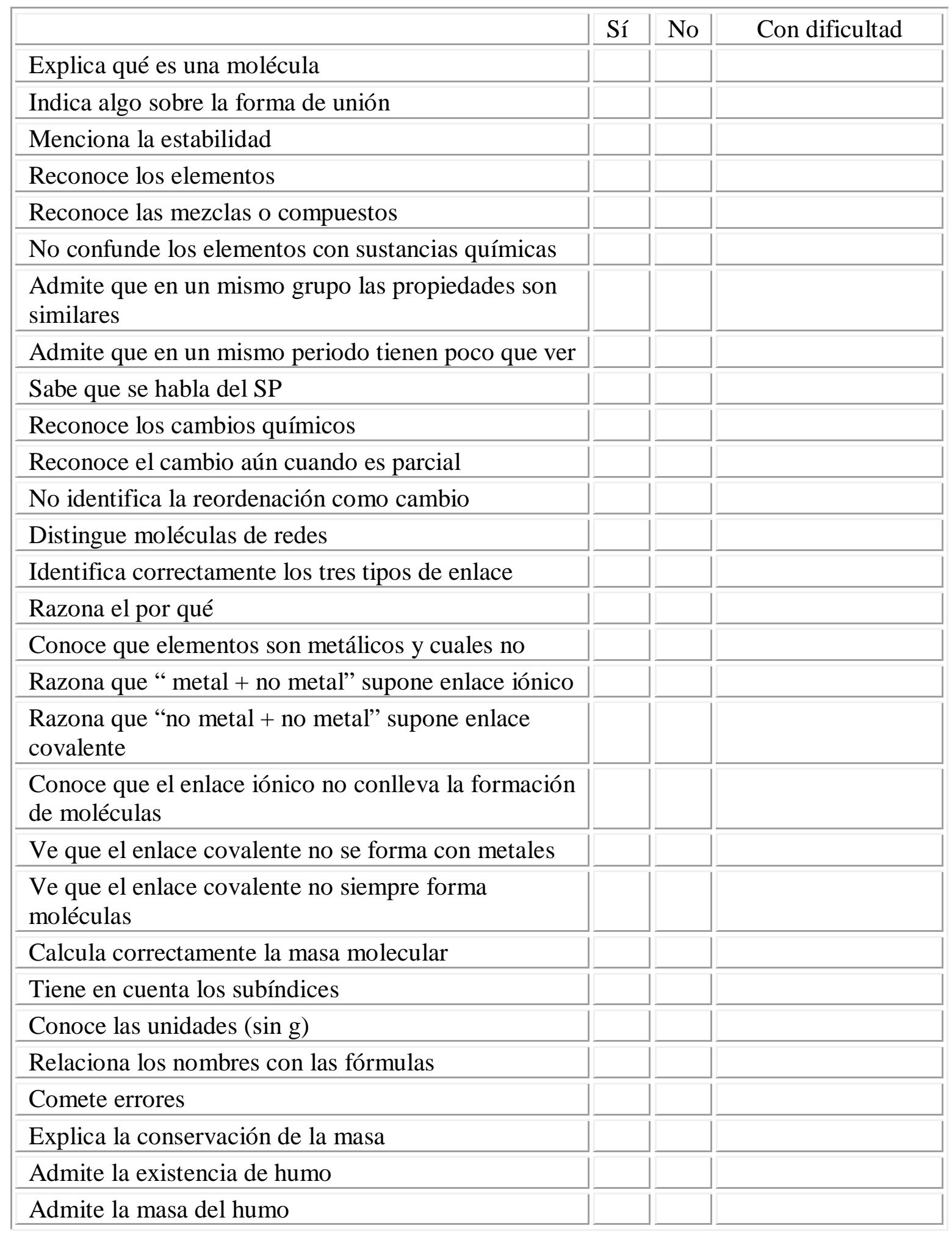

Red de análisis utilizada en la corrección del Post-ESO 


\begin{tabular}{|c|c|c|c|}
\hline & Sí & No & Con dificultad \\
\hline \multicolumn{4}{|l|}{$\begin{array}{l}\text { Conoce perfectamente los símbolos de los } \\
\text { elementos }\end{array}$} \\
\hline \multicolumn{4}{|l|}{ Sitúa los metales y los no metales } \\
\hline \multicolumn{4}{|l|}{ Distingue cuales son los grupos } \\
\hline \multicolumn{4}{|l|}{ Ubica los elementos respecto a su EN } \\
\hline \multicolumn{4}{|l|}{ Es capaz de dibujar un átomo } \\
\hline \multicolumn{4}{|l|}{ Coloca cada componente en su lugar } \\
\hline \multicolumn{4}{|l|}{ Dibuja órbitas } \\
\hline \multicolumn{4}{|l|}{ Escribe correctamente la configuración electrónica } \\
\hline \multicolumn{4}{|l|}{ Distingue correctamente entre A y Z } \\
\hline \multicolumn{4}{|l|}{ Conoce el número de e en el caso de un ión } \\
\hline \multicolumn{4}{|l|}{ Interpreta correctamente los diagramas de cajas } \\
\hline \multicolumn{4}{|l|}{ Conoce la valencia iónica del elemento } \\
\hline \multicolumn{4}{|l|}{$\begin{array}{l}\text { Relaciona con la configuración electrónica con el } \\
\text { comportamiento químico }\end{array}$} \\
\hline \multicolumn{4}{|l|}{ Obtiene alguna información ¿Cuál? } \\
\hline \multicolumn{4}{|l|}{ Distingue correctamente entre átomo e ión } \\
\hline \multicolumn{4}{|l|}{ Razona correctamente la diferencia } \\
\hline \multicolumn{4}{|l|}{$\begin{array}{l}\text { Admite que un elemento puede estar formado por } \\
\text { moléculas }\end{array}$} \\
\hline \multicolumn{4}{|l|}{ Es capaz de definir la energía de ionización } \\
\hline \multicolumn{4}{|l|}{ La relaciona con la configuración electrónica } \\
\hline \multicolumn{4}{|l|}{ Nombra correctamente los compuestos binarios } \\
\hline \multicolumn{4}{|l|}{ Nombra correctamente los compuestos ternarios } \\
\hline \multicolumn{4}{|l|}{ Formula correctamente los compuestos binarios } \\
\hline Formula correctamente los compuestos ternarios & & & \\
\hline
\end{tabular}

Red de análisis utilizada en la corrección del Pre-BAC 


\begin{tabular}{|c|c|c|c|}
\hline & $\mathrm{Si}$ & No & Con dificultad \\
\hline \multicolumn{4}{|l|}{ Utiliza correctamente los símbolos de Lewis } \\
\hline \multicolumn{4}{|l|}{$\begin{array}{l}\text { Calcula correctamente el número de enlaces } \\
\text { en el caso de ampliación y contracción del octeto }\end{array}$} \\
\hline \multicolumn{4}{|l|}{ No deja electrones solitarios } \\
\hline \multicolumn{4}{|l|}{ Dibuja los pares no compartidos } \\
\hline \multicolumn{4}{|l|}{ Relaciona la polaridad con la geometría } \\
\hline \multicolumn{4}{|l|}{ Busca previamente las estructuras de Lewis } \\
\hline \multicolumn{4}{|l|}{ Distingue entre polaridad de enlace o molécula } \\
\hline \multicolumn{4}{|l|}{ Dibuja correctamente las fórmulas resonantes } \\
\hline \multicolumn{4}{|l|}{ Discrimina entre todos los tipos de enlace } \\
\hline \multicolumn{4}{|l|}{ Tiene en cuenta los enlaces intermoleculares } \\
\hline \multicolumn{4}{|l|}{ Justifica las respuestas } \\
\hline \multicolumn{4}{|l|}{ Localiza a los enlaces de mayor polaridad } \\
\hline \multicolumn{4}{|l|}{ Escribe correctamente la estructura de Lewis } \\
\hline \multicolumn{4}{|l|}{ Conoce la geometría de las moléculas } \\
\hline \multicolumn{4}{|l|}{ Dibuja correctamente los momentos bipolares } \\
\hline \multicolumn{4}{|l|}{ Reconoce la polaridad de la molécula } \\
\hline \multicolumn{4}{|l|}{$\begin{array}{l}\text { Entiende el concepto de deslocalización } \\
\text { electrónica en las redes metálicas }\end{array}$} \\
\hline \multicolumn{4}{|l|}{ Conoce qué sustancias se disuelven entre sí } \\
\hline \multicolumn{4}{|l|}{ Conoce el efecto de los iones en disolución } \\
\hline \multicolumn{4}{|l|}{ Conoce los tipos de interacciones intermoleculares } \\
\hline \multicolumn{4}{|l|}{ Razona el por qué de estas interacciones } \\
\hline \multicolumn{4}{|l|}{$\begin{array}{l}\text { Reconoce enlaces interatómicos e } \\
\text { intermoleculares en la misma sustancia }\end{array}$} \\
\hline $\begin{array}{l}\text { Distingue los casos en que hay que romper enlaces } \\
\text { intermoleculares, pero no interatómicos }\end{array}$ & & & \\
\hline
\end{tabular}

Red de análisis utilizada en la corrección del Post-BAC. 


\section{ANEXO XII}

PARÁMETROS ESTADíSTICOS EMPLEADOS EN EL ANÁLISIS DE DATOS EN LAS INVESTIGACIONES PREVIAS DIAGNÓSTICAS 
A continuación describiremos brevemente estos estadísticos empleados. Los cálculos se han llevado a cabo mediante el programa SPSS ${ }^{1}$.

\section{Media aritmética}

La media aritmética es el cociente entre la suma de todas las medidas y el tamaño de la muestra.

$$
M=\frac{\sum x_{i}}{n_{i}}
$$

Si se representan en una recta los datos de una muestra correspondientes a una variable, la media es aquel punto tal que, la suma de los cuadrados de las distancias que hay desde cada puntuación hasta la media, es menor que la suma de los cuadrados de los cuadrados a cualquier otro punto. Como propiedad fundamental de la media, cabe señalar que la media aritmética de la muestra está más próxima al centro de la mayor agrupación de valores, que la posición de la moda y la mediana.

\section{Desviación típica}

Las medidas de tendencia central se refieren a la concentración de valores de la variable en una escala numérica. Se necesita conocer la homogeneidad o dispersión de los datos, es decir, las desviaciones de los valores de la variable, respecto de las medias de tendencia central.

El estadígrafo más utilizado es la desviación típica, que tiene el valor de la raíz cuadrada de la varianza, que se designa por s $(\sigma)$, y cuya expresión matemática es:

$$
\sigma=\sqrt{\frac{\sum_{i=1}^{n}\left(x_{i}-\bar{x}\right)^{2}}{n-1}}=\sqrt{\frac{\sum x_{i}^{2}-\left[\left(\sum x_{i}\right)^{2} / n\right]}{n-1}}
$$

La desviación típica tiene una utilidad especial para representar la dispersión de una muestra. Si la distribución de la variable es normal, conocemos los porcentajes aproximados de las puntuaciones situadas a una, dos o tres desviaciones típicas respecto de la media.

\footnotetext{
${ }^{1}$ El SPSS (Statistical Package for the Social Sciences) es un paquete estadístico de SPSS Inc. Chicago, USA.
} 


\begin{tabular}{|c|c|}
\hline $\begin{array}{l}\text { Desviaciones } \\
\text { de la media }\end{array}$ & $\begin{array}{l}\text { Porcentaje de } \\
\text { valores (aprox.) }\end{array}$ \\
\hline Media $\pm \sigma$ & $68 \%$ \\
\hline Media $\pm 2 \sigma$ & $95 \%$ \\
\hline Media $\pm 3 \sigma$ & $99,7 \%$ \\
\hline
\end{tabular}

Tabla 7.8.- Porcentajes de distribución, en una curva normal, en función de $\sigma$

Si se representa la frecuencia frente a los valores de una variable continua, se obtiene un polígono de frecuencias. $\mathrm{Si}$ los valores que adquiere son de tipo probabilístico, la ecuación matemática que relaciona la frecuencia con la variable tiene la forma:

$$
f(x)=\frac{1}{\sigma \sqrt{2 \pi}} e^{\frac{(x-\bar{x})^{2}}{2 \sigma^{2}}}
$$

Donde $\mathrm{f}(\mathrm{x})$ es la función de densidad, $\mathrm{x}$ es la media, $\sigma$ es la desviación típica y $\sigma^{2}$ la varianza. La ecuación anterior recibe el nombre de función de distribución normal de Gauss. Una variable que cumpla la ecuación se llama variable normal o normalizada

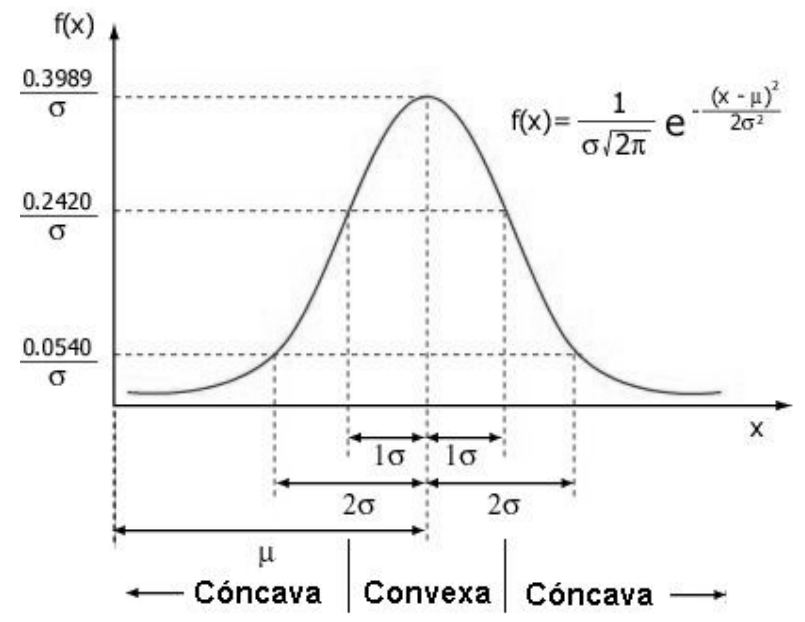

Figura 7.2.- Curva normal de Gauss. 


\section{Asimetría}

El grado de asimetría o sesgo es una magnitud que da idea de la desviación de las frecuencias respecto a una media. Es decir, se trata de valorar cual es la asimetría de la curva de distribución, con respecto a la recta paralela a la ordenada, que pasa por el valor medio.

Asimetría $=\frac{\sum_{i=1}^{n}\left(x_{i}-\bar{x}\right)^{3} / n}{s_{x}^{3}}$

Cuando el valor de la asimetría es positivo, se tiene una desviación o sesgo de la curva hacia la derecha, hay más valores de la variable superiores a la media, y se denomina asimetría positiva. En el caso de que haya mayor número de valores inferiores a la media, la curva sufre una desviación hacia la izquierda, es decir, se produciría un sesgo negativo.

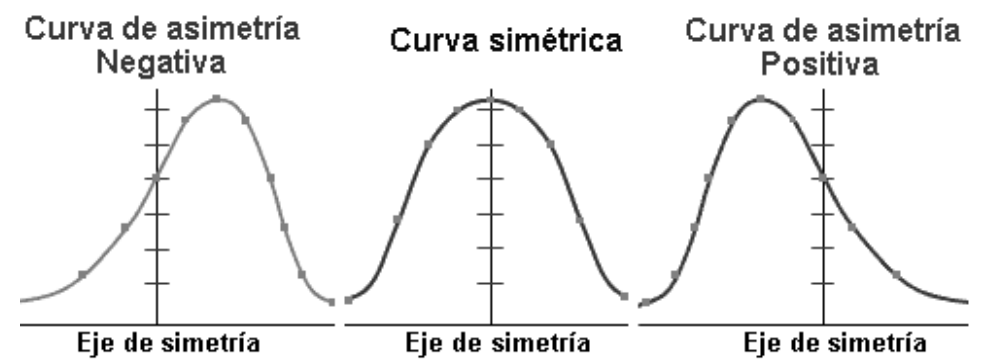

Figura 7.3.- silueta de curvas según su simetría

\section{Curtosis}

La curtosis indica la variación de la pendiente de una curva o polígono de frecuencias. Se calcula elevando a la cuarta potencia las puntuaciones estándar y se dividiendo por el tamaño de la muestra. Su expresión matemática es:

$$
\text { Curtosis }=\frac{\sum_{i=1}^{n}\left(x_{i}-x\right)^{-4} / n}{s_{x}^{4}}
$$

El coeficiente de curtosis sirve para comparar una curva con la distribución normal que es mesocúrtica (inclinación intermedia) que corresponde a la curva normal y toma un valor igual 3. Si la pendiente de la curva tiene un grado de curvatura inferior al 
normal (es poco inclinada), la curtosis es menor que 3 se hace más aplanada según sea menor este valor y se denomina platocúrtica. Si por el contrario la curtosis es mayor que 3, la curva es más empinada y se denomina leptocúrtica.
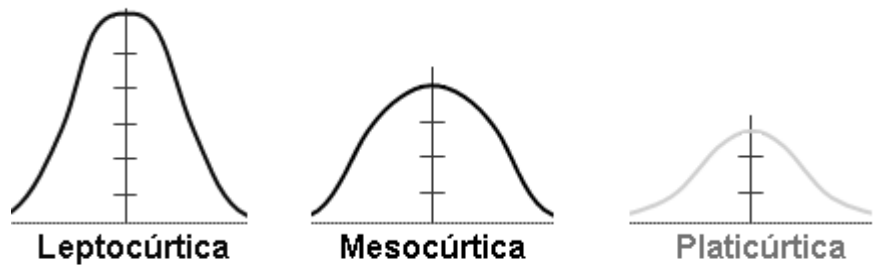

Figura 7.4.- silueta de curvas según su curtosis, $>3,=3,<3$.

\section{Coeficiente de contingencia basado en $\chi^{2}$}

Cuando se trabaja con datos ordenados en tablas de contingencia, las opciones estadísticas más utilizadas son Chi-cuadrado y Coeficiente de contingencia:

Chi-cuadrado mide, de forma global, la dependencia o independencia de las variables entre sí (igual a cero indica que las variables son independientes), pudiendo alcanzar unos u otros valores dependiendo de los grados de libertad empelados y siendo su expresión matemática:

$$
\chi^{2}=\sum_{i, j} \frac{\left(n_{i j}-e_{i j}\right)^{2}}{e_{i j}}
$$

El coeficiente de contingencia es un parámetro que toma un valor entre $0 \mathrm{y} 1$, de modo que cuanto más cerca de 0 se encuentra indica mayor dependencia entre las dos variables.

Coeficiente de Contingencia: $C C=\sqrt{\frac{\chi^{2}}{\chi^{2}+n}}$

Siendo $\mathrm{n}$ el número de datos 


\section{V de Cramer}

Se trata de un parámetro estadístico basado en $\chi^{2}$ que permite obtener la relación existente entre variables nominales. Da valores entre 0 y 1 . El 0 corresponde a ausencia de asociación, y 1 a asociación perfecta. La expresión matemática de este valor es:

$$
V=\sqrt{\frac{\chi^{2}}{N \cdot m}}
$$

Donde, $\mathrm{N}$ es el número total de observaciones del cuadro, $\mathrm{m}$ puede ser definido como "mínimo (f-1; c-1)". Se refiere a tomar un solo valor: el que sea menor entre el número de las filas menos 1 o el número de las columnas menos 1.

\section{G de Goodman}

La Gamma de Goodman es una medida simétrica que oscila entre -1 y +1 , e indica la relación entre el número de predicciones correctas menos el de incorrectas, divido por el número total de predicciones. Por ejemplo, un valor de gamma de $+0,30$ significa que existen un $30 \%$ más de pares de valores que concuerdan que de pares discordantes. Para un coeficiente comprendido entre 0,2 y 0,4 se trata de un grado de asociación moderado, y si es superior a 0,4 indica un grado de asociación entre variables alto (Díaz de Rada, 1999). 


\section{ANEXO XIII}

CUESTIONARIO SOBRE LAS LEYES DE LA QUÍMICA (Test 1) 
1.- Señala cuál de las expresiones que siguen se corresponde con la ley de las proporciones múltiples:

a) Cuando dos o más elementos se combinan entre sí para formar un compuesto lo hacen en una relación de masas constante.

b) Las cantidades de un elemento que se combinan con una cantidad fija de otro elemento, para formar compuestos diferentes, mantienen una relación de números enteros y sencillos.

c) En una reacción química, la masa se conserva.

d) Cuando un elemento se combina con otros, hay una relación de números enteros entre las masas de estos últimos.

2.- Apoyándonos en la hipótesis de Avogadro, ¿cuál de las afirmaciones que se proponen es verdadera?

a) Las moléculas de los gases son todas diatómicas.

b) Medidos en las mismas condiciones de presión y de temperatura, un litro de hidrógeno contiene el mismo número de moléculas que uno de vapor de agua.

c) Medidos en las mismas condiciones de presión y de temperatura, un litro de hidrógeno contiene el mismo número de átomos que uno de vapor de agua.

d) Dos moles de cualquier sustancia, en estado gaseoso, ocupan siempre 44,8 litros.

\section{3.- ¿Cuál de las siguientes afirmaciones es falsa?:}

a) Un mol de cualquier sustancia contiene siempre el mismo número de moléculas.

b) Un mol de gas ocupa 22,4 litros, sin que ello dependa de la naturaleza del gas.

c) 4 gramos de hidrógeno gaseoso ocupan, en condiciones normales, 44,8 litros.

d) 32 gramos de oxígeno equivalen a $6,022 \cdot 10^{23}$ moléculas de oxígeno.

4.- Un gas ocupa $1.5 \mathrm{~L}$ a $25{ }^{\circ} \mathrm{C}$ y 2.0 atm. Si el gas se transfiere a un recipiente de 3.0 L a la misma temperatura, ¿cuál será su nueva presión?
(A) $1.0 \mathrm{~atm}$
(B) $2.0 \mathrm{~atm}$
(C) $3.0 \mathrm{~atm}$
(D) $4.0 \mathrm{~atm}$ 
5.- De todos los enunciados de la hipótesis de Avogadro que se hacen, ¿cuál es cierto?

a) Volúmenes iguales de gases diferentes contienen siempre el mismo número de moléculas.

b) En las mismas condiciones de presión y de temperatura, volúmenes iguales de gases diferentes contienen el mismo número de átomos.

c) El volumen de un gas depende del número de moléculas que contiene, que no tiene que ser siempre el mismo.

d) Volúmenes iguales de gases diferentes contienen el mismo número de moléculas, siempre que estén medidos en las mismas condiciones de presión y de temperatura.

6.- ¿Qué hipótesis de la teoría atómica de Dalton tubo que revisarse o descartarse como consecuencia del descubrimiento de la radioactividad?

a) Las partículas más pequeñas de la materia son los átomos de los elementos, que son indivisibles e indestructibles.

b) Todos los átomos de un elemento dado son iguales.

c) Los átomos de diferentes elementos difieren en una o más propiedades.

d) Los compuestos se forman por combinación de diferentes tipos de átomos.

7.- La densidad del tetracloruro de carbono es de $1.60 \mathrm{~g} \cdot \mathrm{mL}^{-1}$ ¿ ¿Cuántos moles hay en un litro de $\mathrm{CCl}_{4}$ puro? $\operatorname{Ar}(\mathrm{C})=12 ; \mathrm{Ar}(\mathrm{Cl})=35,5$
a) $10.4 \mathrm{~mol}$
c) $23.7 \mathrm{~mol}$
b) $11.3 \mathrm{~mol}$
d) $33.7 \mathrm{~mol}$

8.- ¿Qué valor se aproxima más a la masa molar $\left(\right.$ en $\left.\mathbf{g} \cdot \mathrm{mol}^{-1}\right)$ del sulfato de hierro (III) $\mathrm{Fe}_{2}\left(\mathrm{SO}_{4}\right)_{3}$ ? $\operatorname{Ar}(\mathrm{Fe})=55,8 ; \operatorname{Ar}(\mathrm{O})=16,0 ; \operatorname{Ar}(\mathrm{S})=32,1$
a) 104
b) 248
c) 336
d) 400

9.- Inflamos cuatro globos idénticos con la misma cantidad en masa con los gases indicados. ¿Cuál de los globos será el primero en explotar? $\operatorname{Ar}(\mathrm{Ne})=20 ; \operatorname{Ar}(N)=14$; $\operatorname{Ar}(\mathrm{O})=16 ; \operatorname{Ar}(\mathrm{H})=1 ; \operatorname{Ar}(\mathrm{C})=12$
a) $\mathrm{Ne}$
b) $\mathrm{N}_{2}$
c) $\mathrm{O}_{2}$
d) $\mathrm{CH}_{4}$

10.- En condiciones normales, una masa molar de cualquier gas ocupa aproximadamente 22.4 L. Por lo tanto:

a) La masa molecular de cualquier gas es siempre la misma.

b) Todas las moléculas de todos los gases tienen la misma velocidad en condiciones estándar .

c) Todos los gases son diátomicos.

d) Existe el mismo número de moléculas en una masa molar de cualquier gas. 


\section{1.- Un mol de oxígeno gasesoso:}

a) Tiene una masa de $16 \mathrm{~g}$.

b) Contiene dos átomos.

c) Contiene aproximadamente $6,022 \cdot 10^{23}$ átomos.

d) Ocupa el mismo volumen que un mol de $\mathrm{Cl}_{2}$ en condiciones normales.

12.- Bajo las mismas condiciones de temperatura y presión, compara la densidad del monóxido de carbono $\mathrm{CO}$ y la del hidrógeno. $\operatorname{Ar}(\mathrm{C})=12 ; \operatorname{Ar}(\mathrm{H})=1 ; \operatorname{Ar}(\mathrm{O})=16$
a) 7 veces más grande.
b) 14 veces más grande.
c) 28 veces más grande.
d) no lo podemos determinar.

13.- ¿Qué volumen ocuparán $30 \mathrm{~g}$ de oxígeno medidos a 2 atm de presión y una temperatura de $20^{\circ} \mathrm{C}$ ?
a) $12,03 \mathrm{~L}$
b) $22,4 \mathrm{~L}$
c) $0,082 \mathrm{~L}$
d) $11,26 \mathrm{~L}$

14.- Un litro de un gas tiene una masa de $4 \mathrm{~g}$ en condiciones normales. De éste hecho se deduce que: $\operatorname{Ar}(\mathrm{He})=4$
a) el gas es helio.
b) la masa molar del gas es $4 \mathrm{~g} \cdot \mathrm{mol}^{-1}$.
c) la masa molar del gas es $89.6 \mathrm{~g} \cdot \mathrm{mol}^{-1}$.
d) $6,022 \cdot 10^{23}$ moléculas del gas tiene una masa de $4 \mathrm{~g}$.

15.- Bajo las mismas condiciones de temperatura y presión, un litro de hidrógeno comparado con un litro de oxígeno contiene:
a) Más moléculas que el litro de oxígeno.
b) Menos moléculas que el litro de oxígeno.
c) El mismo número de moléculas que el litro de oxígeno.
d) La misma masa total del gas que el litro de oxígeno. 
16.- Las sustancias puras:

a) se corresponden con los elementos de la tabla periódica.

b) No se pueden descomponer mediante procesos físicos ni químicos.

c) Son mezclas perfectamente homogéneas.

d) Pueden estar formadas por moléculas Todas iguales entre si

17.- el cobre reacciona con el azufre en una proporción de 1,98:1. ¿qué cantidad de azufre reaccionara con 8,5 gramos de cobre
a) $8,5 \mathrm{~g}$
b) $4,29 \mathrm{~g}$
c) $0,23 \mathrm{~g}$
d) $16,83 \mathrm{~g}$

18.- Cual es el porcentaje de nitrógeno en una muestra de nitrato de calcio $\mathrm{Ca}\left(\mathrm{NO}_{3}\right)_{2}$ ? $\operatorname{Ar}(\mathrm{Ca})=40,08 ; \operatorname{Ar}(N)=14,01 ; \operatorname{Ar}(O)=16,00$
a) 17,08
b) 57,18
c) 40,08
d) 11,11

19.- La composición centesimal de una sustancia orgánica es de, 39,998\% en C, $6,718 \%$ en hidrógeno y 53,284\% en oxígeno. Su fórmula empírica es:
a) $\mathrm{C}_{4} \mathrm{H}_{6} \mathrm{O}_{5}$
b) $\mathrm{CHO}_{2}$
c) $\mathrm{CH}_{2} \mathrm{O}$
d) $\mathrm{C}_{2} \mathrm{H}_{2} \mathrm{O}_{4}$

20.- Un mol de dióxido de azufre, $\mathrm{SO}_{2}$, y un mol de monóxido de carbono, $\mathrm{CO}$, siempre tienen igual: $\operatorname{Ar}(S)=32 ; \operatorname{Ar}(O)=16 ; \operatorname{Ar}(C)=12$
a) Masa.
c) Número de átomos.
b) Presión.
d) Número de moléculas. 
ANEXO XIV

CORRECCIÓN Test 1 


\section{Respuestas correctas}

\begin{tabular}{|c|c|}
\hline $\mathbf{1} \rightarrow \mathbf{B}$ & $11 \rightarrow D$ \\
\hline $\mathbf{2} \rightarrow \mathbf{B}$ & $12 \rightarrow B$ \\
\hline $\mathbf{3} \rightarrow \mathbf{B}$ & $13 \rightarrow D$ \\
\hline $4 \rightarrow A$ & $14 \rightarrow C$ \\
\hline $5 \rightarrow D$ & $15 \rightarrow C$ \\
\hline $6 \rightarrow A$ & $16 \rightarrow D$ \\
\hline $7 \rightarrow A$ & $\mathbf{1 7} \rightarrow \mathbf{B}$ \\
\hline $8 \rightarrow D$ & $18 \rightarrow A$ \\
\hline $9 \rightarrow D$ & $19 \rightarrow C$ \\
\hline $\mathbf{1 0} \rightarrow \mathrm{D}$ & $20 \rightarrow D$ \\
\hline
\end{tabular}




\section{ANEXO XV}

CUESTIONARIO SOBRE ESTRUTURA ATÓMICA Y SISTEMA PERIÓDICO (Test 2) 


$1^{\text {o }}$ bachillerato control estructura atómica y sistema
periódico 23/03/09

\section{I.E.S. "LA MARXADELLA"
Departament de Física i Química}

1.- Cuándo las partículas alfa se lanzan sobre una lamina de oro la mayoría de las partículas no sufren desviación. Esto le sirvió a Rutherford para explicar que:
(A) la lámina de oro era materia continua.
(B) la masa de oro estaba dispuesta en una capa delgada.
(C) los átomos de oro estaban constituidos mayoritariamente por espacios vacíos, y una masa y carga central concentradas.
(D) las partículas alfa tenían un gran poder de penetración.

\section{2.- ¿Qué afirmación acerca de la estructura del átomo es correcta?}

(A) Los protones y neutrones poseen la mayor parte de la masa y ocupan la mayoría del volumen en el átomo.

(B) Los electrones poseen la mayor parte de la masa y ocupan la mayoría del volumen en el átomo.

(C) Los electrones poseen la mayor parte de la masa pero ocupan un pequeño volumen del átomo.

(D) Los protones y neutrones poseen la mayor parte de la masa pero ocupan un pequeño volumen del átomo.

\section{3.- El isótopo estable del flúor es ${ }_{9}^{19} F$. La carga en el núcleo de ión fluoruro, $F^{-}$, es:}

(A) $1+$ (B) $7+$ (C) $9+$ (D) $1-$

\section{4.- Un átomo de estroncio $\left({ }_{38}^{90} \mathrm{Sr}\right)$ contiene:}
(A) 38 electrones, 38 protones, 52 neutrones.
(B) 38 electrones, 38 protones, 90 neutrones.
(C) 52 electrones, 52 protones, 38 neutrones.
(D) 52 electrones, 38 protones, 38 neutrones. 


\section{5.- ¿Qué tienen éstas especies en común?}

$$
{ }_{10}^{20} \mathrm{Ne} \quad{ }_{9}^{19} \mathrm{~F}^{-} \quad{ }_{12}^{24} \mathrm{Mg}^{2+}
$$
(A) el mismo número de protones.
(B) el mismo número de neutrones.
(C) el mismo número de electrones.
(D) el mismo tamaño.

6.- ¿Cuál es la diferencia entre un átomo de magnesio y un ión magnesio $\left(\mathrm{Mg}^{2+}\right)$ ?

(A) El ión magnesio, $\mathrm{Mg}^{2+}$ tiene una distribución electrónica más estable que el átomo $\mathrm{Mg}$, por haber perdido dos electrones.

(B) La carga positiva en el núcleo del ion es dos unidades mayor que la carga nuclear en el átomo.

(C) El ión tiene dos protones más que el átomo neutro.

(D) El ión tienen dos electrones exteriores más que el átomo.

7.- ¿Qué cambio energético se produce cuando un electrón se mueve desde un nivel de energía en un átomo a otro nivel más externo del núcleo del mismo átomo?
(A) Se absorbe energía.
(B) Se libera energía.
(C) No hay cambio de energía.
(D) Se emite luz de una longitud de onda definida.

8.- El espectro de emisión (espectro de línea) se produce cuando un electrón de un átomo:
(A) va dando vueltas en espiral en torno al núcleo.
(B) cambia su nivel de energía atómica.
(C) invirtie su dirección de spin.
(D) escapa del átomo

9.- ¿Qué configuración electrónica es imposible?
(A) $1 s^{2} 2 s^{2} 2 p^{6} 3 s^{2}$
(C) $1 s^{2} 2 s^{2} 2 p^{6} 3 s^{2} 3 p^{6}$
(B) $1 s^{2} 2 s^{2} 2 p^{6} 2 d^{2}$
(D) $1 s^{2} 2 s^{2} 2 p^{5} 3 s^{1}$ 
10.- La configuración electrónica en estado fundamental del átomo de manganeso $\left({ }_{25}^{55} \mathrm{Mn}\right)$ es:
(A) $1 s^{2} 2 s^{2} 2 p^{6} 3 s^{2} 3 p^{6} 4 s^{2} 4 d^{5}$
(B) $1 s^{2} 2 s^{2} 2 p^{6} 3 s^{2} 3 p^{6} 3 d^{7}$
(C) $1 s^{2} 2 s^{2} 2 p^{6} 3 s^{2} 3 p^{6} 4 s^{2} 4 p^{5}$
(D) $1 s^{2} 2 s^{2} 2 p^{6} 3 s^{2} 3 p^{6} 3 d^{5} 4 s^{2}$

11.- ¿Qué conjunto de números cuánticos son posibles para un electrón en un átomo?
(A) $n=3, l=0, m_{l}=1, m_{S}=-1 / 2$
(B) $n=2, l=2, m_{l}=-2, m_{S}=-1 / 2$
(C) $n=5, l=2, m l=2, m_{S}=+1 / 2$
(D) $n=4, l=3, m_{l}=-4, m_{S}=-1 / 2$

12.- ¿Cuál de estos iones isoelectrónicos es el más pequeño en tamaño?
(A) $\mathrm{Al}^{3+}$
(B) $\mathrm{Na}^{+}$
(C) $\mathrm{F}^{-}$
(D) $\mathrm{O}^{2-}$

13.- ¿En cuál de los pares la primera partícula es más grande que la segunda?
(A) $\mathrm{Li}^{+} ; \mathrm{Be}^{2+}$
(C) $\mathrm{Li}^{+} ; \mathrm{Na}^{+}$
(B) $\mathrm{Li}^{+} ; \mathrm{Li}$
(D) $\mathrm{Be} ; \mathrm{Mg}$

14.- ¿Qué ocurre cuando un átomo de bromo se convierte en ión bromuro?
(A) Se forma un ion positivo.
(B) El núcleo adquiere una carga negativa.
(C) Se convierte en un ión de mayor diámetro que el átomo.
(D) Su número atómico disminuye en una unidad.

15.- De acuerdo con su situación en el SP ¿Qué elemento es más electronegativo?
(A) $\mathrm{P}$
(B) As
(C) $\mathrm{Si}$
(D) $\mathrm{Al}$ 
16.- El orden creciente correcto para el valor de la energía necesaria para arrncar el primer electrón a los elementos $\mathrm{Li}$, $\mathrm{Ne}, \mathrm{Na}, \mathrm{y} \mathrm{Ar}$, es:
(A) $\mathrm{Na}<\mathrm{Li}<\mathrm{Ar}<\mathrm{Ne}$
(C) $\mathrm{Na}<\mathrm{Li}<\mathrm{Ne}<\mathrm{Ar}$
(B) $\mathrm{Li}<\mathrm{Na}<\mathrm{Ar}<\mathrm{Ne}$
(D) $\mathrm{Ar}<\mathrm{Ne}<\mathrm{Na}<\mathrm{Li}$

17.- El elemento X tiene estas energías de ionización:

\begin{tabular}{|lr|}
\hline \multicolumn{2}{|l|}{ Energía de Ionización } \\
\hline Primera & $419 \mathrm{~kJ} / \mathrm{mol}$ \\
Segunda & $3051 \mathrm{~kJ} / \mathrm{mol}$ \\
Tercera & $4411 \mathrm{~kJ} / \mathrm{mol}$ \\
\hline
\end{tabular}

El elemento $\mathbf{X}$ probablemente es:
(A) $\mathrm{Ca}$
(B) $\mathrm{Si}$
(C) $\mathrm{Br}$
(D) $\mathrm{K}$

18.- ¿Qué par de elementos tienen sus propiedades químicas más parecidas?
(A) $\mathrm{Ca}$ y $\mathrm{Ba}$
(C) $\mathrm{Ag}$ y $\mathrm{Rb}$
(B) $\mathrm{S}$ y $\mathrm{P}$
(D) Cs y Ba

19.- A partir del estudio de los modelos atómicos propuestos actualmente conocemos que:

(A) los electrones giran en orbitas alrededor del núcleo.

(B) los electrones pueden girar en varias orbitas alrededor del núcleo. El transito entre ellas supone un aumento o disminución de la energía de los electrones implicados.

(C) los electrones ocupan espacios donde la posibilidad de encontrarlos es máxima.

(D) los electrones se encuentran siempre en un determinado orbital. Su ubicación responde al orden de llenado respetando un orden de mínima energía.

20.- La afirmación de que los distintos electrones que posee un átomo se encuentran en distintas situaciones energéticas se puede explicar:

(A) por la continuidad de las sucesivas energías de ionización.

(B) por las bruscas diferencias que se producen en la energía necesaria para extraerlos.

(C) por la proporcionalidad regular a medida que se van perdiendo electrones.

(D) una disminución constante de la energía necesaria para extraerlos, según se van perdiendo más electrones. 
21.- Indica cuantos electrones tienen en su última capa los siguientes átomos e indica cual de ellos tendrá tendencia a ganar o ceder electrones y en que cantidad:

$\mathrm{Na}$

$\mathrm{Ca}$

$\mathrm{F}$

$\mathrm{Ne}$

$\mathrm{O}$

22.- Responde a las cuestiones utilizando los datos proporcionados por la tabla.
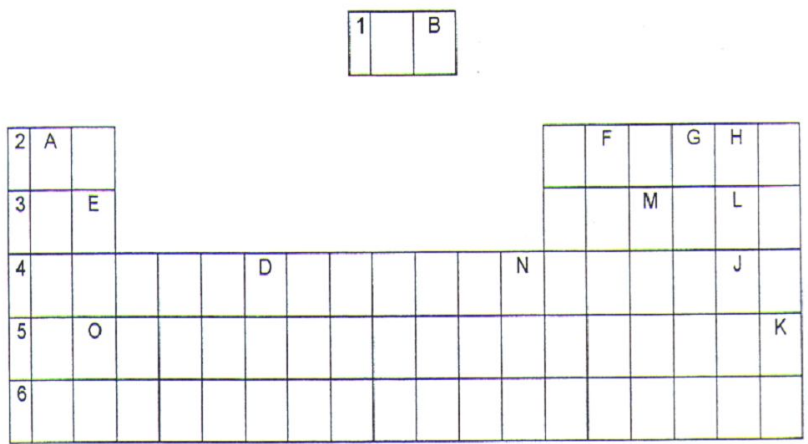

a) Indica en la tabla el símbolo de los elementos que conozcas.

b) ¿Cuál de estos son halógenos?

c) ¿Cuál de estos son metales alcalinos?

d) ¿Cuál de estos son gases nobles?

e) ¿Qué 3 elementos tienen la menor AE?

f) ¿Cuál tiene mayor radio atómico?

23.- Indicar, dadas las siguientes configuraciones electrónicas de átomos neutros:
A: $1 s^{2} 2 s^{2} 2 p^{3}$
B: $1 s^{2} 2 s^{2} 2 p^{5}$
C: $1 s^{2} 2 s^{2} 2 p^{6}$
D: $1 \mathrm{~s}^{2} 2 \mathrm{~s}^{2} 2 \mathrm{p} 63 \mathrm{~s}^{1}$
E: $1 s^{2} 2 s^{2} 2 p^{6} 3 s^{2}$

a) El elemento de mayor afinidad electrónica.

b) Si la afinidad electrónica de B es mayor o menor que la de C.

c) El elemento con mayor carácter metálico.

d) El elemento con menor energía de ionización.

24.- Escribir las configuraciones electrónicas en su estado fundamental del Fe,F $e^{2+} y$ $\mathrm{Fe}^{3+} . \mathrm{Z}(\mathrm{Fe})=26$

25.- ¿Cuál de las siguientes configuraciones electrónicas de átomos en estado fundamental es correcta?

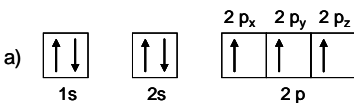

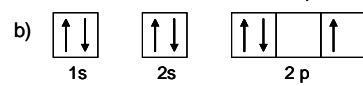

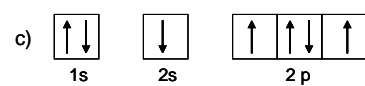

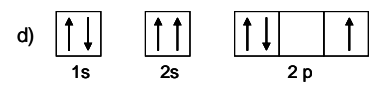


ANEXO XVI

CORRECCIÓN Test 2 


\section{Respuestas correctas}

\begin{tabular}{|c|c|}
\hline $1 \rightarrow C$ & $11 \rightarrow C$ \\
\hline $2 \rightarrow D$ & $12 \rightarrow A$ \\
\hline $3 \rightarrow C$ & $\mathbf{1 3} \rightarrow \mathbf{A}$ \\
\hline $4 \rightarrow A$ & $14 \rightarrow C$ \\
\hline $5 \rightarrow C$ & $15 \rightarrow A$ \\
\hline $6 \rightarrow A$ & $16 \rightarrow A$ \\
\hline $7 \rightarrow \mathrm{A}$ & $17 \rightarrow D$ \\
\hline $8 \rightarrow B$ & $18 \rightarrow A$ \\
\hline $\mathbf{9} \rightarrow \mathbf{B}$ & $19 \rightarrow C$ \\
\hline $10 \rightarrow D$ & $20 \rightarrow B$ \\
\hline
\end{tabular}

\begin{tabular}{|c|c|c|c|}
\hline \multicolumn{4}{|c|}{ Codificación de los resultados de los ítems 21-25 } \\
\hline \multirow{5}{*}{ Ítem 21} & A & Error en el número de e- & \\
\hline & B & $\begin{array}{l}\text { Error al indicar si se ganan o } \\
\text { pierden e- }\end{array}$ & \\
\hline & $\mathrm{C}$ & Todo mal & \\
\hline & $\mathrm{D}$ & Respuesta correcta & \\
\hline & $\mathrm{E}$ & En blanco & \\
\hline \multirow{5}{*}{ Ítem 22} & A & Respuesta correcta & \\
\hline & $\mathrm{B}$ & Todo mal & \\
\hline & $\mathrm{C}$ & $\begin{array}{l}\text { Error en la posición de los } \\
\text { elementos. }\end{array}$ & \\
\hline & $\mathrm{D}$ & $\begin{array}{l}\text { Error en las propiedades } \\
\text { periódicas }\end{array}$ & \\
\hline & $\mathrm{E}$ & En blanco & \\
\hline Ítem 23 & B & & \\
\hline \multirow{5}{*}{ Ítem 24} & A & Añade e- en lugar de quitarlos & \\
\hline & B & $\begin{array}{l}\text { Deja las tres configuraciones } \\
\text { iguales }\end{array}$ & \\
\hline & $\mathrm{C}$ & Respuesta correcta & \\
\hline & $\mathrm{D}$ & Todo mal & \\
\hline & $\mathrm{E}$ & En blanco & \\
\hline Ítem 25 & A & & \\
\hline
\end{tabular}




\section{ANEXO XVII}

CUESTIONARIO SOBRE ENLACE QUÍMICO (Test 3) 


\begin{tabular}{|lc|}
\hline $\begin{array}{l}1^{\circ} \text { bachillerato } \\
\text { químico }\end{array} 8 / 04 / 09$ & control Enlace \\
\hline
\end{tabular}

\section{I.E.S. "LA MARXADELLA"
Departament de Física i Química}

\section{1.-¿Cuál es la mejor y más completa descripción de un enlace covalente?}

(A) Un sistema de dos núcleos con un par de electrones localizados situados exactamente en la mitad entre ambos núcleos.

(B) La fuerza de atracción entre dos átomos de carga opuesta.

(C) Un enlace dativo en el cual un átomo cede un par de electrones no compartidos al otro.

(D) Un sistema formado por dos núcleos donde cada átomo cede un electrón al otro átomo, formándose así el enlace

\section{2.-¿Qué característica es casi siempre cierta en los óxidos no-metálicos?}

(A) Son generalmente compuestos iónicos.

(B) Son generalmente compuestos covalentes.

(C) Reaccionan con el agua para dar bases.

(D) No se pueden formar directamente a partir de los elementos.

3.-El enlace de hidrógeno se presenta en aquellas moléculas que poseen hidrógenos enlazados con:
(A) átomos muy electronegativos.
(B) átomos muy electropositivos.
(C) cualquier átomo.
(D) sólo con el oxígeno.

4.-La mejor explicación teórica que se puede aportar para justificar el hecho de que la formula del sulfuro de hidrógeno gaseoso es $\mathrm{H}_{2} \mathrm{~S}$ consiste en que:

(A) En condiciones normales, la masa de $22.4 \mathrm{~L}$ de gas sulfuro de hidrógeno es $34 \mathrm{~g}$, de los cuales $32 \mathrm{~g}$ son azufre.

(B) Los átomos de azufre e hidrógeno se combinan en una relación de dos a uno.

(C) El gas hidrógeno libre está formado por moléculas de $\mathrm{H}_{2}$, pero el azufre es sólido.

(D) El átomo de azufre tiene seis electrones en su capa más externa, y obtiene los dos electrones necesarios para una estructura estable al combinarse con dos átomos de hidrógeno. 
5.-¿Qué molécula contiene un par de electrones de valencia solitarios?
(A) $\mathrm{H}_{2} \mathrm{O}$
(B) $\mathrm{NH}_{3}$
(C) $\mathrm{CH}_{4}$
(D) $\mathrm{NaCl}$

6.-La estructura de Lewis más aproximada para el HOCl es:
(A) $H: \ddot{O}: \ddot{C l}:$
(C) $\mathrm{H}: \mathrm{O}:$ : C̈l:
(B) $\mathrm{H}: \ddot{\mathrm{Cl}}: \ddot{\mathrm{O}}$ :
(D) $\mathrm{H}:: \mathrm{O}:$ : C̈l:

7.- ¿En cuál de estos compuestos el enlace que predomina es el enlace covalente?
(A) LiI
(B) $\mathrm{CaCl}_{2}$
(C) $\mathrm{NaH}$
(D) $\mathrm{CH}_{4}$

8.-Una sustancia pura funde a $113^{\circ} \mathrm{C}$ y no conduce la electricidad ni en estado sólido ni líquido. El enlace en esta sustancia es principalmente:
(A) iónico.
(C) metálico.
(B) red cristalina.
(D) covalente (molecular).

9.-¿Qué molécula es principalmente apolar?
(A) $\mathrm{CH}_{4}$
(B) $\mathrm{HCl}$
(C) $\mathrm{H}_{2} \mathrm{O}$
(D) $\mathrm{NH}_{3}$

10.-Entre éstos metales, las fuerzas interatómicas son probablemente más débiles en:
(A) $\mathrm{Li}$
(B) $\mathrm{Cs}$
(C) $\mathrm{Mg}$
(D) $\mathrm{Al}$

11.-La maleabilidad, conductividad, ductilidad y brillo de los metales se puede explicar por:
(A) la movilidad de los electrones.
(B) los electrones localizados.
(C) que los pares de electrones están compartidos por igual.
(D) pares de electrones compartidos pero desplazados hacia un átomo.

12.-¿Qué par de compuestos presentan predominantemente enlace iónico?
(A) $\mathrm{SO}_{2}$ y $\mathrm{HCl}$
(B) $\mathrm{KNO}_{3}$ y $\mathrm{CH}_{4}$
(C) $\mathrm{NaF}$ y $\mathrm{MgO}$
(D) $\mathrm{KCl}_{\text {y } \mathrm{CO}_{2}}$ 


\section{3.-Los elementos en un compuesto iónico se mantienen unidos por:}
(A) un par de electrones.
(B) fuerzas de van der Waals.
(C) el "spin" de electrones apareados.
(D) fuerzas electrostáticas de atracción.

14.-El fluoruro de potasio sólido está formado por iones de potasio y de flúor. ¿Cuál es el mejor hecho experimental que muestra ésta afirmación?

(A) El fluoruro de potasio fundido conduce la corriente eléctrica.

(B) Una disolución acuosa de fluoruro de potasio puede electrolizarse.

(C) El potasio y el flúor tienen la mejor estructura electrónica para formar iones que una vez formados son más estables que cada uno de los átomos.

(D) Cuando el sólido se calienta, la energía cinética es lo suficientemente grande para superar las fuerzas que mantienen los componentes unidos.

15.-Un sólido no presenta conductividad eléctrica a temperatura ambiente. Se calienta a $600^{\circ} \mathrm{C}$, se funde, y a partir de entonces tiene conductividad eléctrica. ¿Qué tipo de enlace presenta este sólido?
(A) enlace iónico
(C) enlace metálico
(B) enlace covalente
(D) fuerzas de Van der Waals

16.-En cristales moleculares como $\mathrm{Ne}$ y $\mathrm{N}_{2}$, ¿qué tipo de enlace existe entre las moléculas?
(A) iónico
(B) covalente
(C) metálico
(D) van der Waals

17.-¿Cuál de las estructuras representa mejor como se enlaza el hidrógeno en el metanol líquido $\left(\mathrm{CH}_{3} \mathrm{OH}\right)$ ?

(A)<smiles>COCCO</smiles>

(B)<smiles>OCCCO</smiles>

(C)<smiles>COCOC</smiles>

(D)<smiles>COCCO</smiles> 
18.-Basándote en la información que aparece en el gráfico, cuál de las interpretaciones es válida?

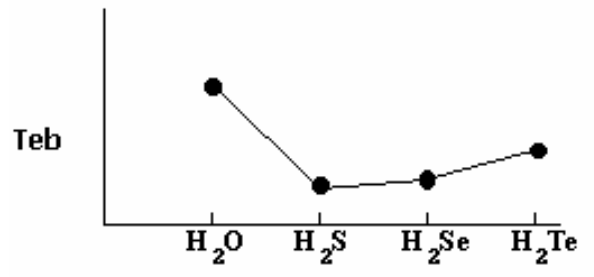

(A) La elevada temperatura de ebullición del agua se debe al enlace de hidrógeno.

(B) La baja temperatura de ebullición del $\mathrm{H}_{2} \mathrm{~S}$ se debe a las fuertes fuerzas de van der Waals.

(C) El aumento de la temperatura de ebullición desde el $\mathrm{H}_{2} \mathrm{~S}$ al $\mathrm{H}_{2} \mathrm{Te}$ se considera anormal.

(D) La disminución en la temperatura de ebullición desde el $\mathrm{H}_{2} \mathrm{Te}$ al $\mathrm{H}_{2} \mathrm{~S}$ se debe la disminución de la volatilidad.

19.-¿Cuál de los compuestos contiene al mismo tiempo enlaces covalentes e iónicos?
(A) $\mathrm{NH}_{4} \mathrm{NO}_{3}$
(C) $\mathrm{BaCl}_{2}$
(B) NF3
(D) $\mathrm{CH}_{2} \mathrm{O}$

20.- ¿cuál de estos compuestos se espera que tenga mayor temperatura de fusión?
(A) $\mathrm{LiCl}$
(B) $\mathrm{BeCl}_{2}$
(C) $\mathrm{CCl}_{4}$
(D) $\mathrm{NCl}_{3}$

21.- Escribe las estructuras de Lewis para los siguientes compuestos e indica su geometría:
a) $\mathrm{PH}_{3}$
b) $\mathrm{SO}_{2}$
c) $\mathrm{ClO}_{3}{ }^{-}$
d) $\mathrm{PBr}_{5}$

22.- Explica el hecho de que siendo el fósforo y silicio elementos próximos en la tabla periódica la molécula $\mathrm{PF}_{3}$ sea polar mientras que $\mathrm{SiF}_{4}$ no lo sea.

23.- Indica el tipo de enlace químico que predomina en cada una de las siguientes sustancias: 

a) bromuro de cesio
b) cloro
c) yoduro cálcico
d) dióxido de nitrógeno
e) sodio
f) agua
g) cloruro sódico
h) óxido de magnesio

24.- ¿Qué tipos de fuerzas mantienen unidas a los siguientes átomos o moléculas?

a)
$\mathrm{Br} \mathrm{Br}$
$\mathrm{Br} \mathrm{Br}$

b)

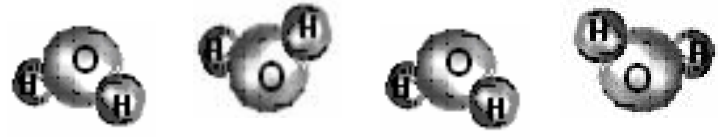

c)
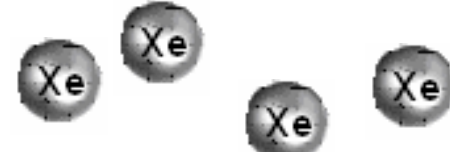

d)

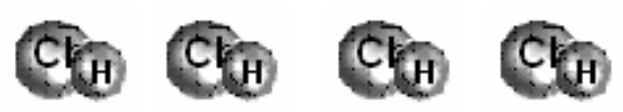

25.- Indica qué tipo de atracción o de enlace químico ha de romperse para:
a) fundir cloruro sódico,
b) sublimar naftalina (naftaleno, $\mathrm{C} 10 \mathrm{H} 8$ ),
c) disolver bromo en agua,
e) fundir oro,
f) vaporizar agua,
g) vaporizar C (diamante) 
ANEXO XVIII

CORRECCIÓN Test 3 


\section{Respuestas correctas}

\begin{tabular}{|l|l|}
\hline $\mathbf{1} \rightarrow \mathbf{D}$ & $11 \rightarrow \mathbf{A}$ \\
\hline $\mathbf{2} \rightarrow \mathbf{B}$ & $12 \rightarrow \mathbf{C}$ \\
\hline $\mathbf{3} \rightarrow \mathbf{A}$ & $13 \rightarrow \mathbf{D}$ \\
\hline $\mathbf{4} \rightarrow \mathbf{D}$ & $14 \rightarrow \mathbf{A}$ \\
\hline $\mathbf{5} \rightarrow \mathrm{B}$ & $15 \rightarrow \mathbf{A}$ \\
\hline $\mathbf{6} \rightarrow \mathbf{A}$ & $16 \rightarrow \mathbf{D}$ \\
\hline $\mathbf{7} \rightarrow \mathrm{D}$ & $17 \rightarrow \mathbf{C}$ \\
\hline $\mathbf{8} \rightarrow \mathbf{D}$ & $18 \rightarrow \mathbf{A}$ \\
\hline $\mathbf{9} \rightarrow \mathbf{A}$ & $19 \rightarrow \mathbf{A}$ \\
\hline $10 \rightarrow \mathrm{D}$ & $20 \rightarrow \mathbf{B}$ \\
\hline
\end{tabular}




\section{ANEXO XIX}

CUESTIONARIO SOBRE FORMULACIÓN (Test 4) 


\begin{tabular}{|lc|}
\hline $\begin{array}{l}1^{\circ} \text { bachillerato } \\
\text { Formulación }\end{array}$ & Control \\
\hline
\end{tabular}

1.- ¿Qué nombre es más correcto según la IUPAC para el compuesto, $\mathrm{Ni}_{2} \mathrm{O}_{3}$ ?
(A) óxido (III) de níquel
(B) óxido de níquel (III)
(C) óxido de níquel (II)
(D) anhídrido níquélico

2.- ¿Cuál es el nombre del compuesto $\mathrm{Fe}_{2}\left(\mathrm{SO}_{4}\right) 3$ ?
(A) sulfato de hidrógeno (II)
(B) sulfato de hierro (III)
(C) trisulfato de hierro (II)
(D) sulfato (III) de hierro (II)

3.- El nombre correcto según la IUPAC para el $\mathrm{N}_{2} \mathrm{O}_{3}$ es:
(A) óxido de nitrógeno
(B) óxido nitroso
(C) óxido de nitrógeno (II)
(D) trióxido de dinitrógeno

4.- ¿Cuál es el nombre del compuesto que tiene por fórmula $\mathrm{MgH}_{2}$ ?
(A) hidruro de magnesio (II)
(B) hidrato de magnesio
(C) hidruro de magnesio
(D) hidróxido de magnesio.

5.- Cual es la fórmula del ácido sulfhídrico:
(A) $\mathrm{H}_{2} \mathrm{SO}_{4}$
(B) $\mathrm{H}_{2} \mathrm{~S}$
(C) $\mathrm{H}_{2} \mathrm{SO}_{3}$
(D) $\mathrm{HSO}_{4}$

6.- ¿Qué fórmula es incorrecta?
(A) $\mathrm{Ba}_{2} \mathrm{CO}_{3}$
(B) $\mathrm{Al}_{2} \mathrm{O}_{3}$
(C) $\mathrm{K}_{2} \mathrm{SO}_{4}$
(D) $\mathrm{ZnCO}_{3}$

7.- ¿Cuál es la fórmula del sulfuro de estroncio?
(A) $\mathrm{SrS}$
(B) $\mathrm{Sr}_{2} \mathrm{~S}$
(C) $\mathrm{SrS}_{2}$
(D) $\mathrm{SrS}_{3}$ 
8.- ¿Cuál es la fórmula del óxido de cromo (III)?
(A) $\mathrm{CrO}$
(B) $\mathrm{Cr}_{2} \mathrm{O}$
(C) $\mathrm{Cr}_{3} \mathrm{O}$
(D) $\mathrm{Cr}_{2} \mathrm{O}_{3}$

9.- ¿Cuál es el nombre correcto para $\mathrm{Fe}(\mathrm{NO} 3) 2$ ?
(A) nitrato de hierro (II)
(B) nitrato de hierro (III)
(C) nitrito de hierro (II)
(D) nitrito de hierro(III)

10.- ¿Qué fórmula está nombrada correctamente?
(A) $\mathrm{FeCl}_{3}$, cloruro de hierro (III)
(B) FeS, sulfito de hierro(II)
(C) $\mathrm{KNO}_{2}$ nitrato de potasio
(D) $\mathrm{HClO}$, oxido hidroclórico

11.- ¿En qué caso la combinación fórmula-nombre es la correcta?
(A) $\mathrm{KNO}_{2}$ - nitrato de potasio
(B) $\mathrm{AlCl}_{3}$ - cloruro de aluminio
(C) $\mathrm{FeS}$ - sulfito de hierro (II)
(D) $\mathrm{Mg}_{3} \mathrm{~N}_{2}$ - nitrito de magnesio

12.- El compuesto no designado correctamente es:
(A) $\mathrm{Pb}_{3} \mathrm{O}_{4}$, tetraóxido de triplomo
(B) $\mathrm{CuCl}_{2}$, cloruro de cobre (II).
(C) $\mathrm{Pb}_{3}\left(\mathrm{SO}_{4}\right) 2$, sulfato de plomo(III)
(D) $\mathrm{P}_{2} \mathrm{~S} 5$, pentasulfuro de difósforo.

13.- ¿Cuál es la fórmula del óxido de cobre (II)?
(A) $\mathrm{CuO}$
(B) $\mathrm{CuO}_{2}$
(C) $\mathrm{Cu}_{2} \mathrm{O}$
(D) $\mathrm{Cu}_{2} \mathrm{O}_{2}$

14.- ¿Cuál es la fórmula del peróxido de sodio?
(A) $\mathrm{NaO}$
(B) $\mathrm{Na}_{2} \mathrm{O}$
(C) $\mathrm{NaO}_{2}$
(D) $\mathrm{Na}_{2} \mathrm{O}_{2}$

15.- Un compuesto con la fórmula $\mathrm{CaH}_{2}$ se denomina:
(A) hidruro de cadmio
(B) carburo de hidrógeno
(C) hidruro de calcio
(D) hidrato de calcio 
16.- La fórmula del nitrito de calcio es:
(A) $\mathrm{Ca}_{3} \mathrm{~N}_{2}$
(B) $\mathrm{Ca}(\mathrm{NO})_{2}$
(C) $\mathrm{Ca}\left(\mathrm{NO}_{2}\right)_{2}$
(D) $\mathrm{Ca}\left(\mathrm{NO}_{3}\right)_{2}$

17.- $\mathrm{El} \mathrm{NaBrO} \mathrm{N}_{3}$ es la fórmula correcta de:
(A) bromato de sodio
(B) oxobromato (V) de sodio
(C) bromito de sodio
(D) hipobromito de sodi

18.- ¿En qué par de aniones sus nombres acaban en -ato-?
(A) $\mathrm{Cl}^{-}, \mathrm{ClO}_{3}^{-}$
(B) $\mathrm{ClO}_{3}^{-}, \mathrm{NO}_{3}^{-}$
(C) $\mathrm{NO}_{2}^{-}, \mathrm{NO}_{3}^{-}$
(D) $\mathrm{SO}_{3}^{2-}, \mathrm{SO}_{4}{ }^{2-}$

19.- La fórmula del vanadato de sodio es $\mathrm{Na}_{3} \mathrm{VO}_{4}$ y la del cloruro de calcio es $\mathrm{CaCl}_{2}$. ¿Cuál es la fórmula del vanadato de calcio?
(A) $\mathrm{CaVO}_{4}$
(B) $\mathrm{Ca}\left(\mathrm{VO}_{4}\right)_{2}$
(C) $\mathrm{Ca}\left(\mathrm{VO}_{4}\right)_{3}$
(D) $\mathrm{Ca}_{3}\left(\mathrm{VO}_{4}\right)_{2}$

20.- ¿Qué par (nombre y fórmula) es el correcto con la nomenclatura sistemática y su formulación correcta?
(A) sulfato férrico, $\mathrm{Fe}_{3}\left(\mathrm{SO}_{4}\right)_{2}$
(B) fluoruro de manganeso (VI), $\mathrm{MnF}_{6}$
(C) hexaoxodisulfato (V) de potasio, $\mathrm{K}_{2} \mathrm{~S}_{2} \mathrm{O}_{6}$
(D) cloruro de cromo, $\mathrm{CrCl}_{4}$

\section{1.-Formula los siguientes compuestos:}

Óxido de azufre (IV)

Peróxido de bario

Ácido iodhídrico

Tetrahidruro de plomo

Sulfuro de magnesio

Óxido de plata

Ácido nitroso

Ácido hiponitroso

Tetraoxoiodato (VII) de potasio

Sulfato de cinc 
22.- Nombra los siguientes compuestos (en todas las nomenclaturas)

$\mathrm{P}_{2} \mathrm{O}_{5}$

$\mathrm{Fe}_{2} \mathrm{O}_{3}$

$\mathrm{LiH}$

$\mathrm{CH}_{4}$

$\mathrm{AuBr}$

$\mathrm{PCl}_{3}$

$\mathrm{HNO}_{3}$

$\mathrm{HIO}_{4}$

$\mathrm{KMnO}_{4}$

$\mathrm{NaClO}$ 


\section{ANEXO XX}

CORRECCIÓN Test 4 


\section{Respuestas correctas}

\begin{tabular}{|l|l|}
\hline $\mathbf{1} \rightarrow \mathbf{B}$ & $11 \rightarrow \mathbf{B}$ \\
\hline $\mathbf{2} \rightarrow \mathbf{B}$ & $12 \rightarrow \mathbf{C}$ \\
\hline $\mathbf{3} \rightarrow \mathbf{D}$ & $13 \rightarrow \mathbf{A}$ \\
\hline $\mathbf{4} \rightarrow \mathbf{C}$ & $14 \rightarrow \mathbf{D}$ \\
\hline $\mathbf{5} \rightarrow \mathbf{B}$ & $15 \rightarrow \mathbf{C}$ \\
\hline $\mathbf{6} \rightarrow \mathbf{A}$ & $16 \rightarrow \mathbf{C}$ \\
\hline $\mathbf{7 \rightarrow \mathbf { A }}$ & $17 \rightarrow \mathbf{A}$ \\
\hline $\mathbf{8} \rightarrow \mathbf{D}$ & $18 \rightarrow \mathbf{B}$ \\
\hline $\mathbf{9 \rightarrow \mathbf { A }}$ & $1 \mathbf{1} \rightarrow \mathbf{D}$ \\
\hline $\mathbf{1 0} \rightarrow \mathbf{A}$ & $\mathbf{2 0 \rightarrow \mathbf { B }}$ \\
\hline
\end{tabular}

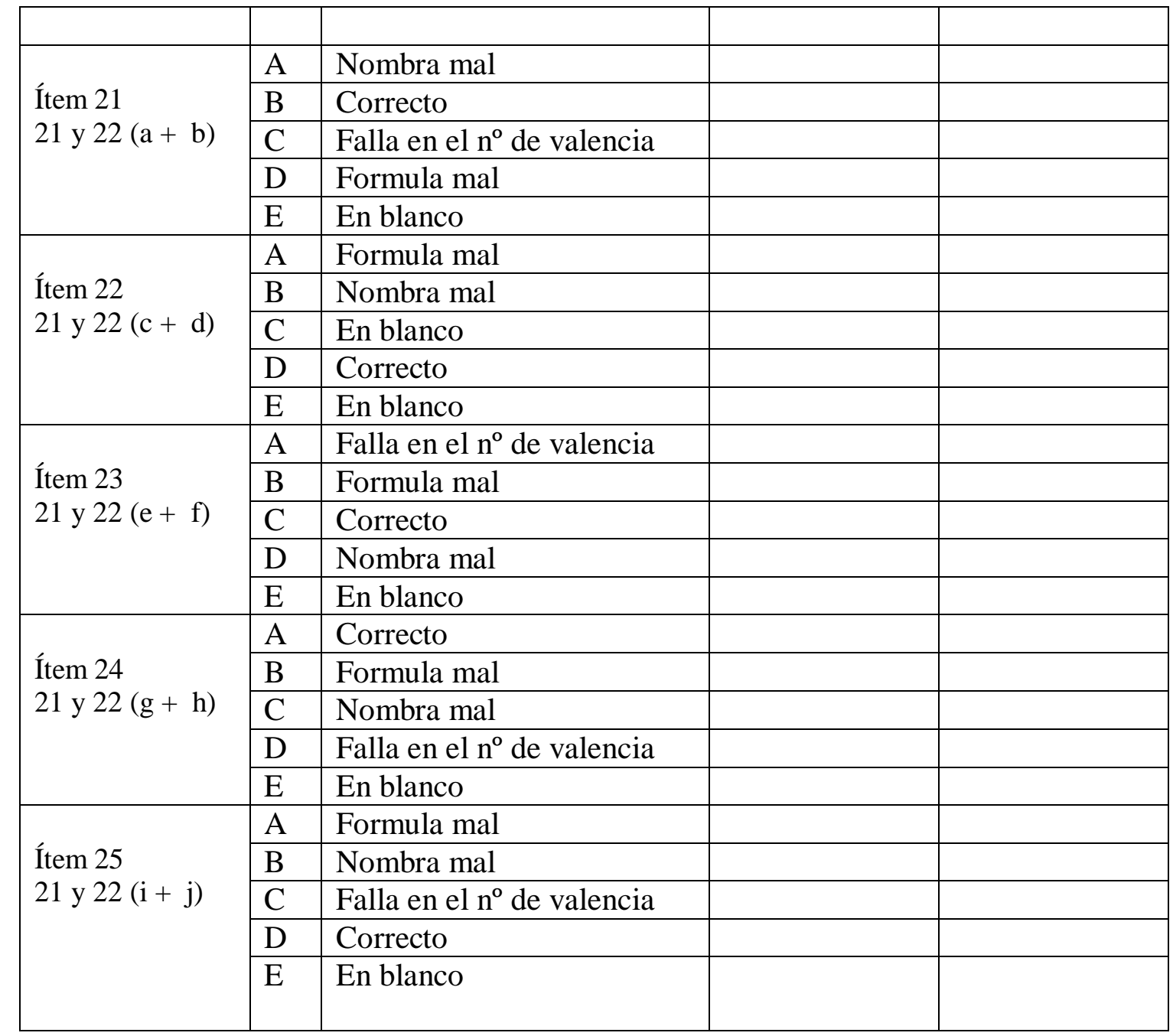




\section{ANEXO XXI}

CUESTIONARIO SOBRE ESTEQUIOMETRÍA (Test 5) 


\begin{tabular}{|c|c|c|}
\hline $1^{\circ}$ bachillerato & & Control \\
\hline Formulación & 20/05/09 & \\
\hline
\end{tabular}

1.- La fórmula para el metano es $\mathrm{CH}_{4}$. Ésto siginifica que en el metano,

\begin{tabular}{|cc|}
\hline \multicolumn{3}{|c|}{ Masas Atómicas Molares } \\
\hline $\mathrm{C}$ & $12.0 \mathrm{~g} \cdot \mathrm{mol}^{-1}$ \\
$\mathrm{H}$ & $1.0 \mathrm{~g} \cdot \mathrm{mol}^{-1}$ \\
\hline
\end{tabular}
(A) por cada 100 átomos de hidrógeno hay 400 átomos de carbono.
(B) el compuesto posee un $80 \%$ de hidrógeno en masa.
(C) por cada gramo de hidrógeno hay doce gramos de carbono.
(D) el compuesto posee un $25 \%$ de hidrógeno en masa.

2.- ¿Cuál es el porcentaje en masa del cloro en el clorato de magnesio, $\mathrm{Mg}\left(\mathrm{ClO}_{3}\right)_{2}$ ?

\begin{tabular}{|ll|}
\hline & \multicolumn{1}{c|}{ Masas Atómicas Molares } \\
\hline $\mathrm{Cl}$ & $35.5 \mathrm{~g} \cdot \mathrm{mol}^{-1}$ \\
$\mathrm{Mg}$ & $24.3 \mathrm{~g} \cdot \mathrm{mol}^{-1}$ \\
$\mathrm{O}$ & $16.0 \mathrm{~g} \cdot \mathrm{mol}^{-1}$ \\
\hline
\end{tabular}
(A) $5.10 \%$
(B) $32.0 \%$
(C) $36.1 \%$
(D) $37.1 \%$

3.- ¿Qué masa de $\mathrm{MgCl}_{2}$ se requiere para preparar $2.00 \mathrm{~L}$ de una disolución $0.55 \mathrm{M}$ ?

Masa Molar $\quad \mathrm{MgCl}_{2}=95.2 \mathrm{~g} \cdot \mathrm{mol}^{-1}$
(A) $1.10 \mathrm{~g}$
(B) $28.9 \mathrm{~g}$
(C) $86.5 \mathrm{~g}$
(D) $105 \mathrm{~g}$

4.- Si $11.2 \mathrm{~L}$ de $\mathrm{NO}_{2}(\mathrm{~g})$ en condiciones normales reaccionan con agua, ¿cuántos moles de $\mathrm{HNO}_{2}$ se formarán?

$$
2 \mathrm{NO}_{2}(g)+\mathrm{H}_{2} \mathrm{O}(l) \leftrightarrow \mathrm{HNO}_{2}(a q)+\mathrm{HNO}_{3}(a q)
$$
(A) 0.25 moles
(B) 0.50 moles
(C) 1.0 moles
(D) 1.5 moles 
5.- ¿Qué volumen de amoniaco gas, $\mathrm{NH}_{3}$, medido en condiciones normales, se producirá al descomponer 2 moles de carbonato de amonio?

$$
\left(\mathrm{NH}_{4}\right)_{2} \mathrm{CO}_{3}(s) \leftrightarrow 2 \mathrm{NH}_{3}(g)+\mathrm{CO}_{2}(g)+\mathrm{H}_{2} \mathrm{O}_{(g)}
$$
(A) $22.4 \mathrm{~L}$
(B) $33.6 \mathrm{~L}$
(C) $44.8 \mathrm{~L}$
(D) $89.6 \mathrm{~L}$

6.- El volumen de oxígeno puro necesario para quemar completamente $800 \mathrm{~mL} \mathrm{de}$ acetileno $\left(\mathrm{C}_{2} \mathrm{H}_{2}\right)$ gaseoso es:
(A) $800 \mathrm{~mL}$
(B) $1600 \mathrm{~mL}$
(C) $2000 \mathrm{~mL}$
(D) $10000 \mathrm{~mL}$

7.- Si la reacción entre el hidrógeno y el oxígeno es completa. ¿Cuál de las afirmaciones es correcta al quemar $10.0 \mathrm{~g}$ de hidrógeno con $64.0 \mathrm{~g}$ de oxígeno? $\operatorname{Ar}(\mathrm{H})=1, \operatorname{Ar}(\mathrm{O})=16$
(A) El reactivo limitante es el oxígeno.
(B) Se formarán $74 \mathrm{~g}$ de agua.
(C) 3 moles de hidrógeno quedarán después de la reacción.
(D)Se formarán $68 \mathrm{~g}$ de agua.

8.- La ecuación ajustada para la combustión de metano es:

$$
\mathrm{CH}_{4}+2 \mathrm{O}_{2} \leftrightarrow \mathrm{CO}_{2}+2 \mathrm{H}_{2} \mathrm{O}
$$

Cuando $32 \mathrm{~g}$ de metano se queman completamente:

$\mathrm{M}_{\mathrm{CH}_{4}}=16 \mathrm{~g} \cdot \mathrm{mol}^{-1 ;} \mathrm{M}_{\mathrm{H} 2 \mathrm{O}}=18 \mathrm{~g} \cdot \mathrm{mol}^{-1 ;} \mathrm{MO}_{\mathrm{O} 2}=32 . \mathrm{g} \cdot \mathrm{mol}^{-1 ;} \mathrm{M}_{\mathrm{CO}_{2}}=44 . \mathrm{g} \cdot \mathrm{mol}^{-1}$
(A) se producen $36 \mathrm{~g}$ de agua.
(B) se consumen 4 moles de oxígeno.
(C) se consume 11.2 L de metano (en condiciones normales).
(D)se forman 22.4 L de dióxido de carbono (en condiciones normales).

9.- Dada la ecuación:

$$
4 \mathrm{FeS}_{2}(\mathrm{~s})+11 \mathrm{O}_{2(g)} \leftrightarrow 2 \mathrm{Fe}_{2} \mathrm{O}_{3}(\mathrm{~s})+8 \mathrm{SO}_{2}(\mathrm{~g})
$$

¿Cuántos gramos de $\mathrm{FeS}_{2}$, deben utilizarse para producir $11.2 \mathrm{~L}$ de dióxido de azufre, $\mathrm{SO}_{2}$, en condiciones normales? $\operatorname{Ar}(\mathrm{Fe})=56 ; \operatorname{Ar}(\mathrm{O})=16 ; \operatorname{Ar}(\mathrm{S})=32$
(A) $30 \mathrm{~g}$
(B) $40 \mathrm{~g}$
(C) $60 \mathrm{~g}$
(D) $120 \mathrm{~g}$ 
10.- ¿Qué masa de $\mathrm{NH}_{3}$ queda sin reaccionar cuando mezclamos $73.0 \mathrm{~g}$ de $\mathrm{NH}_{3}$ y 73.0 g de $\mathrm{HCl}$ bajo la reacción siguiente:

$$
\mathrm{NH}_{3}(g)+\mathrm{HCl}_{(g)} \leftrightarrow \mathrm{NH}_{4} \mathrm{Cl}(s) ?
$$

$\mathrm{M}_{\mathrm{NH}_{3}}=17.0 \mathrm{~g} \cdot \mathrm{mol}^{-1} ; \mathrm{M}_{\mathrm{HCl}}=36.5 \mathrm{~g} \cdot \mathrm{mol}^{-1}$
(A) $0.00 \mathrm{~g}$
(B) $19.5 \mathrm{~g}$
(C) $39.0 \mathrm{~g}$
(D) $73.0 \mathrm{~g}$

11.- ¿Cuántos gramos de $\mathrm{MgSO}_{4}$ contienen $40 \mathrm{~mL}$ de una disolución de $\mathrm{MgSO}_{4}$ 0.1 M?

$\operatorname{Ar}(\mathrm{Mg})=23 ; \operatorname{Ar}(O)=16 ; \operatorname{Ar}(S)=32,1 ;$
(A) $120 \mathrm{~g}$
(B) $24 \mathrm{~g}$
(C) $0,96 \mathrm{~g}$
(D) $0,48 \mathrm{~g}$

12.- ¿Cuántos moles de $\mathrm{NH}_{3}$ se pueden formar al reaccionar 0,50 moles de $\mathrm{NCl}_{3}$ con $\mathbf{0 , 4 0}$ moles de $\mathrm{H}_{2}$ ?

$$
2 \mathrm{NCl}_{3}+3 \mathrm{H}_{2} \leftrightarrow 2 \mathrm{NH}_{3}+3 \mathrm{Cl}_{2}
$$
(A) 0,27 moles
(B) 0,50 moles
(C) 0,60 moles
(D) 0,90 moles

\section{Problemas}

1.- El ácido sulfúrico reacciona con cloruro de sodio, produciendo ácido clorhídrico y sulfato de sodio:

a) escribe y ajusta la ecuación química del proceso

b) calcula el volumen de disolución de ácido sulfúrico de densidad d=1,84 g/cm3 y $98 \%$ de riqueza que se necesita para obtener $20 \mathrm{~g}$ de ácido clorhídrico.

c) Si el ácido clorhídrico obtenido se disuelve en suficiente agua para obtener un litro de disolución, calcula la molaridad de esta.

2.- El clorato de potasio reacciona con el azufre produciendo cloruro de potasio y dióxido de azufre. Se hacen reaccionar 20 gramos de clorato de potasio con $10 \mathrm{~g}$ de azufre. Calcula:

a) La masa de cloruro de potasio que se forma.

b) El volumen de dióxido de azufre que se desprende medido a $22^{\circ} \mathrm{C}$ y $758 \mathrm{mmHg}$. 
ANEXO XXII

CORRECCIÓN Test 5 


\section{Respuestas correctas}

\begin{tabular}{|l|l|}
\hline $\mathbf{1} \rightarrow \mathbf{D}$ & $\mathbf{7 \rightarrow A}$ \\
\hline $\mathbf{2} \rightarrow \mathbf{D}$ & $\mathbf{8 \rightarrow B}$ \\
\hline $\mathbf{3} \rightarrow \mathbf{D}$ & $9 \rightarrow \mathbf{A}$ \\
\hline $\mathbf{4} \rightarrow \mathbf{A}$ & $10 \rightarrow \mathbf{C}$ \\
\hline $\mathbf{5} \rightarrow \mathbf{D}$ & $11 \rightarrow \mathbf{D}$ \\
\hline $\mathbf{6} \rightarrow \mathbf{C}$ & $12 \rightarrow \mathbf{A}$ \\
\hline
\end{tabular}

\begin{tabular}{|c|c|c|}
\hline \multirow{5}{*}{$\begin{array}{l}\text { Ítem } 13 \\
\text { ¿Formula } \\
\text { correctamente? }\end{array}$} & A & Sólo los compuestos binarios \\
\hline & $\mathrm{B}$ & Correctamente \\
\hline & $\mathrm{C}$ & Sólo las sales \\
\hline & $\mathrm{D}$ & No \\
\hline & $\mathrm{E}$ & En blanco \\
\hline \multirow{5}{*}{$\begin{array}{l}\text { Ítem 14 } \\
\text { ¿Ajusta } \\
\text { correctamente } \\
\text { las ecuaciones } \\
\text { químicas? }\end{array}$} & A & $\mathrm{Si}$ \\
\hline & B & Coloca subíndices \\
\hline & $\mathrm{C}$ & No ajusta todos los elementos \\
\hline & $\mathrm{D}$ & Coloca números entre las fórmulas \\
\hline & $\mathrm{E}$ & En blanco \\
\hline \multirow{5}{*}{$\begin{array}{l}\text { Ítem } 15 \\
\text { ¿Utiliza } \\
\text { correctamente } \\
\text { el concepto de } \\
\text { densidad? }\end{array}$} & A & Lo coloca al revés \\
\hline & B & Sí \\
\hline & $\mathrm{C}$ & Lo aplica al número de moles \\
\hline & $\mathrm{D}$ & No lo considera en el ejercicio \\
\hline & $\mathrm{E}$ & En blanco \\
\hline \multirow{5}{*}{$\begin{array}{l}\text { Ítem } 16 \\
\text { ¿utiliza } \\
\text { correctamente } \\
\text { el rendimiento? }\end{array}$} & A & Lo aplica al número de moles \\
\hline & $\mathrm{B}$ & No lo considera en el ejercicio \\
\hline & C & Sí \\
\hline & $\mathrm{D}$ & Lo coloca al revés \\
\hline & $\mathrm{E}$ & En blanco \\
\hline \multirow{5}{*}{$\begin{array}{l}\text { Ítem } 17 \\
\text { ¿Calcula la } \\
\text { molaridad? }\end{array}$} & A & Sí, correctamente \\
\hline & $\mathrm{B}$ & Divide masa/volumen \\
\hline & $\mathrm{C}$ & Lo identifica como $\mathrm{n}^{\circ}$ de moles \\
\hline & $\mathrm{D}$ & Lo relaciona con la reacción \\
\hline & $\mathrm{E}$ & En blanco \\
\hline \multirow{5}{*}{$\begin{array}{l}\text { Item } 18 \\
\text { ¿Identifica } \\
\text { correctamente } \\
\text { el reactivo } \\
\text { limitante? }\end{array}$} & A & $\begin{array}{l}\text { No divide el } \mathrm{n}^{\circ} \text { de moles entre el coeficiente } \\
\text { estequiométrico }\end{array}$ \\
\hline & B & No lo busca \\
\hline & $\mathrm{C}$ & Toma el mayor valor de $n^{\circ}$ de moles $/ v$ \\
\hline & $\mathrm{D}$ & Sí \\
\hline & $\mathrm{E}$ & En blanco \\
\hline \multirow{5}{*}{$\begin{array}{l}\text { Item } 19 \\
\text { ¿Establece } \\
\text { correctamente } \\
\text { la } \\
\text { estequiometria? }\end{array}$} & A & Sí \\
\hline & $\mathrm{B}$ & No relaciona el $\mathrm{n}^{\circ}$ de moles \\
\hline & $\mathrm{C}$ & Se deja pasos \\
\hline & $\mathrm{D}$ & $\begin{array}{l}\text { No establece correctamente la secuencia entre el dato y } \\
\text { la solución }\end{array}$ \\
\hline & $\mathrm{E}$ & En blanco \\
\hline \multirow[t]{2}{*}{ Ítem 20} & A & No despeja correctamente \\
\hline & $\mathrm{B}$ & No utiliza las unidades adecuadas \\
\hline
\end{tabular}




\begin{tabular}{|l|l|l|l|l|}
\hline \multirow{2}{*}{$\begin{array}{l}\text { ¿Aplica } \\
\text { correctamente } \\
\text { la ecuaión de } \\
\text { los gases } \\
\text { ideales? }\end{array}$} & $\mathrm{C}$ & Utiliza directamente 22,4 litros/mol & & \\
\cline { 2 - 5 } & $\mathrm{D}$ & Correcto & En blanco & \\
\cline { 2 - 5 } & & & \\
\hline
\end{tabular}




\section{ANEXO XXIII}

CUESTIONARIO PARA RECOGER LAS OPINIONES DE LOS PROFESORES IMPLICADOS EN LA INTERVENCIÓN DIDÁCTICA 
LA ENSEÑANZA DEL ENLACE QUÍMICO. FUNDAMENTACIÓN, PLANIFICACIÓN, APLICACIÓN Y EVALUACIÓN DE UNA PROPUESTA DIDÁCTICA PARA LA EDUCACIÓN SECUNDARIA.

Cuestionario para conocer la opinión de los profesores respecto a la intervención

\section{Propuesta}

\begin{tabular}{|l|l|l|l|l|l|}
\cline { 2 - 6 } & & & & & \\
\hline $\begin{array}{l}\text { Resulta interesante ensayar propuestas didácticas } \\
\text { en el desarrollo del curso. }\end{array}$ & & & & & \\
\hline $\begin{array}{l}\text { Es necesario buscar actividades alternativas en el } \\
\text { aula para motivar a los alumnos. }\end{array}$ & & & & & \\
\hline $\begin{array}{l}\text { La contextualización de las actividades facilita la } \\
\text { compresión de los conceptos. }\end{array}$ & & & & & \\
\hline $\begin{array}{l}\text { El tema del enlace químico tiene gran } \\
\text { importancia dentro currículo de tercer curso de }\end{array}$ & & & & & \\
ESO. & & & & \\
\hline $\begin{array}{l}\text { El tema del enlace químico tiene gran } \\
\text { importancia dentro currículo de segundo curso de }\end{array}$ & & & & & \\
bachillerato. & & & & \\
\hline $\begin{array}{l}\text { La correcta asimilación de los conceptos } \\
\text { relacionados con el enlace es necesaria para el } \\
\text { desarrollo de temas posteriores. }\end{array}$ & & & & & \\
\hline
\end{tabular}

¿Qué libro de texto utilizas habitualmente?

¿Sueles trabajar siguiendo el libro o utilizas materiales de apoyo cuando lo consideras interesante? 


\section{Desarrollo}

Grupos con los que has trabajado (indica el número en caso de ser varios)

\begin{tabular}{|l|c|c|c|c|}
\hline \multicolumn{3}{|c|}{$3^{\circ}$ de ESO } & \multicolumn{2}{c|}{$2^{\circ}$ de Bachillerato } \\
\hline Experimental & Control & Control externo & Experimental & Control \\
& & & & \\
\hline
\end{tabular}

¿Cuántas clases has utilizado en el desarrollo del tema?

\begin{tabular}{|c|c|c|c|c|c|}
\hline & 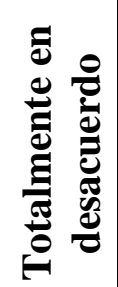 & 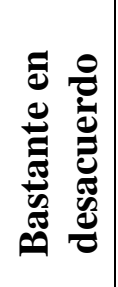 & 党 & 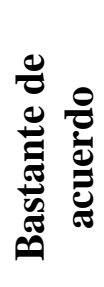 & 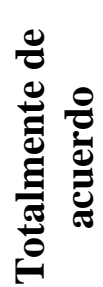 \\
\hline 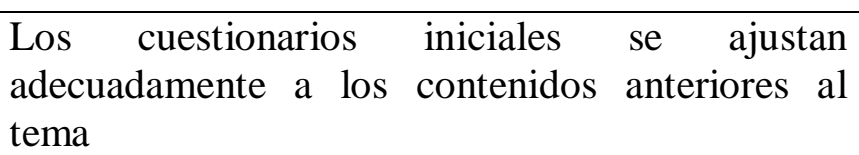 & & & & & \\
\hline $\begin{array}{l}\text { Los cuestionarios finales se ajustan a los } \\
\text { contenidos trabajados en el tema del enlace. }\end{array}$ & & & & & \\
\hline $\begin{array}{l}\text { Las sesiones propuestas se ajustan a las que has } \\
\text { necesitado para impartir el tema. }\end{array}$ & & & & & \\
\hline $\begin{array}{l}\text { El trabajo práctico propuesto se ha podido } \\
\text { combinar fácilmente con el resto de actividades. }\end{array}$ & & & & & \\
\hline $\begin{array}{l}\text { El progreso del tema ha llevado una expectación } \\
\text { paralela a la resolución del problema propuesto. }\end{array}$ & & & & & \\
\hline $\begin{array}{l}\text { En el caso de haberla ha supuesto una ayuda a } \\
\text { profesor o alumnos. }\end{array}$ & & & & & \\
\hline
\end{tabular}

Comenta las diferencias encontradas a la hora de trabajar con los alumnos

¿Los alumnos han realizado las tareas propuestas para casa?

¿Te ha supuesto alguna dificultad el hecho de desarrollar un tema de forma diferente al resto, de forma puntual dentro del programa del curso?¿En que sentido? 


\section{Metodología}

\begin{tabular}{|c|c|c|c|c|c|}
\hline & 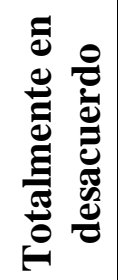 & 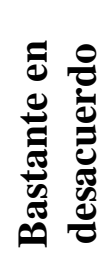 & 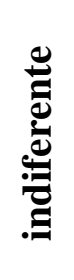 & 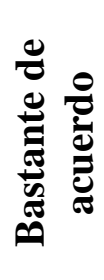 & 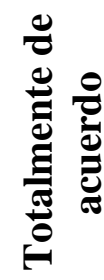 \\
\hline $\begin{array}{l}\text { El problema propuesto inicialmente ha ayudado a } \\
\text { los alumnos ha implicarse en el estudio del tema. }\end{array}$ & & & & & \\
\hline $\begin{array}{l}\text { Se ha conseguido contextualizar el tema, y dar } \\
\text { credibilidad a los contenidos. }\end{array}$ & & & & & \\
\hline $\begin{array}{l}\text { El hecho de dirigir parcialmente a los alumnos } \\
\text { mediante la utilización de un dossier ayuda a su } \\
\text { implicación en el tema. }\end{array}$ & & & & & \\
\hline $\begin{array}{l}\text { El trabajo práctico propuesto ha complementado } \\
\text { correctamente a los contenidos implicados. }\end{array}$ & & & & & \\
\hline
\end{tabular}

¿Qué aspectos destacarías de la intervención?

¿Cuáles son las diferencias más importantes que has encontrado, con la metodología utilizada en otros cursos en este mismo tema?

¿Ha supuesto algún contratiempo la realización de la parte práctica?¿en qué sentido? 


\section{Resultados}

\begin{tabular}{|c|c|c|c|c|c|}
\hline & 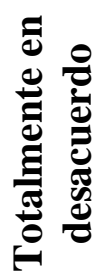 & 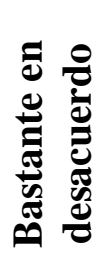 & 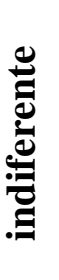 & 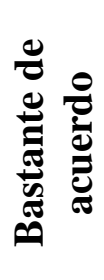 & 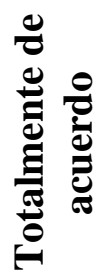 \\
\hline \multicolumn{6}{|l|}{$\begin{array}{l}\text { Consideras que las respuestas dadas por los } \\
\text { alumnos a los cuestionarios han sido } \\
\text { satisfactorias. }\end{array}$} \\
\hline \multicolumn{6}{|l|}{$\begin{array}{l}\text { El resultado global de la propuesta ha sido } \\
\text { satisfactorio. }\end{array}$} \\
\hline \multicolumn{6}{|l|}{$\begin{array}{l}\text { Los alumnos han mostrado satisfacción con esta } \\
\text { propuesta. }\end{array}$} \\
\hline $\begin{array}{l}\text { Al margen de la implicación de los alumnos, de } \\
\text { los resultados obtenidos o del grado de distorsión } \\
\text { académica provocado ha resultado interesante } \\
\text { realizar esta experiencia. }\end{array}$ & & & & & \\
\hline
\end{tabular}

¿Qué añadirías o eliminarías de la propuesta?

¿Repetirás este procedimiento en los próximos cursos? ¿Por qué?

¿Crees que seria factible desarrollar todo el temario del curso de esta forma? 


\section{ANEXO XXIV}

RELACIÓN DE CENTROS CUYOS PROFESORES Y ALUMNOS HAN PARTICIPADO EN LA INVESTIGACIÓN 
RELACIÓN DE CENTROS CUYOS PROFESORES Y ALUMNOS HAN PARTICIPADO EN LA INVESTIGACIÓN

\begin{tabular}{|l|l|l|}
\hline Centro & Localidad & \\
\hline IES ${ }^{\circ}$ 3 de Aldaia & Aldaia & \\
\hline IES Tirant lo Blanc & Torrent & \\
\hline IES Massamagrell & Massamagrell & \\
\hline IES La Marxadella & Torrent & \\
\hline
\end{tabular}

